\title{
Utilising Marine Collagen as a Niche Structure for Enhanced Osteoarthritic Repair
}

\author{
Zara Ahmed
}

Submitted to Swansea University in fulfillment of the requirements for the degree of Doctor of Philosophy

\author{
Swansea University \\ Medical School
}

2018 


\begin{abstract}
Collagen is an abundant structural protein in the extracellular matrix and plays a role in both structural integrity and support that guides tissue formation and homeostasis. Collagen or matrix disruption, leading to altered cell-matrix interactions, is implicated in disease pathophysiology. Collagen has in turn become an attractive biomaterial in regenerative medicine, proving valuable in various long-term, robust repair strategies. Osteoarthritis (OA) is a multifactorial disease leading to the degeneration of articular cartilage, affecting approximately 8.5 million in the UK population. Current repair procedures require surgical interventions, with varying degrees of success, easing pain and recovery time. Future repair strategies are now being focused around the formation of new tissue for implantation, incorporating collagen scaffolds, donor cell populations and functional differentiation.
\end{abstract}

This thesis presents a thorough characterization of a novel jellyfish (R.pulmo) source of collagen, benchmarked against mammalian collagen like material compatible with human and bovine chondroprogenitor cell invasion, proliferation, and differentiation. Significantly, no increased immune response was observed compared to research and clinical grade mammalian collagen sources during in vitro examination. Excitingly, jellyfish collagen ( $\mathrm{JCol}$ ) also demonstrated hallmarks of chondro-mimicry, enabling bovine chondroprogenitor cell invasion, proliferation and differentiation. Using a sponge scaffold design JCol provides adequate structural cell-matrix support appropriate for enhanced chondrogenesis in the presence of TGF $\beta 1$.

The robust body of evidence presented supports the development of JCol, a seemingly inert collagen source, for tissue engineering and/or regenerative medicine applications. Analogous to native articular cartilage, this supports further development of jellyfish collagen as a biomaterial for matrix assisted chondrocyte implantation (MACI) approaches in OA repair. Jellagen, industrial sponsor for the project, have adopted central observations from this thesis and are now progressing with wider commercial and development activities to support market and clinical research expansion. 


\section{Declaration}

This work has not previously been accepted in substance for any degree and is not being concurrently submitted in candidature for any degree.

Signed

ZARA AHMED

Date

\section{STATEMENT 1}

This thesis is the result of my own investigations, except where otherwise stated. Where correction services have been used, the extent and nature of the correction is clearly marked in a footnote(s).

Other sources are acknowledged by footnotes giving explicit references. A bibliography is appended.

Signed

ZARA AHMED

Date

\section{STATEMENT 2}

I hereby give consent for my thesis, if accepted, to be available for photocopying and for inter-library loans after expiry of a bar on access approved by the Swansea University.

Signed

ZARA AHMED

Date 


\section{Acknowledgments}

$$
\text { أكبر الله | | الحمدالله | الله سبحان }
$$

I am profoundly grateful to my supervisors Dr. Lewis Francis and Dr. Ilyas Khan whose guidance, encouragement and friendship throughout this project has been invaluable. Your joy and enthusiasm towards research has been a constant source of motivation even in difficult times. Thank you for always challenging my thinking and helping me grow both personally and professionally.

I would like to thank my industrial partner Jellagen for their support and belief in me and wish them the best of luck as they continue their journey. I also extend my thanks the European Social Fund (ESF) who part funded this work through the European Union's Convergence programme administered by the Welsh Government.

Thank you to the Regenerative Medicine and Reproductive Biology and Gynaecological Cancer group members past and present. You have all contributed to my personal and professional development through your friendship, collaborations and discussions. In particular, I would like to thank Dr. Seydou Yao for never saying 'no' to answering my question, which inevitably turned into multiple questions. I appreciate the time and effort you have given in order to teach me various techniques and the advice imparted to make me a better scientist. Special thanks must also be given to Dr. Yadan Zhang and Navid Matin both of who made endless hours and problems in the lab seem so simple with their kindness and humour.

To my friends, Samantha Thomas, Ryan Bigham and Leen Intabli thank you so much for listening, offering advice and supporting me throughout this process. Your support, patience and friendship mean more to me than I can describe in words. I have been blessed to go through this experience with you all by my side.

Finally, the greatest thanks goes to my parents, Jan and Mon, and my sister, Saira. I will never be able to thank you enough for the belief you instilled in me that I am capable of anything I put my mind to. Your unwavering faith and unconditional love have continued to push me to be my best and this would not have been possible without you. 
"I'm so lucky we lived through who we were to become who we are."

-Neil Hilborn 


\section{Table of Contents}

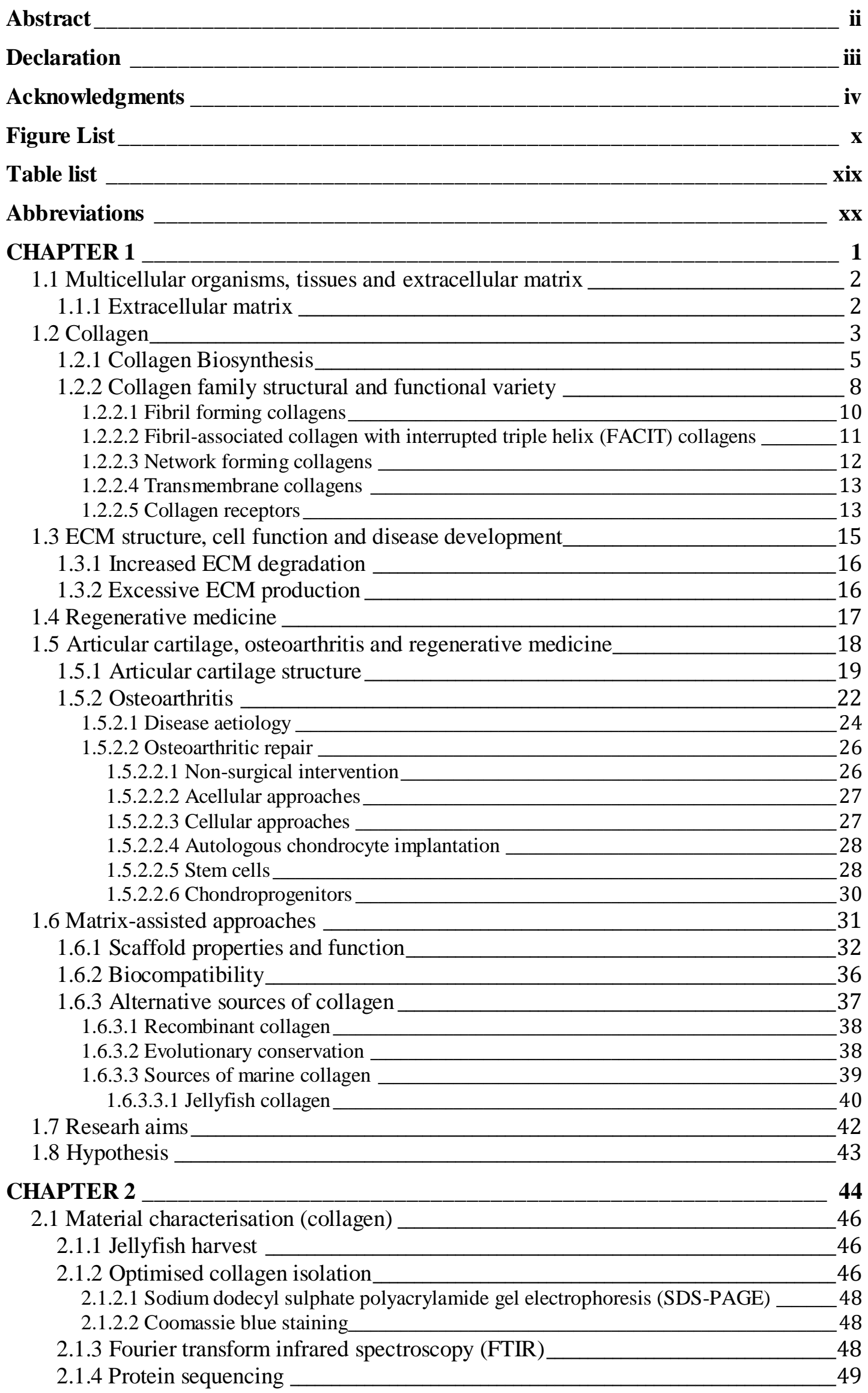


2.1.4.1 Informatics 50

2.2 Material characterisation (scaffold)

2.2.1 Scaffold fabrication

2.2.1.1 Scanning electron microscopy (SEM)__ 51

2.2.1.2 Pore size analysis _ 51

2.2.2 Plastic compression

2.2.3 Differential scanning calorimetry__ 51

2.2.4 Collagenase digest__ 52

2.3 JCol biocompatibility testing __ 53

2.3.1 Tissue culture of human cell lines __ 53

2.3.2 Sources of articular cartilage___ 53

2.3.2.1 Bovine tissue isolation

2.3.2.2 Enzymatic digestion and cell isolation

2.3.2.3 Differential fibronectin adhesion assay__ 54

2.3.2.4 Clonal population isolation __ 55

2.3.3 Cell culture medium __ 55

2.3.3.1 Monolayer expansion__ 55

2.3.4 Cellular differentiation

2.3.4.1 Chondrogenic differentiation

2.3.4.2 Osteogenic differentiation__ 56

2.3.4.3 Adipogenic differentiation

2.3.5 Coating plates__ 57

2.3.6 InCell image acquisition _ـ 57

2.3.6.1 InCell analysis _ 58

2.3.7 Cell morphology

2.3.8 Whole blood patient recruitment

2.3.9 Fluorescent activated cell sorting _ 59

2.3.9.1 Leukocyte activation analysis__ 59

2.3.9.2 Platelet activation analysis _ 60

2.3.10 Whole blood culture 60

2.3.11 ELISA _ 60

2.4 Biomaterial application__ 62

2.4.1 Pellet formation__ 62

2.4.2 Scaffold seeding _ 62

2.4.3 Paraffin wax embedding __ 63

2.4.3.1 Paraffin wax sectioning _ 63

2.4.3.2 Haematoxylin and eosin 63

2.4.3.3 Toluidine blue __ 63

2.4.3.4 Picrosirius red 64

2.4.3.5 Immunohistochemistry _ 64

2.4.4 Scaffold and pellet digestion _ 65

2.4.4.1 DNA quantification__ 65

2.4.4.2 DMMB assay _ 66

2.4.4.3 Hydroxyproline assay _ 66

2.4.5 RNA extraction from native tissue __ 67

2.4.6 RNA extraction from pellets and scaffolds __ 67

2.4.6.1 RNA quantification__ 67

2.4.6.2 cDNA conversion__ 68

2.4.6.3 Quantitative polymerase chain reaction (qPCR)__ 68

2.5 Statistical analysis _ـ 69

CHAPTER 3 ________________ $\mathbf{7 0}$

3.1 Introduction __ 71

3.1.1 Sequence informed structure function analysis _ 71

3.1.1.2 Collagen Extraction and Characterisation__ 72

3.1.2 Scaffold fabrication 
3.1.3 Hypothesis

3.1.3.1 Aims and objectives _ 74

3.2 Results__ 75

3.2.1 Sodium citrate collagen extraction __ 77

3.2.2 Acetic acid extraction __ 79

3.2.3 Scalable collagen extraction __ 83

3.2.4 Collagen protein analysis__ 87

3.2.4.1 Peptide sequence quality control__ 87

3.2.4.2 Alignment__ 91

3.2.4.3 Collagen alignment _ 96

3.2.5 Collagen plasticity and moulding_ 103

3.2.5.1 Moulding__ 106

3.2.5.1.1 Scaffold characterisation__ 107

3.2.5.2 Plastic compression 112

3.2.5.3 Collagen scaffold stability __ 114

3.2.5.3.1 Thermal stability _ 114

3.2.5.3.2 Collagen enzymatic degradation __ 117

3.3 Discussion__ 120

CHAPTER 4

4.1 Introduction 132

4.1.1 In vitro immunogenicity _ 133

4.1.2 In vitro immune surveillance _ـ 134

4.1.3 Collagen immunogenicity___ 136

4.1.4 Chapter hypothesis _ـ 136

4.1.4.1 Aims and objectives 137

4.2 Results_ 137

4.2.1 Collagen supported 2D culture __ 138

4.2.1.1 Human endometrial stromal cell culture _ 140

4.2.1.2 Cellular viability _ 140

4.2.1.3 Cellular morphology _ـ 143

4.2.2 Human endometrial epithelial cell culture __ 146

4.2.2.1 Cellular viability__ 146

4.2.2.2 Cellular morphology _ 149

4.2.3 Type II endometrial epithelial cell culture _ 152

4.2.3.1 Cellular viability__ 152

4.2.3.2 Cellular morphology _ 155

4.2.4 Bovine chondroprogenitor cell culture ___ 158

4.2.4.1 Cellular viability__ 159

4.2.4.2 Cellular morphology _ 161

4.2.5 In vitro immunogenicity _ 164

4.2.5.1 Platelet activation 164

4.2.5.2 Leukocyte activation; innate immune response___ 166

4.2.5.2.1 LPS established baseline___ 167

4.2.5.2.2 Neutrophil specific activation __ 171

4.2.5.2.3 Monocyte specific activation 173

4.2.5.3 Leukocyte activation; adaptive immune response __ 176

4.2.5.4 Leukocyte cell death__ 180

4.2.5.5 Cytokine release profile_ 184

4.2.5.5.1 Pro-inflammatory cytokine - interleukin $6 \_184$

4.2.5.5.2 Anti-inflammatory cytokine - interleukin $10 \_186$

4.3 Discussion__ 189

CHAPTER 5 _____________________________ 201

5.1 Introduction _ـ 202

5.1.1 Matrix assisted environment__ 203

5.1.2 Chondrogenesis__ 204 
5.1.3 Different matrix types

5.1.4 Cell source 206

5.1.5 Hypothesis 207

5.1.5.1 Aims and objectives _ 207

5.2 Results__ 208

5.2.1 Bovine chondroprogenitor isolation and culture__ 208

5.2.1.1 CP isolation and tri-lineage potential__ 209

5.2.2 3D enhanced chondrogenesis _ 211

5.2.2.1 Scaffold characteristics for 3D culture __ 212

5.2.3 Cellular invasion and proliferation 215

5.2.3.1 Native bovine punch biopsy baseline___ 215

5.2.3.2 Scaffold assisted CP invasion ___ 216

5.2.3.3 DNA quantification__ 222

5.2.4 Proteoglycan synthesis _ 224

5.2.4.1 Native immature baseline _ 224

5.2.4.2 Scaffold assisted matrix deposition__ 226

5.2.4.3 Glycosaminoglycan quantification _ 230

5.2.5 Collagen content__ 232

5.2.5.1 Native immature baseline _ 232

5.2.5.2 Scaffold assisted collagen content _ 234

5.2.5.3 Hydroxyproline quantification__ 238

5.2.6 Histology summary _ 239

5.2.7 Gene expression analysis _ 239

5.2.8 Protein expression _ 246

5.3 Discussion__ 247

CHAPTER 6 _________________________ 255

6.1 Thesis Summary ___ 256

6.2 JCol structural composition, isolation and sponge fabrication __ 258

6.3 CPs, scaffold assisted enhanced chondrogenesis __ 261

6.4 Biocompatibility _ 263

6.5 Concluding remarks _ 265

Bibliography _________________________ $\mathbf{2 6 7}$ 


\section{Figure List}

\section{CHAPTER 1}

FIGURE 1.1: TYPE 1 COLLAGEN STRUCTURE. A CHAINS COME TOGETHER TO FORM A TRIPLE HELIX. REPETITIVE GLY-X-Y REGIONS ALLOW FOR TIGHT PACKING OF THE HELIX AND MAJOR LIGAND BINDING REGIONS (MLBR) ALLOW FOR COLLAGENS TO INTERACT WITH OTHER COLLAGENS AND ECM PROTEINS. THE PRO-COLLAGEN MOLECULE HAS AMINO AND CARBOXY REGIONS CLEAVED TO BECOME A MATURE COLLAGEN MOLECULE (MARINI ET AL., 2017).

FIGURE 1.2: COMPARISON OF GENE STRUCTURE OF HUMAN PROCOLLAGENS. HUMAN PROCOLLAGEN A1 (IV), A2 (I), A1 (II) AND A1 (III) GENES. SOLID LINES REPRESENT INTRON SEQUENCES BLACK BOXES REPRESENT GLY-X-Y REPEATS AND HATCHED BOXES REPRESENT NC-1 DOMAIN CODING EXONS. SIZES OF INTRON AND EXONS ARE INDICATED BY THE CORRESPONDING NUMBERS ABOVE SEQUENCES (SOININEN ET AL., 1986).

FIGURE 1.3: TISSUE ENGINEERING TRIAD. SUCCESSFUL TISSUE ENGINEERING IS DEPENDENT ON THE WORK BETWEEN CELLS, SIGNALS AND MATERIALS (O'BRIEN, 2011)

FIGURE 1.4: SCHEMATIC REPRESENTATION OF HEALTH ARTICULAR CARTILAGE ALONG SIDE HISTOLOGICAL STAINING OF CARTILAGE TISSUE. CHONDROCYTES MAINTAIN A FLATTENED MORPHOLOGY AT THE SUPERFICIAL ZONE BEFORE BECOMING MORE ROUNDED DEEPER INTO THE TISSUE. COLLAGEN FIBRILS CHANGE THEIR ORIENTATION THROUGHOUT THE TISSUE TO GIVE ITS TENSILE PROPERTIES (FOX ET AL., 2009)

FIGURE 1.5: HISTOLOGICAL STAINING OF ARTICULAR CARTILAGE DEMONSTRATING GRADES 0-5 OF OA. HISTOLOGICAL STAINING WITH HAEMATOXYLIN AND EOSIN, SAFRANIN O AND COUNTERSTAINED WITH FAST GREEN SHOWS DEPLETION OF PROTEOGLYCAN AND LESION FORMATION (WALDSTEIN ET AL., 2015).

FIGURE 1.6: STRUCTURAL CHANGES AND SIGNALING PATHWAYS INVOLVED IN THE DEVELOPMENT OF OA (GLYN-JONES ET AL., 2015) ...........................................................24

FIGURE 1.7: DIFFERENTIATION OF MSCS THROUGH DIFFERENT LINEAGES. MSCS ARE OFTEN CHOSEN FOR REGENERATIVE MEDICINE DUE TO THEIR PLASTICITY. MINIMAL CRITERIA DICTATE THAT MSCS MUST BE ABLE TO UNDERGO CHONDROGENESIS, OSTEOGENESIS AND ADIPOGENESIS (CAPLAN AND BRUDER, 2001).

FIGURE 1.8: SCHEMATIC DIAGRAM SHOWING ANATOMY OF A JELLYFISH. JELLYFISH COLLAGEN IS OFTEN ISOLATED FROM THE COLLAGEN RICH MESOGLOEA OR ORAL ARMS (CRONODON, 2016)

FIGURE 2.1: APPROACH TO JELLYFISH COLLAGEN EXTRACTION AND CHARACTERISATION

FIGURE 3.1: RESEARCH GRADE RAT-TAIL COLLAGEN TYPE I FTIR SPECTRUM. FTIR SPECTRA OF RAT-TAIL COLLAGEN DEPICTING AMIDE I, AMIDE II AND AMIDE III PEAKS AT $1635 \mathrm{CM}^{-1}, 1528 \mathrm{CM}^{-1}$ AND $1245 \mathrm{CM}^{-1}$, RESPECTIVELY.

FIGURE 3.2: OPTIMISED EXTRACTION PROCESS FOR TESTING. CRITICAL STAGES IN COLLAGEN EXTRACTION OUTLINED (A-D) AND MAPPED AGAINST KNOWN COLLAGEN EXTRACTION FOR RHIZOSTOMA PULMO (E).

FIGURE 3.3: SODIUM CITRATE R.PULMO COLLAGEN EXTRACTION IN THE PRESENCE AND ABSENCE OF PEPSIN. A BESPOKE EXTRACTION PROTOCOL WAS DEVISED USING SODIUM CITRATE STABILISATION AND DOWNSTREAM CENTRIGUGATION (A). IMAGES OF FREEZE DRIED MATERIAL AND FTIR SPECTRA WERE OBTAINED AFTER EXTRACTION IN THE ABSENCE (B) AND PRESENCE (C) OF PEPSIN...............78

FIGURE 3.4: ACETIC ACID R.PULMO EXTRACTION IN THE PRESENCE AND ABSENCE OF PEPSIN. EXTRACTION PROTOCOL WAS DEVISED USING ACETIC ACID (A) AND IMAGES OF FREEZE DRIED MATERIAL AND FTIR SPECTRA WERE OBTAINED AFTER EXTRACTION IN THE ABSENCE (B) AND PRESENCE (C) OF PEPSIN.

FIGURE 3.5: ACETIC ACID R.PULMO EXTRACTION WITH SALT PRECIPITATION. EXTRACTION PROTOCOL WAS DEVISED USING ACETIC ACID WITH SALT PRECIPITATION (A) AND IMAGES OF FREEZE DRIED MATERIAL (B) AND FTIR SPECTRA WERE OBTAINED AFTER EXTRACTION (C). 
FIGURE 3.6: OPTIMISED SCALABLE EXTRACTION FOR CONSERVED COLLAGEN CONFIRMATION. AN EARLY R. PULMO EXTRACTION PROTOCOL ADOPTED BY JELLAGEN TAKING A TOTAL OF 12 DAYS USED 0.5M ACID TO SOLUBILISE COLLAGEN (LEFT) WHEREAS AN IN HOUSE EXTR ACTION PROTOCOL USED A PRE-WASH STEP USING SODIUM ACETATE AND SALT PRECIPITATION TO OBTAIN COLLAGEN (RIGHT). A FINAL PROTOCOL WAS ADOPTED BY COMBINING BOTH IN HOUSE AND JELLAGEN'S EARLY PROTOCOL TO INCLUDE A PRE-WAS STAGE AND TO USE A LESS CONCENTRATED FORM OF ACETIC ACID (CENTRE)

FIGURE 3.7: JELLAGEN B ATCH COLLAGEN EXTRACTION ANALYSIS. FTIR (A AND C) AND GEL ELECTROPHORESIS (B AND D) WERE USED TO ANALYSE COLLAGEN EXTRACTION FROM 2 SEPARATE BATCH RUNS.

FIGURE 3.8: ALPHA1 COLLAGEN BAND EXTRACTION FOR SEQUENCING. RAT-TAIL AND BOVINE COLLAGEN TYPE I RUN AGAINST JELLYFISH COLLAGEN TO LOCATE ALPHA 1 BAND. ALPHA 1 BAND FOR RAT-TAIL AND BOVINE COLLAGEN IS FOUND AT 135KDA (GREEN ARROW) AND JELLYFISH COLLAGEN ALPHA 1 IS FOUND AT $\sim 175 \mathrm{KDA}$ (RED ARROW)

FIGURE 3.9: SEQUENCE ALIGNMENT OF HUMAN COL1A1 SEQUENCE TO R.PULMO PEPTIDES. 32 PEPTIDES WITH AN ACL\% OF 90 AND ABOVE WERE COMPARED AGAINST HUMAN COL1A1 USING CLUSTAL OMEGA TO GIVE AN ALIGNMENT....98

FIGURE 3.10: SEQUENCE ALIGNMENT OF HUMAN COL3A1 SEQUENCE TO R.PULMO PEPTIDES. 32 PEPTIDES WITH AN ACL\% OF 90 AND ABOVE WERE COMPARED AGAINST HUMAN COL3A1 USING CLUSTAL OMEGA TO GIVE AN ALIGNMENT....99

FIGURE 3.11: ABDESIGNER OUTPUT FOR HUMAN COL1 A1. POSITIONS 998 TO 1015 (A) AND 1070 TO 1080 (B) HIGHLIGHTED TO SHOW FUNCTIONAL FEATURES OF THE PROTEIN.

FIGURE 3.12: ABDESIGNER OUTPUT FOR HUMAN COL3A1. POSITIONS 926 TO 960 ARE HIGHLIGHTED TO SHOW AREAS OF FUNCTIONAL RELEVANCE AND INTEREST.

FIGURE 3.13: SEQUENCE ALIGNMENT OF PFAM01391 TO R.PULMO PEPTIDES................... 103

FIGURE 3.14: FLOW DIAGRAM OF WORK CONCERNING COLLAGEN ISOLATION AND SCAFFOLD FABRICATION.

FIGURE 3.15: 3D COLLAGEN MOULDING AND GROSS STURCTURE. SCAFFOLDS FABRICATED FROM RTCOL, JCOL AND BGEL VIEWED FROM THE SIDE (A) AND TOP DOWN (B). SCALE BARS INDICATE 5MM.

FIGURE 3.16: SEM IMAGES OF RTCOL SCAFFOLDS AND PORE SIZE AT DIFFERENT CROSSLINKING CONCENTRATIONS. LOW MAGNIFICATION (A) AND HIGH MAGNIFICATION (B) SEM IMAGES WERE TAKEN TO ASSESS ARCHITECTURE AT $0.25,0.5$ AND $1 \%$ EDC CONCENTRATION. HIGH MAGNIFICATION IMAGES WERE USED TO CALCULATE AVERAGE PORE SIZE (C). DATA SHOWN IS THE STANDARD DEVIATION OF FROM A MINIMUM OF THREE INDEPENDENT REPEATS, STATISTICAL SIGNIFICANCE SHOWN ACCORDING TO PAIRED MANN WHITNEY U TEST $(* \mathrm{P}<0.05 ; * * \mathrm{P}<0.01 ; * * * \mathrm{P}<0.001)$. 109

FIGURE 3.17: SEM IMAGES OF JCOL SCAFFOLDS AND PORE SIZE AT DIFFERENT CROSSLINKING CONCENTRATIONS. LOW MAGNIFICATION (A) AND HIGH MAGNIFICATION (B) SEM IMAGES WERE TAKEN TO ASSESS ARCHITECTURE AT $0.25,0.5$ AND $1 \%$ EDC CONCENTRATION. HIGH MAGNIFICATION IMAGES WERE USED TO CALCULATE AVERAGE PORE SIZE (C). DATA SHOWN IS THE STANDARD DEVIATION OF FROM A MINIMUM OF THREE INDEPENDENT REPEATS, STATISTICAL SIGNIFICANCE SHOWN ACCORDING TO PAIRED MANN WHITNEY U TEST $(* \mathrm{P}<0.05 ; * * \mathrm{P}<0.01 ; * * * \mathrm{P}<0.001)$. 110

FIGURE 3.18: SEM IMAGES OF BGEL SCAFFOLDS AND PORE SIZE AT DIFFERENT CROSSLINKING CONCENTRATIONS. LOW MAGNIFICATION (A) AND HIGH MAGNIFICATION (B) SEM IMAGES WERE TAKEN TO ASSESS ARCHITECTURE AT $0.25,0.5$ AND $1 \%$ EDC CONCENTRATION. HIGH MAGNIFICATION IMAGES WERE USED TO CALCULATE AVERAGE PORE SIZE (C). DATA SHOWN IS THE STANDARD DEVIATION OF FROM A MINIMUM OF THREE INDEPENDENT REPEATS, STATISTICAL SIGNIFICANCE SHOWN ACCORDING TO PAIRED MANN WHITNEY U TEST $(* \mathrm{P}<0.05 ; * * \mathrm{P}<0.01 ; * * * \mathrm{P}<0.001)$ 111

FIGURE 3.19: SEM IMAGES OF COMPRESSED JCOL SCAFFOLDS AT DIFFERENT CROSSLINKING CONCENTRATIONS. LOW (X50) AND HIGH (X300) MAGNIFICATION 
IMAGES OF COMPRESSED JCOL SCAFFOLDS CROSSLINKED AT 0.25, 0.5 AND 1\% EDC.

FIGURE 3.20: WEIGHT OF JCOL SCAFFOLDS BEFORE AND AFTER COMPRESSION AND RESWELLING. JCOL SCAFFOLDS CROSSLINKED WITH 1, 0.5 AND 0.25\% EDC WERE WEIGHED BEFORE AND AFTER COMPRESSION AND WERE PLACED IN PBS BEFORE WEIGHING TO CHECK FOR RESWELLING. ALL DATA SHOWN IS THE STANDARD DEVIATION FROM A MINIMUM OF THREE INDEPENDENT REPEATS, STATISTICAL SIGNIFICANCE SHOWN ACCORDING TO T TEST $\left({ }^{*} \mathrm{P}<0.05 ; * * \mathrm{P}<0.01\right.$; $* * * \mathrm{P}<0.001)$

FIGURE 3.21: DSC OF SCAFFOLDS CROSSLINKED AT VARIOUS EDC CONCENTRATIONS. DSC DATA FOR RTCOL (A), JCOL (B) AND BGEL (C) SCAFFOLDS CROSSLINKED AT $0.25 \%, 0.5 \%$ AND $1 \%$ EDC.

FIGURE 3.22: COLLAGENASE TREATMENT OF SCAFFOLDS CROSSLINKED WITH EDC. SCAFFOLDS CROSSLINKED WITH 0.25\% (A), 0.5\% (B) AND 1\% (C) EDC WERE INCUBATED WITH COLLAGENASE AND WEIGHED REGULARLY TO ASSESS RESISTANCE TO DEGRADATION.

FIGURE 3.23: EDC CROSSLINKING REACTION. CARBOXYL GROUPS REACT WITH PRIMARY AMINE GROUPS VIA EDC FORMED INTERMEDIATE TO FORM AMIDE BONDS (SUBHAN ET AL., 2015).

FIGURE 4.1: HOST REPONSE TO IMPLANTED BIOMATERIALS. A SCHEMATIC DETAILING THE IMMUNE RESPONSE FOLLOWING THE IMPLANTATION OF A BIOMATERIAL. SERUM PROTEINS ADHERE TO THE SURFACE OF THE MATERIAL AND INFLAMMATORY CELLS SUCH AS NEUTROPHILS AND MACROPHAGES ARE RECRUITED TO THE SITE OF INJURY. MATURE MACROPHAGES ALSO SECRETE PRO-INFLAMMATORY CYTOKINES TO AID IN ACUTE AND CHRONIC INFLAMMATION. AFTER A PERIOD OF DAYS, MACROPHAGES WILL BEGIN THE HEALING PROCESS BY SECRETING ANTI-INFLAMMATORY CYTOKINES. WITHIN WEEKS TO MONTHS THE ADAPTIVE IMMUNE RESPONSE IS TRIGGERED THROUGH ANTIGEN RECOGNITION VIA T LYMPHOCYTES AND B LYMPHOCYTES. THE END STAGE OF THE IMMUNE RESPONSE UPON IMPLANTATION EITHER LEADS TO RESOLUTION OR THE FORMATION OF A FIBROTIC CAPSULE (KIM ET AL., 2016).

FIGURE 4.2: EXPERIMENTAL PROCEDURE TO ASSESS JELLYFISH COLLAGEN SUITABILITY FOR COATED 2D CULTURE. 139

FIGURE 4.3: HESC CELL VIABILITY IN COATED CULTURE VESSELS. HESC CELLS SEEDED ONTO RTCOL, JCOL AND BGEL COATED CULTURE DISHES WERE COMPARED TO PLASTIC ONLY CONTROL. DIRECT COMPARISON IS SHOWN BETWEEN THE PLASTIC CONTROL AND RTCOL (B); JCOL (C); BGEL (D). ALL DATA SHOWN IS FROM A MINIMUM OF 3 INDEPENDENT BIOLOGICAL REPEATS, STATISTICAL SIGNIFICANCE SHOWN ACCORDING TO A MANN WHITNEY U TEST $(* \mathrm{P}<0.05 ; * * \mathrm{P}<0.01 ; * * * \mathrm{P}<0.001)$.

FIGURE 4.4: HESC CELL CIRCULARITY IN COATED CULTURE VESSELS. HESC CELLS SEEDED ONTO PLASTIC (B), RTCOL (C), JCOL (D) AND BGEL (E) COATED CULTURE DISHES. ALL DATA SHOWN IS THE MEDIA +/- MIN/MAX FROM A MINIMUM OF 3 INDEPENDENT BIOLOGICAL REPEATS, STATISTICAL SIGNIFICANCE IS SHOWN ACCORDING TO MANN WHITNEY U TEST $(* \mathrm{P}<0.05 ; * * \mathrm{P}<0.01 ; * * * \mathrm{P}<0.001) \ldots \ldots \ldots . . . .145$

FIGURE 4.5: ISHIKAWA CELL VIABILITY IN COATED CULTURE VESSELS. ISHIKAWA CELLS SEEDED ONTO RTCOL, JCOL AND BGEL COATED CULTURE DISHES WERE COMPARED TO PLASTIC ONLY CONTROL. DIRECT COMPARISON IS SHOWN BETWEEN THE PLASTIC CONTROL AND RTCOL (B); JCOL (C); BGEL (D). ALL DATA SHOWN IS FROM A MINIMUM OF 3 INDEPENDENT BIOLOGICAL REPEATS, STATISTICAL SIGNIFICANCE SHOWN ACCORDING TO A MANN WHITNEY U TEST $(* \mathrm{P}<0.05 ; * * \mathrm{P}<0.01 ; * * * \mathrm{P}<0.001)$.

FIGURE 4.6: ISHIKAWA CELL CIRCULARITY IN COATED CULTURE VESSELS. ISHIKAWA CELLS SEEDED ONTO PLASTIC (B), RTCOL (C), JCOL (D) AND BGEL (E) COATED CULTURE DISHES. ALL DATA SHOWN IS THE MEDIA +/- MIN/MAX FROM A MINIMUM OF 3 INDEPENDENT BIOLOGICAL REPEATS, STATISTICAL SIGNIFICANCE IS SHOWN ACCORDING TO MANN WHITNEY U TEST $(* \mathrm{P}<0.05$; $* * \mathrm{P}<0.01 ; * * * \mathrm{P}<0.001)$. 
FIGURE 4.7: HEC50 CELL VIABILITY IN COATED CULTURE VESSEL. HEC50 CELLS SEEDED ONTO RTCOL, JCOL AND BGEL COATED CULTURE DISHES WERE COMPARED TO PLASTIC ONLY CONTROL. DIRECT COMPARISON IS SHOWN BETWEEN THE PLASTIC CONTROL AND RTCOL (B); JCOL (C); BGEL (D). ALL DATA SHOWN IS FROM A MINIMUM OF 3 INDEPENDENT BIOLOGICAL REPEATS, STATISTICAL SIGNIFICANCE SHOWN ACCORDING TO A MANN WHITNEY U TEST $(* \mathrm{P}<0.05 ; * * \mathrm{P}<0.01 ; * * * \mathrm{P}<0.001)$

FIGURE 4.8: HEC50 CELL CIRCULARITY IN COATED CULTURE VESSELS. HEC50 CELLS SEEDED ONTO PLASTIC (B), RTCOL (C), JCOL (D) AND BGEL (E) COATED CULTURE DISHES. ALL DATA SHOWN IS THE MEDIA +/- MIN/MAX FROM A MINIMUM OF 3 INDEPENDENT BIOLOGICAL REPEATS, STATISTICAL SIGNIFICANCE IS SHOWN ACCORDING TO MANN WHITNEY U TEST $(* \mathrm{P}<0.05 ; * * \mathrm{P}<0.01 ; * * * \mathrm{P}<0.001) \ldots \ldots \ldots \ldots . . . .157$

FIGURE 4.9: BOVINE CP CELL VIABILITY IN COATED CULTURE VESSELS. BOVINE CP CELLS SEEDED ONTO RTCOL, JCOL AND BGEL COATED CULTURE DISHES WERE COMPARED TO PLASTIC ONLY CONTROL. DIRECT COMPARISON IS SHOWN BETWEEN THE PLASTIC CONTROL AND RTCOL (B); JCOL (C); BGEL (D). ALL DATA SHOWN IS FROM A MINIMUM OF 3 INDEPENDENT BIOLOGICAL REPEATS, STATISTICAL SIGNIFICANCE SHOWN ACCORDING TO A MANN WHITNEY U TEST $(* \mathrm{P}<0.05 ; * * \mathrm{P}<0.01 ; * * * \mathrm{P}<0.001)$.

FIGURE 4.10: BOVINE CP CELL CIRCULARITY IN COATED CULTURE VESSELS. BOVINE CP CELLS SEEDED ONTO PLASTIC (B), RTCOL (C), JCOL (D) AND BGEL (E) COATED CULTURE DISHES. ALL DATA SHOWN IS THE MEDIA +/- MIN/MAX FROM A MINIMUM OF 3 INDEPENDENT BIOLOGICAL REPEATS, STATISTICAL SIGNIFICANCE IS SHOWN ACCORDING TO MANN WHITNEY U TEST $(* \mathrm{P}<0.05$; $* * \mathrm{P}<0.01 ; * * * \mathrm{P}<0.001)$.

FIGURE 4.11: PLATELET ACTIVATION IN THE PRESENCE AND ABSENCE OF PMA. BLOOD FROM THREE HEALTHY DONORS WAS ANALYSED FACS FOR CD42B EXPRESSION, EXPRESSED AS A SCATTER PLOT AND HISTOGRAM (A) AND COMPARED TO PMA STIMULATED BLOOD (B). ANALYSIS OF FACS DATA FOR UNSTIMULATED AND STIMULATED BLOOD SAMPLES WERE OBTAINED WITH KALUZA (C). DATA SHOWN ARE INDIVIDUAL VALUES PLOTTED AS A DOT PLOT WITH MEDIAN VALUES DEPICTED AS A LINE. NO STATISTICAL COMPARISON IS CONDUCTED DUE TO LOW DONOR NUMBER.

FIGURE 4.12: PLATELET ACTIVATION IN THE PRESENCE OF COLLAGEN SCAFFOLD MATERIAL

FIGURE 4.13: LPS INDUCED DONOR SPECIFIC NEUTROPHIL CELL RESPONSE. WHOLE BLOOD SAMPLES WERE STAINED FOR CD62L, CD11B AND FMLPR TO INDICATE NEUTROPHIL SPECIFIC RESPONSE IN THE PRESENCE OF LPS. SPECIFIC NEUTROPHIL RESPONSES WERE IDENTIFIED USING CELL TYPE SPECIFIC STAINS CD15+. PANELS A, B AND C INDICATE THE CD62L, CD11B AND FMLPR NEUTROPHIL SPECIFIC RESPONSE AS A FACS SCATTER GRAPH COMPARED TO CONTROL AND KALUZA ANALYSED SUMMATION RESPECTIVELY. ALL DATA SHOWN AS INDIVIDUAL SCATTER READINGS OR SUMMARISED DONOR COHORT.

FIGURE 4.14: LPS INDUCED DONOR SPECIFIC MONOCYTE CELL RESPONSE. WHOLE BLOOD SAMPLES WERE STAINED FOR CD62L, CD11B AND FMLPR TO INDICATE MONOCYTE SPECIFIC RESPONSE IN THE PRESENCE OF LPS. SPECIFIC NEUTROPHIL RESPONSES WERE IDENTIFIED USING CELL TYPE SPECIFIC STAINS CD15+. PANELS A, B AND C INDICATE THE CD62L, CD11B AND FMLPR NEUTROPHIL SPECIFIC RESPONSE AS A FACS SCATTER GRAPH COMPARED TO CONTROL AND KALUZA ANALYSED SUMMATION RESPECTIVELY. ALL DATA SHOWN AS INDIVIDUAL SCATTER READINGS OR SUMMARISED DONOR COHORT.

FIGURE 4.15: NEUTROPHIL ACTIVATION IN THE PRESENCE OF COLLAGEN SCAFFOLDS. SPECIFIC NEUTROPHIL (CD15+) ACTIVATION WAS DETECTED THROUGH LEVELS OF CD62L (A); CD11B (B) AND FMLPR (C), FOLLOWING A 2 HOUR INCUBATION WITH RTCOL, BCOL, JCOL AND BGEL SCAFFOLDS RESPECTIVELY. ALL MARKER STAINS WERE ALSO ANALYSED AS A FUNCTION OF EDC CROSS LINK PERCENTAGE AND ARE SHOWN HERE AS THREE PANELS, (I 0.25\%), (II 0.5\%) AND (III 1\%). ALL DATA SHOWN AS SUMMARISED DONOR COHORT RESPONSES 
FOLLOWING KALUZA COLLATION; MEDIAN VALUE DEPICTED A LINE IN EACH VARIABLE AND SAMPLE TYPE

FIGURE 4.16: MONOCYTE ACTIVATION IN THE PRESENCE OF COLLAGEN SCAFFOLDS. SPECIFIC MONOCYTE (CD14+) ACTIVATION WAS DETECTED THROUGH LEVELS OF CD62L (A); CD11B (B) AND FMLPR (C), FOLLOWING A 2 HOUR INCUB ATION WITH RTCOL, BCOL, JCOL AND BGEL SCAFFOLDS RESPECTIVELY. ALL MARKER STAINS WERE ALSO ANALYSED AS A FUNCTION OF EDC CROSS LINK PERCENTAGE AND ARE SHOWN HERE AS THREE PANELS, (I 0.25\%), (II 0.5\%) AND (III 1\%). ALL DATA SHOWN AS SUMMARISED DONOR COHORT RESPONSES FOLLOWING KALUZA COLLATION; MEDIAN VALUE DEPICTED A LINE IN EACH VARIABLE AND SAMPLE TYPE.

FIGURE 4.17: LPS INDUCED DONOR SPECIFIC T-CELL RESPONSES. WHOLE BLOOD SAMPLES WERE STAINED FOR CD62L, CD11B AND FMLPR TO INDICATE T-CELL SPECIFIC RESPONSE, USING CD3+ STAINS IN THE PRESENCE OF LPS. PANELS A, B AND C INDICATE THE CD62L, CD11B AND FMLPR T-CELL SPECIFIC RESPONSE AS A FACS SCATTER GRAPH COMPARED TO CONTROL AND KALUZA ANALYSED SUMMATION RESPECTIVELY. ALL DATA SHOWN AS INDIVIDUAL SCATTER READINGS OR SUMMARISED DONOR COHORT.

FIGURE 4.18: T-CELL ACTIVATION IN THE PRESENCE OF COLLAGEN SCAFFOLDS. SPECIFIC T-CELL ACTIVATION WAS DETECTED THROUGH LEVELS OF CD62L (A); CD11B (B) AND FMLPR (C), FOLLOWING A 2HR INCUBATION WITH RTCOL, BCOL, JCOL AND BGEL SCAFFOLDS RESPECTIVELY. ALL MARKER STAINS WERE ALSO ANALYSED AS A FUNCTION OF EDC CROSSLINK PERCENTAGE AND ARE SHOWN HERE AS THREE PANELS, (AI 0.25\%), (AII 0.5\%) AND (AIII 1\%). ALL DATA SHOWN AS SUMMARISED DONOR COHORT RESPONSES FOLLOWING KALUZA

COLLATION; MEDIAN VALUE DEPICTED A LINE IN EACH VARIABLE AND SAMPLE TYPE.

FIGURE 4.19: LPS INDUCED SPECIFIC CELL DEATH. WHOLE BLOOD SAMPLES WERE STAINED WITH DRAQ7 TO INDICATE CELL DEATH IN THE PRESENCE AND ABSENCE OF LPS STIMULATION. LPS STIMULATED CELLULAR RESPONSE IS SHOWS AS A FLOW CYTOMETRIC HISTOGRAM COMPARED TO CONTROL AND KALUZA ANALYSED SUMMATION FOR NEUTROPHILS (A), MONOCYTES (B) AND T-CELLS (C), RESPECTIVELY. ALL DATA SHOWN AS INDIVIDUAL READINGS OR SUMMARISED DONOR COHORT.

FIGURE 4.20: LEUKOCUYTE CELL DEATH IN THE PRESENCE OF SCAFFOLD STRUCTURES. LEUKOCYTE CELL DEATH IN THE PRESENCE OF SCAFFOLD STRUCTURE (A) NEUTROPHILS (B) MONOCYTES (C) T CELLS.

FIGURE 4.21: IL-6 RELEASE PROFILE IN THE PRESENCE OF SCAFFOLDS. WHOLE BLOOD SERUM SAMPLES INCUBATED IN MEDIA IN THE ABSENCE (A, C, E) AND PRESENCE OF LPS (B, D, F) WAS SUBJECTED TO ELISA TO OBTAIN CONCENTRATION OF IL-6 RELEASED. ALL DATA SHOWN IS THE STANDARD DEVIATION FROM A MINIMUM OF 3 INDEPENDENT BIOLOGICAL REPEATS, STATISTICAL SIGNIFICANCE SHOWN ACCORDING TO A PAIRED MANN WHITNEY $\mathrm{U}$ TEST $(* \mathrm{P}<0.05 ; * * \mathrm{P}<0.01 ; * * * \mathrm{P}<0.001)$

FIGURE 4.22: IL-10 RELEASE PROFILE IN THE PRESENCE OF SCAFFOLDS. WHOLE BLOOD SERUM SAMPLES INCUBATED IN MEDIA IN THE ABSENCE (A, C, E) AND PRESENCE OF LPS (B, D, F) WAS SUBJECTED TO ELISA TO OBTAIN CONCENTRATION OF IL-6 RELEASED. ALL DATA SHOWN IS THE STANDARD DEVIATION FROM A MINIMUM OF 3 INDEPENDENT BIOLOGICAL REPEATS, STATISTICAL SIGNIFICANCE SHOWN ACCORDING TO A PAIRED MANN WHITNEY U T TEST $(* \mathrm{P}<0.05 ; * * \mathrm{P}<0.01 ; * * * \mathrm{P}<0.001)$

FIGURE 4.0.23: SCHEMATIC OF ESTABLISHED PHASES IN WOUND HEALING. INITIAL INFLAMMATION DECREASES OVER TIME AS REGENERATION OF TISSUE OCCURS (CORRADETTI ET AL., 2017).

FIGURE 5.1: SCHEMATIC REPRESENTATION OF SIGNALLING CROSSTALK FOR CHONDROCYTE DIFFERENTIATION (MARIANI ET AL., 2014) .

FIGURE 5.2: BOVINE METACARPOPHALANGEAL JOINT. MCP JOINT OBTAINED FROM IMMATURE BOVINE LEGS. ANNOTATED AREAS OF THE JOINT DEPICT REGIONS FROM WHICH CARTILAGE WAS TAKEN FOR CHONDROPROGENITOR ISOLATION. 
FIGURE 5.3: IMAGES OF CHONDROPROGENITOR CELLS DURING TRILINEAGE DIFFERENTIATION AND STAINED CELLS AFTER 21 DAYS OF CULTURE. CHONDROPROGENITOR CELLS WERE IMAGED AT DAY 0 AND 21 OF CHONDROGENIC, OSTEOGENIC AND ADIPOGENIC CULTURE. AT DAY 21 CELLS WERE FIXED AND STAINED WITH ALCIAN BLUE, ALIZARIN RED AND OIL RED O TO CONFIRM DIFFERENTIATION INTO CHONDROGENIC, OSTEOGENIC AND ADIPOGENIC LINEAGES, RESPECTIVELY. SCALE B ARS SHOW 0.1MM

FIGURE 5.4: APPROACH FOR ENHANCED CHONDROGENESIS. CPS ISOLATED FROM BOVINE MCP JOINTS WERE CHARACTERISED AND ALLOWED TO CULTURE FOR 21 DAYS IN PELLET OR SCAFFOLD CULTURE IN THE PRESENCE OR ABSENCE OF TGFB. FOLLOWING COMPLETION OF THE CULTURE PERIOD, CONSTRUCTS WERE ANALYSED USING BIOCHEMICAL ANALYSIS, HISTOLOGY AND QPCR TO GIVE AN ENHANCED CHONDROGENIC PROFILE. 212

FIGURE 5.5: EARLY SEEDING STUDIES USING SCAFFOLDS WITH DECREASING EDC CROSSLINK CONCENTRATIONS. BOVINE CPS SEEDED INTO SCAFFOLDS CROSSLINED AT 1\%, $0.5 \%$ AND $0.25 \%$ EDC AND CULTURED FOR 7 DAYS IN CHONDROGENIC MEDIA. SCAFFOLDS WERE IMAGED AT X10 (A, B AND C) AND X40 (D, E AND F). SCALE BARS SHOW 0.1MM.

FIGURE 5.6: AVERAGE PORE SIZE AND PORE STRUCTURE OF JCOL SCAFFOLDS. AVERAGE PORE SIZE OF JCOL SCAFFOLDS (A) AND PORE STRUCTURE IMAGED AT X200 MAGNIFICATION USING SEM (B) CROSSLINKED AT 1\% EDC CONCENTRATION.

FIGURE 5.7: HEMOTOXYLIN AND EOSIN STAINING OF IMMATURE BOVINE CARTILAGE. NATIVE IMMATURE BOVINE CARTILAGE WAS STAINED USING HEMATOXYLIN AND EOSIN AND IMAGED AT LOW MAGNIFICATION (X4) (A) WITH SUPERFICIAL (S), MIDDLE (M) AND DEEP (D) ZONES LABELLED. HIGH MAGNIFICATION IMAGES (X40) WERE TAKEN OF THE SUPERFICIAL (B), MIDDLE (C) AND DEEP (D) ZONES. SCALE BARS ARE EQUAL TO 0.1MM.

FIGURE 5.8: HEMATOXYLINE AND EOSIN STAINING OF JCOL SCAFFOLDS AFTER 21 DAYS OF CHONDROGENIC CULTURE SUPPLEMENTED WITH TGFB1. JCOL SCAFFOLDS (IN THE SAGGITAL PLANE) WERE STAINED USING HEMATOXYLIN AND EOSIN AND IMAGED AT LOW MAGNIFICATION (X4) AFTER 21 DAYS OF CULTURE USING CHONDROGENIC MEDIA CONTAINING TGFB1 WITH SUPERFICIAL (S), MIDDLE (M) AND DEEP (D) ZONES LABELLED. HIGH MAGNIFICATION IMAGES (X40) WERE TAKEN OF THE AREAS REPRESENTING THE SUPERFICIAL (B), MIDDLE (C) AND DEEP (D) ZONES. SCALE BARS ARE EQUAL TO $0.1 \mathrm{MM}$

FIGURE 5.9: HEMATOXYLIN AND EOSIN STAINING OF JCOL SCAFFOLD AFTER 21 DAYS OF CHONDROGENIC CULTURE WITHOUT TGFB1. JCOL SCAFFOLDS IN THE SAGGITAL PLANE WERE STAINED USING HEMATOXYLIN AND EOSIN AND IMAGED AT LOW MAGNIFICATION (X4) AFTER 21 DAYS OF CULTURE USING CHONDROGENIC MEDIA IN THE ABSENCE TGFB1 WITH SUPERFICIAL (S), MIDDLE (M) AND DEEP (D) ZONES LABELLED. HIGH MAGNIFICATION IMAGES (X40) WERE TAKEN OF THE AREAS REPRESENTING THE SUPERFICIAL (B), MIDDLE (C) AND DEEP (D) ZONES. SCALE B ARS ARE EQUAL TO 0.1MM.

FIGURE 5.10: HEMATOXYLIN AND EOSIN STAINING OF CHONDROPROGENITOR CELLS IN PELLET CULTURE WITH TGFB1. PELLETS WERE STAINED AND IMAGED AT LOW MAGNIFICATION (X10) FOLLOWING 21 DAYS OF CHONDROGENIC CULTURE WITH TGFB1 (A). HIGH MAGNIFICATION IMAGES (X20) WERE TAKEN OF THE EDGE OF THE PELLET (B) AND THE CENTRE (C). SCALE B ARS EQUAL TO 0.1MM.

FIGURE 5.11: HEMATOXYLIN AND EOSIN STAINING OF CHONDROPROGENITOR CELLS IN PELLET CULTURE WITHOUT TGFB1. PELLETS WERE STAINED AND IMAGED AT LOW MAGNIFICATION (X10) FOLLOWING 21 DAYS OF CHONDROGENIC CULTURE WITHOUT TGFB1 (A). HIGH MAGNIFICATION IMAGES (X20) WERE TAKEN OF THE EDGE OF THE PELLET (B) AND THE CENTRE (C). SCALE B ARS EQUAL TO 0.1MM.

FIGURE 5.12: DNA CONTENT OF PELLET AND SCAFFOLD STRUCTURES. DNA CONTENT OF NATIVE IMMATURE BOVINE ARTICULAR CARTILAGE (A) WAS TAKEN AS A BENCHMARK. AFTER 21 DAYS OF CHONDROGENIC CULTURE PELLET AND 
SCAFFOLD CULTURES WITH AND WITHOUT TGFB1 WERE ANALYSED FOR THEIR DNA CONTENT. ALL DATA SHOWN IS FROM A MINIMUM OF 3 INDEPENDENT BIOLOGICAL REPEATS, STATISTICAL SIGNIFICANCE SHOWN ACCORDING TO A MANN WHITNEY U TEST $(* \mathrm{P}<0.05 ; * * \mathrm{P}<0.01 ; * * * \mathrm{P}<0.001)$.

FIGURE 5.13: CELL NUMBER FROM PELLET AND SCAFFOLD STRUCTURES FOLLOWING CHONDROGENESIS. CELL NUMBER OF NATIVE BOVINE ARTICULAR CARTILAGE WAS APPROXIMATED FROM DNA CONTENT AND USED AS A BENCHMARK (A). FOLLOWING 21 DAYS OF TGFB1 TREATED AND UNTREATED CHONDROGENESIS PELLET AND SCAFFOLD CULTURES WERE ANALYSED FOR CELL NUMBED USING DNA CONTENT. ALL DATA SHOWN IS FROM A MINIMUM OF 3 INDEPENDENT BIOLOGICAL REPEATS, STATISTICAL SIGNIFICANCE SHOWN ACCORDING TO A MANN WHITNEY U TEST $(* \mathrm{P}<0.05 ; * * \mathrm{P}<0.01 ; * * * \mathrm{P}<0.001)$

FIGURE 5.14: TOLUDINE BLUE STAINING OF IMMATURE BOVINE CARTILAGE. NATIVE IMMATURE BOVINE CARTILAGE WAS STAINED USING TOLUIDINE BLUE AND IMAGED AT LOW MAGNIFICATION (X4) (A) WITH SUPERFICIAL (S), MIDDLE (M) AND DEEP (D) ZONES LABELLED.. HIGH MAGNIFICATION IMAGES (X40) WERE TAKEN OF THE SUPERFICIAL (B), MIDDLE (C) AND DEEP (D) ZONES. SCALE B ARS ARE EQUAL TO 0.1MM.

FIGURE 5.15: TOLUDINE BLUE STAINING OF JCOL SCAFFOLDS AFTER 21 DAYS OF CHONDROGENIC CULTURE SUPPLEMENTED WITH TGF $\beta 1$. JCOL SCAFFOLDS WERE STAINED USING TOLUIDINE BLUE AND IMAGED AT LOW MAGNIFICATION (X4) AFTER 21 DAYS OF CULTURE USING CHONDROGENIC MEDIA CONTAINING TGFB1 WITH SUPERFICIAL (S), MIDDLE (M) AND DEEP (D) ZONES LABELLED.. HIGH MAGNIFICATION IMAGES (X40) WERE TAKEN OF THE AREAS REPRESENTING THE SUPERFICIAL (B), MIDDLE (C) AND DEEP (D) ZONES. SCALE BARS ARE EQUAL TO 0.1MM. 226

FIGURE 5.16: TOLUDINE BLUE STAINING OF JCOL SCAFFOLDS AFTER 21 DAYS OF CHONDROGENIC CULTURE WITHOUT TGFB1. JCOL SCAFFOLDS WERE STAINED USING TOLUIDINE BLUE AND IMAGED AT LOW MAGNIFICATION (X4) AFTER 21 DAYS OF CULTURE USING CHONDROGENIC MEDIA IN THE ABSENCE TGFB1 WITH SUPERFICIAL (S), MIDDLE (M) AND DEEP (D) ZONES LABELLED. HIGH MAGNIFICATION IMAGES (X40) WERE TAKEN OF THE AREAS REPRESENTING THE SUPERFICIAL (B), MIDDLE (C) AND DEEP (D) ZONES. SCALE B ARS ARE EQUAL TO $0.1 \mathrm{MM}$ 228

FIGURE 5.17: TOLUIDINE BLUE STAINING OF CHONDROPROGENITOR CELLS IN PELLET CULTURE WITH TGFB1. PELLETS WERE STAINED WITH TOLUIDINE BLUE AND IMAGED AT LOW MAGNIFICATION (X10) FOLLOWING 21 DAYS OF CHONDROGENIC CULTURE IN THE PRESENCE TGFB1 (A). HIGH MAGNIFICATION IMAGES (X20) WERE TAKEN OF THE EDGE OF THE PELLET (B) AND THE CENTRE (C). SCALE BARS EQUAL TO 0.1MM.

FIGURE 5.18: TOLUIDINE BLUE STAINING OF CHONDROPROGENITOR CELLS IN PELLET CULTURE WITHOUT TGFB1. PELLETS WERE STAINED AND IMAGED AT LOW MAGNIFICATION (X10) FOLLOWING 21 DAYS OF CHONDROGENIC CULTURE IN THE ABSENCE OF TGFB1 (A). HIGH MAGNIFICATION IMAGES (X20) WERE TAKEN OF THE EDGE OF THE PELLET (B) AND THE CENTRE (C). SCALE BARS EQUAL TO $0.1 \mathrm{MM}$

FIGURE 5.19: SULPHATED GLYCOSAMINOGLYCAN CONTENT OF PELLET AND

SCAFFOLD CULTURES AFTER 21 DAYS OF CHONDROGENESIS. SGAG CONTENT OF NATIVE IMMATURE CARTILAGE (A) WAS DETERMINED AND NORMALISED PER UG OF DNA AND USED AS A BENCHMARK. PELLET AND SCAFFOLD CULTURES TREATED AND UNTREATED WITH TGFB DURING CHONDROGENESIS WERE ANALYSED FOR SGAG CONTENT (B). ALL DATA SHOWN IS FROM A MINIMUM OF 3 INDEPENDENT BIOLOGICAL REPEATS, STATISTICAL SIGNIFICANCE SHOWN ACCORDING TO INDEPENDENT SAMPLES T TEST $(* \mathrm{P}<0.05$; $* * \mathrm{P}<0.01 ; * * * \mathrm{P}<0.001)$. 231

FIGURE 5.20: PICROSIRIUS RED STAINING OF NATIVE IMMATURE BOVINE CARTILAGE. IMMATURE BOVINE CARTILAGE STAINED WITH PICROSIRIUS RED IMAGED WITH A LIGHT MICROSCOPE AT LOW MAGNIFICATION (A) AND HIGH MAGNIFICATION (B) AND WITH POLARISED LIGHT TO SHOW BIREFRINGENCE AT LOW 
MAGNIFICATION (C) AND HIGH MAGNIFICATION (D). SCALE BARS EQUAL TO $0.1 \mathrm{MM}$.

FIGURE 5.21: PICROSIRIUS RED STAINING OF JCOL SCAFFOLDS FOLLOWING 21 DAYS OF CHONDROGENIC CULTURE WITH TGFB1. LOW MAGNIFICATION (X4) IMAGE OF JCOL SCAFFOLD IMAGED WITH A POLARISED LIGHT MICROSCOPE (A) WITH LABELLED SUPERFICIAL (S), MIDDLE (M) AND DEEP (D) ZONES. HIGH MAGNIFICATION (X20) IMAGES WERE TAKEN OF AREAS REPRESENTING THE SUPERFICIAL (B), MIDDLE (C) AND DEEP (D) ZONES

FIGURE 5.22: PICROSIRIUS RED STAINING OF JCOL SCAFFOLDS FOLLOWING 21 DAYS OF CHONDROGENIC CULTURE WITHOUT TGFB1. LOW MAGNIFICATION (X4) IMAGE OF JCOL SCAFFOLD IMAGED WITH A POLARISED LIGHT MICROSCOPE(A) WITH LABELLED SUPERFICIAL (S), MIDDLE (M) AND DEEP (D) ZONES. HIGH MAGNIFICATION (X20) IMAGES WERE TAKEN OF AREAS REPRESENTING THE SUPERFICIAL (B), MIDDLE (C) AND DEEP (D) ZONES

FIGURE 5.23: PICROSIRIUS RED STAINING OF CHONDROPROGENITOR CELLS IN PELLET CULTURE WITH TGFB1. PELLETS WERE STAINED AND IMAGED AT LOW MAGNIFICATION (X4) WITH POLARISED LIGHT FOLLOWING 21 DAYS OF CHONDROGENIC CULTURE WITH TGFB1 (A). HIGH MAGNIFICATION IMAGES (X20) WERE TAKEN OF THE EDGE OF THE PELLET (B). SCALE BARS EQUAL TO $0.1 \mathrm{M}$

FIGURE 5.24: PICROSIRIUS RED STAINING OF CHONDROPROGENITOR CELLS IN PELLET CULTURE WITHOUT TGFB1. PELLETS WERE STAINED AND IMAGED AT LOW MAGNIFICATION (X4) WITH POLARISED LIGHT FOLLOWING 21 DAYS OF CHONDROGENIC CULTURE WITHOUT TGFB1 (A). HIGH MAGNIFICATION IMAGES (X10) WERE TAKEN OF THE EDGE OF THE PELLET (B). SCALE BARS EQUAL TO $0.1 \mathrm{MM}$

FIGURE 5.25: HYDROXYPROLINE CONTENT OF PELLET AND SCAFFOLD CULTURES AFTER 21 DAYS OF CHONDROGENESIS. HYDROXYPROLINE CONTENT OF IMMATURE BOVINE CARTILAGE (A) NORMALISED PER UG OF DNA. TGFB TREATED AND UNTREATED PELLET AND SCAFFOLD CULTURES WERE ASSESSED FOR HYDROXYPROLINE CONTENT FOLLOWING CHONDROGENESIS (B). ALL DATA SHOWN IS FROM A MINIMUM OF 3 INDEPENDENT BIOLOGICAL REPEATS, STATISTICAL SIGNIFICANCE SHOWN ACCORDING TO MANN WHITNEY U TEST $(* \mathrm{P}<0.05 ; * * \mathrm{P}<0.01 ; * * * \mathrm{P}<0.001)$

FIGURE 5.26: SUMMARY PANEL OF HISTOLOGICAL ANALYSIS OF NATIVE TISSUE AND JCOL SCAFFOLDS WITH AND WITHOUT TGF 1 TREATMENT.

FIGURE 5.27: FOLD CHANGE OF SOX9 GENE EXPRESSION COMPARED TO NATIVE CARTILAGE. FOLD CHANGE OF SOX9 GENE EXPRESSION OF PELLET AND SCAFFOLD CULTURES FOLLOWING 21 DAYS OF CHONDROGENESIS IN THE PRESENCE AND ABSENCE OF TGFB COMPARED TO IMMATURE NATIVE BOVINE CARTILAGE.

FIGURE 5.28: FOLD CHANGE OF COL2A1 GENE EXPRESSION COMPARED TO NATIVE CARTILAGE. FOLD CHANGE OF COL2A1 GENE EXPRESSION OF PELLET AND SCAFFOLD CULTURES FOLLOWING 21 DAYS OF CHONDROGENESIS IN THE PRESENCE AND ABSENCE OF TGFB COMPARED TO NATIVE IMMATURE BOVINE CARTILAGE.

FIGURE 5.29: FOLD CHANGE OF ACAN GENE EXPRESSION COMPARED TO NATIVE CARTILAGE. FOLD CHANGE OF ACAN GENE EXPRESSION OF PELLET AND SCAFFOLD CULTURES FOLLOWING 21 DAYS OF CHONDROGENESIS IN THE PRESENCE AND ABSENCE OF TGFB COMPARED TO IMMATURE NATIVE BOVINE CARTILAGE.

FIGURE 5.30: FOLD CHANGE OF RUNX2 GENE EXPRESSION COMPARED TO NATIVE CARTILAGE. FOLD CHANGE OF RUNX2 GENE EXPRESSION OF PELLET AND SCAFFOLD CULTURES FOLLOWING 21 DAYS OF CHONDROGENESIS IN THE PRESENCE AND ABSENCE OF TGFB COMPARED TO NATIVE IMMATURE BOVINE CARTILAGE.

FIGURE 5.31: FOLD CHANGE OF COL1A1 GENE EXPRESSION COMPARED TO NATIVE CARTILAGE. FOLD CHANGE OF COL1A1 GENE EXPRESSION OF PELLET AND SCAFFOLD CULTURES FOLLOWING 21 DAYS OF CHONDROGENESIS IN THE 
PRESENCE AND ABSENCE OF TGFB COMPARED TO NATIVE IMMATURE BOVINE CARTILAGE.

FIGURE 5.32: FOLD CHANGE OF COL10A1 GENE EXPRESSION COMPARED TO NATIVE CARTILAGE. FOLD CHANGE OF COL10A1 GENE EXPRESSION OF PELLET AND SCAFFOLD CULTURES FOLLOWING 21 DAYS OF CHONDROGENESIS IN THE PRESENCE AND ABSENCE OF TGFB COMPARED TO NATIVE IMMATURE BOVINE

CARTILAGE

FIGURE 5.33: IMMUNOHISTOCHEMISTRY OF TGFB1 TREATED SCAFFOLDS. SCAFFOLDS WERE STAINED FOR CHONDROGENIC MARKERS COLLAGEN TYPE II AND AGGRECAN AS WELL AS COLLAGEN TYPE I, TYPICALLY FOUND IN FIBROCARTILAGE. IMAGES WITH A LIGHT MICROSCOPE AT X20 OBJECT. SCALE BARS ARE 50MM

FIGURE 6.1: SCHEMATIC OF EXPERIMENTAL AREAS AND OUTPUTS ACHIEVED IN THIS PROJECT. 


\section{Table list}

TABLE 1.1: COLLAGEN SUBFAMILY MEMBERS. COLLAGEN TYPES DIVIDED INTO SUBFAMILIES WITH GIVEN GENE AND TISSUE DISTRIBUTION (GELSE ET AL., 2003)

TABLE 1.2: NATURAL AND SYNTHETIC MATERIALS USED IN TISSUE ENGINEERING. A EXAMPLE OF THE RANGE OF NATURAL AND SYNTHETIC BIOMATERIALS HAS BEEN USED FOR DIFFERENT TISSUE ENGINEERING APPLICATIONS, OFTEN FOR THE SAME TISSUE WITH DIFFERENCES IN CELLULAR RESPONSE (MELTON, 2008)

TABLE 1.3: EXAMPLES OF OPTIMAL PORE SIZES FOR SPECIFIC APPLICATIONS IN TISSUE ENGINEERING (BRUŽAUSKAITÉ ET AL., 2016) ………………………....................

TABLE 2.1: PRIMERS USED FOR QPCR …………………………………………………….....69

TABLE 3.1: SUMMARY OF COLLAGEN EXTRACTION YIELD AND PURITY..........................83

TABLE 3.2: OUTPUT FROM MASS SPECTOMETRY FOLLOWING TRYPSIN DIGESTION OF R.PULMO ALPHA1 B AND.

TABLE 3.3: BLAST RESULTS FOR INDIVIDUAL R.PULMO PEPTIDES. PEPTIDES SEQUENCES RUN THROUGH BLAST DATABASE AND RESULTS SHOWING TOP 3 RELATED PROTEIN, SPECIES AND E VALUE FOR CORRESPONDING PEPTIDES. .....96

TABLE 3.4: ABBREVIATIONS FOR MATERIALS USED TO FABRICATE SCAFFOLDS....... 105 TABLE 5.1: TABLE OF COMMERCIALLY AVAILABLE SCAFFOLDS FOR MACI PROCEDURES (JEUKEN ET AL., 2016) 


\section{Abbreviations}

\#
2D
Two dimensional
3D
Three dimensional

$\underline{\mathbf{A}}$

AC

ACI

ADAMT

AFM

ATR FTIR
Articular cartilage

Autologous chondrocyte implantation

A disintergrin and metalloproteinase with thrombospondin motif

Atomic force microscopy

Attenuated reflectance Fourier transform infrared

spectroscopy

B

$\begin{array}{ll}\text { BCol } & \text { Bovine collagen } \\ \text { BGel } & \text { Bovine gelatin } \\ \text { BLAST } & \text { Basic local alignment search tool } \\ \text { BM } & \text { Basement membrane } \\ \text { BMP } & \text { Bone morphogenetic protein } \\ \text { BSA } & \text { Bovine serum albumin } \\ \text { BSE } & \text { Bovine spongiform encephalopathy }\end{array}$

C

$\begin{array}{ll}\text { COX } & \text { Cyclooxygenase } \\ \text { CP } & \text { Chondroprogenitor } \\ \text { CRR } & \text { Cysteine rich repeat } \\ \text { CS } & \text { Chondroitin sulphate }\end{array}$

D

$\begin{array}{ll}\text { DDR } & \text { Discoidin domain receptor } \\ \text { DMEM } & \text { Dulbecco's modified eagles medium } \\ \text { DMMB } & \text { 1,9-dimethylmethylene blue } \\ \text { DSC } & \text { Differential scanning calorimetry }\end{array}$

$\mathbf{E}$

ECM Extracellular matrix

EDC 1-ethyl-3-(3-dimethylaminopropyl)-carbodiimide

ELISA Enzyme linked immunosorbent assay

F

FACIT Fibril associated collagens with interrupted triple helices 
FBS

FGF

FSC

FTIR

$\underline{\mathbf{G}}$

$\begin{array}{ll}\text { GAGs } & \text { Glycosaminoglycans } \\ \text { GD } & \text { Globular domain } \\ \text { GMP } & \text { Good manufacturing practice }\end{array}$

$\underline{\mathbf{H}}$

HA

hESC

HRP

HSP47

$\underline{\text { I }}$

$\begin{array}{ll}\text { IBMX } & \text { Isobutylmethylxanthine } \\ \text { IL } & \text { Interleukin } \\ \text { iPSC } & \text { Induced pluripotent stem cells } \\ \text { ITS } & \text { Insulin, transferrin, selenium }\end{array}$

$\underline{\mathbf{J}}$

JCol Jellyfish collagen

$\underline{\mathbf{K}}$

KS Keratan sulphate

$\underline{\mathbf{M}}$

MACI

MCP

MLBR

MMP

MRI

MSC

$\underline{\mathbf{N}}$

NBFS

NSAIDs

Neutral buffered formalin with saline

Non steroidal anti inflammatory drugs
Matrix assisted chondrocyte implantation

Metacarpophalangeal

Major ligand binding region

Matrix metalloproteinase

Magnetic resonance imaging

Mesenchymal stem cells

$\underline{\mathbf{O}}$

OA Osteoarthritis 
$\mathbf{P}$

PBMC

Peripheral blood mononuclear cells

PBS

PGs

PMA

Phosphate buffered saline

PPI

Proteoglycans

4 beta-phorbol-12-myristate-13-acetate

Peptidyl-prolyl cis trans isomerase

$\underline{Q}$

qPCR Quantitative polymerase chain reaction

$\underline{\mathbf{R}}$

$\begin{array}{ll}\text { RTCol } & \text { Rat-tail collagen } \\ \text { RUNX2 } & \text { Runt related transcription factor } 2\end{array}$

$\underline{\mathbf{S}}$

SDS PAGE

SEM

SOX9

SSC

$\underline{\mathbf{T}}$

TGF $\beta$
TSPN

TGF $\beta$
TSPN
Sodium dodecyl sulphate polyacrylamide gel electrophoresis Scanning electron microscopy

Sex determining region Y Box 9 protein

Side scatter

Transforming growth factor beta

Thrombospondin N-terminal like 
CHAPTER 1

\section{Introduction}




\subsection{Multicellular organisms, tissues and extracellular matrix}

Within multicellular organisms, tissues are organised as communities of cells that work together to carry out specific functions, such as protection, movement and response to stimuli. The exact role of a tissue in an organism depends on what types of cell it contains. The multitude of tissue specific cell types and functions are maintained by differential transcriptional programs and rates, which are essential to tissue maintenance and repair (Ong and Corces, 2011). The spatial organisation of the cells that form tissues is also central to their function and survival. This organisation depends in part on polarity and external signals from neighbouring cells and or from the extracellular matrix (ECM) (Frantz et al., 2010).

The ECM is critical to tissue structure, providing attachment sites for cells and relaying information regarding the spatial position of the cell. The ECM consists of a mixture of proteins and polysaccharides produced by nearby cells. Once synthesised, these molecules move to the appropriate side of the cell - such as the basal or apical face - where they are secreted (Overeem et al., 2015). Final ECM construction and organisation then occurs outside of the cell and is in general a mix of collagen, proteoglycan and polysaccharide that undergo turnover over time as a consequence of growth, development and homeostatic maintenance (Birk, 2011).

\subsubsection{Extracellular matrix}

As well as a supportive function, the ECM has been shown to be involved in cellular processes such as migration, differentiation and apoptosis (Naahidi et al., 2017). At the most basic level, the ECM is composed of water, proteins and polysaccharides (Frantz et al., 2010). The exact composition of the ECM is tissue specific and offers specialised cues to cells through mechanical properties and acting as a reservoir for growth factors (Kayabolen et al., 2017).

The ECM can be divided into two categories: basement or interstitial with each having distinct properties. The interstitial matrix is responsible for the tensile strength exhibited by the tissue. It is hydrated and highly charged due to its content of fibrillar collagens, proteoglycans (PGs) and glycosaminoglycans (GAGs). 
Alternatively, the basement membrane (BM) primarily contains collagen IV and is compact and less porous than its counterpart (Lu et al., 2012).

The basement membrane is a specialised extracellular matrix, approximately 50 $100 \mathrm{~nm}$ thick, and separates cells from connective tissue within the human body (LeBleu et al., 2007). The sheet-like structure of the basement membrane is composed of individual collagen type IV and laminin networks that are linked by extracellular proteins including nidogen and perlecan. The BM's interaction with cells is dependent on its anchorage to the cell surface, which is mediated through adhesion receptors and sulphated glycolipids (Jayadev and Sherwood, 2017). A difference in the molecular composition of BMs allow for them to be tissue specific and defines plasticity between epithelial and endothelial cells in different organs. The interaction with cellular components of tissue gives the BM various functions including the compartmentalisation of tissues, cellular support and regulation of cell behaviour (Kalluri, 2003).

The interstitial matrix, also known as the extracellular matrix, appears in the same location as the BM however it may also appear between connective tissue cells. The ECM can be seen as an amorphous gel that is composed from collagens, elastin and fibronectin (Kular et al., 2014). Although the ECM was once viewed as a simple structural framework within tissue, a more dynamic role has been elucidated. A number of functions can be assigned to the ECM including highly regulated homeostasis and behaving as a reservoir for molecules such as growth factors and cytokines (Wilson, 2014). As well as these functions, the ECM also serves as a cellular microenvironment, influencing cell behaviour such as migration and proliferation (Hubmacher and Apte, 2013). The combination of different roles highlights the importance of the extracellular matrix and the necessity of the matrix during developmental and repair processes within the human body (Wilson, 2014).

\subsection{Collagen}

Collagen is an insoluble, fibrous protein that can be found both in the extracellular matrix and connective tissues. Although it was originally believed that connective 
tissue fibroblasts secreted collagen, it has now been shown that epithelial cells are able to produce various different isoforms of the protein that vary in their structure, allowing tissues to have different, functionally driven, tensile properties (Lodish et al., 2000a).

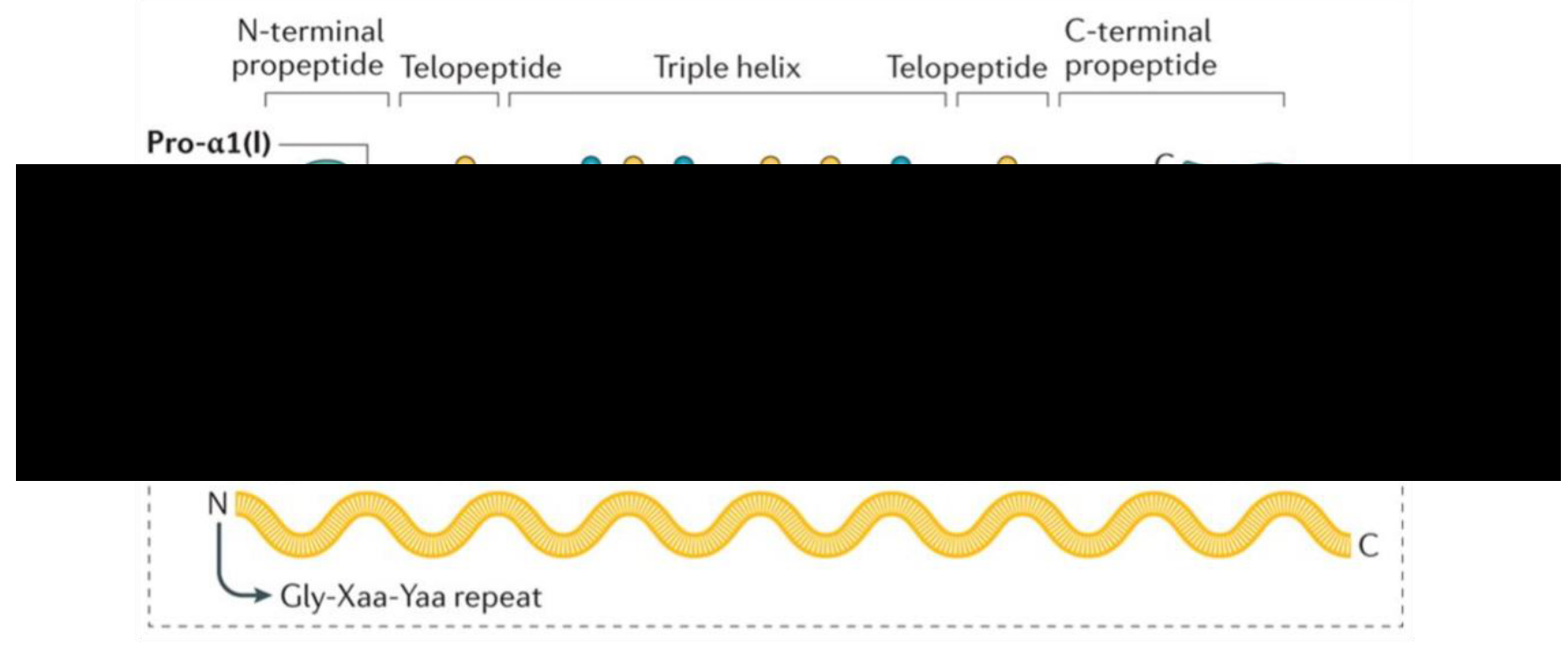

Figure 1.1: Type 1 collagen structure. $\alpha$ chains come together to form a triple helix. Repetitive Gly-X-Y regions allow for tight packing of the helix and major ligand binding regions (MLBR) allow for collagens to interact with other collagens and ECM proteins. The pro-collagen molecule has amino and carboxy regions cleaved to become a mature collagen molecule (Marini et al., 2017)

Currently, the collagen superfamily is comprised of 28 members that present common structural features. Collagen molecules are formed by a combination of three homotrimeric or heterotrimeric alpha chains giving rise to a triple helix, seen in Figure 1.1 (Exposito et al., 2002). The definitive feature of collagen is the combination of three polypeptide chains in a left handed helix formation with a single amino acid residue stagger between each chain to form a right handed triple helical structure associated with tensile strength (Shoulders and Raines, 2009). The tightly packed helix is reliant upon the repetitive Gly-X-Y amino acid sequence within each individual polypeptide chain, with glycine taking the first position in each repeat and is depicted in $\alpha$ chain gene structures in Figure 1.2 (Parenteau-Bareil et al., 2010). This triple helical region can account for $95 \%$ of the total structure in collagen I to less than $10 \%$ in collagen XII (Ricard-Blum, 2011). 


\subsubsection{Collagen Biosynthesis}

Extensive research has been conducted centred on collagen biosynthesis, leading to a high level of understanding of fibrillar collagens and the single cells that have been shown to synthesise various types of collagen (Exposito et al., 2010). Precursor molecules, containing large amino $(\mathrm{N})$ and carboxy (C) terminal pro-peptides are synthesised, with each pro-peptide $\mathrm{N}$-terminus containing a signal sequence to allow for translocation into the lumen of the rough endoplasmic reticulum (Mouw et al., 2014). A 15 amino acid region has been identified in the C-terminal pro-peptide that is thought to be involved in recognition of different chains showing that it plays a pivotal role in the assembly of the helix. Multiple sequence alignment of mammalian C-terminal peptides revealed that this region is composed of two hydrophilic portions of 12 and 3 amino acids separated by a highly conserved hydrophobic sequence (Exposito et al., 2010). 

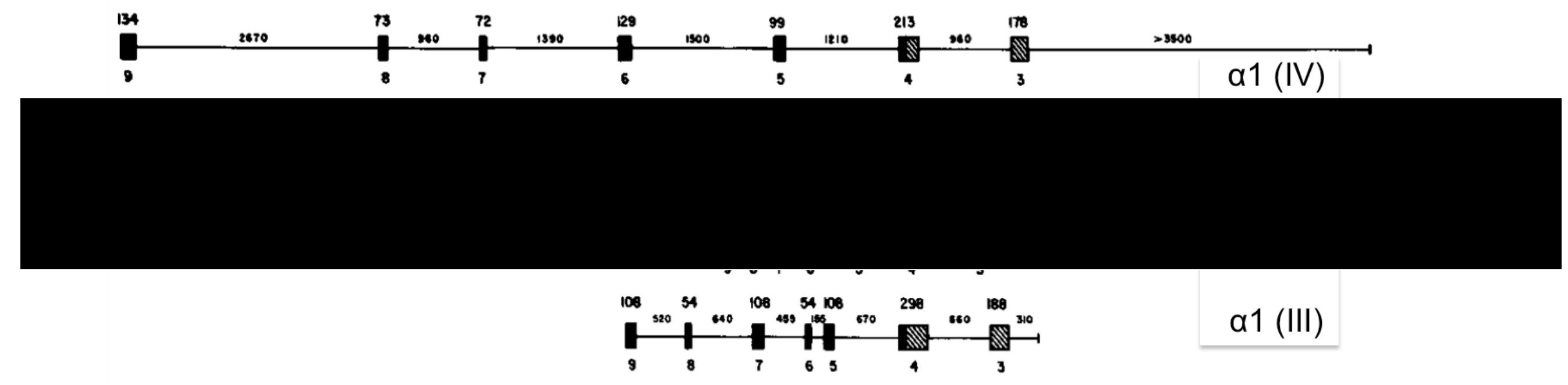

Figure 1.2: Comparison of gene structure of human procollagens. Human procollagen $\alpha 1$ (IV), $\alpha 2$ (I), $\alpha 1$ (II) and $\alpha 1$ (III) genes. Solid lines represent intron sequences black boxes represent Gly-X-Y repeats and hatched boxes represent NC-1 domain coding exons. Sizes of intron and exons are indicated by the corresponding numbers above sequences (Soininen et al., 1986). 
Post-translational modification of the polypeptide chain is initiated during translocation. These modifications include prolyl-4-hydroxylation and prolyl-3hydroxylation at the $\mathrm{Y}$ and $\mathrm{X}$ positions respectively, and lysyl hydroxylation giving rise to hydroxylysine residues (Koide and Nagata, 2005). During this process, galactose and glucose residues are also attached to hydroxylysine residues whilst oligosaccharides are added to the C-terminal pro-peptide. Following translocation and modification, pro-peptide chains trimerize at the $\mathrm{C}$-terminal domain forming intermolecular disulphide bonds and halting any further modification, with association only occurring if the correct chains are present for the distinct collagen type (Lodish et al., 2000a).

Many proteins are involved in the triple helix formation of procollagen molecules including heat shock protein 47 (HSP47) and peptidyl-prolyl cis-trans isomerase (PPI). The stabilisation of procollagen at body temperature takes an average of more than 20 heat shock proteins (Ricard-Blum, 2011). The importance of these two proteins in helix formation has been indicated through in vitro experiments involving murine models, leading to fatal consequences (Gelse et al., 2003). Previous reports have shown that HSP47 knockout mice cause improper formation of type I and IV collagen, aggregating in the endoplasmic reticulum and leading to cell death (Kawasaki et al., 2014)

Once secreted into the extracellular matrix both amino and carboxy pro-peptides are enzymatically cleaved producing mature collagen molecules that proceed to assemble into fibrils. N-terminal peptides are cleaved by a disintegrin and metalloproteinase with thrombospondin motif (ADAMTs) family members 2 and 3, whilst C-terminal peptides are removed by bone morphogenetic protein 1 (BMP1) (Ricard-Blum, 2011). Following telopeptide cleavage, collagen chains come together to form fibrils. Their longitudinal orientation is staggered creating alternating areas of high and low density that is known as a D periodicity repeating at approximately $67 \mathrm{~nm}$ and can be seen at the ultrastructural level (Yamauchi and Sricholpech, 2012).

The stabilisation of collagen fibrils is enhanced with the formation of covalent crosslinks that occur due to the hydroxylation of lysines at the telopeptide region. 
The proportion of hydroxylated lysine varies between tissues and is dependent on their function within tissues such as cartilage showing a larger percentage of hydroxylation compared to skin. Lysyl oxidases are copper dependent oxidodeaminases that catalyse the formation of aldehydes between lysine and hydroxylysine residues whilst spontaneous reactions form intermediate crosslinks. During maturation of tissues these intermediate reducible crosslinks can be converted into non-reducible crosslinks changing the physical and mechanical properties of the tissues (Gelse et al., 2003).

Assembly of supramolecular structures begins with the trimerization of three alpha chains to form a triple helical protomer with each helical portion flanked by non collagenous regions varying in sequence and length (Veit et al., 2006). Specific protomers organise themselves into suprastructures by forming end to end connections, lateral associations and supercoiling of helices (Khoshnoodi et al., 2006). The exact mechanisms of how alpha chains recognize each other to form superstructures is not fully understood. In the case of collagen I and III it is thought that the non collagenous C-terminal domain are key in the selection binding and recognition of alpha chains to complete trimerization (Doege and Fessler, 1986).

\subsubsection{Collagen family structural and functional variety}

Collagen molecules occur in various suprastructures, such as fibrils and networks outlined in Table 1.1. These basic scaffold structures form attachments to other macromolecular complexes such as cell surface receptors and proteoglycans in order to fulfill a variety of functional roles in tissue development and homeostasis (Khoshnoodi et al., 2006). These distinct subfamilies are then outlined in more detail in Table 1.1. 


\begin{tabular}{|c|c|c|c|}
\hline Subfamily & Type & Gene & Tissue \\
\hline \multirow{8}{*}{ Fibrillar collagens } & $\mathrm{I}$ & COL1A1-2 & $\begin{array}{l}\text { Bone, dermis, } \\
\text { tendon, ligaments, } \\
\text { cornea }\end{array}$ \\
\hline & II & COL2A1 & $\begin{array}{l}\text { Cartilage, vitreous } \\
\text { body }\end{array}$ \\
\hline & III & COL3A1 & $\begin{array}{l}\text { Skin, vessel wall, } \\
\text { reticular fibres }\end{array}$ \\
\hline & $\mathrm{V}$ & COL5A1-3 & Lung, cornea, bone \\
\hline & $\mathrm{XI}$ & COL11A1-2 & $\begin{array}{l}\text { Cartilage, vitreous } \\
\text { body }\end{array}$ \\
\hline & XXIV & COL24A1 & $\begin{array}{l}\text { Bone, brain, } \\
\text { muscles, testis, } \\
\text { ovaries }\end{array}$ \\
\hline & XXVI & COL26A1 & Testis, ovaries \\
\hline & XXVII & COL27A1 & $\begin{array}{l}\text { Cartilage, skin, } \\
\text { tendon }\end{array}$ \\
\hline $\begin{array}{l}\text { Basement } \\
\text { membrane }\end{array}$ & IV & COL4A1-6 & $\begin{array}{l}\text { Basement } \\
\text { membranes }\end{array}$ \\
\hline Microfibrillar & VI & COL6A1-3 & $\begin{array}{l}\text { Dermis, cartilage, } \\
\text { placenta, lungs }\end{array}$ \\
\hline Anchoring fibrils & VII & COL7A1 & $\begin{array}{l}\text { Skin, cervix, oral } \\
\text { mucosa }\end{array}$ \\
\hline \multirow[t]{2}{*}{ Network forming } & VIII & COL8A1-2 & Endothelial cells \\
\hline & $\mathrm{X}$ & COL10A1 & $\begin{array}{l}\text { Hypertrophic } \\
\text { cartilage }\end{array}$ \\
\hline \multirow{7}{*}{ FACIT } & IX & COL9A1-3 & Cartilage, cornea \\
\hline & XII & COL12A1 & $\begin{array}{l}\text { Ligaments, } \\
\text { tendons, } \\
\text { perichondrium } \\
\end{array}$ \\
\hline & XIV & COL14A1 & $\begin{array}{l}\text { Dermis, tendon, } \\
\text { placenta, liver }\end{array}$ \\
\hline & XIX & COL19A1 & $\begin{array}{l}\text { Human } \\
\text { rhabdomyosarcoma }\end{array}$ \\
\hline & $\mathrm{XX}$ & COL20A1 & $\begin{array}{l}\text { Sternal cartilage, } \\
\text { corneal epithelium, } \\
\text { embryonic skin }\end{array}$ \\
\hline & XXI & COL21A1 & Blood vessel wall \\
\hline & XXII & COL22A1 & $\begin{array}{l}\text { Heart, skeletal } \\
\text { muscle }\end{array}$ \\
\hline \multirow{4}{*}{ Transmembrane } & XIII & COL13A1 & $\begin{array}{l}\text { Epidermis, lungs, } \\
\text { liver }\end{array}$ \\
\hline & XXV & COL17A1 & $\begin{array}{l}\text { Dermal-epidermal } \\
\text { junctions }\end{array}$ \\
\hline & XXIII & COL23A1 & $\begin{array}{l}\text { Lungs, tongue, } \\
\text { kidney, cornea, } \\
\text { brain }\end{array}$ \\
\hline & XXV & COL25A1 & Brain \\
\hline
\end{tabular}




\begin{tabular}{|llll|}
\hline & XXVIII & COL28A1 & Peripheral nerves \\
\hline \multirow{4}{*}{ Multiplexins } & XV & COL15A1 & $\begin{array}{l}\text { Smooth muscle, } \\
\text { kidney, pancreas }\end{array}$ \\
\cline { 2 - 4 } & XVI & COL16A1 & $\begin{array}{l}\text { Amnion, } \\
\text { keratinocytes }\end{array}$ \\
\cline { 2 - 4 } & XVIII & COL18A1 & Lungs, liver \\
\hline
\end{tabular}

Table 1.1: Collagen subfamily members. Collagen types divided into subfamilies with given gene and tissue distribution (Gelse et al., 2003).

\subsubsection{Fibril forming collagens}

The collagen family was previously considered to form fibrillar structures that contribute to the structural integrity of tissues and organs. They are found in the extracellular matrix and the interstitial tissue of parenchymal organs and behave as a scaffold structure lending their properties to tissues. Any disruption in the collagen metabolism and degradation also leads towards diseases, such as osteoarthritis and osteoporosis, further highlighting the importance of collagen as a structural protein (Gelse et al., 2003).

Fibril forming collagens include type I, III and V, which are widely distributed throughout the body whilst other types, such as II and XI are predominantly found in cartilage and eye (Ricard-Blum and Ruggiero, 2005). The 12 fibril forming $\alpha$ chains contain an uninterrupted collagenous domain (COL1) flanked by non collagenous $\mathrm{N}$ and C-terminal pro-peptides that are cleaved in order to aid in fibril formation (Khoshnoodi et al., 2006). The C-terminal pro-peptide is also referred to as the NC1 domain whilst the N pro-peptide is split into a short NC2 sequence that links the main triple helix to a minor version (COL2) and NC3, a globular N terminal (RicardBlum and Ruggiero, 2005).

The NC3 domain of $\alpha$ chains $\alpha 1(\mathrm{I}), \alpha 1(\mathrm{IIA}), \alpha 1(\mathrm{III})$ and $\alpha 2(\mathrm{~V})$ all contain a cysteine rich repeat (CRR) domain characterised by the presence of 10 cysteine residues that are able to form disulphide bonds (Bornstein, 2002). CRR domains have been found present in homologous proteins of Xenopus chordin and Drosophila sog and bind to members of the TGF $\beta$ superfamily. The release of these growth factors plays a crucial role in dorsal-ventral patterning (Zhu et al., 1999). However, deletions of 
CRR-containing domains in mice have shown normal development is unaffected (Bornstein, 2002). Although the exact mechanism of CRR domains have not been found it is believed that they are involved in roles such as molecular assembly and regulation of procollagen synthesis and fibrillogenesis (Ricard-Blum and Ruggiero, 2005).

Conversely, the NC3 domain of $\alpha 1(\mathrm{~V}), \alpha 3(\mathrm{~V}), \alpha 1(\mathrm{XI}), \alpha 2(\mathrm{XI}), \alpha 1(\mathrm{XXIV})$ and $\alpha 1($ XXVII) contain a 200 residue thrombospondin N-terminal like (TSPN) domain (Eyre et al., 2002). The function of TSPN domains in fibrillar collagens has not been elucidated however it is observed that the domain is released during $\mathrm{N}$-terminal maturation of collagen type $\mathrm{V}$ and XI. Spontaneous mutation of human COL5A1 restricting the release of the TSPN domain disrupted fibrillogenesis and caused classical symptoms of Ehlers-Danlos syndrome (Takahara et al., 2002).

The vast majority of collagen fibrils are heterotypic, comprised of different types of collagen ( $\mathrm{Wu}$ et al., 2010). Although the initial stages of fibrillogenesis have not been clearly defined, it is a process that relies upon leucine-rich proteoglycans and collagen V and XIV for regulation and these molecules are also thought to play roles in collagen crosslinking (Ricard-Blum, 2011).

\subsubsection{Fibril-associated collagen with interrupted triple helix (FACIT) collagens}

FACIT collagens are a specific collagen subtype, grouped together due to the regions of high homology combined with unique regions not found in other collagen classifications (Shaw and Olsen, 1991). Collagens classified as FACITs include types IX, XII, XIX, XX and XXII (Khoshnoodi et al., 2006). These collagens are classified by the presence of two or more short triple helical domains interrupted by several non collagenous domains (Ricard-Blum, 2011). The helical conformation is comprised of glycine side chains occupying the centre of the helix whilst Xaa and Yaa amino acids of the side chains point outwards. This organisation ensures that there are numerous amino acids at the surface of the protein that have the ability to interact with other molecules (Rest et al., 1991). Another characteristic feature of FACITs is a short C-terminal triple helical domain, comprised of 75 residues in 
collagen XII to fewer than 30 residues in collagen IX that is contained by a cysteine containing motif and a non helical region (Birk, 2011).

FACIT collagens display variances in the size and composition of their $\mathrm{N}$-terminal domains. Collagens IX, XVI and XIX maintain a single TSPN module at the Nterminal however in collagens XXI and XXII a von Willebrand factor A-like domain next to the TSPN domain. In certain species alternative splicing of collagens XIV, XII and XIX mRNA occurs in the N-terminal domains making FACIT collagens a complex molecule to study at protein level (Ricard-Blum et al., 2000). The specific function of FACIT collagens has yet to be elucidated however they are believed to stabilise the extracellular matrix. The expression of FACITs appears in developmentally regulated patterns suggesting that they have more diverse functions (Ricard-Blum and Ruggiero, 2005).

Whilst fibrillar collagens aggregate, FACITs may interact with them in order to control fibril diameter and also aid in interaction with other ECM components (Rest and Garrone, 1991). Of the several collagens in the FACIT family, collagen IX is the most well studied FACIT collagen in structure and function. In the case of collagen IX and its association with fibrillar collagen, the non-C-terminal triple helix domains are incorporated into the collagen fibrils and stabilise the fibrillar organisation. Although this function has been elucidated in type IX collagen it is not seen as a phenomenon that occurs with all FACITs (Birk, 2011).

\subsubsection{Network forming collagens}

Individual types of collagen (type IV, VI, VIII and X) are able to aggregate in a linear and lateral fashion in order to form open networks that carry out a variety of functions such as anchorage and support for cells and serving as a molecular filter. Type IV collagen is often seen as the most important network forming collagen as it is the major constituent of the basement membrane (Knupp and Squire, 2005).

Collagen VI is expressed throughout connective tissues and is formed by 3 alpha chains, $\alpha 1, \alpha 2$ and $\alpha 3$ that form beaded filaments (Ball et al., 2001). Each alpha 
chain consists of a collagenous domain of approximately 335 residues that is capped by non-collagenous domains at the $\mathrm{C}$ - and $\mathrm{N}$-terminals. Whilst the $\alpha 1$ and $\alpha 2$ chains are similar in size and possess three non-collagenous subdomains (N1, C1 and C2), the $\alpha 3$ chain is significantly longer with the $\mathrm{N}$-terminal possessing 10 subdomains and the C-terminal possessing five (Khoshnoodi et al., 2006).

Unlike fibrillar collagens, network-forming collagens, in particular type IV collagen, do not require cleavage of $\mathrm{C}$ - and $\mathrm{N}$-terminal propeptides to form networks at the basement membrane. Collagen in the basement membrane is unique in its structure due to the self-assembly of individual protomers via aggregation and crosslinking forming a complex meshwork (Harvey and Thorner, 2005).

\subsubsection{Transmembrane collagens}

Transmembrane collagen function as cell surface receptors and matrix components and include collagen types XIII, XVII, XXIII and XXV as well as collagen related proteins such as macrophage receptor MARCO and ectodysplasin A (Franzke et al., 2005). The alpha chains of this collagen type host a non collagenous $\mathrm{N}$ terminal domain that has three subdomains (intracellular, single transmembrane and extracellular linker) and a large extracellular domain (Khoshnoodi et al., 2006). Deletion studies conducted on type XIII and XVII N terminal regions show that they are necessary for the formation of the triple helix and that the process occurs in a $\mathrm{N}$ to C-terminal manner, which is unlike all other collagen classifications (Areida et al., 2001).

\subsubsection{Collagen receptors}

As well as offering a supportive role as part of the extracellular matrix, collagens also participate in cell-matrix interactions through receptor families that aid in various physiological processes including cell anchorage, polarity and differentiation (Ricard-Blum, 2011). Interaction of matrix components with collagen may occur in the helical COL domain or non-collagenous domains (Leitinger, 2011). Within the COL region specific amino acid motifs provide a site for interactions however the 
COL region also plays host to cryptic binding sites that are able to form interactions following denaturation of the protein (Heino, 2007). Cryptic motifs have been shown to be important in the removal of denatured and degraded collagen (Engelholm et al., 2009). Specific 6-12 amino acid motifs are found within the COL region for integrins and dimeric discoidin receptors (DDRs) whilst common motifs such as GPO, where O represents hydroxylysine, are recognised by GPVI and LAIR-1 (Leitinger, 2011).

Integrins are a family of extracellular matrix receptors for cell adhesion that are formed through the non-covalent association of $\alpha$ and $\beta$ subunits (Hynes, 2002). Four integrins behave as collagen receptors: $\alpha 1 \beta 1$ expressed by mesenchymal cells, $\alpha 2 \beta 1$ primarily expressed in epithelial cells as well as platelets, $\alpha 10 \beta 1$ in chondrocytes and $\alpha 11 \beta 1$ in fibroblasts. GFOGER was the first motif identified as a high affinity binding site for $\alpha 1 \beta 1$ and $\alpha 2 \beta 1$ as well as $\alpha 11 \beta 1$ whilst a later study also identified GLOGER and GASGER as two additional binding motifs (Leitinger, 2011).

The discoidin domain receptors DDR1 and DDR2 belong to a subfamily of receptor tyrosine kinases where the ectodomain is split into two domains: $\mathrm{N}$-terminal discoidin homology (DS) domain and a unique DDR globular domain. A single transmembrane domain connects the extracellular domain and the cytoplasmic domain (Leitinger, 2011). Both DDR1 and DDR2 are found throughout foetal and adult tissues with DDR1 found in epithelial cells and DDR2 found in mesenchymal (Alves et al., 1995). DDRs bind to a broad range of collagen types and have been shown to need an intact triple helix in order to bind (Leitinger, 2003).

DDRs are regulators of cell adhesion, migration, proliferation and differentiation. They also influence matrix metalloproteinases to remodel the matrix (Leitinger, 2011). Once DDR binding to collagen has occurred, phosphorylation of cytoplasmic tyrosine residues takes place and behaves as a docking site for adaptor molecules however it is uncertain how this process links to cellular processes (Ikeda et al., 2002). As with integrins, DDRs bind to specific motif within the collagen molecule. DDR1 and DDR2 binding had been found to occur in the COL region at a GVMGF motif that appears in collagens I-III (Xu et al., 2011). DDR1 and DDR2 extracellular 
domains regulate collagen deposition within the extracellular matrix by inhibiting fibrillogenesis. When bound to collagen I, DDR2 affects mechanical properties of the fibre by reducing their length and Young's modulus (Ricard-Blum, 2011).

\subsection{ECM structure, cell function and disease development}

Combinations of characteristics possessed by the ECM have an effect upon cellular functions, ranging from physical properties such as stiffness to the biochemical signature of tissue specific ECM exhibited by proteins, growth factors and signal receptors (Kim et al., 2011). The dynamic environment within a tissue is dependent upon the interactions of cells with the ECM as well as neighbouring cells. These interactions allow for the regulation of cell function and homeostasis of the tissue, with a lack of interaction between cells and ECM leading to anoikis, a specific form of cell death (Marastoni et al., 2008). Adherent cells are protected from anoikis and the phenomenon is seen as a hallmark of cancer and is linked with tumour metastasis (Barthes et al., 2014).

The primary function of the ECM is as a supportive structure and the physical properties of the extracellular matrix plays a role in cell fate, migration, proliferation and survival (Kim et al., 2011). The human body presents a wide range of tissues with various degrees of elasticity, from pliable brain tissue with an elastic modulus in kilopascal to hard, calcified bone exhibiting a modulus in megapascals. Cells within these tissues become accustomed to the environment in which they reside and are able to maintain their phenotype. However, studies have shown that the ECM environment is able to guide differentiation of mesenchymal stem cells down osteoblastic, skeletal muscular and neural lineages in an ECM biomechanicaldependent manner (Park et al., 2011).

Cleavage of the ECM is needed for regulating composition and structure as well as the release of specific growth factors and is undertaken by different families of proteases (Bonnans et al., 2014). Two major classes of proteases that are involved in matrix remodelling are matrix metalloproteinases (MMPs) and a disintegrin and metalloproteinases with a thrombospondin motif proteins (ADAMTS). MMPs are 
secreted as zymogens and are activated either by proteolytic cleaveage by Ser preoteases or other MMPs or oxidation that modifies thiol groups, enabling the degradation of ECM proteins (Hynes and Naba, 2012). MMPs are capable of breaking down a multitude of ECM components including proteoglycans, fibronectin and laminin (MMP3 and MMP10). Collagen type III is typically targeted by MMP1 whilst collagen I and II are targets of MMP8 and MMP13, respectively ( $\mathrm{Lu}$ et al., 2011). ADAMTS are proteinases that contain thrombospondin motifs are the carboxy terminal and are known to degrade collagen and proteoglycans found within the ECM (Bonnans et al., 2014).

\subsubsection{Increased ECM degradation}

Deregulation of ECM breakdown by MMPs and ADAMTs proteases, can affect matrix and cell interactions, leading to disease development and pathogenesis (Bonnans et al., 2014). Increased expression of MMP1, which is specific to the heart, results in a loss of collagen and subsequently contractility leading to cardiomyopathy (Kim et al., 2000). Whereas in osteoarthritis an increase of ADAMTS4 and ADAMTS5 are responsible for the degradation of the cartilage tissue (Bondeson et al., 2008). The mechanisms that are responsible for upregulation of these degradative enzymes have yet to be discovered however it is thought that receptors involved in cell-matrix interaction may promote increased activation of MMPs and ADAMTs (Echtermeyer et al., 2009).

\subsubsection{Excessive ECM production}

Following chronic injury, the excessive production and deposition of ECM without appropriate breakdown can lead to fibrosis (Bonnans et al., 2014). The abnormal tissue development may result in fatalities due to organ failure and has also been shown to increase the risk of cancer when occurring in certain organs such as breast and liver (El-Serag, 2011). Fibrosis is primarily mediated by fibroblasts and other stromal cells whereby the expression of approximately 60 ECM related genes are upregulated including those for collagen type I and III (Verrecchia et al., 2001). Fibrosis may also be stimulated immune cells that have been activated by 
interleukin-33 (IL-33), in turn promoting the production of IL-13, which downregulates MMPs and stimulates collagen accumulation at the site of inflammation (Bailey et al., 2013).

\subsection{Regenerative medicine}

Currently, organ donation is unable to meet transplantation needs of patients suffering with chronic conditions (Mahla, 2016). Also, due to the expanding aged population being particularly susceptible to chronic degenerative diseases healthcare expenditure continues to increase (Nelson et al., 2008). Regenerative medicine is a distinct and major field in basic and translational research, linking to clinical need, in addressing the deformation or abnormal homeostasis of tissues in a wide variety of disease. Major advancements in medical treatment have been undertaken based on the principles of cellular and acellular/matrix associated technologies and tissue engineering, in order to replace or regenerate human tissues and organs while aiming to restore function (Mao and Mooney, 2015).

Multiple strategies are being employed in order to achieve regeneration of tissues including stem cell biology, biomechanics and nanotechnology (Sampogna et al., 2015). A successful tissue engineered construct is seen to combine three separate categories; biomaterials, cells and growth factors, shown in Figure 1.3, in order to mimic the numerous properties a single tissue may exhibit. Components of the triad can be used to manipulate the growth and development of tissues for the desired outcome (O'Brien, 2011). This triangular strategy is also known as the $\mathrm{R}^{3}$ paradigm where replacement of tissue, regeneration of damage tissue and rejuvenation of cells must occur (Nelson et al., 2008). 


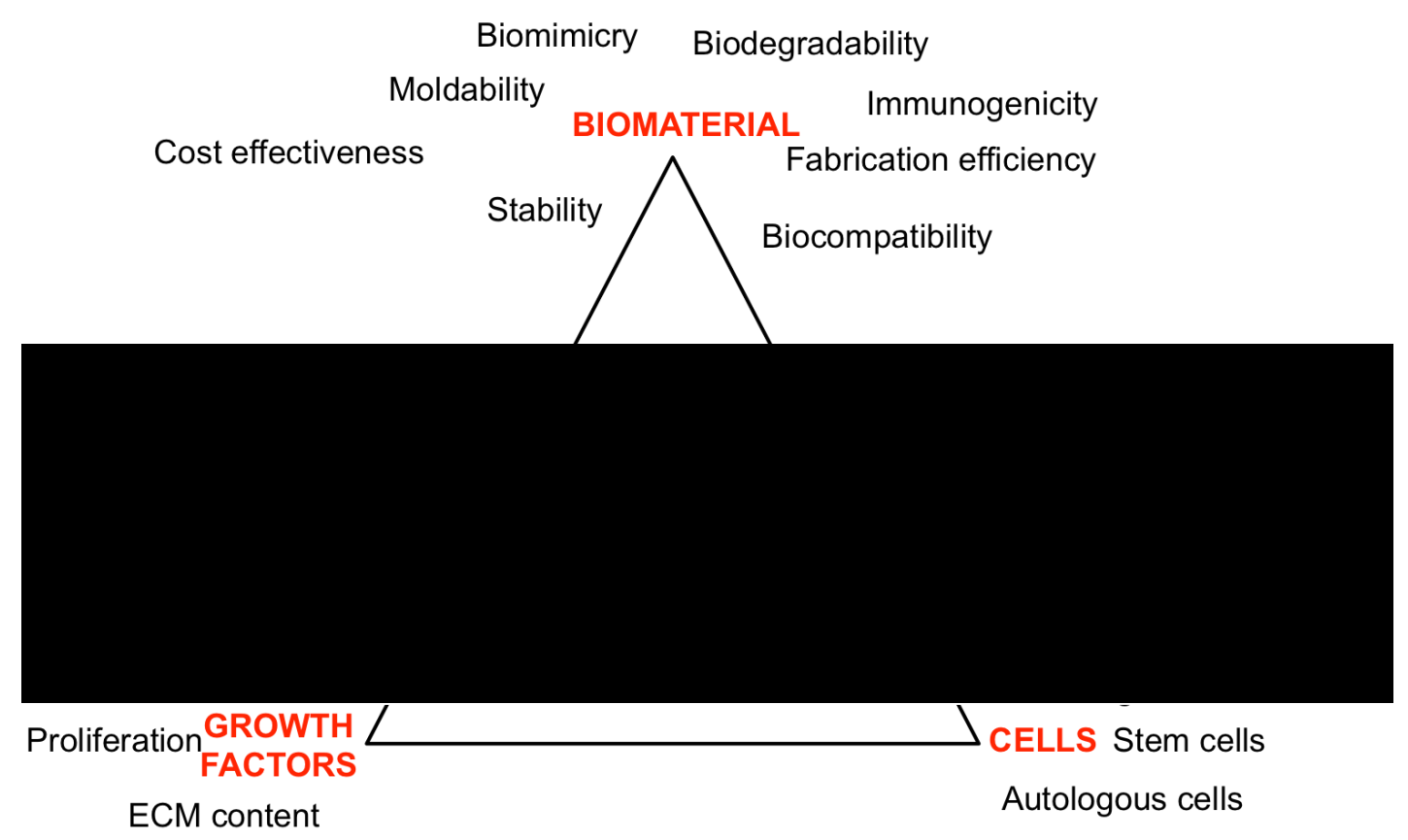

Figure 1.3: Tissue engineering triad. Successful tissue engineering is dependent on the work between cells, signals and materials (O'Brien, 2011)

\subsection{Articular cartilage, osteoarthritis and regenerative medicine}

Adults possess three main types of cartilage: fibrocartilage, elastic cartilage and hyaline cartilage. Fibrocartilage, composed primarily of collagen type I in the form of fibres, is thought to be the strongest form found within the body and appears in intervertebral discs and between ligaments, tendons and bones. Elastic cartilage is present in sections of the trachea, outer ear and epiglottis. Randomly oriented elastin fibres provide the characteristic elasticity that aids in maintaining the shape and flexibility of organs (Camarero-Espinosa et al., 2016).

Articular cartilage (AC) is hyaline cartilage found lining the osseous ends of diarthrodial joints, at approximately $2-4 \mathrm{~mm}$ thick, and protects the underlying bones allowing for frictionless, pain-free movement (Musumeci et al., 2014). The tissue is avascular, aneural, alymphatic and has a white, glassy appearance and unlike fibrocartilage, there is no evidence to show that hyaline cartilage possesses collagen fibres at a macroscopic level (Temenoff and Mikos, 2000). 


\subsubsection{Articular cartilage structure}

The overall composition of articular cartilage can be seen as relatively simplistic as it contains a single, highly specialised cell type, the chondrocyte, which accounts for approximately $2 \%$ of the total volume of articular cartilage. These cells are encased within a dense and organised extracellular matrix that has three main components: water, collagen and proteoglycans (Fox et al., 2009). Indicated in Figure 1.4, articular cartilage has distinct zonal organisation comprising of a superficial, transitional, deep and calcified zone. The varying degrees of organisation found within articular cartilage are key to the mechanical, metabolic and transport properties it exhibits (Klein et al., 2009).

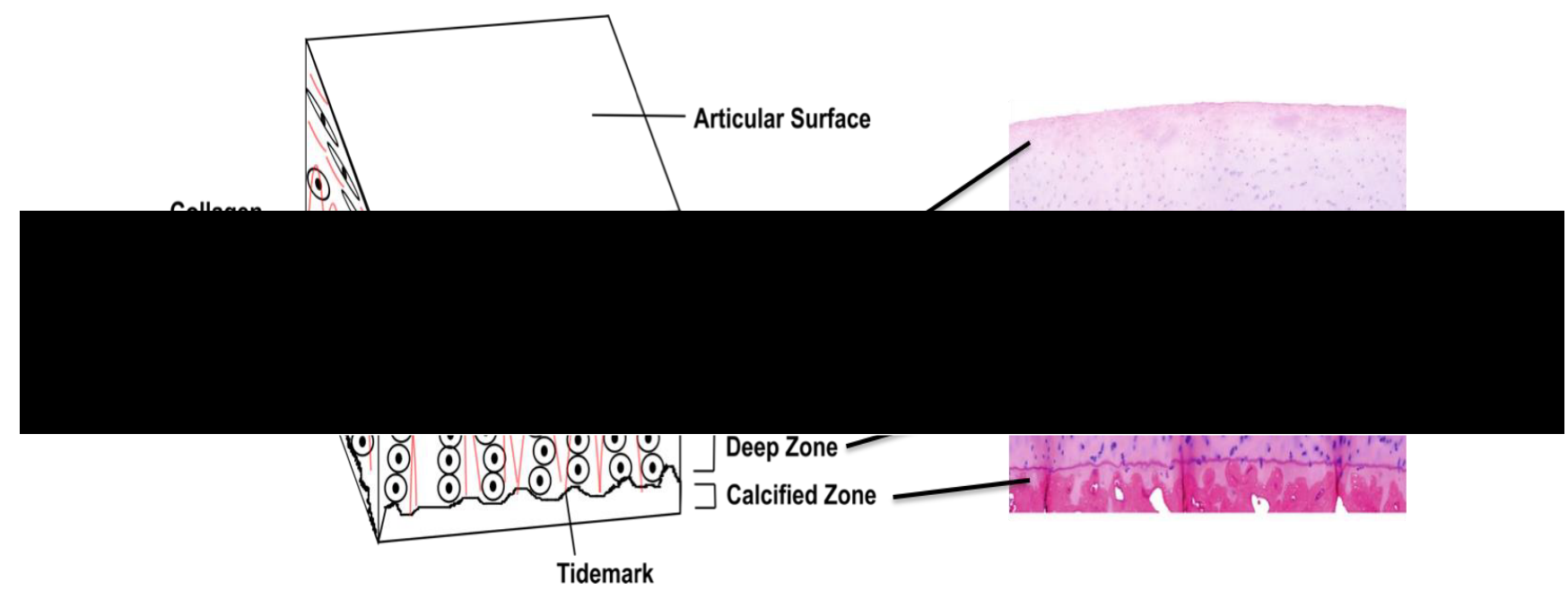

Figure 1.4: Schematic representation of health articular cartilage along side histological staining of cartilage tissue. Chondrocytes maintain a flattened morphology at the superficial zone before becoming more rounded deeper into the tissue. Collagen fibrils change their orientation throughout the tissue to give its tensile properties (Fox et al., 2009)

Zonal organisation transitions from the superficial zone, closest to the synovial fluid, to the calcified zone, adjacent to bone. This zonal structure varies the composition of the extracellular matrix and collagen orientation, increasing in stiffness through the tissue and allowing for cartilage to possess the tensile strength necessary for its role (Zhu et al., 2017). 
The superficial or tangential zone of cartilage is the thinnest zone, closest to synovial fluid, that plays hosts to cells that appear ellipsoidal in morphology (Bhosale and Richardson, 2008). Chondrocytes within this zone secrete lubricin, an important lubricant that allows for the fluid, frictionless movement associated with cartilage. Lubricin or superficial zone protein, synthesised by synoviocytes and chondrocytes, is an $O$-glycosylated protein found on the articular surface and synovial fluid (Gleghorn and Bonassar, 2008). The structure of lubricin is such that the central domain holds a negative charge whilst the terminal portions of the protein are positively charged (Estrella et al., 2010). This charge distribution is believed to be the lubricating properties of the protein (Jay and Hong, 1992). The importance in lubricin is demonstrated in patients presenting with camptodactyly-arthropathy-coxa vara-pericarditis (CACP) syndrome where there is a lack of lubricin expression leading to fibrosis and failure of the joint (Jones et al., 2009).

Three types of collagen are present in the superficial zone, type II, IX and XI, and are aligned parallel to the articular surface (Fox et al., 2009). The orientation of these collagen fibres allows for the articular surface to withstand the high tensile stresses (Klein et al., 2009). The transitional zone, also known as the middle zone, encompasses $40-60 \%$ of articular cartilage volume and is less organised in structure than the other zones (Pearle et al., 2005). Collagen fibrils within the deep zone are tightly packed together in a perpendicular manner and it is this arrangement in the region that leads to the deep zone being the provider of the greatest compressive resistance (Fox et al., 2009). The zone of calcification is separated from the other zones by the tidemark, also known as the chondro-osseous junction, and allows for a smooth transition in the mechanical properties exhibited by cartilage and bone as well as tethering the tissues together (Schultz et al., 2015). It is believed that damage in this zone leads to disease of both cartilage and bone with lesions causing an increase in vascularity and remodelling of the bone whilst a duplication of the tidemark is an indicator of osteoarthritis (Mansfield and Winlove, 2012).

The articular cartilage matrix is predominantly made up of collagen type II, that provides the tensile strength that is characteristic of the tissue (Cohen et al., 1998). Other important contributors to the ECM include proteoglycans (PGs), in particular aggrecan a negatively charged proteoglycan that plays a major role in the ECM of 
articular cartilage (McNary et al., 2012). Aggrecan is composed of a linear core protein that contains 3 globular domains: GD1, GD2 and GD3, that form aggregates, where multiple aggrecan molecules are attached, non-covalently, to a central hyaluronic acid filament, stabilised by the Link protein (Roughley and Mort, 2014). Glycosaminoglycans (GAG) chains are found between GD2 and GD3 and are most frequently found to be chondroitin and keratan sulphate (Chandran and Horkay, 2012).

One such GAG is chondroitin sulphate (CS), which exists as an unbranched sulphated GAG composed of repeating disaccharide units of $\mathrm{N}$-acetylgalactosamine and glucuronic acid. CS is considered a highly charged polyanion due to the 4 and 6 position of the $\mathrm{N}$-acetylgalactosamine being sulphated (Henrotin et al., 2010). Negatively charge, CS is linked to osmotic swelling of cartilage due to its negative charge, while it has also been shown to play various protective roles within cartilage (James and Uhl, 2001). In vitro studies have proven that CS has the ability to reduce chondrocyte apoptosis as well as the production of MMPs, while it is needed to induce proteoglycan production (Martel-Pelletier et al., 2010). Another GAG, is keratan sulphate (KS), a linear polymer of $N$-acetylactosamine that is sulphated at carbon-6 of both sugar moieties (Meyer et al., 1953). KS expression has been observed in both the cornea and cartilage, with the latter tissue containing KSII specifically, which is $O$-linked via GalNAc to serine or threonine residues and binds exclusively to aggrecan in articular cartilage (Funderburgh, 2002).

Hyaluronic acid (HA), also known as hyaluronan, is the simplest GAG as it is unbranched and unsulphated, consisting of between 2500 and 25000 repeating disaccharide units (Bastow et al., 2008). HA associates itself with HA binding proteins significantly contributing to the structural integrity of articular cartilage (Seyfried et al., 2004). HA is found bound to aggrecan in the cartilage matrix. Decrease HA size has ben attributed to diseased cartilage using histological staining (Bastow et al., 2008). Hyaluronic acid has been shown to interact with chondrocytes via the CD44 receptor, which plays a role in pericellular matrix assembly as well as intacellular signalling and matrix remodelling (Responte et al., 2012). 


\subsubsection{Osteoarthritis}

Osteoarthritis (OA) is a degenerative disease that affects the entire synovial joint including bone and synovium. The most critical damage however occurs to the articular cartilage (Amoako and Pujalte, 2014). Diagnosis of OA can be observed radiographically to visualize joint space narrowing, through magnetic resonance imaging (MRI) or optical coherence tomography (OCT), or directly with an endoscope (Braun and Gold, 2012). Histological analysis of cartilage biopsies is a routine procedure that is undertaken in the grading of OA, with the OARSI system commonly used as the chosen guidelines, and is graded from 0 through to 6. Figure 1.5 shows examples of articular cartilage at each grade (Waldstein et al., 2015). Grade 0 is healthy articular cartilage with no signs of OA. As grading increases the smooth superficial surface begins to break down, chondrocytes cluster and undergo apoptosis, formation of fissures and proteoglycan depletion is evident (Pritzker et al., 2006). OA is a chronic condition that has the largest economic burden on medical and social services within the developed world due to healthcare costs and is expected to increase due to the rise in the aging population. Due to these reasons prevention and repair are critical (Bitton, 2009). 


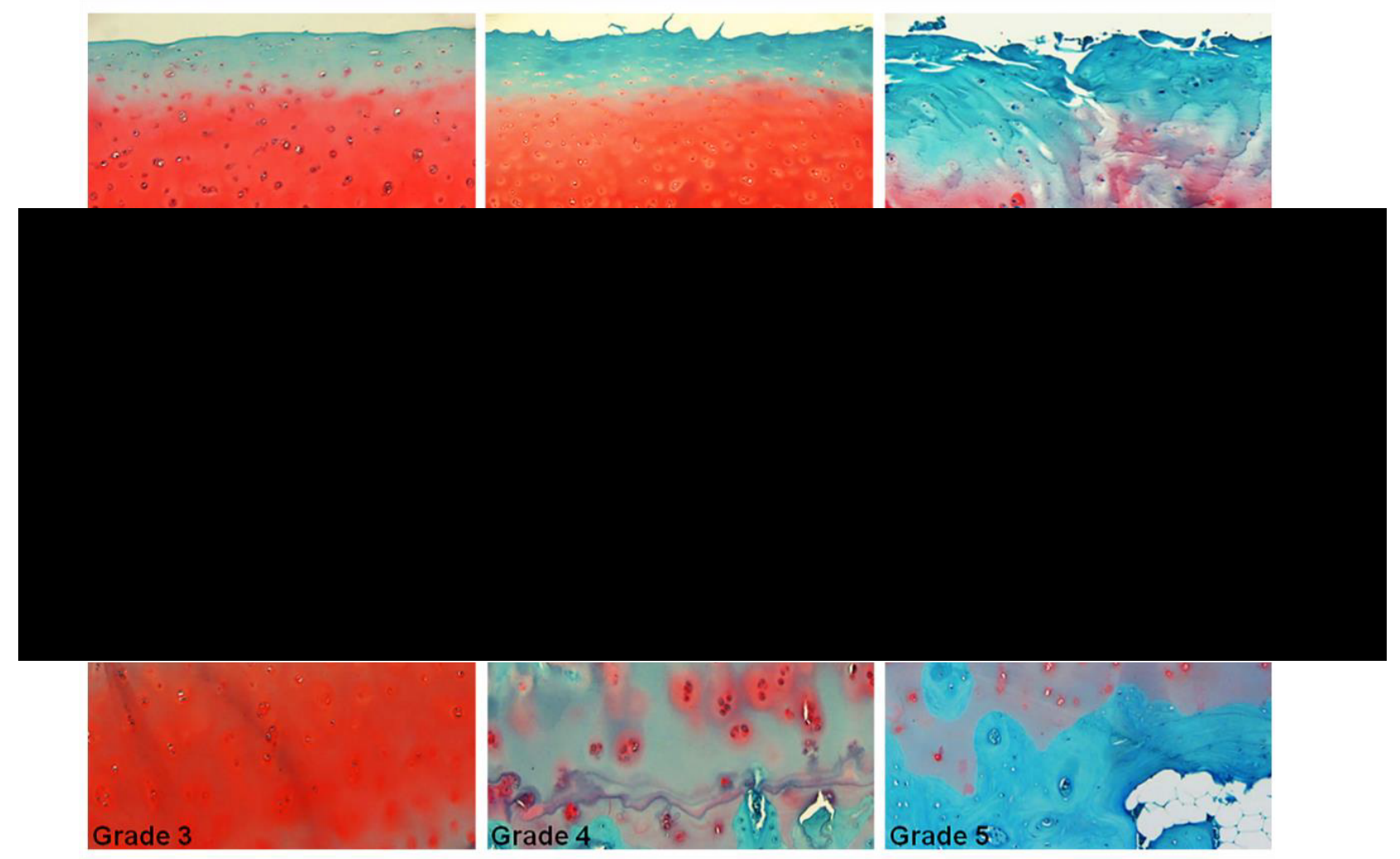

Figure 1.5: Histological staining of articular cartilage demonstrating grades 0-5 of OA. Histological staining with haematoxylin and eosin, Safranin $O$ and counterstained with Fast Green shows depletion of proteoglycan and lesion formation (Waldstein et al., 2015).

The cause of OA is abnormal mechanical loading that increases the vulnerability of the joint and occurs due to a variety of factors including aging, nutritional deficiencies and blunt trauma or injury (Hunter and Felson, 2006). The change in loading leads to inflammation of the joint and deregulation of tissue homeostasis favouring the catabolic process (Goldring and Goldring, 2007). The mechanisms of matrix degradation are shown in Figure 1.6. 


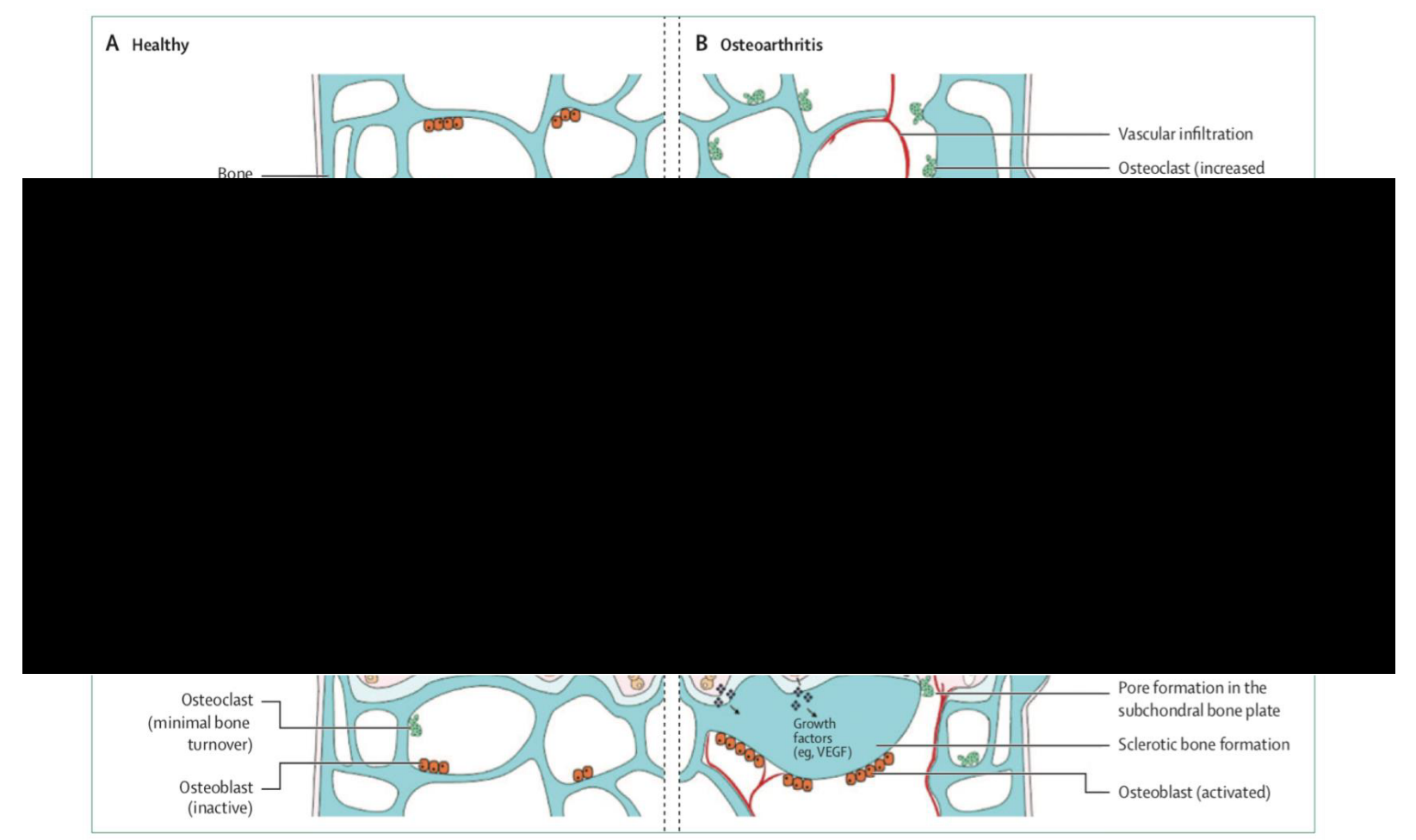

Figure 1.6: Structural changes and signaling pathways involved in the development of OA (Glyn-Jones et al., 2015)

OA is a progressive disease and occurs in stages (Blalock et al., 2015); Firstly, changes or loss of the ECM occur, which are thought to be remodelled and repaired by resident chondrocytes and finally degradation occurs at a faster rate than synthesis/repair causing cartilage loss (Hendren and Larson, 2009). Other common features associated with OA are the spread of hypertrophic chondrocytes, osteophyte formation and narrowing of the joint (Ashkavand et al., 2013).

\subsubsection{Disease aetiology}

$\mathrm{OA}$ is now seen as a multifactorial disease, age however, remains the most common risk factor with the majority of patients over the age of 65 having radiographic differences in at least one joint (Jordan et al., 2007). Aging also affects the muscle and bone that in turn causes additional changes to joint loading. Studies conducted on articular chondrocytes show that aging promotes cell senescence and have reduced reparative capability due to alteration in receptor expression (Chen et al., 2017). 
Obesity has also been shown to be prominent in the aetiology of OA. Patients with obesity (BMI greater than $30 \mathrm{~kg} / \mathrm{m}^{2}$ ) are 6.8 times more likely to develop OA earlier in their life than those classified as normal weight (King et al., 2013). In addition to increased biomechanical loading on the knee joints there is increased secretion of cytokines IL1, IL6, IL8 and TNF linked to obesity, that lead to increased catabolic activity through MMP secretion (Kapoor et al., 2011). Inflammation is also observed in patients that present with OA following blunt trauma from sports injuries causing activation of the NF- $\square$ B pathway, unbalancing anabolic and catabolic activity (Lieberthal et al., 2015).

Degradative enzymes play an important role in the breakdown of cartilage by targeting components of the ECM, such as collagen and aggrecan for proteolysis. The molecular signature of OA cartilage, regardless of the cause, points towards the deregulation of pathways that give rise to excessive hypertrophy. During ossification chondrocytes become hypertrophic, remove ECM by expression of a disintegrin and metalloproteinase with thrombospondin motifs (ADAMTS) and MMPs; eventually undergoing apoptosis and subsequent replacement by osteoblasts. The Wnt/ $\beta$-catenin pathway is also known to drive endochondral ossification due to the upregulation of ADAMTS and MMPs (Takamatsu et al., 2014) causing the loss of proteoglycan in articular cartilage (Yuasa et al., 2008). ADAMTS4 and -5 are key enzymes involved in the degradation of aggrecan (Wang et al., 2011). ADAMTS5 is seen to be widely distributed in OA cartilage however both ADAMTS4 and ADAMTS5 may have variable activity depending on their localisation within the tissue (Dancevic and McCulloch, 2014). Another degradative enzyme involved in AC deterioration is MMP13, which targets collagen type II, IV and IX as well as proteoglycans (Wang et al., 2013). MMP13 has a higher catalytic affinity for collagen type II than any other collagen making it a potent enzyme for degradation of the cartilage matrix (Wang et al., 2011). Clinical studies have shown that patients with articular damage have higher levels of MMP13 whilst research with transgenic mice overexpressing MMP13 has also shown spontaneous OA-like articular cartilage (Wang et al., 2013). 


\subsubsection{Osteoarthritic repair}

Although non-surgical treatment may provide pain relief for the patient it is not seen as a preventative or restorative treatment option (Mushtaq et al., 2011). Partial and full thickness treatments require surgical intervention for long-term repair of the tissue, with the choice of surgery being dependent upon the depth of sustained lesions and surgical preference (García-Carvajal et al., 2013). Total arthroplasty, where the entire load bearing joint is replaced, is a popular option for elderly patients presenting with end stage OA but due to the limited lifespan of the prostheses it is unsuitable for younger patients (Bhosale and Richardson, 2008). Early intervention of damaged cartilage, such as an osteotomy, can be carried out to reduce further deterioration of cartilage however these are not seen as long-term solutions. An array of non-surgical options have been developed for the management and repair of OA cartilage from acellular techniques through to cell based technology with and without the use of scaffold materials (Makris et al., 2015).

\subsection{Non-surgical intervention}

Non-surgical OA treatments to reduce patient pain include both non-pharmacological and pharmacological treatments (Yusuf, 2016). The primary non-pharmacological treatment is exercise to achieve weight loss that can alleviate pressure on the joints however individualised exercise programs must be designed based upon the patient's needs so not to further aggravate the condition (Yusuf, 2016). Non-steroidal antiinflammatory drugs (NSAIDS) are a popular pharmacological treatment for OA patients suffering with moderate-severe pain (Pelletier et al., 2016). These drugs alleviate pain by altering the damaged structure of OA, by reducing the amount of inflamed synovial fluid (Pelletier et al., 2016). NSAIDs block the production of prostaglandins by inhibiting the activity of cyclooxygenase (COX) enzymes and come in a variety of forms, ranging from topical gels and patches, to intravenous and oral preparations. Topical NSAIDs are typically the first line of treatment as they maintain their efficacy whilst reducing systemic exposure, this is however dependent upon patient history, due to concerns around cardiovascular and gastrointestinal complications (Crofford, 2013) (Pelletier et al., 2016). 


\subsection{Acellular approaches}

Arthroscopic treatment of cartilage defects is seen as a minimally invasive and cost effective procedure (Redman et al., 2005). A characteristic symptom of osteoarthritis is the chronic pain suffered by patients. Since the 1940's a popular treatment option available to surgeons was lavage and debridement of the defects (Minas, 2011). During the procedure a saline solution is introduced to the joint to remove loose tissue (lavage) before smoothing the underlying bone of any damaged or dead tissue (debridement) (Ontario, 2005).

A high tibial osteotomy is usually preformed with pain relief as the goal rather that cartilage repair. This surgical procedure realigns the joint so that biomechanical loading is not focused upon the damaged tissue (Hunziker, 2001). Although the aim of the surgery is not concentrated on repairing the tissue, patient follow up studies have shown that approximately 2 years after an osteotomy surgery cartilage lesions exhibit a fibrous, membranous tissue resembling fibrocartilage (Sabzevari et al., 2016).

\section{5.2.2.3 Cellular approaches}

In 1997, Steadman suggested microfracture, a marrow stimulation technique, as a viable treatment of symptomatic focal defects in articular cartilage (Mancò et al., 2016). During this treatment damaged cartilage is removed to reveal the subchondral bone plate and an arthroscopic awl is used to form $3-4 \mathrm{~mm}$ holes, while avoiding lesion merging and/or collapsing (Schrock et al., 2017). The penetration of the underlying bone allows for lesion specific recruitment of mesenchymal stem cells (MSC) that then perform tissue reformation. The MSC clot that is formed is not mechanically stable however, placing emphasis on appropriate post-surgical rehabilitation with regards to creating an environment in which mesenchymal cells can migrate and differentiate within the lesion (Bark et al., 2014) (Erggelet and Vavken, 2016).

While being viewed as a simple technique in terms of execution, with low complication rates, microfracture often fails to produce hyaline cartilage, instead 
forming a tissue that is too rigid for the biphasic characteristic needed for shock absorption (Reilingh et al., 2017). Despite the fact that the tissue produced contains a lower collagen II content, microfracture continues to be an intervention chosen for patients of a younger age, with small $\left(<2 \mathrm{~cm}^{2}\right)$ lesions. It has been noted that patients who have undergone this reparative surgery find improvements in regards to pain however the revision rates for surgery range between $2 \%$ and $31 \%$ and is likely due to the degradation of the fibrocartilage layer (York et al., 2017) (Kraeutler et al., 2018).

\subsection{Autologous chondrocyte implantation}

Autologous chondrocyte implantation (ACI) was first developed in 1994 and has become a routine method in the treatment of full thickness cartilage defects (Brittberg et al., 1994). This surgical option involves implantation of autologous chondrocytes into the defect and sealed under a periosteal patch (Dunkin and Lattermann, 2013). During this two-stage procedure, chondrocytes are harvested from a healthy area of cartilage before undergoing monolayer, cell culture proliferation. Following 3-4 weeks the cells are placed into the defect in hopes of replacing the damaged tissue (McCarthy et al., 2016).

Currently, chondrocytes are the chosen cell source for ACI surgery. When cultured in monolayer however these articular chondrocytes have been shown to reduce their collagen II and proteoglycan expression, as a result of 2D culture shock and dedifferentiation (Dewan et al., 2014). This may be a contributor to the several disadvantages observed with ACI, despite the good clinical outcome observed in 60 to $90 \%$ of follow up (between 1 to 11 years) ACI patients (Iwasa et al., 2009). The main issue is the hypertrophic nature of the regenerated tissue that often leads to the need for another operation (Gooding et al., 2006).

\subsection{Stem cells}

Multiple alternative cell sources have been sought for OA repair purposes, due to the disadvantages of using chondrocytes. Stem or pluripotent cells are a popular option, 
in particular mesenchymal stem cells (MSCs) and induced pluripotent stem cells (iPSCs), due to the capability for self-renewal and ability to differentiate down different lineages (Lietman, 2016). MSCs are multipotent cells that have been proven to differentiate through chondrogenic, osteogenic and adipogenic lineages, outlined in Figure 1.7, and can be harvested from various sources including bone marrow and adipose tissue (Marion and Mao, 2006). Although they have lower differentiation potential than iPSCs they express low levels of major histocompatibility complex, which may lead to a lower risk of immunogenicity (Lee and Wang, 2017).

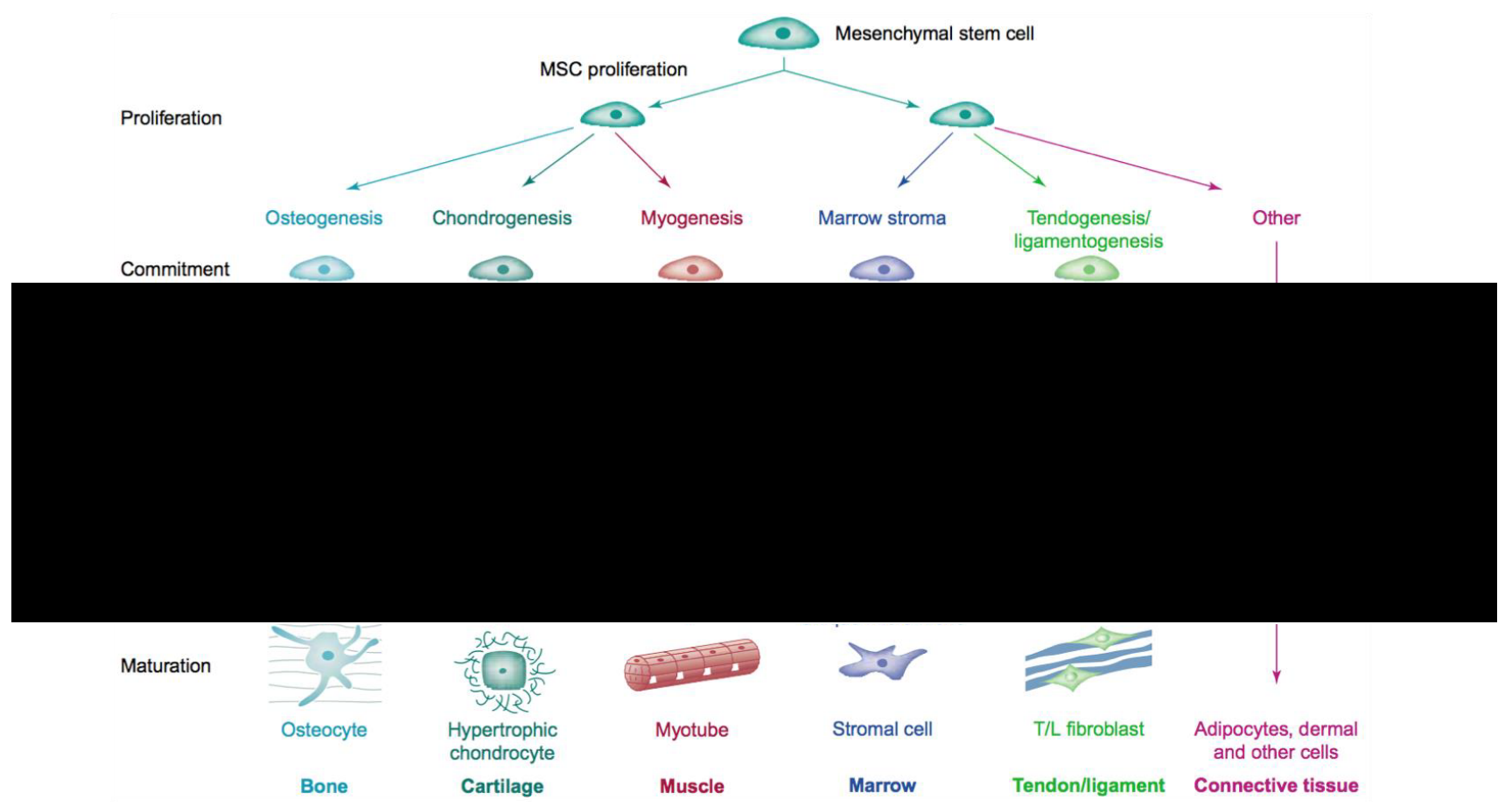

Figure 1.7: Differentiation of MSCs through different lineages. MSCs are often chosen for regenerative medicine due to their plasticity. Minimal criteria dictate that MSCs must be able to undergo chondrogenesis, osteogenesis and adipogenesis (Caplan and Bruder, 2001)

MSCs are multi-lineage non-hematopoietic stem cells that are able to differentiate into cells with a mesodermal origin and can be identified through their expression of specific markers (Mahla, 2016). The minimal criteria for cells to be considered an MSC include the ability to adhere to plastic, differentate into osteoblasts, chondrocytes and adipocytes and express cell surface markers CD105, CD73 and CD90 whilst lacking the expression of haematopoietic markers CD45, CD34, and CD14 (Dominici et al., 2006). MSCs can be isolated from various tissues including 
bone marrow, umbilical cord, adipose tissue and placenta. Aside from their ability to differentiate down osteogenic, chondrogenic and adipogenic lineages, MSCs have also been shown to integrate into the outer walls of arteries of organs and behave as pericytes to support blood vessel stability (Rohban and Pieber, 2017). All of these factors, multipotency, ease of isolation and capability for self-renewal, make MSCs a promising cell source for regenerative medicine purposes (Samsonraj et al., 2017). Allogenic MSCs may be isolated for 'off the shelf' availability but the ability to isolate autologous MSCs eliminates concerns of rejection and disease transmission (Marion and Mao, 2006). Although this cell source holds promise, clinical applications have brought to light the limitations of MSCs in regenerative medicine and tissue engineering. Direct injection and intravenous delivery of MSCs has led to inconsistent results within host tissue due to issues with long term survival (Samsonraj et al., 2017). MSCs have also been shown to exhibit inhibitory effects on $\mathrm{T}$-cell proliferation and secrete cytokines that supress the immune response as well as encourage tumour growth in allogenic transplants (Rosenbaum et al., 2008).

Mesenchymal stem cells have provided satisfactory clinical outcomes in regards to microfracture treatment. Despite this the tissue produced by the clot is often fibrous in nature and lack the durability for sustained movement required from the joint (Elvenes et al., 2009).

\subsection{Chondroprogenitors}

Stem cells are classified by functional attributes that include self-maintenance, proliferation and the ability to differentiate down different lineages (Potten and Loeffler, 1990). Progenitor cells are a populations of cells found within tissues that aid in homeostasis and retain a degree of plasticity and have the ability to differentiate into specific cell types (Mahla, 2016). Under specific biological, chemical and physical conditions tissue specific progenitor cells are able to differentiate and form cells that populate mature tissue and harvesting this potential holds promise within the tissue engineering and regenerative medicine fields (Heath, 2000). Adult progenitor cells are cells that are capable of differentiation and selfrenewal and are usually found in a niche close to tissue containing mature cells 
(Barry et al., 2001). Populations of multipotent mesenchymal progenitor cells have been found to be isolated from various tissues including cartilage, liver, fat and skin (Caplan, 2013).

Chondroprogenitor cells can be harvested from the surface of articular cartilage via their affinity for fibronectin (Dowthwaite et al., 2004). This population of cells exhibits a high colony forming efficiency, expression of Notch-1 and possess the ability to undergo chondrogenesis in a 3D culture (Mazor et al., 2014). Recent studies using equine-derived chondroprogenitor cells have showcased an enhanced ability for cartilage repair when compared to bone marrow derived MSCs due to the lack of expression of RUNX2 and type X collagen, which are markers of epiphyseal chondrocytes (Somoza et al., 2014).

\subsection{Matrix-assisted approaches}

Matrix-assisted autologous chondrocyte implantation (MACI) is a popular next generation surgical technique that is similar to ACI with the addition of a matrix scaffold for guidance of tissue formation (Jacobi et al., 2011). Autologous chondrocytes are harvested and expanded to an appropriate number before being seeded into a 3-dimensional scaffold structure. After 4 weeks of culture within the scaffold the structure is implanted into the defect after being cut to size (Nixon et al., 2015). The use of a 3D matrix is believed to minimise the chance of cell dedifferentiation and increase the chondrogenic potential of the implant (Niethammer et al., 2016).

Various materials have been used for the fabrication of MACI scaffolds and are used within clinical settings including collagen and hyaluronan as well as synthetic materials like polyglycolic and polylactic acid, agarose and alginate based hydrogels and protein based matrices fabricated from collagen and gelatin (Armiento et al., 2018). It is critical that the surrounding cartilage is healthy and any loose tissue is debrided before implantation. Unlike in ACI where the periosteal flap spans the entire defect, MACI requires the matrix to fit within the defect without any overlying flaps to allow for integration into the native tissue (Dunkin and Lattermann, 2013). 
The use of a matrix is seen as an advantage as there is a higher chance of even cell distribution as well as a reduced risk of cell loss from the damaged area (Kreulen et al., 2017).

MACI surgery can be seen as successful however there have been reports of graft failure due to lack of integration and the formation of fibrous tissue. In these cases it is vital to acknowledge that the development of cartilage is dependent on several factors such as exposure to growth factors and mechanical stimulation and the addition of these to MACI surgery may increase successful tissue repair outcome for patients (Collarile et al., 2017). MACI offers a technique that is attractive due to the reproducibility, safety and reduction in intraoperative time but requires further investigation in order to understand whether the long term benefits are superior to other surgical techniques that are available (Makris et al., 2015).

One of the most popular materials to use is collagen due to the fact that the protein accounts for a large proportion of articular cartilage. Membranes such as Maix® and Chondro-Gide ${ }^{\circledR}$ are produced from a bilayer of porcine collagen I/III that can then be seeded with chondrocytes. The surface of these scaffolds provides mechanical strength whilst the inner surface stimulates cells to produce cartilage matrix (Fuss et al., 2000). Studies conducted on this conformation of scaffold have shown cell attachment and maintenance of chondrocytic phenotype as well as the limitation of cell migration from the defect (Ehlers et al., 1999).

\subsubsection{Scaffold properties and function}

Stem cells are often the cell source of choice for regenerative medicine due to their plasticity allowing them to repair the damaged tissue by repopulating the area with mature, differentiated cells (Ding et al., 2013). However, in order for tissues to be functional they require specific mechanical and structural properties that can be acquired through the introduction of a scaffold structure and material (Hosseinkhani et al., 2014). A large research field has developed around biomaterial biomimicry, where the choice material, examples of which are outline in Table 1.2, and basic structure of a scaffold is fabricated to imitate the structure and environment of the 
native tissue that is designated for regeneration (Mahboudi et al., 2018). With this in mind, a number of properties must be taken into account when fabricating a scaffold, including architecture, mechanical integrity, biodegradability, biocompatibility and manufacturing technology (O'Brien, 2011).

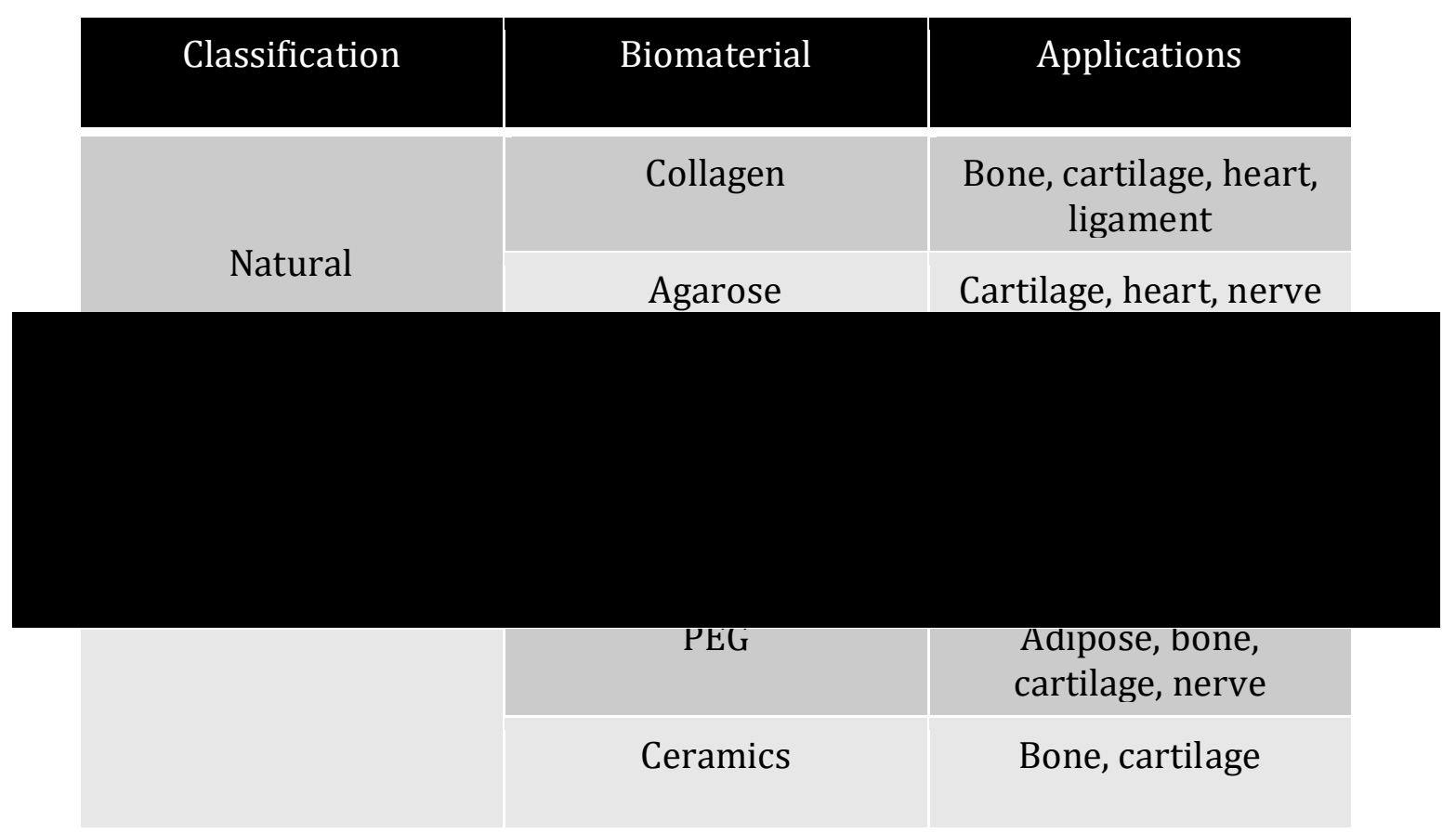

Table 1.2: Natural and synthetic materials used in tissue engineering. A example of the range of natural and synthetic biomaterials has been used for different tissue engineering applications, often for the same tissue with differences in cellular response (Melton, 2008)

Scaffolds fabricated for tissue engineering and regenerative medicine should have a highly porous and interconnected structure to allow for adequate cell migration and nutrient diffusion as well as the diffusion of waste products (Phelps and Garcia, 2009). Pore size is also a crucial characteristic of scaffold design. Cells attach to the scaffold via ligands and peptide sequences, such as the GFOGER and RGD peptide sequences; on the material surface and ligand density is determined by surface area. Therefore average pore size must strike a balance whereby they are large enough to allow for cell migration but small enough to maintain adequate ligand density for efficient binding (Yannas et al., 1989). Scaffolds involved in chondrogenesis have been able to facilitate differentiation of chondrocytes with small pores $(20-150 \mu \mathrm{m})$ 
whilst larger pore sizes $(250-500 \mu \mathrm{m})$ have been found to be better for proliferation and matrix deposition (Matsiko et al., 2015).

Scaffolds produced from natural materials such as collagen, chitosan and cellulose are advantageous due to their occurrence in native ECM and allow for the attachment of cells via surface receptors (Saha et al., 2007). The surface properties of scaffolds play an important role in cell-matrix interaction and are responsible for proliferation and differentiation after attachment (Liu et al., 2014). An example of this is seen in chondrogenic differentiation of adipose derived stem cells which has been proven to be more effective on gelatin compared to alginate and agarose due to the similarity to native ECM environment (Awad et al., 2004).

A range of critical pore sizes exists and is specific to the tissue to be repaired. An example of this is outlined in Table 1.3 (Murphy et al., 2010).

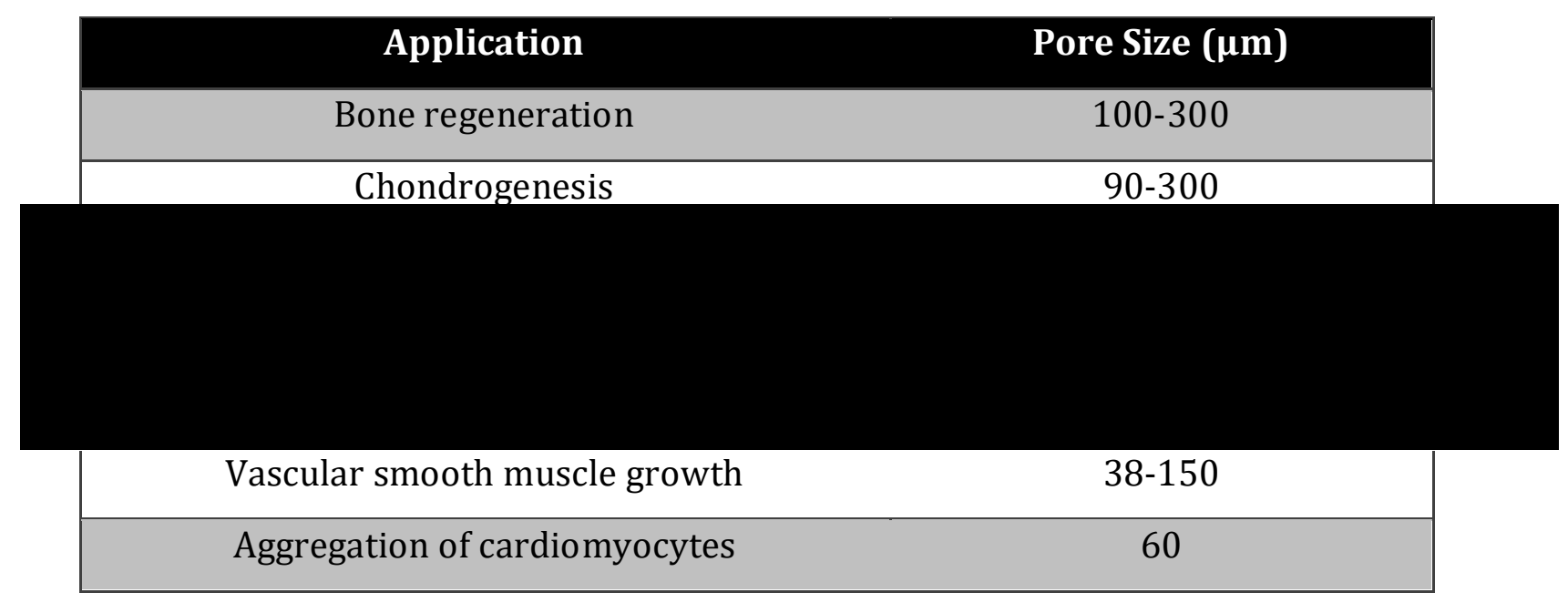

Table 1.3: Examples of optimal pore sizes for specific applications in tissue engineering (Bružauskaité et al., 2016)

Biological and chemical modifications to a scaffold may help to influence cell behaviour through the manipulation of specific signalling pathways (Dawson et al., 2008) through the binding of different integrins (Liu et al., 2014). Synthetic materials used for tissue engineering can be chemically modified in order to help cellular differentiation however this may not be a cost effective method (Dawson et al., 2008). 
Proliferation of cells within a 3D environment occurs with a sufficient supply of oxygen and nutrients as well as the avoidance of the build up of waste materials (Hosseinkhani et al., 2014). The effect of dynamic culture, with the use of bioreactors, has proven effective in the proliferation and differentiation of stem cells as well as a more uniform distribution of nutrients (Ghasemi-Mobarakeh et al., 2015). When static and dynamic culture were compared in chondrogenic culture of human MSCs within a hydrogel, static culture was better in differentiating cells. However, additional compression during dynamic culture improved chondrogenic differentiation (Guo et al., 2016).

The topography of the ECM effects the cell in various ways with nano and micro patterned structures shown to stimulate cell alignment, migration, proliferation and gene expression (Ghasemi-Mobarakeh et al., 2015). These topographical features are often achieved through fabrication methods such as photolithography and chemical vapour deposition. Elecrospinning has been of particular interest as this method produces nanofibers that are similar in morphology to native ECM (Prabhakaran et al., 2012). In vitro chondrogenic differentiation of MSCs has been documented as more effective on chitosan microfibers compared to sponges (Ragetly et al., 2010).

The mechanical properties of the scaffold should resemble the tissue it is to be implanted (Chan and Long, 2008). This has proven to be a difficult task for specific tissues, for example orthopaedic applications prove challenging as they must continue to have mechanical integrity from implantation through to the completion of matrix remodelling (Hutmacher, 2000). Although mechanical properties play an important role, tissue architecture has often been sacrificed in order to achieve a mechanically stable structure, which in turn has been detrimental for tissue growth and vascularisation. Therefore it is crucial that a balance is found between architecture and mechanics for a successful scaffold (O'Brien, 2011).

Matrix stiffness is variable across tissues present in the human body from soft brain tissue $(1 \mathrm{kPa})$ to hard bone (30kPa) (Vincent and Engler, 2011). Stem cells possess the ability to differentiate into cells of different lineages and survive in environments that possess different mechanical properties. The material and overall structure of the scaffold play a role in the physical properties and may affect the differentiation 
potential of cells (Ghasemi-Mobarakeh et al., 2015). As an example, bone tissue engineering studies have shown that MSCs have a higher rate of attachment, increased alkaline phosphatase activity and increased expression of osteopontin and collagen type I when cultured upon a stiff $(25 \mathrm{kPa})$ hydrogel compared to a soft (2kPa) hydrogel (Gandavarapu et al., 2014). Whereas studies considering cardiovascular regeneration showed an increased attachment in softer scaffolds (Wingate et al., 2012) and increased expression in endothelial markers when compared to harder substrates (Wingate et al., 2014).

Scaffolds designed for tissue engineering purposes are not seen as permanent implants and should be resorbed with a balance between degradation and new tissue formation (Peters and Mooney, 1997). The bioresorbability of the material must occur over time via biological processes such as enzymatic degradation or hydrolysis (Parisi et al., 2018). Due to the nature of the scaffold being a temporary implant within the human body, care must be taken when choosing a material to ensure that the native material and its degraded products do not induce response such as inflammation or release toxins, carcinogens and mutagens (Williams, 2008). The most critical characteristic of a scaffold fabricated for tissue engineering purposes is that it should be biocompatible. Biocompatibility encompasses the ability for cells to adhere, function and migrate and proliferate whilst interacting with the construct and producing a negligible immune response so that rejection does not occur (O'Brien, 2011).

\subsubsection{Biocompatibility}

The formal definition of biocompatibility is stated as "the ability of a biomaterial to perform with an appropriate host response in the specific application" (Williams, 2008). Materials chosen for regenerative medicine can be manipulated in order to achieve the functional properties required for its purpose, which include regeneration of the damaged tissue and cellular differentiation whilst inhibiting an immune response (Yang et al., 2008). Once a biomaterial has been implanted the body responds in a natural cascade that consists of interaction with blood and cells, provisional matrix formation and temporary inflammation. Under normal 
circumstances the cascade will end at this point however if the material is not biocompatible the cascade will continue with the formation of granulation tissue and fibrotic tissue that may infiltrate the porous material and render it unfit for purpose (Naahidi et al., 2017).

Aside from scaffold design, biocompatibility of the scaffold must be tested to ensure it does not cause any toxic effect to the body causing side effects. Three major responses that may occur are inflammation, fibrosis and immunogenicity (Anderson et al., 2010). The International Organization for Standardization has implemented standards that are required for the evaluation of medical devices (ISO: 10993) (Naahidi et al., 2017).

Both clinical and research grade collagen is sourced from a wide variety of animals with mammalian collagen being the most common source due to the ease in obtainment and cost effective nature (Rodríguez et al., 2017). Whilst research grade products are produced using good laboratory practice, clinical grade collagen must adhere to set regulations such as those set out in good manufacturing practice (GMP) guidelines and includes quality assurance records, dedicated production suite and validated cleaning methods (Crawford et al., 2015). Porcine and bovine collagen is typically sourced from waste products after slaughter and can be obtained from calfskin, bones and tendons via acid extraction (Karim and Bhat, 2009).

\subsubsection{Alternative sources of collagen}

Collagen is a popular material and has been used in food, medical and pharmaceutical industries. Industrial applications of collagen have primarily been sourced through mammals, in particular bovine and porcine origins (Silva et al., 2014). The concerns regarding the use of collagen from a bovine source has risen due to the outbreak of zoonotic diseases such as bovine spongiform encephalopathy (BSE) as well as the discovery that approximately $3 \%$ of the population are allergic to the material (Silvipriya et al., 2015). Another common mammalian source for collagen is porcine skin and bones, which are also obtained as waste material after slaughter (Karim and Bhat, 2009). Similar concerns of the transmission of zoonotic 
disease is also applied to porcine material with the additional constraints of pigs being forbidden in some religions (Silvipriya et al., 2015). Research for an alternative source of collagen has increased over the past few years due to economical interest in industrial by-products found in the meat and fish industry as well as for sustainability issues (Gómez-Guillén et al., 2011).

\subsubsection{Recombinant collagen}

In vitro production of recombinant collagen I and III from human fibroblast cells was reported in the early 1980s (Uitto et al., 1980). The advances in genetic engineering have lead to the possibility of using a number of hosts, including bacteria, yeast and insect cells, for the production of recombinant collagen (Yu et al., 2014). A key enzyme, prolyl 4-hydroxylase, involved in the folding of collagen into a triple helix has no activity in bacteria and yeast and is only found at low levels in insect cells leading to collagen produced in these hosts as non-functional although this may be amended by the introduction of prolyl 4-hydroxylase into the recombinant system (Dong and Lv, 2016). Due to setbacks such as the lack of cofactor and enzymes needed for stabilisation, high cost and low yield, animal sourced collagen continues to remain the standard in research and clinical tests (Browne et al., 2013)

\subsubsection{Evolutionary conservation}

Collagens have been found in a variety of species and have been linked to metazoan evolution (Hynes, 2012). The ancestral origin of collagen has been investigated through phylogenetic and genomic analysis of the protein as well as studying introexon organisation (Rodrigues-Pascual and Slatter, 2016). Intron-exon organisation analysis had led to specific hypotheses regarding the evolutionary lineage of collagen. The exons encoding for the triple helix in type I and III collagens are 54 base pairs (bp) in length whilst multiples of 54 or 54 minus 9 bp encode other types. These observations have led to the suggestion that the original ancestral fibrillar collagen included an exon of $54 \mathrm{bp}$ with a glycine codon and ending with a Y codon and encoding six Gly-X-Y repeats. Differences in gene length and triplet repeats are 
believed to have arisen from multiple duplications of the primordial unit (Exposito et al., 2010).

\subsubsection{Sources of marine collagen}

Alternative sources of collagen have been investigated in a bid to circumvent the issues raised from traditional mammalian sourced collagen (Silva et al., 2014). Particular interest in marine collagens has arisen, as fish skin and bones are abundant in collagen and a by-product of the fish industry, usually seen as waste (Subhan et al., 2015). The qualities of waste marine collagen, specific to regenerative medicine, depend on a number of factors, including animal age, diet, and the habitat it resides within before capture (Silva et al., 2014).

The denaturation temperature of collagen is highly dependent on the composition of amino acids, notably the proline and hydroxyproline content, with cold-water fish exhibiting lower denaturation temperatures than their mammalian counterparts (Subhan et al., 2015). The thermostability of marine collagen has been shown to be improved with the use of chemical compounds such as 1-ethyl-3-(3dimethylaminopropyl)-carbodiimide (EDC) and glutaraldehyde making it more suitable for implantation in clinical applications (Yamada et al., 2014).

A large amount of fish, approximately $75 \%$, is discarded during processing for the food industry (Silva et al., 2014). A considerable amount of waste from fisheries is discarded back into the sea and so an alternative method of dealing with waste products would be the use of products in collagen and gelatin extraction (Sotelo et al., 2015). Extraction of collagen from marine species is achieved by dilute acid due to fewer crosslinks being present when compared to mammalian sources (Yamaguchi et al., 1976). Despite this, fish collagen has been shown to have structurally similar $\alpha 1$ and $\alpha 2$ chains when compared to collagen type I obtained from calf (Yamada et al., 2014). Elastic salmon collagen has previously been prepared for vascular grafts producing little inflammatory reaction upon subcutaneous implantation in rats (Nagai et al., 2008) whilst Tilapia fish collagen sponges implanted into paravertebral 
muscles in rabbits gave a similar inflammatory response to porcine collagen implants (Sugiura et al., 2009).

Sea urchins have been examined as a source of collagen from the peristomial membrane that surrounds their mouth (Benedetto et al., 2014). Characterisation of the collagen showed it to be similar to mammalian type I in terms of the chain composition and D periodic banding pattern (Ribeiro et al., 2011). Unlike its mammalian counterpart, collagen from sea urchins is extracted in an insoluble fibrillar form, which is believed to be advantageous in mimicking the natural ECM without further modifications (Benedetto et al., 2014)

\subsection{Jellyfish collagen}

Jellyfish are free moving plankton with movement that coincides with the ocean current (Rastogi et al., 2017). These creatures are considered a model source for collagen isolation due to their gelatinous nature and the possession of a collagen rich mesogloea, shown in Figure 1.8. Collagen obtained from various species have been tested for their potential use in regenerative medicine, with promising results (Addad et al., 2011). The structure of jellyfish collagen has previously been reported to contain a high content of glutamine or glutamic acid and alanine whilst proline content was found to be lower when compared to collagen obtained from calfskin (Subhan et al., 2015). Extracts of jellyfish collagen obtained from Rhizostoma pulmo subjected to gel electrophoresis showed bands corresponding to alpha chains at a similar position to that of rat tail collagen (Addad et al., 2011). Isolated collagen from jellyfish is reported to resemble vertebrate collagen type II and support differentiation of cells, maintain cellular phenotype without dedifferentiation and cause little cytotoxicity when cells are cultured upon it (Hoyer et al., 2014). 


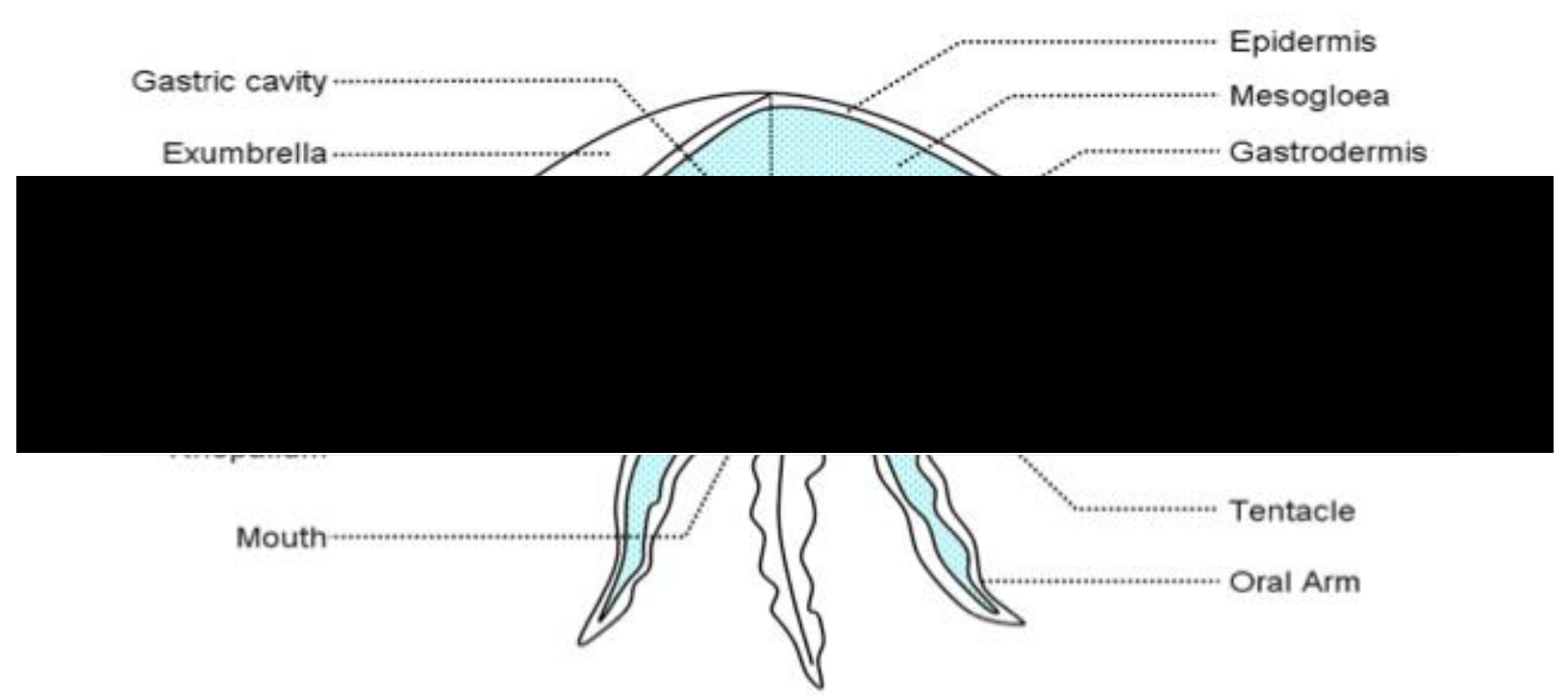

Figure 1.8: Schematic diagram showing anatomy of a jellyfish. Jellyfish collagen is often isolated from the collagen rich mesogloea or oral arms (Cronodon, 2016)

Collagen isolated from jellyfish can be manipulated into constructs, typically sponges, for research into tissue engineering applications. Hoyer and colleagues produced sponges from Rhopilema esculentum, crosslinked with 1\% EDC (Hoyer et al., 2014) whilst other studies have used Rhizostoma pulmo collagen crosslinked with different ratios of EDC/NHS (Addad et al., 2011). Jellyfish collagen ( $R$. esculentum) has also been used in combination with salmon collagen to produce a biphasic scaffold with properties better suited for osteochondral implants (Bernhardt et al., 2018).

Jellyfish derived collagen tested in vitro for biocompatibility has been shown to elicit no toxic effect towards primary human fibroblasts (Song et al., 2006). When compared directly to bovine collagen sources, increased cellular viability was observed for a wide variety of cells including fibroblastic, epithelial and osteoblastic cells (Subhan et al., 2015). Cytotoxicity tests on immune cell populations, antibody secretion and pro-inflammatory cytokines displayed that jellyfish collagen from Stomolophus nomurai meleagris gave a comparable response to the bovine counterpart (Song et al., 2006). Collagen isolated from Rhopilema esculentum has been evaluated for applications in cartilage regeneration producing porous scaffold structures that encourage chondrogenic differentiation of human mesenchymal stem cells with no cytotoxic effects (Hoyer et al., 2014). Another study using R. esulentum 
collagen for nasal cartilage repair also reported that jellyfish collagen scaffolds showed no cytotoxic effect on rat and human nasal chondrocytes and produce an ECM that mimics that of native septal cartilage (Bermueller et al., 2013). The use of collagen obtained from $R$. pulmo has been tested for different applications such as for aptamer sensing applications for thrombin related neurodisease (Derkus et al., 2016).

The extraction of marine collagen can be achieved in a similar fashion to mammalian collagen. Chemical treatment prior to the extraction allows crosslinks between collagen to be broken whilst basic treatment removes any non-collagenous materials without modifying the structure of collagen chains (Ehrlich et al., 2010). Acetic acid is typically used for the extraction of collagen from marine species although citric and lactic acid has also achieved isolation of collagen from marine tissues (Schmidt et al., 2015).

\subsection{Research aims}

Mammalian collagen is isolated from tissues and used in regenerative medicine and tissue engineering scaffolds. This collagen source has the required mechanical and biological properties required for specific tissue growth however ethical and immunological issues have lead to research for alternative sources. Research regarding marine collagen has shown that material isolated from a variety of species, particularly jellyfish, circumvents these problems.

The assessment of alternative collagen sources must be undertaken to assess the maintenance of structural componsition through isolation procedures. Jellyfish collagen was examined for any sequence similarity, against mammalian collagen, for functional properties and as an indication of immunogenic potential. This structural characterization further informs the ability of the material to be moulded into structures and validated for biocompatibility and immunogenicity.

Follow up data from cartilage repair surgery has shown that matrix assisted repair is superior to microfracture, a cell only technique. Matrix free (pellet) cultures has been standard in vitro technique used in research to investigate chondrogenesis. Cells 
seeded in jellyfish collagen scaffolds and pellet cultures were differentiated and compared to analyse enhaced chondrogenic potential.

These objectives were investigated using the following techniques;

- Fourier transform infrared spectroscopy

- Peptide sequencing and multi sequence alignment

- Fluorescence activated cell sorting

- Biochemical analysis of matrix formation

- Histological analysis of matrix formation

- Quantitative polymerase chain reaction

\subsection{Hypothesis}

Collagen can be isolated from $R$. pulmo jellyfish and maintains the structural composition to allow fabrication of robust scaffolds. In depth, in vitro, examination of physical and biological properties of scaffolds and chondrogenic potential will be assessed for suitability of jellyfish collagen as a biomaterial for regenerative medicine applications. 


\section{CHAPTER 2}

Materials and Methods 
In line with the specific aims and objectives designed to test the stated hypothesis, this thesis is split into three results chapters. Identifying novel collagen sources for regenerative medicine requires exhaustive pre clinical development, encapsulating material science, biocompatibility and proof of concept research and development centred on a specific application (O'Brien, 2011), as outlined in Figure 2.1.

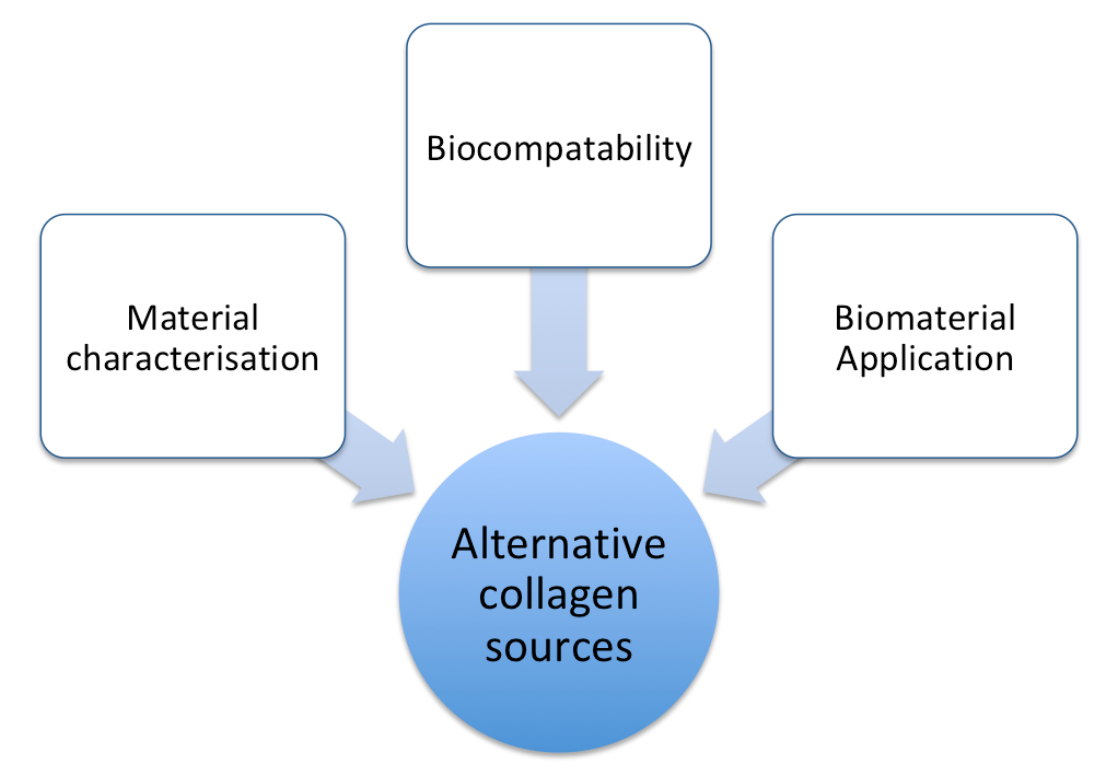

Figure 2.1: Approach to jellyfish collagen extraction and characterisation

Each of these components has identified methodologies, which provide a standard of data required as a body of evidence to support the utility of each collagen source (Abraham et al., 2008). In this section the methods used to derive collagen from jellyfish (harvest), characterise that material for purity, structural integrity and malleability and also assess in vitro biocompatibility are outlined. The utility of pure jellyfish derived collagen is then assessed using an enhanced chondrogenesis model, with all biological assays outlined in detail. 


\subsection{Material characterisation (collagen)}

Jellyfish harvest, collagen isolation and characterisation

\subsubsection{Jellyfish harvest}

Rhizostoma pulmo jellyfish were caught in Camarthen Bay, Wales during MayOctober using a stern trawling vessel with a $25 \mathrm{~mm}$ net. Once caught, jellyfish were separated into bells and tentacles and stored on ice in insulated containers before being taken back to the facility in Cardiff and stored at $-20^{\circ} \mathrm{C}$.

\subsubsection{Optimised collagen isolation}

Established collagen isolation methods utilised in mammalian and marine collagen processes were utilised and optimised during this project to produce high yield jellyfish collagen (JCol). Based on acid solubilisation, a simple flow diagram of this process is outlined in Figure 2.2. Specific acid conditions such as molarity and incubation times/temperatures are outlined in detail in chapter 3. 


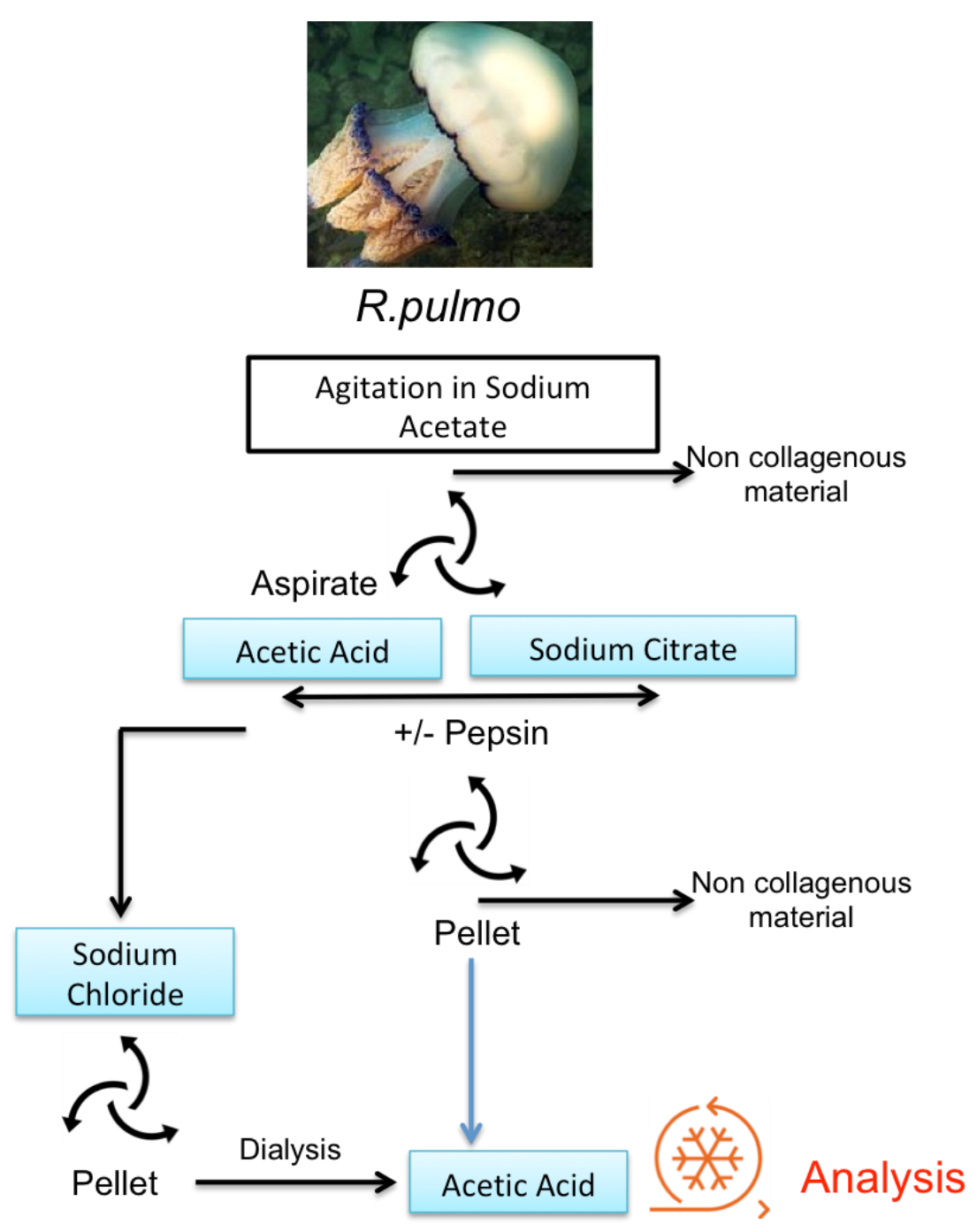

Figure 2.2: Collagen extraction condition testing. Sodium acetate was used to remove non-collagenous materials before testing different acid solubilisation methods. The addition of pepsin was tested to increase yield and salting out stage was also tested. All samples were lyophilised following extraction for further analysis.

At each stage, collagen material was characterised for electrophoretic banding, characteristic amide peak banding (Fourier transform Infra red spectroscopy) and yield (dry weight to starting weight ratio) in line with basic characterisaiton requirements (Abraham et al., 2008). Outlined below are the methodologies used in each assay. The optimised isolation process was then selected based on a combination of these factors allied to speed and scalability. This protocol was then used for each batch isolation prior to downstream analysis for peptide sequencing of the $\alpha 1$ band and analysis of functional peptide composition. 


\subsubsection{Sodium dodecyl sulphate polyacrylamide gel electrophoresis (SDS- PAGE)}

Mini-PROTEAN®TGX® precast 4-20\% gels (cat: 4561093, Bio-Rad) were used for sodium dodecyl polyacrylamide gel electrophoresis to separate proteins according to electrophoretic mobility. Protein samples were diluted 1 in 2 with 2x Laemmli buffer (cat: 1610737, Bio-Rad) and incubated at $95^{\circ} \mathrm{C}$ for 10 minutes to ensure protein samples were denatured, soluble and possessed a negative charge for SDS-PAGE. $30 \mu \mathrm{g}$ of protein were loaded into each well, including a protein molecular weight marker (Dual Colour Protein Standards, cat: 1610374, Bio-Rad). A dual colour marker was used for ease in downstream analysis allowing for gel orientation and excision of chosen bands. The current was set to $120 \mathrm{~V}$ until samples reached the bottom of the gel. After proteins were run by SDS-PAGE they were stained using Coomassie Blue.

\subsubsection{Coomassie Blue staining}

Following electrophoresis gels were stained with Coomassie Blue (94ml methanol, $94 \mathrm{ml}$ water, $38 \mathrm{ml}$ acetic acid and 1.25g Coomassie R250 (Sigma Aldrich, USA) for 30 minutes. Gels were then destained using destaining buffer $(100 \mathrm{ml}$ methanol, $825 \mathrm{ml}$ water, $75 \mathrm{ml}$ acetic acid). Buffer was replaced frequently until background staining was no longer present and stained bands could be seen.

\subsubsection{Fourier transform infrared spectroscopy (FTIR)}

Collagen samples were lyophilized before the experiment. Lyophilsation was achieved using a Scanvac Coolsafe 55-9 freeze drier (Labogene, Denmark). A standard protocol was followed where samples were frozen at $-20^{\circ} \mathrm{C}$ and placed in a vacuum chamber at $-180^{\circ} \mathrm{C}$ until all liquid has sublimated. An equal quantity of collagen was added to the ATR-FTIR ZnSe/ diamond crystal stage. ATR FTIR spectra were performed using the ATR FITR Spectrum Two (Perkin Elmer) equipped with a deuterated triglycine sulphate (DTGS) detector. The system was illuminated by a Globar MIR source. ATR-FTIR spectra were acquired in absorption mode, using 64 co-added scans and a $4 \mathrm{~cm}^{-1}$ spectral resolution. The frequency range 
used during each replicate experiments were varying from $4000 \mathrm{~cm}^{-1}$ to $400 \mathrm{~cm}^{-1}$. Background spectra were achieved using the same parameters as the sample spectra in order to subtract the $\mathrm{CO}_{2}$ bands hence ensuring optimal spectra acquisitions and processing.

Research grade rat tail collagen (cat: 08-115, Merck, UK) was used as a standard to determine amide peak positions in a mammalian collagen source, shown in figure

2.3.

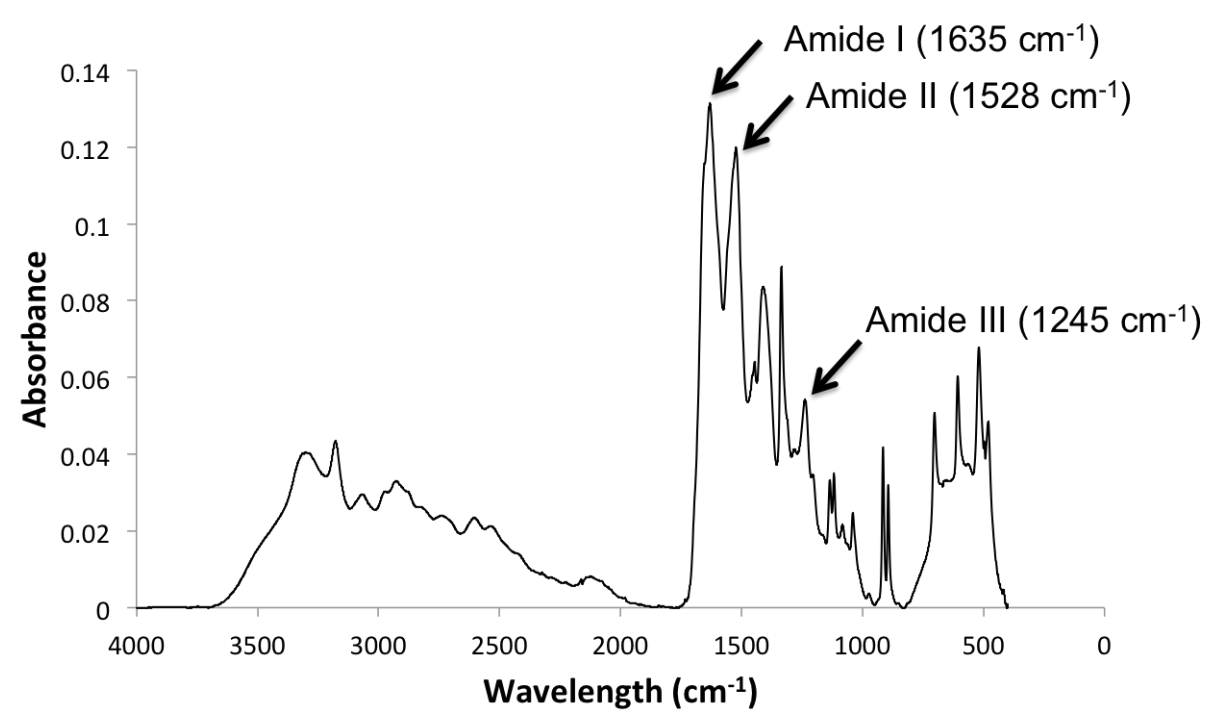

Figure 2.3: Research grade rat-tail collagen type I FTIR spectrum. FTIR spectra of rat-tail collagen depicting amide I, amide II and amide III peaks at $1635 \mathrm{~cm}^{-1}$, $1528 \mathrm{~cm}^{-1}$ and $1245 \mathrm{~cm}^{-1}$, respectively.

Each spectrum was visualised and analysed using Spectrum 10 software (Perkin Elmer) and spectra data points were then extracted and plotted using excel software for convenience purposes.

\subsubsection{Protein sequencing}

Specific bands of interest were excised from the gel using a disposable sterile scalpel and placed in an eppendorf. Samples were then sent to Proteome Factory, Germany for peptide identification. The process consisted of cleavage via trypsin digestion followed by separation and detection with liquid chromatography - mass spectroscopy (LCMS). Mass spectroscopy spectra were then subjected to a database 
search against NCBI or Swissprot and data collated into an excel spreadsheet for further analysis.

\subsubsection{Informatics}

Peptide sequences were individually input into basic local alignment search tool (BLAST) and searched against a non-redundant protein sequences database to identify proteins with sequence similarity. Following BLAST alignment, specific human collagen sequence alignment to jellyfish peptides was conducted using Clustal Omega, a multi sequence alignment tool. Peptides and human collagen FASTA sequences were inputted into the system to give numbered graphical alignment output for ease in identifying nucleotide position. Functional peptide analysis was then conducted using AbDesigner where human FASTA sequence was input and graphical output was used to inform functionality of areas with high sequence similarity to jellyfish peptides from multi sequence alignment.

\subsection{Material characterisation (scaffold)}

Sponge scaffold moulding, fabrication, Scanning electron microscopy, pore size analysis, thermal stability and resistance to collagenase digest

\subsubsection{Scaffold fabrication}

$250 \mu 1$ of collagen was pipetted into a 96 well plate (Corning, UK) at a concentration of $4 \mathrm{mg} \cdot \mathrm{ml}^{-1}$ before being frozen at $-20^{\circ} \mathrm{C}$ and lyophilised. The constructs were then cross-linked using 1-ethyl-(3-3-dimethylaminopropyl) carbodiimide hydrochloride (EDC) (cat no: E1769, Sigma Aldrich) in $80 \%$ ethanol at $1 \%, 0.5 \%$ and $0.25 \% \mathrm{w} / \mathrm{v}$ for 90 minutes. Scaffolds were rinsed in deionised water three times and left in $1 \%$ glycine overnight, at room temperature, to quench the reaction. The cross-linked constructs were then rinsed three times in deionised water before being lyophilised to dry and regain their cylindrical shape. 


\subsubsection{Scanning electron microscopy (SEM)}

Tissue and scaffold samples were washed three times at room temperature, in 50mM sodium cacodylate (Sigma, UK)-HCl buffer solution ( $\mathrm{pH} 7.2-7.4)$ at 10 to 20 minute intervals to remove excess salt. The scaffolds were fixed overnight in $2 \%$ glutaraldehyde and then dehydrated in a series of graded ethanol (30\% to $100 \%)$. Dehydrated samples were rinsed in 50\% hexamethyldiasilazane solution (HMDS, Sigma, UK) in $100 \%$ ethanol for 10 minutes in a fume hood and then three times in $100 \%$ HMDS and left overnight, at room temperature, to dry. The samples were then coated in a thin layer of chromium $(\sim 15 \mathrm{~nm})$ using sputter coating and were imaged using scanning electron microscopy (Hitachi 4800). A standard sputter coating cycle was followed according to manufacturers instruction (Quorum, UK).

\subsubsection{Pore size analysis}

Average scaffold pore size was calculated by measuring the widest point of pores within scaffold structures using proprietary SEM software (Hitachi). A total of 30 pores were analysed per replicate and a total of 3 replicates were analysed from separate fabrication runs.

\subsubsection{Plastic compression}

Collagen scaffolds were fabricated as described in section 2.2.1 using a 24 well plate. Scaffolds were then hydrated with deionised water at room temperature, before a 24 well absorber (cat: 016-1R33, Lonza) was placed on top for 30 minutes to dehydrate and compress structures. Following compression scaffolds were placed in fresh deionised water and weighed. Wet weight prior to and following compression was used to analyse scaffold reswelling, quoted as milligrams.

\subsubsection{Differential scanning calorimetry}

Scaffolds were placed in platinum crucibles and heated in a Netzsch STA 449F1. Heating and cooling were performed in flowing argon gas with a temperature ramp 
of $10 \mathrm{C} \cdot \mathrm{min}^{-1}$ from room temperature to $100^{\circ} \mathrm{C}$. An empty platinum crucible was used for reference. This work was carried out alongside an experienced DSC technician and data provided for downstream analysis.

\subsubsection{Collagenase digest}

Scaffolds were placed in $5 \mathrm{ml}$ bijous tubes containing $3 \mathrm{ml}$ of standard culture (DMEM, Gibco, UK) media supplemented with $300 \mathrm{U} \mathrm{ml}^{-1}$ collagenase and incubated at $37^{\circ} \mathrm{C}$ on a tube rotator (Miltenyi Biotec, UK). At specific time points $(0$, 1, 2, 4, 6 and 12 hours), scaffolds were removed from media, blotted dry and weighed before returning to collagenase solution. All experients were carried out in triplicate. 


\subsection{JCol biocompatibility testing}

2D lawn culture, viability and proliferation, morphology (cell shape), 3D in vitro immunogenicity and cytokine release profiling.

\subsubsection{Tissue culture of human cell lines}

Human endometrial stromal cells (hESC), HEC50 and Ishikawa cells were cultured with DMEM: Nutrient Mixture F-12 supplemented with $10 \%$ foetal bovine serum (FBS), $1.5 \mathrm{mM}$ glutamine, $1 \mathrm{mM}$ sodium bicarbonate, $1 \mathrm{mM}$ sodium pyruvate, $1 \%$ penicillin streptomycin and maintained at $37^{\circ} \mathrm{C}$ and $5 \% \mathrm{CO}_{2}$ until $80 \%$ confluency. At this point cells were washed with PBS before being subjected to trypsin treatment to allow for detachment from plastic. Trypsin was then neutralised before transferring to a $15 \mathrm{ml}$ falcon tube and centrifuging at $1200 \mathrm{rpm}$ for 5 minutes to obtain a pellet. The resultant supernatant was removed and the cell pellet resuspended in culture media before subculturing into a new flask with fresh media.

\subsubsection{Sources of articular cartilage}

Animal models are seen as an effective tool for the development of therapeutic and surgical interventions intended for human application due to their mimicry of human tissue and disease progression. Smaller animals such as mice and rats are regularly used for research purposes however these animals often present with an open growth plate after skeletal maturity and are likely to confer enhanced reparative properties that are not comparable to human tissue (Chu et al., 2010). Larger animals have been shown to more closely mimic human cartilage than smaller animals (Reinholz et al., 2004). Bovine metacarpophalanegeal (MCP) joints have been widely used as a model for human articular cartilage due to similarities in components and structure (Stockwell, 1978). The animal tissue used in this study was obtained from healthy animals entering the food chain. The tissue is classed as a food grade material that is discarded during food processing. 


\subsubsection{Bovine tissue isolation}

Fresh immature (approximately 7-14 days) bovine metacarpophalangeal (MCP) joints were obtained on the day of slaughter (Cig Calon Cymru Cyf, Llanelli, Wales). All joints were cleaned with soap and tap water before removing skin and inspecting for bruising and damaged joints were discarded. Healthy joints were sprayed with $70 \%$ ethanol in order to minimise risk of contamination before being transferred to a sterile cabinet. Full thickness cartilage tissue was harvested from the medial and lateral condyles, as well as condylar ridge, using a $6 \mathrm{~mm}$ biopsy punch. Harvested cartilage was placed in low glucose Dulbecco's Modifies Eagle's Medium (DMEM) (cat: 21885-108, ThermoFisher Scientific) before cell isolation was undertaken.

\subsubsection{Enzymatic digestion and cell isolation}

Whole tissue samples were subjected to sequential digestion using pronase and collagenase, respectively, to isolate cellular components of bovine MCP tissue. Tissue samples were placed in pronase diluted to $70 \mathrm{U} \mathrm{ml}^{-1}$ in DMEM for 2 hours at $37^{\circ} \mathrm{C}$ and $5 \% \mathrm{CO}_{2}$ on a tube rotator (Miltenyi Biotec, UK). Pronase solution was removed and tissue re-suspended in DMEM supplemented with $300 \mathrm{U} \mathrm{ml}^{-1}$ bacterial collagenase (cat: $\mathrm{C} 9263$, Sigma Aldrich) for 16 hours at $37{ }^{\circ} \mathrm{C}$ and $5 \% \mathrm{CO}_{2}$. Following sufficient tissue digestion, assessed by eye, the digest was passed through a $40 \mu \mathrm{m}$ cell strainer (cat: 15360801 , Fisher Scientific) to separate debris and cells were collected into a $50 \mathrm{ml}$ falcon tube. Cells were counted using an automated cell counter (Bio-Rad, UK) and subjected to differential adhesion assay to select for chondroprogenitor (CP) cells.

\subsubsection{Differential fibronectin adhesion assay}

Stem cells can be classified by their ability to adhere to plastic surfaces (Dominici et al., 2006). CPs have previously been shown to be selected for via differential fibronectin adhesion assay (Dowthwaite et al., 2004). Six well plates (Grenier CELLSTAR $^{\circledR}$, cat: M8562, Sigma Aldrich) were coated with 10ug.ml ${ }^{-1}$ of fibronectin (cat: FN, Sigma, UK) in 0.1M phosphate buffered saline (PBS) at pH 7.4 containing $1 \mathrm{mM} \mathrm{MgCl} 2$ and $1 \mathrm{mM} \mathrm{CaCl}_{2}$ at $4^{\circ} \mathrm{C}$ for 24 hours. Following incubation, 
fibronectin was removed and wells washed with serum free DMEM. Full depth populations of cells were seeded at 1000 cells ml-1 and incubated for 30 minutes at $37^{\circ} \mathrm{C}$ and $5 \% \mathrm{CO}_{2}$. Media and non-adherent cells were then removed and replaced with DMEM supplemented with $1 \%$ penicillin and streptomycin, $0.5 \% \mathrm{ml}^{-1} \mathrm{~L}$ glucose, 10mM HEPES, $1 \mathrm{mM}$ sodium pyruvate, $2 \mathrm{mM}$ L-glutamine and $10 \%$ foetal bovine serum (FBS). Plates containing adherent cells were then incubated for 6 days prior to colony isolation.

\subsubsection{Clonal population isolation}

Following 6 days of culture, colonies comprising of 32 cells or more were isolated using sterile cloning rings (Sigma, UK) to discount transit-amplifying cells. Cloning rings were sealed to the plate by the application of Vaseline to the edge of the ring before being positioned upon suitable colonies. Once secured, $200 \mu$ of $0.05 \%$ trypsin (Gibco, UK) was added to detach cells from the surface of the plate. After 3 minutes incubation, cell suspension was removed and transferred to a 6 well plate containing $3 \mathrm{ml}$ of DMEM containing FBS to inactivate trypsin activity.

\subsubsection{Cell culture medium}

DMEM was supplemented with $1 \%$ penicillin and streptomycin, $4.5 \mathrm{~g} \mathrm{~L}^{-1} \mathrm{~L}$-glucose, 10mM HEPES, $1 \mathrm{mM}$ sodium pyruvate, $2 \mathrm{mM}$ 1-glutamine and $10 \%$ foetal bovine serum (DMEM+) was used to culture CP cells.

\subsubsection{Monolayer expansion}

Cells were expanded in DMEM+ in an incubator at $37^{\circ} \mathrm{C}$ and $5 \% \mathrm{CO}_{2}$, with media change taking place every 3 days. At $80 \%$ confluence, culture media was removed and cell monolayer washed with sterile PBS (Gibco, UK). Following PBS wash, cells were incubated in $0.05 \%$ trypsin-EDTA (Gibco, UK) for 5 minutes at $37^{\circ} \mathrm{C}$ and $5 \% \mathrm{CO}_{2}$. After gentle agitation, detached cells were transferred to a $15 \mathrm{ml}$ tube and centrifuged at $1200 \mathrm{rpm}$ for 5 minutes at room temperature. The supernatant was 
discarded and cell pellet re-suspended by aspiration of $5 \mathrm{ml}$ of DMEM+ before cells were reseeded at a suitable density into a sterile tissue culture flask.

\subsubsection{Cellular differentiation}

Differentiation studies were undertaken to determine the phenotypic plasticity of cells.

\subsubsection{Chondrogenic differentiation}

Specific chondrogenic medium was used to induce chondrogenic differentiation of chondroprogenitors in 2D and 3D culture. Chondrogenic medium consisted of high glucose DMEM (Gibco, UK), supplemented with 10\% heat inactivated FBS, $1 \%$ insulin transferring selenium (ITS) and 1\% penicillin and streptomycin and 10ng ml-1 TGF $\beta 1$.

Sulphated GAGs were detected via alcian blue (Sigma, USA) staining (Williams et al., 2010). Monolayer cells were fixed with $10 \%$ NBFS for 20 minutes and washed in PBS 3 times. Cells were stained with $1 \%$ staining solution comprised of $1 \mathrm{~g}$ alcian blue in $100 \mathrm{ml}$ of $0.1 \mathrm{M}$ hydrochloric acid $(\mathrm{pH} 2.5)$ for 30 minutes. Excess stain was removed and well washed with $0.1 \mathrm{M} \mathrm{HCl}$ before immersing in PBS and imaging with a light microscope

\subsubsection{Osteogenic differentiation}

Osteogenesis of cells was induced with $\alpha$-MEM (Gibco, UK) culture media containing $2 \mathrm{mM}$ glutamine and supplemented with $10 \%$ heat inactivated FBS, $1 \%$ penicillin and streptomycin, $0.1 \mu \mathrm{M}$ dexamethasone, $0.2 \mathrm{mM}$ ascorbic acid-2phosphate and 10mM $\beta$-glycerophosphate

Alizarin red staining was used to show tissue calcification of monolayer cultures subjected to osteogenesis (Williams et al., 2010). Monolayer cultures were fixed in $10 \%$ NBFS for 20 minutes and washed 3 times with PBS. After rinsing the cells were 
stained with $2 \%$ Alizarin red $(\mathrm{pH} 4.22)$ solution for 30 seconds and excess stain removed. Samples were blotted dry and immersed in PBS before being viewed under a light microscope.

\subsubsection{Adipogenic differentiation}

Specific adipogenic media was used to induce adipogenesis and consisted of $\alpha$-MEM media containing $2 \mathrm{mM}$ glutamine and supplemented with $10 \%$ heat inactivated FBS, $1 \%$ penicillin and streptomycin, $1 \mu \mathrm{M}$ dexamethasone, $1.72 \mu \mathrm{M}$ of bovine insulin, $0.2 \mathrm{mM}$ indomethacin and $0.5 \mathrm{mM}$ of isobutylmethlxanthine (IBMX).

Oil red-O staining was used to indicate lipid deposits in monolayer culture (Williams et al., 2010). Monolayer cells subjected to adipogenesis were fixed in $10 \%$ NBFS for 20 minutes and washed with PBS. Oil red-O was prepared from $0.5 \%$ Oil red-O in $100 \%$ isopropanol by diluting $30 \mathrm{ml}$ of stock solution in $20 \mathrm{ml}$ distilled water. Cells were washed with $60 \%$ isoproponal prior to staining with Oil red-O for 15 minutes at room temperature. Excess stain was removed and wells immersed in PBS and viewed under a light microscope.

\subsubsection{Coating plates}

24 well plates (Corning, UK) were coated with $30 \mu \mathrm{g} / \mathrm{ml}$ of collagen solution in $0.1 \mathrm{M}$ acetic acid and allowed to dry for overnight in sterile conditions before unoccupied areas were blocked with $1 \%$ BSA. Cells were seeded onto coated plates at a density of 5000 cells per well and cultured for a predetermined period of time.

\subsubsection{InCell image acquisition}

InCell Analyser 2000 (GE Healthcare) was used to analyse viable and dead cells Following culture period media was removed from monolayer cultures and washed gently with PBS. Phenol free media was supplemented with using $5 \mu \mathrm{M}$ carboxyfluorescein succinimidyl ester (CFSE) and $1 \mu \mathrm{M}$ EthD-2 to visualise live and dead cells respectively. $150 \mu \mathrm{l}$ of media containing fluorescent dye was added to each 
well and incubated at $37^{\circ} \mathrm{C}$ for 20 minutes in the dark before removal of media and PBS wash. $4 \mu \mathrm{M}$ Hoescht in phenol free media was added to the wells and incubated at room temperature for 10 minutes before final wash and immersing wells in phenol free media.

Image data was obtained using three emission spectra channels; DAPI nuclear staining (Channel 1 excitation/emission $\lambda 358 / 461 \mathrm{~nm}$ for 0.2 seconds), Texas Red protein staining (Channel 2 excitation/emission $\lambda 589 / 615 \mathrm{~nm}$ for 2.0 seconds) and FITC (Channel 3 excitation/emission $\lambda 492 / 517 \mathrm{~nm}$ for 3.0 seconds). Time exposure for each channel was consistent between experiments. Low magnification images were taken with the $10 \mathrm{x}$ with 20 fields of view taken for each well. The InCell analyser allows for random distribution of fields across the surface of the well, allowing for regions such as the edge of the well boundary to be excluded. Once analysis was completed, a data (XDCE) file is produced containing all accumulated imaged from the channels and fields of views chosen.

\subsubsection{InCell analysis}

XDCE data files were analysed using InCell Developer (GE Healthcare) to quantify number CFSE and EthD-2 stained cells allowing quantification of live and dead cells. Analysis software can segment objects by the intensity of the DAPI channel. The intensity of fluorescence produced by DAPI allows segmentation of the nucleus against background fluorescence. Fluorescence signal was determined pixel by pixel in absolute grey areas across each cell and individual cells were counted based upon the channel fluorescence was identified from. Data was accumulated and compressed before converting to an excel spreadsheet to show cell count.

\subsubsection{Cell morphology}

Cells were seeded at a density of $1 \times 10^{4}$ per well and cultured for a maximum of 5 days. Images of cells were taken every 24 hours using a light microscope (Zeiss, UK). Morphological analysis of cells was undertaken using ImageJ software to obtain the shape index (SI). SI was calculated using the formula: 


$$
\mathrm{SI}=4 \pi \times \text { Area } / \text { Perimeter }^{2}
$$

Cells that are deemed to have a circular shape have an SI of 1 whilst those that are more fibroblastic in morphology will have a value of 0 (Tiryaki et al., 2015).

\subsubsection{Whole blood patient recruitment}

Human peripheral blood was collected from healthy adult volunteers with informed written consent. Blood was collected into either $3.2 \%$ sodium citrate or lithium heparin anticoagulant $9 \mathrm{ml}$ Vacuette ${ }^{\circledR}$ tubes (Grenier Bio-One, Stonehouse, UK). Venesection was performed by trained phlebotomists in the Joint Clinical Research Facility, Institute of Life Science. This study was approved by the Wales Research Ethics Committee 6 (13/WA/0190).

\subsubsection{Fluorescent activated cell sorting}

Cells stained as described below were analysed within 2 hours using a 10 colour, 3 lasers, Navios Flow Cytometer (Beckman Coulter, High Wycombe, UK). The instrument was turned on at least 1 hour prior to running to allow lasers to warm up and for quality control checks. To check instrument performance, FlowCheck and FlowSet beads (Beckman Coulter) were run. All samples were recorded without compensation, which was applied later in data analysis. Voltages were set on unstained samples.

\subsubsection{Leukocyte activation analysis}

Whole blood, taken from 3 individual, healthy donors, was stained with the following: CD15 and CD14; 100ng/ $\mu$ l CD3-APC-AF750 (clone UCHTI, IgG1, Backman Coulter); 25ng/ $\mu$ l CD62L-PE (clone DREG-56, IgG, eBioscience);

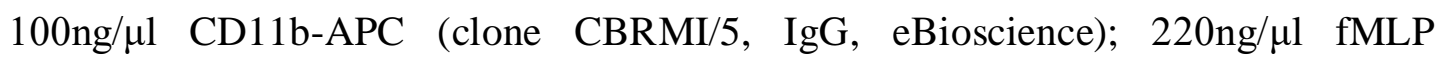
receptor-FITC (clone REA169, IgG, Miltenyi Biotec). Samples were vortexed, incubated and lysed using EasyLyse as it is formaldehyde free and will not affect dead cell staining. 1 $\mu \mathrm{l}$ DRAQ7, final concentration 20uM (BioStatus, UK) was 
added before running the samples. Whole blood stimulated with 10ng/ml LPS for 4 hours at $37^{\circ} \mathrm{C}$ and $5 \% \mathrm{CO}_{2}$ was used as a positive control and unstained samples were used for gating purposes. Blood exposed to $1 \%$ Triton-X 100 was used to determine DRAQ7 positive cell gates. AbC beads (Life Technologies, UK) were stained singly with each antibody and used for compensation. Within 2 hours of staining, samples were acquired on the Navios flow cytometer (three lasers (violet: 405nm, blue: 488nm, red: 638nm) using linear forward scatter (FSC) versus side scatter (SSC) scale, flow rate set to high, and stop gate on $10,000 \mathrm{CD} 15^{+}$events which would allow for the acquisition of approximately 10,000 total lymphocytes and 1,000 monocytes. Compensation and data analysis were performed using Kaluza 1.3 (Beckman Coulter).

\subsubsection{Platelet activation analysis}

For platelet activation analysis, whole blood, from three individual, healthy donors was stained with $200 \mu \mathrm{g} / \mu \mathrm{l} \mathrm{CD} 42 \mathrm{~b}-\mathrm{FITC}$ (clone HIPO, IgG1, eBioscience). Samples were vortexed, incubated and lysed using BD FACS lysing solution. Whole blood stimulated with $4 \mathrm{mM}$ phorbol 12-myristate 13-acetate (PMA) for 20 minutes was used as a positive control; tubes were run on a logarithmic scale with 10,000 events as the stopping gate.

\subsubsection{Whole blood culture}

Whole blood culture (100ul blood/300ul RPMI, $2 \mu \mathrm{M}$ GlutaMax, $0.1 \mathrm{mM} 2$ mervaptoethanol) were left unstimulated or stimlulated with $10 \mathrm{ng} / \mathrm{ml}$ E.coli OIII:B4 lipopolysaccharide (Ultrapure LPS, Invivogen, France). After 24 hours at $37^{\circ} \mathrm{C}$ and $5 \% \mathrm{CO}_{2}$ cell free supernatants were harvested by centrifugation at $4{ }^{\circ} \mathrm{C}, 515 \mathrm{xg}$ for 7 minutes. Supernatants were stored at $-20^{\circ} \mathrm{C}$ until analysis.

\subsubsection{ELISA}

Blood serum collected in section 2.3.8 was thawed for cytokine quantification using enzyme-linked immunosorbant assay (ELISA). IL-6 (cat: DY206, R\&D Systems, 
USA) and IL-10 (cat: DY217B, R\&D Systems, USA) were detected using commercially available kits with protocol and antibodies provided.

Capture antibodies were added to a 96 well ELISA plate (cat: 650001, Grenier BioOne, UK) following dilution to working concentration in PBS and sealed with a polyester film (cat: 391-1250, VWR, UK). The plate was incubated overnight at 4C on a rocker to allow adequate binding of antibodies to the plate. Each plate was washed with wash buffer (PBS with $0.05 \%$ Tween-20) 3 times. Any remaining wash buffer was removed by inversion and blotting against paper towels. Following this, the ELISA plate was blocked using blocking buffer (1\% BSA in PBS) for 1 hour at room temperature to block unbound areas and prevent false positives. The plate was then washed as before and assay could be preformed.

Known concentrations of IL- 6 and IL-10 were used to generate a standard curve. The standards were provided with ELISA kits and contained 180ng/ml human IL-6 standard and $150 \mathrm{ng} / \mathrm{ml}$ of human IL-10 standard. IL-6 and IL-10 standards were produced by serial dilution using blocking buffer for each assay, to concentrations 600, 300, 150, 75, 37.5, 18.75 and $9.38 \mathrm{pg} / \mathrm{ml}$ and 2000, 1000, 500, 250, 125, 62.5, $31.25 \mathrm{pg} / \mathrm{ml}$, respectively. Blocking buffer was prepared without standard to account for background and was subtracted from readings. Standards and samples were added to 96 well plates and incubated for 2 hour at room temperature to allow for IL6 and IL-10 to bind to capture antibodies. After incubation, excess samples were removed and plates washed with wash buffer, three times to remove unbound proteins.

A biotinylated secondary detection antibody, which contained goat anti-human IL-6 and goat anti-human IL-10. The plate was incubated with a secondary antibody for 2 hours at room temperature to allow binding to target protein. The plate was washed with wash buffer, three times before streptavidin-horseradish peroxidase (HRP) was added to the plate and incubated for 20 minutes at room temperature in the dark. Plates were the washed as previously described.

A substrate solution was added to the plate containing hydrogen peroxide and tetramethylbenzidine, which reacts with HRP and results in the development of a 
blue colour that is directly proportional to target protein concentrations. Sulphuric acid $(1 \mathrm{M})$ was used to stop the reaction resulting in a colour change from blue to yellow. Optical density of each well was determined using the FLUOstar plate reader at an absorbance of $450 \mathrm{~nm}$.

\subsection{Biomaterial application}

3D chondrogenic culture, histology, biochemical assays, gene expression.

\subsubsection{Pellet formation}

Confluent cells were removed from the surface of the flask via trypsinisation (section 2.3.3.1). Cells were counted using an automated cell counter and $5 \times 10^{5}$ cells were added to a sterile eppendorf tube containing $500 \mu$ of expansion culture medium. The cell suspension was centrifuged at 2000rpm for 10 minutes at room temperature (5425, Eppendorf). The pellet was incubated for 24 hours at $37^{\circ} \mathrm{C}$ and $5 \% \mathrm{CO}_{2}$. Following 24 hours cell pellets were gently aspirated from the surface of the Eppendorf surface using a pipette in order to facilitate pellet rounding. Chondrogenic media was changed every 2 days until the end of the culture period.

\subsubsection{Scaffold seeding}

Scaffolds were equilibrated in culture media for 10 minutes prior to seeding and placed in 24 well plates coated with $2 \%$ agarose to stop cell attachment to the bottom of the plate. Confluent cells were removed from the surface of the flask and counted using an automated cell counter and $5 \times 10^{5}$ cells were resuspended in $80 \mu$ of media before seeding on the surface of the scaffold. Plates containing scaffolds were placed in an incubator at $37^{\circ} \mathrm{C}$ and $5 \% \mathrm{CO}_{2}$ for 20 minutes to allow cell attachment to scaffolds before filling each well with $200 \mu 1$ of media. After 24 hours, culture media was changed to chondrogenic media and refreshed every 2 days until the end of the culture period. 


\subsubsection{Paraffin wax embedding}

Tissue and scaffold samples were washed in PBS before being fixed in neutral buffered formalin with saline (NBFS) at $4^{\circ} \mathrm{C}$ for 15 minutes. Samples were then washed and stored in PBS before being embedded at Singleton Hospital (ABMU, NHS). Wax embedding consisted of dehydrating samples through a series of graded ethanol (70\%, 95\% and twice at 100\%) before being cleared in xylene for 20 minutes and infiltrated with paraffin wax for 1 hour at $56^{\circ} \mathrm{C}$.

\subsubsection{Paraffin wax sectioning}

Wax embedded samples were sectioned at a thickness of $7 \mu \mathrm{m}$ using a microtome. Wax ribbons containing sections of sample were flattened by placing into a water bath at $45^{\circ} \mathrm{C}$. Sections were removed by transferring onto poly-l-lysine histology slides and dried for 24 hours at $45^{\circ} \mathrm{C}$. Prior to any staining, slides were deparaffinised by washing in xylene twice for two minutes. They were then rehydrated in a series of graded ethanol (100\% twice, $95 \%$ and $70 \%)$ for two minutes and then immersed in tap water for two minutes.

\subsubsection{Haematoxylin and eosin}

Nuclear staining and tissue architecture were detected by haematoxylin and eosin (TSC biosciences, UK). Haematoxylin was diluted in water (1:2 ratio) and 1\% eosin was prepared by dilution in water. Rehydrated slides were stained in haematoxylin for 1 minute and washed in water to remove excess stain. The stain was differentiated in $1 \%$ alcohol and washed in water before staining in eosin for 2 minutes. Slides were washed in water to remove excess stain and dehydrated in ethanol before clearing in xylene and mounted with DPX.

\subsubsection{Toluidine blue}

Sulphated GAG deposition was indicated via Toluidine blue staining (Williams et al., 2010). Rehydrated pellet sections were stained with $0.04 \%$ toluidine blue for 15 
minutes and washed until water was clear. Stained sections were dried over night at $45^{\circ} \mathrm{C}$ and mounted using DPX mounting medium before viewing under a light microscope.

\subsubsection{Picrosirius red}

Collagen fibrils were indicated histologically with picrosirius red staining. Sectioned sampled were hydrated through descending concentrations of ethanol before being stained with $0.1 \%(\mathrm{w} / \mathrm{v})$ picrosirius red solution for 1 hour at room temperature before washing with water. Slides were then dehydrated in ethanol before being mounted in DPX mounting fluid and adding a coverslip before being examined under polarised light.

\subsubsection{Immunohistochemistry}

Paraffin wax embedded samples were dewaxed and rehydrated as described in section 2.4.3.1. Samples were treated in $3 \%$ hydrogen peroxide in methanol to reduce background staining and were then washed in PBST (PBS with 0.05\% Tween-20) for 5 minutes. Following this, samples were treated for antigen retrieval and incubated at $65 \mathrm{C}$ in Tris-EDTA overnight before being washed in PBST and subjected to enzymatic treatment with $2 \mathrm{U} \mathrm{ml}^{-1}$ hyaluronidase in PBST for 1 hour at 37C. Samples were then washed in PBST for 5 minutes before blocking to prevent non-specific binding of antibodies with $2.5 \%$ normal horse block serum (RTU Vectastain Kit, Vector Laboratories, USA) for 30 minutes. Blocking serum was removed and primary antibodies diluted (dilutions stated below) in PBST was added to samples for 30 minutes at room temperature, with negative controls using PBST containing no primary antibodies. Following incubation with antibodies, samples were washed for 5 minutes in PBST and secondary antibodies were added for 10 minutes at room temperature (RTU Biotinylated pan specific antibody Universal biotinylated Anti-Mouse/Rabbit/Goat IgG derived from horse) before washing for 5 minutes in PBST. Streptavidin/peroxidase complex reagent (RTU Vectastain Kit, Vector Laboratories, USA) was applied to samples at room temperature for 5 minutes before rinsing with PBST for a further 5 minutes and samples were 
developed using NovaRED kit (Vector Laboratories, USA) for 5 minutes to allow for detection of streptavidin/peroxidase enzymatic activity.

Samples were washed with deionised water and nuclei were counterstained with haematoxylin for 1 minute before dehydration in a series of graded alcohol. Sampled were then mounted with DPX and analysed via light microscope to examine the extracellular matrix.

Project specific antibodies used;

- Collagen type II (1:250, DHSB II-II6B3 raised in mouse)

- Aggrecan (1:10, DHSB 12/21/1-C-6 raised in mouse)

- Collagen I (1:2000, Sigma C2456, raised in mouse)

\subsubsection{Scaffold and pellet digestion}

Papain is a cysteine protease that is used for the digestion of samples for subsequent biochemical analysis (Estes and Guilak, 2011). Whole scaffold/pellet samples were digested in papain buffer $(20 \mathrm{mM} \mathrm{NaAc} \mathrm{pH} 6.8,1 \mathrm{mM}$ EDTA, $2 \mathrm{mM}$ DTT, 300 $\mu \mathrm{g} \mathrm{ml-}$ 1 papain) following completion of experimentation. Samples were incubated within an eppendorf containing papain buffer at $60^{\circ} \mathrm{C}$ in a water bath for 60 minutes or until no visible tissue remained. Digested samples were stored at $-20^{\circ} \mathrm{C}$ until needed for biochemical analysis of DNA, GAG and hydroxyproline content.

\subsubsection{DNA quantification}

DNA quantification is assessed in order to normalise data obtained from GAG and hydroxyproline assays (Estes and Guilak, 2011). Quant-iT TM Picogreen dsDNA assay kit (cat: P11496, ThermoFisher Scientific, UK) was used to quantify DNA content from scaffolds and pellets, in triplicate from three repeats, in accordance to the manufacturers protocol. Samples were quantified against a standard curve composed of a series of lambda DNA diluted in 1xTE buffer provided in the kit $(0$ $10 \mathrm{ug} / \mathrm{ml}$ ). Fluorescence was measured using a FLUOstar Omega plate reader at 
$520 \mathrm{~nm}$ and cell number calculated with the assumption that every mammalian cell contains 7.7pg of DNA (Röder et al., 2015).

\subsubsection{DMMB assay}

A standard curve consisting of chondroitin sulphate (cat: C4348, Sigma-Aldrich, UK) diluted in water, ranging from $0-10 \mu \mathrm{g} \mathrm{ml}^{-1}$ was produced. For each reaction, $20 \mu 1$ of papain-digested sample was added to $200 \mu 1$ of DMMB reagent $\left(16 \mathrm{mg} \mathrm{L}^{-1}\right.$ dimethlmethylene blue, $3 \mathrm{~g}$ polyvinyl alcohol, $3.04 \mathrm{~g}$ glycine, $2.37 \mathrm{~g} \mathrm{NaCl}, 95 \mathrm{ml} 0.1 \mathrm{M}$ $\mathrm{HCl})$ in a 96 well plate and shaken for 5 seconds. Glycosaminoglycan content from scaffold and pellets was determined, in triplicate from three repeats, by spectrophotometric measurement of absorbance against the standard curve at $525 \mathrm{~nm}$ using a plate reader (FLUOstar Omega, BMG) and normalised through division by the corresponding DNA content.

\subsubsection{Hydroxyproline assay}

Hydroxyproline assays were run to calculate collagen content samples. Papain digested samples were hydrolysed in $6 \mathrm{M} \mathrm{HCl}$ for 24 hours at $110^{\circ} \mathrm{C}$ using a heating block and vacuumed dried overnight before reconstituting in deionized water. Following centrifugation to remove impurities, $30 \mu \mathrm{l}$ of each sample were added to a 96 well plate and $70 \mu \mathrm{l}$ of diluent solution and $50 \mu \mathrm{l}$ oxidant were added to each sample before shaking for 5 minutes at room temperature. $125 \mu 1$ of colour reagents was added and samples shaken prior to 15 minutes incubation at $70^{\circ} \mathrm{C}$. Hydroxyproline content was measured in terms of absorbance at $540 \mathrm{~nm}$ using a plate reader and quantification determined against the standard curve of trans-4-hydroxyL-proline $(0-100 \mu \mathrm{g} / \mathrm{ml})$.

Composition of buffers is as follows

- Stock buffer: $28.5 \mathrm{~g}$ sodium acetate trihydrate, $18.75 \mathrm{~g}$ tri sodium citrate dyhydrate, $2.75 \mathrm{~g}$ citric acid, $200 \mathrm{ml}$ propan-2-ol

- Diluent: $100 \mathrm{ml}$ propan-2-ol, $50 \mathrm{ml} \mathrm{H}_{2} \mathrm{O}$

- Oxidant: $0.7 \mathrm{~g}$ Chloramine $\mathrm{T}, 10 \mathrm{ml} \mathrm{H}_{2} \mathrm{O}, 50 \mathrm{ml}$ stock buffer 
- Colour reagent: $7.5 \mathrm{~g}$ dimethylaminobenzaldehyde, $11.25 \mathrm{ml}$ perchloric acid (60\%), 62.5ml propan-2-ol

\subsubsection{RNA extraction from native tissue}

Articular cartilage biopsy samples were placed in a shaking flask with a grinding ball and $250 \mu \mathrm{l}$ of trizol reagent. The flasks were then sealed and snap frozen in liquid nitrogen before homogenization of the sample via shaking at 2000rpm for 1 minute using a Mikro dismembrator-S (B. Braun Biotech International, Germany). The powdered material was collected and stored at $-80^{\circ} \mathrm{C}$ until needed. RNA was extracted from the powdered material using RNeasy columns with a DNase1 oncolumn digest as outlined in the Qiagen user manual. Isolated RNA was stored at $80^{\circ} \mathrm{C}$ prior to quantification.

\subsubsection{RNA extraction from pellets and scaffolds}

RNA was extracted from samples on the day of experimental completion. Samples were placed in a $2 \mathrm{ml}$ eppendorf with 350ul RLT buffer (Qiagen, UK) and mechanically homogenized for 20 seconds using a TissueRuptor fitted with a sterile probe (Qiagen, UK). RNA was extracted using RNeasy columns with a DNase1 oncolumn digest and stored at $-80^{\circ} \mathrm{C}$ prior to quantification.

\subsubsection{RNA quantification}

Prior to quantification, RNA samples were thawed and mixed gently. RNA concentration was determined by spectrophotometric measurement of UV absorbance at $260 \mathrm{~nm}$ and $280 \mathrm{~nm}$ using a NanoDrop ND2000 instrument (ThermoFisher Scientific, UK) with molecular biology grade RNA free water (Ambion, UK) used as a reference. The shape and ratio of the absorbance curve was used to determine RNA quality and potential contamination. Purity was regarded as suitable if an A260/A280 value of approximately 2.0 was achieved. 


\subsubsection{2 cDNA conversion}

RNA was reverse transcribed to cDNA for the analysis of gene expression from samples. RNA samples were adjusted to a concentration of $100 \mathrm{ng} / \mu \mathrm{l}$ with nuclease free water. $2 \mu \mathrm{l}$ of RNA at $100 \mathrm{ng} / \mu \mathrm{l}$ was diluted with $38 \mu \mathrm{l}$ nuclease free water and used as a negative control for quantitative real-time PCR. A master mix was prepared using components from the high capacity cDNA reverse transcriptase kit (cat: 3468814, Applied Biosystems) to reduce pipetting error. For each sample $2 \mu 110 \mathrm{x}$ RT buffer, $0.8 \mu \mathrm{l} 25 \mathrm{x}$ dNTP mix $(100 \mathrm{mM}), 2 \mu \mathrm{l} 10 \mathrm{x}$ RT random primers, $1 \mu \mathrm{l}$ multiscribe ${ }^{\mathrm{TM}}$ reverse transcriptase, $1 \mu \mathrm{l}$ Rase inhibitor (cat: N8080119, Ambion) and $3.2 \mu \mathrm{l}$ nuclease free water was used. $10 \mu \mathrm{l}$ of master mix was added to $10 \mu \mathrm{l}$ of RNA sample for a $20 \mu \mathrm{l}$ total volume per reaction to obtain single stranded cDNA. The T100 ${ }^{\mathrm{TM}}$ Thermal Cycler (cat: 186-1099, Bio-Rad) was programmed for the following steps $25^{\circ} \mathrm{C}$ for 10 minutes, $37^{\circ} \mathrm{C}$ for 120 minutes, $85^{\circ} \mathrm{C}$ for 5 minutes and then $4{ }^{\circ} \mathrm{C}$. Following completion of cDNA conversion, serial dilutions were made from cDNA stocks using nuclease free water for generation of a standard curve. cDNA at 1:10 was used as the working concentration for target gene expression analysis. cDNA was stored at $-80^{\circ} \mathrm{C}$ until required.

\subsubsection{Quantitative polymerase chain reaction (qPCR)}

Quantitative polymerase chain reaction (qPCR) was undertaken using CFX96 Real Time PCR Detection system (Bio-Rad, UK). Primers were designed to amplify a single PCR product of approximately 75-150bp in length. An internal reference ribosomal protein S19 (RPS19) was used for normalisation as well as non-reverse transcribed RNA as a negative control. Each reaction was prepared to a total volume of $10 \mu 1 ; 2.5 \mu 14 \mu \mathrm{M}$ primer mix (forward and reverse), $2.5 \mu 1$ sample cDNA and $5 \mu 1$ SYBR Green. All PCR reactions were conducted in triplicate to reduce pipetting error. All PCR reactions were preformed in a clear unskirted 96 well plate (cat: MLL-9601, Bio-Rad) sealed with a microseal (cat: MSB-1001, Bio-Rad). Plates were heated for 30 seconds at $95^{\circ} \mathrm{C}$ then real time data was collected during 40 cycles containing a 2 second step at $95^{\circ} \mathrm{C}$ and 5 seconds at the optimal annealing temperature for specific primers outlined in Table 2.1 . 


\begin{tabular}{|c|c|c|c|c|}
\hline Target & Primer & Primer Sequence (5'-3') & $\begin{array}{l}\text { Tm } \\
\text { (C) }\end{array}$ & $\begin{array}{l}\text { Product } \\
\text { size (bp) }\end{array}$ \\
\hline \multirow[t]{2}{*}{ RPS18 } & Forward & CACTGGAGGCCTACACGCCG & 65.26 & \multirow[t]{2}{*}{119} \\
\hline & Reverse & AGGCAATTTTCCGCCGCCCA & 65.84 & \\
\hline \multirow[t]{2}{*}{ COL2A1 } & Forward & CTGGATGCCATGAAGGTTTT & 56.27 & \multirow[t]{2}{*}{93} \\
\hline & Reverse & GCTCCACCAGTTCTTCTTGG & 58.47 & \\
\hline \multirow[t]{2}{*}{ COL1A1 } & Forward & TAGGCCCAACCAGTCACCTGCGTAC & 68.22 & \multirow[t]{2}{*}{64} \\
\hline & Reverse & GTTTCCACACGTCTCGGTCA & 60.25 & \\
\hline \multirow{2}{*}{$\begin{array}{l}\text { COL10A } \\
1\end{array}$} & Forward & CCCATGCTTGGGTAGGTCTG & 60.11 & \multirow[t]{2}{*}{131} \\
\hline & Reverse & CCATACCTGGTCGTTCTCGG & 59.90 & \\
\hline \multirow[t]{2}{*}{ ACAN } & Forward & GCTACCCTGACCCTTCAT & 55.51 & \multirow[t]{2}{*}{76} \\
\hline & Reverse & AAGCTTTCTGGGATGTCCAC & 57.79 & \\
\hline \multirow[t]{2}{*}{ SOX9 } & Forward & TCAGCAAGACTCTGGGCAAG & 59.96 & \multirow[t]{2}{*}{151} \\
\hline & Reverse & CCGTTCTTCACCGACTTCCT & 59.68 & \\
\hline \multirow[t]{2}{*}{ RUNX2 } & Forward & GCGCATTCCTCATCCCAGTA & 59.89 & \multirow[t]{2}{*}{198} \\
\hline & Reverse & TGGATGGACGGAGGAGTCAT & 60.03 & \\
\hline
\end{tabular}

Table 2.1: Primers used for $q P C R$

\subsection{Statistical analysis}

Statistical analysis was performed using SPSS software version 22. All data sets were first analysed for normality using the Shapiro-Wilk test. Statistical significance of parametric data was determined with an independent T-Test. If data was found to be significantly different from normal distribution, non-parametric testing using Mann Whitney $-\mathrm{U}$ testing was applied. All statistical significance threshold values in this study are $\mathrm{p}<0.05$ unless otherwise stated. 


\section{CHAPTER 3}

\section{R.pulmo Collagen Isolation, Characterisation and Scaffold Fabrication}




\subsection{Introduction}

Collagen has proven itself to be an efficacious biomaterial accepted due to its biocompatibility, with a wide variety of clinical requirements and applications (Ramshaw et al., 2009). Type I collagen belongs to the fibrillar collagens and is potentially the best investigated collagen subfamily. It is found abundantly expressed throughout the human body and is a critical component of the interstitial membrane (Henriksen and Karsdal, 2016). The most predominant market source of collagen I is porcine skin and bovine tendons and hide (Silva et al., 2014). New sustainable collagen sources are continually being sought as an alternative to traditional mammalian protein for biomaterial use in regenerative medicine applications (Addad et al., 2011).

There are drawbacks from using mammalian collagen sources, with primary concerns resting around zoonotic disease transmission, allergic reactions to the material and religious restrictions (Browne et al., 2013). Understanding the structure and functional conservation of collagen sources, compared to human/mammalian sources, is a crucial indicator of suitability for purpose. These processes are essential in identifying any indication of potential downstream biocompatibility issues, early in the research and development phase (Lynn et al., 2004). Marine sources are of increasing interest, with waste from the fishing industry as well as sponges and/or jellyfish being used as alternatives to mammalian sources (Silva et al., 2014). Interestingly, jellyfish derived collagen has proven to be an appropriate source, capable of isolation and biocompatible cell expansion (Addad et al., 2011).

\subsubsection{Sequence informed structure function analysis}

Collagen is a triple helical molecule, shown to have evolutionary stability amongst mammalian species (Lynn et al., 2004). A complex structure, collagen comprises of non-helical $\mathrm{C}$ and $\mathrm{N}$ telopeptides that aid with fibrillar formation as well as crosslinking that allows for the stabilisation of the triple helix formation (Artym and Matsumoto, 2010). It is these non-helical regions that contain a greater degree of structural variability with approximately half of the amino acids exhibiting interspecies variation of collagen molecules. (Lynn et al., 2004). 
Native to Mediterranean, North Sea, Black Sea and Atlantic Ocean, numbers of the R. pulmo peak during the spring and summer (March to August) months with an increase in the water temperature (Muhammed and Sultana, 2008). Jellyfish possess a collagen content of approximately $60 \%$ of their body and are thought to have a high degree of conservation with various species showing similarities to vertebrate collagens type I, IV, V and a similar glycosylation patterns to type II (Hoyer et al., 2014). Sequencing jellyfish collagen to confirm its homology with the human protein, as well as others commercially available, is the first step towards understanding biocompatibility.

\subsubsection{Collagen Extraction and Characterisation}

Collagen extraction is typically carried out through (a) chemical hydrolysis or (b) enzymatic hydrolysis, with the chemical process favoured within the food industry (Schmidt et al., 2015). Acid soluble extraction is usually the preferred process, as the traditional extraction procedure is laborious, taking between 7-10 days to complete (Pacak et al., 2011). A pre-wash stage is used to remove all non-collagenous substances, before collagen extraction via solubilisation in neutral saline solutions, acidic solutions or acidic solutions with the addition of enzymes such as pepsin and separation using filtration or centrifugation. The optimisation of particular steps in the extraction protocol, such as the use of inorganic or organic acid during solubilisation, can affect the final collagen yield and must be considered for every new collagen source (Schmidt et al., 2015).

A suite of techniques is currently used to characterise extracted collagen; broadly categorised into structural, chemical and morphological analysis. Collagen purity, helical content as well as thermal properties are assessed through methods such as SDS PAGE and differential scanning calorimetry, respectively. The chemical features of collagen are analysed focusing on surface elemental analysis and hydrophobicity whilst morphological analysis includes the presentation of characteristic D banding, topographical analysis and fibre orientation, determined via SEM or AFM (Abraham et al., 2008). Other techniques, such as fourier transform 
infrared spectroscopy (FTIR) have been used to analyse extracted collagen from different species. Collagen exhibits characteristic amide peaks, that can be used to confirm the presence of the triple helix (Silva et al., 2014).

Attenuated total reflectance Fourier transform infrared spectroscopy (ATR-FTIR) is a fingerprint technique that can be used for molecular identification by measuring the vibrational modes of molecular bonds to obtain a spectrum (Baker et al., 2014). The sensitivity of detection has been demonstrated in various experiments. An example of ATR-FTIR fingerprint detection has been exhibited in experiments by Bobroff et al. where the shift in peaks was observed for poly-L-lysine (PLL) with fatty-acylchains of differing length giving each molecule a distinct spectrum (Bobroff et al., 2016). Collagen has previously been assessed via this technique for confirmation with particular attention paid to amide I, II and III peaks found in the region of approximately $1650 \mathrm{~cm}^{-1}$ as a result of the stretching vibration from peptide carbonyl $(-\mathrm{C}=\mathrm{O})$ groups, $1530 \mathrm{~cm}^{-1}$ resulting from a vibrational bending from amine $(\mathrm{N}-\mathrm{H})$ groups and $1240 \mathrm{~cm}^{-1}$ attributed to amide bending, respectively (Vidal and Mello, 2011).

\subsubsection{Scaffold fabrication}

Tissue engineering scaffolds are a representation of the physical structure and space, supporting cell growth and allowing tissue development (Carletti et al., 2011). Collagen based tissue devices are flexible in their fabrication with characteristics such as strength and durability tailored by variation in the crosslinking materials and methods (Davidenko et al., 2015). Although the triple helix structure of the molecule aids stability, depending on hydroxyproline content, the structure can be further stabilised for different applications ranging from a lesser crosslinked structure for wound healing and heart valves to highly crosslinked and stable scaffolds for osteochondral tissue repair (Ramshaw et al., 2009). Scaffold composition, architecture and mechanical properties all play important roles in guiding correct cell formation for repair of damaged tissues (Davidenko et al., 2015). Another vital component when designing scaffolds for tissue engineering is the biodegradability of the material. A scaffold must degrade in an adequate time frame to allow for the cells 
to remodel the tissue. Collagen scaffold biodegradability can be verified in vitro by the use of collagenase, a family of enzymes that break peptide bonds within the protein (Bitar and Zakhem, 2014).

Scaffolds designed for tissue engineering strike a balance between mechanical function and bio-factor delivery (Iwasa et al., 2009). A critical component of scaffold fabrication is its porous architecture dictating many factors including nutritional transport, cell migration and attachment (Hollister, 2005). SEM is used to assess the porous nature of scaffolds (Zhang et al., 2014b). Extracted collagen must be assessed for its fabrication suitability and potential for ideal scaffold composition and structure. Physical and biochemical scaffold properties can be modified to better mimic natural matrix properties (Davidenko et al., 2015). The degree of crosslinking should ideally mirror the mechanical properties of the tissue being replicated. One of the most successful chemical crosslinking agents for collagen sponges and hydrogels is EDC, which exhibits low cellular toxicity (Bax et al., 2017).

\subsubsection{Hypothesis}

The chapter hypothesis states that $R$. pulmo derived marine collagen is a suitable material for human regenerative medicine. In order to contribute significant evidence base to test this hypothesis, extracted collagen alpha bands are processed for protein level sequencing and analysis conducted to assess homology against mammalian collagen sources. Potential downstream regenerative medicine applications are dependent on the ability to mould or fabricate a 3D scaffold structure compatible with cell invasion. This chapter assesses the suitability of R.pulmo extracted collagen for sponge scaffold fabrication.

\subsubsection{Aims and objectives}

A series of aims and objectives were designed in order to test the stated hypotheses;

- Identify a fast, high yield collagen isolation methodology compatible with industry scale production 
- Incorporate a suite of characterisation techniques to inform quality control at the multiple stages of collagen extraction, including gel electrophoresis, and FTIR analysis to identify amide peaks indicative of maintained collagen confirmation

- Sequence the alpha1 band of the extracted $R$. pulmo collagen to align with published peptide sequences from mammalian sources to assess the degree of sequence conservation

- Develop scaffold fabrication protocols and assess the suitability of the collagen source for moulding methodologies, forming stable, potentially biomimetic 3D scaffolds for downstream applications in regenerative medicine

- Utilise a multidisciplinary suite of material characterisation techniques (porosity, thermal stability and biodegradability properties) to assess scaffold suitability and functional compatibility with downstream regenerative medicine applications

\subsection{Results}

Current industrial scale collagen extraction processes are defined by four major stages; (A) acid extraction for collagen solubilisation (B) pepsin digestion for telopeptide cleavage (C) salt precipitation for efficient collagen isolation and (D) separation, through filtering or centrifugation to yield pure collagen. Following this process, the isolated, pure research grade collagen is re-suspended in acetic acid prior to storage and shipment to customers (Schmidt et al., 2015).

In order to develop a faster, scalable R. pulmo collagen extraction process, a critical review of the literature was conducted, identifying crucial extraction stages and cross referenced to Jellagen Pty Ltd's current/proprietary extraction. From this, a defined, robust optimisation process outlined in Figure 3.1 was identified. 


\section{A Acid Solubilisation}

B Pepsin Digestion

C Salt Precipitation

D Separation
E

Overnight digestion with

$0.5 \mathrm{M}$ acetic acid

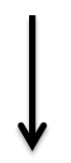

Overnight incubation with pepsin in $0.1 \mathrm{M}$ acetic acid

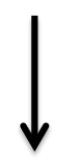

Precipitation of collagen using $\mathrm{NaCl}$

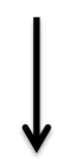

Centrifugation and dialysis to obtain collagen for use

Figure 3.1: Optimised extraction process for testing. Critical stages in collagen extraction outlined (A-D) and mapped against known collagen extraction for Rhizostoma pulmo (E).

For each stage (A to D) a number of variables were identified and tested for their effect on collagen yield, purity and confirmation, using FTIR analysis and gel electrophoresis, respectively. These outputs were used to select quality control end point measurements to inform a new, optimised extraction process compatible with industry scale up.

R.pulmo jellyfish was fished from Camarthen Bay, immediately stored on ice and shipped back to Jellagen UK premises in Cardiff. Flash frozen $R$. pulmo material was stored at $-20^{\circ} \mathrm{C}$ over a period of 6-12 months and used for collagen extraction as and when appropriate. Five individual extraction processes were conducted using the 
same fished batch of $R$. pulmo and the extracted collagen analysed for yield (dry weight relevant to start material), purity and confirmation (FTIR).

\subsubsection{Sodium citrate collagen extraction}

Acid extraction methods for collagen stabilisation are variable in the literature, with differing acids used. Acetic acid, used traditionally, is proven to solubilise collagen. This stage however is slow, with efficient solubilisation requiring up to 3 days (Schmidt et al., 2015). Alternatively, sodium citrate is an alternative acid solubilisation step, which may be as efficient, when combined with agitation (Pacak et al., 2011).

Sodium citrate $(0.1 \mathrm{M})$ was used here, with downstream digestion, in the presence and absence of pepsin, according to the rapid extraction outlined in Pacak et al (Pacak et al., 2011). Centrifugal separation was used to rapidly precipitate. Figure 3.2 demonstrates the results for $R$. pulmo extracted collagen using this method, reported against research grade rat-tail collagen bought from Merck (cat: 08-115, $\mathrm{UK})$. 

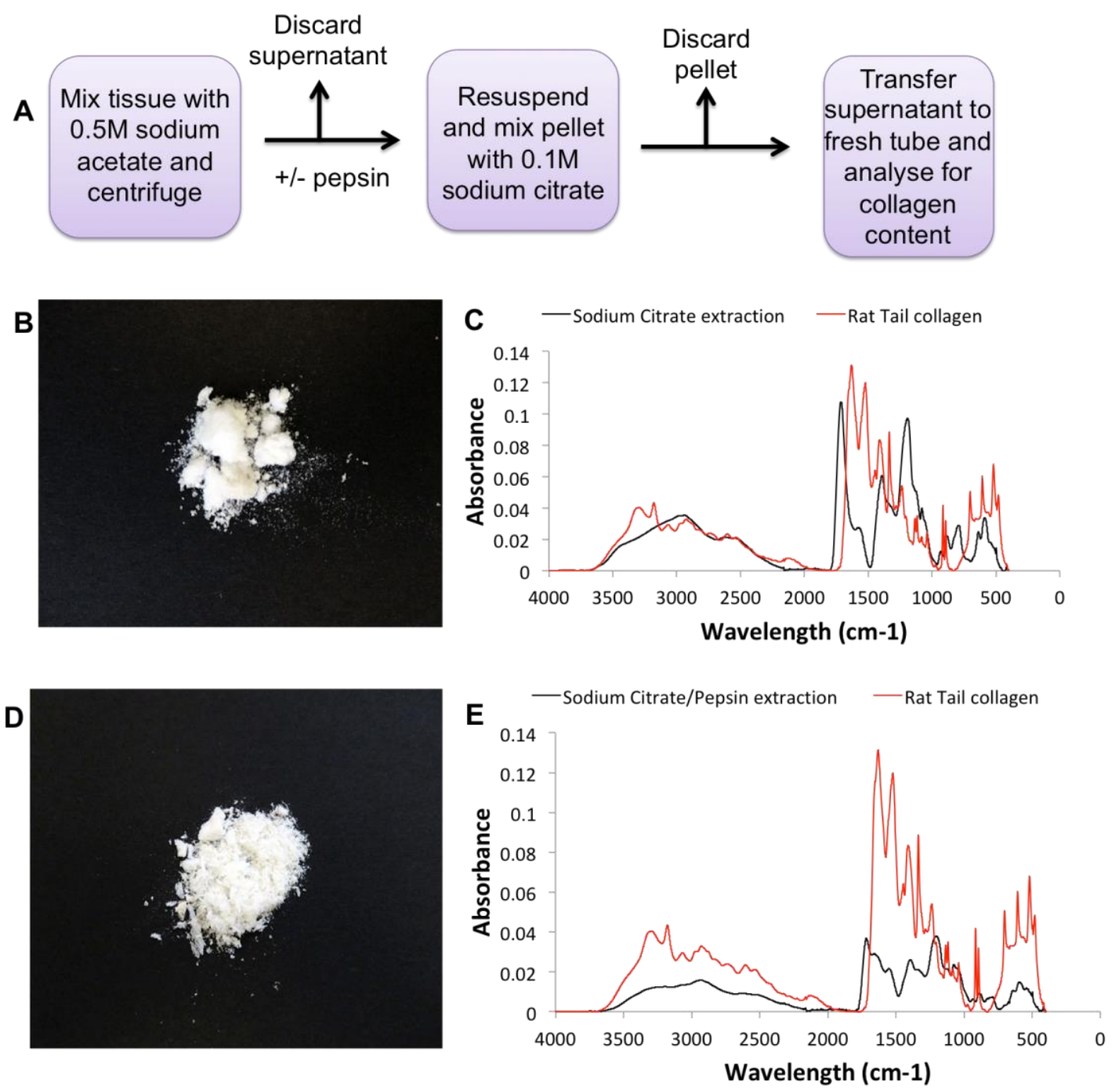

Figure 3.2: Sodium citrate R.pulmo collagen extraction in the presence and absence of pepsin. A bespoke extraction protocol was devised using sodium citrate stabilisation and downstream centrigugation (A). Images of freeze dried material and FTIR spectra were obtained after extraction in the absence (B) and presence (C) of pepsin.

Figure 3.2 (A) shows a simplified flow diagram of the devised sodium citrate extraction. An initial sodium acetate wash and centrifugation was followed by pellet re-suspension in $0.1 \mathrm{M}$ sodium citrate $(17 \% \mathrm{wt} / \mathrm{vol})$. During this point of the protocol, the addition of pepsin is optional. Followed by a final centrifugation step lead to the yield of collagen within the supernatant. The final yield of material (dry weight) from a starting weight of $5 \mathrm{~g}$ jellyfish tissue was $0.278 \mathrm{~g} \pm 0.02(5.55 \%)$ and $0.342 \mathrm{~g} \pm$ $0.02(6.83 \%)$ for extraction without and with pepsin digestion, respectively. 
The image, in Figure 3.2 (B), shows a brittle white powder, obtained following freeze-drying, that was difficult to re-suspend in acid leading to a viscous solution with precipitate. When processed for FTIR, Figure 3.2 (C), a difference in peaks across the collected spectrum was observed, when compared to a control rat-tail collagen preparation. The nearest major peaks from this extraction protocol, when compared to the control, were observed at $1720 \mathrm{~cm}^{-1}, 1599 \mathrm{~cm}^{-1}$ and $1207 \mathrm{~cm}^{-1}$. The peak at $1720 \mathrm{~cm}^{-1}$ is typically associated with aldehydes or ketones $(\mathrm{C}=\mathrm{O})$ showing this extraction causes a loss in the characteristic amide I peak. The loss of the amide II peak is also seen in this extraction, observed at a higher wavelength, $1599 \mathrm{~cm}^{-1}$. Although a shift occurs in the position of the amide III peak it remains within the range of wavelength used for classification, between $1300-1180 \mathrm{~cm}^{-1}$.

An identical extraction, with the addition of a pepsin digestion, was also tested in Figure 3.2 (D). A similar white, brittle powder was obtained after freeze-drying. The collagen was difficult to resuspend in acetic acid, producing a viscous solution with precipitates. FTIR analysis, shown in Figure 3.2 (E), displayed altered spectrum with a change in peaks when compared to a rat-tail collagen standard, with the most similar peaks observed at $1689 \mathrm{~cm}^{-1}, 1593 \mathrm{~cm}^{-1}$ and $1221 \mathrm{~cm}^{-1}$. The addition of pepsin in the extraction allows for the amide I peak to be regained at $1689 \mathrm{~cm}^{-1}$ as well as maintenance of the amide III peak at $1221 \mathrm{~cm}^{-1}$. The addition of pepsin with a sodium citrate extraction leads a peak at $1593 \mathrm{~cm}^{-1}$, which falls outside the amide II classification region of $1575-1500 \mathrm{~cm}^{-1}$.

The lack of particular amide peaks along with the brittle nature of the final material led to the conclusion that sodium citrate was not an appropriate acid for solubilisation and extraction of collagen from R. pulmo.

\subsubsection{Acetic acid extraction}

Organic acids, such as acetic acid, are routinely used for collagen extraction. Acetic acid is capable of solubilising non-crosslinked collagen as well as the inter-strand crosslinks also found in collagen (Schmidt et al., 2015). To test the appropriate use 
of acetic acid, $0.25 \mathrm{M}$ was used with downstream digestion in the absence and presence of pepsin followed by centrifugation yielding $1.9 \%$ and $7.2 \%$, respectively.

A

Mix tissue with
$0.5 \mathrm{M}$ sodium
acetate and
centrifuge

B

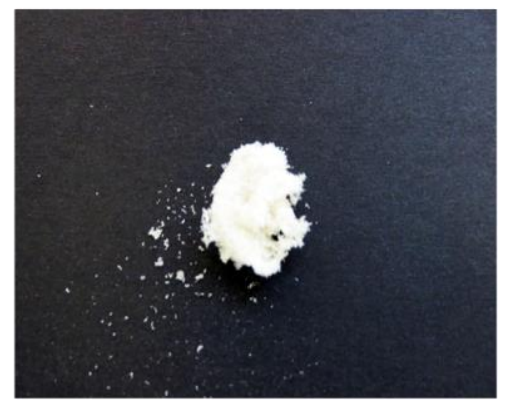

D

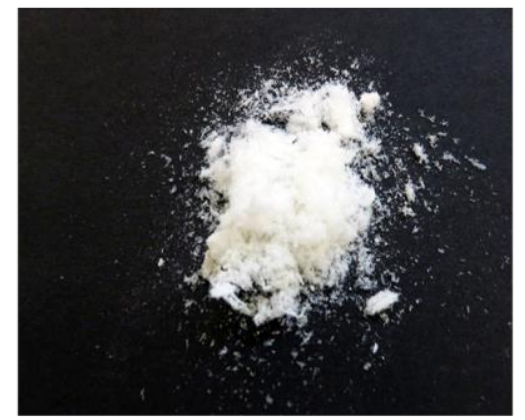

+ - pepsin
Discard supernatant

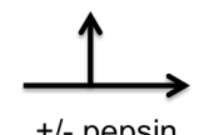

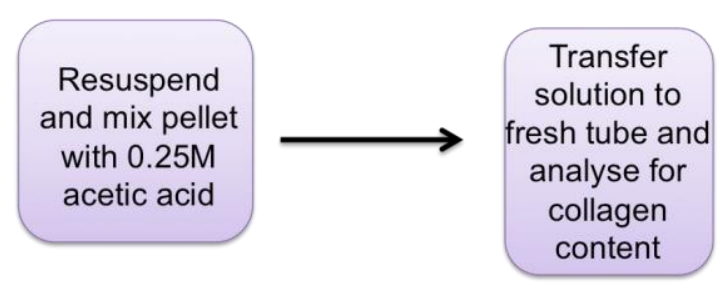

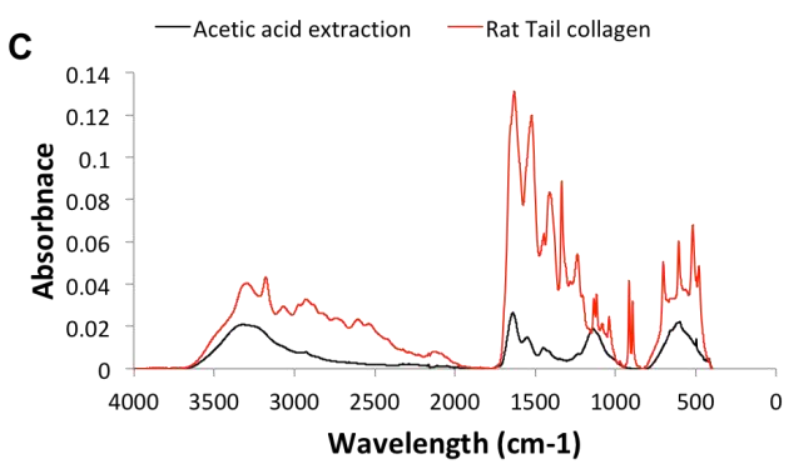

Wavelength (cm-1)

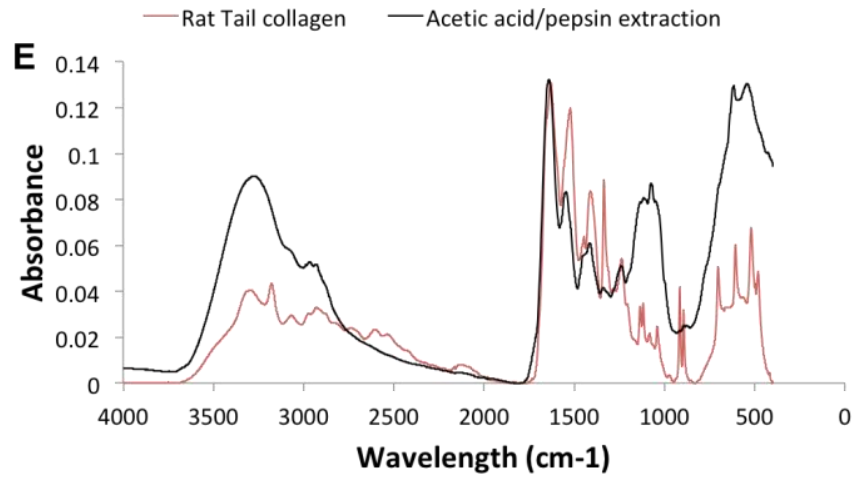

Figure 3.3: Acetic acid R.pulmo extraction in the presence and absence of pepsin. Extraction protocol was devised using acetic acid (A) and images of freeze dried material and FTIR spectra were obtained after extraction in the absence (B) and presence $(\mathrm{C})$ of pepsin.

A flow diagram of the extraction protocol is outlined in Figure 3.3 (A) where, following a sodium acetate wash and centrifugation, the pellet was resuspended in $0.25 \mathrm{M}$ acetic acid to solubilise collagen $(10 \% \mathrm{wt} / \mathrm{vol})$, in the presence and absence of pepsin. The resultant solution was then analysed for collagen content.

Figure 3.3 (B) shows material obtained from acetic acid extraction without the use of pepsin digestion. A yield of $0.038 \mathrm{~g} \pm 0.001(1.9 \%)$ was achieved from $2 \mathrm{~g}$ of raw 
jellyfish tissue. A brittle, white material was obtained after freeze-drying, that became a sticky precipitate when attempting to resuspend in acetic acid. FTIR analysis, Figure 3.3 (C), of this material revealed peaks closest to rat-tail control samples at $1655 \mathrm{~cm}^{-1}, 1597 \mathrm{~cm}^{-1}$ and $1182 \mathrm{~cm}^{-1}$. The spectrum from this extraction revealed that the amide I and amide III peaks remained within the expected wavelength range whilst the amide II peak was positioned at an increased wavelength falling outside the expected amide II range.

Using an identical extraction with the addition of a pepsin digestion stage, material was obtain and analysed, shown in Figure 3.3 (C). Using this extraction method a yield of $0.144 \mathrm{~g} \pm 0.02(7.2 \%)$ was obtained from $2 \mathrm{~g}$ of raw jellyfish tissue. The material obtain from acetic acid extraction with the aid of pepsin yielded a less brittle material than extracted in the absence of pepsin however resuspension lead to a solution with large precipitates. Figure 3.3 (D) shows FTIR analysis of acetic acid extraction with pepsin digestion showed peaks similar to control rat-tail collagen at $1652 \mathrm{~cm}^{-1}, 1560 \mathrm{~cm}^{-1}$ and $1261 \mathrm{~cm}^{-1}$. In a similar manner to the extraction lacking pepsin digestion, the amide I peak is maintained however the addition of pepsin appears to show the amide II and amide III peak within the expected range of wavelengths. 


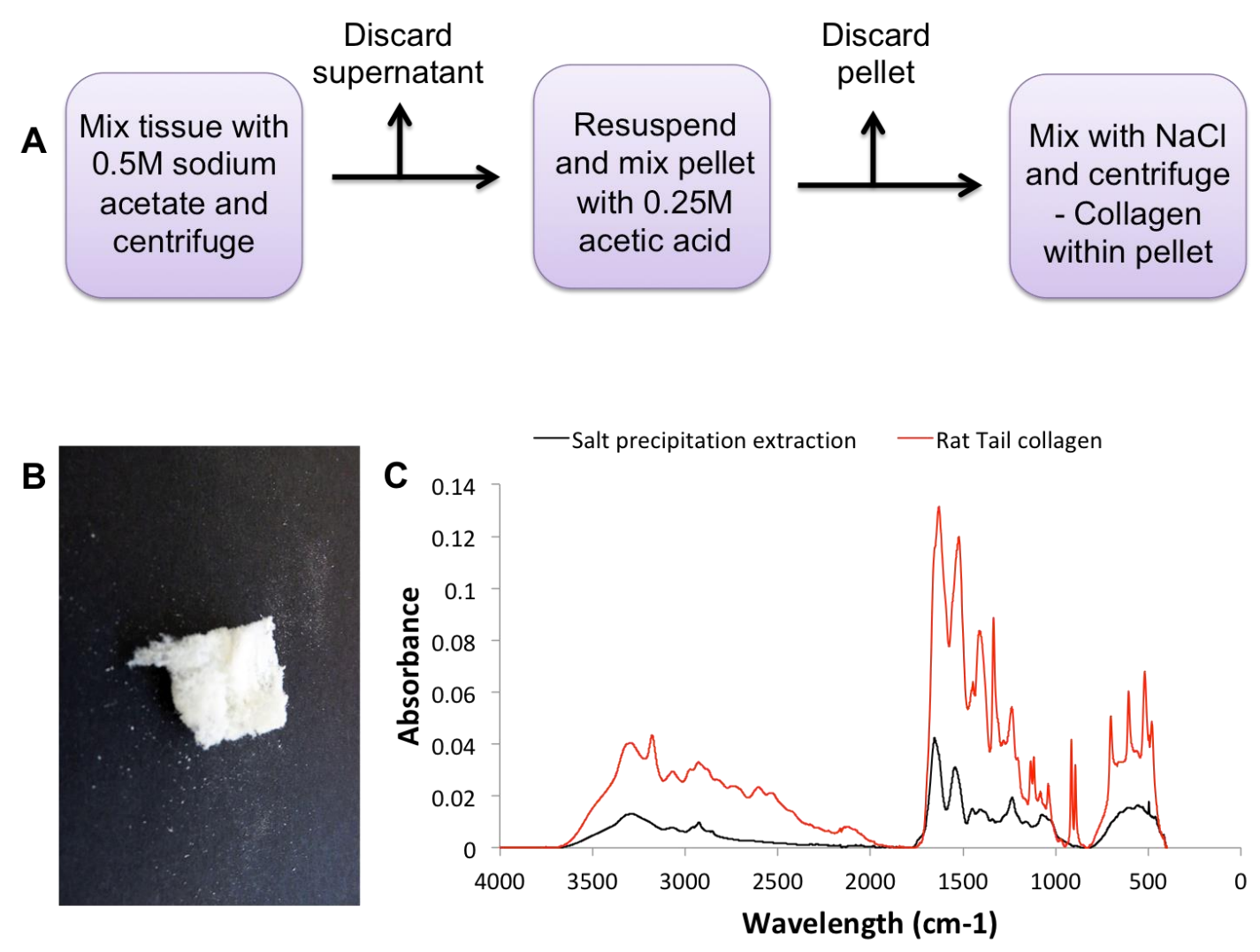

Figure 3.4: Acetic acid R.pulmo extraction with salt precipitation. Extraction protocol was devised using acetic acid with salt precipitation (A) and images of freeze dried material (B) and FTIR spectra were obtained after extraction (C).

A pre-wash stage with an alkaline buffer in addition to salt precipitation, following acid solubilisation, is thought to improve purity and yield by removing noncollagenous material from native tissue samples (Pacak et al., 2011). In Figure 3.4 (A), the protocol of pre-wash and downstream salt precipitation is shown. Depicted in Figure 3.4 (B) is the freeze-dried material that had a soft texture and could be easily resuspended into acetic acid with no visible precipitates. The final yield of material obtained after this extraction was $0.375 \mathrm{~g} \pm 0.01(0.7 \%)$ from $50 \mathrm{~g}(40 \%$ $\mathrm{wt} / \mathrm{vol}$ ) of raw jellyfish tissue. When compared to rat-tail collagen FTIR spectrum, Figure $3.4(C)$, the material gave similar peaks at $1685 \mathrm{~cm}^{-1}, 1554 \mathrm{~cm}^{-1}$ and $1243 \mathrm{~cm}^{-1}$ which although shows a shift in peak positions, are still within the amide regions I, II and III, respectively.

Table 3.1 outlines the summary of the modified rapid extractions protocols and their effect on collagen yield. Clearly indicated here, alongside the physical properties of 
the materials is that acetic acid followed by salt precipitation is the ideal rapid extraction process of choice.

\begin{tabular}{|c|c|c|c|}
\hline Extraction & Average yield (\%) & Physical properties & $\begin{array}{c}\text { Closest peaks to } \\
\text { amide I, II and III } \\
\text { (cm } \mathbf{- 1})\end{array}$ \\
\hline Sodium citrate (0.1M) & $5.55 \pm 0.41$ & $\begin{array}{c}\text { Brittle, resuspends } \\
\text { with precipitates }\end{array}$ & $1720,1599,1207$ \\
\hline $\begin{array}{c}\text { Sodium citrate (0.1)/ } \\
\text { pepsin }\end{array}$ & $6.83 \pm 1.50$ & $\begin{array}{c}\text { Brittle, resuspends } \\
\text { with precipitates }\end{array}$ & $1689,1593,1221$ \\
\hline $\begin{array}{c}\text { Acetic Acid (0.25M) } \\
\text { Acetic Acid (0.25M)/ }\end{array}$ & $1.9 \pm 0.05$ & $\begin{array}{c}\text { Brittle, resuspends } \\
\text { with precipitates }\end{array}$ & $1655,1597,1182$ \\
\hline pepsin & $7.2 \pm 1.15$ & $\begin{array}{c}\text { Soft and brittle, } \\
\text { resuspends with } \\
\text { precipitates }\end{array}$ & $1652,1560,1261$ \\
\hline $\begin{array}{c}\text { Acetic Acid/Salt } \\
\text { Precipitation }\end{array}$ & $0.714 \pm 0.02$ & $\begin{array}{r}\text { Soft, able to } \\
\text { resuspend }\end{array}$ & $1685,1554,1243$ \\
\hline
\end{tabular}

\section{Table 3.1: Summary of collagen extraction yield and characterisation.}

Sodium citrate extraction in the absence and presence of pepsin digestion gave a product that was brittle and sticky and FTIR analysis revealed the shift in peak positions leading to the loss of amide I and II, respectively. Acetic acid extraction in the absence of pepsin yielded a brittle material that was difficult to resuspend and FTIR spectrum obtained showed a shift in the amide II peak, falling out of the characteristic range. When acetic acid was used in the presence of pepsin, FTIR analysis revealed that amide I, II and III peaks were present within the expected wavelength values but resuspension of the material lead to large precipitates remaining in the solution. The removal of the pepsin digestion in favour of a salt precipitation led to a soft material that was resuspended with ease in acetic acid and displayed amide I, II and III peaks on the FTIR spectrum.

\subsubsection{Scalable collagen extraction}

An established, protracted (12 day) collagen extraction protocol exists within Jellagen Pty Ltd and is also used by Contract Research Organisations (CROs) in the field. In order to assess the effect of this process on collagen confirmation and purity, 
specific variable testing and FTIR quality control measurements were conducted. This was done with the aim of integrating the rapid extraction process stages (section 3.2.2). While this process was convoluted, once again a series of extractions were performed where distinct variables were adjusted, merging the scalable and rapid protocols for a new, optimised industry scale process. This process is now embedded in Jellagen production facility, and is outlined in Figure 3.5. 

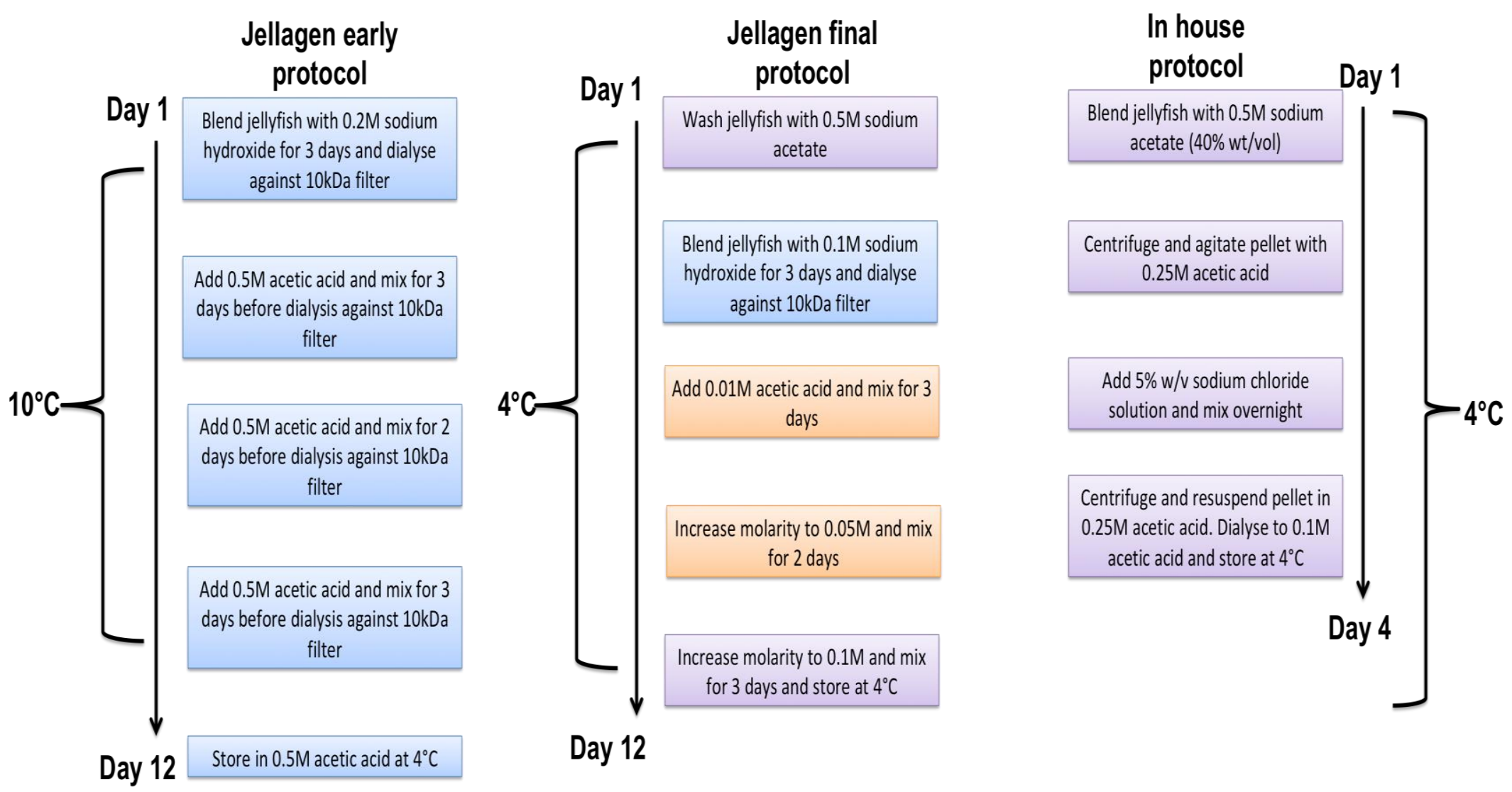

Figure 3.5: Optimised scalable extraction for conserved collagen confirmation. An early $R$. pulmo extraction protocol adopted by Jellagen taking a total of 12 days used $0.5 \mathrm{M}$ acid to solubilise collagen (left) whereas an in house extraction protocol used a pre-wash step using sodium acetate and salt precipitation to obtain collagen (right). A final protocol was adopted by combining both in house and Jellagen's early protocol to include a pre-was stage and add further extraction stages using differing molarities of acetic acid (centre). 
Two batches were analysed from the Jellagen scalable process, outlined in Figure 3.6, aiming to incorporate the rapid scale extraction stages. This process was then modified according the devised in house protocol in Figure 3.5, the results of which are shown in Figure 3.7.

A

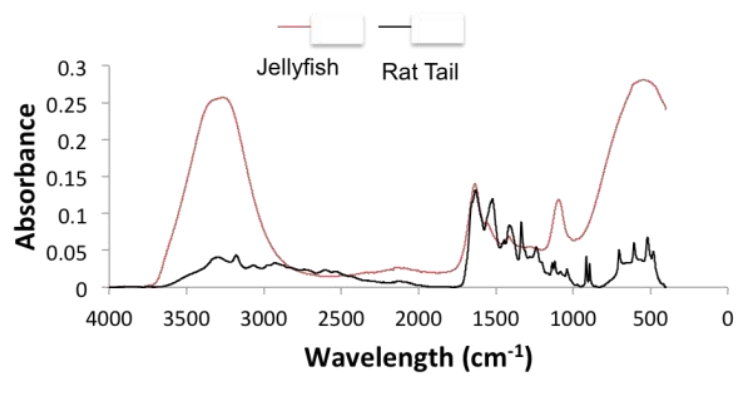

B

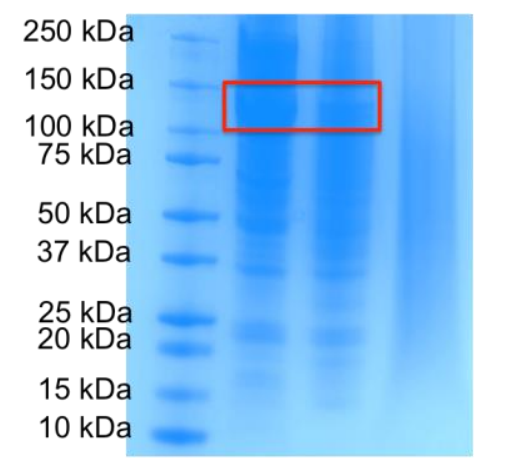

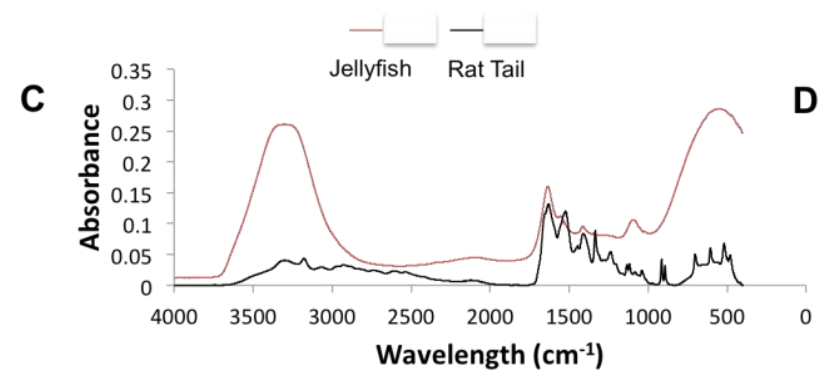

D $250 \mathrm{kDa}$ $150 \mathrm{kDa}$ $100 \mathrm{kDa}$ $75 \mathrm{kDa}$ $50 \mathrm{kDa}$ $37 \mathrm{kDa}$ $25 \mathrm{kDa}$ $20 \mathrm{kDa}$ $15 \mathrm{kDa}$

Figure 3.6: Jellagen batch collagen extraction analysis. FTIR (A and C) and gel electrophoresis (B and D) were used to analyse collagen extraction from 2 separate batch runs.

Figure 3.6 (A) shows the FTIR spectra and gel electrophoresis results from the first batch of collagen extracted via the existing Jellagen protocol. When compared to rattail collagen the FTIR spectra depict the major peaks closest to those found in collagen at $1647 \mathrm{~cm}^{-1}, 1477 \mathrm{~cm}^{-1}$ and $1181 \mathrm{~cm}^{-1}$. Gel electrophoresis of rat-tail and bovine collagen show $\alpha 1$ and $\alpha 2$ bands (highlighted in red) at approximately 115 and $135 \mathrm{kDa}$, respectively. Collagen obtained from batch one extraction was also subjected to gel electrophoresis and no visible bands were revealed upon staining, 
shown in Figure 3.6 (B). The analysis of the second batch of collagen produced by Jellagen was also conducted. FTIR spectrum of jellyfish collagen, shown in Figure 3.6 (C) is compared against commercially available rat-tail collagen with peaks visible at $1645 \mathrm{~cm}^{-1}, 1590 \mathrm{~cm}^{-1}$ and $1112 \mathrm{~cm}^{-1}$. Figure 3.6 (D) shows gel electrophoresis of rat-tail collagen $\alpha 1$ and $\alpha 2$ band at approximately 115 and $135 \mathrm{kDa}$, highlighted, however jellyfish collagen obtained from batch two showed no visible bands at this molecular weight following staining at two different loading concentrations but displays bands at lower molecular weights.

\subsubsection{Collagen protein analysis}

Protein sequence is capable of indicating the degree of conservation between R.pulmo collagen and human variants, in terms of functional peptides and cell binding peptides, providing essential structure/function information, which can determine the suitability of the collagen as a base material for scaffold fabrication. These alongside mechanical and morphological parameters will provide the essential base to assess potential applications in regenerative medicine, later in this thesis. Proteins are coded for by the DNA sequence, which is unknown for the collagen locus in R.pulmo species, however the obtainment of R.pulmo collagen peptide sequences allows for the analysis and subsequent identification of functionally important amino acid chains (Choi et al., 2010).

Alpha chains are of particular interest when investigating collagen. Collagen fibrils are formed through three $\alpha$ chains in heterotrimeric or homotrimeric combinations (Gelse et al., 2003). The polypeptide structures of $\alpha$ chains is primarily composed of Gly-X-Y repeats and are joined together through interstrand hydrogen bonds that aid in the stability of the protein structure (Bhowmick and Fields, 2013).

\subsubsection{Peptide sequence quality control}

Peptide sequencing was used to identify the amino acid composition of the $\alpha 1$ band following tryptic digestion (Grundy et al., 2009). In this 'bottom up' approach the peptides obtained through cleavage are analysed through mass spectrometry however 
this technique undergoes various quality control measures to ensure the achievement of reproducible data (Bittrremieux et al., 2017). These include a minimum length of 12 amino acids and ideally 2 positive changes from tryptic digestion for mass spectrometry without ionisation issues (Steen and Mann, 2004), the identification of contaminants such as skin and hair (Keller et al., 2008) and peak shape during the liquid chromatography phase to avoid oversampling (Rudnick et al., 2010).

Total R.pulmo collagen was denatured and separated using gel electrophoresis prior to extraction of the alpha1 band for sequencing. Shown in Figure 3.7 is the acrylamide gel acquired from pure collagen before processing for sequencing.

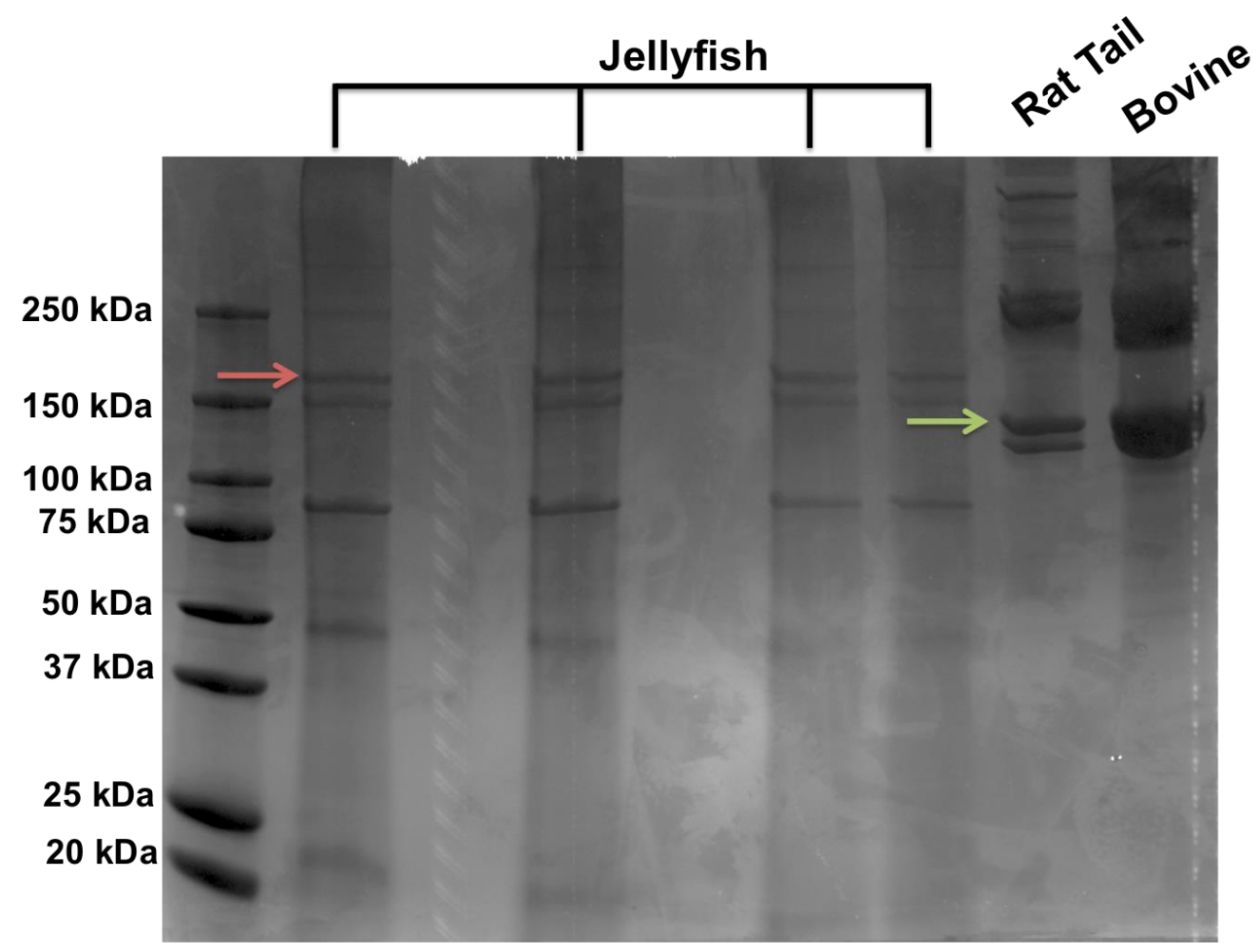

Figure 3.0.7: Alpha1 collagen band extraction for sequencing. Rat-tail and bovine collagen type I run against jellyfish collagen to locate alpha 1 band. Alpha 1 band for rat-tail and bovine collagen is found at $\sim 135 \mathrm{kDa}$ (green arrow) and jellyfish collagen alpha 1 is found at $\sim 175 \mathrm{kDa}$ (red arrow).

R.pulmo derived $\alpha 1$ band sequencing yielded 436 rows of peptides detected. Each data file consisting of detected peptide sequences listed against quality control parameters including tag length that enables identification of peptides, average level of confidence (ALC), length of detected peptide, mass to charge $(\mathrm{m} / \mathrm{z})$ ratio, charge 
(z) value, retention time (RT), area of the peak, mass of the sample, value in parts per million (ppm), accession value for contaminated peptides, post translational modifications (oxidation and hydroxylation), local confidence values and mass spectrometry mode. The resultant peptides were analysed for their quality, using the accepted quality control range of $90 \%$ or above average confidence level, according to Renard et al. (Grundy et al., 2009).

In total, 436 peptides were reported, 123 with an ALC of 90+; 99 with an ALC of 80+; 80 with an ALC of 70+; 63 with an ALC of 60+ and 70 with an ALC of 50+. From these $23.9 \%$ were contaminated and discarded. Of the remaining 331 sequences, only those with an ACL above 90 were considered for analysis. Table 3.2 lists the 32 peptide sequences detected based on the ALC, an arbitrary cut off provided, length and post translational modifications, once all duplicates had been removed. 


\begin{tabular}{|c|c|c|c|}
\hline Peptide Sequence & $\begin{array}{l}\text { ALC } \\
(\%)\end{array}$ & Length & PTM \\
\hline SGLEGEVGPR & 99 & 10 & $\mathrm{~N} / \mathrm{A}$ \\
\hline GPPGQVGPAGLEGK & 98 & 14 & $\begin{array}{l}\text { Oxidation/Hydroxylatio } \\
\mathrm{n}\end{array}$ \\
\hline GNLGPDGLAGR & 97 & 11 & $\mathrm{~N} / \mathrm{A}$ \\
\hline GTAGLLGATGK & 97 & 11 & $\mathrm{~N} / \mathrm{A}$ \\
\hline GPLGNQGLPGPR & 97 & 12 & $\begin{array}{l}\text { Oxidation/Hydroxylatio } \\
\mathrm{n}\end{array}$ \\
\hline GLAGPAGLLGR & 96 & 11 & $\mathrm{~N} / \mathrm{A}$ \\
\hline GENGLTGASGLQGR & 96 & 14 & Deamidation \\
\hline TGSSGLPGMLGR & 96 & 12 & $\begin{array}{l}\text { Oxidation/Hydroxylatio } \\
\mathrm{n}\end{array}$ \\
\hline QGPFGGVGLPGLAGSAQR & 96 & 18 & $\begin{array}{l}\text { Oxidation/Hydroxylatio } \\
\mathrm{n}\end{array}$ \\
\hline GDTGPQGPMGPLGER & 96 & 15 & $\mathrm{~N} / \mathrm{A}$ \\
\hline QAPGVTGVAGETGAMGPR & 96 & 18 & $\begin{array}{l}\text { Oxidation/Hydroxylatio } \\
\mathrm{n}\end{array}$ \\
\hline GLTGQVGQGAGPVGK & 95 & 15 & $\mathrm{~N} / \mathrm{A}$ \\
\hline GMLGNQGDDGLQGK & 95 & 14 & Deamidation \\
\hline GPLDGANGLDGNDGKDGR & 94 & 18 & $\begin{array}{l}\text { Oxidation/Hydroxylatio } \\
\mathrm{n} / \text { Deamidation }\end{array}$ \\
\hline AGAPGVTGVAGETGAMGPR & 94 & 19 & $\mathrm{~N} / \mathrm{A}$ \\
\hline VATGEVGQGAGPVGK & 94 & 15 & $\mathrm{~N} / \mathrm{A}$ \\
\hline GPVGPNGPTGPQR & 94 & 13 & $\mathrm{~N} / \mathrm{A}$ \\
\hline GPNQTGQPGAQGPTGPAANR & 94 & 20 & $\mathrm{~N} / \mathrm{A}$ \\
\hline VLVLLTDGEQTK & 93 & 12 & $\mathrm{~N} / \mathrm{A}$ \\
\hline GPLNGADGLDGNDGKDGR & 93 & 18 & $\begin{array}{l}\text { Oxidation/Hydroxylatio } \\
\mathrm{n}\end{array}$ \\
\hline NGPPGPEGPGGALGSPGASYYR & 93 & 22 & $\begin{array}{l}\text { Oxidation/Hydroxylatio } \\
\mathrm{n}\end{array}$ \\
\hline
\end{tabular}




\begin{tabular}{|llll|}
\hline GPPPGPEGPGGALGSPGASGDPGR & 93 & 24 & $\begin{array}{l}\text { Oxidation/Hydroxylatio } \\
\text { n }\end{array}$ \\
\hline GLTGQVGQEGPVGK & 93 & 14 & N/A \\
\hline GPVGPDGPTGPQR & 93 & 13 & N/A \\
\hline DGQDGEQGDEGSVGPQGDKGPR & 92 & 22 & $\begin{array}{l}\text { Oxidation/Hydroxylatio } \\
\text { n/Deamidation }\end{array}$ \\
\hline QNGDVGALGNAGR & 91 & 13 & $\begin{array}{l}\text { Deamidation } \\
\text { GPERGPPGPDGESGPR }\end{array}$ \\
\hline GPVGPDGPTGPAGR & 91 & 16 & N/A \\
\hline EGNGLTGASGLQGR & 91 & 14 & N/A \\
& 90 & 14 & Deamidation \\
\hline GPVGPNGPTGQPR & 90 & 13 & Deamidation \\
\hline DANGLTGASGLQGR & 90 & 14 & Deamidation \\
\hline DGTGPQGPMGPLGER & 90 & 15 & Oxidation \\
\hline
\end{tabular}

Table 3.2: Output from mass spectometry following trypsin digestion of R.pulmo alpha1 band.

\subsubsection{Alignment}

In order to assess the functional content of the peptides reported all 90+ ACL peptides identified were alignment searched against any known peptide sequence stored within the basic local alignment search tool (BLAST) database (Madden, 2013). BLAST searches through the database to find matches to a query sequence and gives an output highlighting names and lengths of the results from the target database as well as scored and expect (E) value (Pertsemlidis and Fondon, 2001) Individual peptides, as shown in Table 3.2, were inputted and BLAST output recorded according to the related protein, species from which the related protein belongs and an $\mathrm{E}$ value. E values are given as a statistical indicator to how significant a match is. The $\mathrm{E}$ value indicates how well the sequence matches to the database and how likely the similarity occurred by chance. The closer the E value is to 1 , the more 
likely the match is to be genuine rather than by chance due to multiple match searches (Donkor et al., 2014).

Of the unique, high quality peptide sequences identified, 32 with an ALC of $90 \%$ and above were BLAST aligned to show the top three most similar sequences, with $100 \%$ aligned to non-mammalian sources, further sub divided to marine (18.75\%) and bacterial (58.33\%) species as summarised in Table 3.3.

\begin{tabular}{|c|c|c|c|}
\hline Sequence & Related Protein & Species & $\begin{array}{c}E \\
\text { value }\end{array}$ \\
\hline \multirow[t]{3}{*}{ SGLEGEVGPR } & Collagen a2(VIII) chain like & $\begin{array}{l}\text { Sincocyclocheilus } \\
\text { grahami }\end{array}$ & 68 \\
\hline & Hypothetical protein & $\begin{array}{l}\text { Myxococcus } \\
\text { stipitatus }\end{array}$ & 69 \\
\hline & Phage tail region protein & $\begin{array}{l}\text { Myxococcus } \\
\text { stipitatus }\end{array}$ & 69 \\
\hline \multirow[t]{3}{*}{ GPPGQVGPAGLEGK } & Cuticle collagen dpy-5 & Trichinella papuae & 1.1 \\
\hline & $\begin{array}{l}\text { Fibril forming collagen alpha } \\
\text { chain like }\end{array}$ & Spodoptera litura & 1.6 \\
\hline & $\begin{array}{l}\text { Collagen alpha1(V) chain } \\
\text { isoform } \mathrm{X} 2\end{array}$ & Esox lucius & 2.3 \\
\hline \multirow[t]{3}{*}{ GNLGPDGLAGR } & $\begin{array}{l}\text { Class I SAM dependent } \\
\text { methytransferase }\end{array}$ & Olsenella & 42 \\
\hline & $\begin{array}{l}\text { Hypothetical protein } \\
\text { CEUSTIGMA }\end{array}$ & $\begin{array}{l}\text { Chlamydomonas } \\
\text { eustigma }\end{array}$ & 59 \\
\hline & MATE family efflux transporter & $\begin{array}{l}\text { Oleispira } \\
\text { antarctica }\end{array}$ & 84 \\
\hline \multirow[t]{3}{*}{ GTAGLLGATGK } & Hypothetical protein & $\begin{array}{l}\text { Aquabacterium } \\
\text { parvum }\end{array}$ & 118 \\
\hline & Polyketide synthase & Streptomyces & 167 \\
\hline & Type I polyketide synthase & $\begin{array}{l}\text { Streptomyces } \\
\text { catelarensis }\end{array}$ & 167 \\
\hline \multirow[t]{3}{*}{ GPLGNQGLPGPR } & Collagen alpha1(XXVIII) chain & $\begin{array}{l}\text { Nothoprocta } \\
\text { perdicaria }\end{array}$ & 1.5 \\
\hline & Collagen alpha1(XXVIII) chain & Tinamus guttatus & 1.5 \\
\hline & $\begin{array}{l}\text { Collagen alpha1(IX) chain } \\
\text { precursor }\end{array}$ & Danio rerio & 2.2 \\
\hline GLAGPAGLLGR & Hypothetical protein & $\begin{array}{l}\text { Acidobacteria } \\
\text { bacterium }\end{array}$ & 7.4 \\
\hline
\end{tabular}




\begin{tabular}{|c|c|c|c|}
\hline & $\begin{array}{l}\text { Collagen alpha6(IV) chain } \\
\text { isoform X1 }\end{array}$ & $\begin{array}{l}\text { Lepisosteus } \\
\text { oculatus }\end{array}$ & 14 \\
\hline & $\begin{array}{l}\text { Collagen alpha6(IV) chain } \\
\text { isoform X2 }\end{array}$ & $\begin{array}{l}\text { Lepisosteus } \\
\text { oculatus }\end{array}$ & 14 \\
\hline \multirow[t]{3}{*}{ GENGLTGASGLQGR } & $\begin{array}{l}\text { Collagen triple helix repeat } \\
\text { containing protein }\end{array}$ & $\begin{array}{l}\text { Thermoactinomyc } \\
\text { es }\end{array}$ & 3.2 \\
\hline & Collagen alpha1(XXVII) chain & Parus major & 4.5 \\
\hline & Collagen alpha1(I) chain like & $\begin{array}{l}\text { Cyanistes } \\
\text { caeruleus }\end{array}$ & 4.5 \\
\hline \multirow[t]{3}{*}{ TGSSGLPGMLGR } & Glycosyltransferaase & Actinoplanes & 36 \\
\hline & $\begin{array}{l}\text { Acetylcholinesterase collagenic } \\
\text { tail peptide }\end{array}$ & $\begin{array}{l}\text { Krytolebias } \\
\text { Marmoratus }\end{array}$ & 36 \\
\hline & $\begin{array}{l}\text { Acetylcholinesterase collagenic } \\
\text { tail peptide like }\end{array}$ & Monopterus albus & 36 \\
\hline \multirow[t]{3}{*}{ QGPFGGVGLPGLAGSAQR } & Hypothetical protein & $\begin{array}{l}\text { Verruconis } \\
\text { gallopava }\end{array}$ & 4.5 \\
\hline & $\begin{array}{l}\text { Signal recognition particle } \\
\text { protein }\end{array}$ & Jannaschia rubra & 13 \\
\hline & Alpha mannosidase & $\begin{array}{l}\text { Xanthomonas } \\
\text { prunicola }\end{array}$ & 18 \\
\hline \multirow[t]{3}{*}{ GDTGPQGPMGPLGER } & $\begin{array}{l}\text { LPXTG cell wall anchor domain } \\
\text { containing protein }\end{array}$ & $\begin{array}{l}\text { Streptococcus } \\
\text { didelphis }\end{array}$ & 0.06 \\
\hline & Hypothetical protein & $\begin{array}{l}\text { Glaesserella } \\
\text { parasuis }\end{array}$ & 0.084 \\
\hline & Hypothetical protein & $\begin{array}{l}\text { Glaesserella } \\
\text { parasuis }\end{array}$ & 0.084 \\
\hline \multirow[t]{3}{*}{ QAPGVTGVAGETGAMGPR } & Collagen like protein & $\begin{array}{l}\text { Paenibacillus } \\
\text { catalpae }\end{array}$ & 0.8 \\
\hline & $\begin{array}{l}\text { Collagen triple helix repeat } \\
\text { containing protein }\end{array}$ & $\begin{array}{l}\text { Paenibacillus } \\
\text { catalpae }\end{array}$ & 0.8 \\
\hline & Collagen like protein & $\begin{array}{l}\text { Paenibacillus } \\
\text { pectinilyticus }\end{array}$ & 1.1 \\
\hline \multirow[t]{3}{*}{ GLTGQVGQGAGPVGK } & Nitrate reductase & $\begin{array}{l}\text { Marine } \\
\text { microorganism }\end{array}$ & 31 \\
\hline & Hypothetical protein & $\begin{array}{l}\text { Amycolatopsis } \\
\text { orientalis }\end{array}$ & 44 \\
\hline & Hypothetical protein & Paenibacillus & 62 \\
\hline \multirow[t]{3}{*}{ GMLGNQGDDGLQGK } & Collagen alpha1(XXVII) chain & $\begin{array}{l}\text { Melopsittacus } \\
\text { undulatus }\end{array}$ & 6.4 \\
\hline & $\begin{array}{l}\text { Collagen alpha1(XXVII) chain } \\
\text { like }\end{array}$ & Nestor notabilis & 6.4 \\
\hline & Hypothetical protein & $\begin{array}{l}\text { Salpingoeca } \\
\text { rosetta }\end{array}$ & 9.1 \\
\hline
\end{tabular}




\begin{tabular}{|c|c|c|c|}
\hline GPLDGANGLDGNDGKDGR & Autotransporter/adhesin & $\begin{array}{l}\text { Mannheimia } \\
\text { varigena }\end{array}$ & 0.013 \\
\hline & Autotransporter/adhesin & $\begin{array}{l}\text { Mannheimia } \\
\text { varigena }\end{array}$ & 0.013 \\
\hline & Autotransporter/adhesin & $\begin{array}{l}\text { Mannheimia } \\
\text { varigena }\end{array}$ & 0.013 \\
\hline \multirow[t]{3}{*}{$\begin{array}{l}\text { AGAPGVTGVAGETGAMGP } \\
\mathrm{R}\end{array}$} & Collagen like protein & $\begin{array}{l}\text { Lysunubacillus } \\
\text { fusiformis }\end{array}$ & 0.042 \\
\hline & Collagen like protein & $\begin{array}{l}\text { Paenibacillus } \\
\text { catalpae }\end{array}$ & 0.12 \\
\hline & $\begin{array}{l}\text { Collagen triple helix repeat } \\
\text { containing protein }\end{array}$ & $\begin{array}{l}\text { Paenibacillus } \\
\text { catalpae }\end{array}$ & 0.12 \\
\hline \multirow[t]{3}{*}{ VATGEVGQGAGPVGK } & Hypothetical protein & $\begin{array}{l}\text { Streptomyces } \\
\text { noursei }\end{array}$ & 7.7 \\
\hline & Molecular chaperone DnaJ & $\begin{array}{l}\text { Tetrasphaera } \\
\text { duodecadis }\end{array}$ & 31 \\
\hline & Molecular chaperone DnaJ & Tetrasphaera & 31 \\
\hline \multirow[t]{3}{*}{ GPVGPNGPTGPQR } & $\begin{array}{l}\text { C terminal target domain } \\
\text { containing protein }\end{array}$ & $\begin{array}{l}\text { Catalinimonas } \\
\text { alkaloidigena }\end{array}$ & 0.23 \\
\hline & Collagen alpha1(I) chain like & $\begin{array}{l}\text { Mizuhopecten } \\
\text { yessoensis }\end{array}$ & 0.23 \\
\hline & Hypothetical protein & Runella & 0.33 \\
\hline \multirow[t]{3}{*}{$\begin{array}{l}\text { GPNQTGQPGAQGPTGPAA } \\
\text { NR }\end{array}$} & Hypothetical protein & $\begin{array}{l}\text { Rhizobiales } \\
\text { bacterium }\end{array}$ & 0.012 \\
\hline & $\begin{array}{l}\text { Nematode cuticle collagen } \\
\text { domain protein }\end{array}$ & $\begin{array}{l}\text { Oesophagostomu } \\
\text { m dentatum }\end{array}$ & 0.2 \\
\hline & $\begin{array}{l}\text { Nematode cuticle collagen } \\
\text { domain protein }\end{array}$ & $\begin{array}{l}\text { Oesophagostomu } \\
\text { m dentatum }\end{array}$ & 0.2 \\
\hline \multirow[t]{3}{*}{ VLVLLTDGEQTK } & Hypothetical protein & $\begin{array}{l}\text { Alphaproteobacter } \\
\text { ia bacterium }\end{array}$ & 4.4 \\
\hline & BatB protein & Sphingopyxis & 6.3 \\
\hline & $\begin{array}{l}\text { VWA domain containing } \\
\text { protein }\end{array}$ & $\begin{array}{l}\text { Imhoffiella } \\
\text { purpurea }\end{array}$ & 6.3 \\
\hline \multirow[t]{3}{*}{ GPLNGADGLDGNDGKDGR } & Hypothetical protein & $\begin{array}{l}\text { Rodentibacter } \\
\text { myodis }\end{array}$ & 0.036 \\
\hline & $\begin{array}{l}\text { Putative uncharacterised } \\
\text { protein }\end{array}$ & Alistipes & 0.1 \\
\hline & Hsf & $\begin{array}{l}\text { Actinobacillus } \\
\text { minor }\end{array}$ & 0.28 \\
\hline \multirow[t]{2}{*}{$\begin{array}{l}\text { NGPPGPEGPGGALGSPGAS } \\
\text { YYR }\end{array}$} & Hypothetical protein & Bacillus populi & 0.002 \\
\hline & Collagen alpha1(III) chain & Tinamus guttatus & 0.012 \\
\hline
\end{tabular}




\begin{tabular}{|c|c|c|c|}
\hline & $\begin{array}{l}\text { Collagen alpha1(XXII) chain } \\
\text { like }\end{array}$ & $\begin{array}{l}\text { Sinocyclocheilus } \\
\text { anshuiensis }\end{array}$ & 0.067 \\
\hline \multirow{3}{*}{$\begin{array}{l}\text { GPPPGPEGPGGALGSPGAS } \\
\text { GDPGR }\end{array}$} & SMC protein & Elmeria necatrix & 0.006 \\
\hline & Cutile collagen 34 & Loa loa & 0.011 \\
\hline & Hypthetical protein & $\begin{array}{l}\text { Scleropages } \\
\text { formosus }\end{array}$ & 0.012 \\
\hline \multirow[t]{3}{*}{ GLTGQVGQEGPVGK } & Hypothetical protein & Chara braunii & 13 \\
\hline & TonB-dependent receptor & $\begin{array}{l}\text { Woodsholea } \\
\text { maritima }\end{array}$ & 37 \\
\hline & Collagen alpha1(I) chain & $\begin{array}{l}\text { Tetranychus } \\
\text { urticae }\end{array}$ & 52 \\
\hline \multirow[t]{3}{*}{ GPVGPDGPTGPQR } & Putative tail protein & Erwinia phage & 0.23 \\
\hline & Collagen like protein & $\begin{array}{l}\text { Bacillus } \\
\text { thuringiensis }\end{array}$ & 0.47 \\
\hline & Collagen like protein & $\begin{array}{l}\text { Bacillus } \\
\text { thuringiensis }\end{array}$ & 0.47 \\
\hline \multirow{3}{*}{$\begin{array}{l}\text { DGQDGEQGDEGSVGPQGD } \\
\text { KGPR }\end{array}$} & Phage tail fiber protein & Phage NCTB & 0.008 \\
\hline & Collagen alpha1(I) chain like & Orbicella faveolata & 0.009 \\
\hline & Collagen alpha1(V) chain like & $\begin{array}{l}\text { Schistosoma } \\
\text { haematobium }\end{array}$ & 0.024 \\
\hline \multirow[t]{3}{*}{ QNGDVGALGNAGR } & $\begin{array}{l}\text { ABC transporter ATP binding } \\
\text { protein }\end{array}$ & Nocardioides & 7.6 \\
\hline & $\begin{array}{l}\text { ABC transporter ATP binding } \\
\text { protein }\end{array}$ & $\begin{array}{l}\text { Nocardioides } \\
\text { terrigena }\end{array}$ & 7.6 \\
\hline & $\begin{array}{l}\text { ABC transporter ATP binding } \\
\text { protein }\end{array}$ & Nocardioides & 7.6 \\
\hline \multirow[t]{3}{*}{ GPERGPPGPDGESGPR } & Inner ear specific collagen like & $\begin{array}{l}\text { Cyprinodon } \\
\text { variegatus }\end{array}$ & 0.036 \\
\hline & Collagen alpha1(XXIV) chain & $\begin{array}{l}\text { Paramormyrops } \\
\text { kingsleyae }\end{array}$ & 0.051 \\
\hline & $\begin{array}{l}\text { Collagen alpha } 1(\mathrm{I}) \text { chain like } \\
\text { isoform X1 }\end{array}$ & $\begin{array}{l}\text { Haplochromis } \\
\text { burtoni }\end{array}$ & 0.1 \\
\hline \multirow[t]{3}{*}{ GPVGPDGPTGPAGR } & $\begin{array}{l}\text { Collagen alpha1(XVIII) chain } \\
\text { like }\end{array}$ & Clupea harengus & 0.035 \\
\hline & Collagen like protein & $\begin{array}{l}\text { Mesorhizobium } \\
\text { ciceri }\end{array}$ & 0.035 \\
\hline & Collagen like protein & $\begin{array}{l}\text { Mesorhizobium } \\
\text { ciceri }\end{array}$ & 0.035 \\
\hline EGNGLTGASGLQGR & $\begin{array}{l}\text { Collagen triple helix repeat } \\
\text { containg protein }\end{array}$ & $\begin{array}{l}\text { Thermoactinomyc } \\
\text { es }\end{array}$ & 13 \\
\hline
\end{tabular}




\begin{tabular}{|c|c|c|c|}
\hline & Hypothetical protein & Rhodosalinus & 52 \\
\hline & $\begin{array}{l}\text { LysM peptidoglycan binding } \\
\text { domain containing protein }\end{array}$ & Sphingomonas & 74 \\
\hline \multirow[t]{3}{*}{ GPVGPNGPTGQPR } & Hypothetical protein & Bacillus korlensis & 0.48 \\
\hline & $\begin{array}{l}\text { Nematode cuticle collagen } \\
\text { domain protein }\end{array}$ & $\begin{array}{l}\text { Teladorsagia } \\
\text { circumcincta }\end{array}$ & 1.3 \\
\hline & Collagen alpha1(IV) chain & $\begin{array}{l}\text { Latimeria } \\
\text { chalumnae }\end{array}$ & 1.9 \\
\hline \multirow[t]{3}{*}{ DANGLTGASGLQGR } & $\begin{array}{l}\text { Collagen triple helix repeat } \\
\text { containing protein }\end{array}$ & $\begin{array}{l}\text { Thermoactinomyc } \\
\text { es }\end{array}$ & 1.6 \\
\hline & $\begin{array}{l}\text { LysM peptidoglycan domain } \\
\text { containing protein }\end{array}$ & Sphingomonas & 37 \\
\hline & Hypothetical protein & Sphingomonas & 37 \\
\hline \multirow[t]{3}{*}{ DGTGPQGPMGPLGER } & $\begin{array}{l}\text { Collagen alpha1(I) chain like } \\
\text { isoform } \mathrm{X} 1\end{array}$ & Lucilia cuprina & 0.34 \\
\hline & $\begin{array}{l}\text { Collagen alpha1(I) chain like } \\
\text { isoform X2 }\end{array}$ & Lucilia cuprina & 0.34 \\
\hline & $\begin{array}{l}\text { LPXTG cell wall anchor domain } \\
\text { containing protein }\end{array}$ & $\begin{array}{l}\text { Streptococcus } \\
\text { pyogenes }\end{array}$ & 0.48 \\
\hline
\end{tabular}

Table 3.3: BLAST results for individual R.pulmo peptides. Peptides sequences run through BLAST database and results showing top 3 related protein, species and E value for corresponding peptides.

Collagen and collagen related proteins are frequently found amongst related proteins during the database search. Taking $\mathrm{E}$ values into account, peptides such as GTAGLLGATGK show that the peptide has similarity to polyketide synthase in Streptomyces, however the E value is 151 implying that this is likely to be by chance when compared to the peptide AGAPGVTGVAGETGAMGPR, matched to collagen-like protein partial from Lysinibacillus dusiformis which has an E value of 0.038 .

\subsubsection{Collagen alignment}

Sequence alignment compares sequences by searching for a similar arrangement of patterns between sequences. The three common sequence alignments are pairwise, multiple and structural sequence alignment. The overall aim in aligning sequences is 
to understand whether they exhibit similarities as a result of structural, functional or evolutionary relationships (Renard et al., 2010). Data extracted from sequence alignment can identify sequence identity, where the positions of nucleotides and/or amino acids are exactly the same, sequence similarity, where the matches are taken into consideration and any substitutions are scored so that conservative sequences are give a higher score than non-conservative sequences, and sequence homology where the similarity between nucleotide or amino acid position is strictly due to an evolutionary event (Madden, 2013). The alignment of jellyfish collagen peptides to human COL1A1 and COL3A1, chosen due to the use of these collagen types in regenerative medicine, was obtained using Clustal Omega and shown in Figure 3.8 and Figure 3.9, respectively. 


A sp $\mid$ P02452 $\mid$ CO1A1_HUMAN
pulmo1
pulmo2
pulmo3
pulmo4
pulmo5
pulmo6
pulmo7
pulmo8
pulmo9
pulmo10
pulmo11
pulmo12
pulmo13
pulmo14
pulmo15
pulmo16
pulmo17
pulmo18
pulmo19
pulmo20
pulmo21
pulmo22
pulmo23
pulmo24
pulmo25
pulmo26
pulmo27
pulmo28
pulmo29
pulmo30
pulmo31
pulmo32
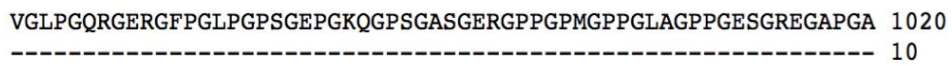

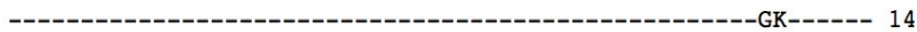
----------------------------------------GNLGPDGLAGR------------- 11

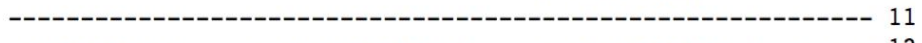

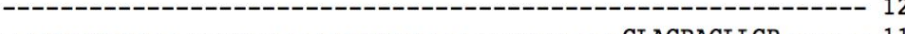

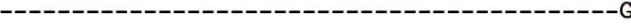

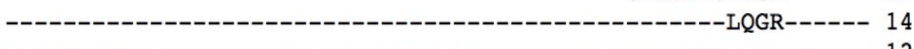

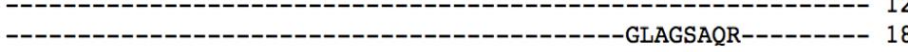

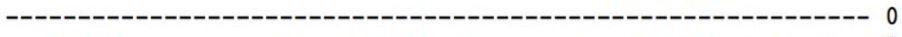
-

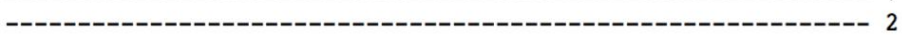

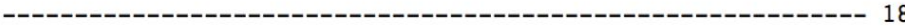

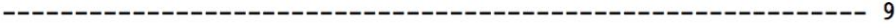

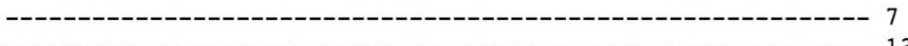

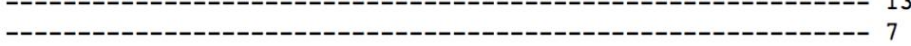

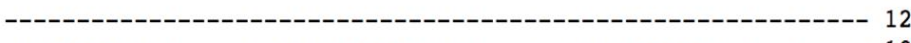

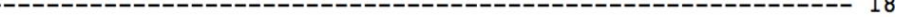
促 22
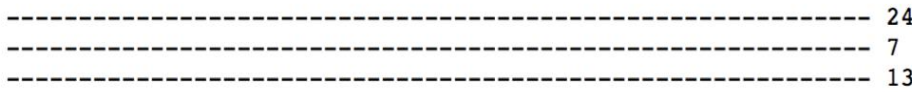

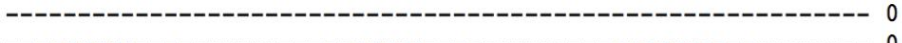
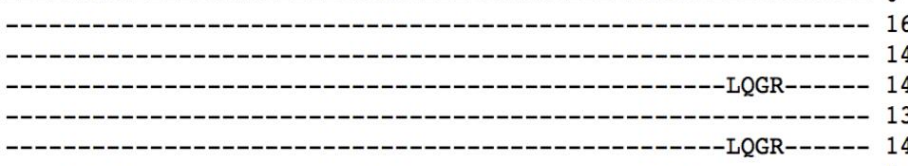

pulmo32

B sp|P02452|C01A1_HUMAN

EGSPGRDGSPGAKGDRGETGPAGPPGAPGAPGAPGPVGPAGKSGDRGETGPAGPTGPVGP 1080

pulmo1

pulmo2

pulmo3

pulmo4

pulmo5

pulmo6

pulmo7

pulmo8

pulmo9

pulmo10

pulmol1

pulmo12

pulmo13

pulmo14

pulmo15

pulmo16

pulmo17

pulmo18

pulmo19

pulmo20

pulmo21

pulmo22

pulmo23

pulmo24

pulmo25

pulmo26

pulmo27

pulmo28

pulmo29

pulmo30

pulmo31

pulmo32

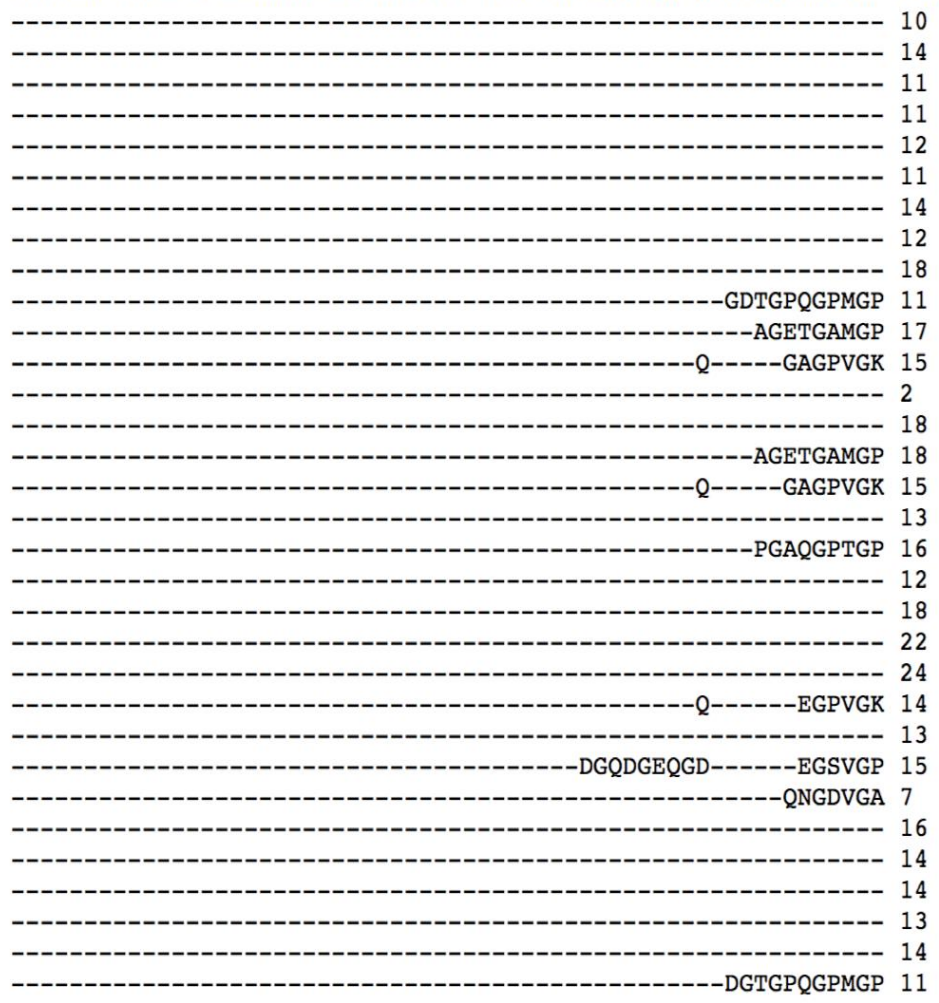

Figure 3.8: Sequence alignment of human COL1A1 sequence to R.pulmo peptides. 32 peptides with an ACL\% of 90 and above were compared against human COL1A1 using Clustal Omega to give an alignment. 
Figure 3.8 (A) shows alignment of peptides against the known human COL1A1 sequence at position 961 to 1020, whilst Figure 3.8 (B) shows positions 1021 to 1080 using Clustal Omega. At nucleotide positions 998 to 1015 a partial alignment is made to 7 R. pulmo peptide sequences. At the positions 1070 to 1080,10 R. pulmo peptides are partially aligned to the human COL1A1 sequence making this area of the human sequence the most highly aligned.
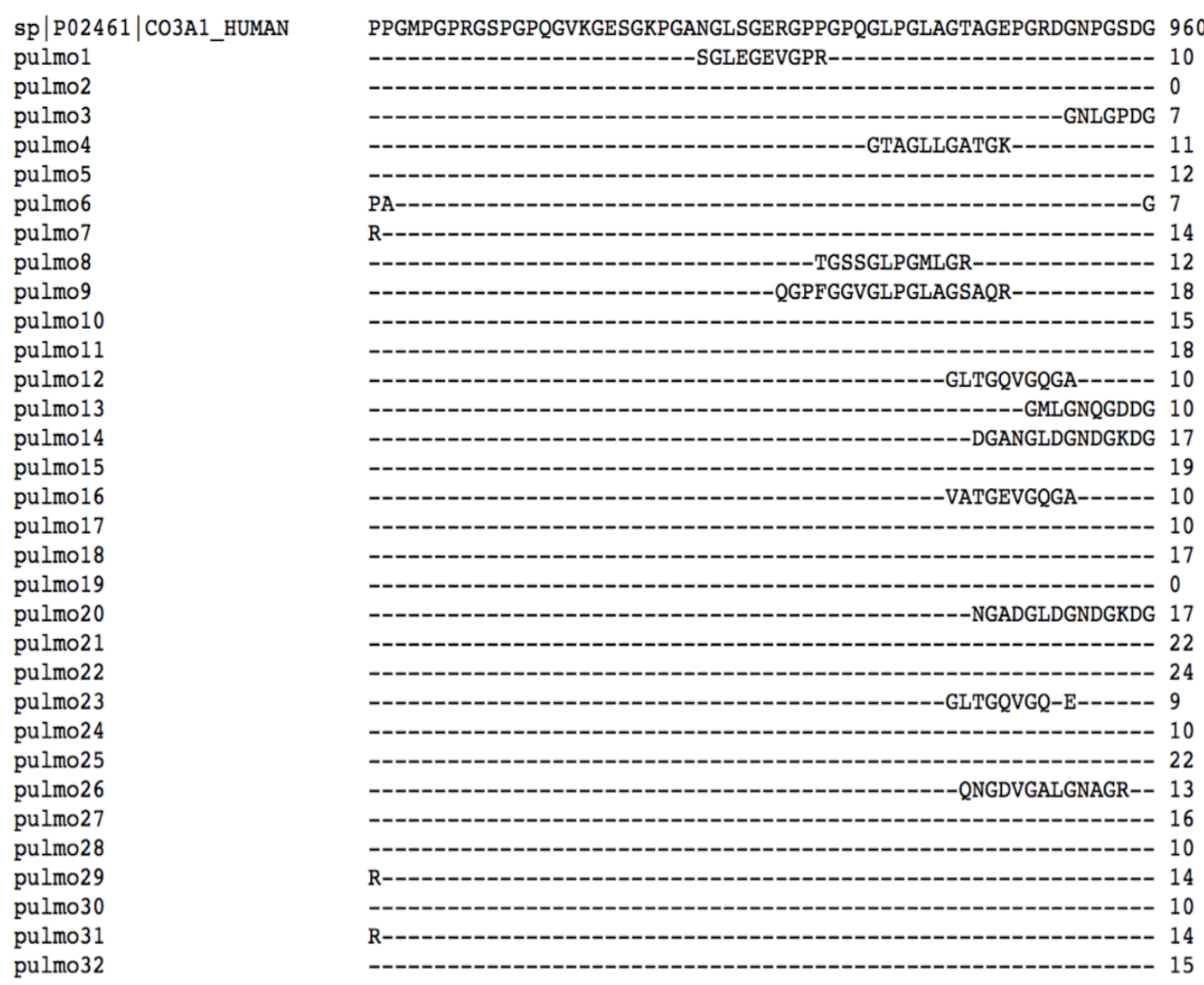

Figure 3.9: Sequence alignment of human COL3A1 sequence to R.pulmo peptides. 32 peptides with an ACL\% of 90 and above were compared against human COL3A1 using Clustal Omega to give an alignment.

Figure 3.9 shows the alignment of $32 R$. pulmo peptides, with an ALC of $90 \%$ and above, against human COL3A1. Of the 32 peptides, 16 peptide sequences were partially aligned at nucleotide positions 926 to 960 . This region of the COL3A1 gene showed the highest proportion of sequence alignment. 
Sequence alignments, both global and local, are used to search databases and obtain similarities against a target sequence. Sequences that provide similarities have traditionally been used in order to infer protein function (Clark and Radivojac, 2011). The identification of specific sites within a protein allows for the understanding of biological processes (Lapidoth et al., 2015).AbDesigner is a web application used for the design of peptide directed antibodies. The software displays protein features as a graphical output denoting regions of interest such as binding sites, posttranslational modification and local secondary structures using the relevant Swiss-Prot protein record (Pertsemlidis and Fondon, 2001).

Human COL1A1 and COL3A1 were input through the AbDesigner software and nucleotide positions with high similarity to R.pulmo peptides were checked for functional relevance, shown below in Figure $\mathbf{3 . 1 0}$ and Figure 3.11, respectively. 


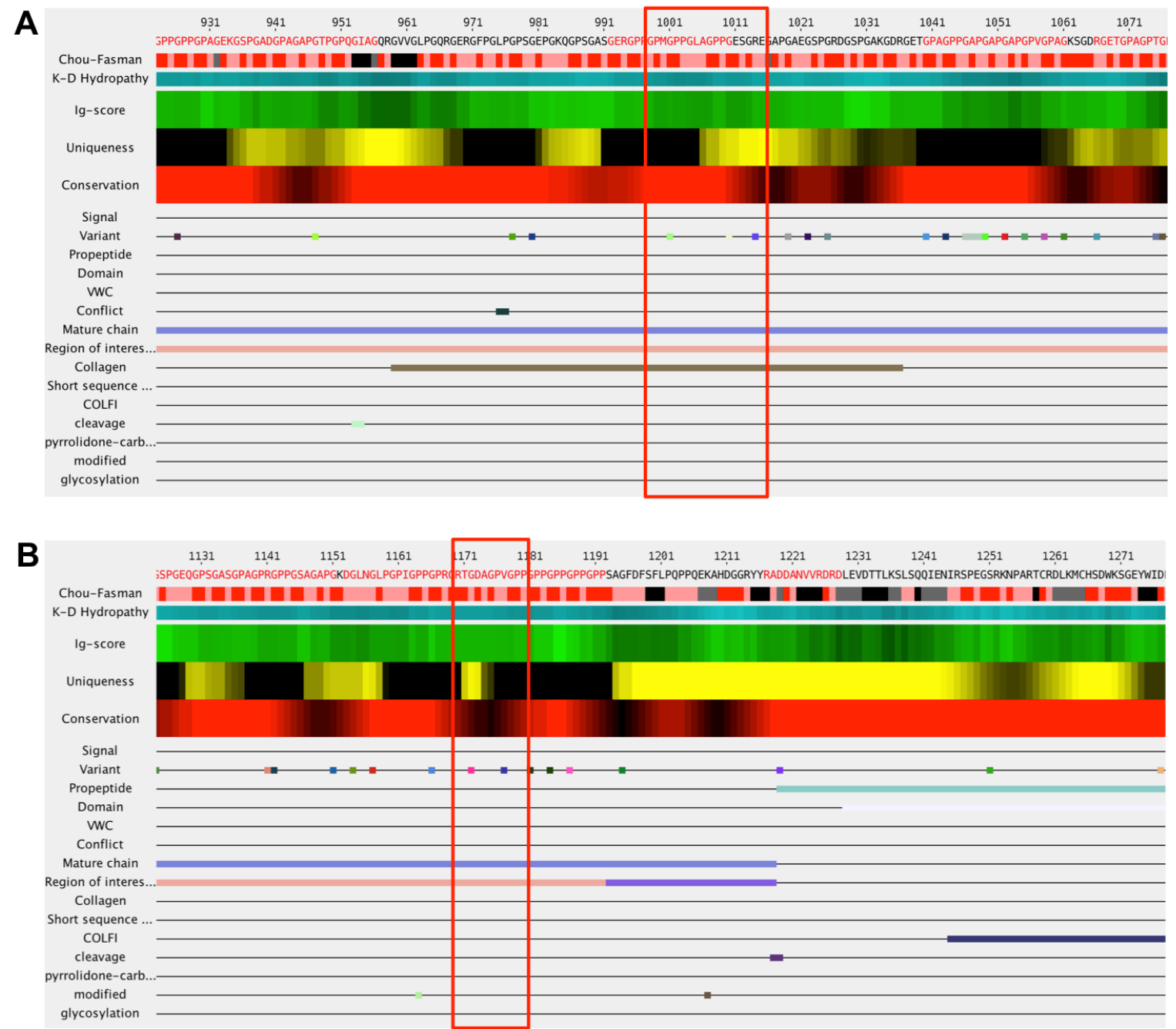

Figure 3.10: AbDesigner output for human COL1A1. Positions 998 to 1015 (A) and 1070 to 1080 (B) highlighted to show functional features of the protein.

Figure 3.10 (A) shows the Abdesigner output for human COL1A1 with position 998 to 1015 highlighted. The graphical output depicts that this portion of the sequence is part of the mature collagen $\alpha 1$ chain, a part of the triple helical region and is also seen in pfam01391 peptide sequence that is crucial for triple helix formation. Figure 3.10 (B) highlights the position 1070 to 1080 and once again shows that the sequence is found in the mature chain and triple helical region of the protein. 


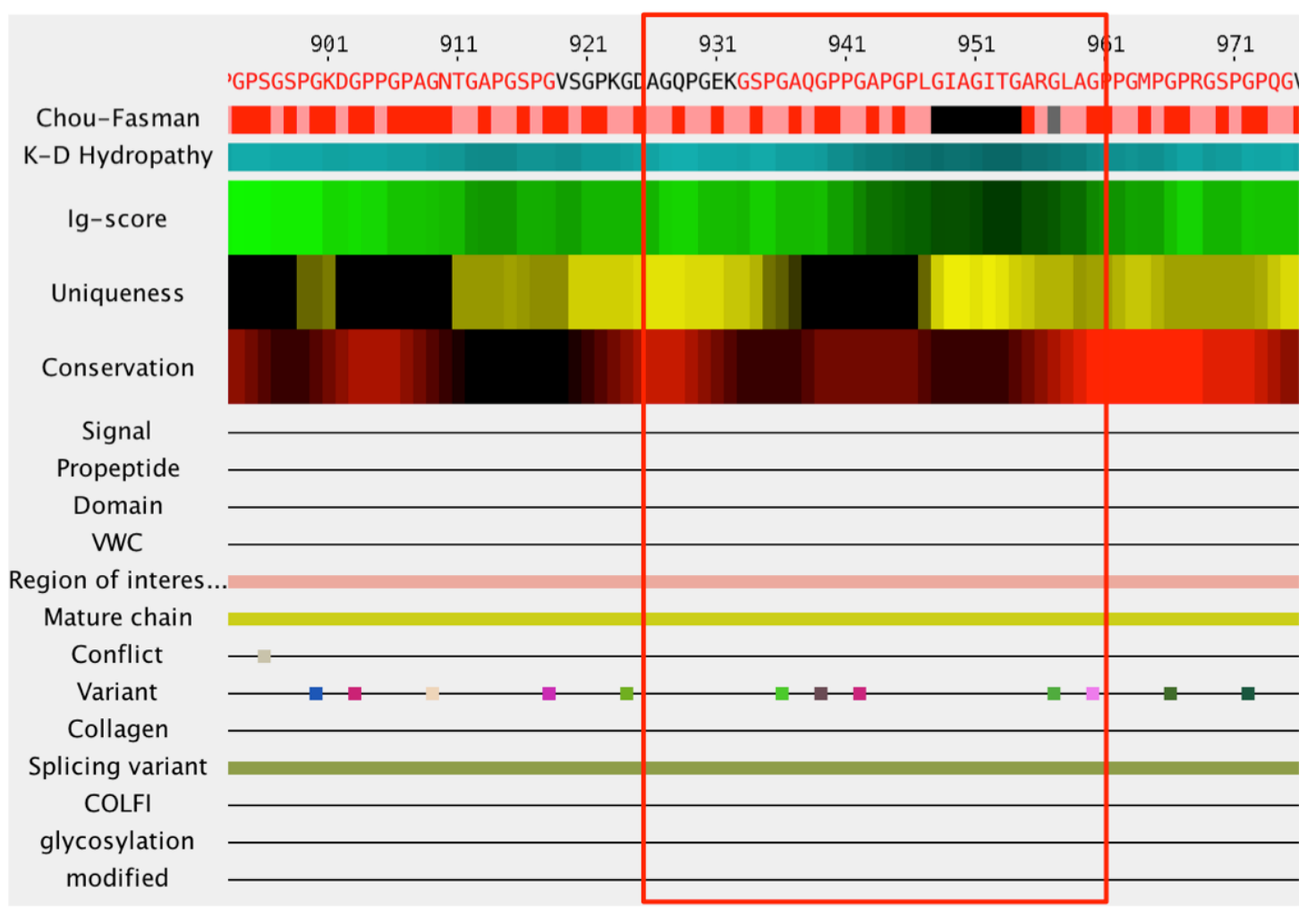

Figure 3.11: AbDesigner output for human COL3A1. Positions 926 to 960 are highlighted to show areas of functional relevance and interest.

Figure 3.11 is the graphical output of human COL3A1 with nucleotide positions 926 to 960 are highlighted in a box. The region corresponds to the area with the highest number of R.pulmo peptides showing partial similarity. In a similar fashion to the COL1A1 gene, the highlighted region shows the mature $\alpha 1$ chain of collagen and belongs to the triple helix region. COL3A1 also exhibits a splice variant in this region where this particular sequence does not occur in isoform 2 of the gene.

The functional search of both human genes found a particular region of interest in COL1A1 for pfam01391. Pfam01391 is also known as the collagen triple helix repeat and contains 20 copies of Gly-X-Y repeat that forms a triple helix. Although this repeat is a critical structural feature to aid in tensile strength of connective tissue the triple helical structure can also be found in other collagens including bacterial collagen-like triple helix repeat proteins (Donkor et al., 2014). A final database search was done to evaluate any similarities between the unique 32 R.pulmo peptides and pfam01391 sequence as a function portion of the human COL1A1 sequence. 


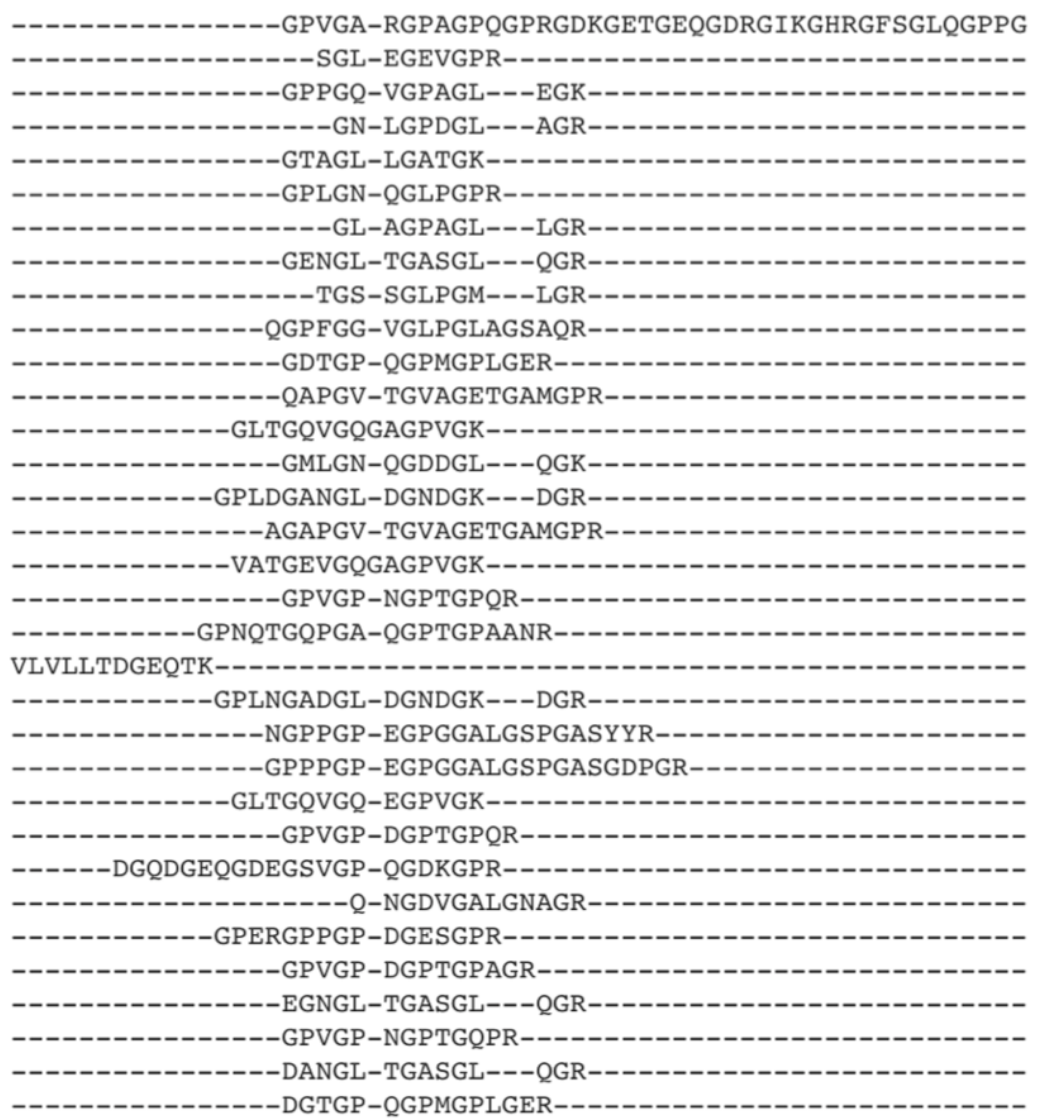

Figure 3.12: Sequence alignment of pfam01391 to R.pulmo peptides.

Figure 3.12 shows Clustal Omega output for the pfam01391 sequence against 32 high quality R.pulmo peptides. The pfam01391 sequence exhibits the typical Gly-X$Y$ repeat expected to be found in the triple helix region of collagen molecules. The 32 peptides analysed for alignment shows varying degrees of sequence similarity apart from peptide 19, which is not aligned to the pfam sequence at any position. All peptides exhibit areas of Gly-X-Y repeats however the substitution of hydroxyproline when compared to the pfam01391 sequence is to be expected due to the lower hydroxyproline content found in marine collagen.

\subsubsection{Collagen plasticity and moulding}

The majority of cells within human tissues reside within an ECM which are tissue specific in their composition (Mount, 2004). Due to the native state of tissue requiring a complex ECM, regenerative medicine employs the field of tissue engineering to mimic the environment and restore or improve tissue function that has 
been lost to disease or trauma (Pertsemlidis and Fondon, 2001). The fabrication of scaffolds for regenerative medicine applications requires particular attention to scaffold architecture. A highly porous structure with interconnected pores is needed to allow diffusion of nutrients and waste products whilst a critical mean pore size is required for cell adhesion and migration, with this latter component being dependent on the tissue that is aiming to be restored (Pisitkun et al., 2012).

In order to assess the plasticity of the collagen, the material was moulded using a 96 well plate and crosslinked using the chemical crosslinking reagent EDC, which has previously been proven to form 3D constructs with collagen extracted from a different species of jellyfish (McElroy et al., 2011).

A concentration of $4 \mathrm{mg} / \mathrm{ml}$ was chosen for scaffold fabrication in this instance. Previous research has used collagen scaffolds of varying concentrations (2-40 $\mathrm{mg} / \mathrm{ml}$ ) however those with a low collagen content $<4 \mathrm{mg} / \mathrm{ml}$ have been used to mimic tissue (Whatmore, 2001). A common source of collagen is that obtained from rat-tail that has been used in research, maintaining cell viability and proliferation (Chan and Long, 2008). Gelatin is thermally denatured collagen that has a disordered, random coil arrangement that has also been used to form scaffolds for answering biomaterials based questions (Dhandayuthapani et al., 2011). With this in mind, jellyfish collagen constructs were compared with rat-tail collagen and bovine gelatin scaffolds as a positive and negative control, respectively, for the ability to form a scaffold, average pore size within the constructs as well as stability and biodegradability.

In the interest of time, scaffold materials will be abbreviated as shown in Table 3.4. 
Material

Rat Tail Collagen

Jellyfish Collagen

Bovine Gelatin

\section{Abbreviation}

\section{RTCol}

JCol

\section{Table 3.4: Abbreviations for materials used to fabricate scaffolds.}

With collagen isolation from R.pulmo jellyfish optimised and characterisation of resultant peptides indicating similarity in specific regions when aligned with COL1A1 and COL3A1, in particular to pfam01391, the peptide sequence which is involved in the triple helix formation. Following these results scaffold fabrication and characterisation was performed. A summary of work for this chapter can be seen below in Figure 3.13. 


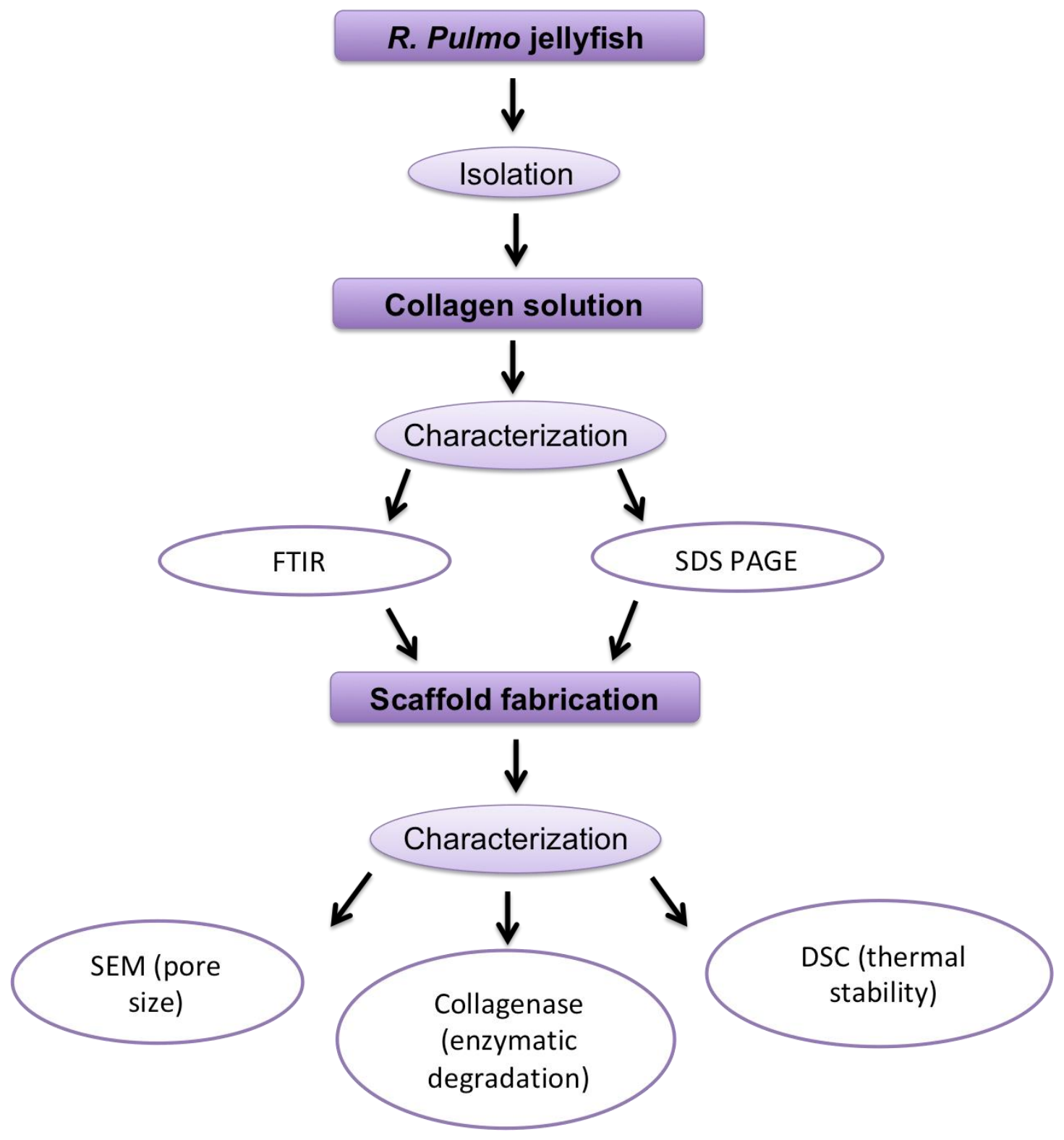

Figure 3.13: Flow diagram of work concerning collagen isolation and scaffold fabrication.

\subsubsection{Moulding}

Scaffold fabrication can be achieved using various techniques, with freeze-drying considered to yield porous, foam-like constructs by sublimating the solution the polymer is frozen in (O'Brien, 2011).

To fabricate scaffolds, $4 \mathrm{mg} / \mathrm{ml}$ of RTCol, JCol or BGel were pipetted into a 96 well plate and freeze dried before crosslinking with the zero length crosslinker, EDC to 
ensure stability against degradation. Following a final freeze-drying process, scaffold structures were analysed for pore size, thermal stability and stability against degradation. Construct gross structure is shown in Figure 3.14.
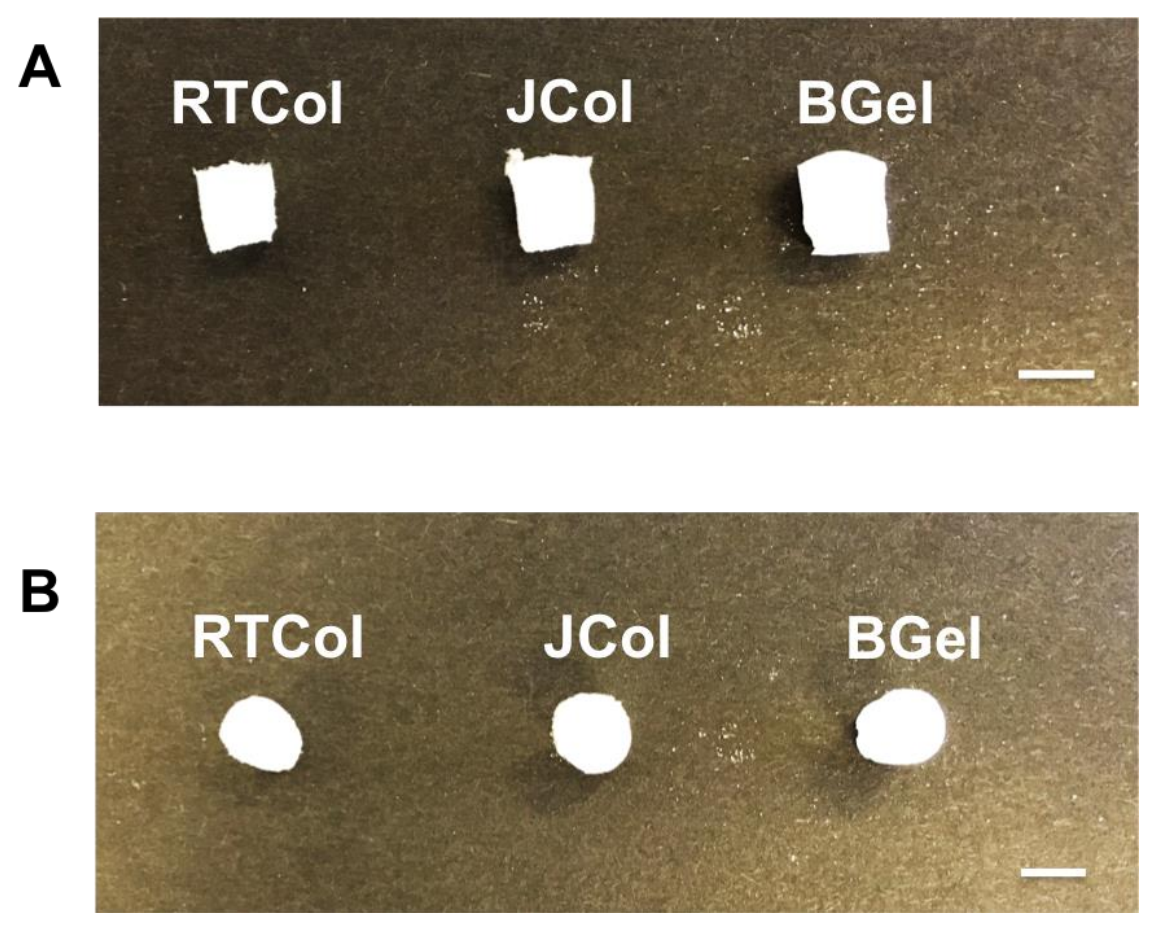

Figure 3.14: 3D collagen moulding and gross sturcture. Scaffolds fabricated from RTCol, JCol and BGel viewed from the side (A) and top down (B). Scale bars indicate $5 \mathrm{~mm}$.

Figure 3.14 shows fabricated scaffolds from side view (A) and top down (B). RTCol, JCol and BGel were all successfully moulded and crosslinked to produce cylindrical, porous scaffolds. All constructs had a height of approximately $5 \mathrm{~mm}$ and width of $3 \mathrm{~mm}$. Scaffolds produced from each material maintained a dry, porous structure that was easily broken however when saturated with liquid scaffolds became sponge like in behaviour and absorbed and expelled liquid upon compression.

\subsection{Scaffold characterisation}

High-resolution morphology imaging is an accepted method to assess interconnected structures (Hoyer et al., 2014). Scanning electron microscopy (SEM) is based on accelerated electrons moving down a column and focused on the sample via various 
electromagnetic lenses. Once the electrons hit the sample, backscattered or secondary electrons are detected and the signal converted to produce an electron micrograph (Antoine et al., 2014). Each collagen mould structure was coated with $15 \mathrm{~nm}$ chromium to ensure conductance and avoid surface charging (Parenteau-Bareil et al., 2010). Figure 3.14 show images for RTCol, JCol and BGel, moulded structures at $4 \mathrm{mg} / \mathrm{ml}$., respectively. All structures were imaged at low $(30-100 \mathrm{~K})$ and high magnification (600-500K).

Scaffold pore size has been shown to impact cell behaviours such as migration, proliferation and differentiation (Gorgieva and Kokol, 2011). Computer software, including SEM software, has previously been used to analyse images and elucidate pore size ( $\mathrm{Lu}$ et al., 2013). Images obtained using Hitachi S-4800 SEM software were used to measure 30 pores to obtain average pore size from scaffolds fabricated from RCol, JCol and BGel, from three replicates, shown in Figure 3.15, 3.16 and 3.17, respectively. 
$0.25 \% \mathrm{EDC}$

A

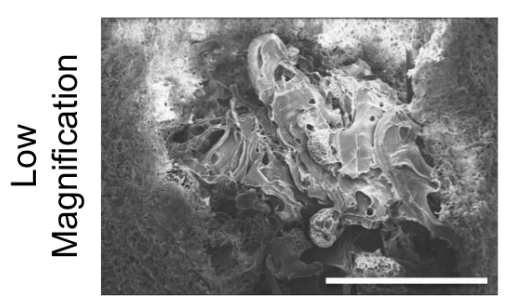

B

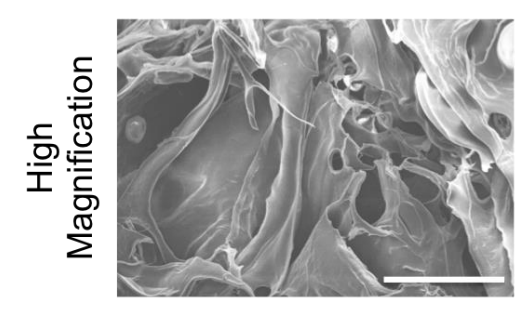

$0.50 \%$ EDC
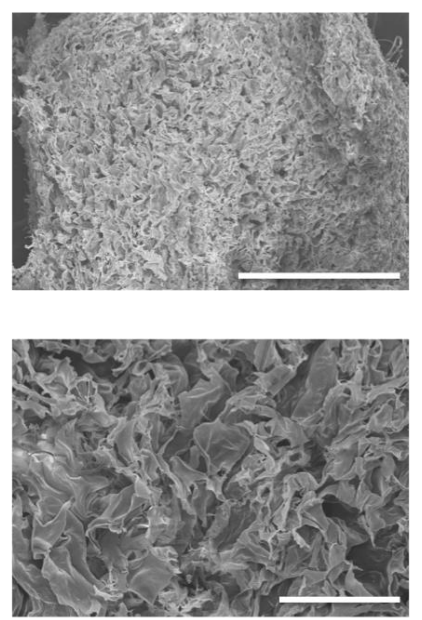

$1 \%$ EDC
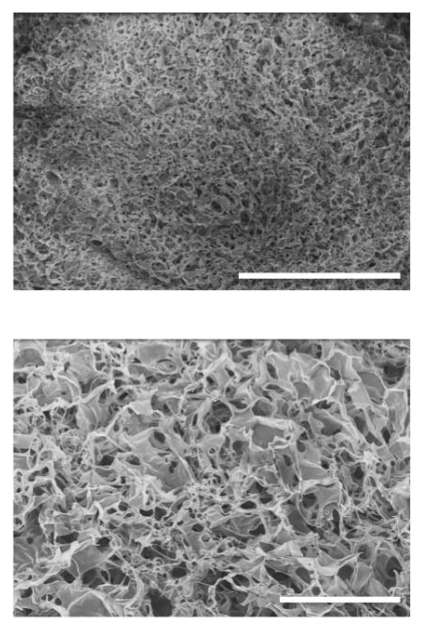

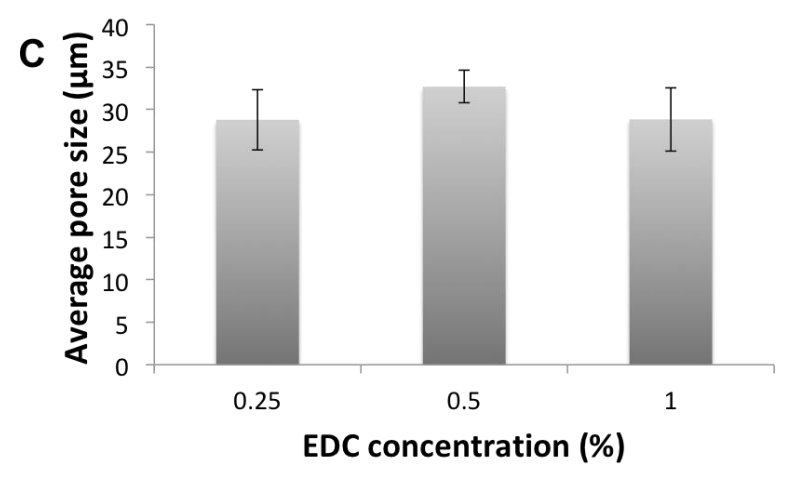

Figure 3.15: SEM images of RTCol scaffolds and pore size at different crosslinking concentrations. Low magnification (A) and high magnification (B) SEM images were taken to assess architecture at $0.25,0.5$ and $1 \%$ EDC concentration. High magnification images were used to calculate average pore size (C). Data shown is the standard deviation from a minimum of three independent repeats, statistical significance shown according to paired Mann Whitney U test $(* \mathrm{p}<0.05 ; * * \mathrm{p}<0.01 ; * * * \mathrm{p}<0.001)$. Scale bars in low and high magnification represent $1 \mathrm{~mm}$ and $200 \mu \mathrm{m}$, respectively.

Figure 3.15 (A) shows RCol scaffolds imaged at low magnification and Figure 3.15 (B) at high magnification using SEM and demonstrate leafy, porous structures with interconnected pores after crosslinking with EDC at $0.25 \%, 0.5 \%$ and $1 \% \mathrm{w} / \mathrm{v}$. Figure 3.15 (C) depicts the average pore size for scaffolds at each crosslinking concentration, obtained from high magnification images. Scaffolds crosslinked at $0.25 \%$ EDC have an average pore size of $28.80 \mu \mathrm{m}, 0.5 \%$ show an average pore size of $32.69 \mu \mathrm{m}$ and $1 \%$ exhibit an average pore size of $28.85 \mu \mathrm{m}$. No significant difference was observed in average pore size between different crosslinking concentrations. 


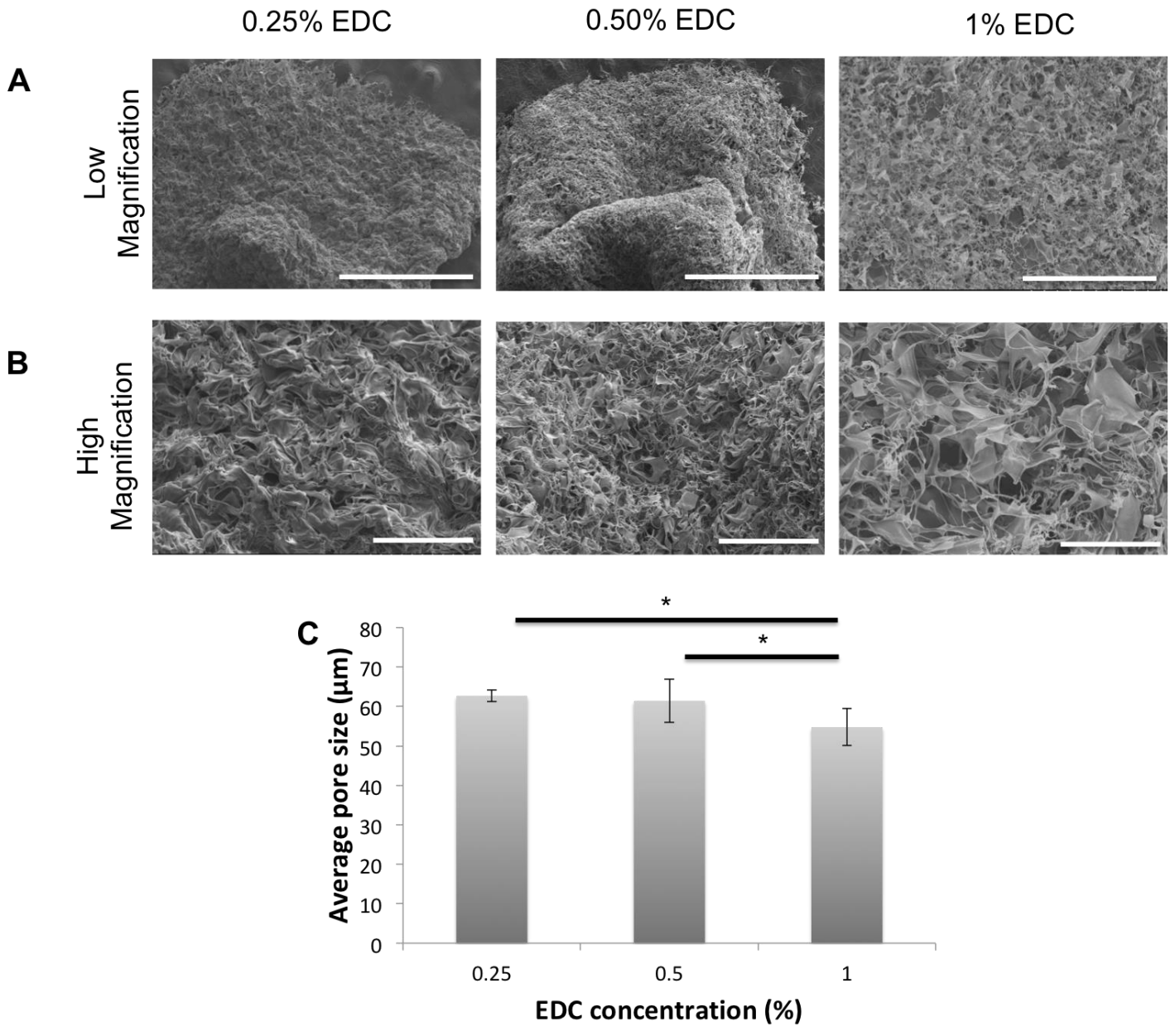

Figure 3.16: SEM images of JCol scaffolds and pore size at different crosslinking concentrations. Low magnification (A) and high magnification (B) SEM images were taken to assess architecture at $0.25,0.5$ and $1 \%$ EDC concentration. High magnification images were used to calculate average pore size (C). Data shown is the standard deviation from a minimum of three independent repeats, statistical significance shown according to paired Mann Whitney U test $(* \mathrm{k}<0.05 ; * * \mathrm{p}<0.01 ; * * * \mathrm{p}<0.001)$. Scale bars in low and high magnification represent $1 \mathrm{~mm}$ and $200 \mu \mathrm{m}$, respectively.

JCol scaffolds crosslinked with $0.25 \%, 0.5 \%$ and $1 \%$ EDC were imaged with SEM at low magnification, Figure 3.16 (A) and high magnification, Figure 3.16 (B), and are show to produced leafy, interconnected porous constructs. Figure 3.16 (C) shows the average pore size of scaffolds at different crosslinking concentrations with average values of $62.70 \mu \mathrm{m}, 61.43 \mu \mathrm{m}$ and $54.76 \mu \mathrm{m}$ for $0.25 \%, 0.5 \%$ and $1 \%$ EDC concentration, respectively. A significant difference in average pore size was 
observed between $0.25 \%$ and $1 \%$ EDC concentration $(\mathrm{p}=0.019)$ and between $0.5 \%$ and $1 \%$ EDC concentration $(\mathrm{p}=0.039)$.

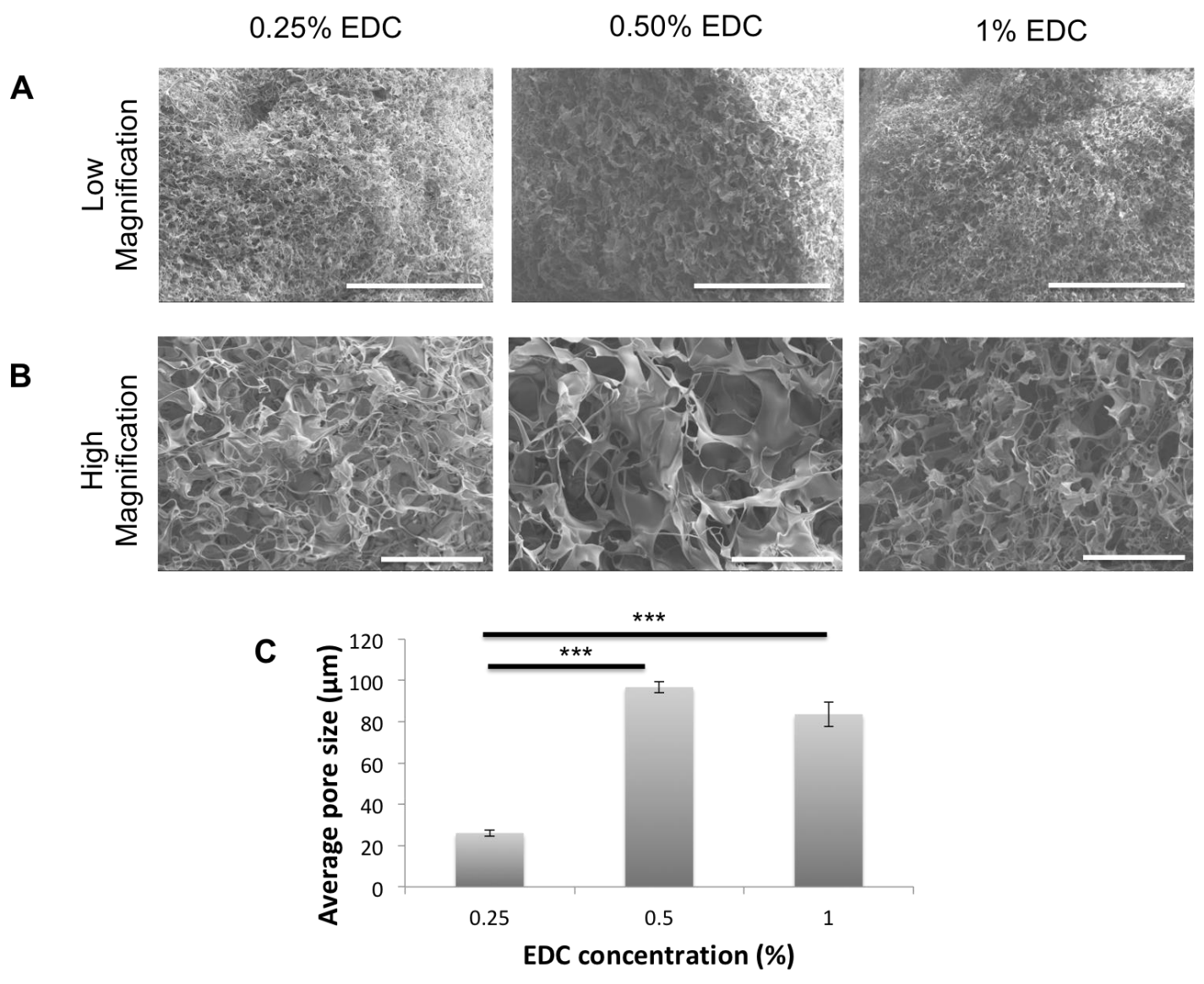

Figure 3.17: SEM images of BGel scaffolds and pore size at different crosslinking concentrations. Low magnification (A) and high magnification (B) SEM images were taken to assess architecture at $0.25,0.5$ and $1 \%$ EDC concentration. High magnification images were used to calculate average pore size (C). Data shown is the standard deviation from a minimum of three independent repeats, statistical significance shown according to paired Mann Whitney $U$ test $(* p<0.05 ; * * p<0.01 ; * * * p<0.001)$. Scale bars in low and high magnification represent $1 \mathrm{~mm}$ and $200 \mu \mathrm{m}$, respectively.

Scaffolds fabricated from BGel were imaged with SEM at both low and high magnification, shown in Figure 3.17 (A) and Figure 3.17 (B), respectively. These images depict that BGel scaffolds crosslinked at $0.25 \%, 0.5 \%$ and $1 \%$ EDC concentration give rise to a porous architecture with interconnected pores. High magnification images were used to obtain average pore size at each crosslinking concentration, shown in Figure 3.17 (C). Average pore sizes of were observed at $26.09 \mu \mathrm{m}$ for $0.25 \% \mathrm{EDC}, 96.77 \mu \mathrm{m}$ for $0.5 \% \mathrm{EDC}$ and $83.66 \mu \mathrm{m}$ for $1 \% \mathrm{EDC}$ with 
BGel. A significant difference in average pore size was seen between $0.5 \%$ and $1 \%$ $(p<0.001)$ and between $0.25 \%$ and $1 \%$ EDC concentration $(p<0.001)$.

\subsubsection{Plastic compression}

Scaffolds produced in the traditional way are hyper hydrated and have properties that do not match native tissue due to the lack of fibril density (Ashworth et al., 2014). Unconfined plastic compression expels liquid from the moulded structure in order to increase fibrillar density (Vernon-Parry, 2000). The application of external mechanical force not only produces a mechanically stronger construct but also reduces the effects of contraction and degradation (Kashi et al., 2014). In order to test the suitability of plastic compression applied to JCol, $2 \mathrm{ml}$ of collagen was pipetted into a 24 well plates and scaffold produced using the method outlined in section 3.2.5.1. Following fabrication, scaffolds were compressed for 30 minutes using RAFT ${ }^{\mathrm{TM}}$ absorbers (Lonza, UK; cat: 016-1R32).
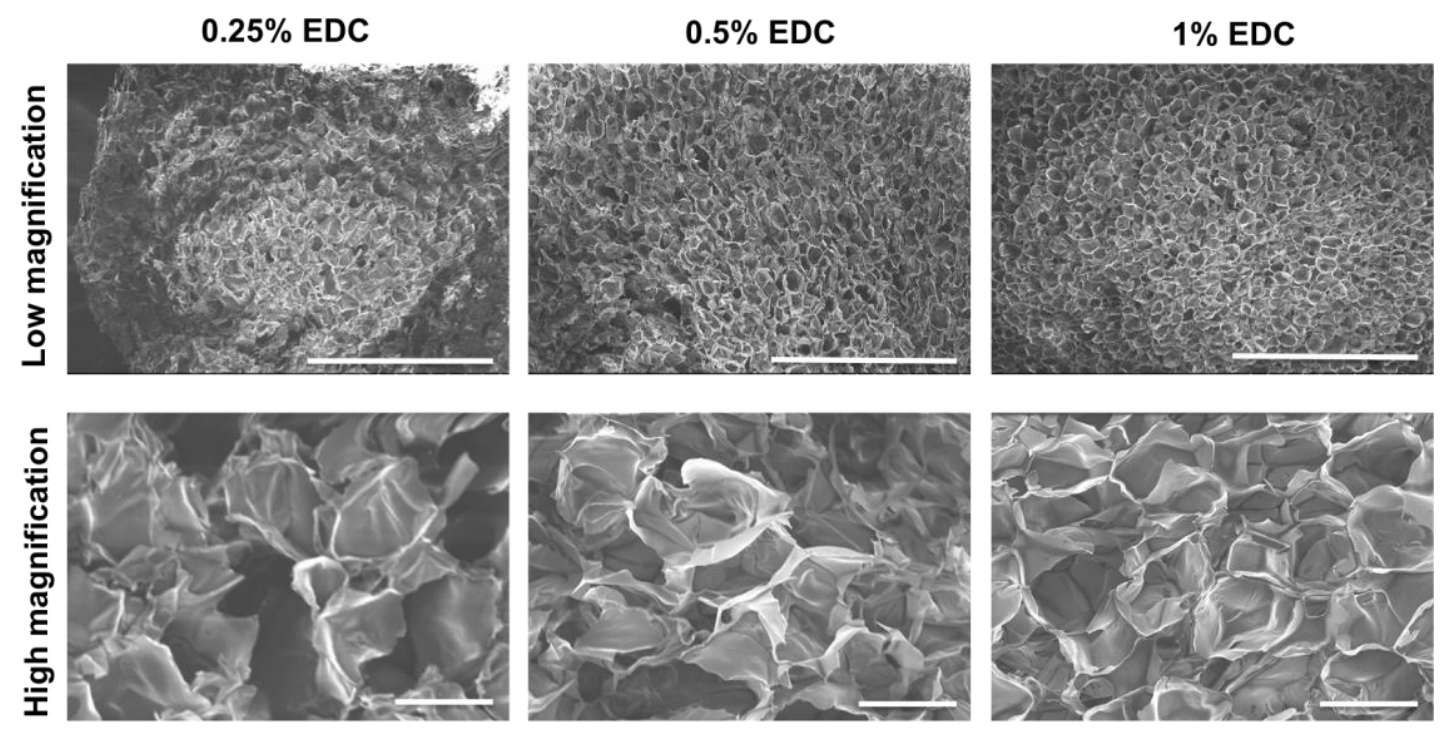

Figure 3.18: SEM images of compressed JCol scaffolds at different crosslinking concentrations. Low (x50) and high (x300) magnification images of compressed JCol scaffolds crosslinked at $0.25,0.5$ and 1\% EDC. Scale bars in low and high magnification represent $1 \mathrm{~mm}$ and $100 \mu \mathrm{m}$, respectively.

Figure 3.18 shows SEM images of JCol scaffolds following compression and crosslinking at $0.25,0.5$ and $1 \%$ EDC. Scaffolds under all crosslinking conditions 
show that constructs maintain a leafy structure with interconnected pores, exhibiting that compression does not change morphological features of scaffolds after being subjected to plastic compression.

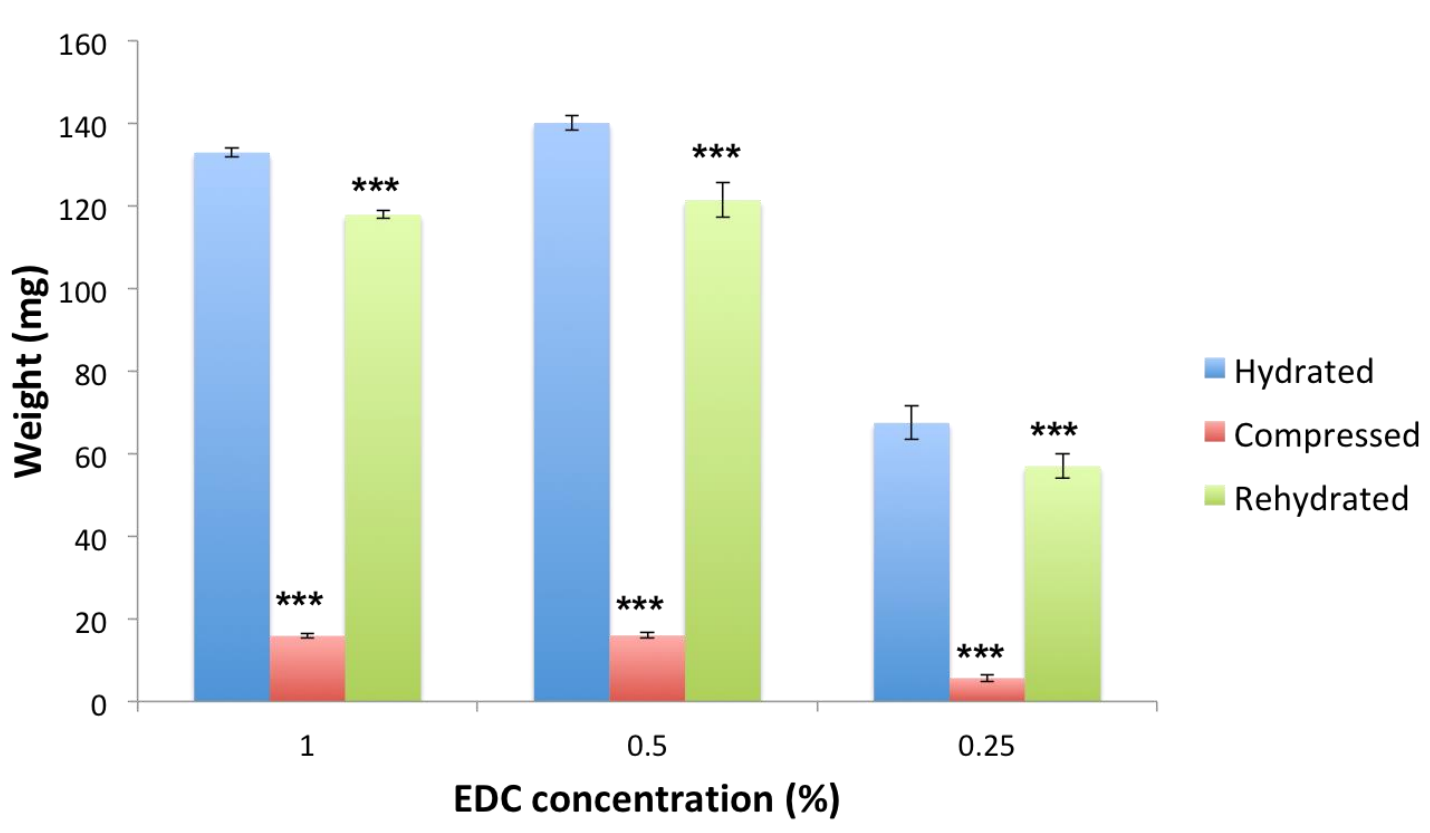

Figure 3.19: Weight of JCol scaffolds before and after compression and reswelling. JCol scaffolds crosslinked with $1,0.5$ and $0.25 \%$ EDC were weighed before and after compression and were placed in PBS before weighing to check for reswelling. All data shown is the standard deviation from a minimum of three independent repeats, statistical significance shown according to $\mathrm{T}$ test $\left({ }^{*} \mathrm{p}<0.05\right.$; $* * \mathrm{p}<0.01 ; * * * \mathrm{p}<0.001)$.

Figure 3.19 depicts weights of JCol scaffolds at $1,0.5$ and $0.25 \%$ EDC crosslinker concentration during compression. Scaffolds crosslinked at $1 \%$ EDC had an initial wet weight of $132.89 \mathrm{mg}$, which decreased to $15.89 \mathrm{mg}$ following compression. When compressed scaffolds were placed in PBS they rehydrated to have a final wet weight of $117.89 \mathrm{mg}$. Both compressed and rehydrated scaffolds showed a significant decrease ( $p<0.001$ for both) in weight compared to the initial samples. The exact same trend was seen for scaffolds crosslinked with $0.5 \%$ EDC. Original scaffold weight was $141.33 \mathrm{mg}$, decreasing to $15.33 \mathrm{mg}$ after compression and increasing again after incubation in liquid to $121.44 \mathrm{mg}$. Weight for compressed and rehydrated scaffolds were significantly decreased $(\mathrm{p}<0.001)$ when compared to the initial weight of fabricated constructs at $0.5 \%$ EDC concentration. Scaffolds produced with $0.25 \%$ 
EDC had an initial wet weight of $67.44 \mathrm{mg}$ before compression where weight decreased to $5.67 \mathrm{mg}$. When allowed to rehydrate in PBS scaffold wet weight increased to $57.0 \mathrm{mg}$. In a similar fashion to scaffolds crosslinked at 1 and $0.5 \%$, scaffolds compressed and rehydrated exhibited a significant $(\mathrm{p}<0.001)$ decrease in weight compared to the original scaffold weight.

\subsubsection{Collagen scaffold stability}

Native collagen possess an array of inter and intramolecular crosslinks that aid in the structural stability found within tissues. Extraction of collagen from tissues reduces the number of crosslinks and changes the physical properties of the material (Bružauskaité et al., 2016). In order to enhance the physical characteristics and resistance against proteolytic degradation of collagen scaffolds, crosslinking can be undertaken in various forms. A popular choice of chemical crosslinking is using the agent EDC that may be coupled with NHS, to form crosslinks that are lower in density that other crosslinking agents but have favourable biological properties (Loh and Choong, 2013). In order to form stable scaffolds from RTCol, JCol and BGel, materials were crosslinked with EDC at $0.25 \%, 0.5 \%$ and $1 \% \mathrm{w} / \mathrm{v}$ and assessed to ensure that an optimal crosslinking concentration would be applied for further experiments.

\subsection{Thermal stability}

Scaffolds produced for regenerative medicine have various characteristics that may be manipulated in order for them to be fit for purpose; this includes resistance against thermal and enzymatic degradation (Cheema and Brown, 2013). Differential scanning calorimetry (DSC) is a technique that allows for the observation of thermodynamic properties of biological macromolecules by measuring the differential heat flow from the calorimeter as reference and sample cells are heated linearly over a period of time. DSC has previously been used to identify biopolymer melting, lipid-protein interactions and conformational changes of proteins (Serpooshan et al., 2010). This technique has also been used to assess the efficiency and extent of crosslinking in scaffolds (Braziulis et al., 2012). In order to assess the 
thermal stability of RTCol, JCol and BGel scaffolds crosslinked at $0.25,0.5$ and $1 \%$ EDC concentration, constructs were placed in platinum crucibles and heated from room temperature to $100^{\circ} \mathrm{C}$ and a graph obtained. An empty platinum pan was also measured as a reference. 

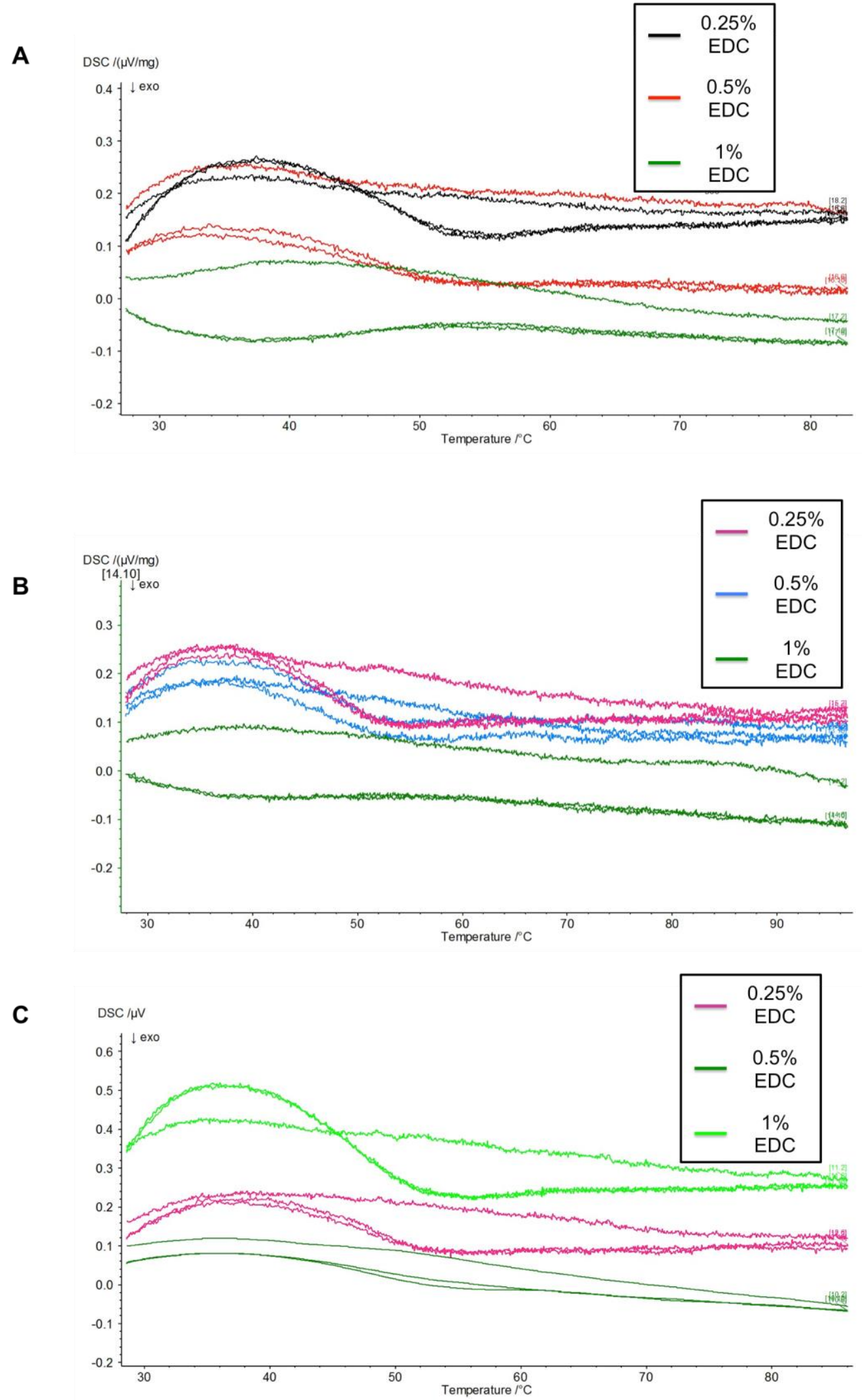

Figure 3.20: DSC of scaffolds crosslinked at various EDC concentrations. DSC data for RTCol (A), JCol (B) and BGel (C) scaffolds crosslinked at $0.25 \%, 0.5 \%$ and $1 \% \mathrm{EDC}$. 
Figure 3.20 (A) shows DSC graphs of RTCol scaffolds crosslinked at 0.25, 0.5 and $1 \%$ EDC. Scaffolds fabricated with $0.25 \%$ and $0.5 \%$ EDC show a peak at $37^{\circ} \mathrm{C}$ whilst those made with $1 \%$ EDC display a broader peak spanning a higher range of temperatures. Figure 3.21 (B) displays DSC graphs from JCol scaffolds. Constructs crosslinked with $0.25 \%$ and $0.5 \%$ EDC exhibit peaks at approximately $37^{\circ} \mathrm{C}$ in a similar fashion to RTCol scaffolds at the same concentration. JCol scaffolds crosslinked with $1 \%$ EDC show a broader peak showing much small change in thermal energy produced by these constructs. DSC of BGel scaffolds are shown in Figure 3.21 (C). These scaffolds display a change in trend from JCol and RTCol scaffolds with $1 \%$ EDC BGel scaffolds showing the greatest change in the thermal energy however the peak of the graph still occurs at $37^{\circ} \mathrm{C}$. BGel scaffolds at $0.5 \%$ and $0.25 \%$ display broader peaks with a smaller change in thermal energy that span over $37^{\circ} \mathrm{C}$.

\subsection{Collagen enzymatic degradation}

Scaffolds designed for regenerative medicine applications must fulfil the requirement of being biodegradable to enable adequate remodelling of the damaged tissue (Davidenko et al., 2015). As a consequence of the break down of the scaffold material, cells are able to produce their own extracellular matrix for tissue repair. It is important that the by-products of degradation be non-toxic in order to maintain a good level of cell viability (Ahmad et al., 2015). In vivo, collagenases such as MMPs are responsible for the degradation of collagen and work by binding to the collagen, unwinding the triple helix and finally cleaving each strand. As bacterial collagenases work under the same principles, they can be used to investigate degradation in vitro (Davidenko et al., 2015). Scaffolds fabricated from RTCol, JCol and BGel crosslinked with $0.25 \%, 0.5 \%$ and $1 \%$ EDC were incubated with serum free DMEM containing $300 \mathrm{U} / \mathrm{ml}$ of collagenase and scaffold weight was monitored over a period of time to assess degradation. 

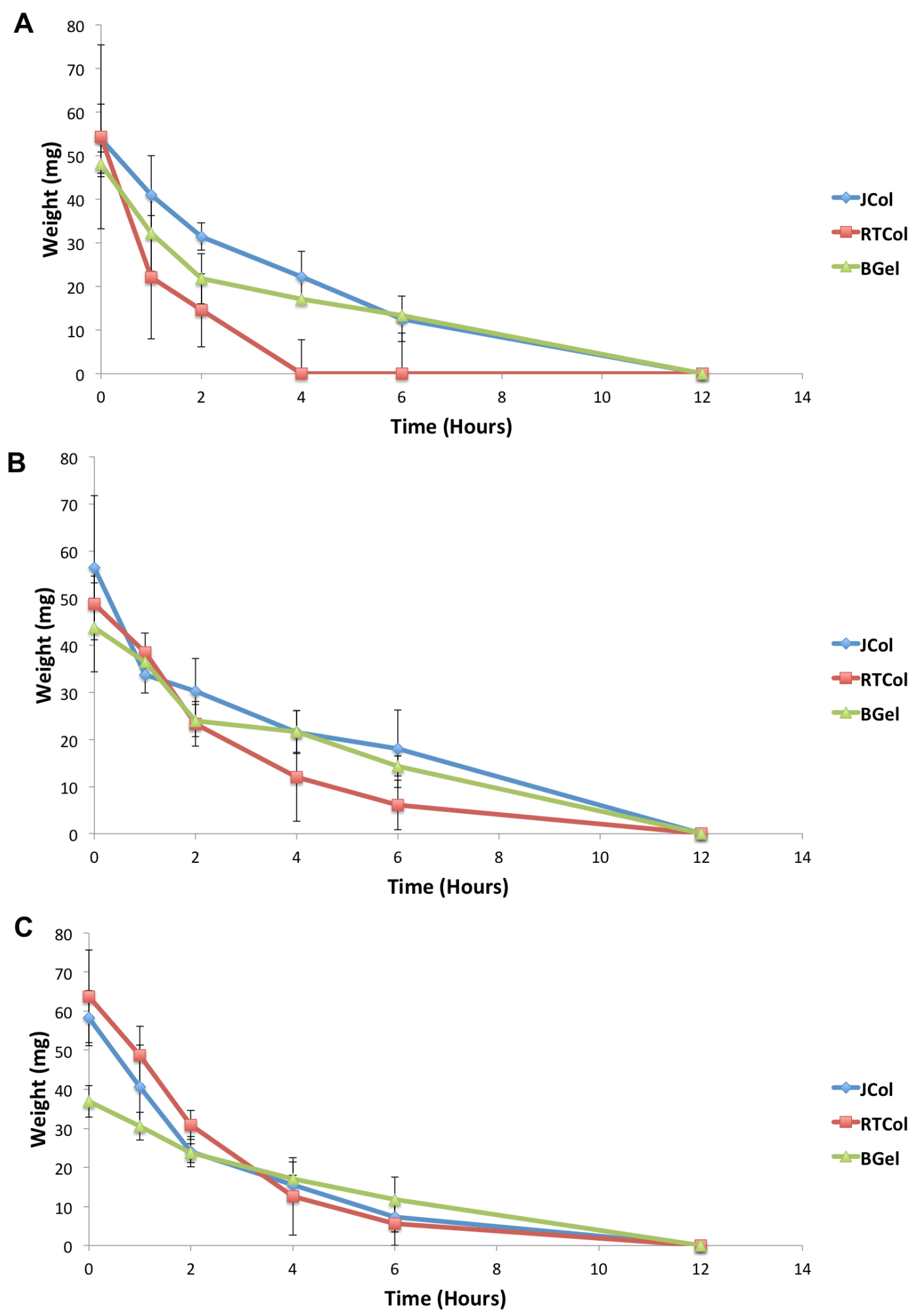

$$
\begin{aligned}
& \curvearrowright \text { JCol } \\
& - \text { RTCol } \\
& - \text { BGel }
\end{aligned}
$$$$
\leadsto \mathrm{JCOl}
$$$$
- \text {-RTCOI }
$$$$
\triangle \text { BGel }
$$

Figure 3.21: Collagenase treatment of scaffolds crosslinked with EDC. Scaffolds crosslinked with $0.25 \%$ (A), $0.5 \%$ (B) and $1 \%$ (C) EDC were incubated with collagenase and weighed regularly to assess resistance to degradation. 
Figure 3.21 (A) shows the weight of RTCol, JCol and BGel scaffolds crosslinked at $0.25 \%$ EDC concentration following collagenase digest over a 12 hour period. RTCol scaffolds decrease in weight over time following incubation with collagenase. Average initial scaffold wet weight was recorded at $54.33 \mathrm{mg}$ and decreased until no remaining scaffold was visible at 4 hours. JCol scaffolds had a similar initial start weight of $53.89 \mathrm{mg}$. At 4 hours JCol scaffolds crosslinked with $0.25 \%$ EDC were still visible and had an average weight $22.22 \mathrm{mg}$ however no scaffold was visible by 12 hours. Gelatin scaffolds fabricated with $0.25 \%$ had a lower initial weight when compared to the other materials at $48.0 \mathrm{mg}$ and decreased in weight following collagenase digestion with an average weight of $17.11 \mathrm{mg}$ at 4 hours and no scaffold available to weight by 12 hours. The same experiment was conducted using scaffolds fabricated with $0.5 \%$ EDC, shown in Figure 3.21 (B). RTCol scaffolds at this crosslinking concentration began with an average weight of $48.78 \mathrm{mg}$, which decreased to $6.11 \mathrm{mg}$ by 6 hours following incubation with collagenase. JCol scaffolds had a slightly higher average starting weight of $56.44 \mathrm{mg}$ that decreased to $18 \mathrm{mg}$ after 6 hours whilst BGel scaffolds had an initial average weight of $43.78 \mathrm{mg}$, decreasing after 6 hours to $14.33 \mathrm{mg}$. At 12 hours no scaffold was visible to be weight for any material crosslinked at $0.5 \%$ EDC concentration. Figure 3.21 (C) shows average scaffold weight following 12 hours collagenase digestion of scaffolds crosslinked with $1 \%$ EDC. RTCol scaffold weight began at $63.78 \mathrm{mg}$ and fell to $5.67 \mathrm{mg}$ after 6 hours. JCol scaffolds had an initial weight of $58.22 \mathrm{mg}$, which decreased after 6 hours to $7.33 \mathrm{mg}$ whilst BGel scaffolds had a lower start weight of $36.89 \mathrm{mg}$ that decreased to $11.78 \mathrm{mg}$ at 6 hours of incubation. At 12 hours no scaffolds fabricated from any tested material remained. 


\subsection{Discussion}

Suitable, alternative sources of collagen that are compatible with large scale extraction are needed to meet the ever-growing demand due to the copious use of collagen in the medical, food and cosmetic industries (Meena et al., 1999). Marine species have been identified as an abundant source of collagen with extraction demonstrated from, scales, skin, bones and cartilage (Silva et al., 2014). Seasonal blooms of jellyfish have been recognised as a potential source of collagen for regenerative medicine. While overfishing has disturbed parts of the world's oceans, these abundant blooms can be harvested, with minimal cause for concern due to their involvement in beach closures, fish deaths and clogging of coastal power and desalination plants (Brotz et al., 2012).

Focusing on identifying and developing a scalable extraction process for $R$. pulmo derived jellyfish collagen; the data presented here demonstrates clearly that acid extraction of jellyfish collagen can be incorporated into large, industry scale production. Jellyfish collagen solutions have been characterised for their similarity with mammalian collagen, using an array of accepted assays (Abraham et al., 2008). SDS PAGE, FTIR, differential scanning calorimetry and SEM analyse collagen purity, amide banding, thermal stability and morphological features such as banding and fibre orientation respectively (Abraham et al., 2008). The $\alpha 1$ band sequencing cross-references with 40 collagen/collagen related proteins when searching sequence similarity, while functional peptide sequencing indicates potential structural variations when compared directly to mammalian collagen. These are also observed when the collagen solution is freeze-dried to a sponge scaffold, potentially explaining differences in collagen scaffold interconnectivity, pore size, collagenase digestion and thermal stability (Terzi et al., 2018)

Marine collagen suitability for applications in human regenerative medicine and tissue engineering is reliant on multiple characteristics determined by biological information such as evolutionary conservation and functional peptide homology (Pawelec et al., 2016). Whilst the evolutionary conservation between jellyfish and human collagens is beyond the scope of this project previous reports have demonstrated that jellyfish collagen exhibits a triple helix flanked by $\mathrm{N}$ and $\mathrm{C}$ 
terminals in a similar fashion to mammalian collagen, see Figure 1.1 (Exposito et al., 2008). Sequence similarity was exhibited in the peptide sequences obtained from the alpha1 band, with top results reporting no alignment to mammalian and $18.75 \%$ marine sources. This observation is supported by electrophoretic migration of the $\alpha 1$ band, at $175 \mathrm{kDa}$ in comparison to $135 \mathrm{kDa}$ observed in mammalian collagen types. Migration of triple helical proteins is not correlated to their molecular mass; Addad and Cheng have also shown difference in electrophoretic pattern. $R$ pulmo jellyfish collagen gave $\alpha 1$ bands in a similar or slightly higher position when compared to rattail collagen (Addad et al., 2011), whilst bands from R. esculentum jellyfish showed bands around $116 \mathrm{kDa}$. The differences in electrophoretic pattern may be attributed to differences in structure that are thought to have arisen during evolution (Cheng et al., 2017a).

Jellyfish collagen from $R$. pulmo and R. esculentum has previously been extracted using the traditional procedure where tissue was allowed to dissolve in acetic acid for overnight (Bermueller et al., 2013). To increase the final collagen yield a pepsin digest step was added and salted out with the use of sodium chloride (Schmidt et al., 2015). Finally, pure collagen was obtained through centrifugation and the pellet resuspended in acetic acid for downstream experimental analysis (Addad et al., 2011). Pacak and colleagues understood the need for a rapid process to be developed for a cost effective way of meeting the ever-growing commercial demand for collagen. Using dermal samples, sources of collagen type I, from lamb, rabbit and human, a vigorous agitation protocol was developed reducing the time scale to approximately 3 hours (Pacak et al., 2011). In this chapter the rapid protocol outlined by Pacak was applied to isolate collagen from R. pulmo jellyfish. Modifications were made including use of different acids (sodium citrate and acetic acid) as well as extraction in the presence and absence of pepsin.

It has previously been reported that acid plays a key role in collagen solubility due to the excess $\mathrm{H}+$ ions that are present, allowing water access to collagen fibres' held by either electrostatic swelling or lyotropic hydration (Kiew and Don, 2013). Acid hydrolysis of collagen is typically carried out using organic acids such as acetic, citric and lactic acids as it is seen as more efficient than the use of inorganic acids such as hydrochloric acid, as well as being capable of solubilising non-crosslinked 
collagens (Schmidt et al., 2015). Extractions were executed using two common organic acids; sodium citrate and, more popularly used in research and industrial settings, acetic acid.

Collagen can be identified from FTIR, a non destructive, vibrational spectroscopic technique due to characteristic peaks that represent amide I $\left(\sim 1600-1700 \mathrm{~cm}^{-1}\right)$, amide II $\left(\sim 1549-1560 \mathrm{~cm}^{-1}\right)$ and amide III $\left(\sim 1240 \mathrm{~cm}^{-1}\right)$ (Belbachir et al., 2009). FTIR analysis of collagen extracted via acetic acid or sodium citrate gave peaks that were not within those previously reported for jellyfish collagen, in line with structural alterations in carboxyl group composition, vibrational banding related to $\mathrm{N}-\mathrm{H}$ and $\mathrm{C}$ $\mathrm{N}$ bending/stretching and/or the crucial triple helical structure. These findings are consistent with Riaz et al, who found differences in all three amide peaks and attributed these to both structural differences between animals and isolation protocols (Riaz et al., 2018). This suggests that acid extraction alone may have altered the structure of jellyfish collagen during the isolation process, confirmed by the brittle material that was produced once solutions had been freeze-dried.

Although acid extraction is an efficient method for obtaining collagen it should be noted that dilute acids are incapable of breaking mature crosslinks (Delgado et al., 2017). The use of alkaline solutions has been tested however the loss of posttranslationally modified amino acids reduces the applicability of the collagen for commercial use (Yang and Shu, 2014). The use of proteolytic enzymes have been used in order to break mature crosslinks and increase the yield of collagen obtained from extraction (Schmidt et al., 2015). Pepsin is a proteolytic enyme that cleave the non-helical telopeptides regions from collagen molecules removing any intermolecular crosslinks and increasing the solubility of collagen in tissues (Duan and Sheardown, 2005). Regardless of the acid chosen for extraction, results show that the addition of a pepsin digest increased the yield of collagen. Extraction using sodium citrate isolated an average of $5.55 \%$ material, which increased to $6.83 \%$ with the addition of pepsin whereas acetic acid extraction isolated an average of $1.9 \%$ of material from jellyfish that increased to $7.2 \%$ when using pepsin.

FTIR analysis of acid extracted collagen in the presence and absence of pepsin have shown similar spectra suggesting that enzymatic hydrolysis does not affect the 
structure of collagen during isolation (Schmidt et al., 2015). However, studies comparing acid solubilised collagen and pepsin solubilised collagen have shown shift in FTIR spectra indicative of the isolation of a more stable triple helix (Riaz et al., 2018). FTIR spectra obtained from isolation experiments show changes in amide peaks between acid extraction and acid with pepsin extraction. Sodium citrate extraction with pepsin saw a change in FTIR spectrum however the peaks witnessed were still out of the range identified in previous jellyfish collagen spectra and maintained a brittle physical property when freeze dried. This indicated that sodium citrate is not a suitable acid for the extraction of jellyfish collagen as it is not efficient potentially changes the structure of the protein during isolation (Schmidt et al., 2015). On the other hand, acetic acid extraction using pepsin saw a shift in spectrum results so all peaks were found within the ranges previously documented for jellyfish collagen indicating that structural integrity was maintained during isolation (Riaz et al., 2018). However, once freeze dried the material proved difficult to resuspend causing us to believe that isolation of collagen contained contaminants.

The addition of salts such as sodium chloride decreases protein solubility in a process termed salting out. This additional stage in isolation allows collagen to be precipitated out of solution for easier collection through centrifugation (Wahl and Czernuszka, 2006). Acetic acid extraction, in the absence of pepsin and the addition of a salting out stage isolated a soft, white material similar to that of mammalian collagen when freeze-dried. The presence of residual salt in collagen solution may be problematic, as it has previously been reported that the presence of $\mathrm{NaCl}$ decreased the thermal stability and affected the rheological properties of the protein (Duan et al., 2013). Salt precipitation using acetic acid revealed an amide I peak at $1685 \mathrm{~cm}^{-1}$ and the change may be due to carboxyl and a mine groups forming new bonds, amide II at $1554 \mathrm{~cm}^{-1}$ and amide III at $1243 \mathrm{~cm}^{-1}$, with the last two peaks in the range found from previous jellyfish collagen studies. Although the yield of collagen was lower than pepsin extraction protocols, peaks from FTIR spectra for collagen obtained from salting out indicate the potential presence of the triple helix. Freeze dried material had a soft, white appearance in line with the physical characteristics of mammalian collagen showing that this extraction protocol produced a purer final product than previous extractions that were tested (Deyl et al., 2003). 
The ability to mould or fabricate collagen into different forms is a characteristic that makes the protein highly desirable, with films, sponges and hydrogel constructs each being developed for tissue engineering and drug delivery (Lee and Shin, 2007). The adaptability of collagen into different forms is a characteristic that makes the protein highly desirable by different industries (Payne and Veis, 1988). Collagen obtained from an alternative source must prove to be malleable for different applications.

Sponges are classified as porous structures that are defined by their interconnectivity and pore size, which affect cell migration, nutrient waste exchange and matrix deposition (Krimm and Bandekar, 1986). On the other hand, hydrogels are described as a network of polymer chains that are hydrophilic and possess the ability to retain a large amount of water (Cheng et al., 2017b). In vivo, collagen molecules undergo fibrillogenesis and aggregate to form supramolecular structures. Fibrillogenesis can be induced in vitro by mimicking physiological conditions such as exposing isolated collagen to neutral solutions and body temperature (Khan and Khan, 2013).

In this study, collagen isolated from $R$. pulmo jellyfish were fabricated into sponge scaffolds using chemical crosslinking and lyophilisation as previously demonstrated with $R$. esculentum jellyfish collagen (Lee and Shin, 2007). Gelling properties of collagen are highly dependent upon the hydroxyproline and proline content of collagen molecules with mammalian collagen exhibiting a high imino acid (hydroxyproline and proline) content (Hoffman, 2002). Hydrogel formation from collagen obtained by marine species may be more difficult to achieve unaided as imino content from these animals has been shown to be significantly reduced compared to mammalian sources (Tronci et al., 2013). Hydrogels have received attention for cartilage repair as they can be injected non-invasively into the injury site, fill defects of different sizes and contain a homogenous mixture of cells in comparison to sponge scaffolds (Hoyer et al., 2014). The major disadvantage to hydrogel use in tissue engineering is their inherent mechanical weakness due to excessive water retention. This can be overcome by increasing the crosslinking density however this may compromise cell viability (Hashim et al., 2015).

In vivo, collagen forms crosslinks in both enzymatic and non-enzymatic manners that are essential in the characteristic tensile strength that the protein exhibits (Chung and 
Burdick, 2008). Due to the lower proline and hydroxyproline content documented in marine animals, fewer corsslinks are formed when compared to mammalian tissues, leading to less stable molecule and overall a lower denaturation temperature. Crosslinks can be efficiently recreated in vitro using physical and chemical methods (Bryant and Anseth, 2002). The chemical crosslinker EDC is a popular choice used during scaffold fabrication (Vickers et al., 2004). EDC is a zero length crosslinker and conjugates carboxyl groups to primary amines without becoming a part of the final bond. EDC reacts with carboxylic groups to form O-acylisourea, an intermediate that is displaced by nucleophilic attack from primary amino groups. Primary amine groups form amide bonds with carboxyl groups and the EDC byproduct is released as a soluble urea derivative that can be washed away, outlined in

Figure 3.22 (Ahmad et al., 2015).

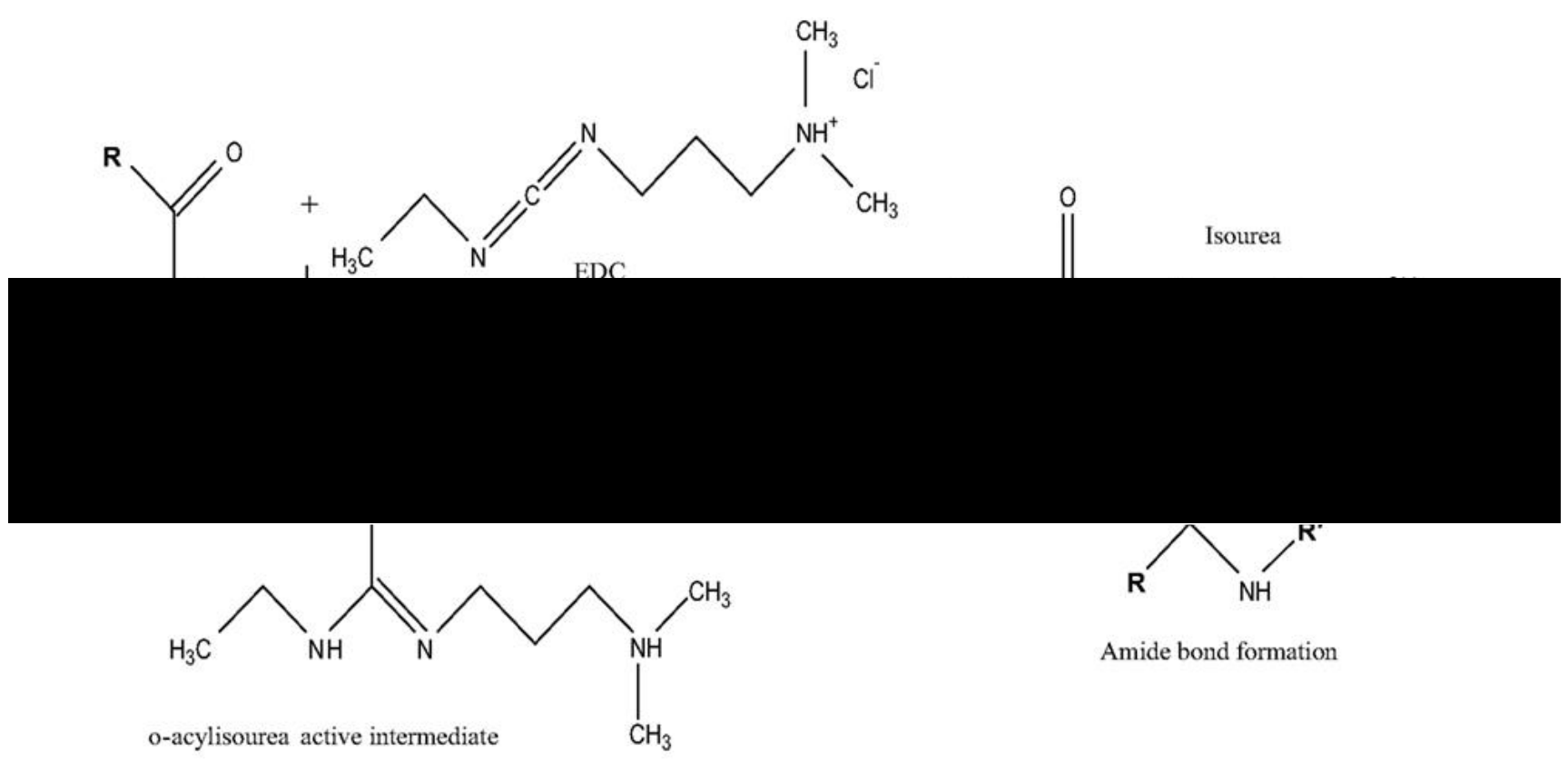

Figure 3.22: EDC crosslinking reaction. Carboxyl groups react with primary amine groups via EDC formed intermediate to form amide bonds (Subhan et al., 2015).

Although EDC results in a lower crosslinking density than other methods that have been researched it is favoured due to previous reports that it causes low levels of cytotoxicity (Suchy et al., 2015). However, further research into EDC crosslinking has shown that cell viability of lymphoma cells is inversely proportional to EDC concentration (Song et al., 2006). As found in the literature, EDC was used as the chosen chemical crosslinker for fabrication of JCol, RTCol and BGel scaffolds to aid 
in mechanical and thermal properties (Rao and Winter, 2009). Scaffolds were crosslinked using a range of concentrations to test effects of crosslinking density on scaffold characteristics in future downstream analysis.

The success of sponge scaffold fabrication from jellyfish collagen is indicative of the use of these constructs in cartilage tissue engineering. Previously, collagen sponges produced from bovine sources have shown their potential in cartilage tissue engineering, exhibiting cell viability and cartilage specific matrix (Glowacki and Mizuno, 2007). More recently, jellyfish collagen scaffolds have been analysed for their chondrogenic potential. $R$. esculentum jellyfish sponge scaffolds were found to redifferentiate human nasal septal chondrocytes following loss of phenotype from monolayer culture (Bermueller et al., 2013) and R. pulmo collagen successfully differentiates human MSCs along a chondrogenic lineage (Pugliano et al., 2017).

Current 3D tissue models involve monolayers of cells or cells embedded into hydrogels or sponges. Collagen gels, although biocompatible, still lack the desired mechanical properties due to the differences in fibril density (Hoyer et al., 2014). Cells interact with collagen via integrins that recognise specific motifs, in particular GFOGER (Ahmad et al., 2015). Davidenko and colleagues assessed the affect of crosslinking density on platelet adherence to collagen scaffolds. Platelets bind to the collagen peptide sequence GFOGER through the $\alpha 2 \beta 1$ integrin. Crosslinking with EDC requires the carboxyl group, in this case focused on the $\mathrm{E}$ (glutamic acid) of the peptide sequence, inhibiting integrin interaction and in turn decreasing the amount of cells attached to the scaffolds (Thoreson et al., 2015). It is important for cells to adhere to collagen scaffolds in large quantities as high stem cell density, in cartilage tissue engineering, is thought to encourage chondrogenic differentiation due to cellcell communication aiding in the expression of cartilage matrix specific proteins (Bax et al., 2017).

Scaffolds produced for tissue engineering and modified by a crosslinking agent should strike a balance between thermal stability and susceptibility to degradation (Leitinger, 2003). The triple helical nature of collagen aids with the formation of networks that are held together through a combination of hydrogen bonds and Van der Waals forces that stabilise structures and enhance the mechanical and thermal 
properties of the protein (Davidenko et al., 2015). As previously discussed the decreased amount of imino acids present in marine collagen leads to a lower denaturation temperature (Chung and Burdick, 2008). It is well documented that collagen derived marine species have a lower denaturation temperature than mammals due to their reduced proline and hydroxyproline content however crosslinking of the material can increase its stability (Davidenko et al., 2015). Denaturation of collagen alters the macromolecular structure of the molecule from a triple helix to random coil formation associated with gelatin (Subhan et al., 2015). This change in structure also leads to changes in cell binding domains whereby the GFOGER motif is lost and RGD becomes the primary integrin binding domain (Karim and Bhat, 2009).

Differential scanning calorimetry is an effective tool used to measure phase transitions that occur as a result of heat energy released or absorbed by a sample (Cheema and Brown, 2013). The endotheromic or exothermic event is determined by the area under the peak whilst the maximum height of the peak is seen as the maximum heat capacity that occurs at phase transitions such as protein unfolding (Siljander et al., 2004). Hoyer previously showed that denaturation temperature of native collagen isolated from $R$. esculentum could be increased by crosslinking using EDC (Barczyk et al., 2010). Crosslinking with varying concentrations EDC revealed that JCol scaffolds are thermally stable at $37^{\circ} \mathrm{C}$ equalling the thermal stability shown by RTCol and BGel scaffolds.

Whilst thermal stability plays an important role for future applications such as implantation into the human body degradation of scaffolds is essential for regenerative medicine as the guide new tissue formation before allowing remodelling and replacement (Wu et al., 2017). Degradation of native tissue ECM is often indicative of injury or disease however during the remodelling process the ECM can be broken down to release active peptides that aid in homeostasis and include peptides with antimicrobial, chemoattractant and angiogenic properties (Durowoju et al., 2017).

In vivo, collagen is cleaved by proteolytic enzymes belonging to the MMP and ADAMTs families (Hoyer et al., 2014). Seven Clostridium hitolyticum (CHC) like 
collagenases have been identified at low levels in human tissues and are found tightly bound to collagen (Zhang et al., 2014a). These enzymes are divided into 2 classes where the first class cleaves collagen molecules at the $\mathrm{N}$ and $\mathrm{C}$ terminals before degrading the collagen into smaller fragments whereas the second class cleaves at the centre of the collagen molecule before further degradation (Badylak et al., 2008). Degradation of scaffolds can be assessed in vitro using collagenase obtained from $\mathrm{CHC}$, which has been shown to cleave collagen into small fragments. In vitro degradation studies using collagenase from this species has been shown to correlate to in vivo degradation rates and therefore results obtained from this assay can be seen a preliminary data for degradation behaviour (Lu et al., 2011). A variety of collagenase concentrations have been used in the assessment of degradation from 125U/ml (Mookhtiar and Wart, 1992) to 390U/ml (Gorgieva and Kokol, 2011). All scaffolds treated with $300 \mathrm{U} / \mathrm{ml}$ of collagenase were degraded over the course of 12 hours indicating that the extent of crosslinking did not cause resistance against degradation and that if implanted degradation would be likely to occur in vivo.

Tissue engineering requires scaffold structures that can either be preloaded with cells or allow for cellular infiltration following implantation into the injury site or risk being impractical (Alberti and $\mathrm{Xu}, 2016$ ). Various methods can be used in order to obtain a porous scaffold including salt leaching, phase separation and freeze-drying. In the instance of freeze-drying, hydrated scaffolds are frozen before being placed in a freeze drier where the ice is sublimated into the gas phase (Alberti and $\mathrm{Xu}, 2016$ ). The walls of the pores are formed when a thin film of material forms at the edge of the ice and grows. Additionally, when acetic acid is used, as can be the case with collagen solutions, the ice takes on a dendritic formation yielding an interconnected pore structure ( $\mathrm{Ng}$ et al., 2009). Pore size produced by this method can be varied depending on different elements, for instance, the viscosity of the solution and the water to polymer ratio, whereas pore structure is dependent on the freezing temperature. Producing pores through freeze-drying is a favourable method as it removed the need of multiple washes and allows direct use of polymer solutions (Bružauskaité et al., 2016).

The freeze-drying process was used to fabricate scaffolds from $R$. pulmo collagen using a 96-well plate as a mould (Caliari et al., 2015). Scaffolds produced in this way 
formed sponge like structures that, upon analysis with SEM, displayed a highly interconnected porous structure that is consistent with literature and suitable for the maintenance of cell attachment, migration and diffusion of nutrients and waste (Jafari-Sabet et al., 2016). SEM analysis also showed JCol scaffolds exhibiting an average pore size between $54-63 \mu \mathrm{m}$ at different crosslinking concentrations, which was larger than RTCol scaffold and smaller than BGel scaffolds. The difference in pore size between marine and mammal sources may be due to differences in the collagen amino acid composition causing differences in the viscosity of solutions produced during extraction. Previous studies have found that scaffolds intended for chondrogenic purposes showed enhanced chondrogenic differentiation with small $(20-150 \mu \mathrm{m})$ pore size whilst large $(250-500 \mu \mathrm{m})$ pore size enhance ECM deposition and chondrocyte proliferation (Davidenko et al., 2015) showing that all scaffolds fabricated would not only be suitable for cell invasion but for applications in cartilage repair.

Cells in human tissues respond to mechanical signals that determine cellular function, stem cell differentiation and homeostasis. Changes in mechanical properties of tissues lead to the onset of disease and so tuning the mechanical properties of scaffolds is important for correct tissue formation (Yamada et al., 2014). It is thought that the force carrying capacity can be increased via the compression of the gel. Plastic compression allows for fibril density to be increased through the removal of fluid from hyper hydrated gels. Pressure is applied to any gel face and the primary fluid leaving surface continuously restricts the outflow of fluid. As the collagen gel becomes denser, through packing, the flow of fluid is blocked and so the process is self-limiting (Matsiko et al., 2015). With an overall aim to produce constructs that are biomimetic, PC collagen constructs have been shown to have tensile properties similar to some native tissues due to their increased protein concentration and interaction between fibrils bringing us closer to that goal (Cheema and Brown, 2013). Inconsistent with reports in current literature, which has used plastic compression of mammalian collagen for ocular surface (Mi et al., 2010) and tendon (Garvin et al., 2004) tissue engineering, JCol constructs did not plastically compress during this study. However plastic compression has been carried out on hydrogels and research has not used this technique on sponge structures (Jansen et al., 2015). Cartilage is described as a biphasic tissue that displays a creep and stress 
response to loading (Cheema and Brown, 2013). The failure of the scaffold to plastically compress may be advantageous as increased fibril crosslink density has been associated with stiffer cartilage affected by conditions such as aging and diabetes (Neel et al., 2006).

In conclusion, the presented data shows that a rapid extraction protocol for the isolation of collagen from $R$. pulmo jellyfish is possible, yielding $0.7 \%$ protein from native jellyfish tissue. This is further validated by incorporation into Jellagen production facility, a crucial step in commercial expansion. Isolation using acetic acid and salt precipitation yielded a soft, white material that gave amide I, II and III peaks that are characteristic of collagen. Further validation of the protein showed that alpha bands appeared in expected regions when subjected to gel electrophoresis and MSA of peptides aligned to triple helical repeats found in human collagen. Jellyfish collagen was found to be manipulated into sponge scaffold structured with the use of EDC chemical crosslinking that stabilised structure and thermal properties to $37^{\circ} \mathrm{C}$ and could be digested using bacterial collagenase, indicating that breakdown is likely to occur in vivo. These findings suggest that jellyfish collagen scaffolds should be further tested for their biocompatibility and application in cartilage tissue engineering. 


\section{CHAPTER 4}

\section{Cell Culture and \\ Immunogenicity; Characterising Material Biocompatibility}




\subsection{Introduction}

In order to be considered biocompatible, a material must have the ability to perform a specific application in a foreign host, whilst eliciting an appropriate host response. Traditional mammalian collagen matrices are known to help natural cell-matrix interactions and are not seen to be cytotoxic (Antoni et al., 2015). Appropriate cellmaterial interactions are crucial, aiming to ensure cellular adhesion as well as the maintenance of cell specific viability and proliferative capacity in contact with an exogenous collagen material. These properties are crucial to the successful use of biomaterials in tissue regeneration (Carletti et al., 2011).

It is essential to characterise cellular viability and any potential phenotypic differentiation once a given candidate collagen structure is obtained. Material biocompatibility testing is routinely conducted in both in vitro and in vivo investigations, using both 2D (basic structure) and 3D (biomaterial specific structures) (Helmus et al., 2008). The assessment of cell viability can be undertaken in various ways including exclusion dyes such as trypan blue or those that gauge metabolic activity, as is the case for tetrazolium based methods (Martin-Piedra et al., 2014).

Alongside aiding cellular proliferation, collagen may have an effect on the morphology of certain cells. An important process in embryogenesis and cancer metastasis is an epithelial to mesenchymal transition (EMT; (Colas et al., 2012). During this process epithelial cells, which usually express E-cadherin, lose their apico-basal polarity and adhesive qualities and gain an increased motility and ability to remodel the stroma they are surrounded by. They also switch their cadherin expression, with an increase in $\mathrm{N}$-cadherin expression observed (O'Brien-Ball and Biddle, 2017). Collagen type I has been found to induce EMT in certain cell types including that of lung, breast and pancreatic carcinomas (Medici and Nawshad, 2010).

Another appropriate response, is that of the host immune system, a key aspect when investigating materials for tissue engineering (Naahidi et al., 2017). It is possible to predict major biocompatibility issues in terms of the host immune system in vitro 
using donor blood cells (Joubert et al., 2016). In this chapter, the suitability of collagen films extracted from the edible jellyfish, Stomolophus nomurai meleagris as a matrix support for mammalian cell culture was tested using human fibroblasts, endothelial cells and smooth muscle cells. Previously, all cell types have been shown to have a higher viability on jellyfish collagen when compared to tissue culture plastic over a 10-day period (Song et al., 2006).

\subsubsection{In vitro immunogenicity}

Immunogenic testing is ideally done within small animals such as rats and rabbits (Ghasemi and Dehpour, 2009). Scaffolds produced from various materials have been tested in order to investigate their ability to elicit an immune response. In the case of bovine and human osteochondral grafts, subcutaneous implantation into collagen sensitive mice has previously been carried out before conducting ELISPOT and ELISA assays. ELISPOT assays examine the cellular immune response measuring induction of IFN-Y, IL-2, IL-4 and IL-5, whilst ELISA assays measure humoral mediated immune response measuring $\operatorname{IgG} 1, \operatorname{IgG} 2 \mathrm{a}$, total $\operatorname{IgG}$ and $\operatorname{IgM}$ from blood samples (Kawalec-Carroll et al., 2006).

In the absence of an animal house at Swansea University, appropriate in vitro methods were sought for this project. Previous work with non-mulberry silk scaffolds were tested for their immunogenicity with the use of human dendritic cells being assessed for their maturation and cytokine release (Musson et al., 2015). However monocyte-derived dendritic cell activation is time-consuming and complicated. Previous work within the Thornton group at Swansea University has assessed the immunogenicity of biomaterials using whole blood samples before analysing for specific leukocyte and platelet activation markers using fluorescence activated cell sorting (FACS) and building a cytokine release profile from blood serum via ELISA assays (Radley et al., 2017). 


\subsubsection{In vitro immune surveillance}

Although the immune system plays a key role in limiting infection and responding to injury it may mean rejection of implanted scaffolds leading to problematic consequences (Boehler et al., 2011). Divided into innate and adaptive responses (Parkin and Cohen, 2001), the human immune system provides provision for an immediate host defence, with the innate immune system encompassing cells such as neutrophils, monocytes and macrophages, depicted in Figure 4.1, whereas the adaptive immune response is considered a more sophisticated antigen specific reaction that incorporates T-cells and B-cells (Parkin and Cohen, 2001). 
Immediate Innate

Immune Response
Induced Innate

Immune Response

\section{Adaptive Immune \\ Response}

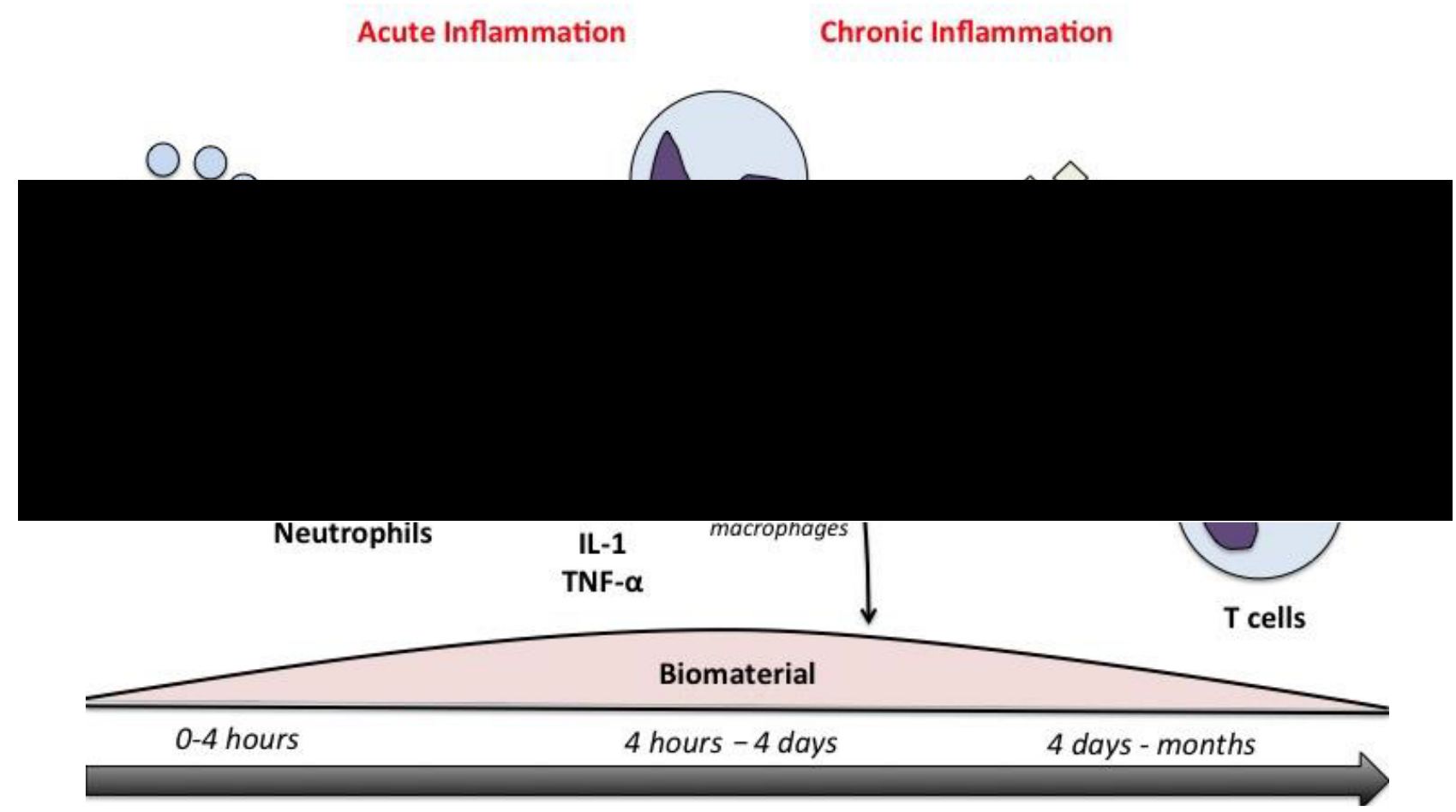

Figure 4.1: Host reponse to implanted biomaterials. A schematic detailing the immune response following the implantation of a biomaterial. Serum proteins adhere to the surface of the material and inflammatory cells such as neutrophils and macrophages are recruited to the site of injury. Mature macrophages also secrete proinflammatory cytokines to aid in acute and chronic inflammation. After a period of days, macrophages will begin the healing process by secreting anti-inflammatory cytokines. Within weeks to months the adaptive immune response is triggered through antigen recognition via $\mathrm{T}$ lymphocytes and $\mathrm{B}$ lymphocytes. The end stage of the immune response upon implantation either leads to resolution or the formation of a fibrotic capsule (Kim et al., 2016).

Upon the triggering of an immune response a characteristic cascade of events occurs. First, blood proteins adhere to the material before inflammation occurs (Anderson et al., 2008). Inflammation causes the recruitment of various cells including neutrophils and macrophages with the end result usually leading to fibrosis in the area of implantation (Jones, 2008). Fibrous encapsulation of the implanted material often leads to failure of the implant as in addition to the immune system effectively supplying protection against a foreign body it also isolates the material from surrounding tissue leading to issues with native tissue integration as well as access to nutrients for continued growth and development (Anderson et al., 2008). Whilst 
matrices produced from synthetic materials can be modulated so that they do not elicit an immune response this is often not the case with matrices fabricated with natural materials as they contain a higher degree of 'non self' signals (Nilsson et al., 2007). The extent of the immune response that is caused is dependent on a number of factors that include the degree of injury caused during implantation, the implantation location and the amount of provisional matrix that has been formed (Anderson et al., 2008).

\subsubsection{Collagen immunogenicity}

Collagen was once considered to be non-immunogenic however the increase in interest in its use as a biomaterial has uncovered some characteristic immunological behaviours, believed to be due to the presence of noncollagenous proteins and cell remnants after extraction (Lynn et al., 2004). Any immune response elicited by collagen is due in part to target epitopes that reside on the telopeptide region of tropocollagen molecules. The immune response can also be influenced by factors including the helical composition of collagen and the amino acids presented on the surface (Gorgieva and Kokol, 2011). These factors in turn lead to a variation in the immunological properties between polymerised collagen and its non-polymerised counterpart as the accessibility of the epitopes decreases upon polymerisation (Parenteau-Bareil et al., 2010).

\subsubsection{Chapter hypothesis}

The hypothesis for this chapter is that marine collagen is a biocompatible biomaterial that allows for cell adhesion, viable proliferation and consistent morphological stability, in both immortalised and primary cell cultures from a variety of mammalian sources. This hypothesis is tested, in the first instance, using a 2D smear of collagen on plastic culture media. Immortalised cell lines and primary cells are seeded onto these collagen surfaces and monitored over time for their cellular phenotypes linked to immunogenicity and functional phenotypes. Secondly, collagen isolated from $R$. pulmo is fabricated to sponge scaffold structure as shown in section 3.2.5.1 and subjected to in vitro immune analysis to define the in vitro immune 
response elicited by R.pulmo derived collagen, compared to current research and clinical grade collagen sources.

\subsubsection{Aims and objectives}

The aims and objective to test this hypothesis are as follows;

- Coat tissue culture plates with collagen isolated from R. pulmo (using methodology from Chapter 3), rat tail collagen, and gelatin.

- Assess a variety of secondary (human endometrial cancer cell lines) cells for adhesion, viability and proliferation rate over a 96 hour period, benchmarking jellyfish derived collagen against the research and clinical grade alternatives.

- Using light microscopy and ImageJ, assess cell type specific shape changes indicative of morphological differentiation over a 96 hour period.

- Conduct an in vitro assay for biocompatibility and immune response elicited by jellyfish derived collagen comparing to rat tail collagen, bovine collagen and bovine gelatin, using blood cells isolated from a healthy volunteer cohort and established platelet (CD42b) and leukocyte (CD62L, CD11b and fMLPr) cell activation markers as well cell death (DRAQ7).

- Analyse blood serum samples via ELISA to build a cytokine release profile.

\subsection{Results}

Collagen is used in both 2D cell culture and as a 3D scaffold for supported 3D culture methods, sometimes to simulate organotypic environments in in vitro culture (Duval et al., 2017). In addition, collagen is a suitable source of scaffolding material in regenerative medicine approaches such as cartilage, heart valves and treatment of corneal defects (Parenteau-Bareil et al., 2010).

Stated simply as 'the ability of a biomaterial to perform its function without eliciting local or systemic responses', the biocompatibility of jellyfish derived collagen was assessed here using multiple in vitro methods (Ratner, 2011). 2D culture (using smears of collagen immobilised on a standard plastic culture dish) were assessed 
initially, before using in vitro immune cell response model using healthy volunteers (13/WA/0190). A range of cellular subtypes were used to screen for biocompatibility, providing proof for proof of concept data aligned with applications markets agreed with Jellagen, UK.

\subsubsection{Collagen supported 2D culture}

Cells within the body exist within specific microenvironments, combined with collagen based matrix support mechanisms to underpin tissue architecture (Schindler et al., 2006).

In order to assess the suitability of jellyfish derived collagen for plastic culture vessel coating, to better simulate the supported microenvironment during cell culture, Corning plastic dishes were coated (overnight at $4^{\circ} \mathrm{C}$ ) with $30 \mathrm{ug} / \mathrm{ml}$ of sterile, extracted (using protocol outlined in section 2.3.5) collagen. The vessels were then washed and used for the culture of a series of mammalian cell types, for a total of 4 days, while monitoring cell viability, proliferation and morphology compared to a plastic only culture control. Research grade rat-tail collagen (RTCol) coated plates were used as a positive control and bovine gelatin (BGel) negative, as comparisons for jellyfish specific collagen ( $\mathrm{JCol})$. The experimental procedure used is shown in Figure 4.2. 


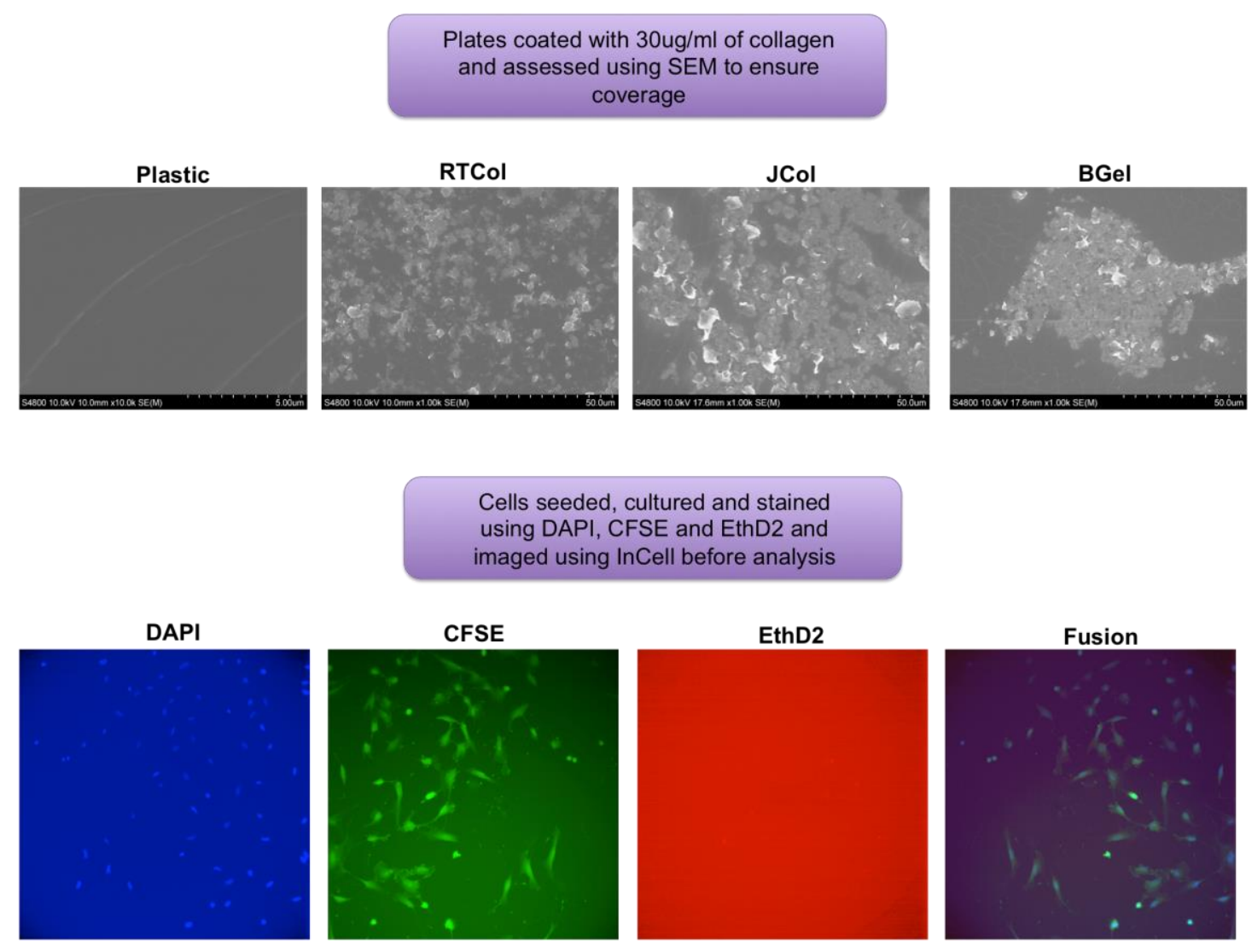

Analysis protocol was devised to create a mask and count stained areas of interest and create a table of values

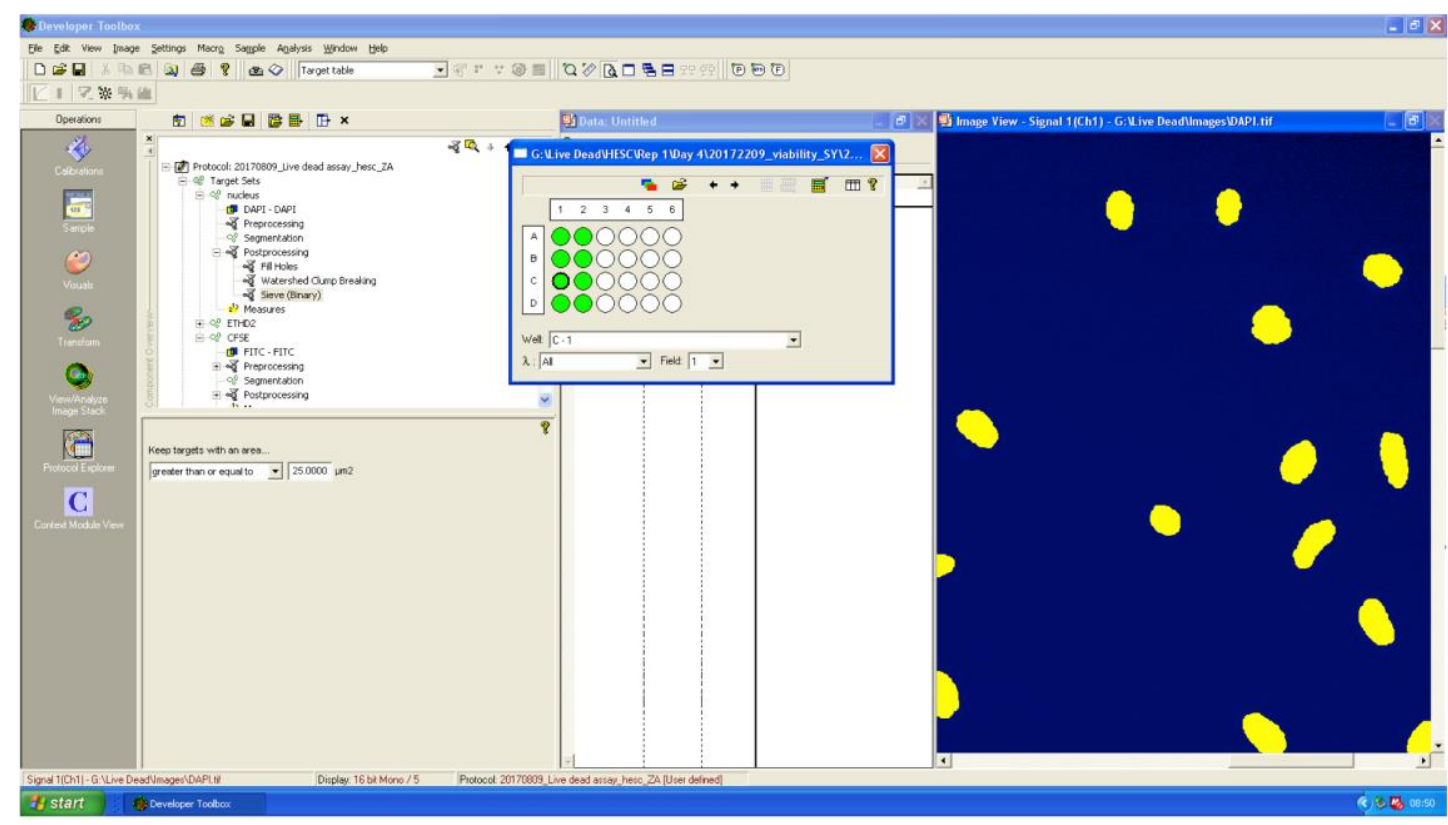

Figure 4.2: Experimental procedure to assess jellyfish collagen suitability for coated $2 \mathrm{D}$ culture. 


\subsubsection{Human endometrial stromal cell culture}

Human endometrial stromal cells (hESC) are essential in the process of human reproduction, undergoing decidualisation an endometrial differentiation process that prepares the tissue for human blastocyst implantation (Dunn et al., 2003). During decidualisation stromal cells undergo a MET process to provide support for the invading embryo (Zhang et al., 2013). In vitro experiments have shown that 3D culture of hESC cells is a closer physiological model to the in vivo environment than when cultured in 2D due to their response to hormone stimulation and withdrawal (Schutte and Taylor, 2012).

Human stromal cell lines (hESC) were cultured in the presence and absence of collagen sources to assess their proliferative capacity in vitro. Live/dead staining (CFSE/EthD2 ratio) was used to assess cellular viability over a 4 day period using In Cell microscopy (Ramirez et al., 2011). Cells were then counterstained with Hoescht in order to monitor cellular proliferation (Mozdziak et al., 2000). Representative images for hESC cells are shown in Figure 4.3, grown on RTCol, BGel and JCol compared to the plastic control.

\subsubsection{Cellular viability}

Live/dead staining showed the effect of collagen coating on hESC cell viability over the four day culture period compared to the plastic only control. In Cell microscopy images multiple fields of view (20-per well) of hESC cells cultured in a 24 well plate on day 1, 2, 3 and 4 of the 4 day culture period. Collated live/dead staining is shown in Figure 4.3, taken on day 2 of culture. 

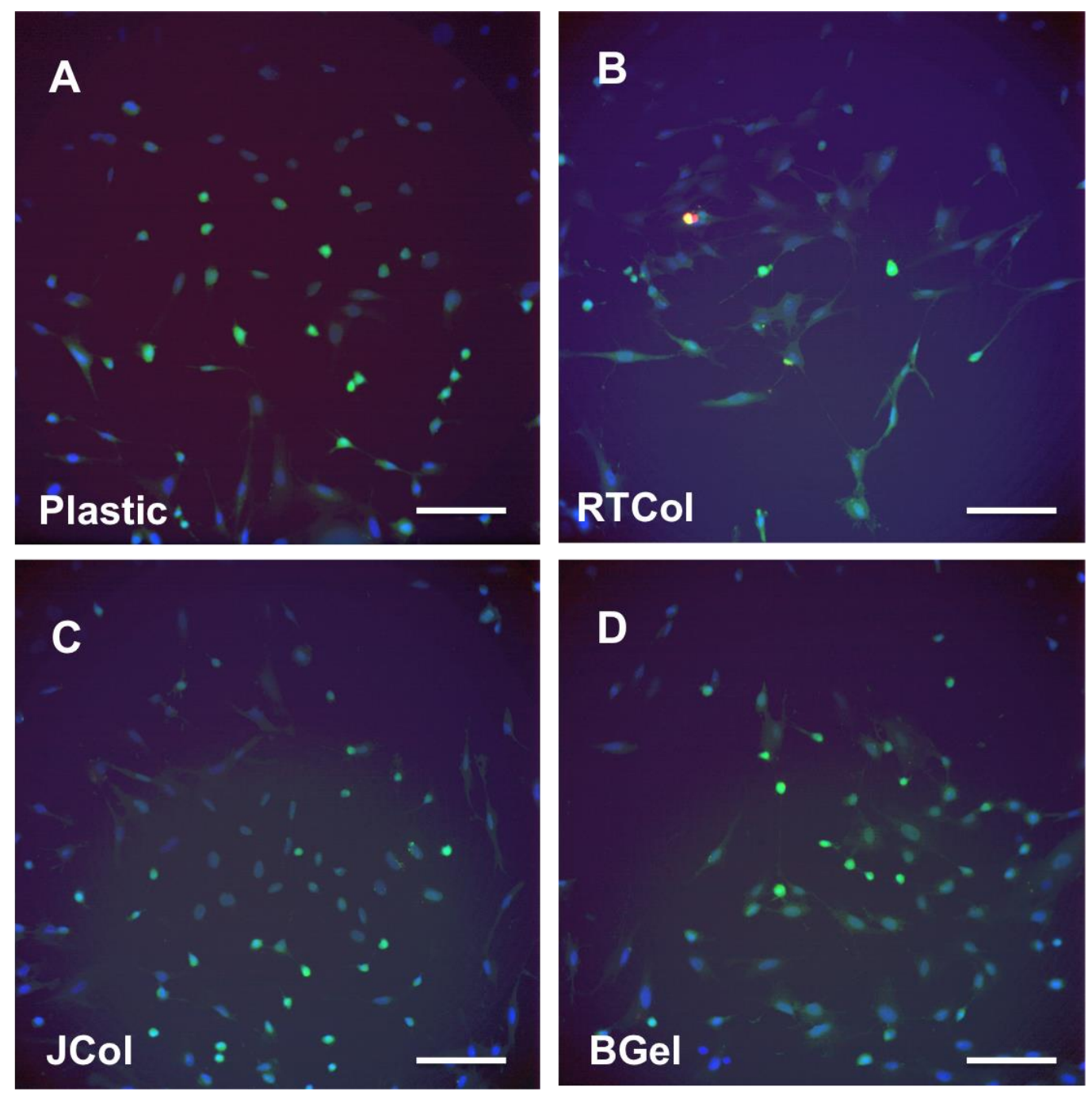

Figure 4.3: Live/dead staining of hESC cells. hESC cells cultured on plastic (A), RTCol (B), JCol (C) and BGel (D) were stained using hoescht, CFSE and EthD-2 and imaged using In Cell microscopy (x20 magnification) to assess viability over a period of 4 days. Individual cells were identified with hoescht nuclear stain (seen in blue). Live cells were identified by CFSE (depicted in green) whilst dead were shown by EthD-2 (depicted in red). Scale bars equal to $0.1 \mathrm{~mm}$. 


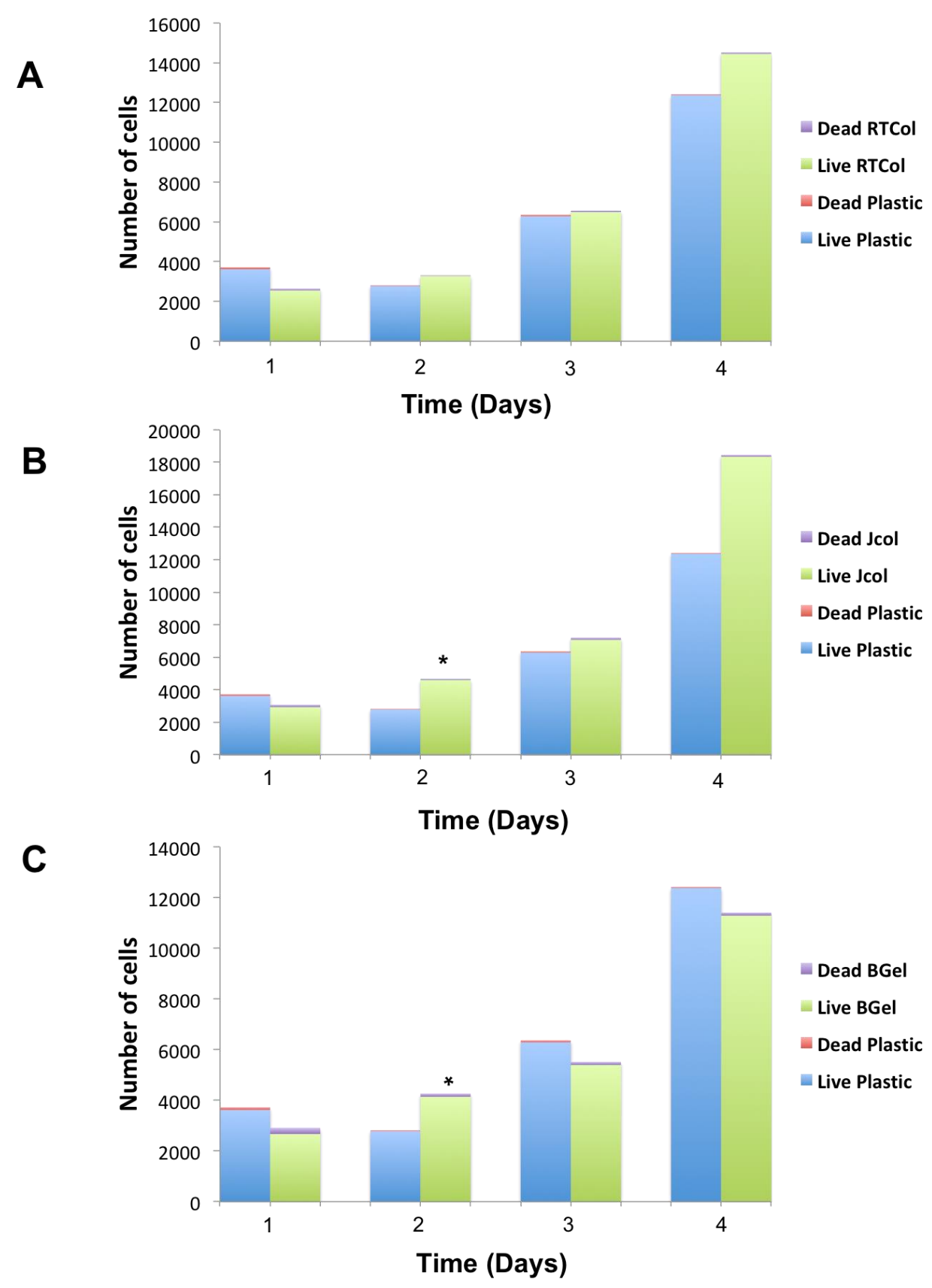

Figure 4.4 : hESC cell viability in coated culture vessels. hESC cells seeded onto RTCol, JCol and BGel coated culture dishes were compared to plastic only control. Direct comparison is shown between the plastic control and RTCol (B); JCol (C); BGel (D). All data shown is from a minimum of 3 independent biological repeats, statistical significance shown according to a Mann Whitney $U$ test $\left({ }^{*} p<0.05\right.$; $* * \mathrm{p}<0.01 ; * * * \mathrm{p}<0.001)$.

Figure 4.4 (A) shows the comparison of hESC cell viability when grown on plastic compared to RTCol coated plates over four days. A decrease in viable cell number was observed at day 2 on plastic, followed by increased viability on day 3 and 4; 2 
and 4 fold, respectively. RTCol cultured cells also exhibited increased viable cell number over each day of the culture period. On day 1 viable cells are higher in number on plastic compared to RTCol, 3,620 and 2,556, respectively, however on day 2, 3 and 4 RTCol cultured cells are increased compared to their plastic cultured counterparts. Dead cells for plastic and RTCol plates are similar in number and do not appear to increase during the culture period with cell numbers ranging from 103 to 41 dead cells on plastic and 89 to 74 dead cells on RTCol over the 4 days. Differences in viable and dead cells between both culture conditions were not proven to be significant on any day of culture.

A comparison to hESC grown on plastic and JCol is shown in Figure 4.4 (B). Viable cells on JCol show the same trend as those grown on RTCol with an increase in cell number over the 4 days. Day 1 viable cell number shows that plastic exhibits more viable cells than JCol however JCol boasts more viable cells than plastic over day 2, 3 and 4 with this difference being significant $(p=0.05)$ on day 2 with values of 2,781 and 4,597 viable cells for plastic and JCol, respectively. Despite JCol exhibiting 111 dead cells on day 4 of culture whilst plastic culture only showed 41 dead cells no significant difference was noted when comparing culture conditions.

Figure 4.4 (C) shows viability of cells grown on BGel compared to plastic. Viable cells grown on BGel follow the same trend as other materials where the number of cells increases over 4 days. Day 1 shows plastic exhibiting a higher number of viable cells than BGel however on day 2 BGel shows a significant increase in viable cell number compared to plastic $(\mathrm{p}=0.05)$. On day 3 and 4 plastic cells are increased in number compared to those grown on BGel. On day 4 of culture 41 cells were shown to be dead on plastic whilst BGel displayed 119 cells however no significant difference was seen on any day when comparing conditions.

\subsubsection{Cellular morphology}

Cell shape is a measurement of circularity, using imageJ standard algorithm, with a circularity of 1 being epithelial in nature and 0 being mesenchymal. Data shown in Figure 4.5 was used to assess the morphological differentiation of hESC cells over 
the chosen culture period. Standard light microscopy (Zeiss) was used in order to monitor hESC cell shape and morphology during the culture period (days 1, 2, 3 and 4) of the 4 day culture period. Images taken at x10 magnification on an inverted light microscope were used, shown in Figure 4.5, with cell boundaries defined using imageJ. A minimum of 30 cells were identified from a minimum of 3 independent biological repeats and used to collate cell shape data.
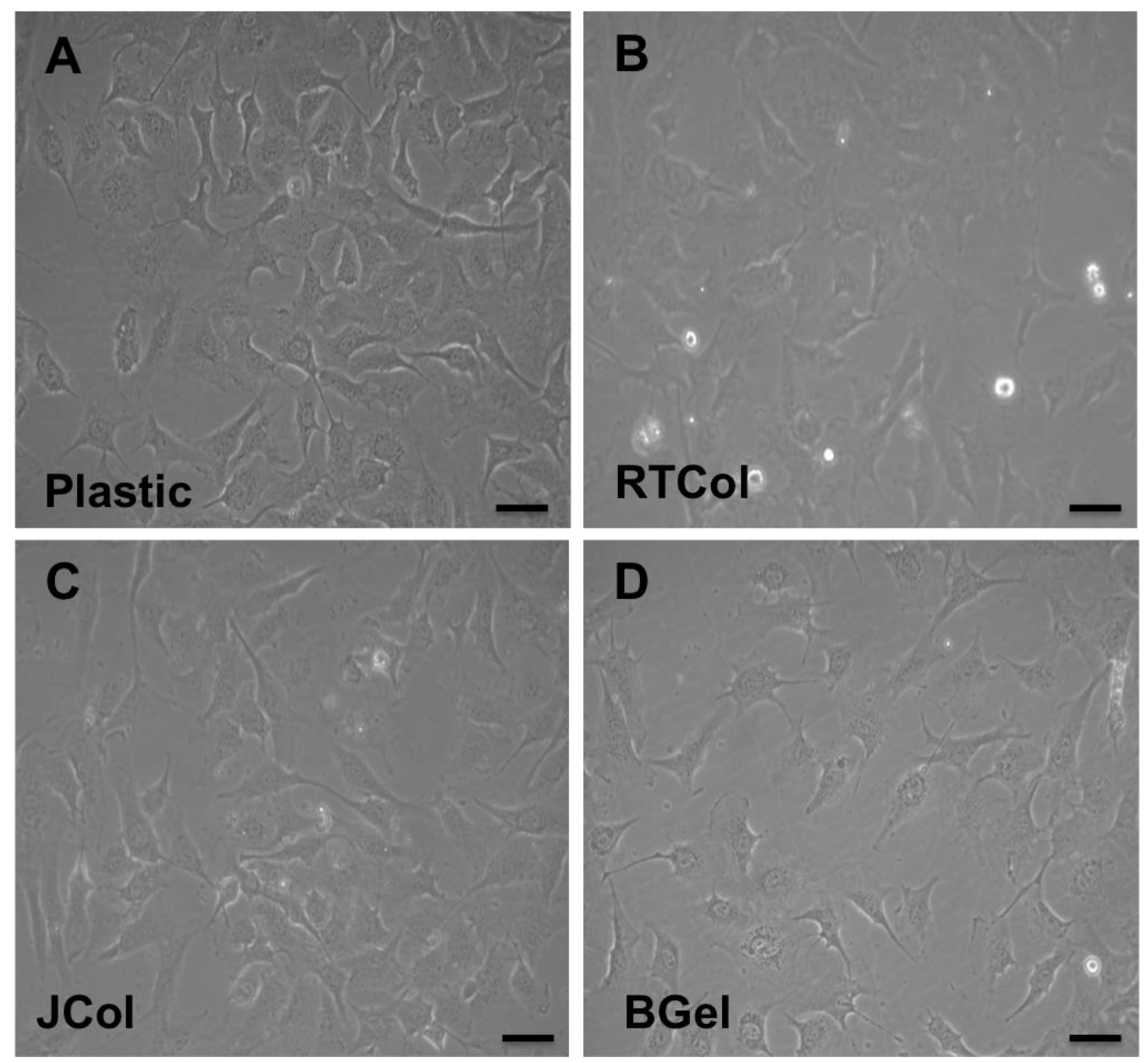

Figure 4.5: hESC cell morphology. hESC cells grown on plastic (A), RTCol (B), JCol (C) and BGel (D) were imaged with a light microscope (x10 magnification) over a 4 day culture period to assess any changed in morphology. Scale bars equal to $0.1 \mathrm{~mm}$. 
A

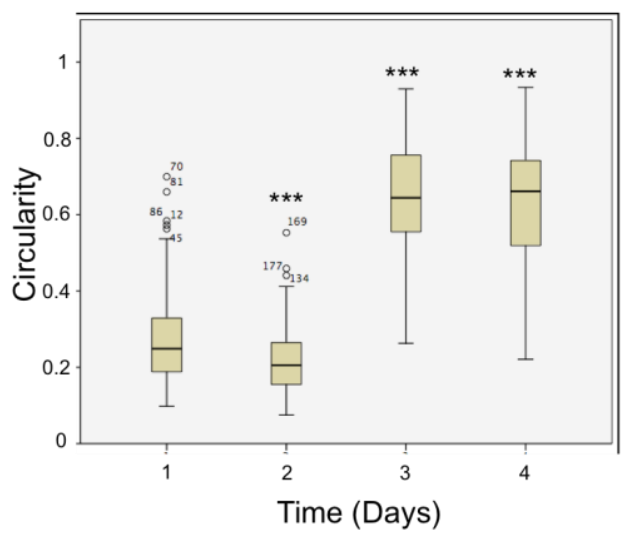

C

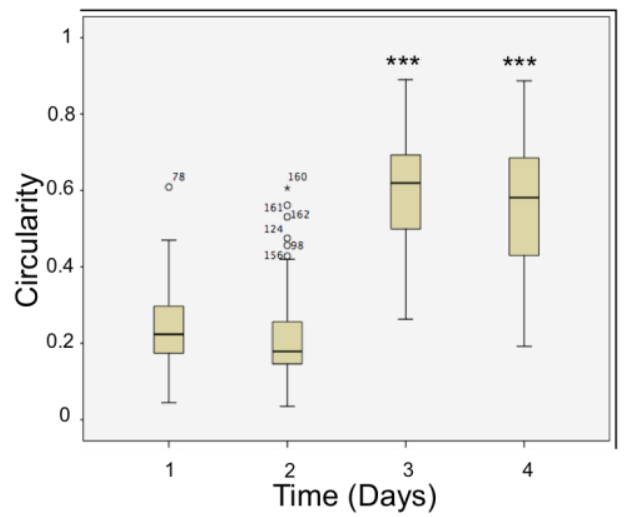

B

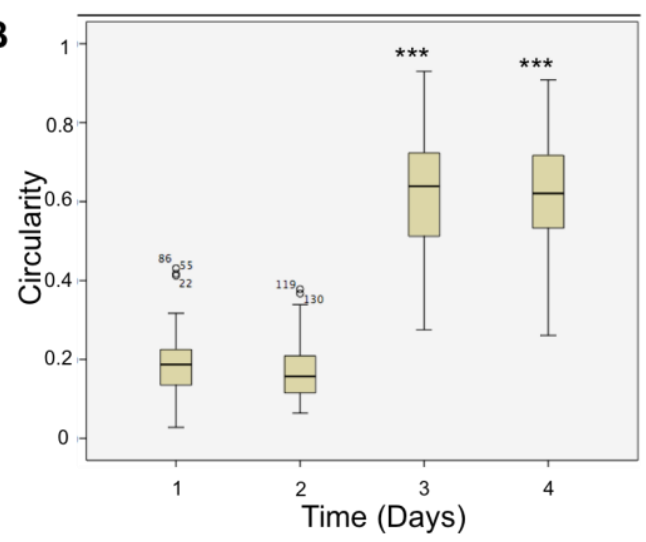

D

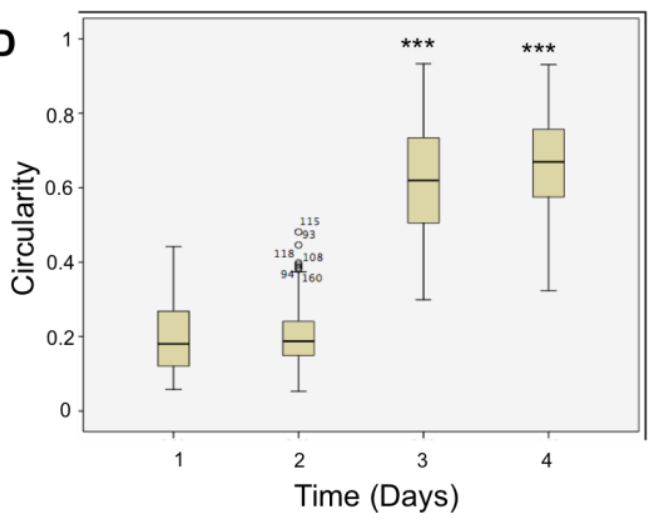

Figure 4.6 : hESC cell circularity in coated culture vessels. hESC cells seeded onto plastic (B), RTCol (C), JCol (D) and BGel (E) coated culture dishes. All data shown is the media $+/-\min / \max$ from a minimum of 3 independent biological repeats, statistical significance is shown according to Mann Whitney $U$ test $(* \mathrm{p}<0.05 ; * * \mathrm{p}<0.01 ; * * * \mathrm{p}<0.001)$.

Figure 4.6 (A) shows the circularity of hESC cells seeded onto plastic culture dishes over a 4 day culture period. On day $1 \mathrm{hESC}$ cells exhibit an average circularity value of 0.27 that decreases significantly $(\mathrm{p}=0.001)$ on day 2 to 0.22 . When comparing cell circularity on day 3 and day 4 to day 1, both days exhibited a higher cell circularity value, both $\mathrm{p}<0.001$, signifying a more circular cell morphology. hESC cells seeded on RTCol coated plates were assessed for their morphology, shown in Figure 4.6 (B). When compared to day 1 cells circularity decreases on day 2 however the difference is not seen as significant however on day 3 and 4 the circularity of hESC cells increases from 0.19 on day 1 to 0.62 on day 3 and day 4 ( $p<0.001$ in both cases). The same trend is seen for hESC cells grown on JCol coated plates, Figure 4.6 (C) where cell circularity increases significantly $(\mathrm{p}<0.001)$ on day 3 and day 4 when compared to day 1 rising from 0.23 to 0.63 and 0.57 , respectively. Figure 4.6 (D) shows circularity on cells cultured on BGel coated dishes. The same trend is 
observed as seen on RTCol and JCol coated plated. On day 1 a circularity value of 0.2 was observed for hESC cells grown on BGel. Cells assessed on day 3 were shown to exhibit an increased circularity value of $0.61(\mathrm{p}<0.001)$ when compared to day 1 and the same significant increase was also witness on day 4 with cells expressing an average value of $0.66(\mathrm{p}<0.001)$.

\subsubsection{Human endometrial epithelial cell culture}

Human endometrial epithelial cells (Ishikawa) are derived from Type I Endometrial cancer biopsies and are commonly used for the investigation of Endometrial Cancer (EC). Ishikawa cells cultured in the presence and absence of collagen sources were assessed for cellular viability, proliferation and morphology over a 4 day period using In Cell microscopy. Representative images are shown in Figure 4.7, grown on RTCol, BGel and JCol compared to the plastic control.

\subsubsection{Cellular viability}

Ishikawa cell viability was assessed over a 4 day period using live/dead staining after culture on collagen coated plates and compared to a plastic control. In Cell microscopy of Ishikawa cells cultured on 24 well plates were taken on each day of the 4 day period and data collated, shown in Figure 4.8, with representative images taken on day 2 of culture. 

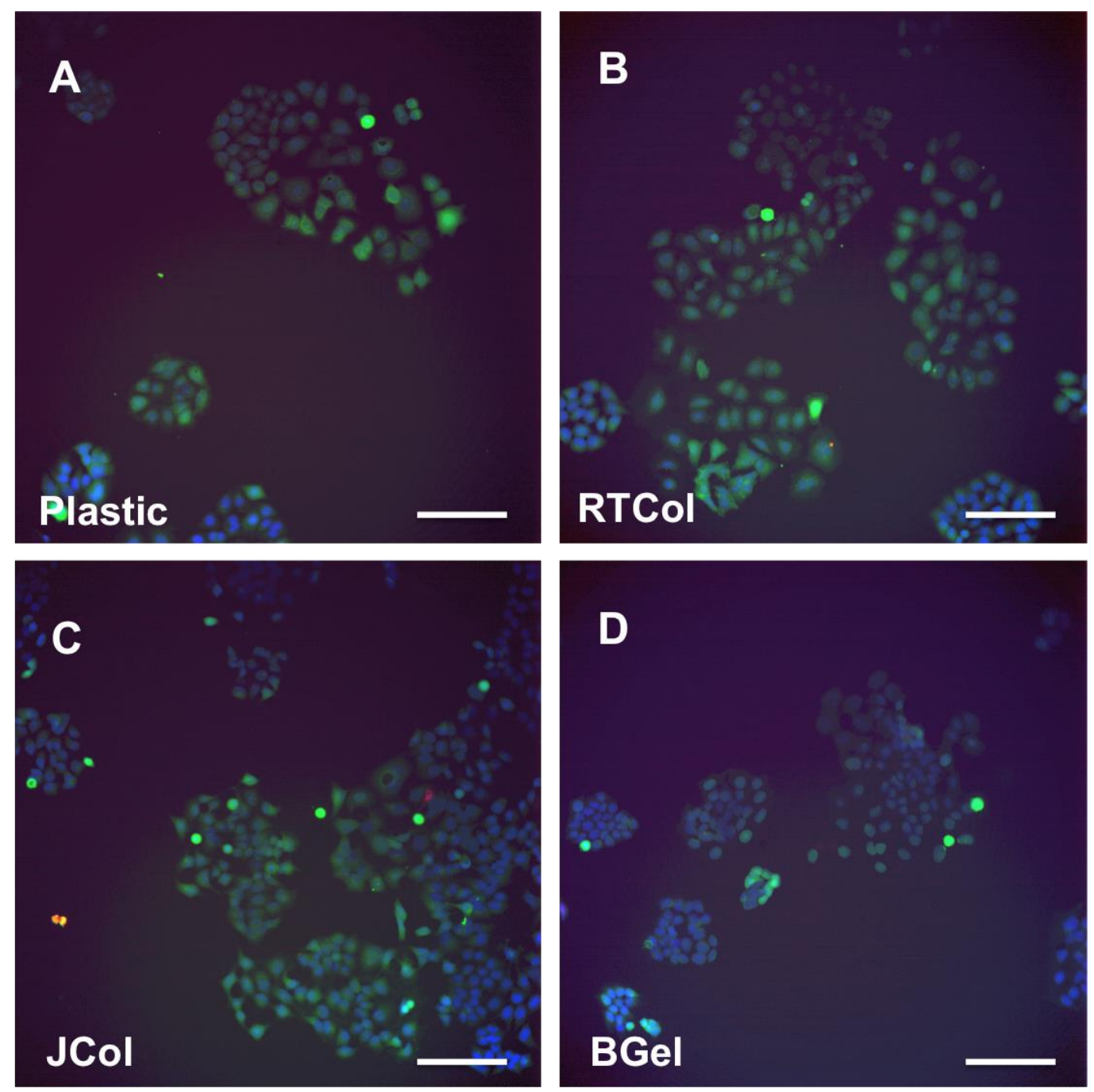

Figure 4.7: Live/dead staining of Ishikawa cells. Ishikawa cells cultured on plastic (A), RTCol (B), JCol (C) and BGel (D) were stained using hoescht, CFSE and EthD2 and imaged using In Cell microscopy (x20 magnification) to assess viability over a period of 4 days. Individual cells were identified with hoescht nuclear stain (seen in blue). Live cells were identified by CFSE (depicted in green) whilst dead were shown by EthD-2 (depicted in red). Scale bars equal to $0.1 \mathrm{~mm}$. 


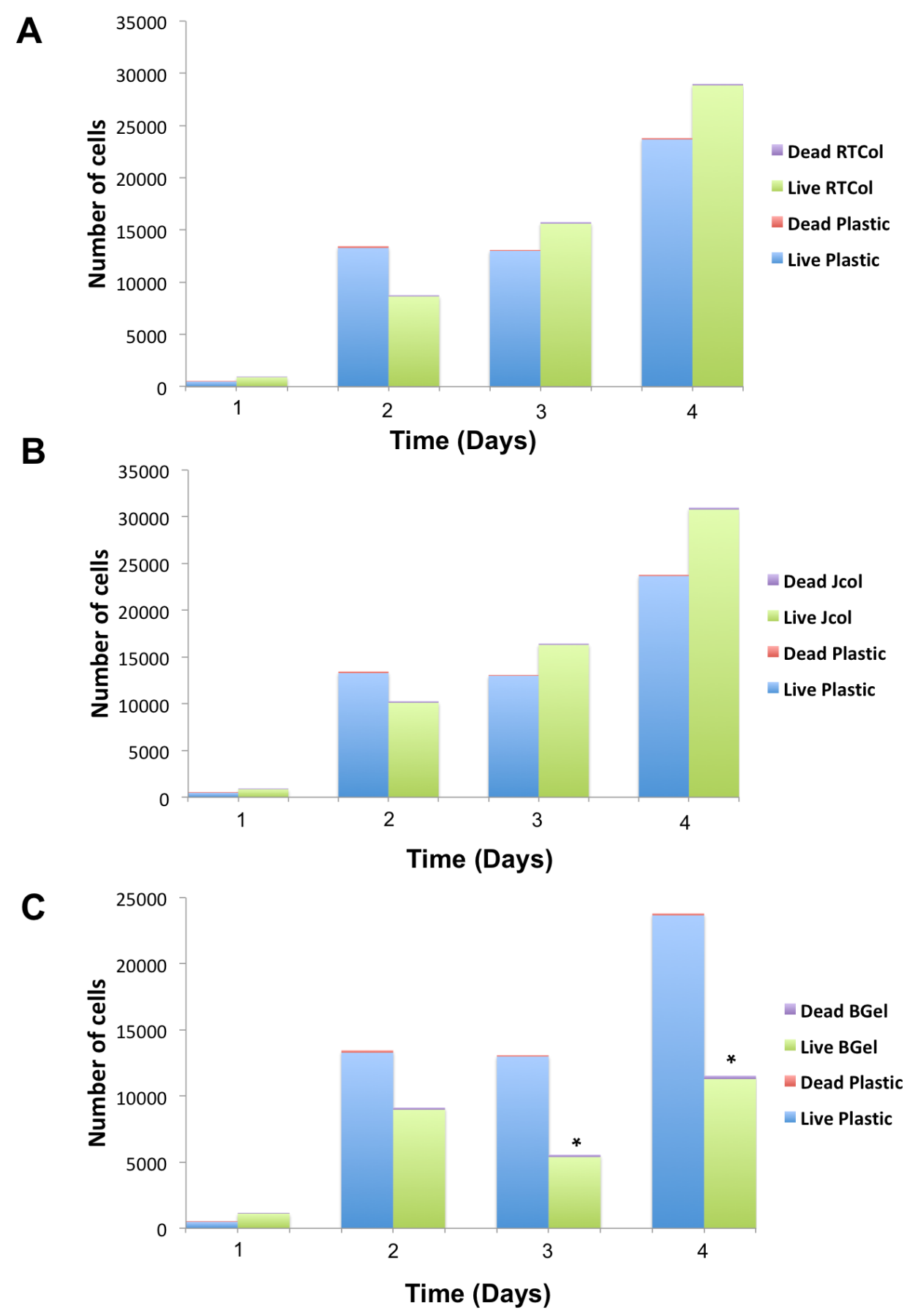

Figure 4.8 : Ishikawa cell viability in coated culture vessels. Ishikawa cells seeded onto RTCol, JCol and BGel coated culture dishes were compared to plastic only control. Direct comparison is shown between the plastic control and RTCol (B); JCol (C); BGel (D). All data shown is from a minimum of 3 independent biological repeats, statistical significance shown according to a Mann Whitney $U$ test $\left({ }^{*} \mathrm{p}<0.05\right.$; $* * \mathrm{p}<0.01 ; * * * \mathrm{p}<0.001)$

Representative images of Ishikawa cells taken by In Cell microscopy are shown in Figure 4.7. Figure 4.8 (A) shows a comparison of viability of Ishikawa cells on 
plastic and RTCol coated plates. Cells cultured under both conditions increased in number over 4 days. An increase in the number of plastic cultured viable cells was seen on day 2 when compared to RTCol at 13,280 and 8,642 cells, respectively, however on day 3 and 4 RTCol cultured cells outnumbered those grown on plastic. These differences were not shown to be statistically significant. The number of dead cells between both culture conditions was similar over the course of 4 days and did not exhibit any significant difference with both plastic and RTCol exhibiting 140 and 146 dead cells on day 4, respectively. Ishikawa cells grown on plastic were compared to cells grown on JCol to assess viability, shown in Figure 4.8 (B). The same trend in JCol is observed as seen in RTCol cultured cells with day 2 showing a lower number of viable cells when compared to plastic and day 3 and 4 showing an increased cell count. Count for Ishikawa cells stained for death remained similar across culture conditions over 4 days. Differences witnessed in cell viability between plastic and JCol cultured cells were not proved to be significant. Figure 4.8 (C) depicts comparison between BGel coated plates and plastic control. Viable cell count of Iskikawa cells grown on BGel is lower on day 2, 3 and 4 when compared to plastic cultured cells. Dead cells identified on BGel coated plates appeared to be significantly higher on day 3 at $173(\mathrm{p}=0.05)$ and day 4 at $258(\mathrm{p}=0.05)$ when compared to plastic at 98 and 140 on day 3 and day 4 , respectively.

\subsubsection{Cellular morphology}

Cell shapes of Ishikawa cells were monitored over the culture period using a standard light microscope. Images taken at x10 magnification, representative images seen in Figure 4.9, were assessed for their circularity, using ImageJ software. A minimum of 30 cells were assessed from 3 independent biological repeats and used to collate cell shape data, depicted in Figure 4.10. 

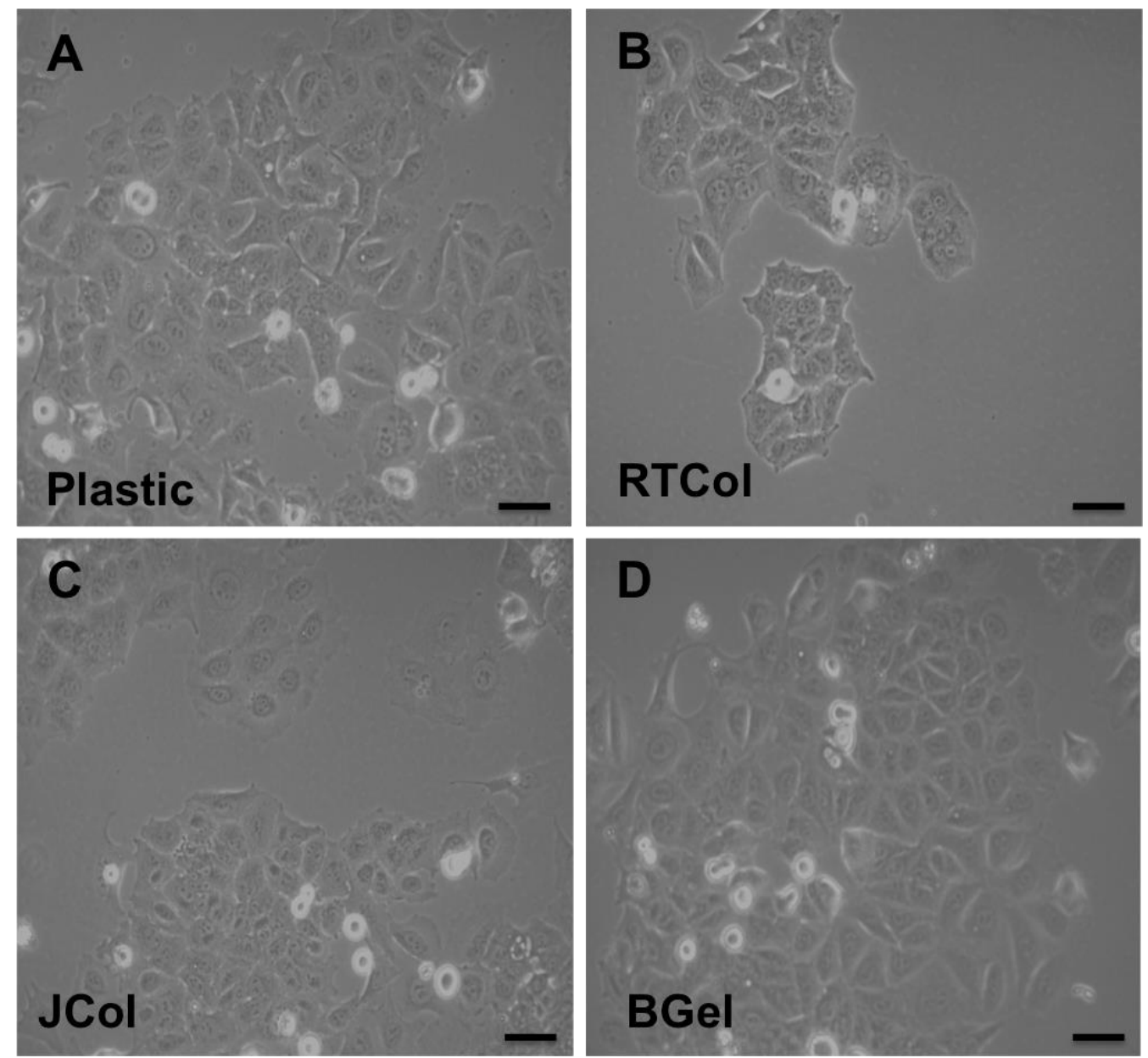

Figure 4.9: Ishikawa cell morphology. Ishikawa cells grown on plastic (A), RTCol (B), JCol (C) and BGel (D) were imaged with a light microscope (x10 magnification) over a 4 day culture period to assess any changed in morphology. Scale bars equal to $0.1 \mathrm{~mm}$. 

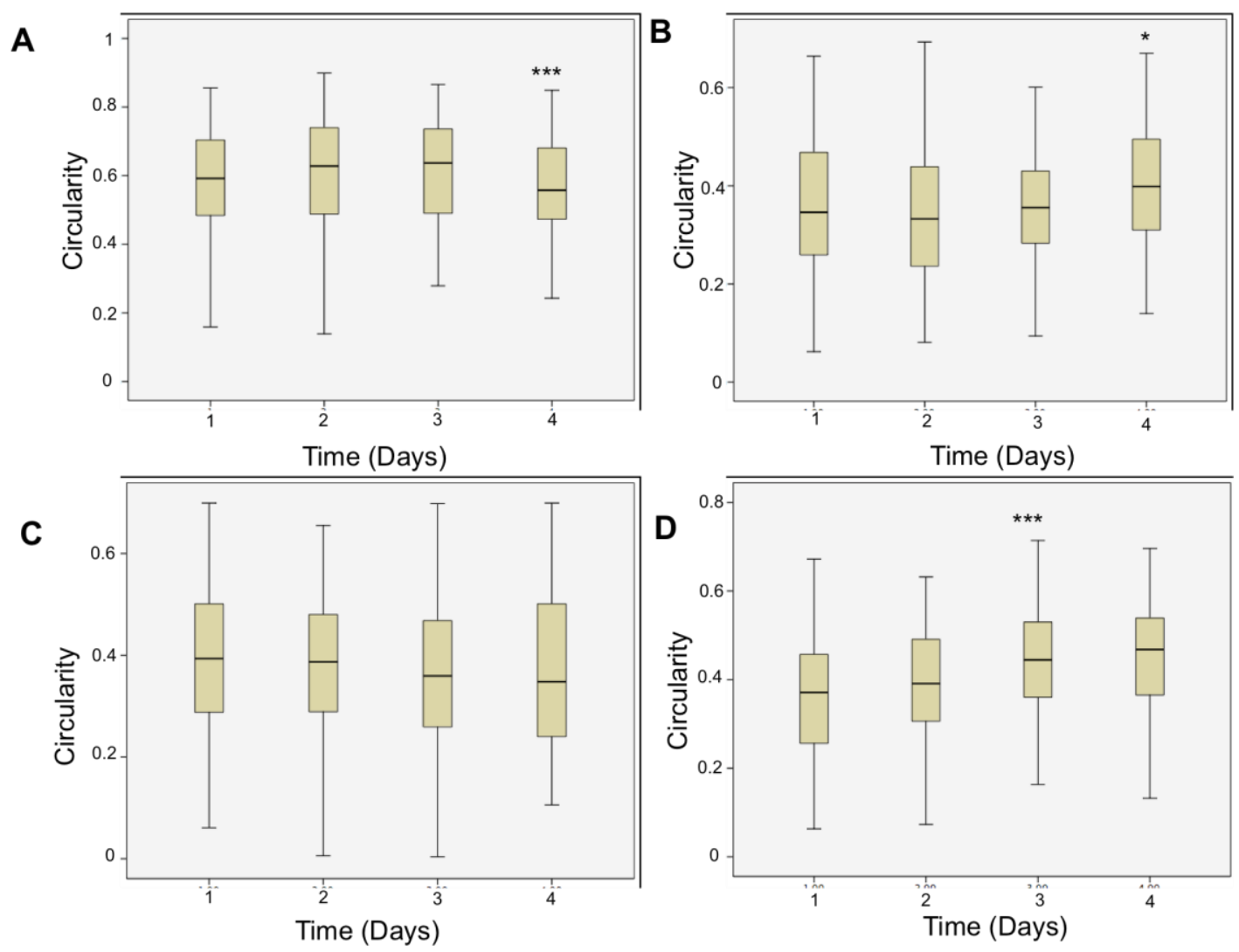

Figure 4.10 : Ishikawa cell circularity in coated culture vessels. Ishikawa cells seeded onto plastic (B), RTCol (C), JCol (D) and BGel (E) coated culture dishes. All data shown is the media $+/-\mathrm{min} / \mathrm{max}$ from a minimum of 3 independent biological repeats, statistical significance is shown according to Mann Whitney $U$ test $(* \mathrm{p}<0.05 ; * * \mathrm{p}<0.01 ; * * * \mathrm{p}<0.001)$.

Ishikawa cells cultured on plastic for four days were assessed for their circularity and data collated, shown in Figure 4.10 (A). Cells maintained a similar cell circularity value over day 1,2 and 3 with values of $0.59,0.61$ and 0.62 , respectively. Ishikawa cells on day 4 possessed a significantly lower $(\mathrm{p}=0.001)$ circularity value of 0.57 when compared to cells on day 1. Figure 4.10 (B) shows circularity values of cells cultured on RTCol. A slightly different trend is seen than when compared to cells grown on plastic. Day 1, 2 and 3 exhibit similar circularity values however cells on day 4 express a significantly higher $(\mathrm{p}=0.032)$ circularity value of 0.60 when compared to day 1 cells with circularity of 0.56. Figure 4.10 (C) shows the circularity of Ishikawa cells cultured on JCol coated plates over 4 days with no significant difference observed over the course of the culture period. Cells cultured on BGel, Figure 4.10 (D), expressed similar average cell values on day 1 and 2 at 
0.57 and 0.6, respectively. Day 3 cell circularity values were shown to be significantly higher $(\mathrm{p}=0.001)$ at 0.65 when compared to day 1 whilst day 4 cells also showed an increased value but was not seen to be significant in comparison to day 1 .

\subsubsection{Type II endometrial epithelial cell culture}

Type II EC is characterised by dedifferentiation of tissues (Yokomizo et al., 2017). This is observed in vitro by a heterogeneous, mixed population of cells exhibiting both epithelial and mesenchymal morphological features in HEC50 cells (RBGO, 2017, data not shown). In order to assess if this is a plastic culture vessel effect or indeed a cellular phenotype of type II cancer, HEC50 cells were cultured on plastic and compared to growth on RTCol, BGel and JCol respectively.

\subsubsection{Cellular viability}

Live/dead staining showed the effect of collagen coating on HEC50 cell viability over the 4 day culture period and compared to the plastic only control. In Cell microscopy images of 20 fields of view per well of HEC50 cells cultured in a 24 well plate on day 1, 2, 3 and 4 of the 4 day culture period. Collated live/dead staining, taken on day 2 of cultres, is shown in Figure 4.11. 

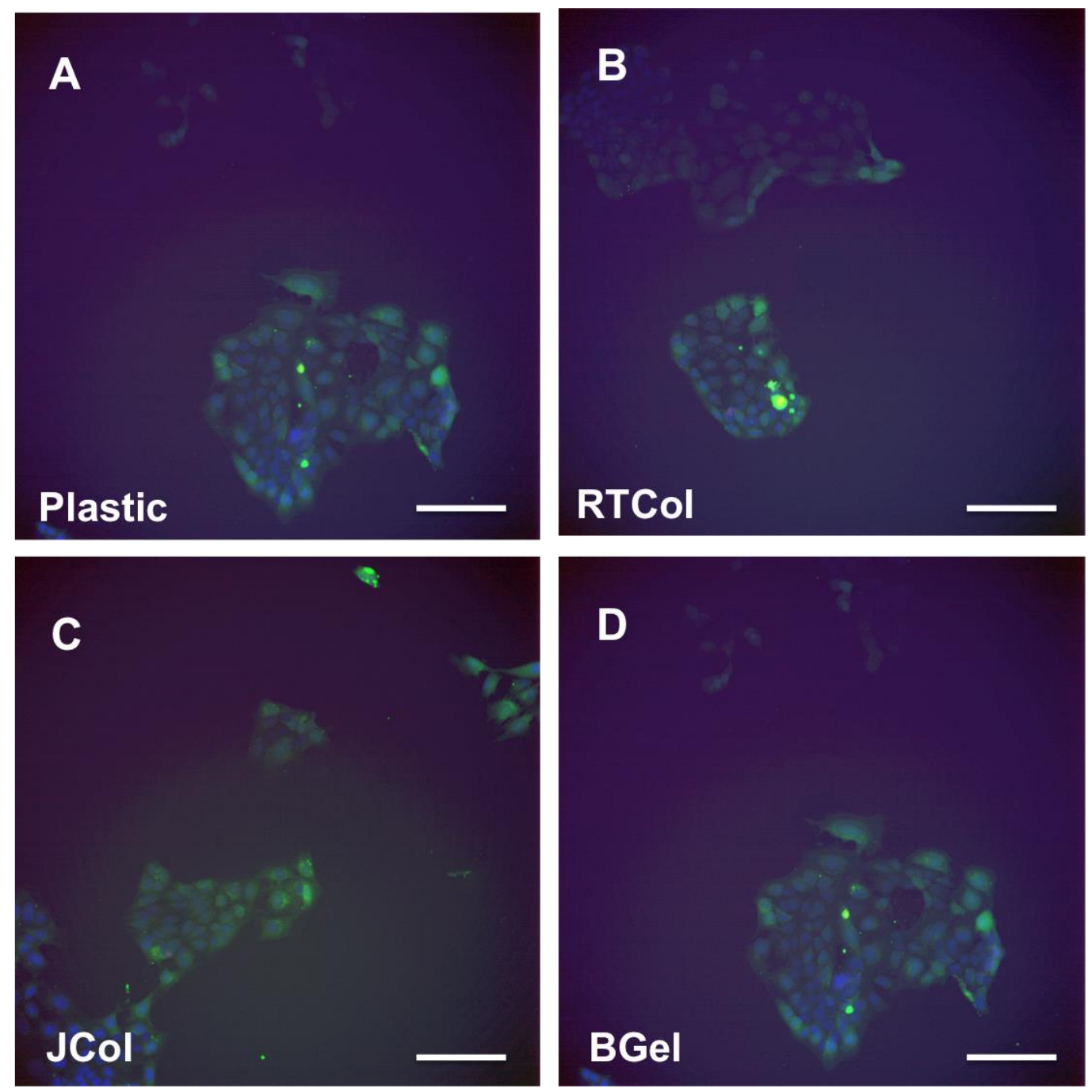

Figure 4.11: Live/dead staining of HEC50 cells. HEC50 cells cultured on plastic (A), RTCol (B), JCol (C) and BGel (D) were stained using hoescht, CFSE and EthD2 and imaged using In Cell microscopy (x20 magnification) to assess viability over a period of 4 days. Individual cells were identified with hoescht nuclear stain (seen in blue). Live cells were identified by CFSE (depicted in green) whilst dead were shown by EthD-2 (depicted in red). Scale bars equal to $0.1 \mathrm{~mm}$. 


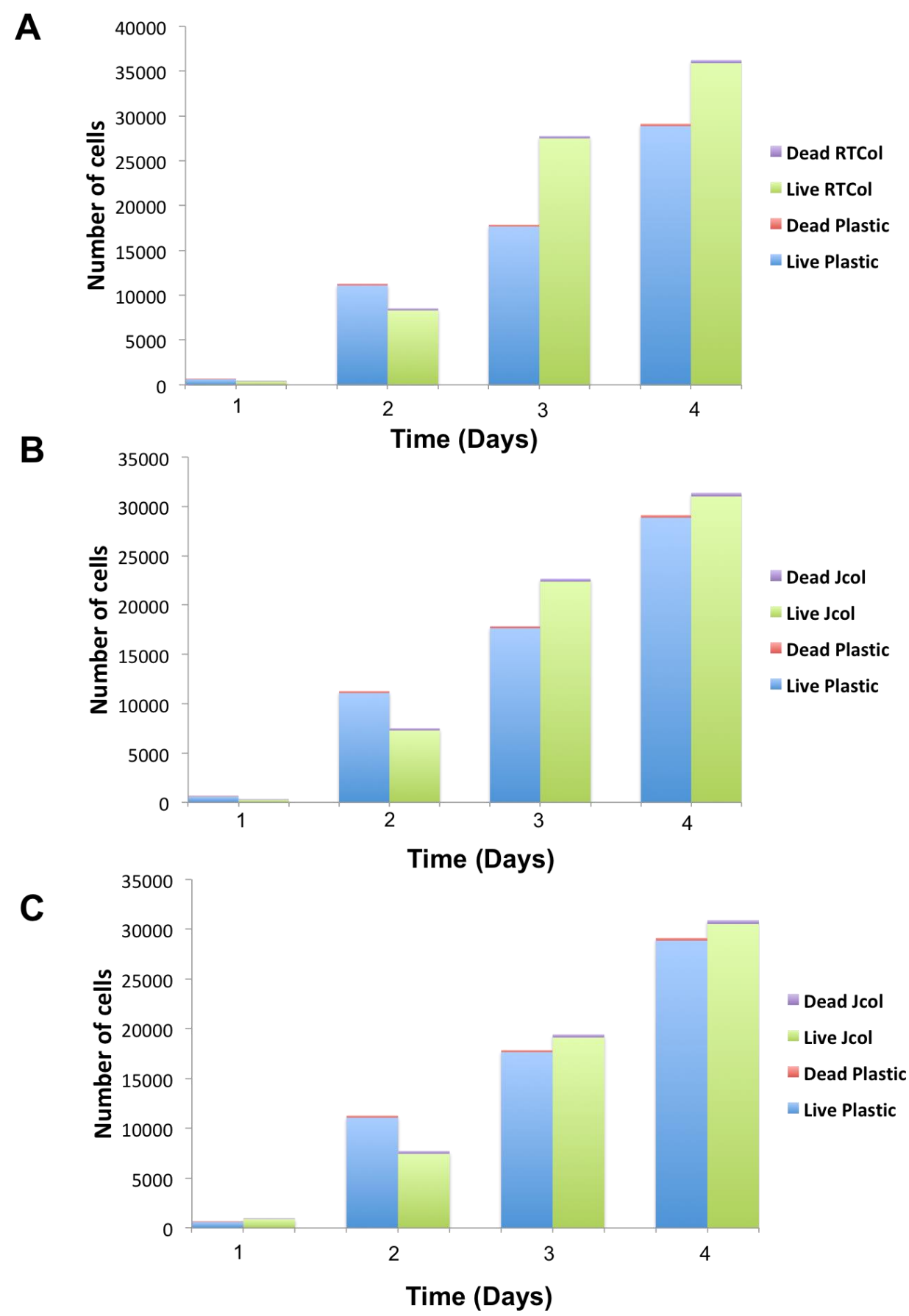

Figure 4.12 : HEC50 cell viability in coated culture vessel. HEC50 cells seeded onto RTCol, JCol and BGel coated culture dishes were compared to plastic only control. Direct comparison is shown between the plastic control and RTCol (B); JCol (C); BGel (D). All data shown is from a minimum of 3 independent biological repeats, statistical significance shown according to a Mann Whitney $U$ test $\left({ }^{*} \mathrm{p}<0.05\right.$; $* * \mathrm{p}<0.01 ; * * * \mathrm{p}<0.001)$

Representative images of HEC50 cells culture on different substrates are shown in Figure 4.11. Figure 4.12 (A) shows cells cultured on plastic compared to RTCol 
coated plates over 4 days. Both culture conditions show an increase in viable cell number over the culture period with number of cells higher in plastic on day 1 (622) and 2 (11082) compared to RTCol at 395 and 8297, repectively and viable cell count higher in RTCol coated plates on day 3 (27494) and 4 (35884) when compared to plastic at 17661 and 28860, respectively. Cells stained for death had similar values for both culture conditions and increased over the culture period. Figure 4.12 (B) compared plastic control to cells cultured on JCol and Figure 4.12 (C) to BGel coated plates. The same trend is seen whereby a higher number of viable cells are seen on day 1 and 2 on plastic culture compared to JCol and BGel and a lower number of viable cells is observed on day 3 and day 4 on plastic when compared to JCol and BGel. Dead cells were seen to higher in number by day 4 of culture JCol and BGel at 379 and 387 cells, respectively when compared to 272 cells when cultured on plastic alone. Despite the difference no statistical significance was observed.

\subsubsection{Cellular morphology}

Data shown in Figure 4.13 is used to assess the morphological differentiation of HEC50 cells over the chosen culture period. Light microscopy was used in order to monitor HEC50 cell shape and morphology during the culture period of the 4 days. Images, shown in Figure 4.13, taken through a x10 magnification objective mounted in an inverted light microscope and taken on day 2 of culture were used, and cell boundaries defined using ImageJ. A minimum of 30 cells were identified from a minimum of 3 independent biological repeats and used to collate cell shape data. 

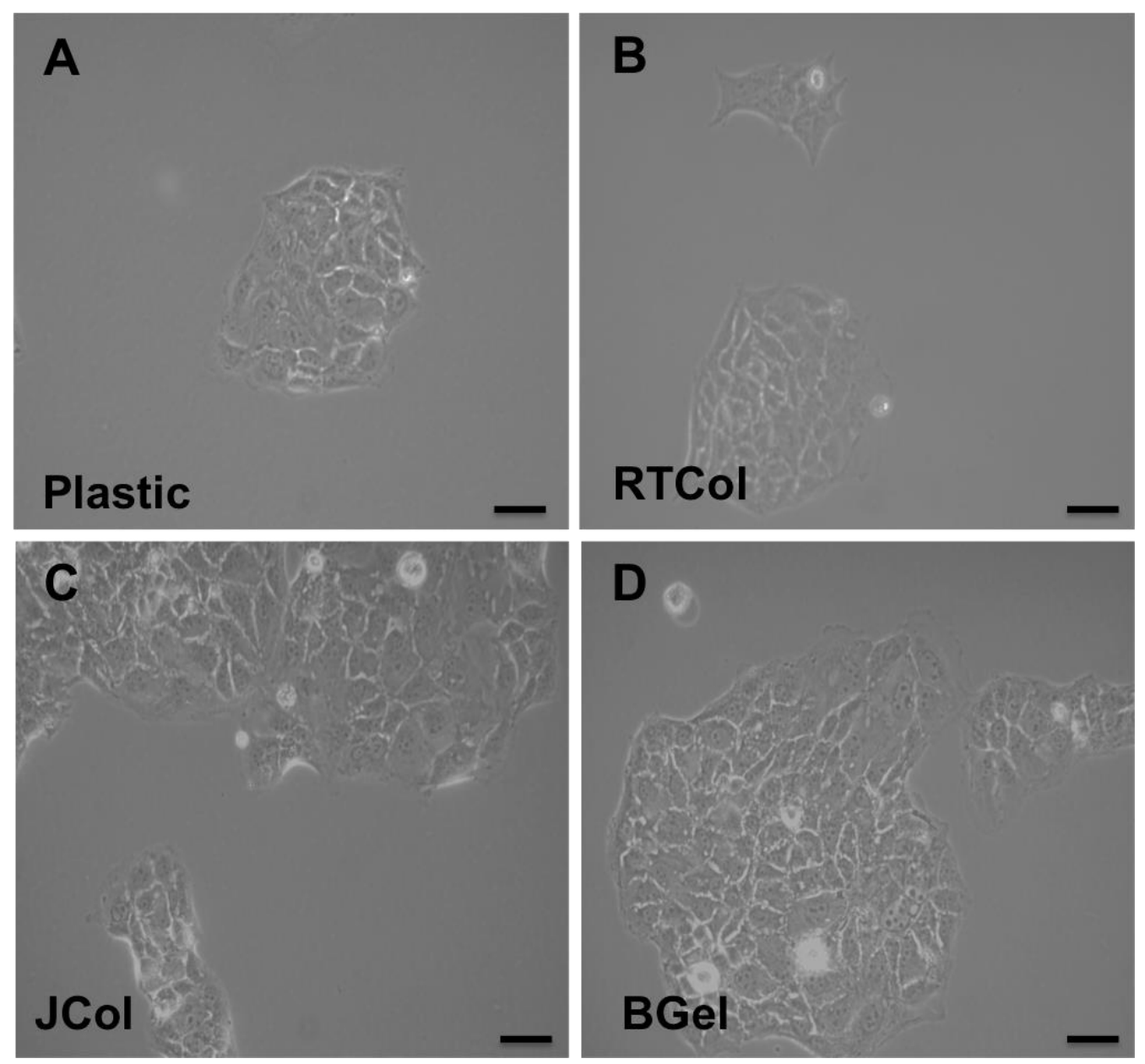

Figure 4.13: HEC50 cell morphology. HEC50 cells grown on plastic (A), RTCol (B), JCol (C) and BGel (D) were imaged with a light microscope (x10 magnification) over a 4 day culture period to assess any changed in morphology. Scale bars equal to $0.1 \mathrm{~mm}$. 

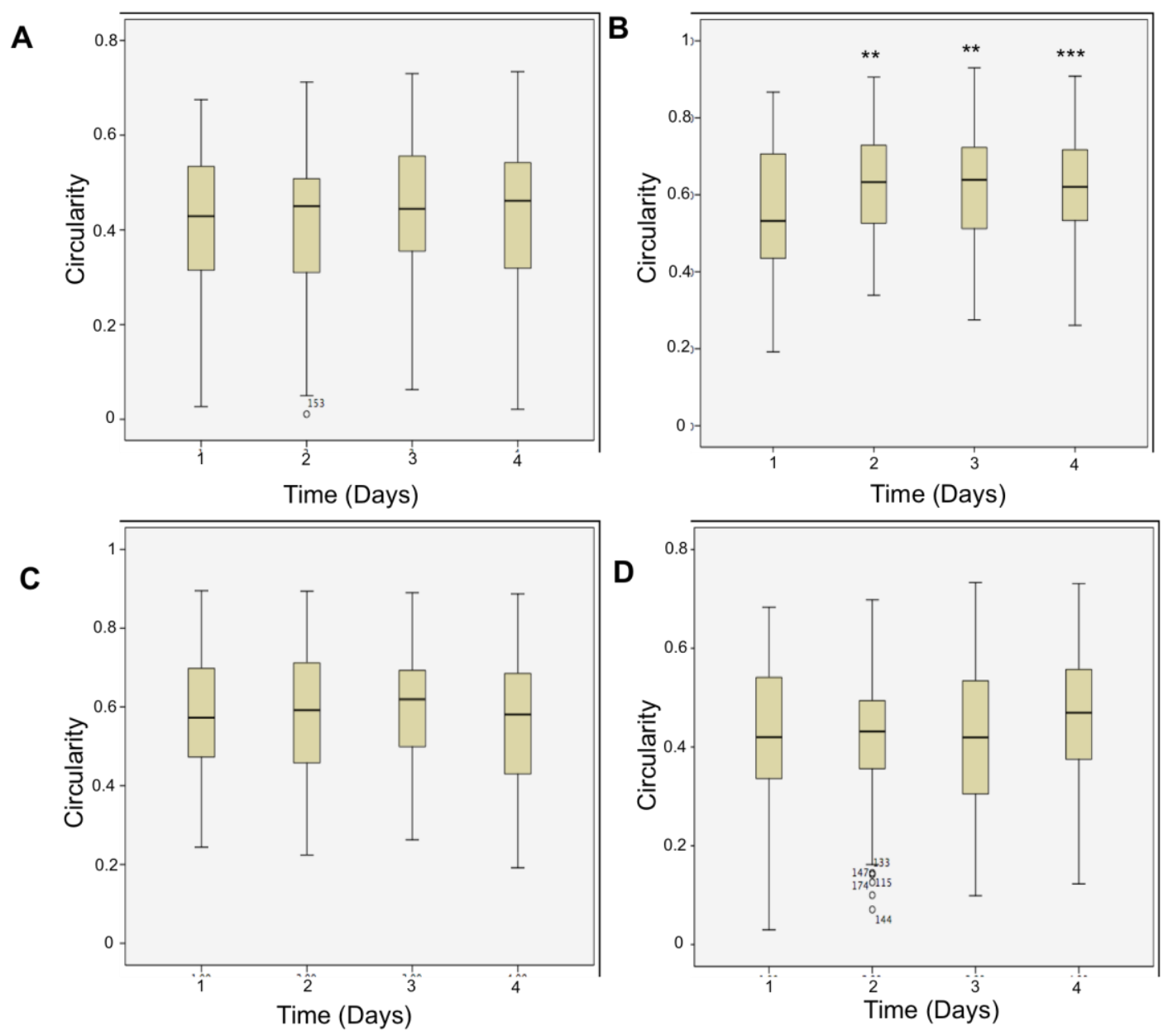

Figure 4.14 : HEC50 cell circularity in coated culture vessels. HEC50 cells seeded onto plastic (B), RTCol (C), JCol (D) and BGel (E) coated culture dishes. All data shown is the media $+/-\min / \max$ from a minimum of 3 independent biological repeats, statistical significance is shown according to Mann Whitney $U$ test $(* \mathrm{p}<0.05 ; * * \mathrm{p}<0.01 ; * * * \mathrm{p}<0.001)$.

Figure 4.14 (A) depicts circularity values for HEC50 cells culture upon plastic dishes for 4 days. Values of cell circularity on day 1,2 3 and 4 are similar with slight changes at $0.61,0.66,0.70$ and 0.68 , respectively, and show no significant difference when compared to day 1. HEC50 cells grown on RTCol, shown in Figure 4.14 (B), do not follow the same trend. Cells on day 1 exhibit an average circularity value of 0.55 but this value increases significantly on day 2 to 0.63 ( $\mathrm{p}=0.004)$, day 3 to 0.62 $(\mathrm{p}=0.004)$ and day 4 to $0.62(\mathrm{p}<0.001)$ when compared to day 1 . Figure 4.14 (C) shows cell circularity for HEC50 cells cultured on JCol showing no significant difference in circularity values over the 4 day culture period when compared to day 1 as the cells exhibit similar values at $0.58,0.58,0.60$ and 0.57 , respectively. The same 
trend is seen in cell cultured on BGel, shown in Figure 4.14 (D) where cells on day 1 express a circularity value of 0.62 and cells on day 2, 3 and 4 possess similar values of $0.62,0.61$ and 0.66 , respectively, and are not shown to be significantly different when compared to cells at day 1.

\subsubsection{Bovine chondroprogenitor cell culture}

Regenerative medicine approaches in cartilage repair, for prevalent diseases such as $\mathrm{OA}$, are based on the use of stem and progenitor cell populations as source for cell based repair mechanisms (Rohban and Pieber, 2017). Autologous repair mechanisms use in situ mesenchymal stem cell populations or tissue-specific chondroprogenitor cell populations, usually in the presence (MACI) or absence (ACI) of a collagen scaffold (Dunkin and Lattermann, 2013). Development of these strategies relies heavily on the availability and compatibility of collagen scaffold materials both as a scaffold for implantation and in culture to ensure the proliferation of progenitor cells to the required numbers needed for enhanced chondrogenesis or repair (Iwasa et al., 2009). It is essential that these cells be close to native form during expansion to maintain their chondrogenic potential (Khan et al., 2009).

Bovine chondroprogenitors are used to model stem cell therapies in OA repair strategies, to optimise proliferative and differentiation conditions in vitro, prior to potential implantation (Marcus et al., 2014). In order to assess the suitability of JCol in this process, bovine $\mathrm{CP}$ populations were extracted from MCP joints using an established differential fibronectin adhesion assay (Dowthwaite et al., 2004). Clonal expansion (to P4) preceded seeding onto plastic culture vessels coated with JCol. Once again, as a comparison RTCol and BGel were used as benchmarks for research and clinical grade collagen respectively. During early culture (a course of 4 days) the CPs were monitored for viability, proliferation and morphological transformation using InCell and light microscopy methods as outlined above (section 4.2.1.1). 


\subsubsection{Cellular viability}

The effect of collagen coating on bovine CPs cell viability was assessed using live/dead staining over a period of four days and compared to a plastic only control. In Cell microscopy images of 20 fields per well of CPs were taken on day 1, 2, 3 and 4 of the culture period. Figure $\mathbf{4 . 1 5}$ shows collated live/dead staining taken on day 2 .
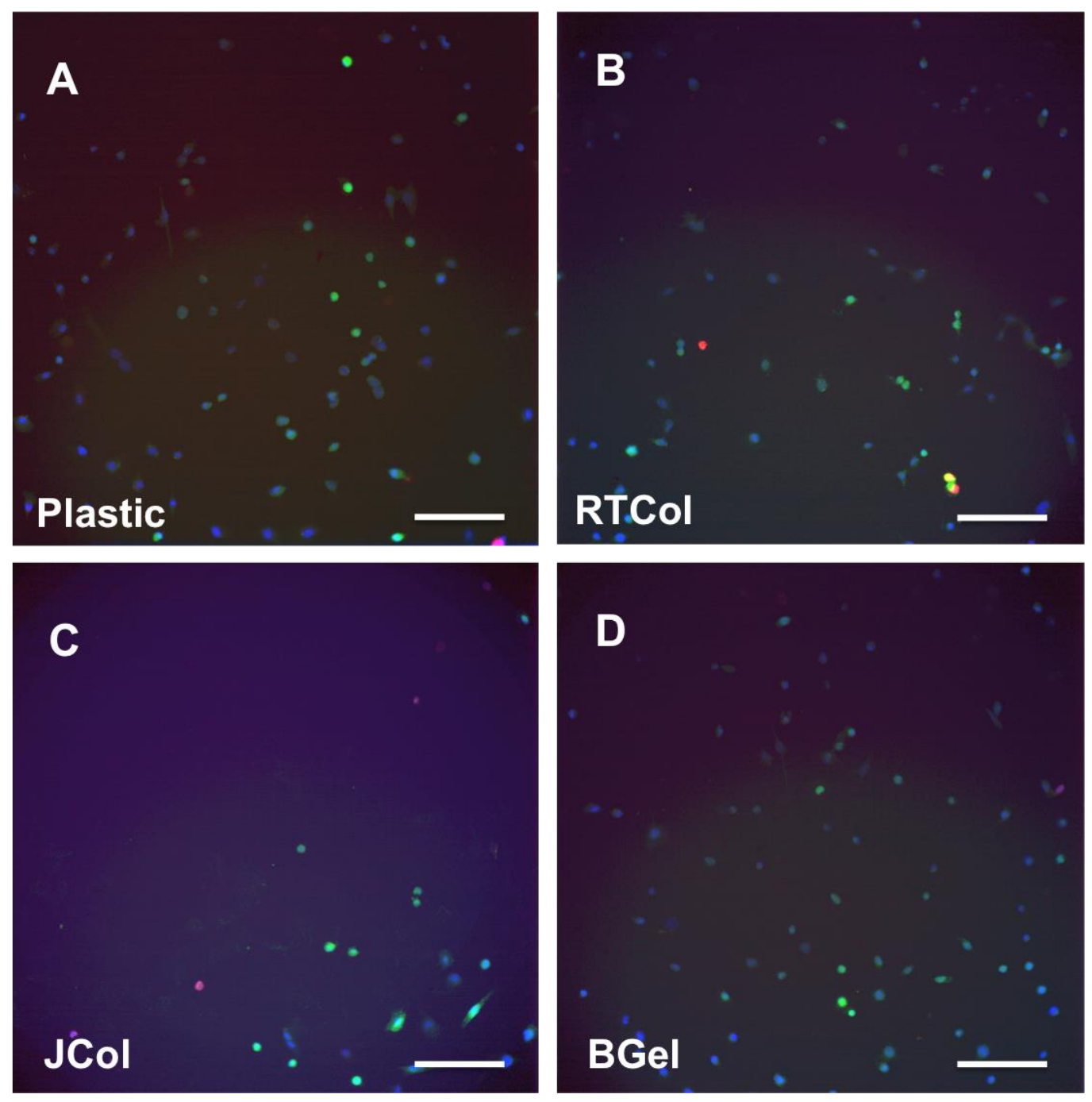

Figure 4.15: Live/dead staining of bovine $\mathrm{CP}$ cells. $\mathrm{CP}$ cells cultured on plastic (A), RTCol (B), JCol (C) and BGel (D) were stained using hoescht, CFSE and EthD2 and imaged using In Cell microscopy (x20 magnification) to assess viability over a period of 4 days. Individual cells were identified with hoescht nuclear stain (seen in blue). Live cells were identified by CFSE (depicted in green) whilst dead were shown by EthD-2 (depicted in red). Scale bars equal to $0.1 \mathrm{~mm}$. 


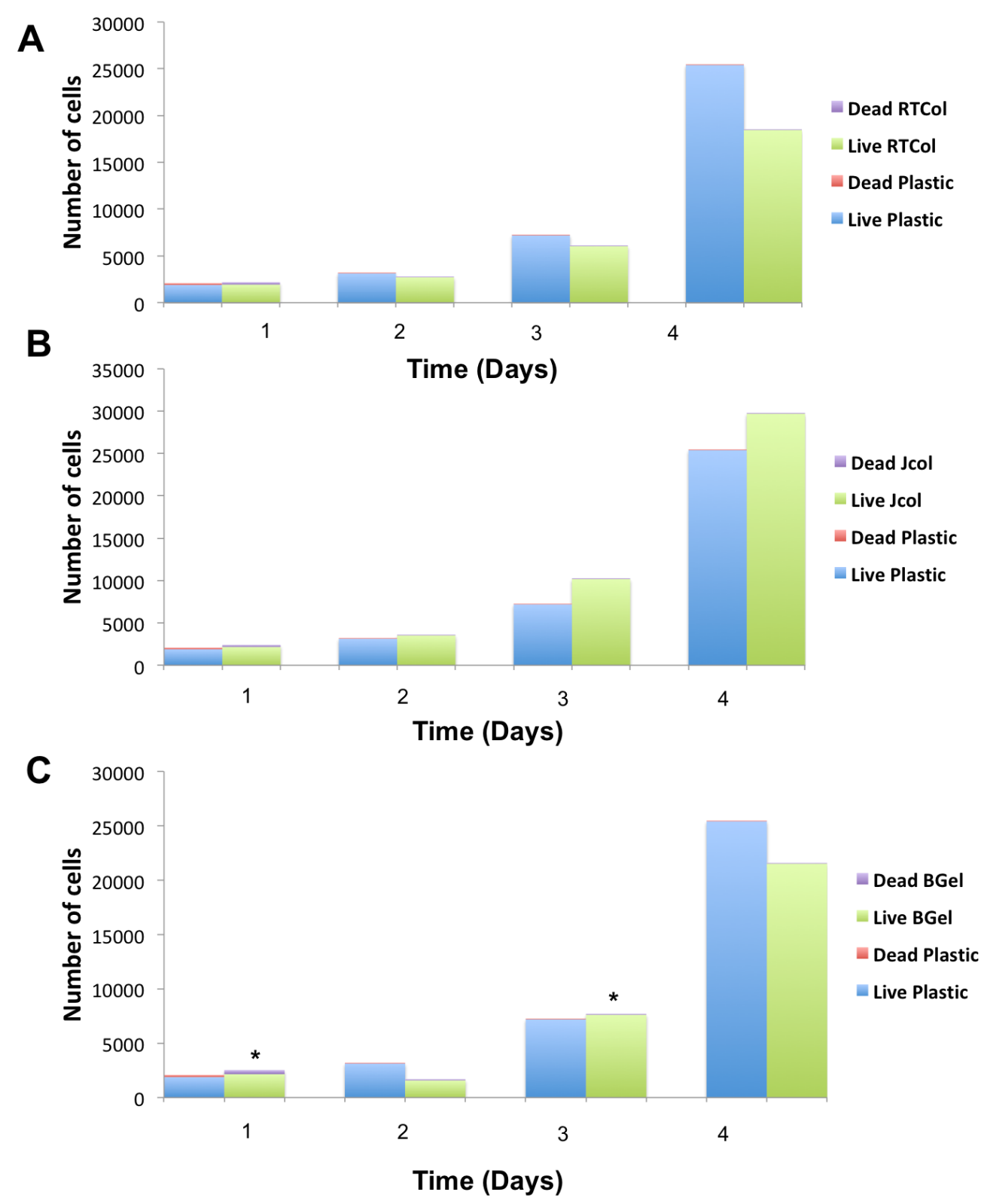

Figure 4.16 : Bovine $\mathrm{CP}$ cell viability in coated culture vessels. Bovine $\mathrm{CP}$ cells seeded onto RTCol, JCol and BGel coated culture dishes were compared to plastic only control. Direct comparison is shown between the plastic control and RTCol (B); $\mathrm{JCol}(\mathrm{C})$; BGel (D). All data shown is from a minimum of 3 independent biological repeats, statistical significance shown according to a Mann Whitney $U$ test ( ${ }^{*} p<0.05$; $* * \mathrm{p}<0.01 ; * * * \mathrm{p}<0.001)$.

Representative images, taken by InCell microscopy, and analysed for cell viability on plastic, RTCol, JCol and BGel coated plates are highlighted in Figure 4.15. Figure 4.16 (A) shows the comparison of cell viability of bovine CP cells when cultured on plastic and RTCol over a 4 day period. At day 1, live cell number is similar between both culture conditions. Both culture conditions show the same trend 
with an increased number of cells over four days however at day 2, 3 and 4, the number of viable cells grown on plastic is increased compared to those grown on RTCol with day 4 exhibiting a total of 25,406 viable cells on plastic and 18,456 on RTCol coated plated. Bovine CP cell death was similar when cultured on both plastic and RTCol at 41 and 35 on day 4 of culture, respectively. No significant differences were observed in the number of live or dead cells at each day under these culture conditions. Bovine CPs grown on plastic and JCol were compared for cell viability, shown in Figure 4.16 (B). The same trend is seen where the number of viable cells increases whilst the number of dead cells remain similar over 4 days. JCol appears to have an increased number of viable cells every day with a smaller difference observed when compared to plastic $(29,707$ and 25,406 on day 4 of culture, respectively) however these difference were not shown to be significant. A final comparison to plastic was made using BGel coated plated, indicated in Figure 4.16 (C). Viable cells grown on BGel coated plates did not see the same trend as plastic control, with a decrease in number seen on day 2 , from 2,158 to 1,581 , before increasing on day 3 and 4. No significant difference was observed in viable cells between plastic and BGel culture conditions. Similar values were observed for bovine CP cell death on day 2 and 4 however a significant level of cell death was witnessed on day 1 at 376 cells $(\mathrm{p}=0.05)$ and 3 at 85 cells $(\mathrm{p}=0.05)$ on BGel coated plates when compared to plastic.

\subsubsection{Cellular morphology}

Circularity of bovine CP cells were assessed over the course of 4 days. Data shown in Figure 4.17 were attained on day 2 of culture and morphology with light and cell boundaries defined using ImageJ. A minimum of 30 cells were identified from a minimum of 3 independent biological repeats and used to collate cell shape data. 

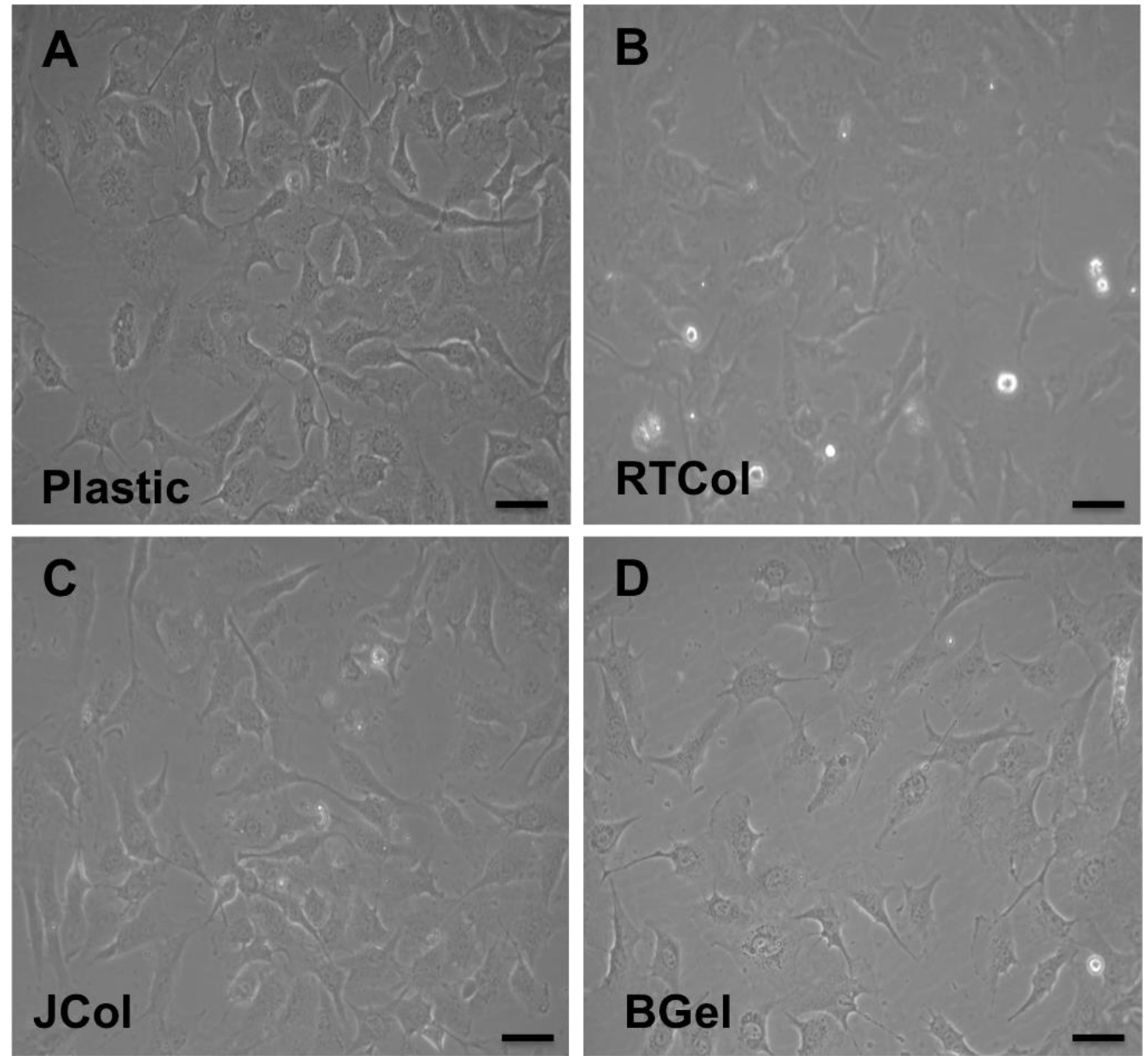

Figure 4.17: Bovine CP cell morphology. CP cells grown on plastic (A), RTCol (B), JCol (C) and BGel (D) were imaged with a light microscope (x10 magnification) over a 4 day culture period to assess any changed in morphology. Scale bars equal to $0.1 \mathrm{~mm}$. 

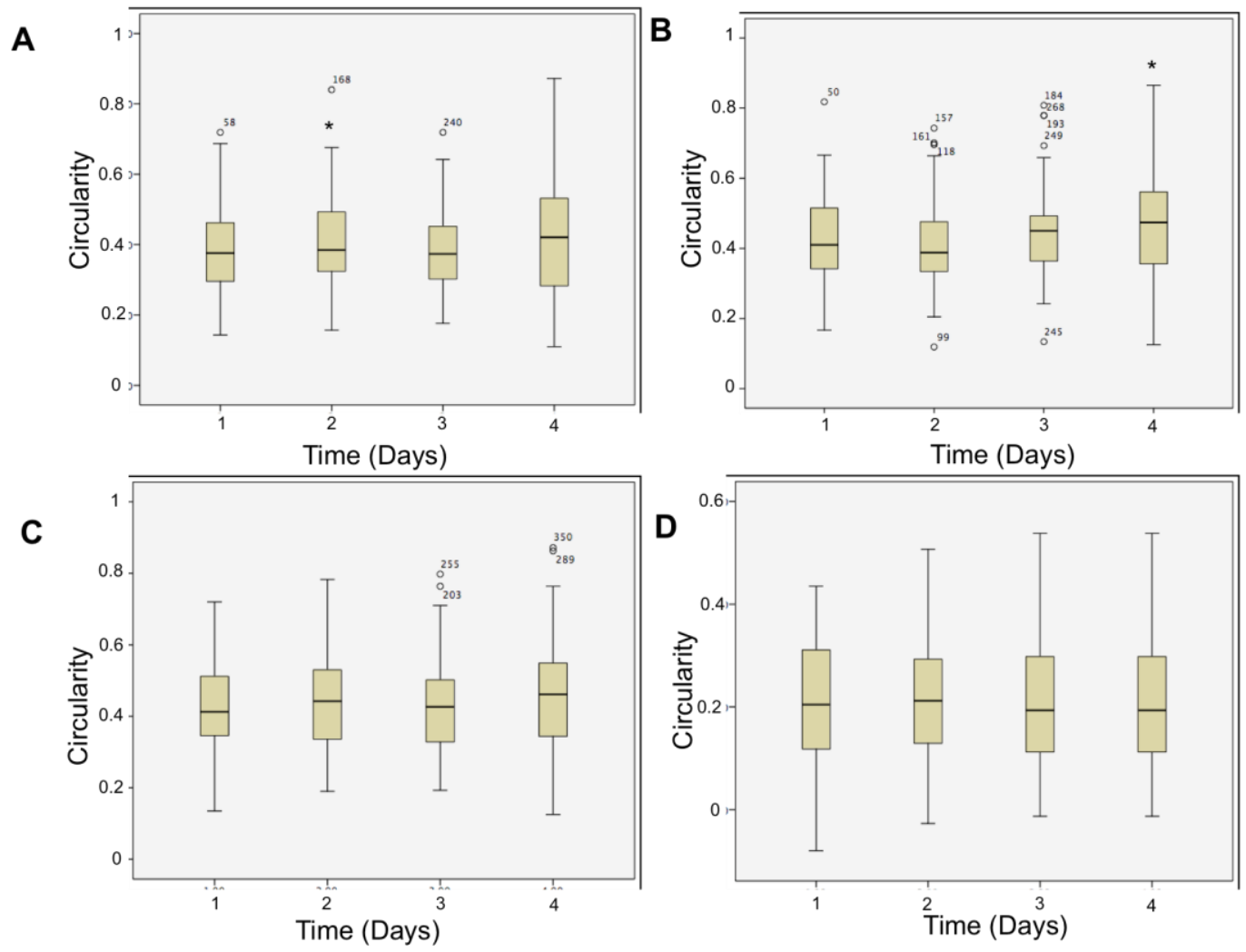

Figure 4.18 : Bovine CP cell circularity in coated culture vessels. Bovine $\mathrm{CP}$ cells seeded onto plastic (B), RTCol (C), JCol (D) and BGel (E) coated culture dishes. All data shown is the media $+/-\mathrm{min} / \mathrm{max}$ from a minimum of 3 independent biological repeats, statistical significance is shown according to Mann Whitney $U$ test $(* \mathrm{p}<0.05 ; * * \mathrm{p}<0.01 ; * * * \mathrm{p}<0.001)$.

Figure 4.18 (A) shows cell circularity of bovine CP cells cultured on plastic dishes over the course of 4 days. Cell circularity on day 1 of culture is 0.39 , which significantly increases on day $2(\mathrm{p}=0.032)$ to 0.4 . Circularity values on day 3 and 4 show no significant difference when compared to day 1 , showing bovine CPs maintain a similar morphology in plastic culture. Circularity of cells cultured on RTCol are shown in Figure 4.18 (B) and show differences from day 1, 2, 3 and 4 with circularity values observed at $0.42,0.41,0.49$ and 0.47 with only day 4 proven to be a significant increase in circularity $(\mathrm{p}=0.09)$ when compared to day 1 . Figure 4.18 (C) shows CPs cultured on JCol where no significant differences were observed between cells cultured over the course of 4 days. The same trend is seen in Figure 4.18 (D) where cells grown on BGel coated plates show no significant difference in cell circularity over the culture period when compared to day 1 of culture. 


\subsubsection{In vitro immunogenicity}

The immunogenic response elicited by the JCol scaffold moulded in Chapter 3 was assayed. In order to assess the effect of JCol on platelet activation, leukocyte activation and cell death, a series of CD markers were identified and used to gate platelet, neutrophil, monocytes and T-cells by cell number (CD42B, CD11B, FMLPR and DRAQ7) and/or median fluorescent intensity (CD62L) respectively. In each instance JCol scaffolds were compared to RTCol and bovine collagen (BCol) as research and clinical grade collagen sources, respectively, as well as BGel as a negative control (denatured collagen source).

EDC, used in Chapter 3, to control scaffold structural integrity and porosity has been shown to be toxic to cells at concentrations above $1 \%$ (Thoreson et al., 2015). In order to assess the effect of EDC concentration on platelet activation, leukocyte activation (using CD62L, CD11B, FMLPR) and cell death (DRAQ7), 0.25\%, 0.5\% and $1.0 \%$ EDC crosslinked scaffolds were assessed. Each collagen source was assessed at each concentration of EDC to ensure comprehensive screening and identify any potential issue with the crosslinker chosen.

\subsubsection{Platelet activation}

4 beta-phorbol-12-myristate-13-acetate (PMA), routinely used to induce platelet activation and subsequent shielding of CD42b in human donor models (Jerushalmy et al., 1988). In order to assess donor suitability for platelet activation, three donor blood samples were exposed to PMA (2 hours) and stained for CD42b (Figure 4.19). Panel A shows the scatter plot and resultant histogram from the control donor blood data while Panel B indicates the altered scatter graph and histogram in the presence of PMA. As a result of proprietary FACS analysis software (Kaluza, UK), this data is then collated to a scatter graph summarising the individual donor effect and median across donor cohort (Figure 4.19, Panel C). 

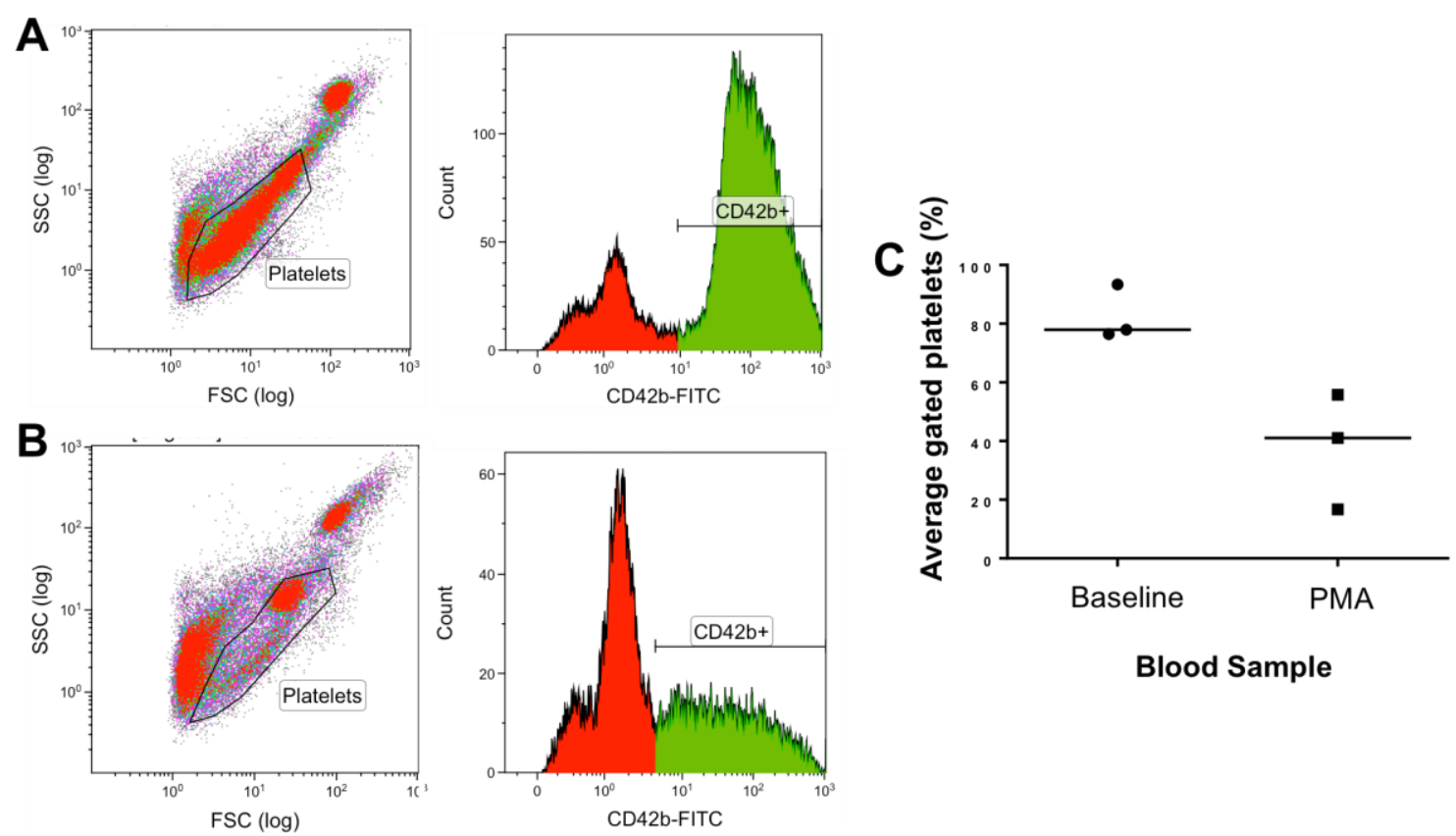

Figure 4.19: Platelet activation in the presence and absence of PMA. Blood from three healthy donors was analysed FACS for CD42b expression, expressed as a scatter plot and histogram (A) and compared to PMA stimulated blood (B). Analysis of FACS data for unstimulated and stimulated blood samples were obtained with Kaluza (C). Data shown are individual values plotted as a dot plot with median values depicted as a line. No statistical comparison is conducted due to low donor number.

Figure 4.19 (A) shows FACS scatter diagram from a single healthy volunteer depicting gating of platelets stained for $\mathrm{CD} 42 \mathrm{~b}$ and representative histogram showing platelet population within the defined gates. Figure 4.19 (B) shows FACS scatter diagram and histogram of a platelets from a single healthy volunteer after treatment with PMA depicting movement of platelets out of the predefined gates. Figure 4.19 (C) shows individual donor variation in $\%$ gated platelets with a decreased in gated values being observed in the PMA treated blood samples when compared to the baseline.

Three healthy donors were recruited to this study and their whole blood samples incubated in the presence and absence of the scaffold materials. Following a 2 hour incubation period the blood was collected, stained for CD42b (FITC) and processed for FACS analysis (see Figure 4.20). 

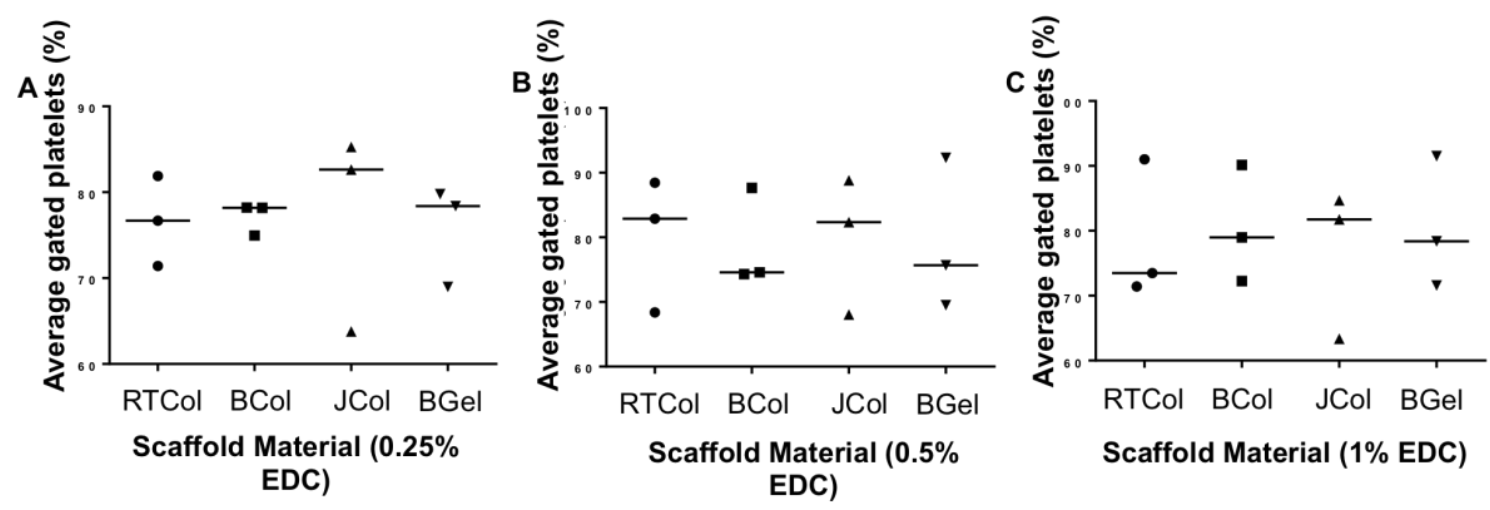

Figure 4.20 : Platelet activation in the presence of collagen scaffold material.

Following whole blood incubation from three donours, JCol platelet activation was compared directly to that of RTCol, BCol and BGel sources at $0.25 \%$ (A); $0.5 \%$ (B) and $1 \%$ (C) EDC cross linker. As a positive control PMA was used to stimulate platelet activation in each case. All data shown are individual values plotted as a scatter plot with median values depicted as a line. No direct statistical comparison is conducted due to the low donor number.

Figure 4.20 (A) shows individual donor variation in their \%-gated platelets, with one donor consistently showing increased platelet \% following incubation with RTCol, $\mathrm{BCol}$, JCol and BGel respectively. Despite this a clear trend observed where Jcol exhibits increased platelet \% compared to the other collagen sources, indicating decreased platelet activation in this scaffold sub type, at this concentration of EDC. Figure 4.20 (B), which is $0.5 \%$ EDC shows a slight difference in trend where JCol and RTCol exhibit a similar number of \% gated platelets whilst BCol and BGel exhibit a lower number of $\%$ gated cells indicating an increase in platelet activation in these latter scaffolds. Figure 4.20 (C) shows JCol exhibits an increase \% number of platelets compared to other scaffold materials at $1 \%$ EDC crosslinker concentration.

\subsubsection{Leukocyte activation; innate immune response}

Leukocyte activation, in the form of neutrophil and monocyte recruitment to the site of implantation is considered an early or innate immune response (Chaplin, 2010). 
Both cell types have been shown to shed CD62L or L-selectin and are thought to mediate migration and adhesion at the site of inflammation (Yang et al., 2011). In addition both cell types are known to express increased levels of CD11b, known to mediate migration and adhesion to the material or foreign/invading object (Muller, 2013). Finally, fMLPr is used as a further marker indicative of leukocyte activation and cytokine release in the presence of an implanted material, with increased detection signifying a stronger immune cell response (Pan et al., 2000).

\subsection{LPS established baseline}

LPS is a known stimulant of the human immune system, used as a positive control to demonstrate active immune cells during in vitro immunogenic screening (Alexander and Rietschel, 2001). In order to establish the immune response capability of each donor, LPS was added for a 2 hour period prior to whole blood staining for CD62L, CD11b and fMLPr. In the presence of CD62L, CD11b and fMLPr staining, neutrophil and monocyte cells were identified from the FACS trace by gating according to CD15+ and CD14+ mean fluorescent staining respectively, as used by Radley and colleagues (Radley et al., 2017). Figure 4.21, shows the neutrophil (CD15+) specific CD62L, CD11b and fMLPr stimulation in the presence of LPS. 

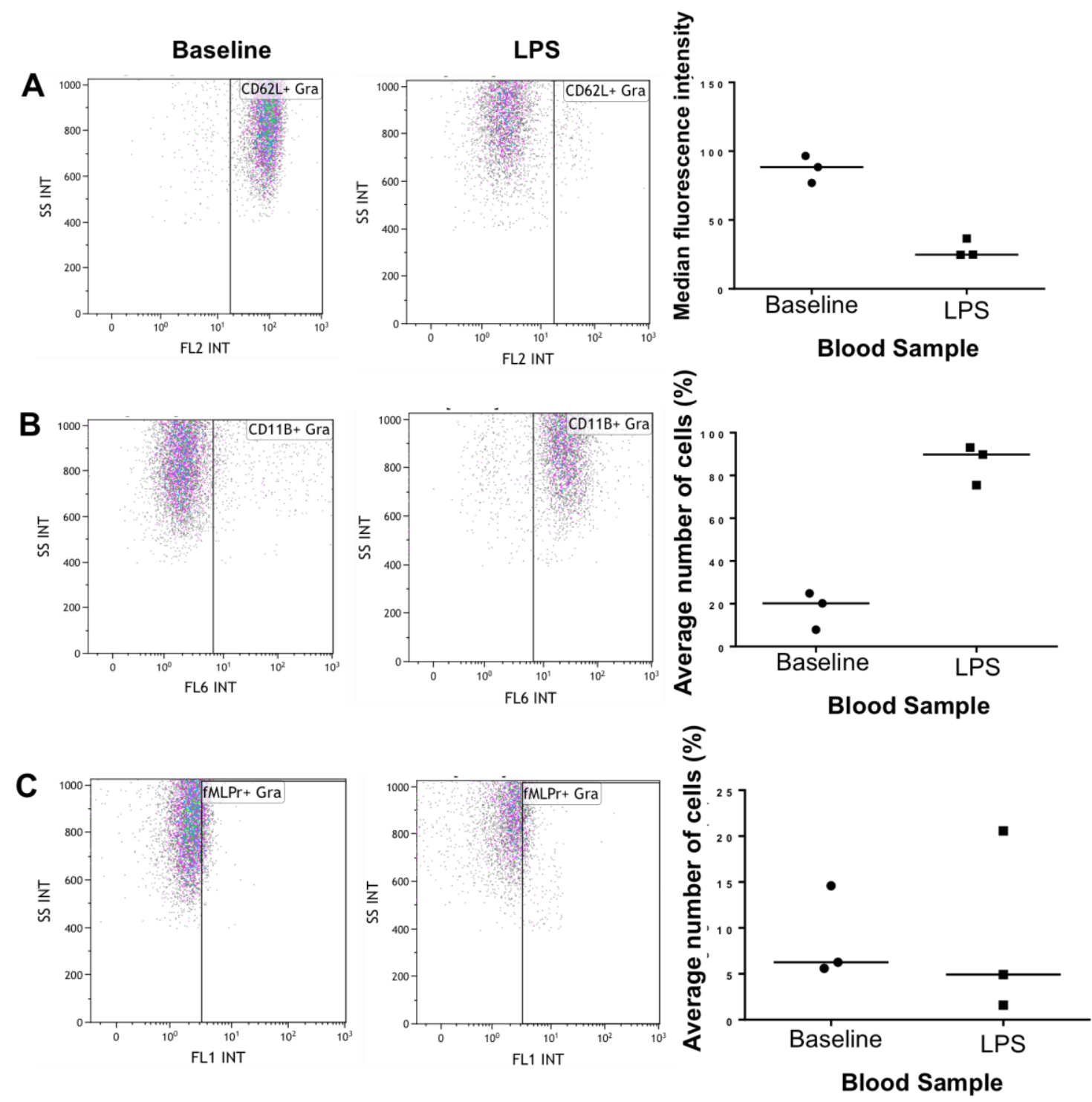

Figure 4.21: LPS induced donor specific neutrophil cell response. Whole blood samples were stained for CD62L, CD11b and fMLPr to indicate neutrophil specific response in the presence of LPS. Specific neutrophil responses were identified using cell type specific stains CD15+. Panels A, B and C indicate the CD62L, CD11b and fMLPr neutrophil specific response as a FACS scatter graph compared to control and Kaluza analysed summation respectively. All data shown as individual scatter readings or summarised donor cohort.

Figure 4.21 (A) shows FACS scatter graphs depicting the change in gating of neutrophils (CD15+) stained for CD62L from unstimulated and LPS stimulated blood from a single healthy donor. Data from three healthy patients were summated in a dot plot showing individual donor variation in their median fluorescence intensity and shows that LPS stimulated blood shows a decrease in median fluorescence intensity of CD62L when compared to baseline unstimulated blood. 
Figure 4.21 (B) shows the change in gating of neutrophils stained for CD1 1b from a single healthy donor, depicted as a FACS scatter graph. Summarised data from three healthy donors is shown in the dot plot expressing individual donor variation in $\%$ gated cells, with LPS stimulated blood exhibiting an increase in $\%$ gated cells expressing CD11b when compared to unstimulated blood. Figure 4.21 (C) shows FACS scatter graphs depicting the change in gating for fMLPr stained neutrophils from unstimulated and stimulated blood. Individual donor variation in $\%$ gated cells from three healthy donors shows a small decrease in the \% gated neutrophils expressing fMLPr when compared to unstimulated blood. 

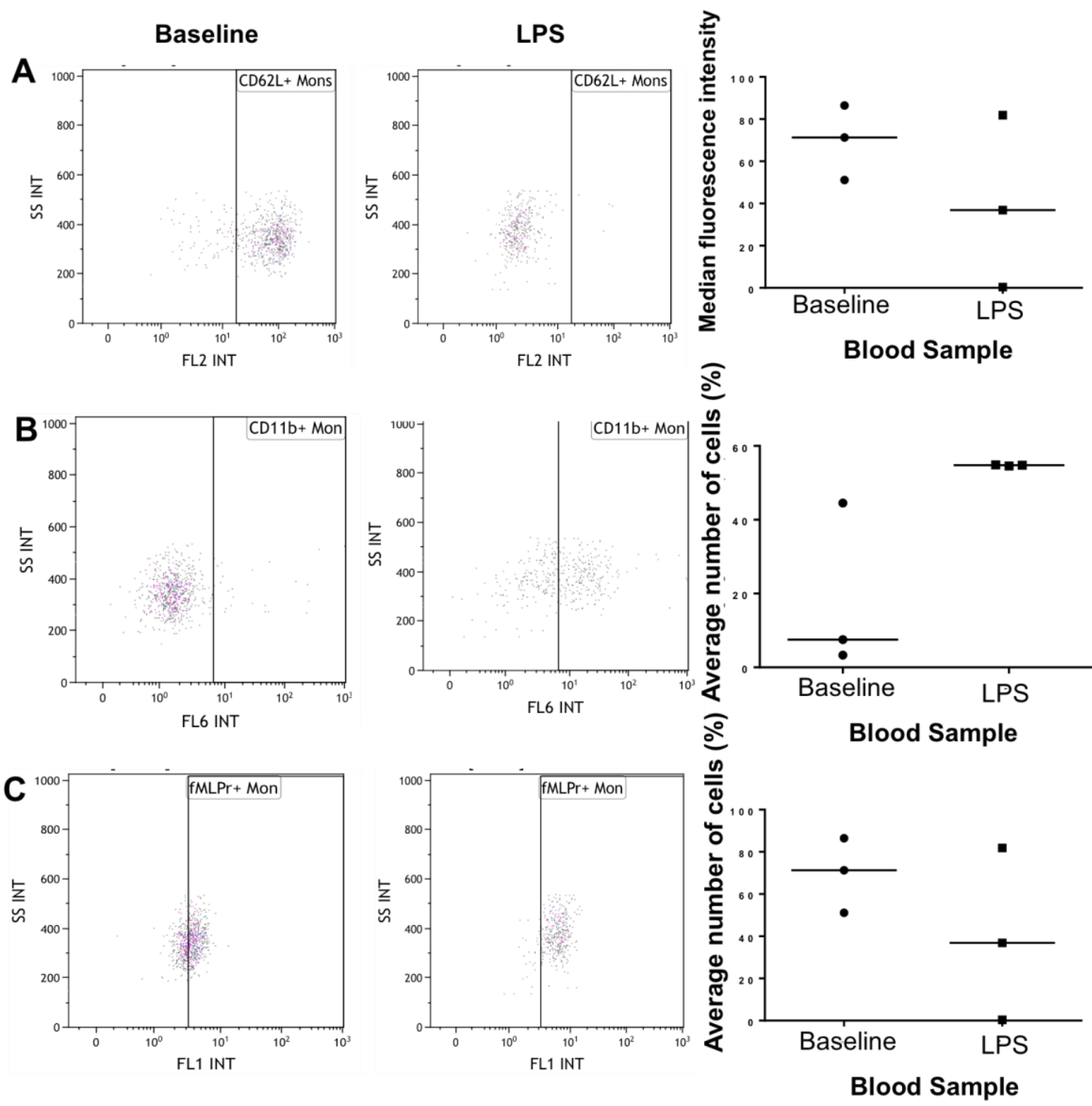

Blood Sample

Figure 4.22: LPS induced donor specific monocyte cell response. Whole blood samples were stained for CD62L, CD11b and fMLPr to indicate monocyte specific response in the presence of LPS. Specific neutrophil responses were identified using cell type specific stains CD15+. Panels A, B and C indicate the CD62L, CD11b and fMLPr neutrophil specific response as a FACS scatter graph compared to control and Kaluza analysed summation respectively. All data shown as individual scatter readings or summarised donor cohort.

Figure 4.22 (A) shows a change in gating of monocytes (CD14+) stained for CD62L from unstimulated and LPS stimulated blood. Data from three donors were summarised as a dot plot exhibiting individual donor variation in median fluorescence intensity, with LPS stimulated blood showing a decrease in median fluorescence intensity of CD62L when compared to baseline blood. Figure 4.22 (B) shows FACS scatter graphs depicting the change in gating of monocytes stained for 
CD11b. Data from three donors were summated in a dot plot showing individual donor variation in $\%$ gated cells and shows that LPS stimulated blood has an increased number of \% gated monocytes expressing CD11b when compared to the unstimulated counterpart. Figure 4.22 (C) depicts the change in gating of monocytes related to their expression of fMLPr from a single donor. A dot plot collated from three donors shows individual donor variation in $\%$ gated cells and shows a decrease in the \% gated monocytes expressing fMLPr in LPS stimulated blood when compared to unstimulated blood samples.

\subsection{Neutrophil specific activation}

Whole blood from the three donors was then exposed to the RTCol, BCol, JCol and BGel scaffolds over a period of 2 hours, prior to collection, staining with CD62L, $\mathrm{CD} 11 \mathrm{~b}$ as well as fMLPr and counter stained with CD15+ to identify specific neutrophil activation. Data shown in Figure 4.23 depicts the donor cohort median activation for neutrophil specific CD62L, CD11b and fMLPr activation in the presence of $0.25,0.5$ and 1.0\% EDC cross linker (Figure 4.23). 
A

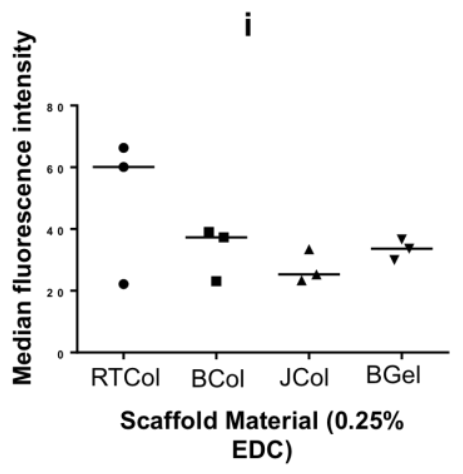

B

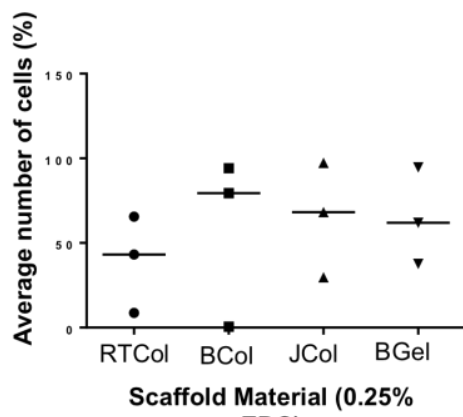

EDC)
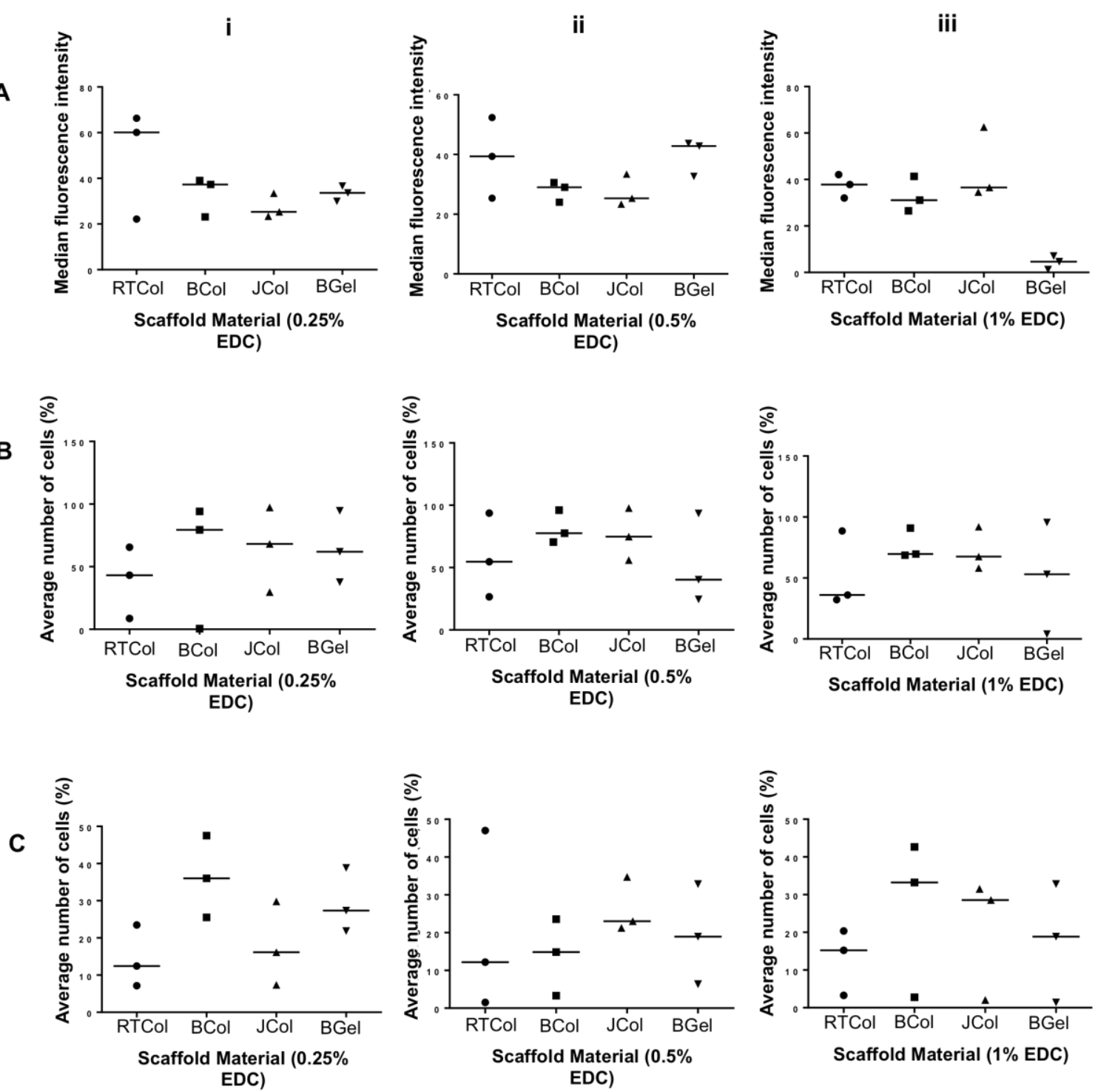

Figure 4.23: Neutrophil activation in the presence of collagen scaffolds. Specific neutrophil (CD15+) activation was detected through levels of CD62L (A); CD11b (B) and fMLPr (C), following a 2 hour incubation with RTCol, BCol, JCol and BGel scaffolds respectively. All marker stains were also analysed as a function of EDC cross link percentage and are shown here as three panels, (i $0.25 \%$ ), (ii $0.5 \%$ ) and (iii $1 \%$ ). All data shown as summarised donor cohort responses following Kaluza collation; median value depicted a line in each variable and sample type.

Figure 4.23 (Ai) shows individual donor variation in their median fluorescence intensity following incubation with RTCol, BCol, JCol and BGel at $0.25 \%$ crosslinking concentration. RTCol exhibits a higher median fluorescence intensity value than when compared to other scaffold material, indicating decreased shedding of CD62L in blood incubated with RTCol at this EDC concentration. Figure 4.23 
(Aii), at 0.5\% EDC, shows a difference in trend where RTCol and BGel exhibit similar values in median fluorescence intensity whilst a decreased median fluorescent intensity is observed in BCol and JCol samples. Figure 4.23 (Aiii) shows RTCol, BCol and JCol to have similar median fluorescence intensity values whilst BGel exhibits a decrease in value at 1\% EDC concentration. Figure 4.23 (Bi) shows donor variation in \% gated neutrophils showing an increase in neutrophil percentage following incubation with $\mathrm{RTCol}, \mathrm{BCol}, \mathrm{JCol}$ and $\mathrm{BGel}$, respectively. A trend is observed where RTCol exhibits a lower number of \% gated neutrophils expressing $\mathrm{CD} 11 \mathrm{~b}$ when compared to $\mathrm{BCol}$, JCol and $\mathrm{BGel}$ at $0.25 \%$ EDC concentration indicating decreased neutrophil activation for this specific scaffold material. Figure 4.23 (Bii) shows BCol and JCol have similar \% gated neutrophils, which are increased when compared to RTCol and BGel at 0.25\%. Figure 4.23 (Biii) shows \% gated neutrophils expressing CD11b following incubation with scaffolds at 1\% EDC concentration. A similar trend is observed where RTCol exhibits a decreased number of \% gated neutrophils when compared to BCol, JCol and BGel. Figure 4.23 (Ci) shows individual donor variation in in \% gated neutrophils stained for fMLPr following incubation with RTCol, BCol, JCol and BGel at $0.25 \%$ crosslinker concentration. A trend is observed where RTCol and JCol exhibit a decreased \% gated neutrophils when compared to BCol and BGel, indicating an increase in neutrophil activation in the former scaffold subtypes at this concentration. Figure 4.23 (Cii) shows a difference in trend with RTCol and BCol showing increased \% gated neutrophils when compared to JCol and BGel counterparts at $0.5 \%$ crosslinker concentration. Figure 4.23 (Ciii) depicts \% gated neutrophils expressing fMLPr following incubation with scaffolds crosslinked with 1\% EDC. At this concentration RTCol and BGel show a decreased in \% gated neutrophils in comparison to BCol and JCol, indicating the former scaffold materials have an increase in neutrophil activation.

\subsection{Monocyte specific activation}

Donor whole blood exposed to RTCol, BCol, JCol and BGel scaffolds (2 hours) were stained with CD62L, CD11b as well as fMLPr and counter stained with CD14+ to identify specific monocyte activation, with all data depicted in Figure 4.24. 

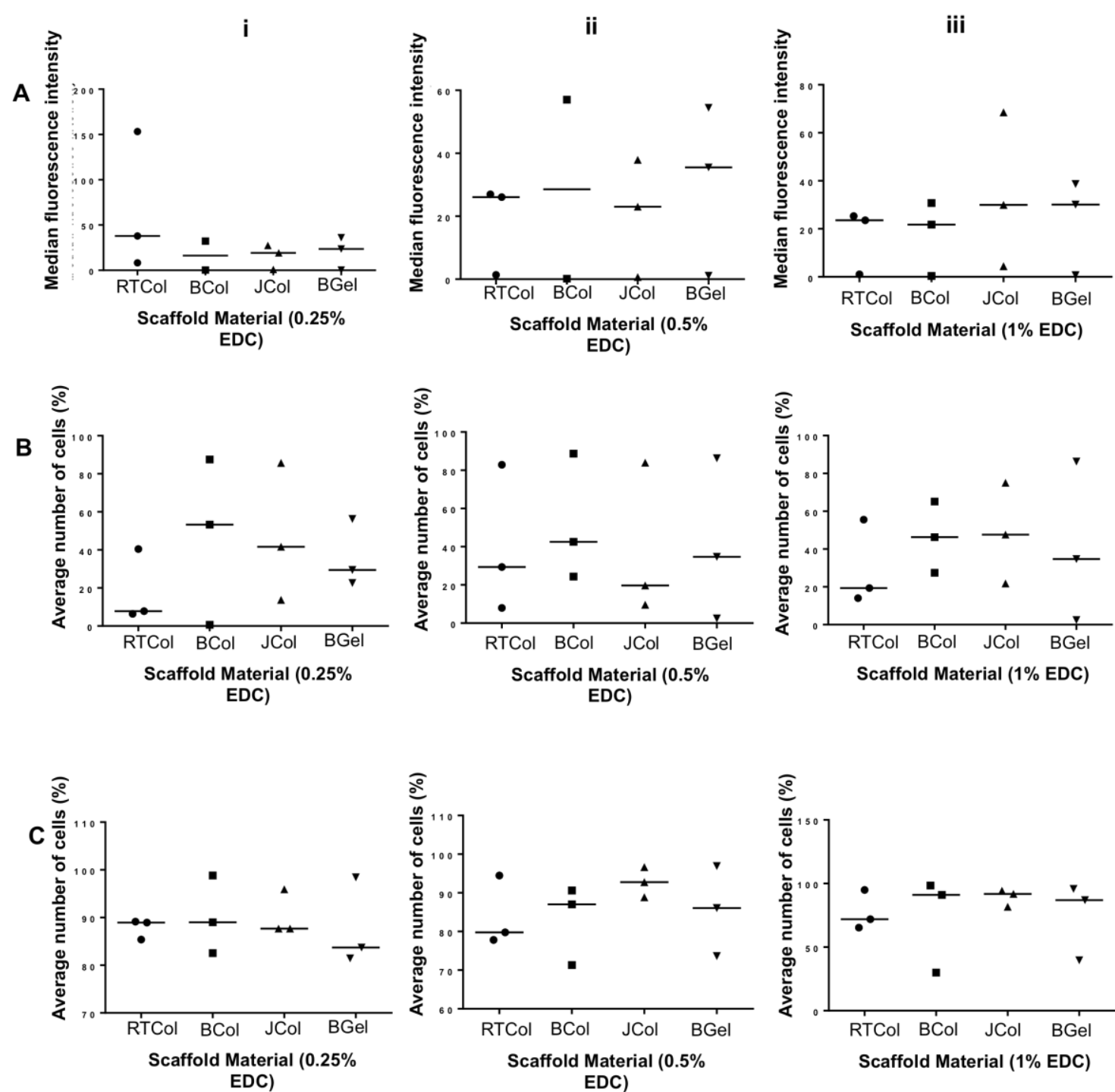

Figure 4.24: Monocyte activation in the presence of collagen scaffolds. Specific monocyte (CD14+) activation was detected through levels of CD62L (A); CD11b (B) and fMLPr (C), following a 2 hour incubation with RTCol, BCol, JCol and BGel scaffolds respectively. All marker stains were also analysed as a function of EDC cross link percentage and are shown here as three panels, (i 0.25\%), (ii 0.5\%) and (iii $1 \%$ ). All data shown as summarised donor cohort responses following Kaluza collation; median value depicted a line in each variable and sample type.

Figure 4.24 (Ai) shows variation between individual donors in median fluorescence intensity after incubating blood with scaffolds fabricated from RTCol, BCol, JCol and BGel crosslinked at $0.25 \%$. When compared to other scaffold subtypes, RTCol exhibits increased median fluorescence intensity for CD26L indicating a decrease in monocyte activation compared to other tested materials at this crosslinker 
concentration. Figure 4.24 (Aii) shows median fluorescence intensity of monocytes stained for $\mathrm{CD} 62 \mathrm{~L}$ at $0.5 \%$ EDC concentration. A change in trend is observed with RTCol, BCol and JCol expressing lower median fluorescence intensity values that BGel. Figure 4.24 (Aiii) shows a difference in trend again with RTCol and BCol expressing similar median fluorescence intensity values whilst JCol and BGel express similar, increased median fluorescence intensity values at $1 \%$ EDC concentration, indicating and increase in monocyte activation in the former scaffold materials. Figure 4.24 (Bi) shows individual donor variation in \% gated monocytes stained for CD11b following incubation with RTCol, BCol, JCol and BGel. At $0.25 \%$ EDC concentration, $\mathrm{BCol}$ exhibits the highest value of \% gated monocytes when compared to other scaffold materials whilst RTCol shows the lowest \% gated monocytes. Figure 4.24 (Bii) shows a similar trend at 0.5\% EDC concentration with BCol exhibiting increased \% gated, RTCol and BGel showing similar values and JCol exhibiting the lowest $\%$ gated monocytes indicating that JCol has a decreased level of monocyte activation compared to its counterparts. Figure 4.24 (Biii) shows $\%$ gated monocytes expressing CD11b following incubation with scaffolds at $1 \%$ EDC concentration. RTCol exhibits a decreased number of \% gated monocytes when compared to BCol, JCol and BGel. Figure 4.24 (Ci) shows \% gated monocytes stained for fMLPr following incubation with RTCol, BCol, JCol and BGel at $0.25 \%$ EDC concentration. A trend is observed where RTCol, BCol and JCol similar increased expression in \% gated monocytes when compared to BGel. Figure 4.24 (Cii) shows a difference in trend where BCol expresses and increased \% gated monocytes, BCol and JCol exhibit similar values and RTCol exhibits the lowest value of $\%$ gated monocytes stained for $\mathrm{CD} 11 \mathrm{~b}$ at $0.5 \%$ crosslinker concentration.

Figure 4.24 (Ciii) depicts \% gated monocytes expressing fMLPr following incubation with scaffolds crosslinked with $1 \%$ EDC. At this concentration a change in trend occurs once again with BCol, JCol and BGel expressing similar increase values in \% gated monocytes compared to RTCol at this crosslinker concentration. 


\subsubsection{Leukocyte activation; adaptive immune response}

Leukocyte activation, in the form of T-cell recruitment to the site of implantation is considered a later, or adaptive immune response (Chaplin, 2010). T-cells function to recognise antigens bound to major histocompatibility (MHC) molecules to help discriminate from non-self (Kennedy, 2010). CD62L, CD11B and fMLPr are also accepted markers for $\mathrm{T}$ cell activation and are monitored here in $\mathrm{T}$-cells specifically through counter staining using antibodies (APC-Vio770) to identify CD3+ cells.

In order to establish the capability of the specific $\mathrm{T}$ cell populations in the peripheral blood donor cohorts, CD62L, CD11B and fMLPr expression was monitored following LPS incubation ( 2 hours). Following the establishment of this baseline response (shown in Figure 4.25), the scaffold materials were each assessed for T-cell activation profiles. 

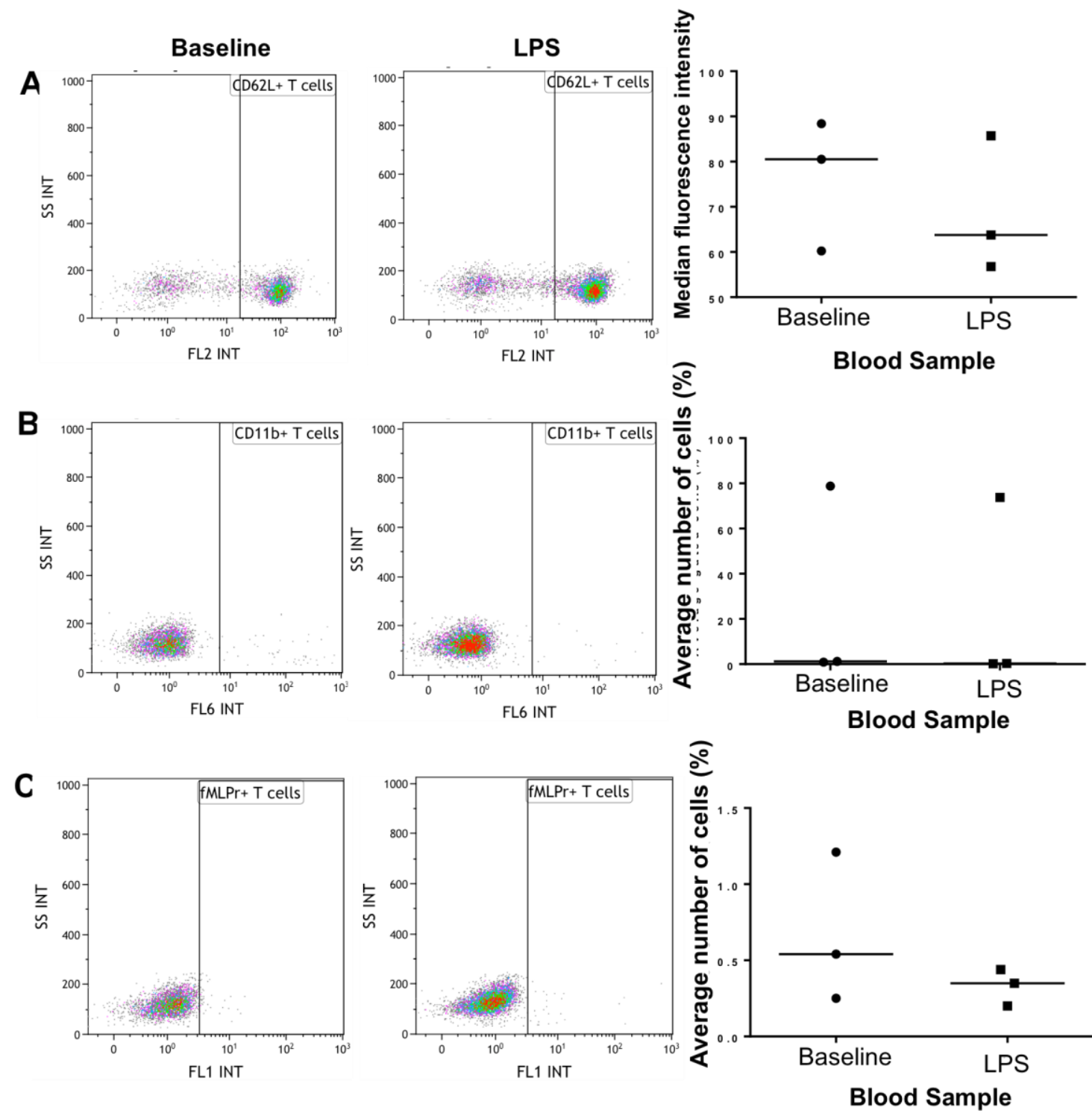

Figure 4.25: LPS induced donor specific T-cell responses. Whole blood samples were stained for CD62L, CD11b and fMLPr to indicate T-cell specific response, using CD3+ stains in the presence of LPS. Panels A, B and C indicate the CD62L, CD11b and fMLPr T-cell specific response as a FACS scatter graph compared to control and Kaluza analysed summation respectively. All data shown as individual scatter readings or summarised donor cohort.

Figure 4.25 (A) depicts a change in gating of T-cells (CD3+) stained for CD62L from unstimulated and LPS stimulated blood from a single healthy donor. Data from three healthy donors were summated in a dot plot showing individual donor variation in their median fluorescence intensity and show LPS stimulated blood has a decreased median fluorescence intensity of CD62L when compared to baseline, unstimulated blood. Figure 4.25 (B) shows a change in gating for T-cells stained for 
CD11b from a single healthy donor. Data summated in a dot plot showing individual donor variation in \% gated T-cells shows similar values between that of unstimulated and LPS stimulated blood. Figure 4.25 (C) shows FACS scatter plots depicting the change in gating for fMPLr stained T-cells from unstimulated and LPS stimulated blood. Individual donor variation in $\%$ gated from three healthy donors shows a decrease in \% gated T-cells expressing fMLPr in LPS stimulated blood when compared to the unstimulated control.

Figure 4.26, shows the T-cell specific response (CD3+) through CD62L, CD11b and fMLPr stimulation in the presence of RTcol, BCol, JCol and BGel in turn, across the three EDC \% cross linking concentrations respectively. 
A
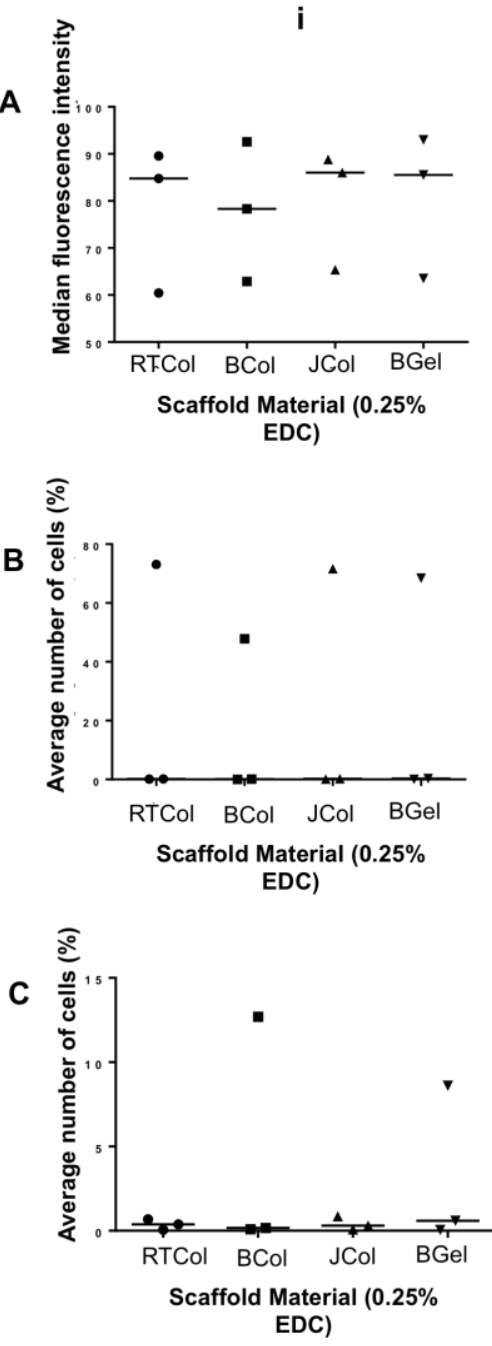
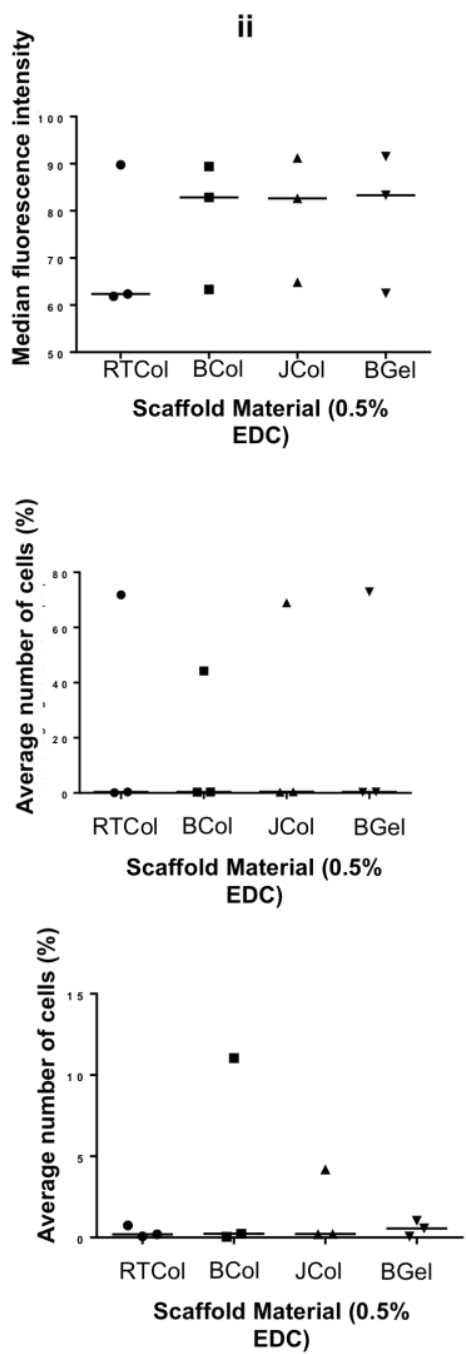

iii
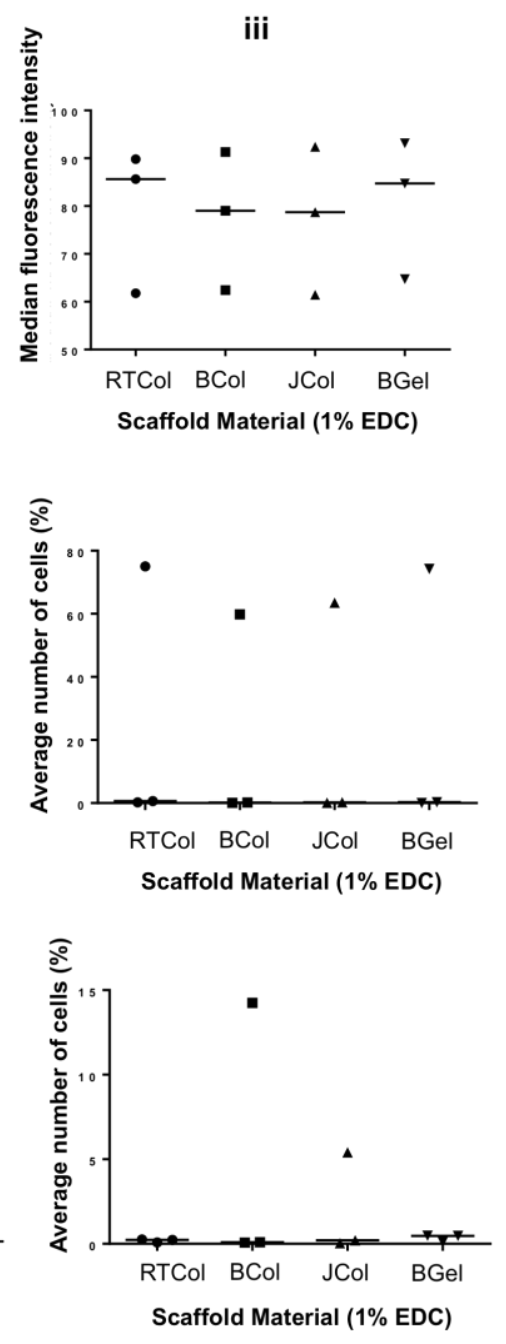

Figure 4.26: $\mathrm{T}$-cell activation in the presence of collagen scaffolds. Specific T-cell activation was detected through levels of CD62L (A); CD11B (B) and FMLPr (C), following a $2 \mathrm{hr}$ incubation with RTCol, BCol, JCol and BGel scaffolds respectively. All marker stains were also analysed as a function of EDC crosslink percentage and are shown here as three panels, (Ai 0.25\%), (Aii 0.5\%) and (Aiii 1\%). All data shown as summarised donor cohort responses following Kaluza collation; median value depicted a line in each variable and sample type.

Figure 4.26 (Ai) shows individual donor variation in their median fluorescence intensity following incubation with RTCol, BCol, JCol and BGel at $0.25 \%$ crosslinking concentration. RTCol, JCol and BGel exhibit similar values for T-cell median fluorescent intensity whilst $\mathrm{BCol}$ exhibits decreased median fluorescence intensity when compared to the other scaffold materials. At $0.5 \%$ EDC concentration, Figure 4.26 (Aii), there is a change in trend with BCol, JCol and BGel expressing similar median fluorescence intensity values and RTCol showing 
decreased median fluorescence intensity for CD62L indicating $\mathrm{T}$-cell activation in the latter material compared to other subtypes. Figure 4.26 (Aiii) shows BCol and JCol exhibit similar decreased median fluorescence intensity than RTCol and BGel at 1\% EDC concentration. Figure 4.26 (Bi) shows individual donor variation in \% gated T-cells stained for CD11b, with one donor consistently showing increased platelet $\%$ following incubation with RTCol, BCol, JCol and BGel at 0.25\% EDC concentration. A trend is established with RTCol, BCol, JCol and BGel \% gated Tcells exhibit similar low values. Figure 4.26 (Bii) shows the same trend with all scaffold materials showing decreased $\%$ gated $\mathrm{T}$-cells stained for CD11b at $0.5 \%$ EDC concentration. Figure 4.26 (Biii) shows the same trend at $1 \%$ EDC concentration where RTCol, BCol, JCol and BGel express a similar, low \% gated Tcell population. Figure 4.26 (Ci) shows individual donor variation in $\%$ gated $\mathrm{T}$-cells stained for fMLPr following incubation with RTCol, BCol, JCol and BGel at $0.25 \%$ crosslinker concentration. A trend is seen where RTCol, BCol and JCol express similar \% gated T-cells whilst BGel exhibits increased \% gated T-cells stained for fMLPr. This trend is seen again at $0.5 \%$ EDC concentration (Figure 49 Cii) and at $1 \%$ EDC concentration (Figure 4.26 Ciii).

\subsubsection{Leukocyte cell death}

The initiation of the immune system in response to a biomaterial leads to the activation of various different cell types. Immobilised platelets recruit neutrophils and monocytes, which in turn activate and recruit T-cells to the surface of the biomaterial. This build up of cells can induce cell death causing a defective cellular immune response (Radley et al., 2017). DRAQ7 is an anthracycline derivative that exclusively stains dead cells, capitalising on membrane permeability and binding to nuclear DNA (Akagi et al., 2013).

In order to establish whether scaffold materials at any given EDC concentration were causing excessive cell death, blood samples were stained with DRAQ7 following incubation with RTCol, BCol, JCol and BGel. A baseline was established with the use of healthy donor blood and LPS stimulated blood, seen in Figure 4.27. 


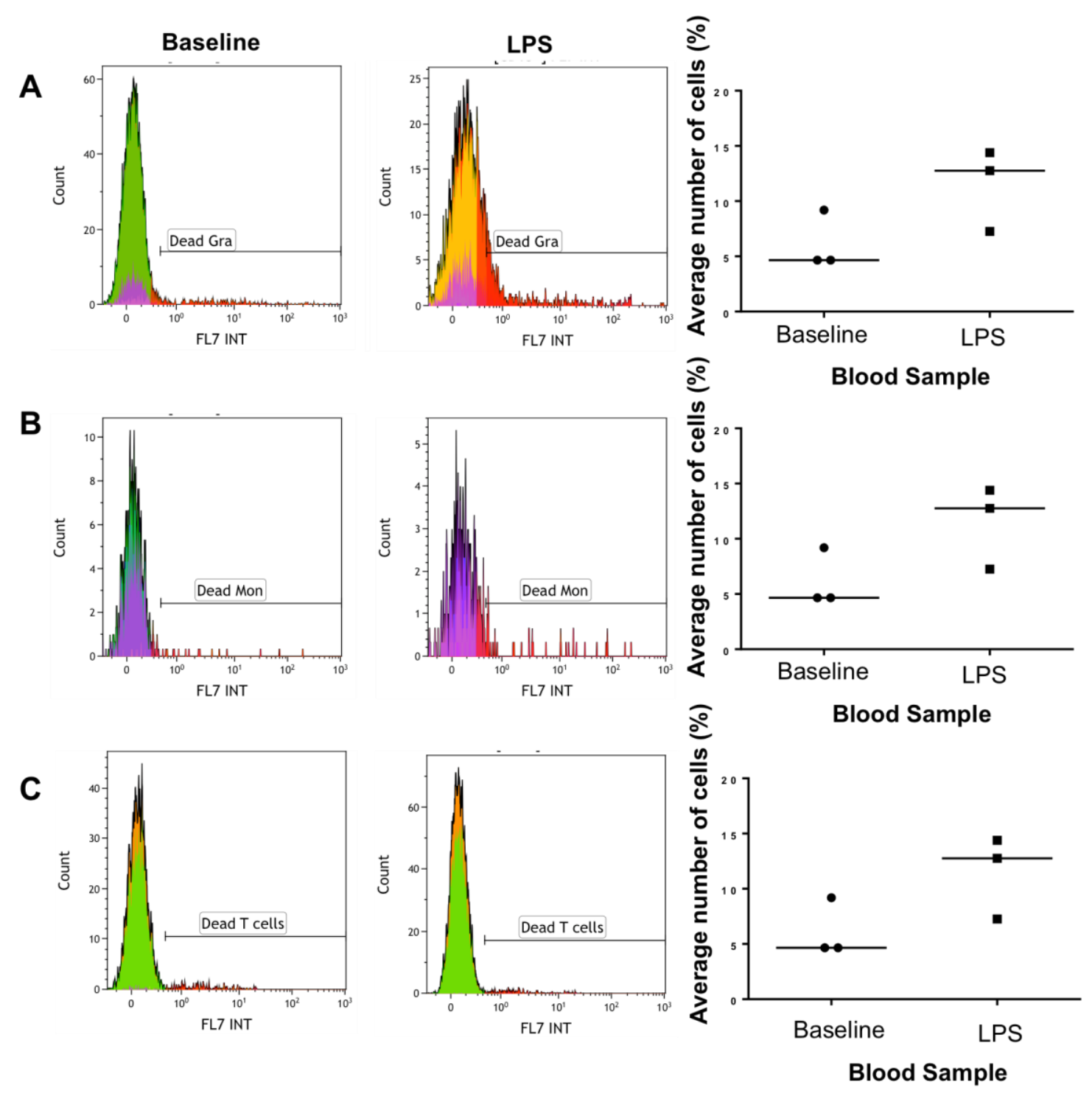

Figure 4.27: LPS induced specific cell death. Whole blood samples were stained with DRAQ7 to indicate cell death in the presence and absence of LPS stimulation. LPS stimulated cellular response is shows as a flow cytometric histogram compared to control and Kaluza analysed summation for neutrophils (A), monocytes (B) and Tcells (C), respectively. All data shown as individual readings or summarised donor cohort.

Figure 4.27 (A) shows a change gating in neutrophil (CD15+) stained for DRAQ7 from a single healthy donor in the presence and absence of LPS stimulation showing a broader peak with LPS stimulation indicative of cell death. Data from three healthy donors were summated in a dot plot showing individual donor variation in their \% gated neutrophils. Increased \% gated neutrophils are seen in LPS stimulated samples compared to control. Figure 4.27 (B) shows a histogram depicting a change in gating of monocytes stained with DRAQ7 in the presence and absence of LPS. A shift in 
the gating is seen towards the left indicating cell death in LPS treated blood. Summated data from three patients shows an increase in \% gated monocytes in stimulated blood compared to its unstimulated counterpart. Figure 4.27 (C) exhibits the same trend when observing $\mathrm{T}$ cells $(\mathrm{CD} 3+)$. Flow histograms show a change in gating indicative of increased cell death when observing a single healthy patient after treatment with LPS. A dot plot accounting for individual donor variation in $\%$ gated T-cells stained for DRAQ7 shows and increased percentage when comparing LPS stimulated blood to unstimulated baseline blood.

Figure 4.28, shows the neutrophil (CD15+), monocyte (CD14+) and T-cell (CD3+) specific cell death response through DRAQ7 staining in the presence of RTcol, $\mathrm{BCol}$, JCol and BGel in turn, across the three EDC \% cross linking concentrations respectively. 

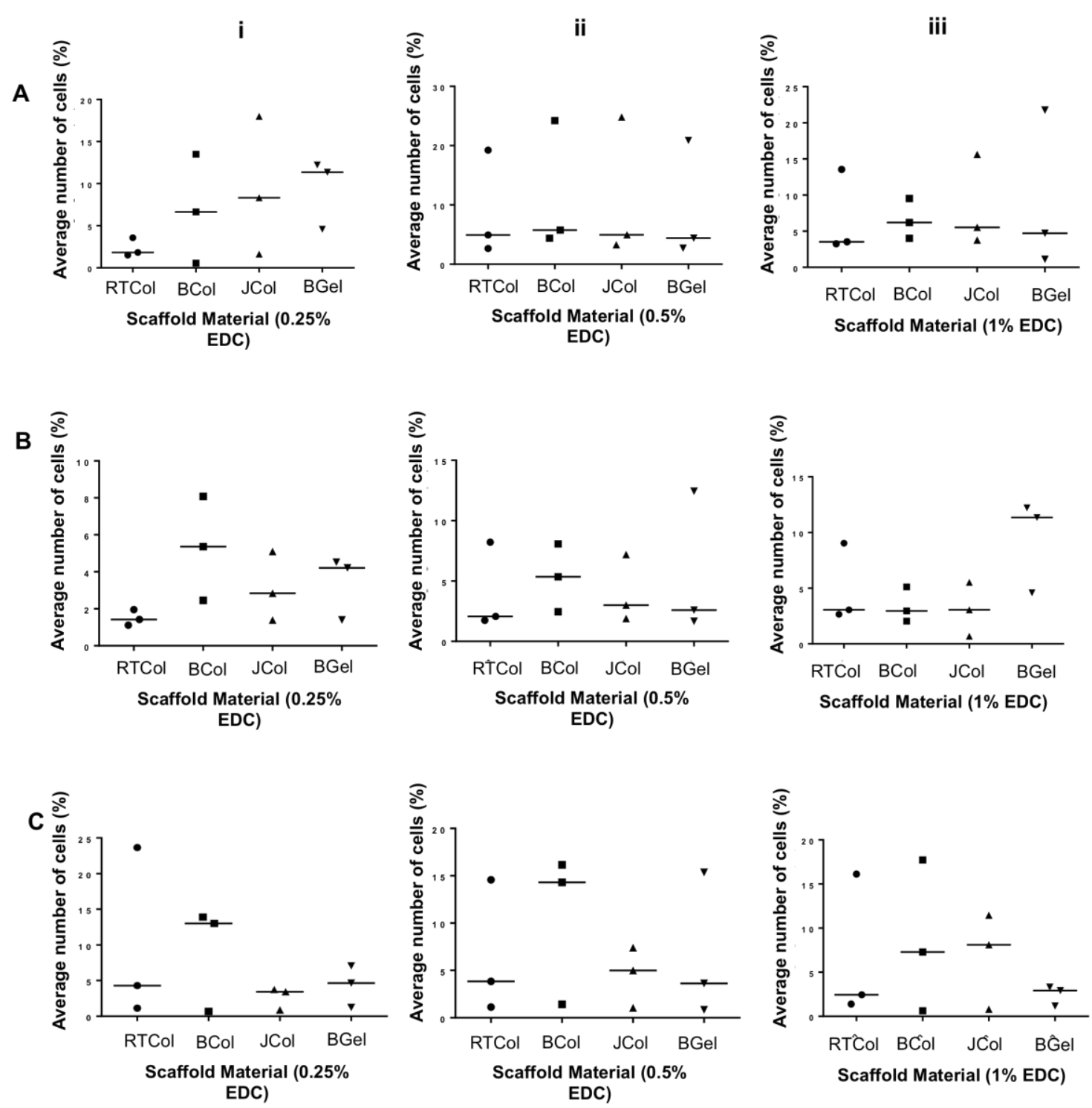

Figure 4.28: Leukocuyte cell death in the presence of scaffold structures. Leukocyte cell death in the presence of scaffold structure (A) neutrophils (B) monocytes $(\mathrm{C}) \mathrm{T}$ cells

Figure 4.28 (Ai) shows individual donor variation in \% gated neutrophils following incubation with $\mathrm{RTCol}, \mathrm{BCol}, \mathrm{JCol}$ and $\mathrm{BGel}$ at $0.25 \%$ crosslinker concentration. A trend if observed in which there is an increasing value in \% gated neutrophils expressing DRAQ7 from RTCol, BCol, JCol and BGel, respectively, and BGel showing the more increased value. Figure 4.28 (Aii) shows a difference in trend with one donor consistently showing increased \% gated neutrophils at $0.5 \%$ EDC concentration however median values of all scaffold sub types are similar. Figure 4.28 (Aiii) shows BCol exhibiting increased \% gated neutrophils expressing DRAQ7 when compared to other scaffold materials at 1\% EDC concentration. Figure 4.28 
(Bi) shows increased \% gated monocytes stained for DRAQ7 in BCol culture when compared to other materials at 0.25\% EDC concentration. Figure 4.28 (Bii) depicts similar \% gated monocyte values for RTCol, BCol and JCol at whilst an increased \% gated monocyte value is seen for $\mathrm{BCol}$ at $0.5 \%$ EDC concentration. A slight change in trend is seen at 1\% EDC crosslinking concentration, depicted in Figure 4.28 (Biii) with similar \% gated values seen for RTCol, BCol, JCol whilst increased \% gated value is seen for BGel at this concentration. Figure 4.28 (Ci) shows individual donor variation in \% gated T cells stained for cell death with DRAQ7 following incubation with scaffolds crosslinked at $0.25 \%$. A trend is observed where BCol has increased $\%$ gated monocytes compared to other scaffold subtype that exhibit similar, lower values. The same trend is observed in Figure 4.28 (Cii) where BCol has increased \% gated $\mathrm{T}$ cells compared to all other scaffold materials tested. Figure 4.28 (Ciii) shows a change in trend at $1 \%$ crosslinker concentration where RTCol and BGel have similar decreased $\%$ gated $\mathrm{T}$ cells when compared to $\mathrm{BCol}$ and $\mathrm{JCol}$ at this concentration.

\subsubsection{Cytokine release profile}

Cytokines, released upon activation of immune cells, are key modulators in inflammation and can be categorised as either pro-inflammatory or antiinflammatory (Turner et al., 2014). In order for the immune system to function in an orderly manner, cytokine release is regulated in cascades responding to initial inflammatory response followed by another cascade in order to allow for the reaction to subside (Lacy and Stow, 2011).

\subsection{Pro-inflammatory cytokine - interleukin 6}

Interleukin 6 (IL-6) is seen as a pro-inflammatory cytokine that is involved in the activation of the immune system (Scheller et al., 2011). Although IL-6 plays a prominent role in immune initiation it is also prevalent in chronic disease showcasing its role in both acute inflammation during innate immune response and in the development of the humoral response including $\mathrm{T}$ cell activation (Gabay, 2006). In order to establish if RTCol, BCol, JCol and BGel scaffolds crosslinked at varying 
concentrations released an increased concentration of IL-6, blood from healthy donor volunteers was incubated with scaffolds for a 2 hour period before further 24 hour incubation with media in the presence and absence of LPS. Following centrifugation to obtain blood serum an IL-6 ELISA was run to create a release profile for each material.

A

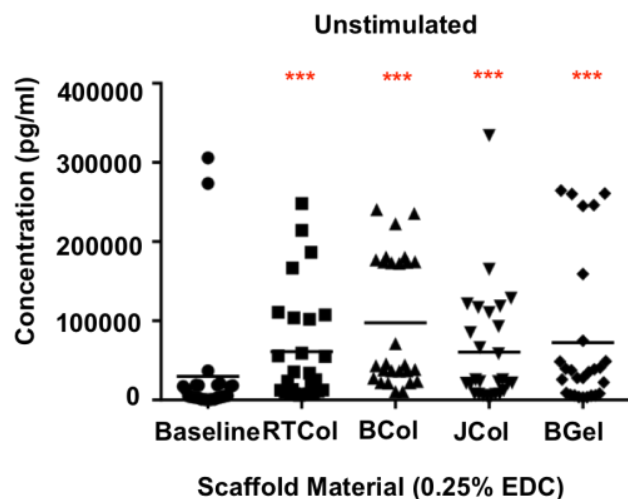

C
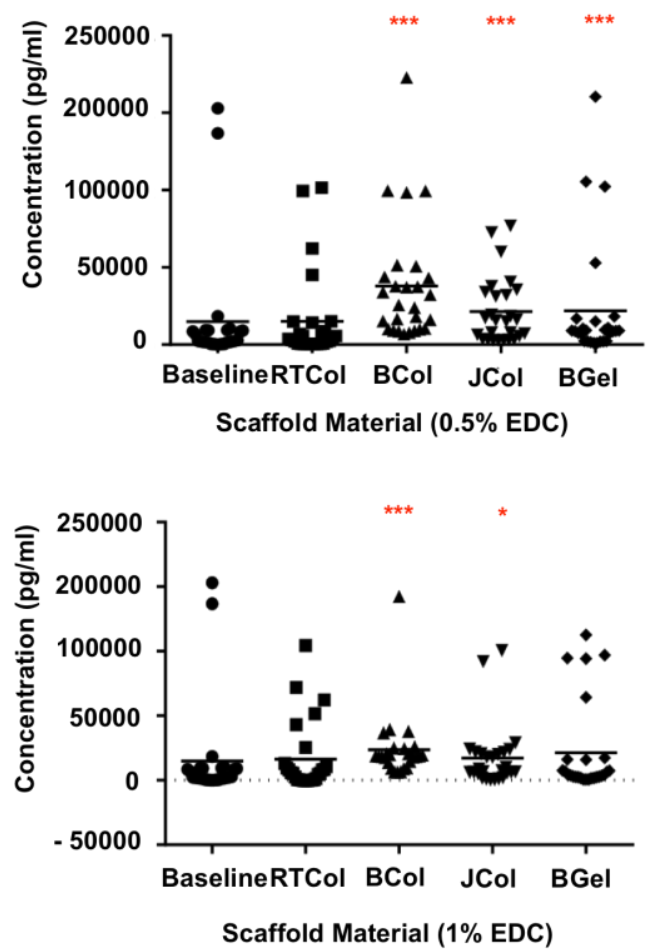

B

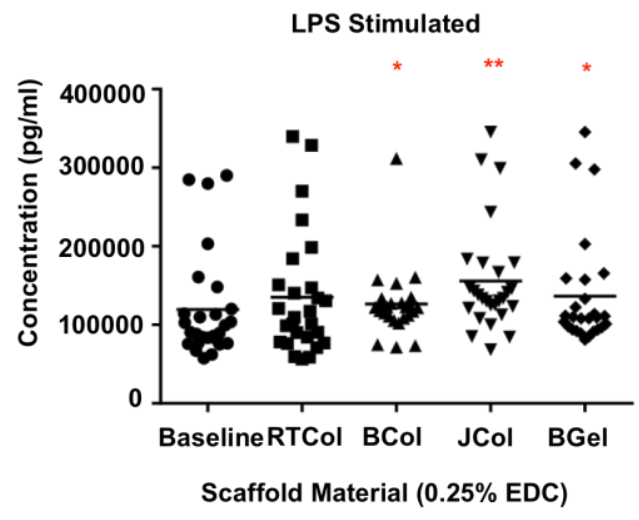

D
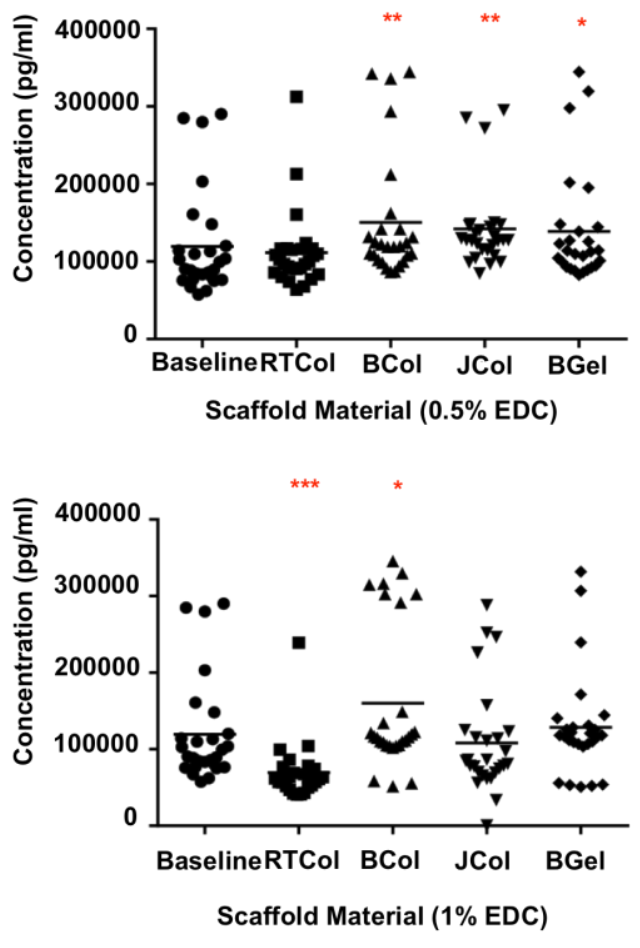

Figure 4.29: IL-6 release profile in the presence of scaffolds. Whole blood serum samples incubated in media in the absence (A, C, E) and presence of LPS (B, D, F) was subjected to ELISA to obtain concentration of IL-6 released. All data shown is the standard deviation from a minimum of 3 independent biological repeats, statistical significance shown according to a paired Mann Whitney $U$ test $\left({ }^{*} p<0.05\right.$; $* * \mathrm{p}<0.01 ; * * * \mathrm{p}<0.001)$. 
Figure 4.29 (A) and (B) show the IL-6 concentration for scaffolds crosslinked at $0.25 \%$ EDC concentration from unstimulated and stimulated samples, respectively. In unstiumlated culture conditions (A), RTCol, BCol, JCol and BGel all show a significant $(\mathrm{p}<0.001)$ increase in the average IL-6 concentration in blood serum after 24-hour incubation when compared to baseline donor blood samples. The addition of LPS to culture conditions (B) sees a change in trend where RTCol shows no significant difference in IL-6 concentration compared to baseline blood whereas BCol and BGel both show a significant increase $(\mathrm{p}=0.020$ and $\mathrm{p}=0.002)$ and JCol exhibits a further significant difference $(\mathrm{p}<0.001)$ at this crosslinking concentration.

Figure 4.29 (C) shows IL-6 concentration for scaffolds crosslinked at 0.5\% EDC concentration in the absence of LPS. At this concentration RTCol shows no significant difference in IL-6 levels when compared to baseline blood however, BCol $(\mathrm{p}<0.001)$, JCol $(\mathrm{p}<0.001)$ and BGel $(\mathrm{p}=0.028)$ all display significant increase in their IL- 6 concentration when compared to blood incubated in the absence of a scaffold. Figure 4.29 (D) displays data from the LPS stimulated samples crosslinked at $0.5 \% \mathrm{EDC}$ and show a similar trend to the unstimulated counterpart. Once again it is observed that RTCol has no significant difference in IL-6 concentration when compared to baseline blood samples whilst BCol $(\mathrm{p}=0.005)$, JCol $(\mathrm{p}=0.002)$ and BGel $(p=0.029)$ all display a significant increase in IL-6 concentration following 24hour incubation. Figure 4.29 (E) depicts IL-6 concentration in blood serum samples following incubation of scaffolds crosslinked with 1\% EDC. At this concentration both RTCol and BGel show no significant difference in concentration when compared to baseline blood samples however BCol $(\mathrm{p}<0.001)$ and JCol $(\mathrm{p}=0.036)$ exhibit significant increased levels of IL-6. Figure 4.29 (F) shows IL-6 concentration of blood serum samples in the presence of LPS and displays a difference in trend with RTCol $(\mathrm{p}<0.001)$ and $\mathrm{BCol}(\mathrm{p}=0.012)$ showing a significant increase in concentration whilst JCol and BGel show no significant difference when incubated with scaffolds at $1 \%$ EDC concentration.

\subsection{Anti-inflammatory cytokine - interleukin 10}

Interleukin 10 (IL-10) is a potent anti-inflammatory cytokine that inhibits specific immune specific cells limiting the damage sustained by tissues (Couper et al., 2008). 
IL-10 is produced by nearly all leukocytes including monocytes, macrophages and T cells. The interaction of IL-10 with other anti-inflammatory molecules enables the inhibition of allergic responses as well as enhancing the regulatory function of $\mathrm{T}$ cells (Iyer and Cheng, 2012). All scaffolds crosslinked with $0.25 \%, 0.5 \%$ and $1 \%$ EDC were incubated with human blood for 2 hours before transferring blood to media in the presence and absence of LPS for a further 24 hour incubation period. On completion of incubation, blood serum was collected and subjected to ELISA to obtain IL-10 concentrations and create a release profile. 
A

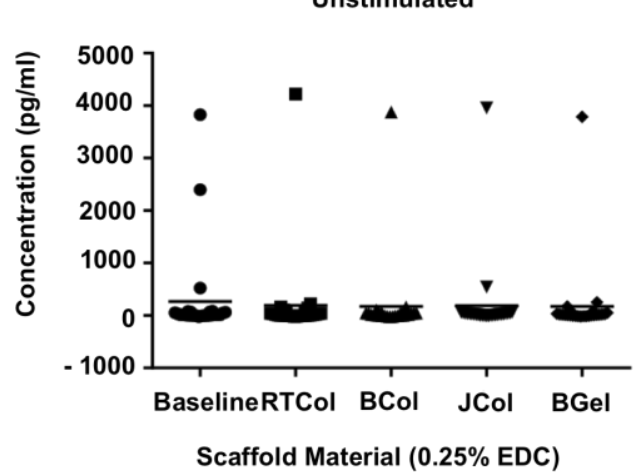

C

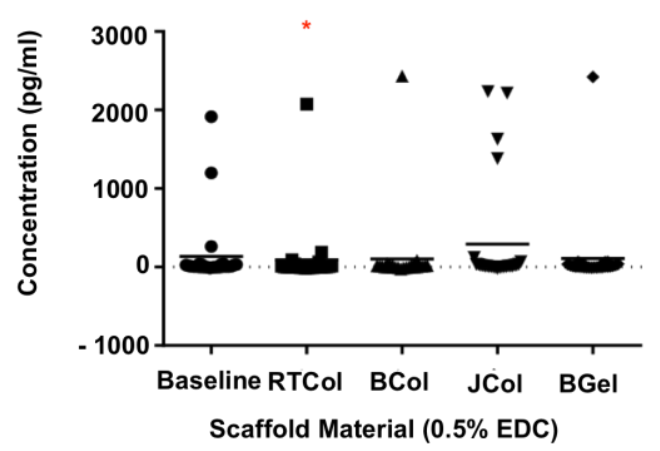

E

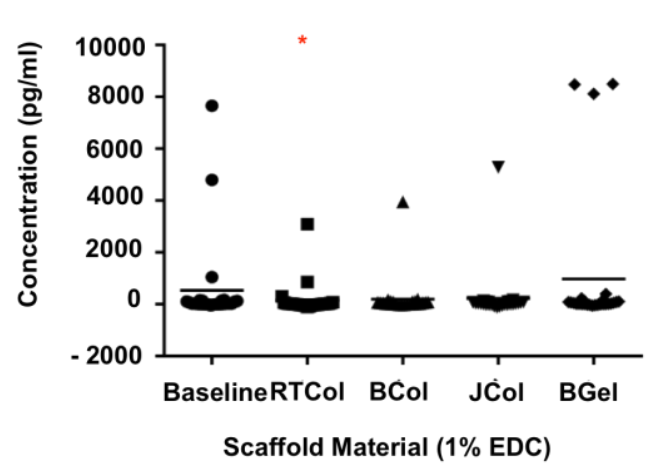

B
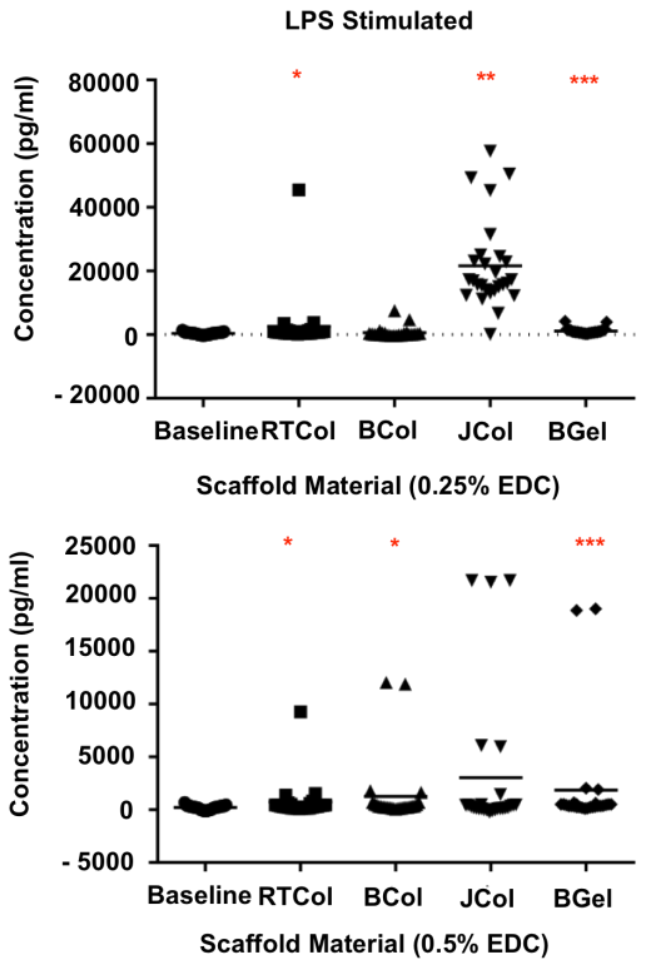

$\mathbf{F}$

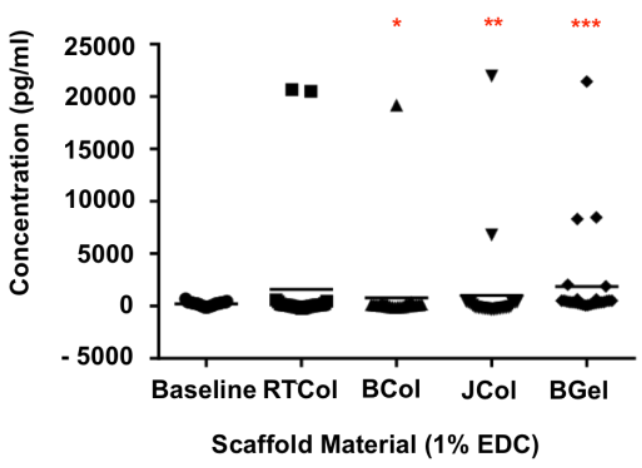

Figure 4.30: IL-10 release profile in the presence of scaffolds. Whole blood serum samples incubated in media in the absence (A, C, E) and presence of LPS (B, D, F) was subjected to ELISA to obtain concentration of IL-6 released. All data shown is the standard deviation from a minimum of 3 independent biological repeats, statistical significance shown according to a paired Mann Whitney $U$ T test $\left({ }^{*} \mathrm{p}<0.05 ; * * \mathrm{p}<0.01 ; * * * \mathrm{p}<0.001\right)$.

Figure 4.30 (A) depicts IL-10 concentration in blood serum samples following incubation of scaffolds crosslinked with $0.25 \%$ EDC in the absence of LPS. At this EDC concentration no significant difference was observed with any scaffold material (RTCol, BCol, JCol and BGel) when compared to baseline blood samples. Figure 4.30 (B) shows IL-10 concentration of blood serum samples in the presence of LPS and displays a difference in trend with RTCol $(\mathrm{p}=0.012)$, JCol $(\mathrm{p}=0.003)$ and BGel ( $>$ >0.001) exhibiting a significant increase in the serum IL-10 concentration whilst 
BCol showed no significant difference in comparison with baseline LPS stimulated blood. Figure 4.30 (C) and 4.30 (D) show the IL-10 concentration for scaffolds crosslinked at $0.5 \%$ EDC concentration from unstimulated and stimulated samples, respectively. In unstiumlated culture conditions (C), BCol, JCol and BGel all no significant difference in IL-10 concentration after 24-hour incubation when compared to baseline donor blood samples, whilst RTCol appears to show a significant decrease in IL-10 concentration ( $\mathrm{p}=0.033$ ). The addition of LPS to culture conditions (D) sees a change in trend where JCol exhibits no significant difference when compared to baseline blood but RTCol ( $\mathrm{p}=0.019), \mathrm{BCol}(\mathrm{p}=0.045)$ and BGel $(\mathrm{p}<0.001)$ display significant increase in IL-10 concentration levels compared to baseline. Figure 4.30 (E) shows IL-10 concentration for scaffolds crosslinked at $1 \%$ EDC concentration in the absence of LPS. At this concentration BCol, JCol and BGel display no significant difference in serum IL-10 concentration when compared to the baseline sample whilst RTCol exhibits a significant decrease in IL-10 concentration $(p=0.031)$. Figure 4.30 (F) displays data from the LPS stimulated samples crosslinked at $1 \%$ EDC and show a similar trend to the unstimulated counterpart. At this concentration, when compared to baseline samples, RTCol exhibits no significant difference whereas BCol $(p=0.023)$. JCol $(p=0.004)$ and BGel $(\mathrm{p}<0.001)$ exhibit a significant increase in IL-10 concentration when compared to baseline blood following incubation.

\subsection{Discussion}

Following successful scalable isolation of JCol solutions in Chapter 3, the objective of this chapter was to assess JCol biocompatibility. Defined as the ability of a material to perform with an appropriate host response, JCol biocompatibility was assessed here in two ways. Firstly in assessing its effect on cellular viability and phenotypic stability using a host of human cancer cell lines and progenitor populations isolated from bovine donors. Secondly, JCol biocompatibility was assessed in terms of inducing a potential human immunogenic response, assaying for in vitro effects of JCol sponge scaffolds on peripheral blood mononuclear cells (PBMC) isolated from healthy human donors. JCol solution coated cell culture plastics demonstrated compatibility with human derived functional epithelial and mesenchymal cell line populations, maintaining cellular viability, proliferation rate 
and morphology in short term culture. No adverse affects were witnessed in comparison to mammalian sources of research grade collagen. Similarly, no significant activation of isolated PBMC cells were observed across a spectrum of innate and adaptive immune cells, in an in vitro immunogenicity model. Significantly, in line with the initial inflammatory response observed in the critical first 1-7 days post biomaterial implantation, PBMC cell cytokine release profiles in the presence of JCol scaffolds were found to be comparable to commercial bovine collagen sources. These results indicate that jellyfish derived collagen solutions are compatible with both coated plate cell culture and potential regenerative medicine approaches.

\section{Cell culture support matrix}

The ECM is a dynamic structure that is intimately linked to cellular behaviour such as proliferation, morphology and viability (Liberio et al., 2014). Integrins expressed by cells allow for the attachment of cells to ECM components, such as collagen, generating intercellular signalling cascades that control gene expression patterns. The microenvironment in which a cell exists therefore is an important determinant of it's functional development (Damsky and Ilic, 2002). Isolated ECM components such as collagen, elastin, fibronectin, laminin, vitronectin and even ECM peptides have been used in tissue culture to better mimic in vivo cell behaviour (Liberio et al., 2014).

Collagen, as the main component of connective tissue, has become an integral addition to cell culture practices for basic coating and gel preparations, enabling attachment cells to be grown (Somaiah et al., 2015b). Collagen coated tissue culture plates are used for cell attachment, growth and differentiation for many cell applications, providing rapid cell attachment, rapid recovery and healthy cell growth (Cooke et al., 2008). These plates are found in research labs for projects such as controlled differentiation of human embryonic stem cells and induced pluripotent stem cells into cells that resemble adult mesenchymal stem cells (Liu et al., 2012).

The influence of JCol on cellular function was initially tested here, in a 'pseudo' 3D environment. Routine tissue culture plastics were coated with JCol using methods previously employed by Sewing and colleagues (Sewing et al., 2017). Both the 
epithelial and mesenchymal cells grown on the JCol lawns adhered, proliferated and exhibited a wide distribution of cellular shape, indicative of biocompatible substrate. This may be due in part, to the non-mammalian peptide presentation (shown in Chapter 3) and or potential variations in triple helical structure, once again observed in Chapter 3, albeit in a sponge scaffold confirmation. The structure of collagen coated onto plates, both from the collagen source and the method of coating, has been shown to play an important role in material driven cell responses (Plant et al., 2009). Denatured collagen binds cells via the $\alpha v \beta 3$ integrin through recognition of the RGD peptide (Elliot et al., 2005). Cell response on denatured collagen has shown to have spread morphology and develop actin stress fibres compared to intact fibrillar collagen (Plant et al., 2009).

Epithelial cells are attached to the basement membrane, which signals for cell survival, proliferation and differentiation as well as cues that enable the cells to establish polarity (Lee and Streuli, 2014). Loss of cell polarity is associated with tumour initiation and is thought to be due, in part, to defective ECM turnover (Lee and Vasioukhin, 2008). Data obtained from R. pulmo collagen coated plates show that epithelial cancer cells remain viable and retain their proliferative capacity over a 4-day culture period. More importantly, using shape index as an indicator, the morphology of multiple cell types were seen to remain stable over the culture period. The importance of collagen binding motifs in cancer is highlighted by research that shows that vinculin may be important in the suppression of tumour metastasis as it reduces cell motility (Goldmann et al., 2013). Cell migration relies upon contractile forces and causes the alteration of cell shape to a more elongated form allowing movement through pores (Friedl and Gilmour, 2009).

The effect of collagen coating on cellular function may also be dependent on the time of cells cultured on the material. In vitro culture of cancer stem cells (CSCs) from cancers such as breast, ovarian and colon has been established using serum-free media, changing their anchorage-dependent nature to non-adherent and causing CSCs to form 3D spheroids (Arab-Bafrani et al., 2016). The culture of CSCs on collagen type I coated substrates has shown phenotypic maintenance of cells and increased expression of the CSC characteristic surface marker CD133 (Kirkland, 2009). Whilst lymphnode carcinoma of the prostate (LNCaP) cells, a prostate cancer 
cell line, were shown to display a round morphology and aggregate on collagen IVcoated cultures however they exhibited lower cell viability when compared to laminin, fibronectin and poly-amino acid coating (Liberio et al., 2014). On the other hand, bone marrow derived MSCs showed enhanced proliferation, cell adhesion and viability on collagen I culture dishes compared to traditional tissue culture plastic (Somaiah et al., 2015a).

Cells adhere to the ECM via large protein complexes termed focal adhesions (Maziveyi and Alahari, 2017). Actin filaments of stress fibres are found attached to the $\beta$ subunits of integrins via adapter proteins such as vinculin and vimentin (Lodish et al., 2000b). The clustering of integrins forms focal adhesions with the connection between ECM and cells allowing for signals to be bidirectionally transmitted (Radinsky et al., 2002). HESC cells were the only cells to exhibit a significantly rounder morphology on day 3 and 4 all coated plates when compared to day 1 . This may be due to a high cell density within the individual well rather than an effect of collagen coating. Human MSCs have been shown to take on a round morphology at higher cell densities even when seeded on soft substrates leading to the belief that cell morphology is governed not only by cell-matrix interactions but also cell-cell interactions (Venugopal et al., 2018). Pseudo 3D models produced by collagen coating have also been found to induce apical-basal polarity, which does not naturally occur in all cell types and therefore may change cell spreading and migration which may be another reason why HESC cells exhibited changes in morphology (Duval et al., 2017).

Chondrocytes undergo dedifferentiation during in vitro expansion exhibiting fibroblast morphology and altering collagen expression from type II to type I (Lee et al., 2017). The differentiation potential of these cells is lost with the increasing number of passages, which is needed in order to obtain the high cell number needed for cartilage repair strategies (Mark et al., 1977). R. esculentum collagen was been used to coat plates and assess the phenotypic stability of chondrocytes. Porcine chondrocytes were found to maintain the characteristic ovoid morphology showing that jellyfish derived collagen behaved in a similar fashion to vertebrate collagen type II in the stability of cell morphology (Sewing et al., 2017). Van den Dolder and Jansen worked on the culture of rat bone marrow derived cells on collagen-coated 
titanium meshes and found that cells decreased proliferation and stimulated osteoblastic differentiation compared to uncoated titantium mesh (Dolder and Jansen, 2006). Other studies have demonstrated that collagen-coated microcarriers enhance cell attachment and can maintain long term expansion of embryonic stem cells (McKee and Chaudhry, 2017a).

Culture of cells in 2D for in vitro expansion and analysis can often alter the function of cells. Primary human hepatocytes have been shown to lose hepatic function hours after 2D culture in vitro (Bell et al., 2018), embryonic stem cells (ESCs) have exhibited altered shape and gene expression (McKee and Chaudhry, 2017b) and pluripotent stem cells grown in collagen-coated culture flasks cause undesired gradients in media components, gas and waste (Kropp et al., 2017). Culture of cells on collagen coating may be improved by the addition of other ECM proteins to enhance biological complexity and better mimic the native $3 \mathrm{D}$ environment however this was beyond the scope of the project (Grun et al., 2009).

\section{JCol in vitro immunogenicity}

The immune response is a sophisticated biological reaction to foreign bodies (Andorko and Jewell, 2017). Divided into two phases, innate immunity is a rapid response involving leucocytes and cytokines whilst adaptive immunity requires $\mathrm{T}$ and B lymphocytes that can take days or weeks to develop (Parkin and Cohen, 2001). Biomaterials used for scaffold fabrication must not only have an architecture and mechanical integrity conducive for cell growth and differentiation but also avoid the elicitation of an immune response (Brown and Badylak, 2014). The failure of a scaffold to integrate into native tissue due to an adverse immune response can cause inflammation, infection and potentially necrosis of the tissue (Velnar et al., 2016).

Animal models are routinely used in the development of constructs for tissue engineering; both in primary experiments and stages before clinical application (Zorlutuna et al., 2013). Immunogenicity testing is typically carried out using mice however these animals are too small to properly evaluate the tissue that is formed so larger animals such as rabbits should instead be used for analysis of regenerated tissue formation (Ikada, 2006). The use of animal models does however raise ethical 
issues with researchers having to justify the use of animals by the purpose of the research having a clear significance to increasing scientific knowledge (Ghasemi and Dehpour, 2009). Immunogenicity can be evaluated through in vitro examinations to give preliminary results to support how a biological system may respond to a scaffold structure, which in turn, would give some justification towards moving to a more expensive, ethically challenging animal model (Hartung and Daston, 2009).

When designing an in vitro immunogenicity model, it is important to follow the guidelines stated by the International Organisation of Standardisation for biological evaluation of medical devices (Musson et al., 2013). The protocol outlines clear guidance for in vitro tests, which requires direct contact of cells to the material followed by quantitative or qualitative analysis of cell viability. This allows researchers to have a large degree of freedom when designing their experiments in terms of the chosen cell types and additional analysis (Scheideler et al., 2013). Most in vitro models consider varying aspects of both innate and adaptive immune systems using flow cytometry, from activation of immune cells to the concentration of cytokines released following exposure to the biomaterial of interest (Musson et al., 2013).

Radley and colleagues investigated the immunogenic potential of biomaterials as ventricular assist devices. Using FACS analysis and ELISAs and whole blood samples to assess cell death, activation of immune cells and cytokine release (Radley et al., 2017). The use of whole blood for immunogenicity testing is believed to be indicative of in vivo immune response as these assays aim to replicate the response involving immune cells such as neutrophils, monocytes and T-cells (Joubert et al., 2016).

The native mammalian response to tissue injury is well documented and can be categorised into different phases, outlined in Figure 4.31 (Brown and Badylak, 2014). Following tissue injury or insult, platelets are activated and form a provisional fibrin clot that signals for further cell migration (Broughton et al., 2006). Neutrophils are recruited to the site of inflammation and phagocytose any foreign material as well as signalling for the recruitment of macrophages, which are pro-inflammatory in their phenotype, secreting cytokines for further leukocyte recruitment (Barrientos et 
al., 2008). The secretion of cytokines subsequently initiates a proliferative phase at the injury site that exhibits the production and deposition of new ECM forming granulation tissue (Brown and Badylak, 2014). The final stage of the healing process is remodelling where MMPs degrade and remodel the tissue leading to either scar tissue formation or maturation (Diegelmann and Evans, 2004).

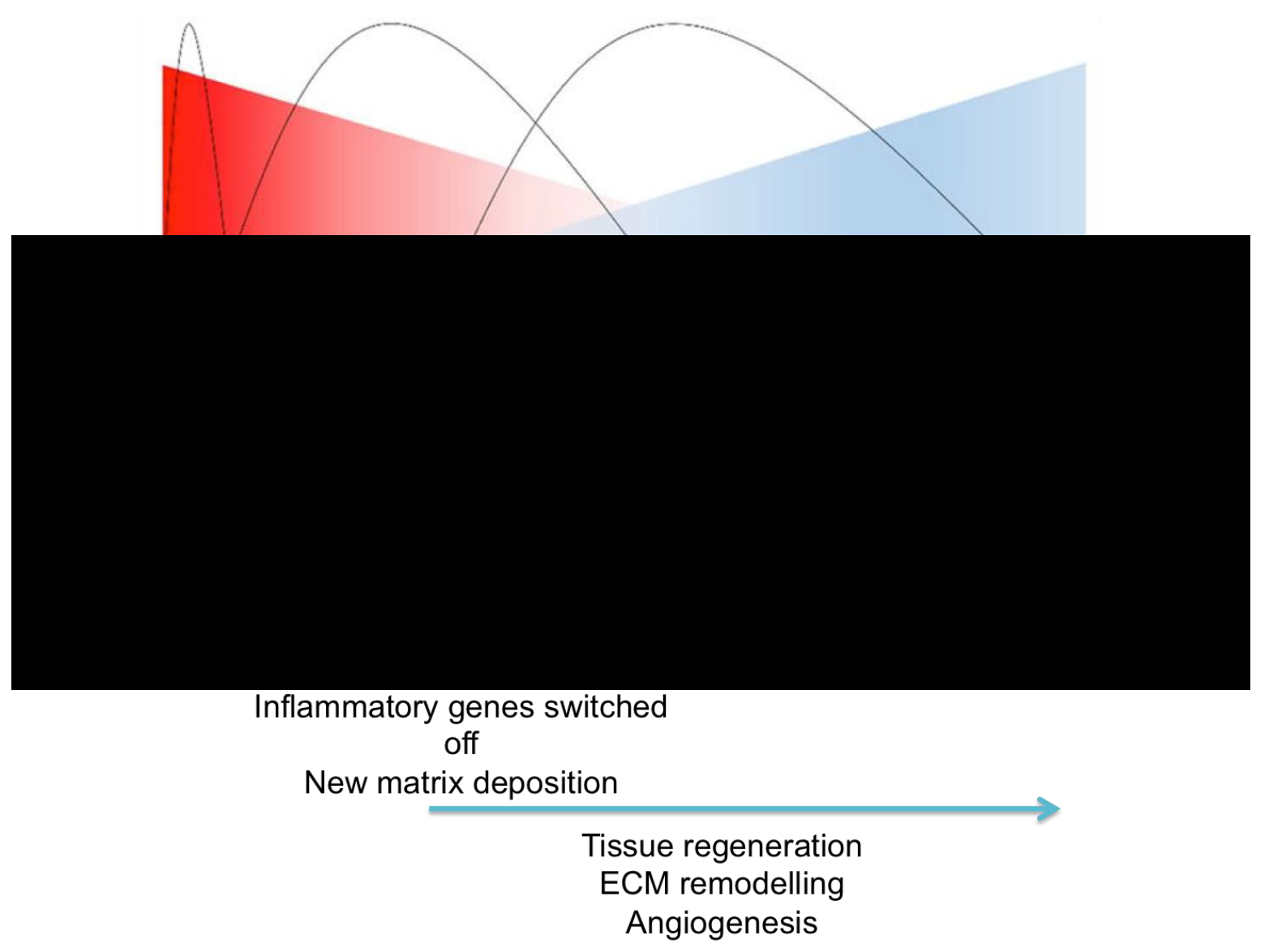

Figure 4.31: Schematic of established phases in wound healing. Initial inflammation decreases over time as regeneration of tissue occurs (Corradetti et al., 2017)

Blood is usually the first biological fluid to come into contact with tissue-engineered devices (Jones, 2008). The blood-material interface triggers a number of reactions including protein adsorption to the construct and platelet activation that may lead to coagulation and thrombosis (Andorko and Jewell, 2017). Collagen is seen as an important protein involved in the early stages of platelet activation during thrombosis (Morishige et al., 2011). Data from this chapter shows that platelet activation occurs 
in whole blood samples incubated with JCol scaffolds, however it was not as prominent as platelets stimulated with PMA. Comparable platelet activation occurred in all scaffolds tested, with comparable results between JCol and mammalian collagen sponge scaffolds.

Collagen is thought to be a suitable biomaterial for tissue engineering applications as it has previously been shown to exhibit low levels of immunogenicity (Lynn et al., 2004). Biomaterials composed of collagen and/or other native ECM components have been successful in the regeneration of functional tissues in both preclinical and clinical stages (Dziki et al., 2017). Intact, collagen triple helical structures are thought to contain telopeptide regions (Exposito et al., 2010). The R.pulmo extraction process described in Chapter 3, without pepsin digest, is thought to result in maintenance of the telopeptide region (Schmidt et al., 2015). Epitopes present at telopeptide region of tropocollagen molecules have been shown to be responsible for the initiation of an immune response, both in vivo and in vitro (Lynn et al., 2004). The conformation of the triple helix therefore, as well as the subsequent fibrillogenesis, may influence the immunogenic potential of collagen, possibly through controlling the accessibility of antigenic determinants (Parenteau-Bareil et al., 2010).

Jellyfish-derived collagen has previously been tested for its immunogenic properties and in vivo data has shown responses comparable to bovine collagen and gelatin (Song et al., 2006). However, jellyfish-derived collagen that maintained telopeptides displayed enhanced production of immune markers including IgM and IgG in human peripheral blood lymphocytes and cytokines release. This data indicates that structural composition of collagen plays a role in the immunogenic properties of the biomaterial (Nishimoto et al., 2008).

Data obtain in this experiment demonstrates that activation of neutrophils and monocytes occurs in blood incubated with scaffold structures however response from JCol scaffolds are comparable with that elicited from commercial and research grade BCol scaffolds and RTCol scaffolds, respectively. Within 24-48 hours of scaffold implantation, neutrophils begin to infiltrate the construct and undertake various roles in the innate immune response (Anderson et al., 2008). Typically, these cells are 
tasked with clearing pathogens via phagocytosis and recruiting other immune cell types to the site of injury (Cravedi et al., 2017). As well as clearing the implant of any pathogens, neutrophils are also responsible for beginning the degradation of biomaterial implants via MMPs and proteinase 3 and releasing cytokines to modulate the continuation of the immune response (Soehnlein, 2012).

Monocytes also play a role in the initiation of the inflammatory response through phagocytosis of pathogens and the release of inflammatory cytokines (Parihar et al., 2010). Stimulation of monocytes can cause differentiation into macrophages that continue the progression the immune response (Jakubzick et al., 2017). The excessive accumulation of monocytes has been associated with the aggravation of diseases such as multiple sclerosis and arthritis (Linker et al., 2009).

IL-6 is a pleiotropic pro-inflammatory cytokine primarily produced by monocytes and macrophages but can also be secreted by neutrophils, T and B cells (Horii et al., 1988). IL-6 has multiple functions including the differentiation of myeloid cells, activation of natural killer cells and affecting the adaptive immune response by stimulating the differentiation of T-cells (Striz et al., 2014). The IL-6 cytokine data shown here, indicates that scaffolds produced by jellyfish collagen cause a significant increase in IL-6 production compared to baseline blood however it should be noted that levels of IL- 6 production are similar to those produced by bovine collagen, currently commercially available, and therefore we believe the response caused by JCol could be overcome in vivo. With regards to the final application of jellyfish collagen scaffolds in cartilage tissue engineering, interestingly, anti-IL-6 antibodies have been shown to inhibit damage to joints and improve joint function in patients suffering with rheumatoid arthritis (Buckland, 2013). The results obtained from this study indicate that the levels of IL-6 should not be disruptive to tissues within the native joint therefore causing no increase in damage via IL-6 signalling pathway.

J774.1 cells, a mouse macrophage-like cell line, have previously been used in conjunction with collagenase treated Nemopilema nomurai jellyfish collagen to show enhanced immunostimulatory properties, particularly in the production of IL-6 (Putra 
et al., 2014). This, once again, suggests that the conformation of collagen molecules is important in the immunogenicity of the material.

The adaptive immune response is stimulated by the innate phase, which causes the proliferation and differentiation of T- and B-cells (Pennock et al., 2013). The primary role of T-cells is the destruction of infected cells however they are also able to recognise peptide fragments on antigen presenting cells such as macrophages and dendritic cells (Chaplin, 2010). T-cells are able to discriminate between self and nonself via MHC molecules (Bjorkman, 1997). The T-cell activation data from in vitro tests in this project show that T-cell activation levels were similar to baseline blood when whole blood was incubated with scaffolds from BCol, RTCol, BGel and JCol.

IL-10 is an anti-inflammatory cytokine that was originally associated with T-cells however recent research has discovered that IL-10 secretion can occur in a number of immune cells including monocytes/macrophages (Magombedze et al., 2015). The IL-10 data collected from our study is most likely to occur from secretion of monocytes as the time frame suggests that the adaptive immunity would not have taken effect. IL-10 has been shown to inhibit the differentiation of monocytes to dendritic cells and repress expression of inflammatory cytokines such as IL-1 and IL6 (Mosser and Zhang, 2009). Results of IL-10 data from this work show that it is expressed at much lower concentration $(\sim 0-60,000 \mathrm{pg} / \mathrm{ml})$ compared to IL-6 ( 0 $350,000 \mathrm{pg} / \mathrm{ml})$. The relative expression levels of cytokines may be due to the time frame in which the immune response occurs. Initial IL-6 expression is likely to occur, as inflammation is one of the key events that primarily occur in the immune response cascade. The lower expression of IL-10 may be contributed to the fact that inflammation has not been sustained over a long time period, becoming chronic, and therefore the need for an increased anti-inflammatory response is not yet required. More specifically, our IL-10 data showed that JCol scaffolds increased IL-10 production compared to baseline blood in LPS stimulated samples indicating that jellyfish collagen may have an additive effect upon immune response with LPS, however IL-10 production was comparable to that of commercial bovine collagen.

It is important to note that materials can be modified to enhance the immuosuppresive capabilities (Andorko and Jewell, 2017). Synthetic materials are 
often seen to elicit immune response upon implantation however this has been rectified through coating with native ECM material (Dziki et al., 2017). Studies have shown that polypropylene meshes coated with porcine dermal hydrogels reduced macrophage recruitment and formed loose connective tissue following ECM degradation (Wolf et al., 2014). ECM hydrogel coating of polypropylene fibres also decreased the amount of collagen deposition around the site of implantation leading to better integration of implant and native tissue (Faulk et al., 2014).

The augmentation of biomaterial-based scaffold, using cytokines in the immune cascade, can also be considered to potentially enhance the regenerative capacity of the construct. IL-4 is regarded as a pro-remodelling cytokine and meshes coated with IL-4 have exhibited a reduction in the formation of a fibrotic capsule, allowing for a better tissue-implant interface (Hachim et al., 2017). Preliminary in vitro immunogenicity results from this study seem to suggest that jellyfish collagen has a similar immunogenic effect on cells as bovine collagen, indicating that immunomodulation of the material is currently unnecessary. However, immunomodulation may be of interest following potential in vivo testing of jellyfish collagen scaffolds for cartilage tissue engineering, to enhance regeneration, as a shortened rehabilitation period is ideal for cartilage repair (Dunkin and Lattermann, 2013).

Notably, MSCs have been shown to modulate the immune response upon implantation into biological systems (Fahy et al., 2015). In vitro studies of MSCs have shown their capability of supressing $\mathrm{T}$-cell proliferation, regardless of the donor source leading to the belief that MSCs would be capable of dampening of evading the adaptive immune response (Abdi et al., 2008). Promisingly, in vivo clinical trials using MSC based cell therapy have displayed accelerated recovery of patients suffering with severe cases of graft versus host disease, however a limited number of studies have followed up on these results (Blanc et al., 2004). Nevertheless, it is important to understand that multiple components of the tissue engineering triad can affect the biocompatibility and immunogenicity of the final engineered tissue (O'Brien, 2011). 
In conclusion, this chapter shows that multiple cell types remain viable and maintain their proliferation rate when grown on jellyfish collagen coated plates, with cells cultured in this way also exhibiting phenotypic stability. Preliminary data was obtained by in vitro testing of immunogenicity, using human whole blood samples, showing clearly that JCol scaffolds have comparable platelet and leukocyte activation compared to $\mathrm{RTCol}$ and $\mathrm{BCol}$ scaffolds, considered research and commercial grade materials, respectively. Cytokine release profiles for proinflammatory IL-6 and anti-inflammatory IL-10 also showed comparable results across scaffold structures. These results show that $R$. pulmo derived jellyfish collagen scaffolds can be moulded into a stable structure that shows little in vitro immunogenicity and may be suitable for applications in regenerative medicine. 


\section{CHAPTER 5}

\section{R. pulmo Collagen Scaffolds for Enhanced Chondrogenesis}




\subsection{Introduction}

Once seen as a disease brought on by 'wear and tear' recent research has shown that $\mathrm{OA}$ is a multifactorial disease, taking into account factors such as genetics, ethnicity and physical activity (Musumeci et al., 2015). OA is an age-related disease resulting in pain, loss of joint mobility and disability, with its prevalence expected to rise as life expectancy increases, especially in the western world (Blalock et al., 2015). Affecting the entire synovial joint $\mathrm{OA}$ is characterised by the loss of articular cartilage (Amoako and Pujalte, 2014).

Combinations of abnormal mechanical loading and synovial inflammation are known to cause deregulation in chondrocytes that populate articular cartilage, causing a shift in the equilibrium of anabolic and catabolic processes in ECM remodelling (Goldring and Goldring, 2007). This shift, leading to cartilage tissue breakdown due to defective homeostasis results in a loss of tissue function. In addition, chondrocytes, the principal cellular components begin to undergo phenotypic change such as hypertrophy and osteophyte formation occurs (Goldring and Goldring, 2007). In cases where chondrocytes undergo epiphyseal differentiation, they begin to express collagen type $\mathrm{X}$, symptomatic of calcified tissue formation, leading to vascular invasion and loss of resistance against compression (Saito and Kawaguchi, 2010).

As cartilage has a limited capacity for self repair most partial and full thickness lesions require surgery. The choice of surgery is dependent on the type of lesion and surgical preference (García-Carvajal et al., 2013). As chondrocytes are characterised by their inability to migrate through matrix, early surgical approaches include microfracture and autologous chondrocyte implantation (ACI) (Windt et al., 2013), where the aim is to bring an exogenous source of cells to fill defects, either beneath the subchondral bone plate or autologous cells from joint cartilage. A two-step procedure, ACI requires the harvesting of the patients chondrocytes from a non weight-bearing portion of cartilage. Cells are then expanded for four weeks before being implanted into the defect and covered with a periosteal flap (McCarthy et al., 2016). Chondrocytes obtained in this manner can however lead to donor site 
morbidity, while chondrocytes cultured in monolayer have been known to dedifferentiate into a fibroblastic phenotype (Vinod et al., 2017).

\subsubsection{Matrix assisted environment}

Articular cartilage is avascular and contains a high extracellular matrix to cell ratio (Fox et al., 2009). The ECM, consisting of collagen and proteoglycans, provides an environment within tissues that supports cellular differentiation and function; impacting upon cellular behaviour by regulating processes such as gene expression, homeostasis and regeneration (Liu et al., 2017). It is accepted that the ECM provides particular cellular cues, sets physical boundaries for developing tissues and plays a particularly important role in the differentiation and maturation of multiple cell types during development. Interaction between cells and matrix can either occur through direct contact or through the matrix bound morphogens and growth factors (Behonick and Werb, 2003).

Matrix-assisted autologous chondrocyte implantation (MACI) is a regenerative medicine technique that is similar to ACI, with the addition of a matrix scaffold, to support guided tissue formation (Jacobi et al., 2011). Autologous chondrocytes are harvested and expanded to an appropriate number before being seeded into a biocompatible, biodegradable and mechanically suitable 3-dimensional (3D) scaffold structure (O'Brien, 2011). After four weeks of supported 3D cell culture, the scaffold is cut to size and implanted into the defect (Nixon et al., 2015).

By providing a more physiological growth environment, the use of a 3-dimensional matrix is believed to minimise the chance of cell de-differentiation and increase the chondrogenic potential of the implant (Niethammer et al., 2016). A number of collagen-based scaffolds are currently commercially available for MACI procedures including MACI, Novocart3D and CaRes. MACI is a type I/III collagen membrane whilst Novocart 3D is a chondroitin sulphate containing biphasic sponge, both of which are seeded with autologous cells and cultured before implantation. On the other hand, $\mathrm{CaReS}$ is a type I collagen gel where cells can be immediately mixed following harvesting and implanted after two weeks of culture (Chicatun et al., 
2017). Five year follow up studies following patients that have received MACI surgery for cartilage defects in the knee reported satisfactory and improved pain and movement from $58 \%$ to $98 \%$ of patients (Basad et al., 2014).

With MACI proving a successful surgical option, a myriad of materials have been tested for their cartilage producing properties in search for clinically relevant biomaterials (Jacobi et al., 2011). Synthetic polymers such as polylactic acid, agarose and alginate based hydrogels and protein based matrices fabricated from collagen and gelatin have all been tested for their capability for inducing chondrogenic differentiation to form cartilage, following seeding with cell sources and shortmedium term culture (Armiento et al., 2018). In vitro studies have routinely used pellet culture (matrix-free) as a control 3D model for the induction of chondrogenesis in MSCs (Watts et al., 2013). In this chapter, R.pulmo derived collagen is fabricated into a scaffold matrix and tested for its suitability in supporting chondroprogenitor differentiation in vitro.

\subsubsection{Chondrogenesis}

Chondrogenesis is a dynamic process that occurs during the development of vertebrates where cells undergo a specific differentiation process to form cartilage. Hyaline cartilage, composed of clusters of chondrocytes, originates from condensed mesenchymal tissues and is the precursor for endochondral bone development (Zuscik et al., 2008). The various stages of the process, including joint patterning, interzone formation, cavitation and morphogenesis are dependent upon a myriad of growth factors (Handorf et al., 2015).

When considering chondrogenic differentiation of stem cells, a critical component is the transforming growth factor beta (TGF $\beta$ ) family, which was once described as cartilage-inducing factor (Yu et al., 2012). The TGF $\beta$ superfamily contains a number of TGF $\beta$ isoforms as well as bone morphogenetic proteins (BMPs). The isoforms bind to ligands that activate type 1 (BMP) and 5 (TGF $\beta$ ) activin-like kinase receptors (ALKs), which in turn phosphorylate SMAD proteins that translocate to the nucleus and modulate cell-specific gene expression, outlined in Figure 5.1 (Kroon et al., 
2015). Previous developmental studies have shown a high level of TGF $\beta 2$ and TGF $\beta 3$ to be present in articular cartilage, whilst expressing a much lower level of TGF $\beta 1$. However in vitro experiments have shown that immature cartilage explants treated regularly with TGF $\beta 1$ promotes homeostasis of the tissue (Khan et al., 2013).

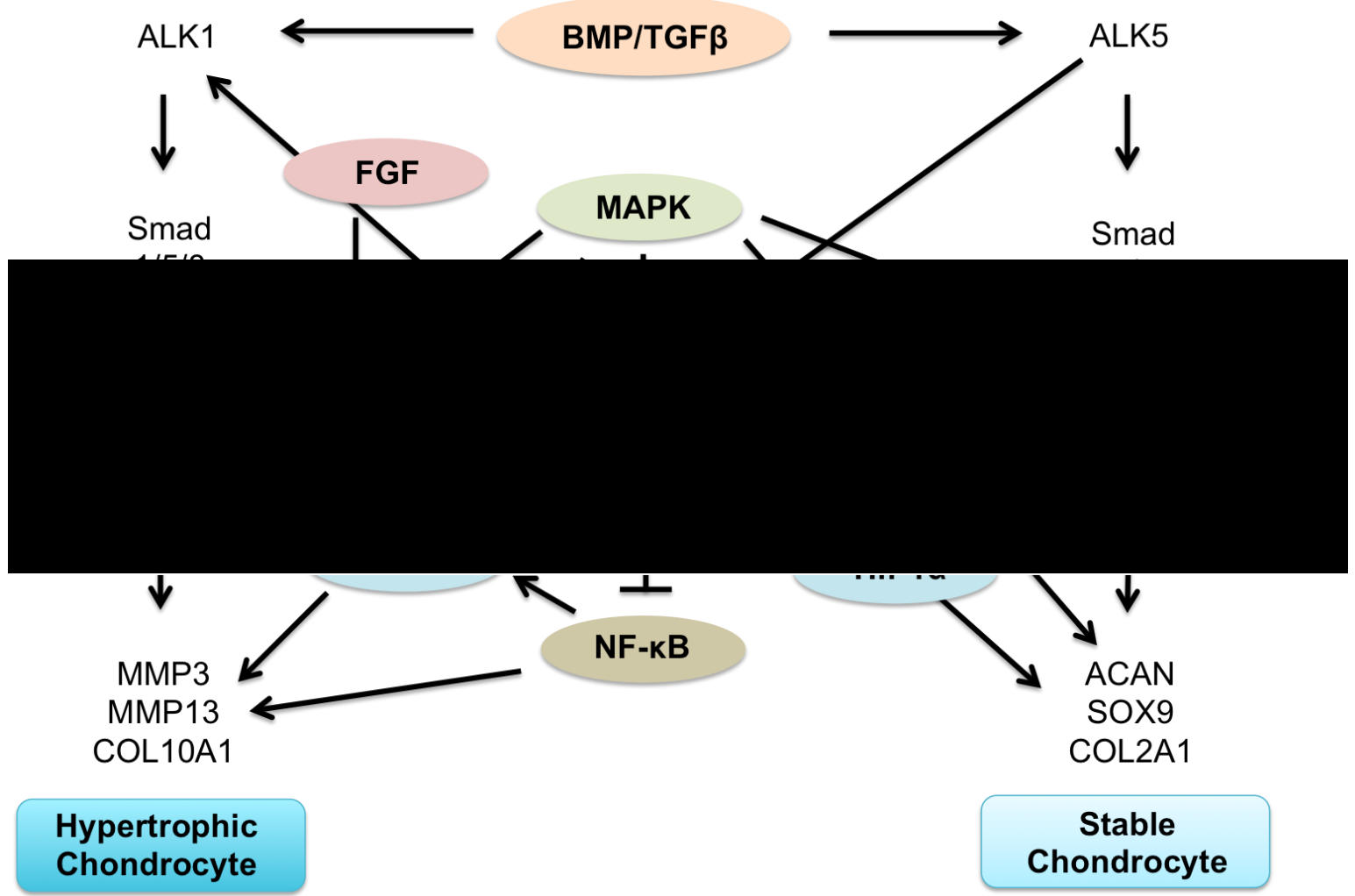

Figure 5.1: Schematic representation of signalling crosstalk for chondrocyte differentiation (Mariani et al., 2014)

The use of TGF $\beta 1$ as a growth factor to promote chondrogenesis may be ideal as it prevents terminal differentiation and formation of hypertrophic cells along with the over-expression of collagen $\mathrm{X}$, associated with the formation of calcified cartilage (Wang et al., 2014). Pellet cultures treated with TGF $\beta 1$ have shown to be larger and contain greater amounts of collagen type II as well as DNA content than their counterparts lacking the growth factors; further strengthening the argument that TGF $\beta 1$ is a suitable growth factor for cartilage regeneration (Goldberg et al., 2005). 


\subsubsection{Different matrix types}

A number of mammalian collagen-based materials are commercially available and used for MACI cartilage repair, however, research efforts are still focussed into finding suitable, sustainable sources of collagen that will aid in enhanced chondrogenesis (Jeuken et al., 2016). Previous studies have utilised jellyfish collagen from the jellyfish species Rhopilema esculentum as a scaffold material for cartilage repair. Both bodies of work produced a 3-D matrix that required crosslinking to maintain stability before seeding their preferred cell types; human bone marrow derived mesenchymal stem cells for cartilage repair. Culture of human MSCs on $R$. esculentum collagen scaffolds with chondrogenic media lead viable cells throughout the scaffold and an increase in chondrogenic markers such as COL2, ACAN and SOX9 (Hoyer et al., 2014).

\subsubsection{Cell source}

Within the clinical setting, chondrocytes are used routinely for cartilage restoration with both ACI and MACI using autologous chondrocytes to repair damaged tissue, correlating with better pain management and increased range of motion within the joint (Munirah et al., 2010). Using chondrocytes however, can be problematic due to their low proliferative capacity, leading to larger portions of cartilage being taken from healthy areas, increasing the chance of donor site morbidity. In addition, chondrocytes tend to dedifferentiate and produce collagen type I, characteristic of mechanically inferior fibrocartilage that is unsuitable for functional joint repair (Phull et al., 2016).

Cartilage tissue maintains a population of progenitor cells at the articular surface which are thought to be involved in appositional growth and are capable of chondrogenic differentiation (Marcus et al., 2014). The advanatges of such a progenitor population are two-fold; as a result of maintained niche-specific expression repertoire they maintain the ability to undergo chondrocyte differentiation and drive enhanced chondrogenesis and they are also compatible with culture expansion in large numbers (Jayasuriya and Chen, 2015b). In ovo studies involving 
bovine-derived chondroprogenitor cells have previously been engrafted into the wing bud of a juvenile chick and found to produce tissue specific matrix, further highlighting the plasticity of chondroprogenitor cells and their ability to form cartilage (Karlsson and Lindahl, 2009).

\subsubsection{Hypothesis}

The hypothesis for this chapter states that $R$. pulmo derived collagen scaffolds support bovine chondroprogenitors to undergo chondrogenesis (with TGF $\beta 1$ treatment) and will enhance cartilage production when compared to a non-matrix assisted (pellet) culture, under the same conditions.

\subsubsection{Aims and objectives}

The aims and objectives to test this hypothesis are as follows;

- Isolate chondroprogenitor cells from immature bovine cartilage and characterise these cells for plasticity by undergoing chondrogenesis, osteogenesis and adipogenesis in a $2 \mathrm{D}$ environment

- Undertake 21 day induction of chondrogenesis of cells with and without TGF $\beta 1$ in collagen scaffolds and pellet culture

- Assess structural properties of pellet and scaffold culture compared to native bovine cartilage using SEM

- Characterise ECM composition of scaffold and pellet culture compared to native bovine cartilage through analysis of hydroxyproline content, sulphated GAG content and collagen deposition via biochemical assays and histological staining

- Assess cartilage specific-gene expression of scaffold and pellet cultured chondroprogenitor cells in comparison to native bovine cartilage 


\subsection{Results}

Tissue engineering is a multidisciplinary field that requires a supporting structure with a 3D architecture, an appropriate cell source and media constituents to affect a functional differentiation to support new tissue formation (O'Brien, 2011). Collagen scaffold fabrication must take into account the porosity to enable cell invasion, nutrient diffusion and, in the case of this application, chondrogenesis. Stem cells have gained favour as a suitable cell source in regenerative medicine due to their plasticity, availability and lack of donor morbidity (Makris et al., 2015). The TGF $\beta$ family are known to have an extensive role in skeletal and cartilage formation, with TGF $\beta 1$ expression found at proliferative and upper hypertrophic zones whilst the tissue undergoes endochondral ossification (Grimaud et al., 2002).

\subsubsection{Bovine chondroprogenitor isolation and culture}

Chondroprogenitor cells isolated from articular cartilage have been show to have trilineage capability in vito and in ovo (Dowthwaite et al., 2004). The use of progenitor cells for cartilage regeneration is thought to circumvent issues that arise from using fully differentiated chondrocytes such as dedifferentiation and limited cell expansion in vitro (Marcus et al., 2014). Furthermore, the presence of growth factors and ECM molecules such as TGF $\beta$ and matrilin-3, have been shown to promote chondrogenesis in chondroprogenitor cells, with matrilin-3 also showing inhibition of hypertrophy, a common issue in cartilage regeneration (Jayasuriya and Chen, 2015a).

Due to an abundant supply and less stringent ethical implications bovine cartilage was chosen as the tissue source (Reinholz et al., 2004). The animal tissue used in this study was obtained from healthy animals entering the food chain, classified as food grade material that is discarded during food processing. 


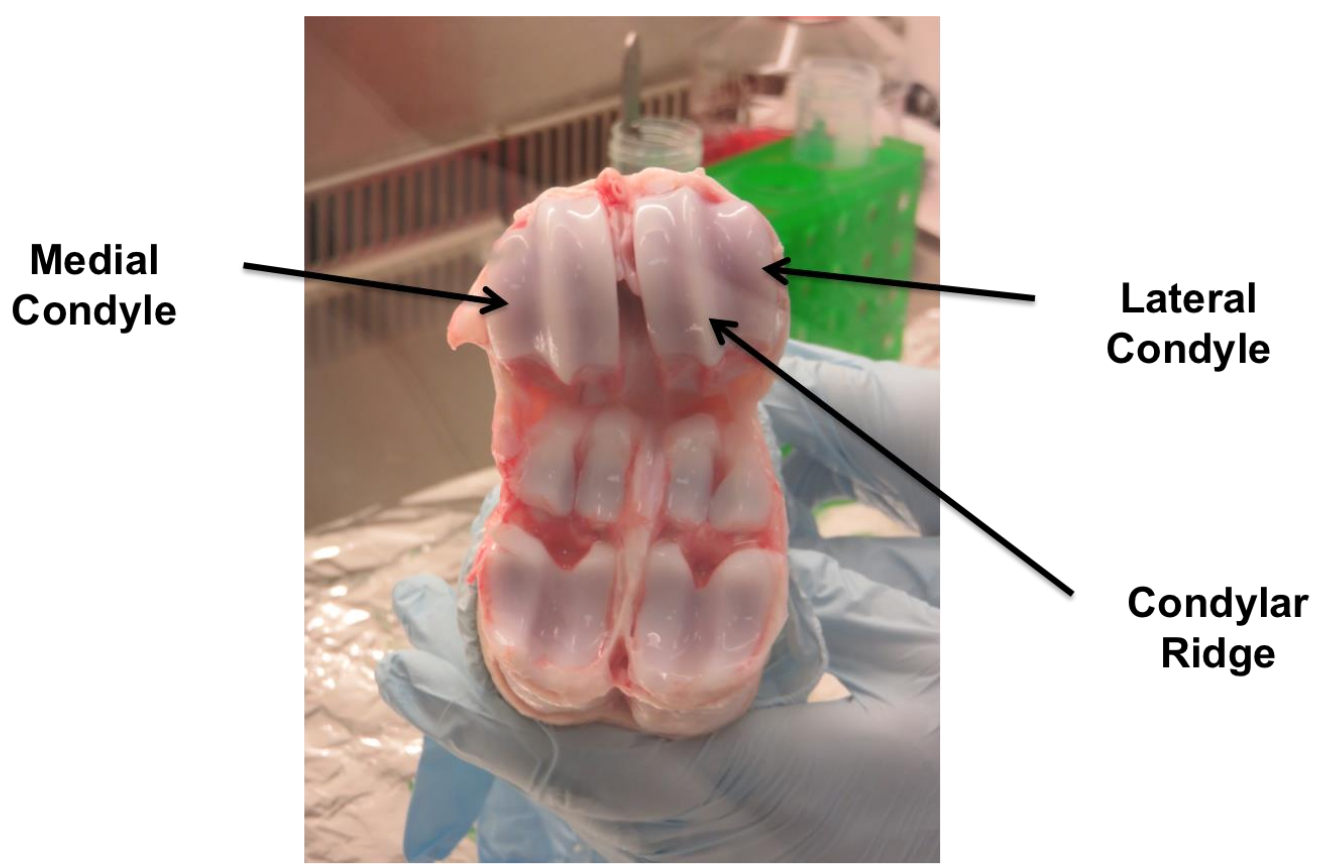

Figure 5.2: Bovine metacarpophalangeal joint. MCP joint obtained from immature bovine legs. Annotated areas of the joint depict regions from which cartilage was taken for chondroprogenitor isolation.

Following harvesting, the immature bovine legs were washed and decontaminated prior to MCP joints being opened to access the cartilage. Sections of cartilage were obtained from the medial and lateral condyle as well as the condylar ridge for digestion and isolation of chondroprogenitor cells as well as for histological staining and biochemical analysis, as depicted in Figure 5.2.

\subsubsection{CP isolation and tri-lineage potential}

Chondroprogenitors have a capacity to self-renew in vivo, in order to maintain a resident progenitor population to facilitate growth and repair. This capability to selfrenew enables chondroprogenitors to form colonies in 2D culture, where each individual colony is formed through repeated replication of an original cell (Jayasuriya \& Chen 2015). Colonies comprised of over 32 cells, representing colonyforming cells, were isolated from each other and expanded in basal culture media as monoclonal populations and prepared for tri-lineage assessment. 
Stem cells possess the ability of multi-lineage differentiation (Ullah et al., 2015). The minimum criteria for classification of MSCs is outlined by the International Society of Cellular Therapy and includes display of specific cell surface markers, plastic adherence and the ability to differentiate into adipocytes, chondrocytes and osetoblasts in vitro (Dominici et al., 2006). Figure $\mathbf{5 . 3}$ shows images of chondroprogenitor cells during trilineage differentiation.
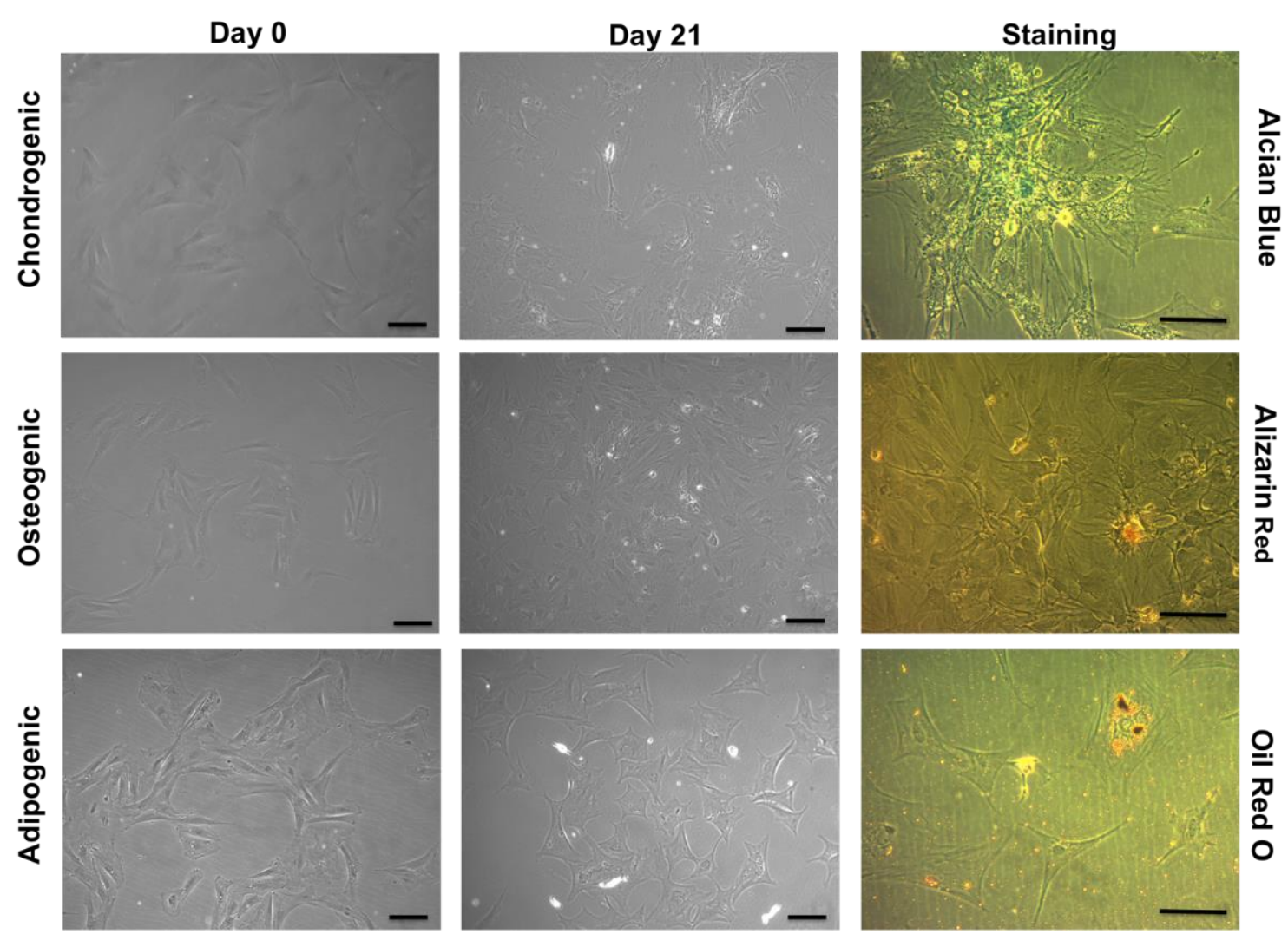

Figure 5.0.3: Images of chondroprogenitor cells during trilineage differentiation and stained cells after 21 days of culture. Chondroprogenitor cells were imaged at day 0 and 21 of chondrogenic, osteogenic and adipogenic culture. At day 21 cells were fixed and stained with Alcian Blue, Alizarin Red and Oil Red O to confirm differentiation into chondrogenic, osteogenic and adipogenic lineages, respectively. Scale bars show $0.1 \mathrm{~mm}$.

Figure 5.3 shows images of chondroprogenitor cells during tri-lineage differentiation. During chondrogenesis cells are plastic adherent and have a primarily fibroblastic morphology at day 0. By day 10 of chondrogenic culture, cells proliferate and maintain close contact with some cells losing their fibroblastic shape and becoming more rounded. At day 21, many cells can be seen to maintain a circular morphology, continue to maintain close contact to each other and clusters of 
cells are visibly stained with alcian blue confirming the production of extracellular matrix associated with chondrogenesis. Cells undergoing osteogenesis kept a fibroblastic morphology as well as being plastic adherent at day 0. Similar to chondrogenesis, cells underwent proliferation by day 10 and 21 and formed clusters where cells began to take on more circular morphology. When stained with alizarin red after 21 days of osteogenic differentiation to identify calcification, areas of cell cultures stained positively. When cells were subjected to adipogenic culture, at day 0 they maintained a fibroblastic morphology as well as being plastic adherent in the same fashion as cells undergoing chondrogenic and osteogenic culture. At day 10, unlike the other lineages, cells did not appear to proliferate at the same rate and morphological changes were more prominent, changing from fibroblastic to triangular and by day 21 cells did not appear to undergo proliferation and kept a triangular shape. After fixation cells were stained with Oil Red O and vacuoles within cells were stained red indicating the presence of fatty acid deposits.

\subsubsection{D enhanced chondrogenesis}

In order to facilitate the production of cartilage for regenerative medicine cells must undergo chondrogenic differentiation. The use of TGF $\beta 1$ is well documented as a growth factor to induce chondrogenesis and is used in vitro due to the role of the TGF $\beta$ superfamily in chondrogensis during development (Wang et al., 2014). Chondrogenic differentiation has previously been proven to be enhanced in a 3D culture environment when compared to $2 \mathrm{D}$ culture (Watts et al., 2013). The signature for in vitro enhanced chondrogenesis includes the production of collagen type II, aggrecan and SOX9 following 21 days of culture (Khan et al., 2009). Analysis of these characteristics can be accomplished in various ways including histological and biochemical examination as well as qPCR to quantify gene expression.

In this chapter, the assessment of enhanced chondrogenesis was carried out following isolation of bovine CPs, cell seeding into scaffold or pellet and 21 days of culture in chondrogenic media in the presence and absence of TGF $\beta 1$, outlined in Figure 5.4. 


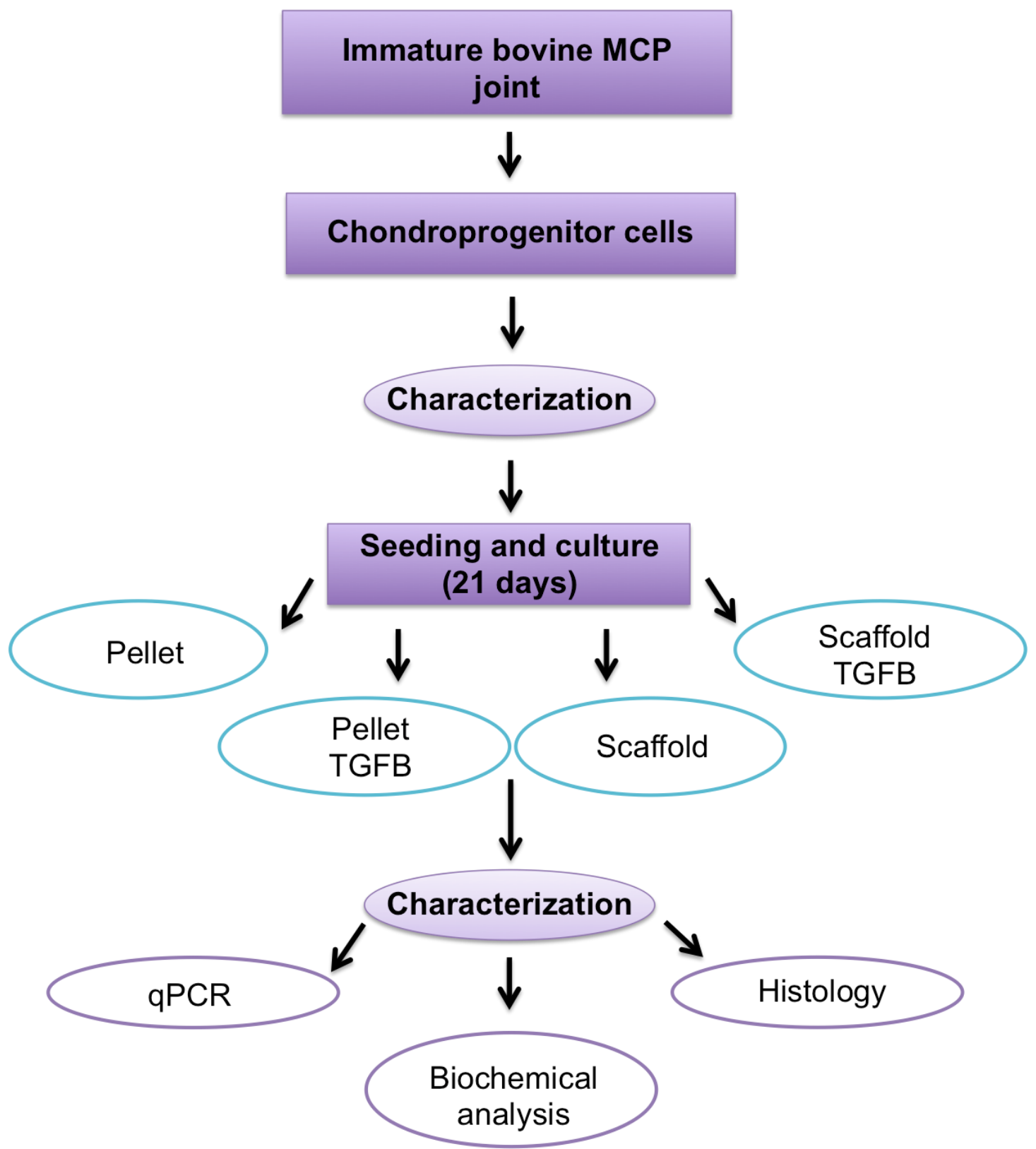

Figure 5.4: Approach for enhanced chondrogenesis. CPs isolated from bovine MCP joints were characterised and allowed to culture for 21 days in pellet or scaffold culture in the presence or absence of TGF $\beta$. Following completion of the culture period, constructs were analysed using biochemical analysis, histology and qPCR to give an enhanced chondrogenic profile.

\subsubsection{Scaffold characteristics for 3D culture}

Cellular function and tissue regeneration is closely related to pore size and so the fabrication of scaffolds with desirable pore size is fundamental step in tissue engineering (Zhang et al., 2014b). As shown in section 3.2.5.1.1 sponge scaffolds produced by JCol are highly porous and interconnected structures. EDC is a well 
characterised chemical crosslinking reagent that forms a network of crosslinks within collagen scaffolds and increases mechanical stability of the construct (Ma et al., 2014). Scaffolds fabricated 1\% EDC crosslinker concentration were chosen for chondrogenesis in agreement with work previously conducted by Hoyer and colleagues (Hoyer et al., 2014).

In order to determine which EDC crosslinking concentration would be appropriate for 3D chondrogenesis studies, scaffolds crosslinked with $1 \%, 0.5 \%$ and $0.25 \%$ EDC were seeded with bovine CPs and cultured for 7 days. Scaffolds were then fixed, embedded in paraffin wax and stained with haematoxylin before being imaged with a light microscope, shown in Figure 5.5.
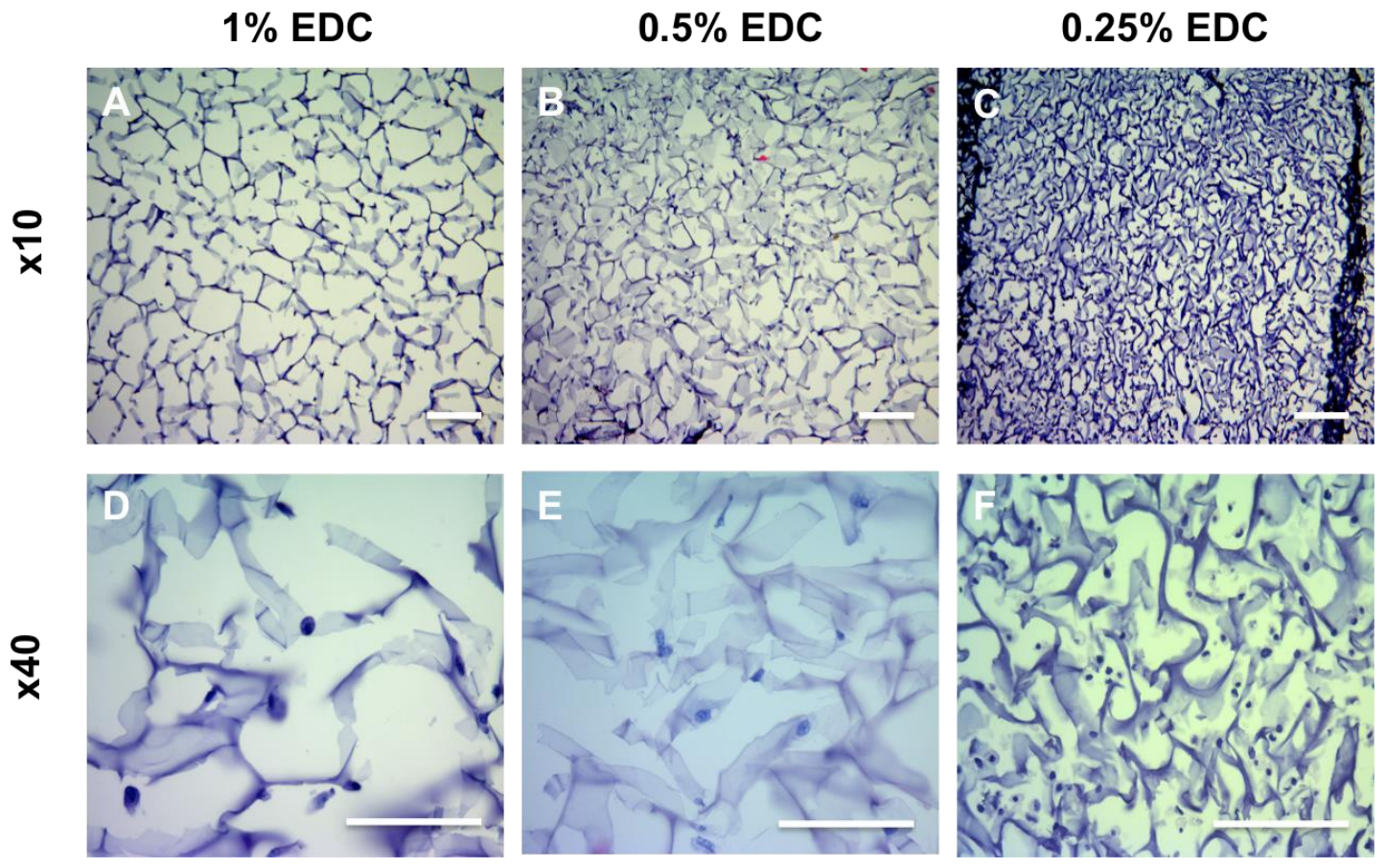

Figure 5.5: Early seeding studies using scaffolds with decreasing EDC crosslink concentrations. Bovine CPs seeded into scaffolds crosslined at $1 \%, 0.5 \%$ and $0.25 \%$ EDC and cultured for 7 days in chondrogenic media. Scaffolds were stained with haemotoxylin and eosin and imaged at x10 (A, B and C) and x40 (D, E and F). Scale bars show $0.1 \mathrm{~mm}$.

Figure 5.5 (A) is a low magnification (x10) image of a scaffold seeded with bovine CPs and stained with haematoxylin following 7 days of culture. The porous structure of the scaffold is maintained. When imaged at a higher magnification (Figure $\mathbf{5 . 5}$ (D)) circular cells are seen in close proximity to ribbons of collagen. Scaffolds 
crosslinked with 0.5\% EDC and imaged at low magnification are seen in Figure 5.5 (B). The porous structure of the scaffold was maintained however areas of the scaffold appeared to have contracted. At higher magnification, Figure 5.5 (E), circular cells stained with haematoxylin were present and attached or near to collagen ribbons in the same fashion as cells seen in scaffolds crosslinked at $1 \%$ EDC. Figure 5.5 (C) shows scaffolds crosslinked at $0.25 \%$ and stained with haematoxylin. At this concentration the scaffold exhibited the most contraction during the 7-day culture period altering the pore size within the scaffold. At $x 40$ magnification, Figure $5.5(\mathbf{F})$, a higher amount of cells can be seen compared to $1 \%$ and $0.5 \%$ crosslinked scaffolds they had a circular morphology and are attached to collagen ribbons in a similar manner to the other scaffolds.

Following preliminary results, it was decided that scaffolds crosslinked with $1 \%$ EDC would be taken forward for chondrogenesis studies as cells were found to invade the structure and minimal contraction of the scaffold occurring during culture.

JCol scaffolds were fabricated to a sponge support and crosslinked using 1\% EDC.

This resulted in a freeze-dried product with an average porosity of $54.76 \mathrm{um} \pm 4.72$ and a stable structure of interconnected pores seen using SEM (Figure 5.6 (A) and (B), respectively).
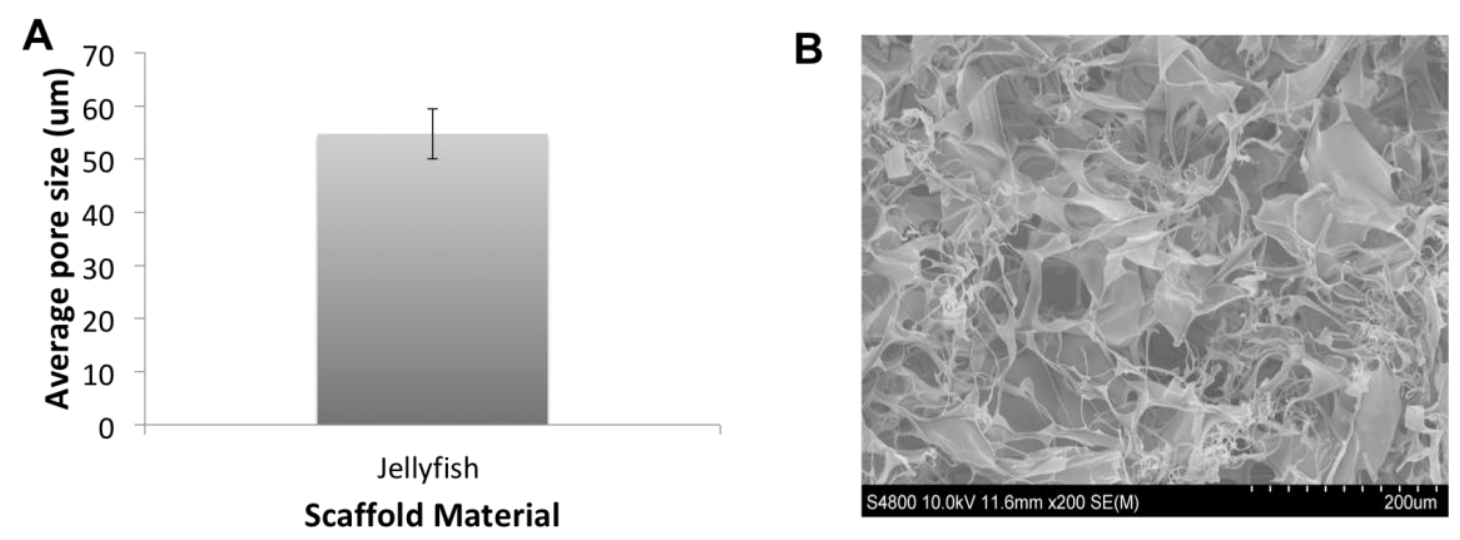

Figure 5.6: Average pore size and pore structure of JCol scaffolds. Average pore size of JCol scaffolds (A) and pore structure imaged at x200 magnification using SEM (B) crosslinked at 1\% EDC concentration. 


\subsubsection{Cellular invasion and proliferation}

Related to pore size, the permeability of a scaffold allows for cellular invasion and distribution as well as allowing for the diffusion of nutrients and waste, as well as the formation of essential cell-cell contact (Ashworth et al., 2016). Bovine CP cultures were seeded onto the scaffolds and assessed for their invasion and proliferation capacity. Haematoxylin and eosin (H\&E) staining is a standard stain used for histological examination of tissues allowing for the identification of tissue morphology and distribution (Chan, 2014).

\subsubsection{Native bovine punch biopsy baseline}

As a benchmark for enhanced chondrogenesis in vitro immature bovine MCP derived hyaline articular cartilage was stained using H\&E. Immature joint punch biopsies $(6 \mathrm{~mm})$ were washed in PBS, fixed in $10 \%$ NBF and wax embedded before being sectioned (7um) and stained with H\&E. Sections were then imaged using a light microscope at low and high magnification.

A

\section{S}

\section{M}

\section{D}

B

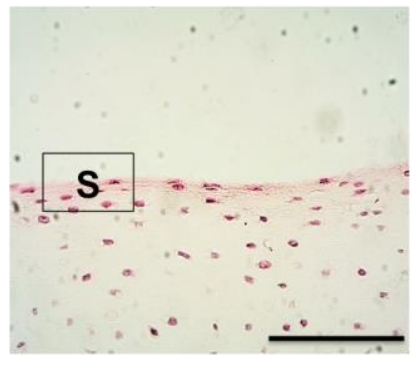

C

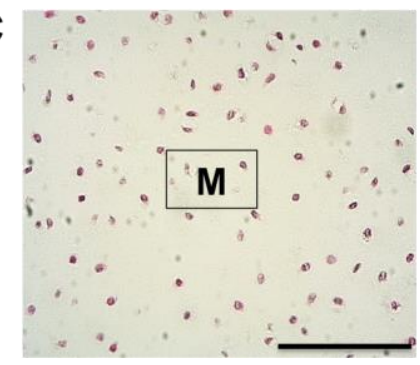

D

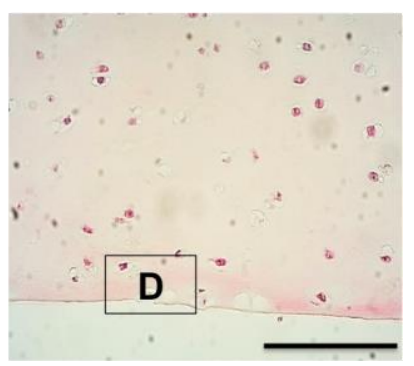

Figure 5.7: Hemotoxylin and eosin staining of immature bovine cartilage. Native immature bovine cartilage was stained using hematoxylin and eosin and imaged at low magnification (x4) (A) with superficial (S), middle (M) and deep (D) zones labelled. High magnification images (x40) were taken of the superficial (B), middle (C) and deep (D) zones. Scale bars are equal to $0.1 \mathrm{~mm}$. 
Figure 5.7 (A) shows the full depth of a section of native immature bovine cartilage obtained from the MCP joint and imaged at low magnification (x4). The depth of the cartilage is approximately $0.9 \mathrm{~mm}$ at the thickest section and the width of the section of tissue is approximately $5.1 \mathrm{~mm}$ and stained pink throughout. Figure 5.7 (B) shows the superficial zone of the cartilage at high magnification (x40). Cellular content is easily identified in this region, appearing as a dark pink colour, exhibiting a more flattened and discoid morphology. Superficial zone cells seem to maintain a closer proximity to each other with visible pink background staining of the tissue. The middle zone of the cartilage, seen in Figure 5.7 (C), also displays prominently pink stained cells that have a more circular morphology compared to those in the superficial zone. This zone exhibits numerous cells that are further spaced apart compared to the superficial zone, while there is no visible staining of the tissue.

Figure 5.7 (D) is a high magnification image of the deep zone of cartilage tissue. Cells again in pink, maintain a circular morphology and are sparse in appearance when compared to the other zones. Staining of the tissue is also consistently visible in the deep zone.

\subsubsection{Scaffold assisted CP invasion}

Culture-medium equilibrated scaffolds were seeded with $0.5 \times 10^{6}$ immature chondroprogenitor cells and cultured in 24 well plates for 21 days (Corradetti et al., 2016). In order to assess cell distribution throughout scaffold and pellet cultures following 21 days of chondrogenesis, constructs were fixed, embedded and sectioned before staining with H\&E. Sections were assessed using light microscopy and imaged at low and high magnification. 
A

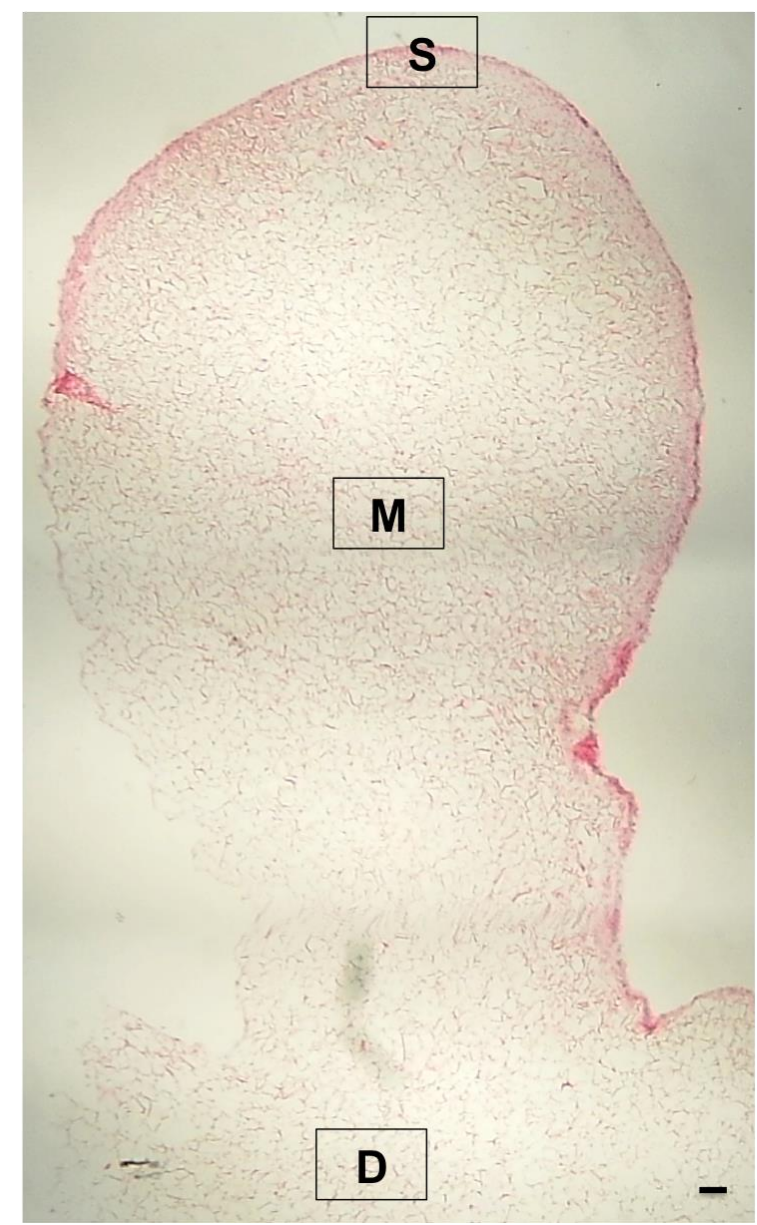

B

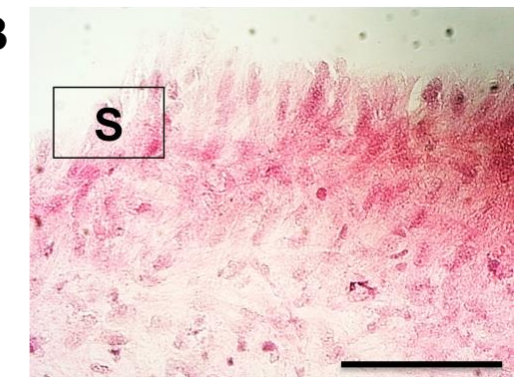

C

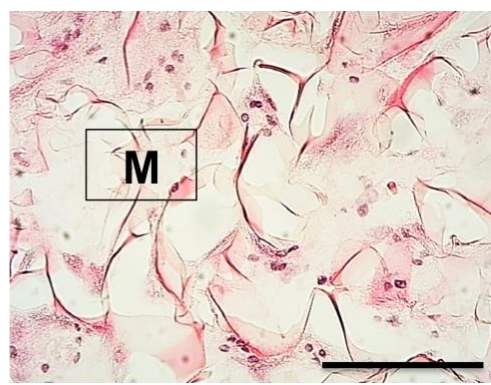

D

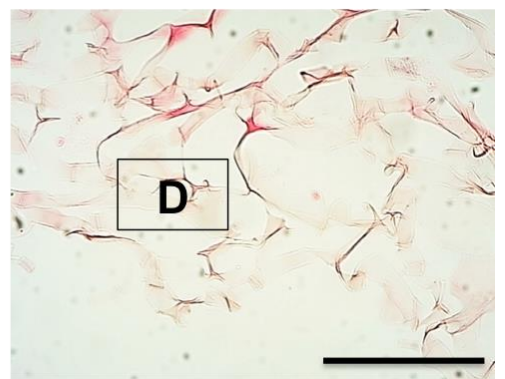

Figure 5.8: Hematoxyline and eosin staining of JCol scaffolds after 21 days of chondrogenic culture supplemented with TGFß1. JCol scaffolds (in the saggital plane) were stained using hematoxylin and eosin and imaged at low magnification (x4) after 21 days of culture using chondrogenic media containing TGF $\beta 1$ with superficial (S), middle (M) and deep (D) zones labelled. High magnification images (x40) were taken of the areas representing the superficial (B), middle (C) and deep (D) zones. Scale bars are equal to $0.1 \mathrm{~mm}$.

Figure 5.8 (A) shows a JCol scaffold in the saggital plane stained with hematoxylin and eosin and imaged at low magnification (x4) following CP seeding 21 days of chondrogenic culture with TGF $\beta 1$. The length of the scaffold is approximately $4.5 \mathrm{~mm}$ from superficial to deep zone. The width of the scaffold differed at different points, with an approximate width of $2.4 \mathrm{~mm}$ at $1 \mathrm{~mm}$ depth into the scaffold and $1.43 \mathrm{~mm}$ at $3.2 \mathrm{~mm}$ depth. A network of collagen can be seen stained in pink at this magnification with a more intense staining seen around some of the edges of the scaffold. 
A high magnification image of the area thought to represent the superficial zone, seen in Figure 5.8 (B), shows intense pink staining of the tissue. Some cells can be seen stained pink and are circular in morphology unlike those found in native cartilage that appear more disc-like in shape. The area believed to represent the middle zone, depicted in Figure 5.8 (C), shows collagen ribbons stained red with areas nearby stained a less intense pink colour. The cells in this area are circular in shape and maintain close contact. Figure 5.8 (D) shows a high magnification image of the area believed to be the deep zone. In a similar fashion to the middle zone, collagen ribbons are stained red with nearby areas stained less intensely. No cells are apparent in the deep zone of the scaffold. 
A

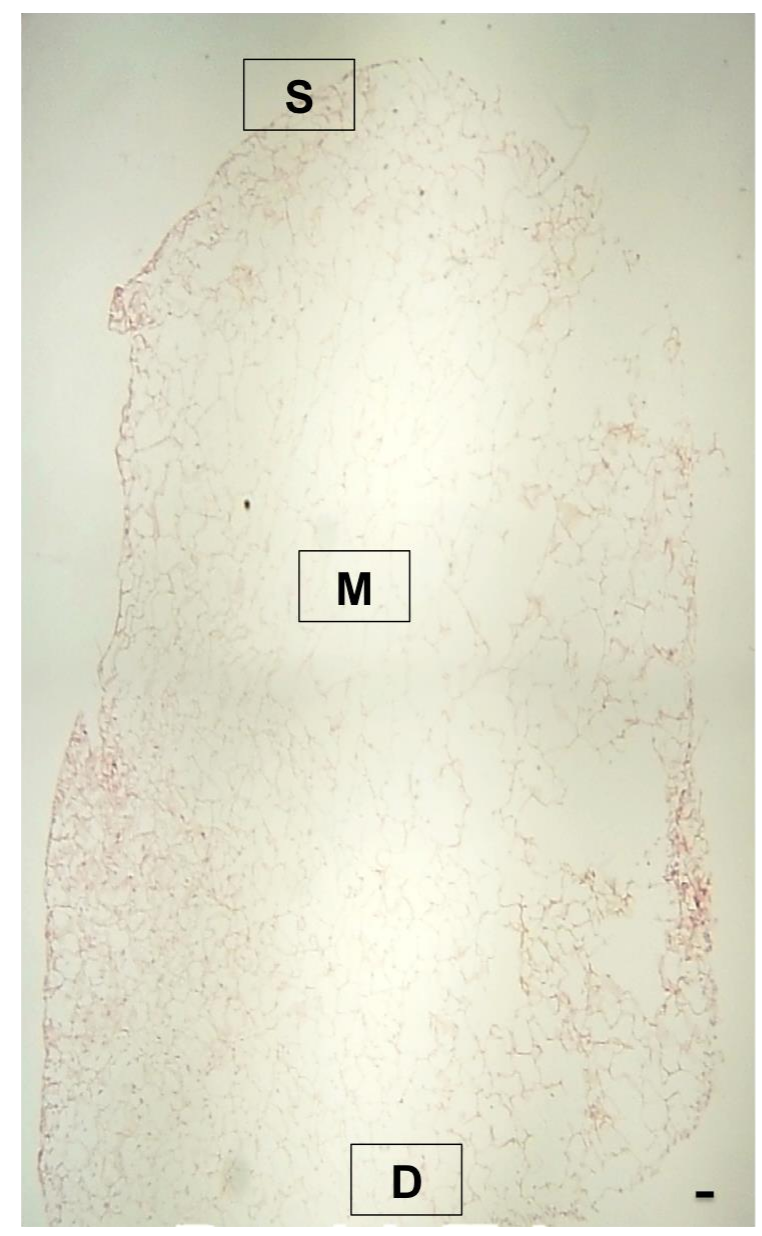

B

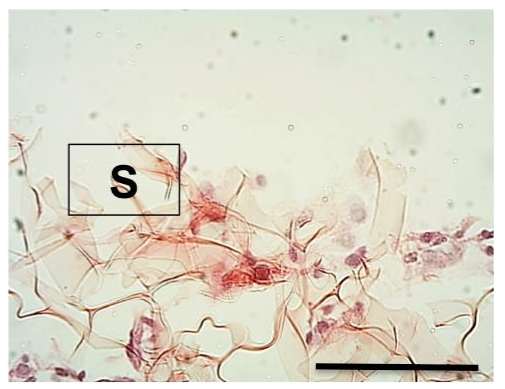

C

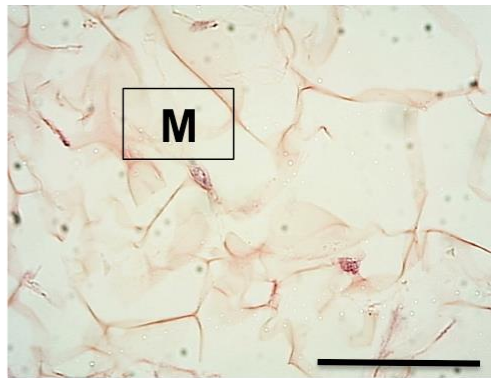

D

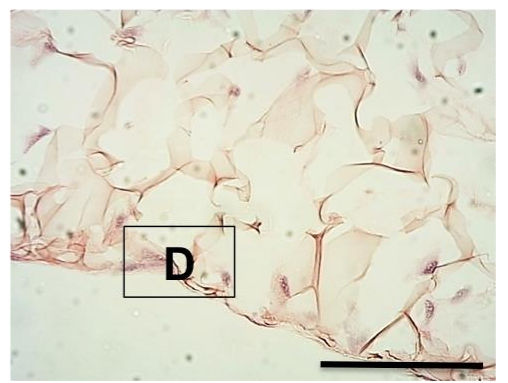

Figure 5.9: Hematoxylin and eosin staining of JCol scaffold after 21 days of chondrogenic culture without TGFß1. JCol scaffolds in the saggital plane were stained using hematoxylin and eosin and imaged at low magnification (x4) after 21 days of culture using chondrogenic media in the absence TGF $\beta 1$ with superficial (S), middle (M) and deep (D) zones labelled. High magnification images (x40) were taken of the areas representing the superficial (B), middle (C) and deep (D) zones. Scale bars are equal to $0.1 \mathrm{~mm}$.

Figure 5.9 (A) shows a low magnification (x4) image of a JCol scaffold following 21 days of chondrogenic culture without TGF $\beta 1$. At this resolution a network of collagen ribbons can be seen, stained pink, throughout the scaffold, which is approximately $5.86 \mathrm{~mm}$ in length and $3.01 \mathrm{~mm}$ in width. The width of the scaffold is more uniform unlike the scaffold with TGF $\beta 1$ treatment. Figure 5.9 (B) is a high magnification (x40) image of an area representing the superficial zone. Unlike TGF $\beta 1$ treatment scaffolds collagen ribbons were stained in red but at a decreased intensity and cells can be seen clearly stained in pink. The morphology of these cells is a mix of circular and discoid shapes maintaining close contact to one another. The middle zone of the scaffold, Figure 5.9 (C), depicts red stained collagen ribbons 
with large unstained areas between them when compared to the same zone of TGF $\beta 1$ treatment scaffolds. No cells appear to be visible within this zone showing a difference between untreated scaffold in comparison to treated scaffold and native tissue. Figure 5.9 (D) shows the deep zone of the scaffold imaged at high magnification. Staining of the deep zone of this scaffold highlights the collagen ribbons in red but does not show any cells to be present this far down into the scaffold.
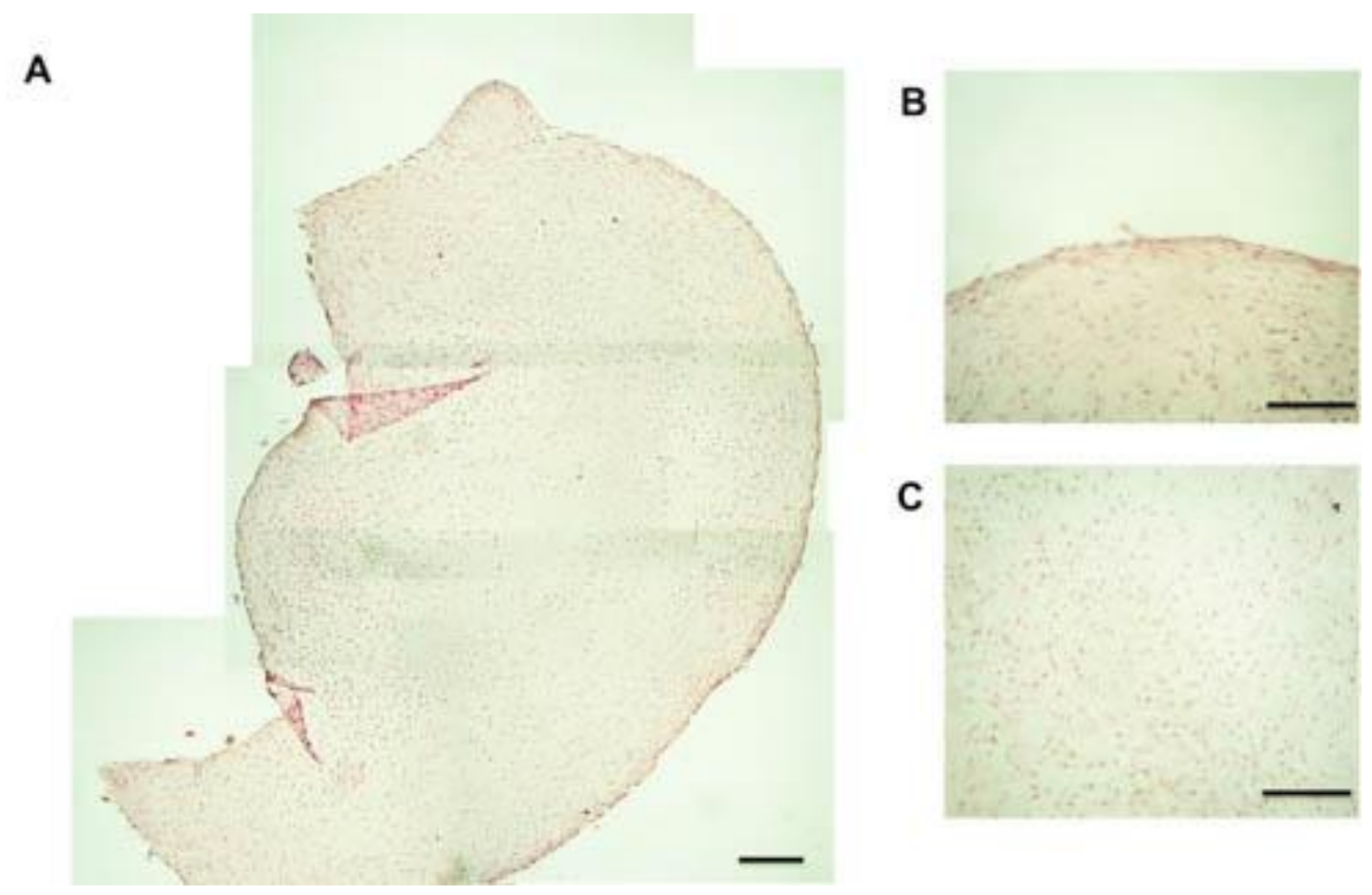

C

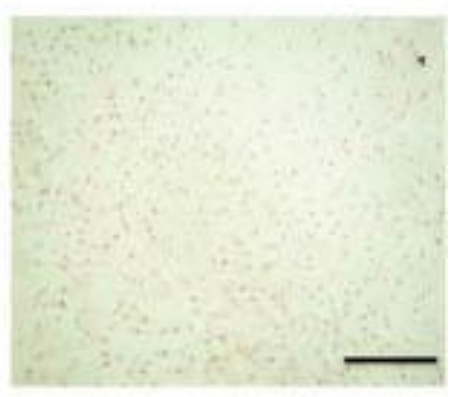

Figure 5.10: Hematoxylin and eosin staining of chondroprogenitor cells in pellet culture with TGFß1. Pellets were stained and imaged at low magnification (x10) following 21 days of chondrogenic culture with TGF $\beta 1$ (A). High magnification images (x20) were taken of the edge of the pellet (B) and the centre (C). Scale bars equal to $0.1 \mathrm{~mm}$.

Figure 5.10 (A) is a low magnification (x10) image of chondroprogenitor cells following 21 days of chondrogenesis in pellet culture in the presence of TGF $\beta 1$. The pellet is approximately $1.32 \mathrm{~mm}$ in length and $0.94 \mathrm{~mm}$ in width and has not kept a typical spherical shape. Faint pink staining is seen throughout the pellet however the intensity of staining is increase at the edges of the construct. The edge of the pellet is seen at high magnification (x20) in Figure 5.10 (B) a thin band of intense pink staining is seen at the edge before becoming more evenly distributed as it moves 
away from the edge. Figure 5.10 (C) is an image of the centre of the pellet at high magnification. A large number of cells can be seen throughout the entire image unlike what is seen in the scaffolds where the cells appear in contact with collagen ribbons leaving areas unpopulated by cells.
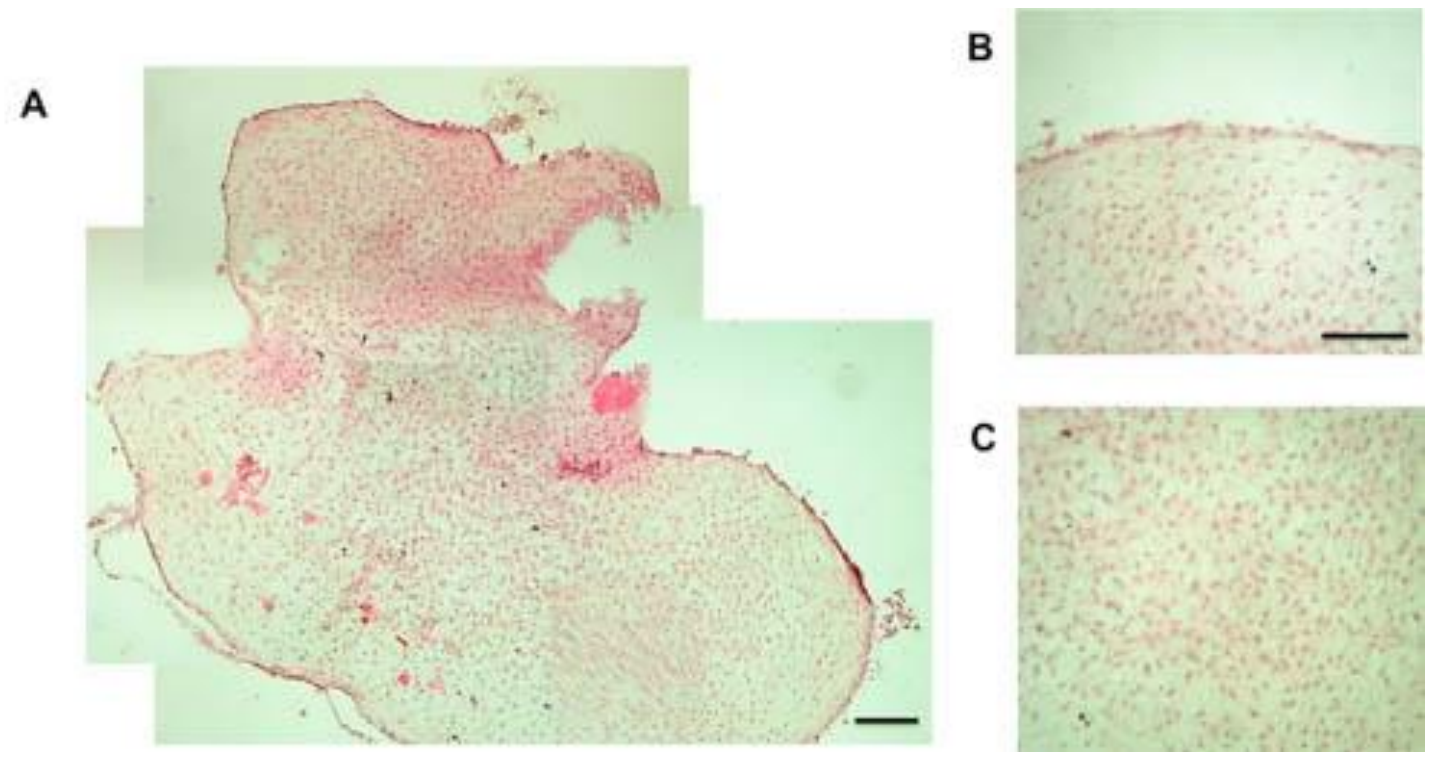

Figure 5.11: Hematoxylin and eosin staining of chondroprogenitor cells in pellet culture without TGFß1. Pellets were stained and imaged at low magnification (x10) following 21 days of chondrogenic culture without TGF $\beta 1$ (A). High magnification images (x20) were taken of the edge of the pellet (B) and the centre (C). Scale bars equal to $0.1 \mathrm{~mm}$.

Figure 5.11 (A) is a low magnification image (x10) of chondroprogenitor pellet culture in the absence of TGF $\beta 1$. The construct is approximately $1.06 \mathrm{~mm}$ wide and $1.02 \mathrm{~mm}$ in length. The pellet has not kept a typical spherical structure and appears to be less structured than pellets treated with TGF $\beta 1$. Staining for cells can be seen throughout the construct however the intensity varies throughout with darker staining seen towards the edges of the pellet. Figure 5.11 (B) shows the edge of the pellet at high magnification (x20) where a thin band of intense staining can be seen and even cell distribution is witnessed below the band and through the centre of the pellet, highlighted in Figure 5.11 (C). 


\subsubsection{DNA quantification}

To assess whether scaffold and pellet culture systems were conducive towards cell proliferation, quantification of cell number was obtained following 21 days of culture in chondrogenic media. On the completion of culture all samples were subjected to papain digestion and DNA quantified using a picogreen assay, shown in Figure 5.12. Each mammalian cell is believed to contain approximately $7.7 \mathrm{pg}$ of DNA allowing for an approximation of cell number, Figure 5.13 (Talukdar et al., 2011).
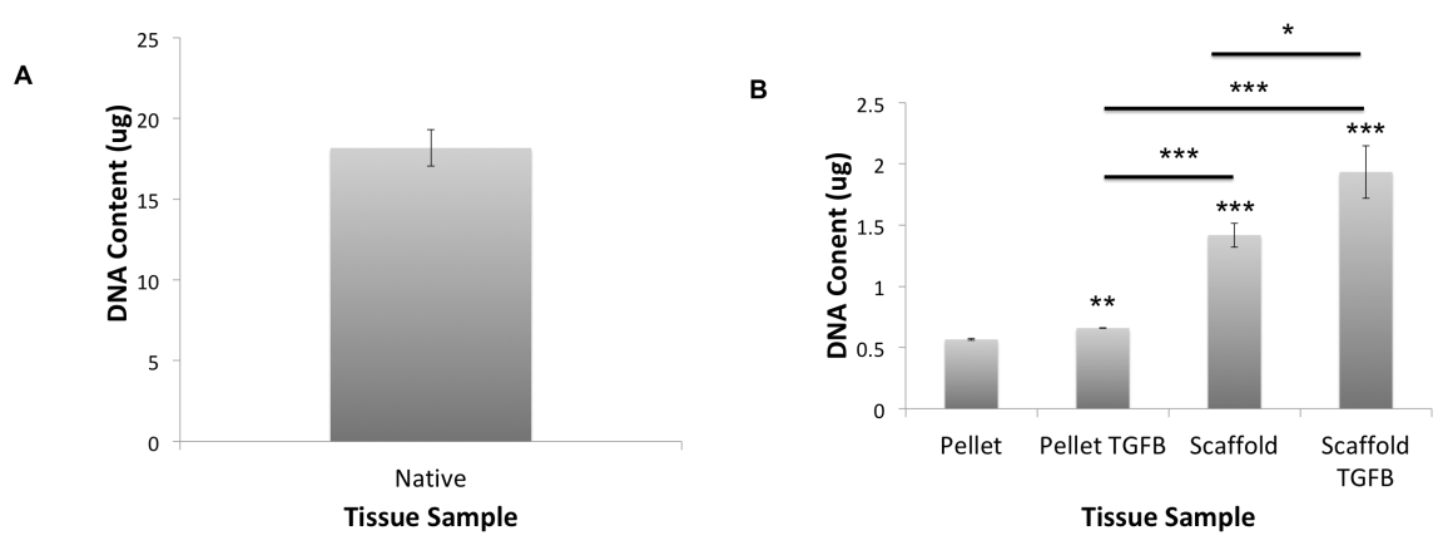

Figure 5.12: DNA content of pellet and scaffold structures. DNA content of native immature bovine articular cartilage (A) was taken as a benchmark. After 21 days of chondrogenic culture pellet and scaffold cultures with and without TGF $\beta 1$ were analysed for their DNA content. All data shown is from a minimum of 3 independent biological repeats, statistical significance shown according to a Mann Whitney U test $(* \mathrm{p}<0.05 ; * * \mathrm{p}<0.01 ; * * \mathrm{p}<0.001)$.

Figure 5.12 (A) shows DNA content of immature bovine articular cartilage obtained from the MCP joint via punch biopsy $(6 \mathrm{~mm})$. The average DNA content from native tissue was $18.17 \mu \mathrm{g} \pm 1.12$ and was used as a benchmark sample. The same number of cells were used to seed pellet as well as scaffold cultures. Figure 5.12 (B) depicts the DNA content of pellet and scaffold cultures following 21 days of chondrogenesis in the presence and absence of TGF $\beta 1$. Pellet cultures were shown to have $0.57 \mathrm{ug}$ of DNA, which was significantly lower when compared to scaffolds and TGF $\beta 1$ treated pellets and scaffolds, $\mathrm{p}=0.000, \mathrm{p}=0.002$ and $\mathrm{p}=0.000$, respectively. DNA content for TGF $\beta 1$ treated pellets was 0.66 ug, which was significantly lower than scaffolds in the absence and presence of TGF $\beta, p=0.000$ for both. When analysed for DNA content, scaffolds in the presence and absence of TGF $\beta 1$ had 1.93ug and 1.41ug 
DNA, respectively and TGF $\beta 1$ treated scaffolds exhibiting a significantly higher amount of DNA than the untreated counterpart, $\mathrm{p}=0.011$.

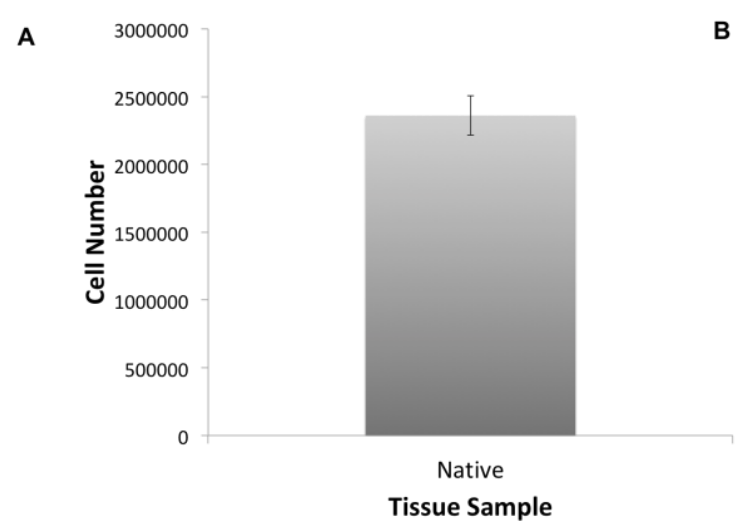

Figure 5.13: Cell number from pellet and scaffold structures following chondrogenesis. Cell number of native bovine articular cartilage was approximated from DNA content and used as a benchmark (A). Following 21 days of TGF $\beta 1$ treated and untreated chondrogenesis pellet and scaffold cultures were analysed for cell numbed using DNA content. All data shown is from a minimum of 3 independent biological repeats, statistical significance shown according to a Mann Whitney U test $(* \mathrm{p}<0.05 ; * * \mathrm{p}<0.01 ; * * * \mathrm{p}<0.001)$.

Figure 5.13 (A) shows the cell number from $6 \mathrm{~mm}$ punch biopsies of immature bovine MCP articular cartilage to be $235,999 \pm 145,689$. Cell number was also calculated for pellet and scaffold cultures in the presence and absence of TGF $\beta 1$, shown in Figure 5.13 (B). The trend displayed from cell number data is the same as DNA content. Pellet cultures exhibited an average cell number of 73,533, which was significantly lower than treated pellet $(\mathrm{p}=0.002)$ and scaffold $(\mathrm{p}=0.000)$ cultures and untreated scaffold $(\mathrm{p}=0.000)$ culture. The average cell number for treated pellet culture was 85,565 cells that were significantly lower than scaffolds in the presence $(p=0.000)$ and absence $(p=0.000)$ of TGF $\beta 1$. Scaffold cultures yielded a higher cell number after 21 days with untreated scaffold exhibiting 251, 219 cells and treated scaffolds exhibiting 184, 190 cells, displaying a significant difference between both conditions $(\mathrm{p}=0.011)$. 


\subsubsection{Proteoglycan synthesis}

Cartilage possesses a characteristically high amount of proteoglycan that plays various roles within the tissue from aiding in the initial assembly of the ECM to allowing for osmotic swelling following decompression (Knudson and Knudson, 2001). Osmotic pressure is obtained due to the proteoglycans drawing cations into the tissue through their negatively charged GAGs that are added during post translational modification, providing compressive resistance (McNary et al., 2012). The degradation of proteoglycans within cartilage is a characteristic of osteoarthritis and causes the breakdown of cell-matrix communication and fibrillar networks as well as altering the biochemical properties of the tissue making it unfit for the purpose of absorbing impact (Stanton et al., 2011).

Toluidine blue is a metachromatic dye that can be used to help identify the composition of tissues. Metachromasia is highly selective meaning that it can only stain certain structures within tissues by absorbing light at a different wavelength, changing the colour of the dye without altering chemical structures (Sridharan and Shankar, 2012).

\subsubsection{Native immature baseline}

Punch biopsies (6mm) from immature MCP joints were washed in PBS, fixed in $10 \%$ NBF. $7 \mu \mathrm{m}$ sections of wax embedded tissues were strained with toluidine blue and imaged with a light microscope. 


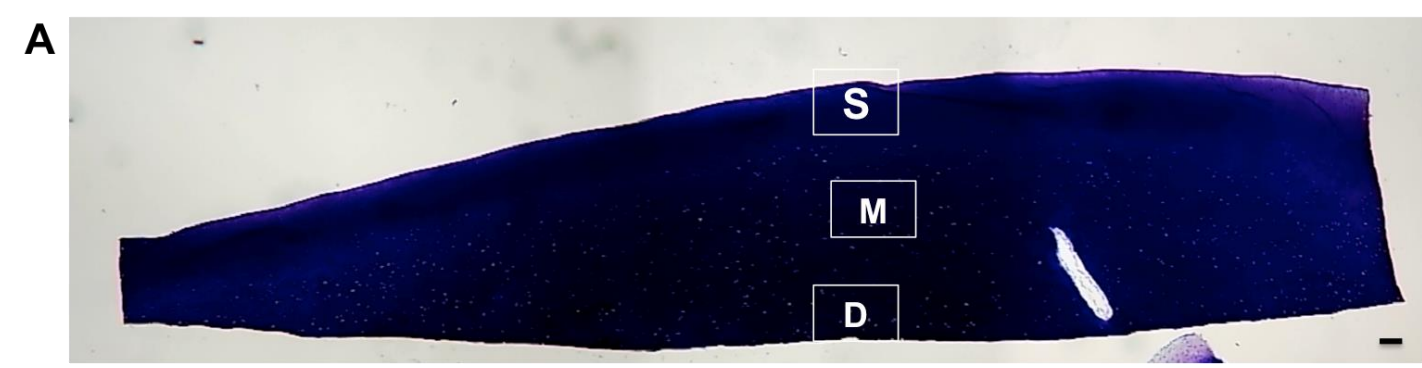

B
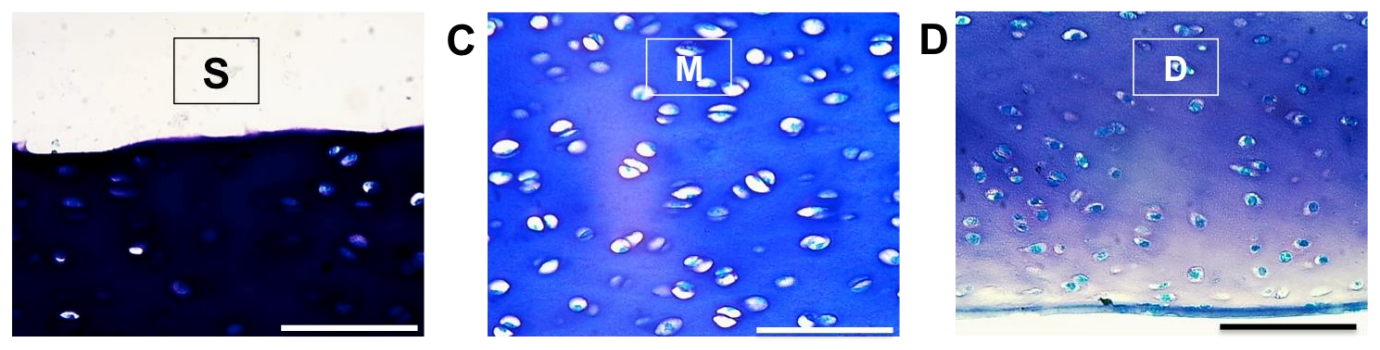

Figure 5.14: Toludine blue staining of immature bovine cartilage. Native immature bovine cartilage was stained using toluidine blue and imaged at low magnification (x4) (A) with superficial (S), middle (M) and deep (D) zones labelled.. High magnification images (x40) were taken of the superficial (B), middle (C) and deep (D) zones. Scale bars are equal to $0.1 \mathrm{~mm}$.

Figure 5.14 (A) shows a section of native immature bovine cartilage stained with toluidine blue. The approximate length and width of the section of tissue is $5.71 \mathrm{~mm}$ and $1.14 \mathrm{~mm}$, respectively. Dark blue staining is seen throughout the tissue whilst some regions appear to have been stained in a less intensely. Figure 5.14 (B) shows the superficial zone of cartilage at high magnification $(x 40)$ stained in a dark blue colour. The middle zone of cartilage, Figure 5.14 (C), is stained in a paler blue colour than the superficial zone. White areas with faint blue staining indicate areas populated by a cell depicting that the middle zone contains numerous cells that are close together. Figure 5.14 (D) shows the deep zone of cartilage, which appears blue towards the middle zone and a light purple colour the further down the stained tissue section. The edge of the deep zone is a deep blue colour. Just as seen in the middle zone, unstained sections containing bright blue dots indicated space occupied by cells that appear circular in shape and seem to be sparser than in the middle zone. 


\subsubsection{Scaffold assisted matrix deposition}

Scaffold seeded with immature CP cells and cultured for 21 days. Following culture, constructs were washed, fixed, embedded and sectioned. The assessment of proteoglycan production and deposition was done via toluidine blue staining on $7 \mu \mathrm{m}$ section of sample and imaged under a light microscope.

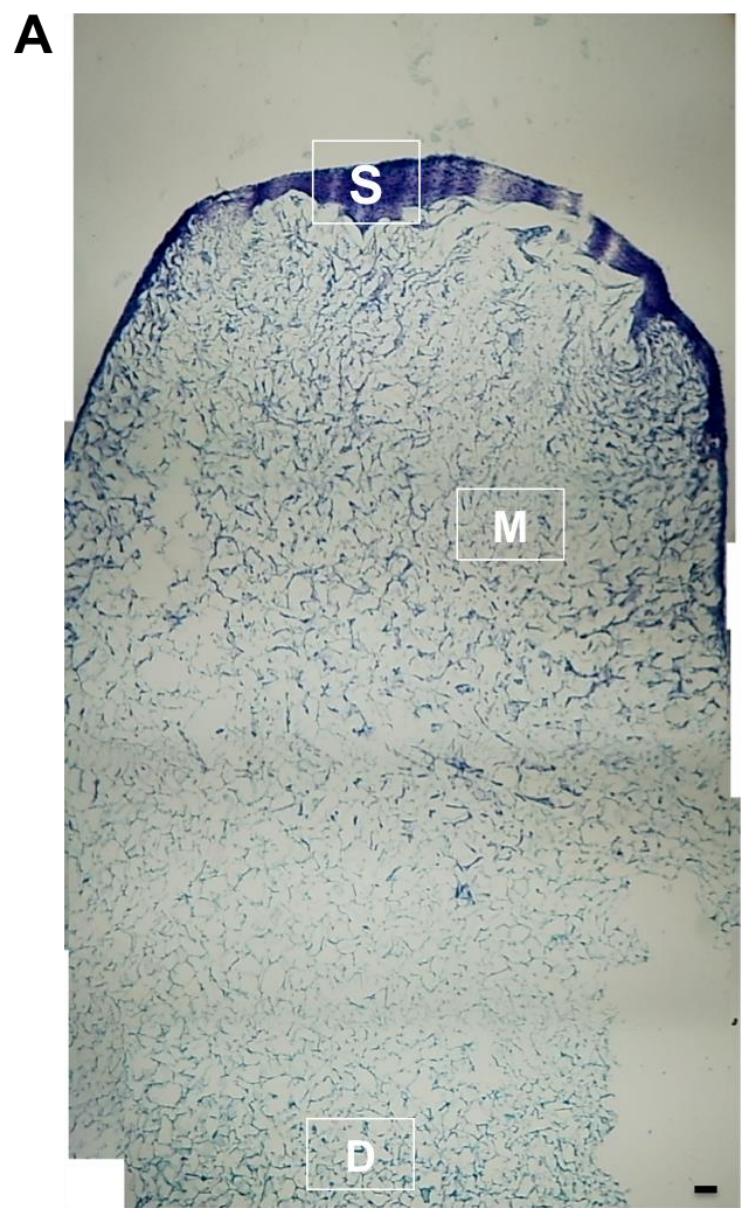

B

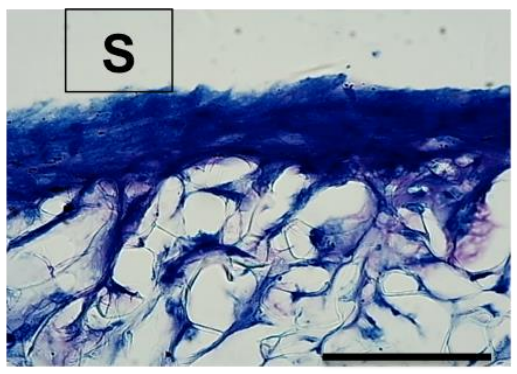

C

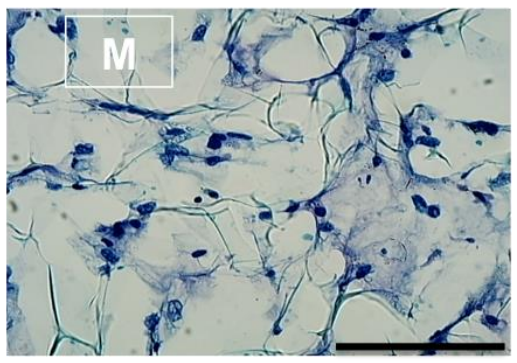

D

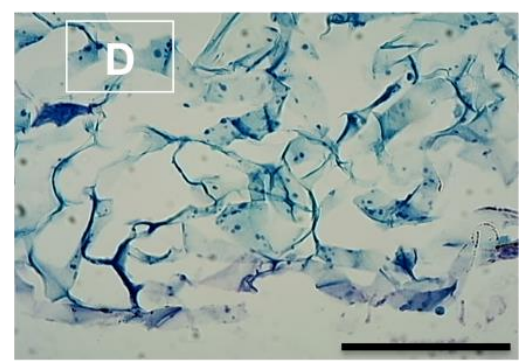

Figure 5.15: Toludine blue staining of JCol scaffolds after 21 days of chondrogenic culture supplemented with TGF $\beta 1$. JCol scaffolds were stained using toluidine blue and imaged at low magnification (x4) after 21 days of culture using chondrogenic media containing TGF $\beta 1$ with superficial (S), middle (M) and deep (D) zones labelled.. High magnification images (x40) were taken of the areas representing the superficial (B), middle (C) and deep (D) zones. Scale bars are equal to $0.1 \mathrm{~mm}$.

Figure 5.15 (A) is a low magnification ( $x 4$ ) image of a JCol scaffold after chondrogenic culture with TGF $\beta 1$ with an approximate length and width of $4.71 \mathrm{~mm}$ and $2.77 \mathrm{~mm}$, respectively. At this magnification the network of collagen has been 
stained blue, with darker staining seen up to $0.067 \mathrm{~mm}$ before the staining becomes less intense. Unlike native tissue there are unstained areas throughout the scaffold whilst the edge of the scaffold has a deep blue stain that is $0.15 \mathrm{~mm}$ thick. Figure 5.15 (B) shows the superficial section of the scaffold at high magnification ( $x 40)$ exhibiting a thick blue layer at the edge with some purple staining in areas surround the collagen ribbons. In the middle zone, Figure 5.15 (C), collagen and cells are stained in dark blue. Areas close to collagen ribbons are stained in a faint purple colour in a similar fashion to that of the superficial zone of the scaffold. Figure 5.15 (D) depicts the deep zone of the scaffold. In this section the collagen is stained in dark blue as it has been throughout the entire construct however there does not appear to be any staining bridging collagen ribbons in the same fashion seen in the middle and superficial zones. 

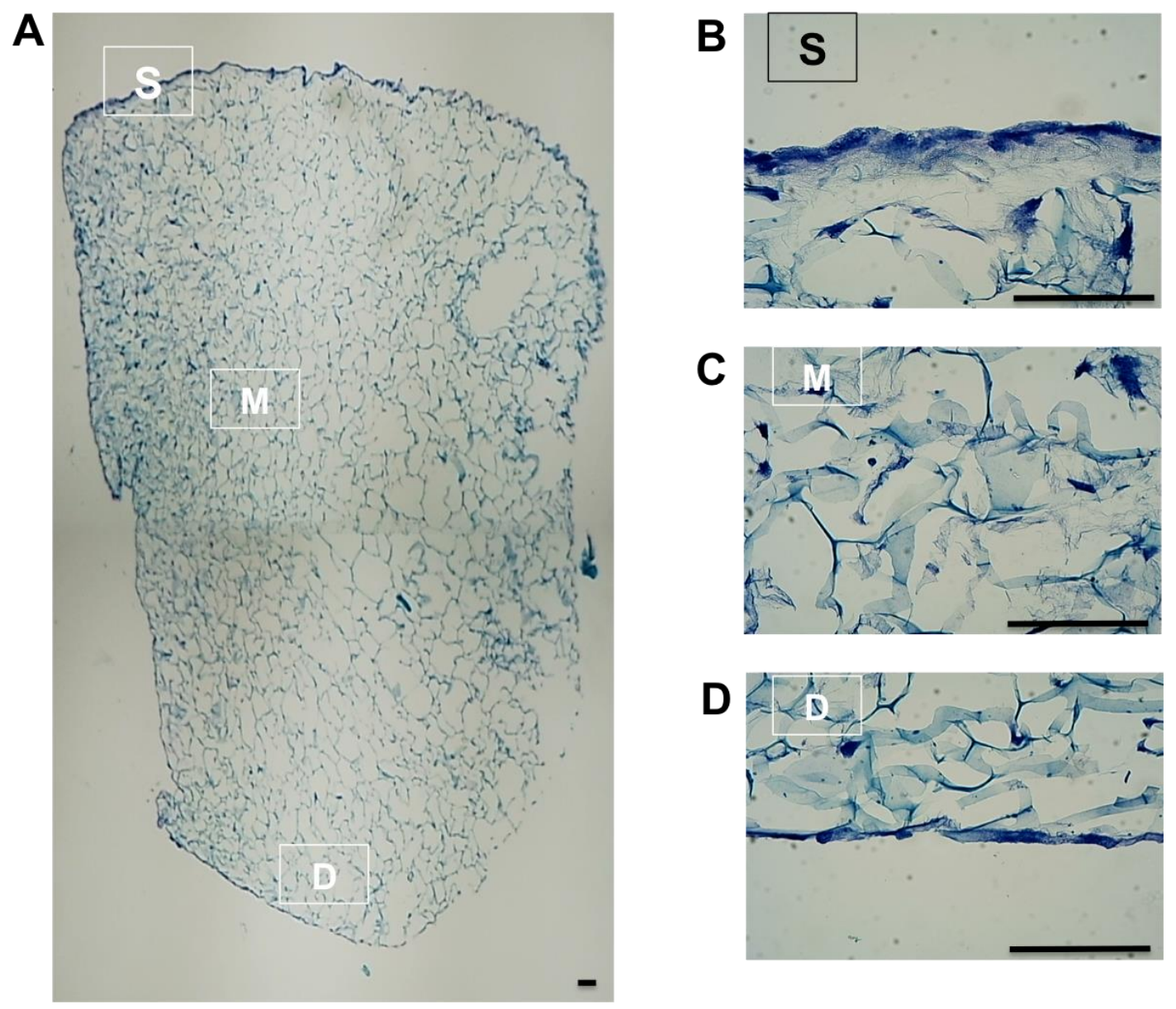

Figure 5.16: Toludine blue staining of JCol scaffolds after 21 days of chondrogenic culture without TGFß1. JCol scaffolds were stained using toluidine blue and imaged at low magnification (x4) after 21 days of culture using chondrogenic media in the absence TGF $\beta 1$ with superficial (S), middle (M) and deep (D) zones labelled. High magnification images (x40) were taken of the areas representing the superficial (B), middle (C) and deep (D) zones. Scale bars are equal to $0.1 \mathrm{~mm}$.

Figure 5.16 (A) shows a JCol scaffold, imaged at low magnification (x4), without TGF $\beta 1$ treatment, with a length of $4.95 \mathrm{~mm}$ and a width of $2.93 \mathrm{~mm}$ at $1 \mathrm{~mm}$ depth and $2.22 \mathrm{~mm}$ at a depth of $3.72 \mathrm{~mm}$. The network of collagen is stained in blue throughout the entire scaffold with visible unstained gaps within the pores. Figure 5.16 (B) depicts the superficial region of the scaffold with collagen stained in blue and the edge of the scaffold have a slightly thicker blue stain but this is not as prominent as the TGF $\beta 1$ treated scaffold. Figure 5.16 (C) shows the middle zone of the scaffold at high magnification (x40) with collagen stained in blue however the areas between collagen ribbons do not appear to be as intensely stained as those in the same zone of TGF $\beta$ treated scaffolds. The deep zone of the scaffold, shown in 
Figure 5.16 (D), shows collagen ribbons stained in blue with no apparent staining in between ribbons and no cells visibly stained in this region.

A

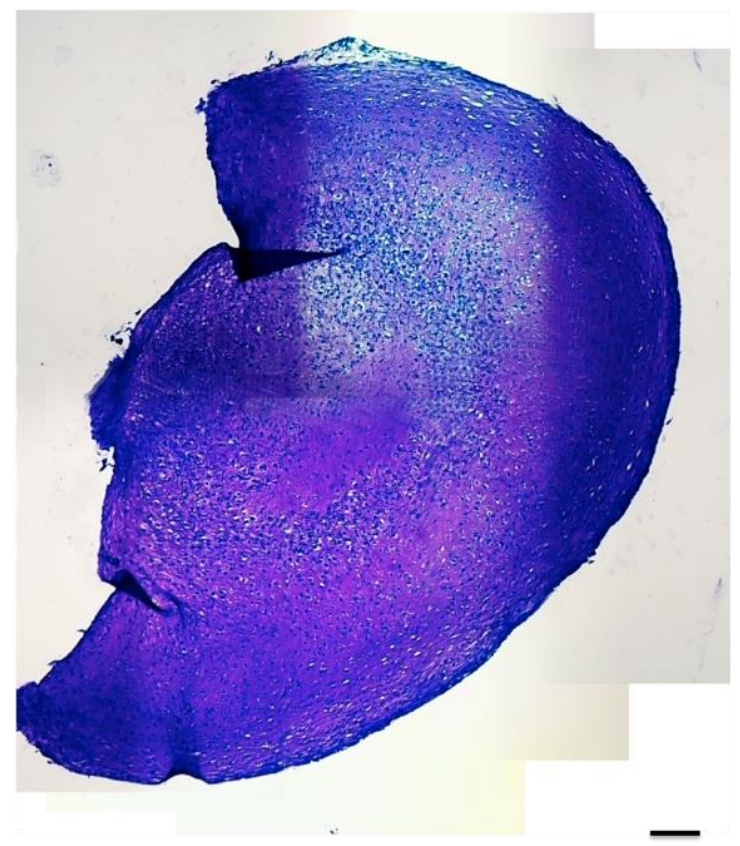

B

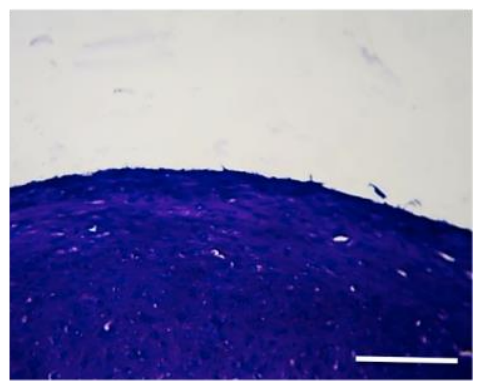

C

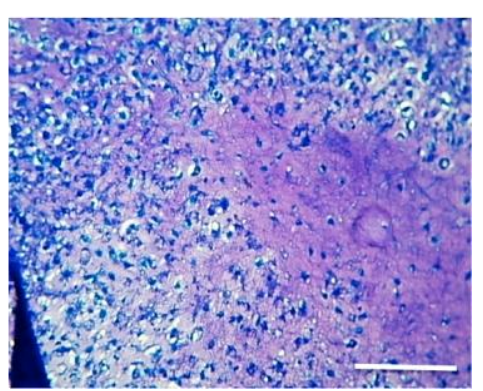

Figure 5.17: Toluidine blue staining of chondroprogenitor cells in pellet culture with TGFß1. Pellets were stained with toluidine blue and imaged at low magnification (x10) following 21 days of chondrogenic culture in the presence TGF $\beta 1$ (A). High magnification images (x20) were taken of the edge of the pellet (B) and the centre (C). Scale bars equal to $0.1 \mathrm{~mm}$.

Figure 5.17 (A) is a low (x10) magnification image of a pellet following 21 days of chondrogenesis in the presence of TGF $\beta 1$ that is approximately $1.43 \mathrm{~mm}$ in length and $1.16 \mathrm{~mm}$ in width. The pellet has not kept the spherical shape throughout the culture period but appears to be intact with staining visible through the entire construct. The edge of the pellet, seen in Figure 5.17 (B), is stained a dark blue indicating a high level of proteoglycan in these areas. Figure 5.17 (C) is the centre of the pellet imaged at high magnification (x20). In this area the staining is purple and less intense than at the edges indicating lower GAG content. 

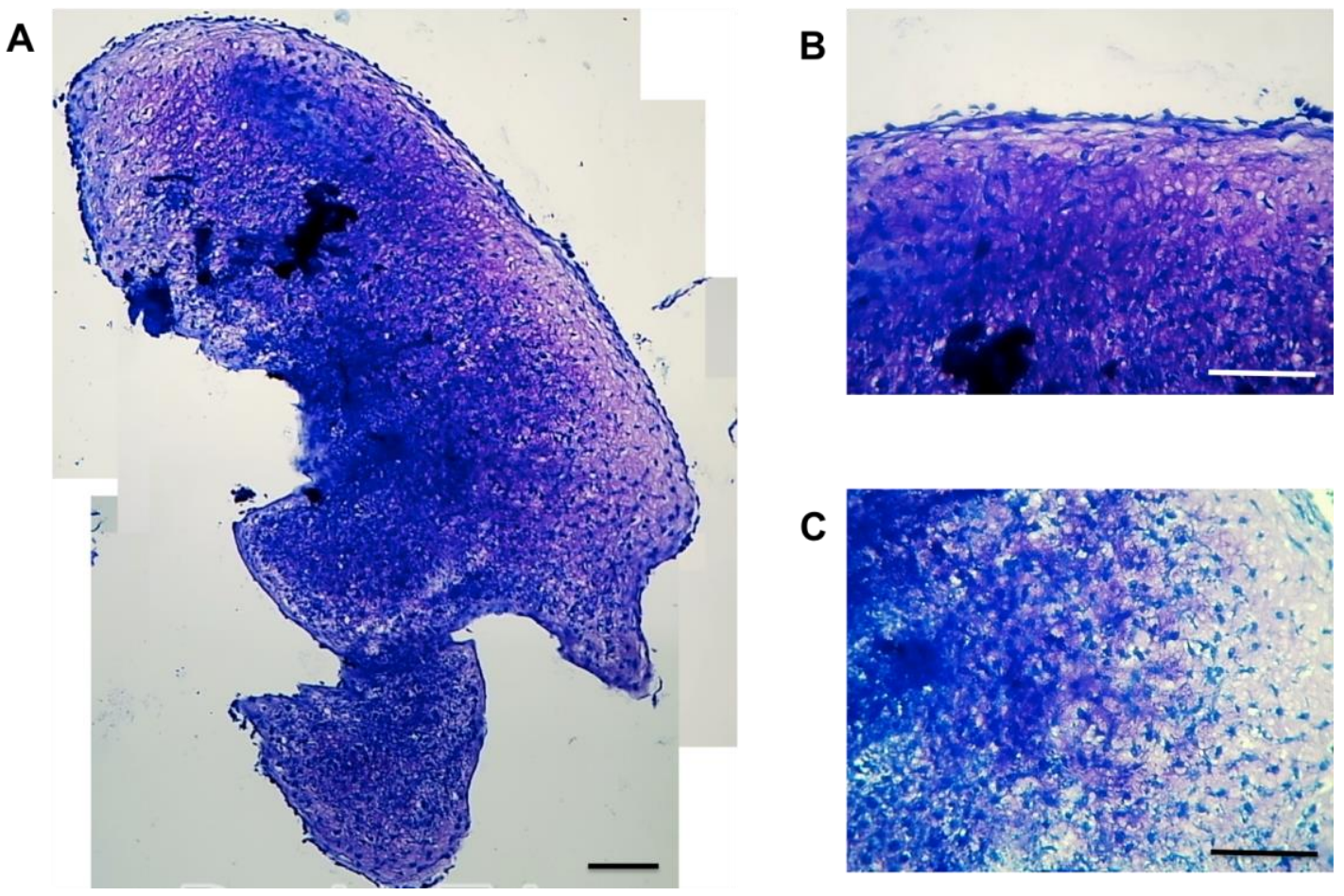

Figure 5.18: Toluidine blue staining of chondroprogenitor cells in pellet culture without TGFß1. Pellets were stained and imaged at low magnification (x10) following 21 days of chondrogenic culture in the absence of TGF $\beta 1$ (A). High magnification images (x20) were taken of the edge of the pellet (B) and the centre (C). Scale bars equal to $0.1 \mathrm{~mm}$.

Figure 5.18 (A) is a low magnification (x10) image of pellet culture following 21 days of chondrogenesis in the absence of TGF $\beta 1$ and stained with toluidine blue. The pellet is an irregular shape and measures $1.15 \mathrm{~mm}$ and $0.65 \mathrm{~mm}$ at the longest and widest points, respectively, and stained throughout. Figure 5.18 (B) is the edge of the pellet stained in a mixture of blue and purple staining indicating slightly weaker and uneven proteoglycan deposition when compared to TGF $\beta 1$ treated pellet. Figure 5.18 (C) shows an area toward the centre of the pellet with variation in the intensity of staining. The staining appears in a gradient from intense blue at the centre and become a faint purple as it moves towards the edge showing the uneven production of proteoglycan.

\subsubsection{Glycosaminoglycan quantification}

To quantitatively assess GAG content a DMMB assay was conducted following completion of 21 days of chondrogenesis. Samples were digested enzymatically 
using papain and GAG content of the digest determined using 1,9-dimethylmethylene blue (DMMB) dye. DMMB is a cationic dye that binds specifically to negatively charges sulphated glycosaminoglycans including chondroitin sulphate that is found in aggrecan within cartilage (Lakin et al., 2013).
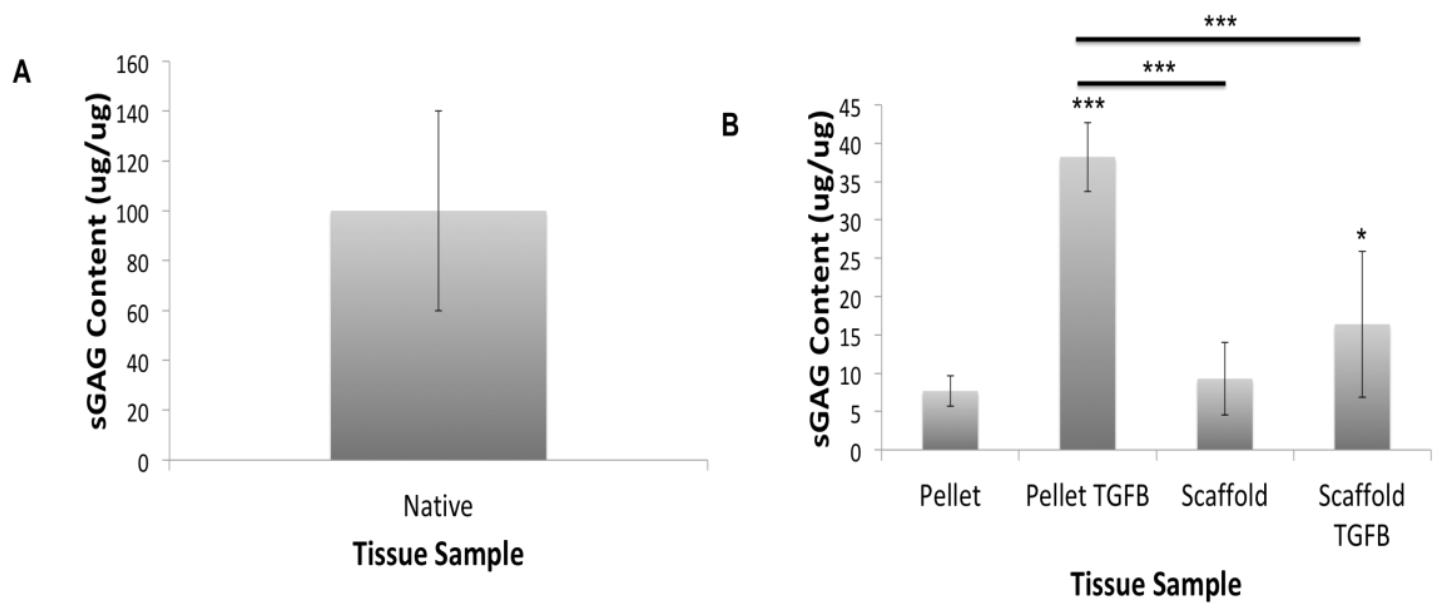

Figure 5.19: Sulphated glycosaminoglycan content of pellet and scaffold cultures after 21 days of chondrogenesis. SGAG content of native immature cartilage (A) was determined and normalised per ug of DNA and used as a benchmark. Pellet and scaffold cultures treated and untreated with TGF $\beta$ during chondrogenesis were analysed for sGAG content (B). All data shown is from a minimum of 3 independent biological repeats, statistical significance shown according to independent samples T Test $(* \mathrm{p}<0.05 ; * * \mathrm{p}<0.01 ; * * * \mathrm{p}<0.001)$.

Native immature bovine cartilage was used for a benchmark for sGAG content, Figure 5.19 (A). Analysis showed that the average sGAG content of bovine MCP joint cartilage was $100.03 \mu \mathrm{g} / \mu \mathrm{g}$ of DNA \pm 40.09 . Figure 5.19 (B) shows the sGAG content from pellet and scaffold cultures following 21 days of chondrogenesis. Pellet cultures contained $7.68 \mu \mathrm{g} / \mu \mathrm{g}$ of sGAG after 21 days that was significantly lower when compared to the TGF $\beta$ treated pellet and scaffold counterparts $(p=0.000$ and $\mathrm{p}=0.048$, respectively). Pellet cultures treated with TGF $\beta$ during chondrogenesis exhibited the highest amount of sGAG at $38.21 \mu \mathrm{g} / \mu \mathrm{g}$, which was significantly increased compared to treated and untreated scaffolds ( $\mathrm{p}=0.000$ for both). Scaffolds that underwent chondrogenesis without growth factor treatment contained $9.28 \mu \mathrm{g} / \mu \mathrm{g}$ whilst treated scaffold exhibited sGAG content of $16.39 \mu \mathrm{g} / \mu \mathrm{g}$ with no significant difference found between the two culture conditions. 


\subsubsection{Collagen content}

Collagen is the most abundant protein in the ECM of articular cartilage and accounts for approximately two thirds of its dry mass (Eyre, 2002). Although type II collagen represents $90 \%$ of the collagen in the ECM other collagens are also present in small proportions and include collagen type III, IV, V, VI, IX and XI and enable the tissue to function by aiding the formation and stabilisation of the type II fibrillar network (Fox et al., 2009).

Picrosirius red is a staining method used in order to identify fibrillar collagen networks (Lattouf et al., 2014). It is a linear anionic dye containing six sulfonate groups that associate to cationic collagen fibres, in particular reacting with amino groups of lysine, hydroxylysine and guanidine groups of arginine. This enhances collagen birefringence when viewed under polarised light (Montes and Junqueira, 1991). The birefringence is specific to collagen and the amount of light absorbed by the dye is dependent on the orientation of collagen fibres (Bhutda et al., 2017).

\subsubsection{Native immature baseline}

Cartilage obtained from immature MCP joints (6mm punch biopsy) were washed, fixed and embedded in preparation for histological analysis. Section of native tissue were stained with picrosirius red and imaged using a light microscope with a polarised light filter. 

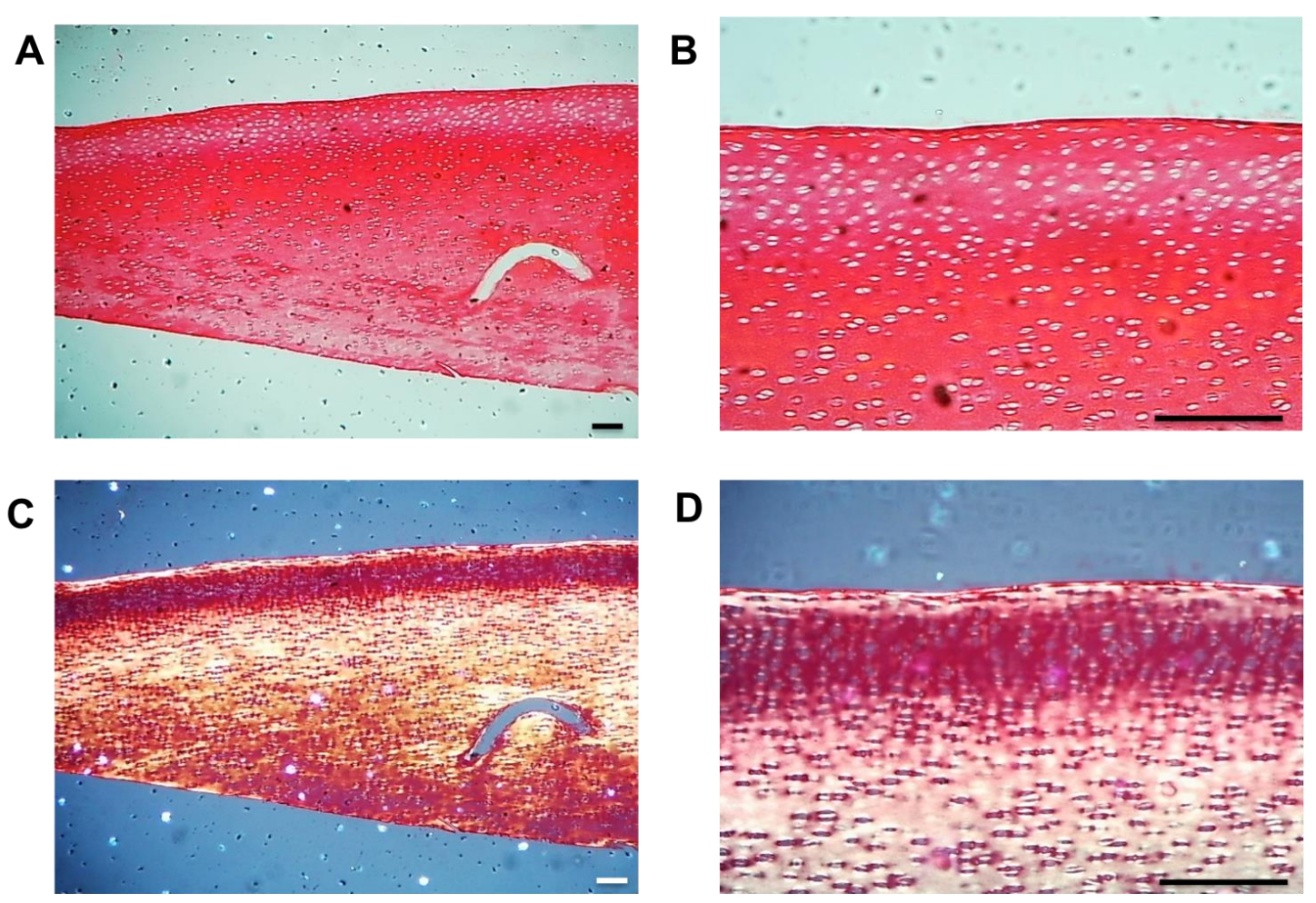

Figure 5.20: Picrosirius red staining of native immature bovine cartilage. Immature bovine cartilage stained with picrosirius red imaged with a light microscope at low magnification (A) and high magnification (B) and with polarised light to show birefringence at low magnification (C) and high magnification (D). Scale bars equal to $0.1 \mathrm{~mm}$.

Figure 5.20 (A) is a low magnification (x4) image of a section of native immature bovine cartilage stained with picrosirius red taken with a light microscope. The depth of the tissue is approximately $0.93 \mathrm{~mm}$ at the thickest point and is stained entirely red. Figure 5.20 (B) is a high magnification (x20) image of the tissue focusing on the superficial and transition into the middle zone of the cartilage. The tissue is stained in red, indicating the collagen distribution through the tissue, with unstained regions representing areas populated by cells. Figure 5.20 (C) and Figure 5.20 (D) are the same images imaged under polarised light. Under polarised light native immature cartilage fluoresces a yellow colour at the very surface of the superficial zone and through the middle zone. The deep zone and a region of the middle zone, approximately $0.27 \mathrm{~mm}$, beneath the superficial zone do not appear to exhibit a lot of fluorescence although the high magnification image seen in Figure 5.20 (D) shows some fluorescence directly around areas where cells are present. 


\subsubsection{Scaffold assisted collagen content}

Scaffolds equilibrated in serum free media were seeded with $0.5 \times 10^{6}$ chondroprogenitor cells and cultured for 21 days with chondrogenic media. Following the culture period, collagen deposition was assessed histologically via picrosirius red staining of samples and imaging using polarised light microscope.
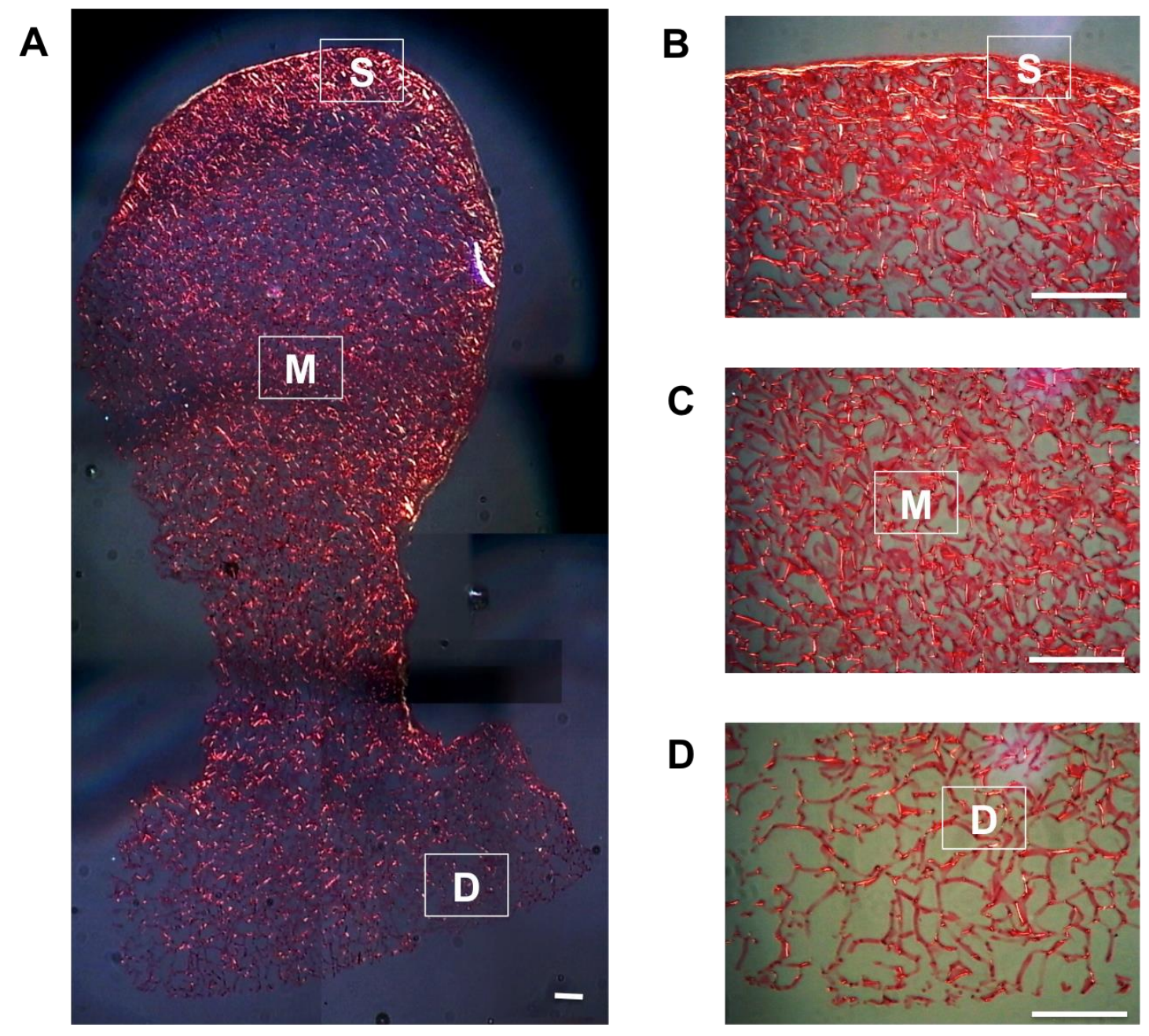

Figure 5.21: Picrosirius red staining of JCol scaffolds following 21 days of chondrogenic culture with TGFß1. Low magnification $(x 4)$ image of JCol scaffold imaged with a polarised light microscope (A) with labelled superficial (S), middle (M) and deep (D) zones. High magnification (x20) images were taken of areas representing the superficial (B), middle (C) and deep (D) zones.

Figure 5.21 (A) is a low magnification (x4) image of a JCol scaffold stained with picrosirius red following 21 days of chondrogenic culture with TGF $\beta 1$. The collagen network is stained throughout, with the majority of the scaffold fluorescing in red. 
The scaffold has maintained its shape until $1.7 \mathrm{~mm}$ where it begins to constrict for $0.68 \mathrm{~mm}$ before maintaining the original shape again. Figure 5.21 (B) shows the superficial zone of the scaffold at high magnification (x20). The superficial region gives off a yellow fluorescence similar to what is seen in native immature tissue. The middle zone, depicted in Figure 5.21 (C), show the edges of ribbons of collagen fluorescing in yellow whilst the majority of the network remains red in colour. The same pattern can be seen in the deep zone of the scaffold, Figure 5.21 (D). The collagen network in the deep zone appears to be broken towards the edge of the tissue with larger swollen pores when compared to the superficial and middle zone.

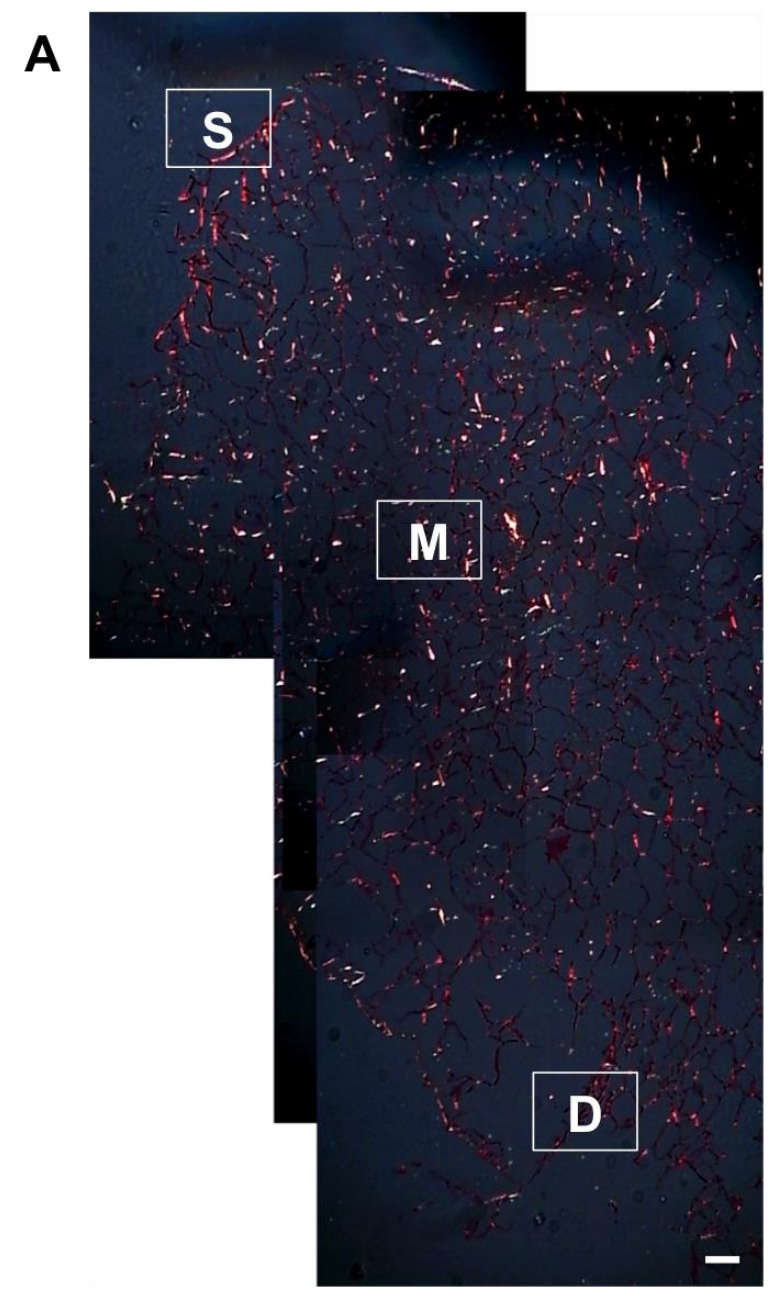

B

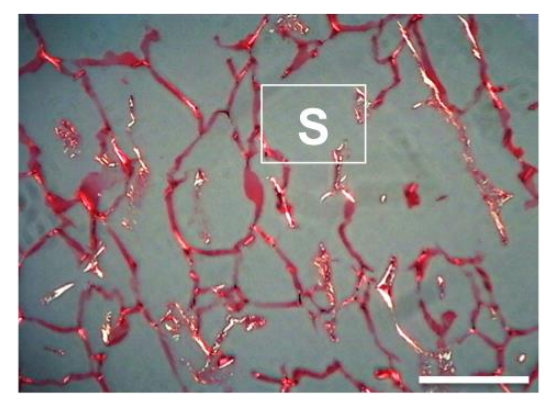

C

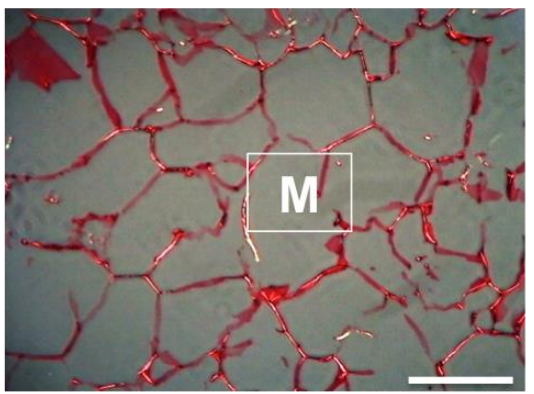

D

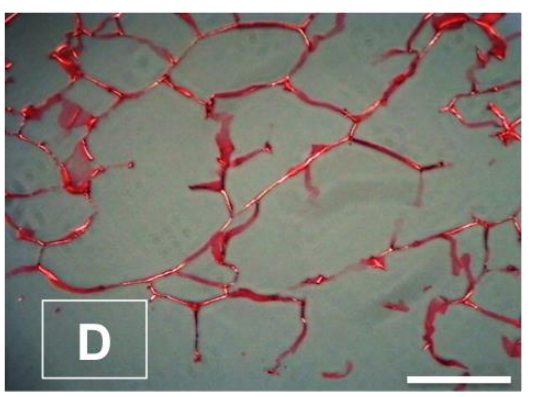

Figure 5.22: Picrosirius red staining of JCol scaffolds following 21 days of chondrogenic culture without TGFß1. Low magnification (x4) image of JCol scaffold imaged with a polarised light microscope (A) with labelled superficial (S), middle (M) and deep (D) zones. High magnification (x20) images were taken of areas representing the superficial (B), middle (C) and deep (D) zones. 
Figure 5.22 (A) is a low magnification image $(\mathrm{x} 4)$ of a JCol scaffold cultured without TGF $\beta 1$ for 21 days. The overall collagen network does not appear to fluoresce with the same intensity as scaffolds treated with TGF $\beta 1$ and the shape of the scaffold has been altered during the culture period. A clear defined fluorescence is not seen across the entire superficial region as seen in native tissue and treated scaffolds. In the high magnification image of the superficial zone, Figure 5.22 (B), ribbons of collagen are seen in red with yellow fluorescence present at the edges of the protein. The pattern of fluorescence is similar in the middle and deep zones, shown in Figure 5.22 (C) and Figure 5.22 (D), respectively, at a decreased intensity. Pores appear the be larger throughout the scaffold when compared to growth factor treated scaffolds that only exhibited larger pores in the deep zone of the scaffold. At the deep zone, the scaffold does not appear to have held its integrity with broken pores visible in the region.
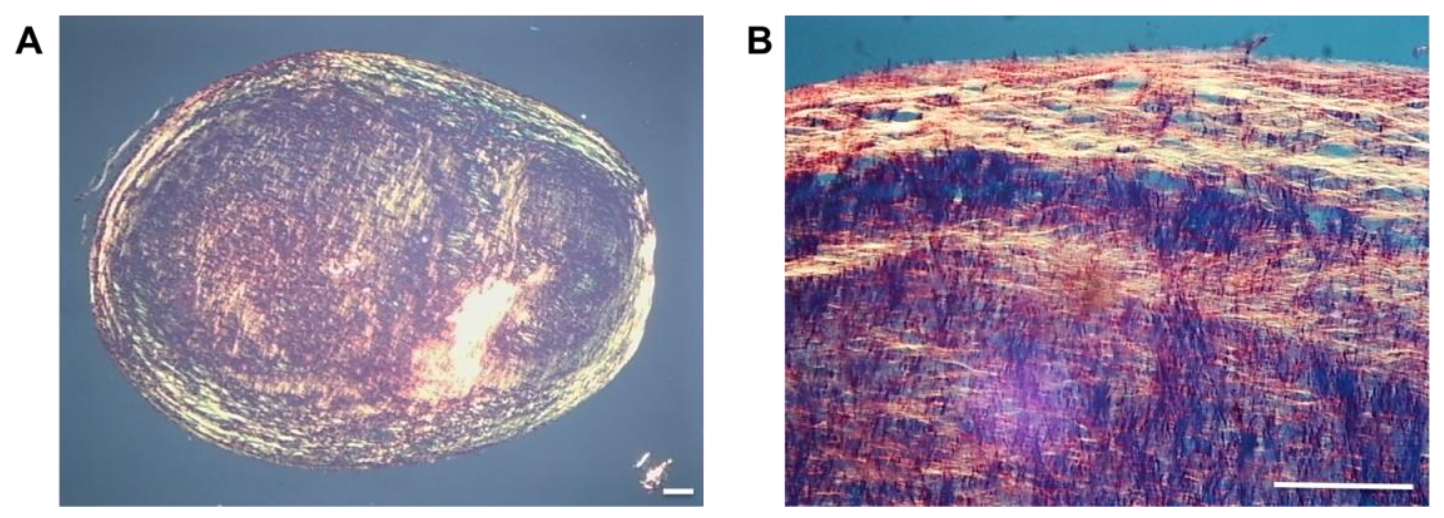

Figure 5.23: Picrosirius red staining of chondroprogenitor cells in pellet culture with TGFß1. Pellets were stained and imaged at low magnification $(x 4)$ with polarised light following 21 days of chondrogenic culture with TGF $\beta 1$ (A). High magnification images (x20) were taken of the edge of the pellet (B). Scale bars equal to $0.1 \mathrm{~m}$.

Figure 5.23 (A) is a polarised light image of a pellet after 21 days of chondrogenesis in the presence of TGF $\beta 1$. The pellet has kept its spherical shape and measures approximately $1.93 \mathrm{~mm}$ in width and $1.46 \mathrm{~mm}$ in length. Yellow and green birefringence is seen around the edge of the pellet with less intense birefringence seen towards the centre. Figure 5.23 (B) is a high magnification image of the edge of the pellet highlighting the birefringence in this area, which is approximately $0.1 \mathrm{~mm}$ in depth. 


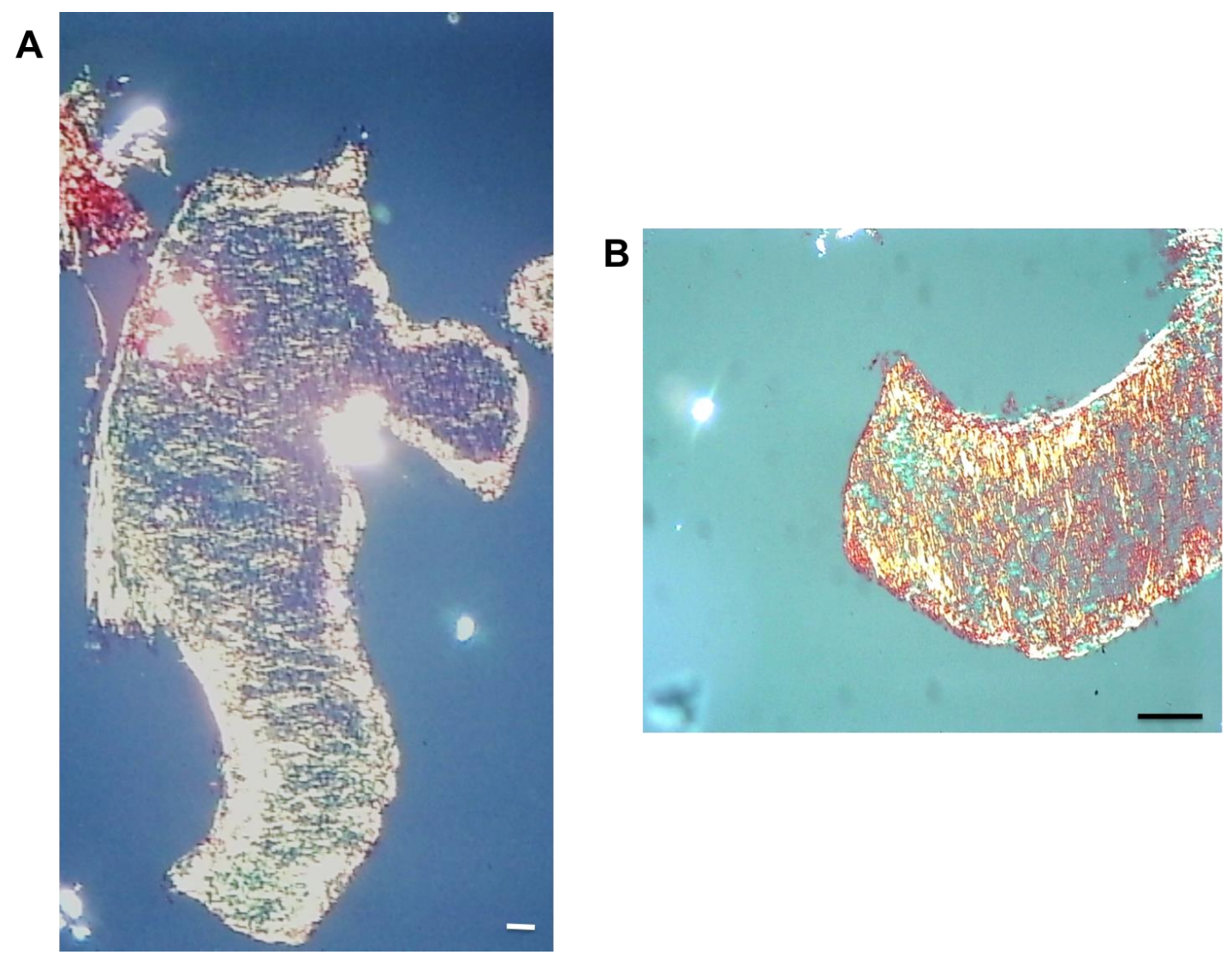

Figure 5.24: Picrosirius red staining of chondroprogenitor cells in pellet culture without TGFß1. Pellets were stained and imaged at low magnification (x4) with polarised light following 21 days of chondrogenic culture without TGF $\beta 1$ (A). High magnification images (x10) were taken of the edge of the pellet (B). Scale bars equal to $0.1 \mathrm{~mm}$.

Figure 5.24 (A) is a low magnification polarised light image of a pellet following 21 days of chondrogenesis in the absence of TGF $\beta 1$. The pellet has lost its spherical structure and is $2.74 \mathrm{~mm}$ in length. The width of the pellet varies throughout the length with it measuring $1.48 \mathrm{~mm}$ in width at $0.71 \mathrm{~mm}$ and $0.92 \mathrm{~mm}$ in width at $1.52 \mathrm{~mm}$. Birefringence is seen along the edges of the pellet and is yellow in colour. Figure 5.24 (B) is a high magnification image of the edge of the pellet. The image depicts the yellow birefringence at the edge of the structure whilst the collagen fibres appear red towards the centre. 


\subsubsection{Hydroxyproline quantification}

The collagen content from construct was quantified spectrophotometrically following 21 days of culture. Papain digested samples were subject to hydroxyproline assay to quantify the amount of 4-hydroxyproline found in collagen of cartilage that aids in the stabilisation of the triple helix.
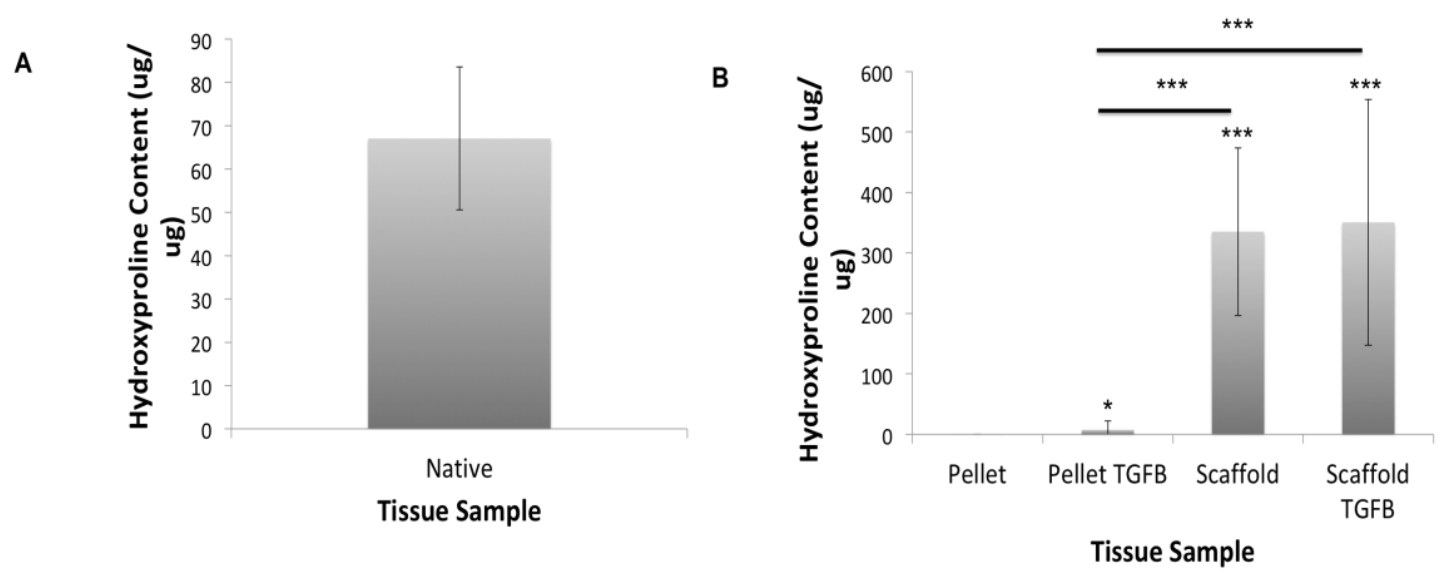

Figure 5.25: Hydroxyproline content of pellet and scaffold cultures after 21 days of chondrogenesis. Hydroxyproline content of immature bovine cartilage (A) normalised per ug of DNA. TGF $\beta$ treated and untreated pellet and scaffold cultures were assessed for hydroxyproline content following chondrogenesis (B). All data shown is from a minimum of 3 independent biological repeats, statistical significance shown according to Mann Whitney U test $(* \mathrm{p}<0.05 ; * * \mathrm{p}<0.01 ; * * * \mathrm{p}<0.001)$.

Figure 5.25 (A) shows hydroxyproline content of immature bovine cartilage normalised to DNA content to be $67.02 \mathrm{ug} / \mathrm{ug}$ of DNA \pm 16.50 and was used as a benchmark. Figure 5.25 (B) displays hydroxyproline content of pellet and scaffold cultures following 21 days of chondrogenesis. Untreated pellets were analysed and shown to have no hydroxyproline content that could be detected by the assay. TGF $\beta$ treated pellet $(\mathrm{p}=0.02)$ scaffolds $(\mathrm{p}=0.000)$ and untreated scaffolds $(\mathrm{p}=0.000)$ all had a significant increase in hydroxyproline content when compared to untreated pellets. The hydroxyproline content of TGF $\beta$ treated pellet culture was $7.62 \mathrm{ug} / \mathrm{ug}$, which was significantly lower, compared to scaffold cultures with and without growth factor treatment $(\mathrm{p}=0.000$ for both). When comparing TGF $\beta$ treated scaffolds and untreated scaffolds, no significant difference was observed with hydroxyproline content determined to be $350.57 \mathrm{ug} / \mathrm{ug}$ and $335.25 \mathrm{ug} / \mathrm{ug}$, respectively. 


\subsubsection{Histology summary}

Following 21 days of chondrogenic culture, JCol scaffolds were stained for the presence of characteristic components of cartilage matrix GAGs and collagen. These were compared to native bovine cartilage to understand whether scaffold structures had similar matrix deposition to native tissue.
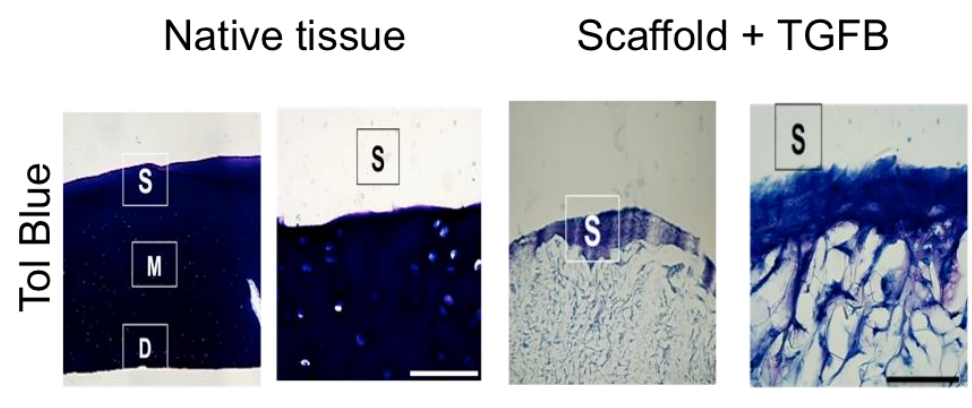

\section{Scaffold - TGFB}
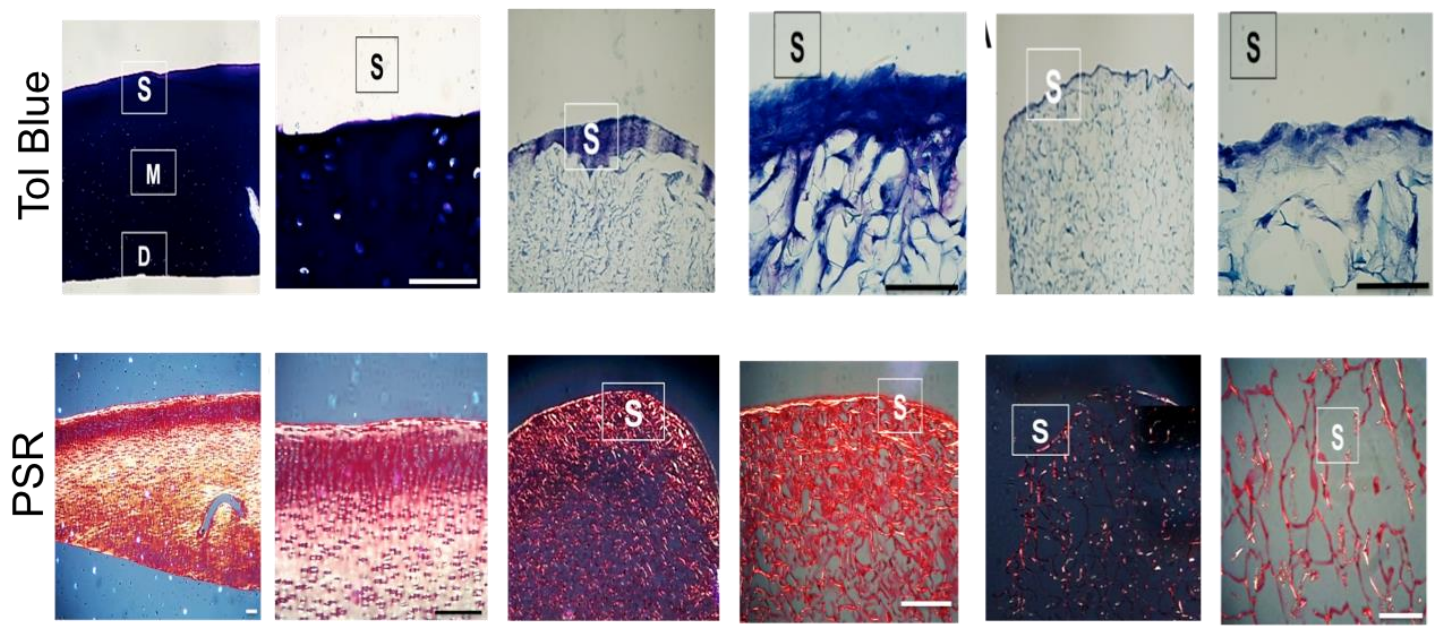

Figure 5.26: Summary panel of histological analysis of native tissue and JCol scaffolds with and without TGF $\beta 1$ treatment.

Figure 5.26 is a summary panel of histology images showing the comparison of GAG content (Tol Blue) and collagen deposition (PSR) between native bovine articular cartilage and JCol scaffolds with and without TGF $\beta 1$ supplementation. In summary, Tol Blue staining of native cartilage is present throughout the biopsy sample compared to the appearance of a band of staining at the top of scaffold structures that is enhanced by growth factor treatment. PSR analysis of native cartilage shows a thin area of fluorescence at the superficial zone that can also be seen in treated scaffolds but is not observed as clearly in untreated scaffolds.

\subsubsection{Gene expression analysis}

Enhanced chondrogenesis in vitro is characterised by the expression of SOX9, ACAN and COL2A1, which are expressed during development of cartilage 
(Yamashita et al., 2010). SOX9 establishes condensation and initiates chondrogenesis and regulates expression of COL2A1, which is a major component of cartilage ECM along with aggrecan (Bell et al., 1997).

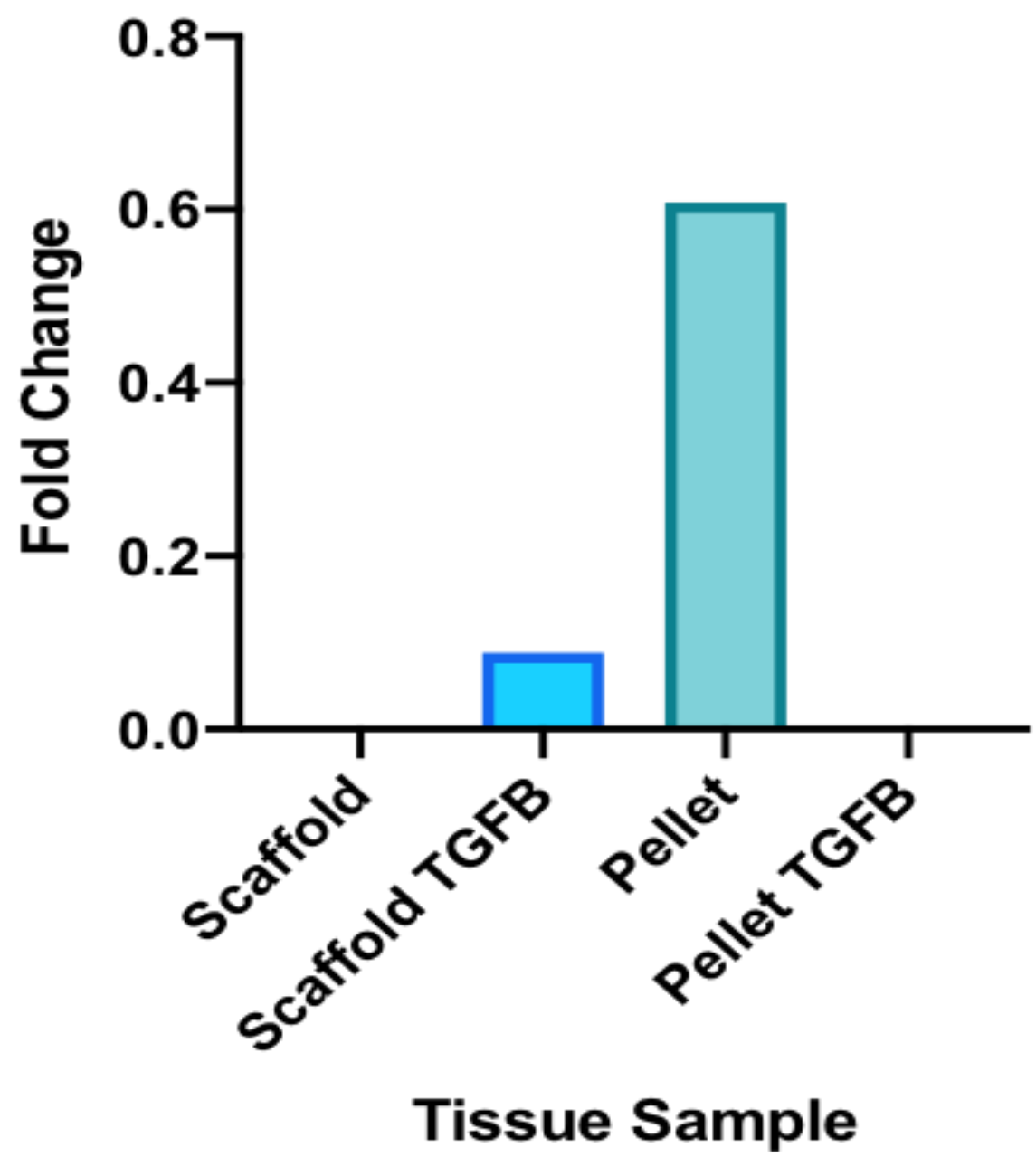

Figure 5.27: Fold change of SOX9 gene expression compared to native cartilage. Fold change of SOX9 gene expression of pellet and scaffold cultures following 21 days of chondrogenesis in the presence and absence of TGF $\beta$ compared to immature native bovine cartilage.

Figure 5.27 shows the fold change in gene expression of SOX9 from pellet and scaffold cultures following 21 days of chondrogenic culture in the presence and absence of TGF $\beta$. Untreated pellet cultures showed a decrease of SOX9 gene expression by a fold change of 14692.97 (min: 436.01; max: 28949.92; medium: 14692.97) when compared to native bovine articular cartilage and exhibited the biggest decrease in SOX9 expression when compared to all other culture conditions. TGF $\beta$ treated pellet cultures displayed a decreased fold change of $5.66(0.89 ; 10.42$; 
5.66) in comparison to native cartilage. When compared to all other conditions, growth factor treated pellet culture showed the smallest fold change in gene expression. Untreated scaffold cultures showed a decreased fold change in SOX9 gene expression by $14.29(8.68 ; 22.82 ; 14.29)$ whilst TGF $\beta$ treated scaffold cultures showed a decrease by 332.41 fold $(14.45 ; 648.52 ; 332.41)$ when compared to native bovine cartilage.

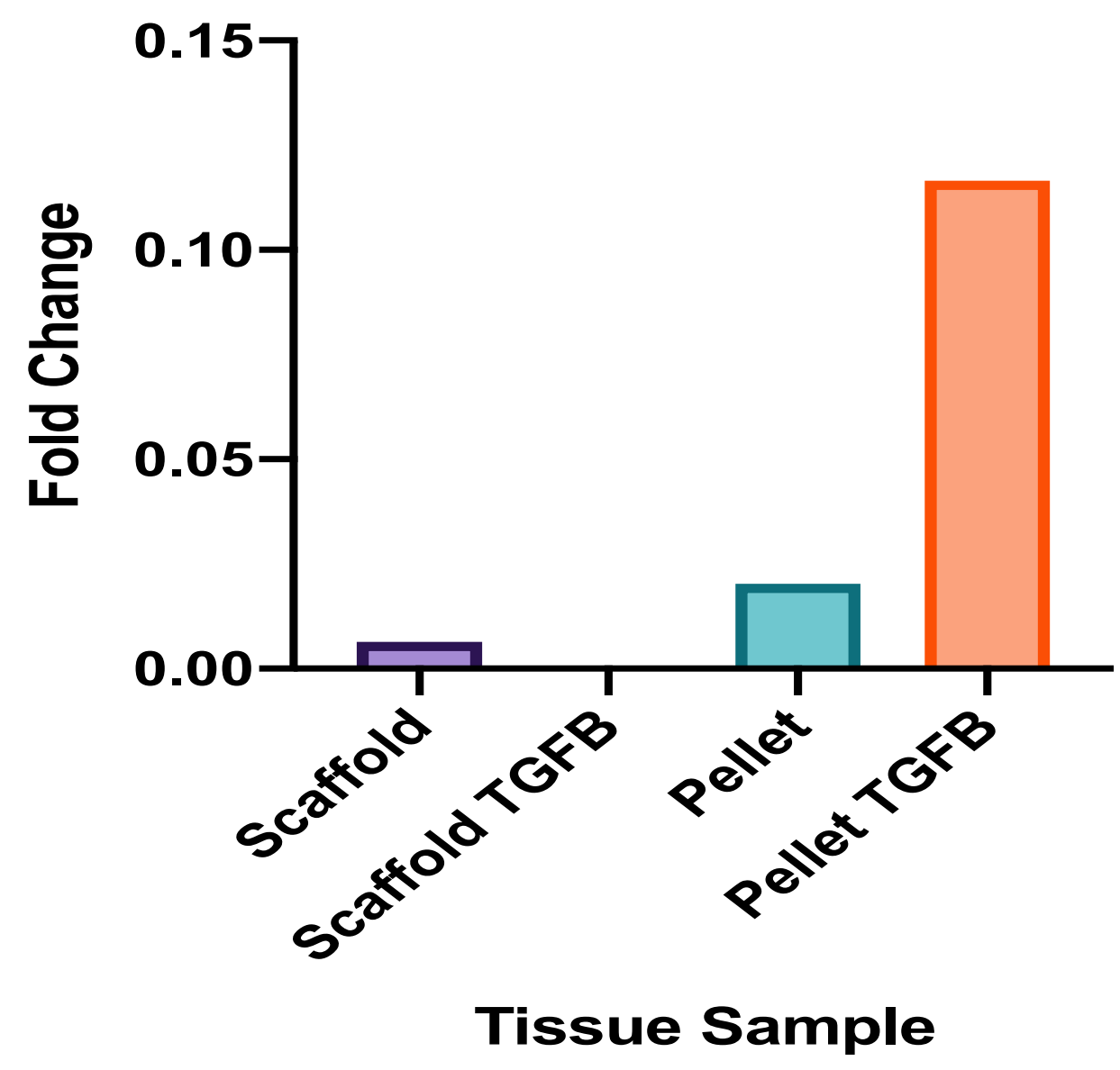

Figure 5.28: Fold change of COL2A1 gene expression compared to native cartilage. Fold change of COL2A1 gene expression of pellet and scaffold cultures following 21 days of chondrogenesis in the presence and absence of TGF $\beta$ compared to native immature bovine cartilage.

Figure 5.28 shows the decrease in COL2A1 gene expression, expressed as fold change, of pellet and scaffold cultures in the presence and absence of TGF $\beta$ compared to native immature bovine cartilage. Pellets cultured without TGF $\beta$ displayed a decrease in COL2A1 gene expression by $939.86(4.30 ; 1875.41 ; 939.86)$ when compared to native tissue and exhibited the lowest change when compared to 
all other conditions. TGF $\beta$ treated pellets had a decrease in expression by 1564.04 $(24.77 ; 3103.31 ; 1564.04)$. The largest change in COL2A1 gene expression occurred in untreated scaffold cultures and decreased by $1860.31(492.05 ; 2781.17 ; 1860.31)$ in comparison to native tissue whilst treated scaffold cultures only decreased by $1092.1(103.51 ; 3017.91 ; 1092.1)$.

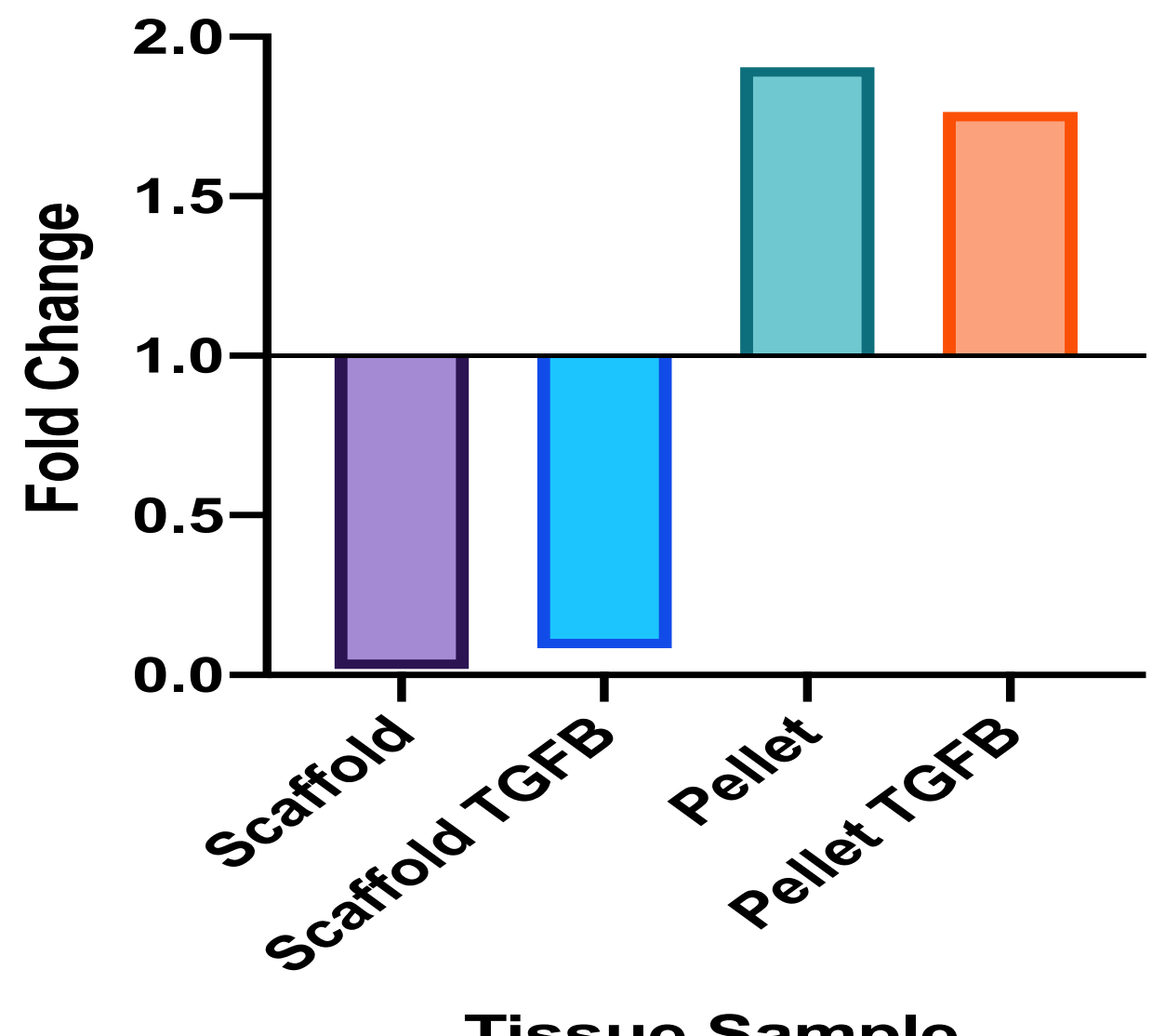

Figure 5.29: Fold change of ACAN gene expression compared to native cartilage. Fold change of ACAN gene expression of pellet and scaffold cultures following 21 days of chondrogenesis in the presence and absence of TGF $\beta$ compared to immature native bovine cartilage.

Figure 5.29 displays the difference in ACAN gene expression, in terms of fold change, of pellet and scaffold cultures following 21 days of chondrogenic culture compared to native bovine articular cartilage. Untreated and treated pellet cultures showed an increase in ACAN gene expression by $53.49(3.80 ; 103.17 ; 53.49)$ and $18.90(3.50 ; 34.29 ; 18.90)$, respectively, when compared to native tissue. Conversely, 
scaffold cultures without growth factor treatment showed a decrease in ACAN expression by $41.77(3.18 ; 69.13 ; 41.77)$ whilst treated scaffold cultures showed less of a decrease in gene expression at $10.96(6.08 ; 14.88 ; 10.96)$ compared to immature bovine cartilage.

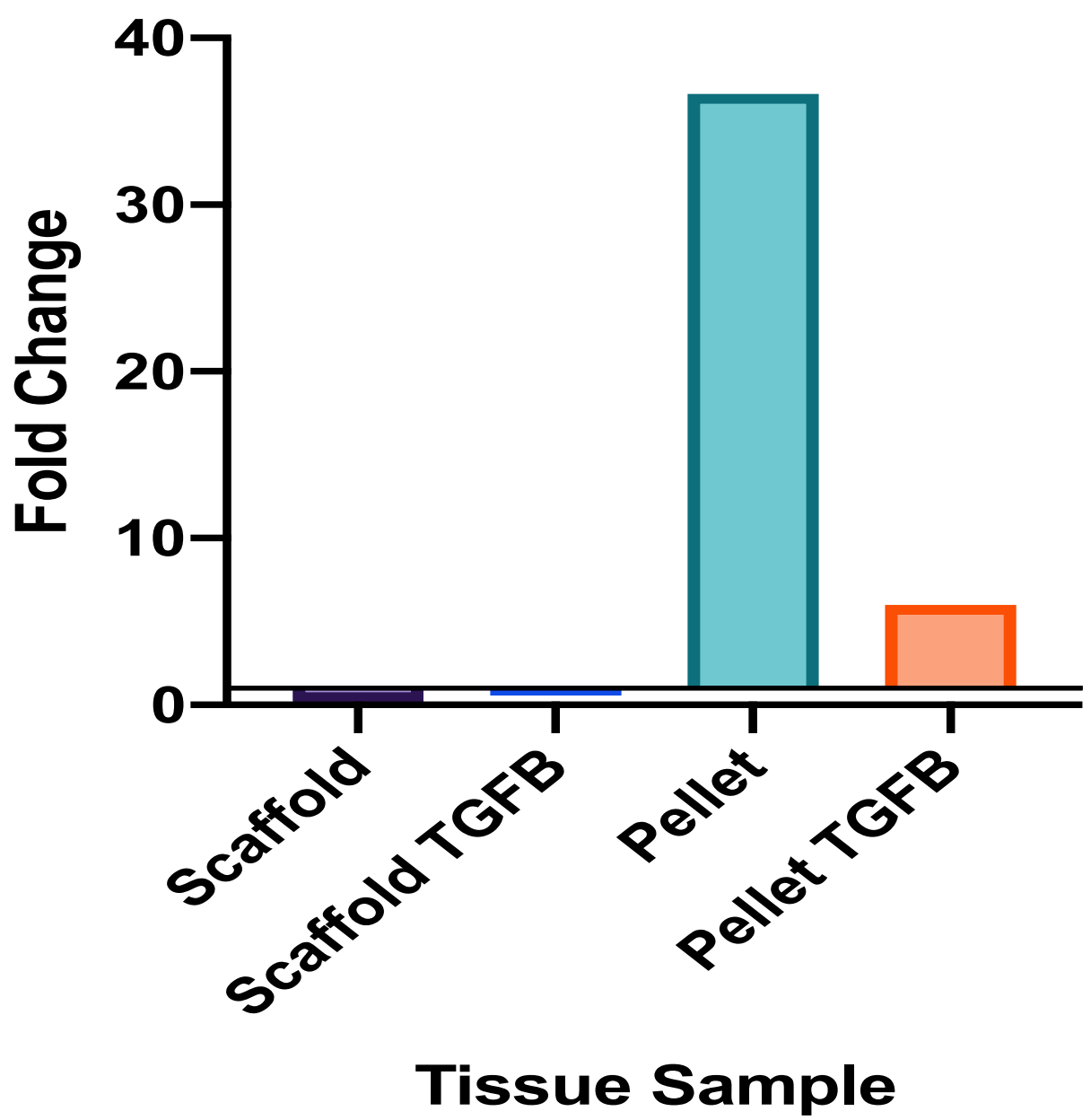

Figure 5.30: Fold change of RUNX2 gene expression compared to native cartilage. Fold change of RUNX2 gene expression of pellet and scaffold cultures following 21 days of chondrogenesis in the presence and absence of TGF $\beta$ compared to native immature bovine cartilage.

Figure 5.30 shows the difference in RUNX2 gene expression, expressed as fold change, from pellet and scaffold cultures following 21 days of culture and compared to immature bovine cartilage. Pellet cultures show a decrease in RUNX2 expression by $6.02(0.28 ; 11.76 ; 6.02)$ whilst TGF $\beta$ treated pellets were shown to increase gene expression by $36.07(0.57 ; 71.56 ; 36.07)$ compared to native tissue. Treated pellets were the only culture condition tested to show an increase in RUNX2 gene 
expression. Scaffold cultures exhibited a decreased gene expression by $2.49(0.19$; $1.71 ; 2.49)$ and TGF $\beta$ treated scaffold cultures showed the largest decrease in RUNX2 gene expression when compared to native bovine cartilage by $45.29(0.19$; $133.98 ; 45.29)$.

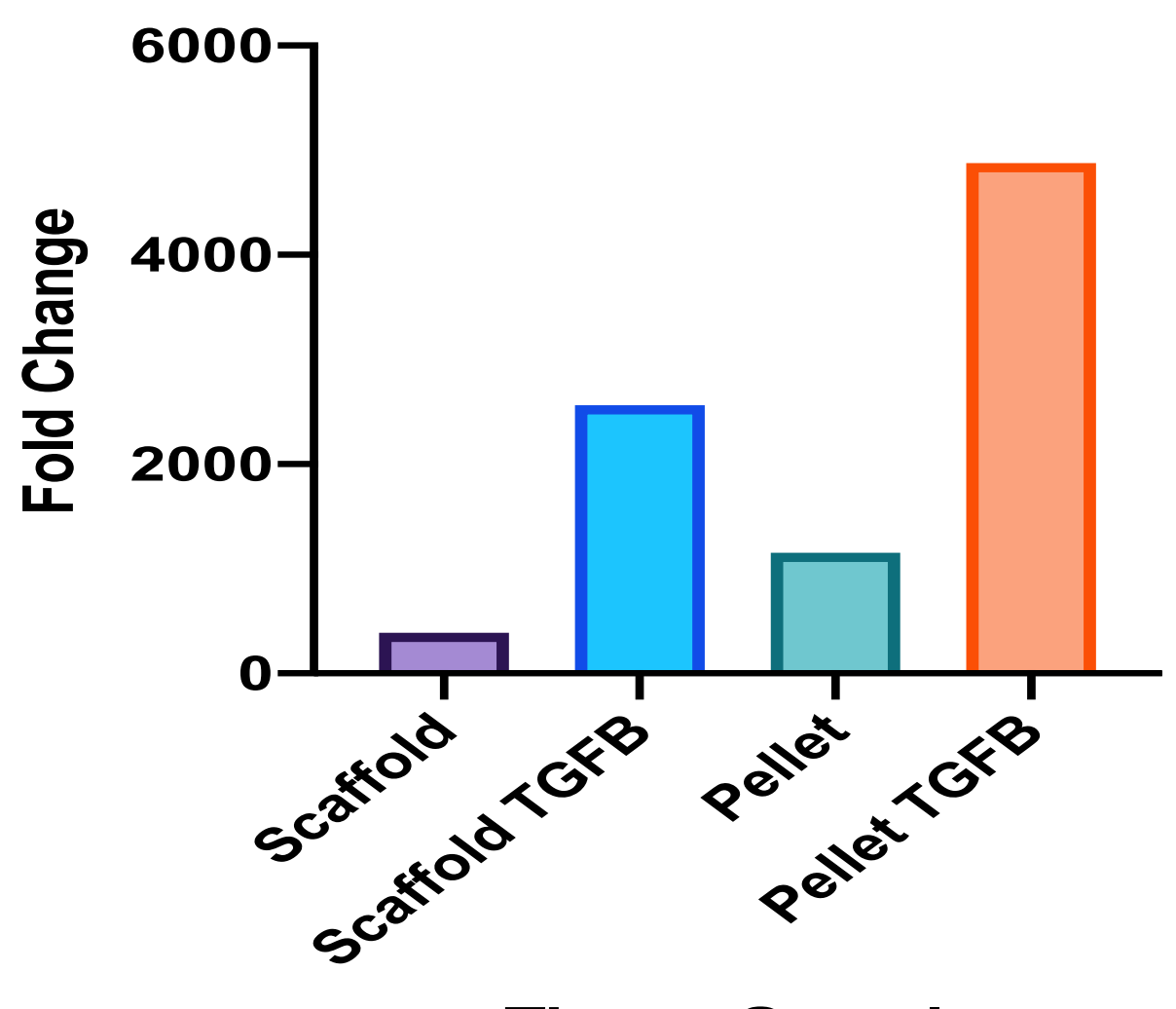

Tissue Sample

Figure 5.31: Fold change of COL1A1 gene expression compared to native cartilage. Fold change of COL1A1 gene expression of pellet and scaffold cultures following 21 days of chondrogenesis in the presence and absence of TGF $\beta$ compared to native immature bovine cartilage.

Figure 5.31 is the fold change difference in COL1A1 gene expression of pellet and scaffold cultures on completion of 21 days of chondrogenesis compared to bovine articular cartilage. All culture conditions tested showed an increase in COL1A1 gene expression. Untreated and growth factor treated pellet cultures showed an increase in gene expression by $4831.74(0.01 ; 9662.48 ; 4831.74)$ and $1150.02(1.37 ; 2298.68$; 1150.02), respectively, compared to bovine cartilage. Untreated scaffold cultures exhibited an increased gene expression by $2139.27(782.35 ; 3074.63 ; 2139.27)$ compared to native tissue. The largest increase in COL1A1 gene expression 
compared to immature bovine cartilage was witnessed in TGF $\beta$ treated scaffold cultures at $32681.15(782.35 ; 3074.63 ; 2139.27)$.

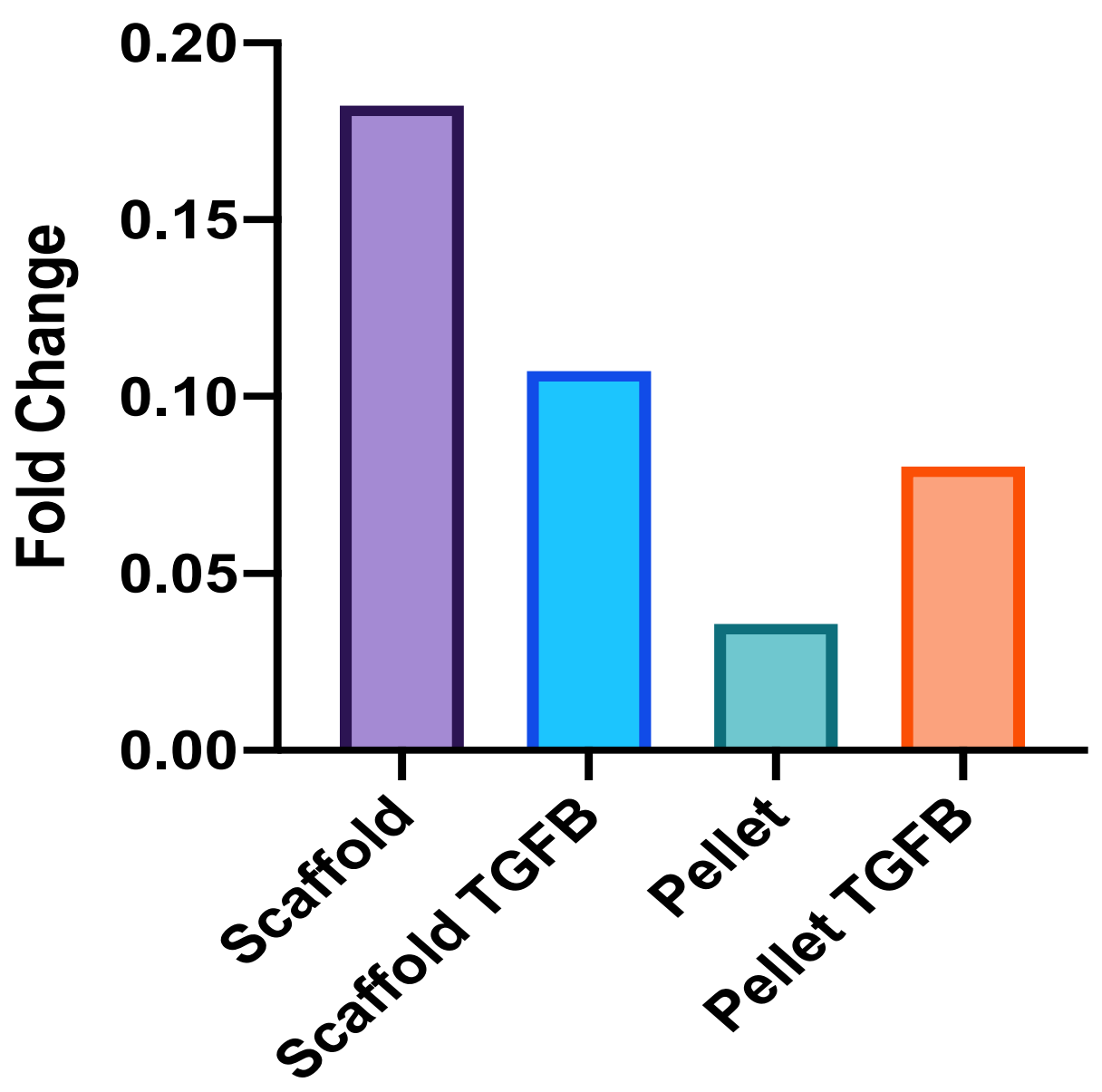

Tissue Sample

Figure 5.32: Fold change of COL10A1 gene expression compared to native cartilage. Fold change of COL10A1 gene expression of pellet and scaffold cultures following 21 days of chondrogenesis in the presence and absence of TGF $\beta$ compared to native immature bovine cartilage.

Figure 5.32 shows the decrease in COL10A1 gene expression, displayed as fold change, for scaffold and pellet cultures in the presence and absence of TGF $\beta$ compared to immature bovine articular cartilage. Pellet cultures in the absence of TGF $\beta$ expressed a decrease in gene expression by $36.2(0.15,72.25 ; 36.2)$ compared to native tissue. TGF $\beta$ treated pellet culture showed the lowest fold change in COL10A1 gene expression when compared to all other culture conditions at 13.99 $(0.00 ; 27.97 ; 13.99)$. Scaffold cultures without TGF $\beta$ treatment decreased gene 
expression by $27.81(1.06 ; 73.05 ; 27.81)$ when compared to native tissue whilst TGF $\beta$ treated scaffold cultures exhibited the highest decrease in COL10A1 expression at $60.29(0.46 ; 174.92 ; 60.29)$.

\subsubsection{Protein expression}

Successful regeneration using tissue engineered constructs is dependent upon matrix remodelling and deposition by cells residing in scaffolds (O'Brien, 2011). Immunohistochemistry (IHC) is the identification of tissue constituents by antibody recognition of specific antigens (Shi et al., 2011).

TGFB treated scaffolds were stained using bovine aggrecan and collagen type II and type I antibodies to evaluate whether bovine CPs had deposited matrix and undertake matrix remodelling.

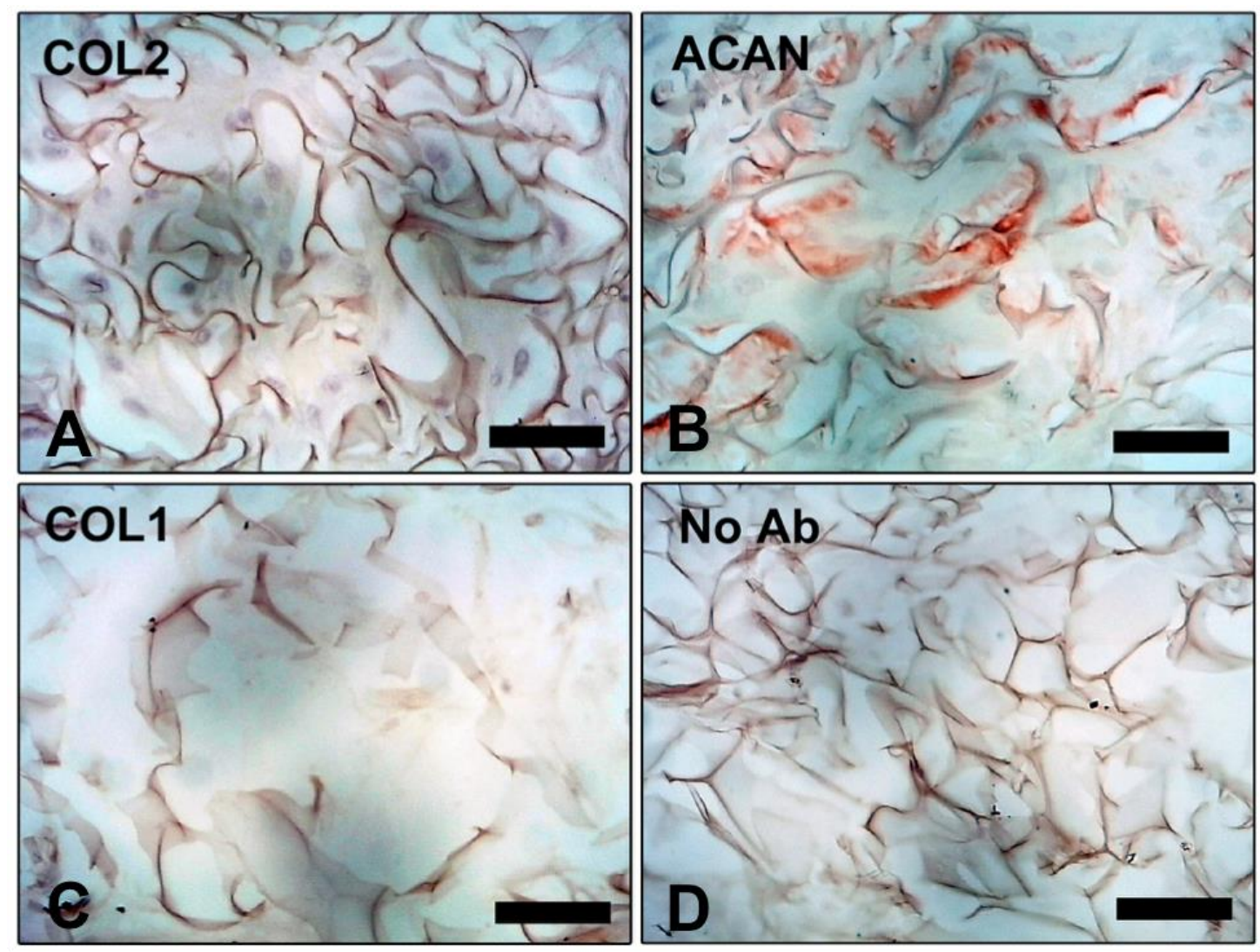


Figure 5.33: Immunohistochemistry of TGF $\beta 1$ treated scaffolds. Scaffolds were stained for chondrogenic markers collagen type II and aggrecan as well as collagen type I, typically found in fibrocartilage. Images with a light microscope at x20 object. Scale bars are $50 \mu \mathrm{m}$.

Figure 5.33 is a panel of immunohistochemistry images of TGF $\beta$ treated scaffolds. A no antibody control was used to account for any false positive (Figure 33 (D)). Figure 5.33 (A) and Figure 5.33 (C) representative staining of collagen type I and type II in scaffolds showing no staining by their respective antibodies. Figure 33 (B) shows staining of aggrecan within TGF $\beta 1$ treated scaffolds after chondrogenesis. Aggrecan antibody staining is apparent in areas around collagen ribbons indicating matrix deposition.

\subsection{Discussion}

The limited regenerative capacity of cartilage has lead to the development of different intervention techniques including the fabrication of cartilage that can be implanted into cartilage defects (Zhang et al., 2009). Although these surgical interventions have exhibited varying degrees of success, research into chondrogenesis has continued, in order to improve patient outcome and decrease the duration of rehabilitation (Redman et al., 2005). Current methods involve both cellular approaches and matrix-assisted approaches displaying advantages in chondrogenesis and cartilage production (Bernstein et al., 2009). An early proof of concept pre-clinical study is outlined in this chapter, demonstrating the suitability of inert, JCol scaffolds in combination with bovine $\mathrm{CP}$ populations, for a next generation regenerative medicine approach to cartilage repair capitalising on enhanced in vitro chondrogenesis.

JCol scaffolds are a suitable environment for CP chondrogenesis. Cell invasion is observed through the construct apart from the 'deep zone' and cell content is higher than pellet culture, when starting with the same seeding concentration. Histological, biochemical and gene analysis shows that JCol scaffolds express genes typically associated with chondrogenesis and that matrix deposition is enhanced with TGF $\beta$ 
although gene expression was lower than that observed in pellet culture. Hypertrophic markers were observed in scaffold cultures however they were expressed at lower levels compared to pellets indicating that cellular hypertrophy and osteogenesis may be less likely to occur in scaffold structures. These results indicate that JCol scaffolds are suitable for development in this space, with focus placed on the mechanical stability of structures and cell seeding efficiency for the homogenous deposition of matrix, which may lead to better functional tissue development.

\section{Sponge scaffold supported chondrogenesis}

$1 \%$ EDC JCol sponge scaffolds were fabricated and seeded (density of $0.5 \times 10^{6}$ ) with bovine CPs, with cell invasion observed throughout the construct depth, meeting the requirement of high cell density favoured by in vitro chondrogenesis (Bornes et al., 2016). No significant contraction occurred after the initial 7 days of culture. Contraction of gels has previously been shown to reduced cell attachment collagen synthesis both of which would be counterproductive for cartilage regeneration (Nakagawa et al., 1989).

Following the full 21 day culture period, data obtained from pellet cultures showed a decrease in cell number from initial seeding thought to be caused by the generation of a hypoxic core at the centre of the dense structure causing uneven oxygen tension (Dexheimer et al., 2012). On the other hand scaffold cultures were shown to have a higher cell number although this was still below the initial cell seeding density. The porous structure of scaffolds allows for oxygen to be passed throughout the entire structures and so loss of cells in scaffold constructs may have occurred due to the efficiency of the seeding method. Cells were seeded at high density and low volume at the top of the scaffold and allowed to attach for 20 minutes before flooding with media potentially causing the loss of any unattached cells (Bueno et al., 2007). Cells may also have been lost if they were not able to attach to binding motifs present on JCol scaffolds causing anoikis (Lee et al., 2015).

Scaffolds produced from type I and II collagen have been shown to promote chondrogenesis in vitro however degradation products released during remodelling of type II collagen may cause catabolic events to occur in vivo (Dewan et al., 2014). 
A variety of commercially available scaffolds used in MACI procedures are composed of collagen (type I and III) or collagen hybrids including NeoCart and CaReS and NovaCART 3D, shown in Table 5.1 (Jacobi et al., 2011).

\begin{tabular}{|l|l|l|l|}
\hline \multicolumn{1}{|c|}{ Product } & \multicolumn{1}{|c|}{ Composition } & \multicolumn{1}{c|}{ Procedure } & \multicolumn{1}{c|}{ Comparative findings } \\
\hline NeoCart & Bovine type I collagen & 2 step-MACl & $\begin{array}{l}\text { Superior results to } \\
\text { microfracture }\end{array}$ \\
\hline NovoCART 3D & Collagen/chondroitin & 2 step-MACl & High rates of hypertrophy \\
\hline
\end{tabular}

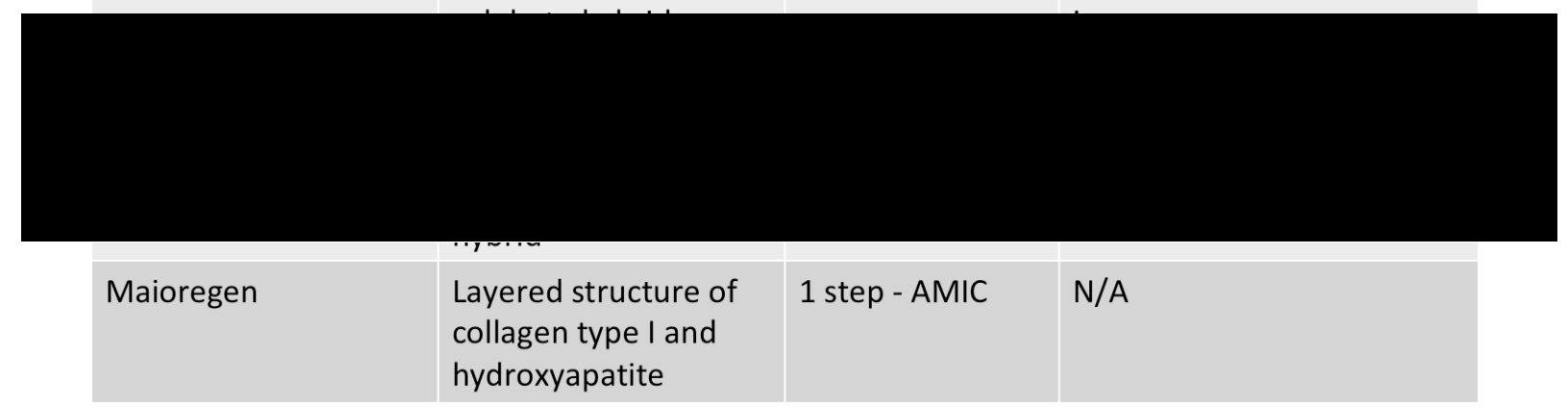

Table 5.1: Table of commercially available scaffolds for MACI procedures (Jeuken et al., 2016)

Commercially available collagen based scaffolds have been used in MACI surgery with varying degrees of success (Iwasa et al., 2009). Although, they are typically shown to be superior to microfracture surgery in their repair capabilities in long term follow up studies there are still issues regarding cellular differentiation and the onset of hypertrophy in chondrocytes (Jeuken et al., 2016). Research with jellyfish derived collagen scaffolds has been shown to be a promising alternative matrix material with cells expressing chondrogenic markers (Hoyer et al., 2014), displaying higher cell viability and comparable in vivo immune response to bovine collagen (Song et al., 2006).Work outlined in Chapters 3 and 4 have shown that $R$. pulmo jellyfish collagen can be moulded into a scaffold structure and is biocompatible with cells, eliciting a response similar to commercially available collagen.

As well as the biomaterial source for scaffold construction, cell source plays an important step in being able to produce the desired tissue type (O'Brien, 2011). CPs were used here, demonstrating an ability to undergo chondrocyte differentiation. In comparison, the use of chondrocytes has proven to have limitations including donor site morbidity, limited cell source and dedifferentiation during 2D in vitro expansion 
before seeding into scaffolds ( $\mathrm{Li}$ et al., 2015). Multipotent cells such as MSCs, while they have the capability to differentiate into osteogenic, chondrogenic and adipogenic lineages (Murray and Péault, 2015), are epiphyseal in nature if isolated from bone marrow, and usually produce chondrocytes that undergo terminal differentiation and hypertrophy (Williams et al., 2010).

MSCs can be harvested from a number of other tissues due to their broad distribution throughout the human body, including adipose tissue, synovial tissue and umbilical cords (Williams et al., 2011). Cartilage repair research using such MSCs have given promising results with a high proliferative capacity, induction of a minimal immune response following implantation and good chondrogenic potential exhibiting COL2A1 and ACAN in culture (Zhang et al., 2009). Using an autologous population that can be harvested from the same injured joint, due to their clonogenic potential and culture proliferation however is advantageous. CPs obtained from cartilage are believed to be further along the stages of commitment to the chondrogenic lineage compared to MSCs (Jayasuriya and Chen, 2015a). Effective in vivo cartilage repair has been observed in caprine models where CPs gave similar results in terms of repair and integration as full depth chondrocytes (Williams et al., 2010).

\section{Enhanced chondrogenesis}

In developmental biology, chondrogenesis is the process by which chondrocytes arise from mesechymal progenitor cells and produce cartilage anlagen for developing bone (Goldring, 2012). The process begins through mesenchymal condensation to form anlagen where cells actively express ECM components and cell adhesion molecules including aggrecan and collagen type II (Boyce et al., 2018). At a certain cell per volume ratio, cells at the centre of the condensed structure cease proliferation and establish cartilaginous nodules (Berge et al., 2008). Formation of the anlagen is driven by Sonic Hedgehog (Shh) through interaction with the transmembrane receptors Patched 1 and 2 and the subsequent recruitment and activation of Smoothened and Gli transcription factors, respectively (Wilson and Chuang, 2010).

The activation of this signalling system induces the expression of SOX9, which is critical during chondrogenesis and can be regulated by Notch signalling (Monsoro- 
Burq, 2005). Once SOX9 is activated chondrogenesis continues, the anlagen elongates, and endochondral ossification occurs where chondrocytes continue to express SOX9 but also express RUNX2 and Osterix, important transcription factors seen as critical for the skeleton mineralisaion and bone formation. They are responsible for causing enlargement of cells and expression of collagen type $\mathrm{X}$ as well as alkaline phosphatase, characteristics of hypertrophy and calcification (Nishimura et al., 2012).

Chondrogenic media used in this chapter was supplemented with TGF $\beta 1$ to in order to stimulate chondrogenesis in line with research findings in literature. TGF $\beta$ and BMP families are essential in the initiation of chondrogenesis (Mariani et al., 2014). TGF $\beta$ signals via activin-like kinase (ALK) 1 and 5 to activate Smad pathways, outlined in Figure 5.1 (Finnson et al., 2008). Both pathways regulate the differentiation and phenotypic characteristics, to stabilise chondrocyte phenotypes (in the superficial and medial zones) or induce chondrocyte specific hypertrophic differentiation in the deep zone cartilage (Mariani et al., 2014). TGF $\square 1$ specifically, is considered an essential molecule in the anabolic processes in cartilage formation (Serra et al., 1997). Experiments involving TGF $\beta 1$ null mice showed no defect in cartilage formation however $50 \%$ of embryos underwent early termination suggesting a lethal effect due to the lack of TGF $\beta 1$ family (Wang et al., 2014).

Differentiation of cells causes the loss and expression of different genes depending on the lineage that is to be created therefore analysis of specific gene expression profiles can indicate whether the desired tissue is being formed during regenerative medicine (Alberts et al., 2002). In this chapter, a panel of genes was chosen for analysis, that are present in chondrogenesis, shown in Figure 5.1, with hypertrophic marker (RUNX2, COL10A1) chosen as negative controls.

SOX9 is considered the master regulator of chondrogenesis due to its role in proliferation and differentiation of cells via direct control of the expression of specific chondrogenic genes (Green et al., 2015). Most notably, SOX9 binds to a 48 base pair enhancer region in COL2A1 and works with SOX5 and SOX6 to regulate aggrecan expression, leading to SOX9, COL2A1 and ACAN being seen as characteristic markers of chondrogenesis (Kupcsik et al., 2010). Data from this 
project shows that pellet cultures had the highest SOX9 expression compared to JCol scaffold cultures. The chondrogenic potential of pellets is further witnessed by TGF $\beta$ treated cultures exhibiting the highest expression of ACAN and COL2A1. This may be due to pellet culture emulating condensation events that occur naturally during development through close cell-cell contact (Goldring, 2012).

Developmental studies have also shown that SOX9 is upregulated in hypoxic conditions, which may occur at the centre of pellet structures (Yodmuang et al., 2015). This is observed here, as pellet cultures stained with Toluidine Blue are labelled throughout whereas scaffold cultures show the most intense Toluidine Blue staining at the seeding interface, where the majority of cells are present. In a similar fashion to previous research with $R$. pulmo collagen in cartilage engineering, our data also showed an increase in SOX9 and ACAN expression in TGF $\beta$ treated scaffolds compared to the untreated counterpart displaying the additive effect of growth factors in regenerative medicine (Pugliano et al., 2017). Cell density is thought to be key in GAG accumulation with high cell density leading to increased production (Kobayashi et al., 2007).

Pore size is a critical component when designing scaffolds for tissue engineering (Murphy et al., 2010). Although JCol scaffolds were proven to have an average pore size that is condusive to chondrogenesis (Matsiko et al., 2015) our results show chondrogenic genes are better expressed in pellets where cell-cell contact is apparent. Large pore sizes result in a decrease of surface area leading to reduction in ligand density for cell binding (Murphy et al., 2010). This may be the case with JCol scaffolds whereby cell attachment is lower and reduces cellular processes such as differentiation (O'Brien et al., 2005). The development of scaffolds with different pore sizes will help to further our understanding and enhance chondrogenesis.

Collagen was observed in all culture conditions via polarised light microscopy from picrosirius red staining. Gene expression analysis of cells from different culture conditions displayed the type of collagen produced during differentiation. Untreated JCol scaffolds exhibited the highest expression of COL1A1 and one of the lowest expressions of COL2A1 compared to other culture conditions. The expression of COL1A1, typically seen in abundance in fibrocartilage, may be due to the 
mechanical weakness of JCol scaffolds, with mechanotransduction signalling to cells for the production collagen suitable for the environment in which they are attached to (Kock et al., 2012). A decrease in COL1A1 was observed in JCol scaffolds treated with TGF $\beta$ treatment and is potentially linked to the upregulated expression of SOX9 leading to expression of COL2A1.

Type II collagen accounts for approximately $90 \%$ of the total dry weight of articular cartilage and aids in the tensile strength of the tissue (Bhosale and Richardson, 2008). The production of the correct collagen type is important in order to produce a functionally relevant tissue for implantation (Roberts et al., 2009). Fibrocartilage is an inherently mechanically weaker form of cartilage that is predominantly composed of type I collagen (Hollander et al., 2003). The production of type I collagen in cartilage tissue engineered constructs would lead to a weaker cartilage and higher risk of readmission for surgery and therefore COL2A1:COL1A1 ratio is often seen as an important aspect of in cartilage regeneration (Albrecht et al., 2011). However, it should be noted that collagen type $\mathrm{I}$ is expressed in native immature articular cartilage in the superficial zone (Teshima et al., 2004). Immunohistochemistry of TGF $\beta$ treated scaffolds did not show collagen type I or II to be present, following culture period however this may be due to the specificity of the antibody used and the inability to recognize epitopes presented on jellyfish collagen (Matos et al., 2010).

As a master regulator, SOX9 is also linked with the transcription regulation of RUNX2, inhibiting its expression during chondrogenesis (Zhou et al., 2006). RUNX2 is responsible for the maturation and hypertrophy of chondrocytes, which suggests that during skeletal development RUNX2 supresses SOX9 expression to allow for endochondral ossification and bone development (Cheng and Genever, 2010). Once hypetrophic, chondrocytes express collagen type $X$ which in turn influences the environment for matrix deposition and tissue mineralisation (Gu et al., 2014). The overexpression of RUNX2 is also believed to play a role in the pathogenesis of OA as it induces the expression of MMP13 and ADAMTS5 that are responsible for the degradation of the cartilage matrix (Komori, 2018). 
Interestingly, data from this project shows that untreated pellet cultures although displaying the highest SOX9 expression, also displayed the highest levels of RUNX2 and COL10A1 suggesting more cells were beginning to undergo hypertrophy in comparison to other culture conditions. A decrease in RUNX2 and COL10A1 was observed in TGF $\beta 1$ treated pellet cultures showing the effect of TGF $\beta 1$ in chondrogenesis. Treated and untreated scaffold structures show similar levels of RUNX2 expression, with TGF $\beta$ scaffolds showing a lower level of COL10A1 expression compared to the untreated scaffold. Human MSCs cultured in jellyfish collagen scaffolds have previously been shown to upregulate COL10A1 gene expression following 3 weeks of chondrogenic culture (Hoyer et al., 2014). However, the reliability of COL10A1 as a hypetrophic marker in vitro has been questioned as previous research has shown that COL10A1 expression occurred earlier than COL2A1 expression in chondrogenic pellet culture (Mwale et al., 2006). The data here suggests that collagen scaffold support is needed to mitigate the temporal expression of these collagen variants, in line with that observed in developmental biology.

Overall, this chapter demonstrates that JCol scaffolds are a suitable environment for chondrogenesis of bovine derived CPs. Cell invasion is observed through the construct, though does not appear apparent in the 'deep' zone, and cell content is higher than pellet culture. Histological, biochemical and gene analysis shows that JCol scaffolds express genes typically associated with chondrogenesis and that matrix deposition is enhanced with the use of growth factors such as TGF $\beta$. Hypertrophic markers were observed in scaffold cultures however they were expressed at lower levels compared to pellets indicating that cellular hypertrophy may be less likely to occur in scaffold structures. These results indicate that JCol scaffolds should be developed further for regenerative medicine and tissue engineering of cartilage with focus placed on the mechanical stability of structures and cell seeding efficiency for the homogenous deposition of matrix for functional tissue development. 


\section{CHAPTER 6}

\section{General Discussion}




\subsection{Thesis Summary}

Collagen is an integral component of the ECM and contributes to the structural integrity of tissues as well as influencing multiple cellular functions (Frantz et al., 2010). The deregulation of, or imbalance between anabolic and catabolic processes regarding the ECM is a contributing factor towards the development of disease (Bonnans et al., 2014). Although some tissues, such as skin, have the ability to regenerate after injury others lack the capability to do so and require intervention through tissue engineering strategies. Surgical techniques to repair damage which results from such disease processes have evolved from cellular and gene therapies, to matrix assisted implantation techniques that are beginning to rival allogneic implantation of donor material (Hosseinkhani et al., 2014).

Traditionally mammalian derived collagens used in such repair approaches present widespread challenges, from environmental (farming), ethical, immunological and contamination considerations (Karim and Bhat, 2009). 3\% of the population exhibit allergic reactions to bovine derived collagen (Lee and Lee, 2016). Collagens are a robust protein family, with a high degree of evolutionary conservation indicating a wider pool of sources being available (Exposito et al., 2002). In addition, synthetic variants that capitalise on collagen structural composition have been explored (Saha et al., 2007).

Marine sources (from animals including fish, jellyfish and sea urchins) are becoming more prominent and further explored (Subhan et al., 2015). As well as overfishing leading to the decline of specific fish species, cold and warm water fish display differences in their collagen properties, indicating that fish may not be a suitable sustainable collagen source (Karim and Bhat, 2009). Particular interest has been given to jellyfish as their anatomy is largely composed of collagen and the increase in heat has caused seasonal blooms that are disruptive to both sea and terrestrial life (Brotz et al., 2012).

R.Pulmo harvested collagen represents a possible alternative, inert and structurally compatible, next generation collagen source to furnish cleaner, more robust regenerative medicine approaches tailored made for individual applications. 
Mammalian collagen isolation methods have proven to produce high yields whilst maintaining the triple helix structure, presenting cell binding motifs for attachment and providing mechanical strength for scaffolds (Exposito et al., 2010). Presented here is a large body of evidence; from triple helical structure, peptide sequence conservation and mammalian homology, to sponge scaffold fabrication and in depth characterisation, to support the adoption of such marine collagens in human regenerative medicine. JCol is biocompatible in that it supports non differentiated mammalian cell culture (in 2D and 3D), does not initiate an adverse immunogenic response in vitro and is an appropriate scaffold for enhanced mammalian cell chondrogenesis.

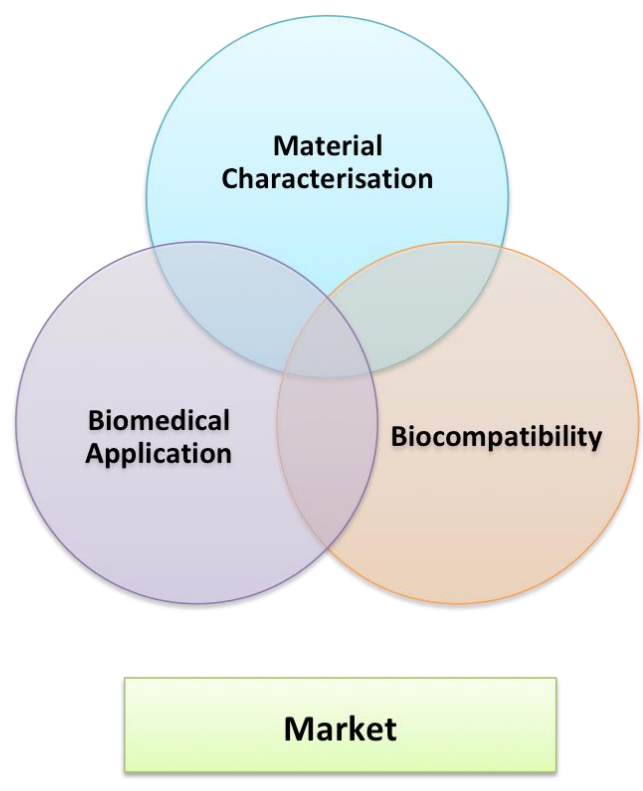

Acid soluble; characteristic amide peaks; functional peptide; moldable; thermally stable with EDC crosslinking

Compatible with human cell viability/ proliferation; comparable leukocyte activation to mammalian collagen in vitro

Chondroprogenitor invasion; functional differentiation; matrix deposition

Jellagen adopted and integrated isolation protocol for further product research and development

Figure 6.1: Schematic of experimental areas and outputs achieved in this project.

Articular cartilage is a tissue with limited regenerative capacity and tissue trauma can lead to the development and progression of OA (Goldring and Goldring, 2007). Many commercially available polymer like scaffolds for procedures such as MACI exist, with collagen being favoured (Jeuken et al., 2016). JCol sponge scaffolds used as a natural matrix derivative support chondroprogenitor cell growth, chondrogenic differentiation and now need to be tested for integration with native tissue, in humans (Khan et al., 2008). 


\subsection{JCol structural composition, isolation and sponge fabrication}

Maintenance of collagen structure following isolation is imperative as disturbance can cause loss of function (Bonnans et al., 2014). The development of a more efficient and rapid $R$. pulmo jellyfish collagen isolation method was fully optimised here and has since been adopted by our industrial partner (Pacak et al., 2011). Incorporating measurements for purity, yield and the conservation of all important amide I, II, III peaks using techniques such as FTIR enabled modified isolations, through the use of different acids, enzymatic digestion and salting out procedures (Schmidt et al., 2015).

Acetic acid solubilisation followed by salting out with sodium chloride provides a collagen preparation re-suspended in acetic acid with maintained amide peaks supportive of a collagen sub type capable of triple helix structure formation. Altered electrophoretic patterns observed in the alpha1/2 bands compared to RTCol, where the migration was slower, provide an indication that this helical structure is altered in JCol (Addad et al., 2011). Peptide analysis preformed on $\alpha 1$-derived band showed sequence alignment with human collagen peptides that are imperative to triple helix structure, validating that our isolation method maintained the essential building blocks for a 'collagen like' triple helical structure. When fabricated to a 3D sponge, JCol collagen provided a larger pore size when compared to mammalian collagen sources, at each cross-linking concentration. The differences in structural composition of collagen between the species may lead to overall changes in aspects such as fibre diameter and density, which in turn causes changes in architecture and pore size (Lang et al., 2013). Certain pore sizes have been shown to favour specific regenerative applications and so these differences may prove to be advantageous however structural differences in collagen can also alter mechanical properties and therefore adjustments may be required to achieve a biomimetic matrix model (Yang and Kaufman, 2009).

Collagen derived scaffold structures can form varying constructs with hydrogels and sponge scaffolds being prominent (Lee and Shin, 2007). Mammalian collagens are 
compatible with sponge structures and also gel between room temperature and $37^{\circ} \mathrm{C}$, during the process of fibrillogenesis (zhu and Kaufman, 2014). JCol fabrication techniques produce a sponge scaffold typical of marine collagen (Hoyer et al., 2014) however no gelation occurred between 4 and 37C. Fibril formation is informed by the amino acid composition, with Cheng et al. showing a lower hydroxyproline content compared to mammalian counterparts, leading to a lower crosslinking density and a lower denaturation temperature (Cheng et al., 2017a).

EDC cross-linking stabilised this sponge structure, providing mechanical, structural and thermal integrity (Davidenko et al., 2015). The low hydroxyproline content in JCol results in a low denaturation temperature $\left(29^{\circ} \mathrm{C}\right)$, making it unsuitable for implantation into the human body (Subhan et al., 2015). Thermal stability increased after crosslinking. This trend was also witnessed in scaffold degradation properties with $1 \%$ crosslinked jellyfish scaffolds taking more time to undergo full digestion with collagenase however the scaffold did not show resistance.

The mechanical properties of scaffolds have been closely linked with functional cellular differentiation (Plant et al., 2009). AFM analysis of scaffold during this project was unable to obtain mechanical data as hydrated constructs proved too soft in their nature. This is an issue often seen in hydrogels whereby water retention causes gels to be inherently weak (Brown et al., 2005). Increasing the concentration of EDC may further enhance the mechanical properties of scaffolds however it has been reported cell viability decreases with increasing EDC concentration. Also, as EDC capitalises on glutamic acid, found in the GFOGER cell binding motif, increasing concentration may lead to lower cell attachment (Thoreson et al., 2015).

Previous reports have shown that plastic compression can remove excess water and increase fibril density, producing a stronger product (Cheema and Brown, 2013). Applied to jellyfish collagen scaffolds, plastic compression was unsuccessful as reswelling occurred, which is not seen in mammalian collagen constructs. It should be noted that literature based around plastic compression appears to have been conducted on hydrogels and not on collagen sponges and therefore it may be the form of scaffold that caused reswelling. To tailor scaffolds for specific applications it would be interesting to look at parameters involved in compression such as initial 
fibril density and further develop the technique (Brown et al., 2005). In the absence of plastic compression, fabrication of size and shape scaffolds may affect cell-cell and cell-matrix interactions as well as the all important matrix cell density ratio, which drives functional differentiation in many tissues (Mao et al., 2016). During the project, scaffold fabrication was limited to a $3 \mathrm{ml}$ cylinder due to company interaction and restrictions around IP development.

Scaffolds for tissue engineering are not seen as permanent implants but rather as temporary structures to provide guidance for the regeneration of tissues and therefore must be able to be remodelled by cells (Peters and Mooney, 1997). Sponge scaffold pore sizes fell within the critical range for applications in cartilage tissue engineering with the range obtained $(20-150 \mu \mathrm{m})$ previously reported to facilitate chondrocyte differentiation (Matsiko et al., 2015). Chondroprogenitor cell invasion, over 21 days, supports the suitability of a wider porosity as well as the presentation of appropriate mammalian cell binding motifs throughout the structure (Davidenko et al., 2016). Peptide alignment indicated areas of high sequence similarity with human COL1A1 and COL3A1 and further functional analysis indicating these regions belong to pfam01391, the triple helical motif belonging to collagen. Collagen composition and structure plays a role in binding of cells through integrin binding (Emsley et al., 2000). CP cell invasion and proximity to collagen ribbons, observed through histological staining, indicate that specific binding motifs such as GFOGER are present allowing cell-matrix interactions (Rentsch et al., 2014).

Our results indicate show that JCol can be isolated from native tissue and shows presence of triple helix composition through functional peptide analysis and FTIR in a similar fashion to mammalian collagens. JCol scaffolds manipulated into sponges facilitate cell invasion and growth of cells within a 3D environment due to the similarity of the niche with native ECM of tissue when compared to cell only alternatives. The natural ECM environment guides cellular functions and the loss of this can cause alterations in cell phenotype and behaviour (Bonnans et al., 2014). A number of cell types have proved difficult to culture in 2D whilst maintaining their native biological including cancer cells and hepatocytes, whilst differentiation of stem cells into functional mature tissue cells show varying characteristics (Duval et al., 2017). Initial results regarding CPs and JCol scaffolds indicate that these 
structures may present themselves as a suitable source for the in vitro culture of cells whilst maintaining their native biological phenotype and function.

\subsection{CPs, scaffold assisted enhanced chondrogenesis}

Biomimetic structures have been developed in order to produce a more functionally relevant engineered tissue for repair purposes (Zhang, 2012). The aim of biomimetic constructs is to provide a familiar niche for stem and progenitor cells to enable interaction and to enhance their differentiation capacity (Vinatier et al., 2009). Biomimicry can take multiple forms from matrix informed scaffold design, decoration of structure with ligands and mechanical tuning (Ravichandran et al., 2012). Scaffolds in this project fulfil the requirements of biomimicry as they are produced from collagen, a natural matrix component and facilitate cell invasion.

The MACI technique aims to produce a biomimetic environment by providing a scaffold to guide the growth of cells and enhance the production of cartilage specific matrix. Previous publications have shown that cartilage tissue engineering continues to aim for biomimicry of the native tissue through the alteration of pore size, use of different cell sources and biomaterials during in vitro examination (Taraballi et al., 2017) . Although preclinical testing is basic as it removed from the entire tissue system, behaviour exhibited by the cells is seen as indicative of physiological function due to the mimicry of the construct involved.

Pellet culture is the standard practice used for studying in vitro chondrogenesis, replicating the high cellular density needed to assess chondrocyte production of distinct cartilage matrix properties and protein components including distinct collagen architecture, as well as COL2A1 and GAG production (Bernstein et al., 2009). Missing the fundamental complexity of the tissue due to the absence of ECM support, this model is inadequate to predict the in vivo potential of next generation MACI approaches (Achilli et al., 2012). Clinical studies have already shown that MACI surgery gives better cartilage repair in patients compared to those who were treated using microfracture or ACI indicating that matrix models have an enhanced chondrogenic capacity (Jeuken et al., 2016). This may indeed be due to the enhanced 
progenitor or stem cell migration to a familiar niche, relying on mechanical properties, concentration gradients of growth factors or simply the presentation of cell collagen peptides such as those detected in JCol.

Bovine chondroprogenitors migrated throughout the JCol scaffold and showed enhanced differentiation in the presence of TGF $\beta 1\left(10 \mathrm{ng} / \mathrm{ml}^{-1}\right)$, previously shown to induce mesencymal cell condensation and initiate chondrogenesis in MSCs (Wang et al., 2014). Although pellet cultures exhibited a higher expression of SOX9, ACAN and COL2A1 when compared to scaffolds, interestingly they also exhibited the highest expression of hypertrophic markers RUNX2 and COL10A1. These results indicate that the presence of a matrix structure enables the guidance of $\mathrm{CP}$ cells towards chondrogenic lineage without inducing high amount of hypertrophic markers (Watts et al., 2013).

Native Immature cartilage is seen to be softer and weaker than mature cartilage (Julkunen et al., 2009). Implantation of a scaffold in early chondrogenic stages would still require maturation and risks damage whereas in vitro maturation may produce tissue closer to native cartilage, increasing the likelihood that the cartilage implant could withstand the forces applied through the injured joint post operation (Jin et al., 2011). Initial models should show the process of chondrogenesis and cartilage formation and limited immunogeniticy occurs in vivo using heterotropic and orthotropic models where the construct is placed in at a non cartilage and non-weight bearing cartilage site (Reinholz et al., 2004). The presence of chondrogenesis in these constructs would allow for further in vivo testing for immunogenicity and finally in a weight-bearing model. While a non-weight bearing approach is one method of progressing a pre clinical study, in vitro maturation is an alternative option (Khan et al., 2013). Maturation is the process whereby cartilage undergoes resorption to form organised zonal structure and collagen fibre orientation resulting in increased mechanical integrity (Hunziker et al., 2007). Previous work has shown that a combination of growth factors can induce maturation including FGF2 and TGF $\beta 1$ (Khan et al., 2013) and members of the BMP family causing growth and resorption as well as hypertrophy (Kraan et al., 2010). Enhanced chondrogenesis and maturation within the 3D JCol sponge could provide a tissue engineered construct, requiring a shorter rehabilitation process benefiting patient rehabilitation and 
potentially reducing the economic burden of $\mathrm{OA}$ patients recovering from repair surgery (Schrock et al., 2017).

The zonal variation throughout the depth of articular cartilage allows for its compressive resistance and therefore the advancement of chondromimetic scaffolds may potentially take native structure into account (Fox et al., 2009). Matrix based approaches have been researched in an attempt to emulate the structure (Klein et al., 2009). These techniques have primarily involved the formation of biomaterial density throughout the construct leading to a more natural distribution found within the tissue to encourage hapotaxis before differentiation (Mimura et al., 2008). The development of JCol scaffolds through the modelling of concentration gradient may not only better mimic native cartilage but would potentially allow for better cell distribution and matrix deposition.

\subsection{Biocompatibility}

Whilst preclinical demonstration provides a robust defence of specific applications, ultimately these constructs need to be implanted. The initial implantation of a biomaterial is accompanied by injury that triggers the immune system (Franz et al., 2011). This is characterised by adsorption of blood proteins to the biomaterial and acute inflammation caused by the activation of leukocytes (Brown and Badylak, 2014). The persistence of leukocyte activation eventually results in chronic inflammation and fibrotic capsule formation with the risk of rejection and necrosis of implant and native tissue (Wiles et al., 2016).

Using a bovine model, no information could be garnered regarding the compatibility of our cartilage construct. In the absence of ethical permissions and financial scope, an in vitro model was used during this project to identify any JCol characteristics indicative of abnormal immunogencicity, using human donor blood samples. Fulfilling the requirements set out by the International Organisation of Standardisation (Radley et al., 2017), immune cells from innate and adaptive phase were screened via FACS for activation markers (CD62L, CD11b and fMLPr) in the 
presence and absence of JCol scaffolds, comparing favourably to research and clinical grade collagen.

Cytokines are released by immune cells as a response to foreign material and have different functions (Turner et al., 2014). A cytokine release profile was also collated from in vitro testing with IL-6, a pro-inflammatory cytokine, and IL-10, an antiinflammatory cytokine chosen for investigation and shown to be comparable across all scaffold materials. Carbodiimide crosslinking has been shown to increase M1 response leading to an upregulation of proinflammatory cytokines (Boehler et al., 2011) however our results showed that a there was minimal differences seen between crosslinking concentrations. The immune response is a cascade of reactions that are dependent on one another with neutrophil and monocytes activation leading to the increase in pro-inflammatory cytokine release and the subsequent activation of the adaptive arm of the response and anti-inflammatory cytokine release (Chaplin, 2010). JCol scaffolds show that the levels of leukocyte activation lead to the relative cytokine release, exhibiting a favourable response compared to rejection of tissue.

The preliminary data shown was gathered from a cohort of three donors, with donor variability clearly observed. Despite this variability, a similar trend was observed in mammalian research and clinical grade collagen, sources that are already used in vivo (Song et al., 2006). Similarly our in vitro testing incubated scaffolds with blood for 2 hours before analysing leukocyte activation and allowed 24 hours before cytokine analysis. This would suggest that the response to jellyfish scaffold is representative of the innate immune response and that in vivo analysis through an animal model over a longer time period would account for the adaptive immune response. In order to enhance the reliability of this data and account for variability a larger cohort would need to be screened prior to a full in vivo analysis.

In vitro testing does not mimic the complex in vivo environment and response to biomaterials (Chu et al., 2010). The development of in vitro models allows for preliminary results to guide research towards the use of animal models that can assess immunogenicity in response to biomaterial implantation as well as regeneration through analysis of gene and protein expression (Al-Maawi et al., 2017). 
Heterotropic models take into account the performance of the construct under in vivo conditions by assessing tissue formation and immune response. However the response may be altered compared to when placed at the defect and therefore heterotropic models will inform in vitro and in vivo studies (Reinholz et al., 2004). In vivo cartilage studies are typically conducted using small animals however the small joint size leads to thin cartilage that does not benefit clinical translation (Chu et al., 2010). Large animal, caprine, ovine and equine, models by-pass the limitation of rodent and lapine models, with larger joints that mimic load bearing patterns more similar to that seen in humans (Cook et al., 2014).

Previous publications have reported different ways in which scaffolds can be immune tuned in order to avoid the elicitation of an immune response and potential rejection of the construct. Scaffold material choice and topography play a role in immune response modulation can be acquired by surface treatment and coating (Boehler et al., 2011). Increasing hydrophobicity of scaffolds has been shown to limit dendritic cell maturation (Kou and Babensee, 2011) whilst osteopontin coating displayed a reduction in the thickness of fibrotic capsule formed around the implant (Liu et al., 2008) and serum coated biomaterials induced anti-inflammatory cytokine, IL-10 (Boehler et al., 2011).

ACI circumvents graft rejection by utilising cells from the patients however the limited number of cells and donor site morbidity make the technique less appealing (McCarthy et al., 2016). The use of allogenic cells, either alone or in combination with a scaffold for MACI can evade the further damage of healthy tissue via harvesting but may elicit an immune response (Dunkin and Lattermann, 2013). Research has been conducted in the immunomodulation of scaffold for cartilage tissue engineering with biomaterials coated in anti-inflammatory proteins shown to modulate inflammation in subcutaneous implantation (Fahy et al., 2015).

\subsection{Concluding remarks}

Currently, mammalian collagen is used in 2D and 3D culture to varying success and growing concerns over economic and ethical issues have resulted in the 
interest of alternative sources. This thesis has shown that $R$. pulmo jellyfish collagen can be extracted at industrial scale whilst maintaining structural integrity and can be used to fabricate sponge scaffold structures. This thesis has demonstrated jellyfish collagen is biocompatible with multiple cell types displaying viability and phenotypic stability in comparison to traditional tissue culture plastic and other collagen sources. Furthermore, the in vitro immunogenic profile was found to be comparable to rat-tail and bovine collagen, both of which are used for research and clinical applications. In addition, chondrogenesis of bovine CPs within JCol scaffolds exhibited an enhanced chondrogenesis observed through chondrogenic gene expression and matrix deposition, with minimal expression of hypertrophic markers. Results from this thesis indicate that R. pulmo derived jellyfish collagen is a suitable alternative source of collagen that fulfils minimal requirements for tissue engineering purposes, specifically cartilage engineering. The knowledge from this body of work can now inform industrial partner, Jellagen, movements towards the development of R. pulmo collagen solutions and biomaterials for 2D and 3D culture models for preclinical and clinical application. 
Bibliography

\section{Bibliography}

ABDI, R., FIORINA, P., ADRA, C. N., ATKINSON, M. \& SAYEGH, M. H. 2008. Immunomodulation by mesenchymal stem cells. A potential therapeutic strategy for type 1 diabetes. Diabetes, 57, 1759-1767.

ABRAHAM, L. C., ZUENA, E., PEREZ-RAMIREZ, B. \& KAPLAN, D. L. 2008. Guide to collagen characterization for biomaterial studies. Journal of Biomedical Materials Research, 87B, 264-285.

ACHILLI, T.-M., MEYER, J. \& MORGAN, J. R. 2012. Advances in the formation, use and understanding of multi-cellular spheroids. Expert Opinion on Biological Therapy, 12, 1347-1360.

ADDAD, S., EXPOSITO, J.-Y., FAYE, C., RICARD-BLUM, S. \& LETHIAS, C. 2011. Isolation, characterisation and biological evaluation of jellyfish collagen for use in biomedical applications. Marine Drugs, 9, 967-983.

AHMAD, Z., SHEPHERD, J. H., SHEPHERD, D. V., GHOSE, S., KEW, S. J., CAMERON, R. E., BEST, S. M., BROOKS, R. A., WARDALE, J. \& RUSHTON, N. 2015. Effect of 1-ethyl-3-(3-dimethylaminopropyl) carbodiimide and Nhydroxysuccinimide concentrations on the mechanical and biological characteristics of cross-linked collagen fibres for tendon repair. Regenerative Biomaterials, 2, 77-85.

AKAGI, J., KORDON, M., ZHAO, H., MATUSZEK, A., DOBRUCKI, J., ERRINGTON, R., SMITH, P. J., TAKEDA, K., DARZYNKIEWICZ, Z. \& WLODKOWIC, D. 2013. Real-time cell viability assays using a new anthracycline derivative DRAQ7. Cytometry Part A, 83A, 227-234.

AL-MAAWI, S., ORLOWSKA, A., SADER, R., KIRKPATRICK, C. J. \& GHANAATI, S. 2017. In vivo cellualr reaction to different biomaterialas- physiological and pathological aspects and their consequences. Seminars in Immunology, 29, 49-61.

ALBERTI, K. A. \& XU, Q. 2016. Biocompatibility and degradation of tendonderived scaffolds. Regenerative Biomaterials, 3, 1-11.

ALBERTS, B., JOHNSON, A., LEWIS, J., RAFF, M., ROBERTS, K. \& WALTER, P. 2002. Molecular Biology of the Cell, New York, Gardland Science.

ALBRECHT, C., TICHY, B., NÜRNBERGER, S., HOSINER, S., ZAK, L., ALDRIAN, S. \& MARLOVITS, S. 2011. Gene expression and cell differentiation in matrixassociated chondrocyte transplantation grafts: a comparative study. Osteoarthritis and Cartilage, 19, 1219-1227.

ALEXANDER, C. \& RIETSCHEL, E. T. 2001. Bacterial lipopolysaccharides and innate immunity. Journal of Endotoxin Research, 7, 167-202.

ALVES, F., VOGEL, W., MOSSIE, K., MILLAUER, B., HÖFLER, H. \& ULLRICH, A. 1995. Distinct structural characteristics of discoiding I subfamily receptor tyrosine kinases and complementary expression in human cancer. Oncogene, 10, 609-618.

AMOAKO, A. O. \& PUJALTE, G. G. A. 2014. Osteoarthritis in young, active and athletic individuals. Clinical Medicine Insight: Arthritis and Musculoskeletal Disorders, 7, 27-32.

ANDERSON, J. M., RODRIGUEZ, A. \& CHANG, D. T. 2008. Foreign body reaction to biomaterials. Seminars in Immunology, 20, 86-100. 
ANDERSON, N. J., BONAUTO, D. K. \& ADAMS, D. 2010. Work-related amputations in Washington state, 1997-2005. American Journal of Industrial Medicine, 53, 693-705.

ANDORKO, J. I. \& JEWELL, C. M. 2017. Designing biomaterials with immunomodulatory properties for tissue engineering and regenerative medicine. Bioengineering \& Translational Medicine, 2, 139-155.

ANTOINE, E. E., VLACHOS, P. P. \& RYLANDER, M. N. 2014. Review of collagen I hydrogels for bioengineered tissue microenvironments: characterization of mechanics, structure, and transport. Tissue Engineering: Part B 20, 683-696.

ANTONI, D., BURCKEL, H., JOSSET, E. \& NOEL, G. 2015. Three-dimensional cell culture: a breakthrough in vivo. International Journal of Molecular Sciences, 16, 5517-5527.

ARAB-BAFRANI, Z., SHAHBAZI-GAHROUEI, D., ABBASIAN, M., SABERI, A., FESHARAKI, M., HEJAZI, S. H. \& MANSHAEE, S. 2016. Culturing in serumfree culture medium on collagen type I coated plate increasses expression of CD133 and retains original phenotype of HT-29 cancer stem cell. Advanced Biomedical Research, 5.

AREIDA, S. K., REINHARDT, D. P., MÜLLER, P. K., FIETZEK, P. P., KÖWITZ, J., MARINKOVICH, M. P. \& NOTBOHM, H. 2001. Properties of the collagen type XVII ectodomain. Journal of Biological Chemistry, 276, 1596-1601.

ARMIENTO, A. R., STODDART, M. J., ALINI, M. \& EGLIN, D. 2018. Biomaterials for articular cartilage tissue engineering: learning from biology. Acta Biomaterialia, 65, 1-20.

ARTYM, V. V. \& MATSUMOTO, K. 2010. Imaging cells in three-dimensional collagen matrix. Current Protocols in Cell Biology.

ASHKAVAND, Z., MALEKINEJAD, H. \& VISHWANATH, B. S. 2013. The pathophysiology of osteoarthritis. Journal of Pharmacy Research, 7, 132138.

ASHWORTH, J. C., BEST, S. M. \& CAMERON, R. E. 2014. Quantitative architectural description of tissue engineering scaffolds. Materials Technology 29, 281295.

ASHWORTH, J. C., MEHR, M., BUXTON, P. G., BEST, S. M. \& CAMERON, R. E. 2016. Parameterizing the transport pathways for cell invasion in complex scaffold architectures. Tissue Engineering Part C: Methods, 22, 409-417.

AWAD, H. A., WICKHAM, M. Q., LEDDY, H. A., GIMBLE, J. M. \& GUILAK, F. 2004. Chondrogenic differentiation of adipose-derived adult stem cells in agarose, alginate and gelatin scaffolds. Biomaterials, 25, 3211-3222.

BADYLAK, S., GILBERT, T. \& MYERS-IRVIN, J. 2008. The extracellular matrix as a biologic scaffold for tissue engineering Tissue Engineering. Academic Press.

BAILEY, J. R., BLAND, P. W., TARLTON, J. F., PETERS, I., MOORGHEN, M., SYLVESTER, P. A., PROBERT, C. S. J. \& WHITING, C. V. 2013. IL-13 promotes collagen accumulation in Crohn's disease fibrosis by downregulation of fibroblast MMP synthesis: a role for innate lymphoid cells? PLoS One [Online], 7.

BAKER, M. J., TREVISAN, J., BASSAN, P., BHARGAVA, R., BUTLER, H. J., DORLING, K. M., FIELDEN, P. R., FOGARTY, S. W., FULLWOOD, N. J., HEYS, K. A., HUGHES, C., LASCH, P., MARTIN-HIRSCH, P. L., OBINAJU, B., 
SOCKALINGUM, G. D., SULÉ-SUSO, J., STRONG, R. J., WALSH, M. J., WOOD, B. R., GARDNER, P. \& MARTIN, F. L. 2014. Using Fourier transform IR spectroscopy to analyse biological materials. Nature Protocols, 9, 17711791.

BALL, S. G., BALDOCK, C., KIELTY, C. M. \& SHUTTLEWORTH, C. A. 2001. The role of the $\mathrm{C} 1$ and $\mathrm{C} 2 \mathrm{~A}$-domains in type VI collagen assembly. Journal of Biological Chemistry, 276, 7422-7430.

BARCZYK, M., CARRACEDO, S. \& GULLBERG, D. 2010. Integrins. Cell and Tissue Research, 339, 269-280.

BARK, S., PIONTEK, T., BEHRENS, P., MKALALUH, S., VAROGA, D. \& GILLE, J. 2014. Enhanced microfracture techniques in cartilage knee surgery: fact or fiction? World Journal of Orthopedics, 5, 444-449.

BARRIENTOS, S., STOJADINOVIC, O., GOLINKO, M. S., BREM, H. \& TOMIC-CANIC, M. 2008. Growth factors and cytokines in wound healing. Wound Repair Regeneration, 16, 585-601.

BARRY, F., BOYNTON, R. E., LIU, B. \& MURPHY, J. M. 2001. Chondrogenic differentiation of mesenchymal stem cells from bone marrow: differentiation-dependent gene expression of matrix components. Experimental Cell Research, 268, 189-200.

BARTHES, J., ÖZÇELIK, H., HINDIÉ, M., NDREU-HALILI, A., HASAN, A. \& VRANA, N. E. 2014. Cell microenvironment engineering and monitoring for tissue engineering and regenerative medicine: the recent advances. BioMed Research International [Online], 2014. Available: https://www.hindawi.com/journals/bmri/2014/921905/.

BASAD, E., WISSING, F. R., FEHRENBACH, P., RICKERT, M., STEINMEYER, J. \& ISHAQUE, B. 2014. Matrix-induced autologous chondrocyte implantation (MACI) in the knee: clinical outcomes and challenges. Knee Surgery, Sports Traumatology, Arthroscopy, 23, 3729-3735.

BASTOW, E. R., BYERS, S., GOLUB, S. B., CLARKIN, C. E., PITSILLIDES, A. A. \& FOSANG, A. J. 2008. Hyaluronan synthesis and degradation in cartilage and bone. Cellular and Molecular Life Sciences, 65, 395-413.

BAX, D. V., DAVIDENKO, N., GULLBERG, D., HAMAIA, S. W., FARNDALE, R. W., BEST, S. M. \& CAMERON, R. E. 2017. Fundamental insight into the effect of carbodiimide crosslinking on cellular recognition of collagen-based scaffolds. Acta Biomaterialia, 49, 218-234.

BEHONICK, D. J. \& WERB, Z. 2003. A bit of give and take: the relationship between the extracellular matrix and the developing chondrocyte. Mechanisms of Development, 120, 1327-1336.

BELBACHIR, K., NOREEN, R., GOUSPILLOU, G. \& PETIBOIS, C. 2009. Collagen types analysis and differentiation by FTIR spectroscopy. Analytical and Bioanalytical Chemistry, 395, 829-837.

BELL, C. C., DANKERS, A. C. A., LAUCHKE, V. M., SISON-YOUNG, R., JENKINS, R., ROWE, C., GOLDRING, C. E., PARK, K., REGAN, S. L., WALKER, T., SCHOFIELD, C., BAZE, A., FOSTER, A. J., WILLIAMS, D. P., VEN, A. W. M. V. D., JACOBS, F., HOUDT, J. V., LÄHTEENMÄKI, T., SNOEYS, J., JUHILA, S., RICHERT, L. \& INGELMAN-SUNDBERG, M. 2018. Comparison of hepatic 2D sandwich cultures and 3D spheroids for long term toxicity applications: a multicenter study. Toxicological Sciences, 162, 655-666. 
Bibliography

BELL, D. M., LEUNG, K. K., WHEATLEY, S. C., NG, L. J., ZHOU, S., LING, K. W., SHAM, M. H., KOOPMAN, P., TAM, P. P. \& CHEAH, K. S. 1997. SOX9 directly regulates the type-II collagen gene. Nature Genetics, 16, 174-178.

BENEDETTO, C. D., BARBAGLIO, A., MARTINELLO, T., ALONGI, V., FASSINI, D., CULLORÀ, E., PATRUNO, M., BONASORO, F., BARBOSA, M. A., CARNEVALI, M. S. C. \& SUGNI, M. 2014. Production, characterisation and biocompatibility of marine collagen matricies from an alternative and sustainable source: the sea urchin Paracentrotus lividus. Marine Drugs, $12,4912-4933$.

BERGE, D. T., BRUGMANN, S. A., HELMS, J. A. \& NUSSE, R. 2008. Wnt and FGF signals interact to coordinate growth with cell fate specification during limb development. Development, 135, 3247-3257.

BERMUELLER, C., SCHWARZ, S., ELSAESSER, A. F., SEWING, J., BAUR, N., BOMHARD, A. V., SCHEITHAUER, M., NOTBOHM, H. \& ROTTER, N. 2013. Marine collagen scaffolds for nasal cartilage repair: prevention of nasal septal perforations in a new orthotopic rat model using tissue engineering techniques. Tissue Engineering: Part A, 19, 2201-2214.

BERNHARDT, A., PAUL, B. \& GELINSKY, M. 2018. Biphasic scaffolds from marine collagens for regeneration of osteochondral defects. Marine Drugs, 16.

BERNSTEIN, P., DONG, M., CORBEIL, D., GELINSKY, M., GÜNTHER, K.-P. \& FICKERT, S. 2009. Pellet culture elicits superior chondrogenic redifferentiation than alginate-based systems. Biotechnology Progress, $25,1146-1152$.

BHOSALE, A. M. \& RICHARDSON, J. B. 2008. Articular cartilage: structure, injuries and review of management. British Medical Bulletin, 87, 77-95.

BHOWMICK, M. \& FIELDS, G. B. 2013. Stabilization of collagen model, triple helical peptides for in vitro and in vivo applications. Methods in Molecular Biology, 1081, 167-194.

BHUTDA, S., SURVE, M. V., ANIL, A., KAMATH, K. G., SINGH, N., MODI, D. \& BANERJEE, A. 2017. Histochemical staining of collagen and identification of its subtypes by picrosirius red dye in mouse reproductive tissues. Bioprotocol, 7, 1-10.

BIRK, D. E. 2011. The Extracellular Matrix: an overview, Springer-Verlag

BITAR, K. N. \& ZAKHEM, E. 2014. Design strategies of biodegradable scaffolds for tissue regeneration. Biomedical Engineering and Computational Biology, 6, 13-20.

BITTON, R. 2009. The economic burden of osteoarthritis. American Journal of Managed Care, 15, S230-235.

BITTRREMIEUX, W., TABB, D. L., IMPENS, F., STAES, A., TIMMERMAN, E., MARTENS, L. \& LAUKENS, K. 2017. Quality control in mass spectrometry based proteomics. Mass Spectrometry Reviews, 37, 697-711.

BJORKMAN, P. J. 1997. MHC restriction in three dimensions: a view of T cell receptor/ligand interaction. Cell, 89, 167-170.

BLALOCK, D., MILLER, A., TILLEY, M. \& WANG, J. 2015. Joint Instability and Osteoarthritis. Clinical Medicine Insights: Arthritis and Musculoskeletsl Disorders, 8, 15-23.

BLANC, K. L., RASMUSSON, I., SUNDBERG, B., GOTHERSTROM, C., HASSAN, M., UNZEL, M. \& RINGDEN, O. 2004. Treatment of severe acute graft versus 
Bibliography

host disease with third party haploidentical mesenchymal stem cells. Lancet, 363, 1439-1441.

BOBROFF, V., RUBIO, C., VIGIER, V. \& PETIBOIS, C. 2016. FTIR spectroscopy characterization of fatty-acyl-chain conjugates. Analytical and Bioanalytical Chemistry, 408, 319-326.

BOEHLER, R. M., GRAHAM, J. G. \& SHEA, L. D. 2011. Tissue engineering tools for modulation of the immune response. Biotechniques, 51, 239-240.

BONDESON, J., WAINWRIGHT, S., HUGHES, C. \& CATERSON, B. 2008. The regulation of the ADAMTS4 and ADAMTS5 aggrecanases in osteoarthritis: a review. Clinical \& Experimental Rheumatology, 26, 139145.

BONNANS, C., CHOU, J. \& WERB, Z. 2014. Remodelling the extracellular matrix in development and disease. Nature Reviews Molecular Cell Biology, 15, 786-801.

BORNES, T. D., JOMHA, N. M., MULET-SIERRA, A. \& ADESIDA, A. B. 2016. Optimal seeding densities for in vitro chondrogenesis of two and three dimensional isolated and expanded bone marrow derived mesenchymal stromal stem cells within a porous collagen scaffold. Tissue Engineering: Part C, 22, 208-220.

BORNSTEIN, P. 2002. The NH(2)-terminal propeptides of fibrillar collagens: highly conserved domains with poorly understood functions. Matrix Biology, 21, 217-226.

BOYCE, B. F., ZUSCIK, M. J. \& XING, L. 2018. Biology of bone and cartilage. In: THANKKER, R., WHYTE, M., EISMAN, J. \& IGARASHI, T. (eds.) Genetics of Bone Biology and Skeletal Disease. 2 ed.: Academic Press.

BRAUN, H. J. \& GOLD, G. E. 2012. Diagnosis of osteoarthritis: imaging. Bone, 51, 278-288.

BRAZIULIS, E., DIEZI, M., BIEDERMANN, T., PONTIGGIA, L., SCHMUCKI, M., HARTMANN-FRITSCH, F., LUGINBÜHL, J., SCHIESTL, C., MEULI, M. \& REICHMANN, E. 2012. Modified plastic compression of collagen hydrogels provides an ideal matrix for clinically applicable skin substitutes. Tissue Engineering: Part C, 18, 464-474.

BRITTBERG, M., LINDAHL, A., NILSSON, A., OHLSSON, C., ISAKSSON, O. \& PETERSON, L. 1994. Treatment of Deep Cartilage Defects in the Knee with Autologous Chondrocyte Transplantation. The New England Journal of Medicine, 331, 889-895.

BROTZ, L., CHEUNG, W. W. L., KLEISNER, K., PAKHOMOV, E. \& PAULY, D. 2012. Increasing jellyfish populations: trends in large marine ecosystems. Hydrobiologia, 690, 3-20.

BROUGHTON, G., JANIS, J. E. \& ATTINGER, C. E. 2006. The basic science of wound healing. Plastic and Reconstructive Surgery, 117, 12S-34S.

BROWN, B. N. \& BADYLAK, S. F. 2014. The role of the host immune response in tissue engineering and regenerative medicine. Principles of Tissue Engineering. Academic Press.

BROWN, R. A., WISEMAN, M., CHUO, C.-B., CHEEMA, U. \& NAZHAT, S. N. 2005. Ultrarapid engineering of biomimetic materials and tissues: fabrication of nano- and microstructures by plastic compression. Advances Functional Materials, 15, 1762-1770. 
BROWNE, S., ZEUGOLIS, D. I. \& PANDIT, A. 2013. Collagen: finding a solution for the source. Tissue Engineering: Part A, 19, 1491-1494.

BRUŽAUSKAITÉ, I., BIRONAITĖ, D., BAGDONAS, E. \& BERNOTIENĖ, E. 2016. Scaffolds and cells for tissue regeneration: different scaffold pore sizes different cell effects. Cytotechnology, 68, 355-369.

BRYANT, S. J. \& ANSETH, K. S. 2002. Hydrogel properties influence ECM production by chondrocytes photoencapsulated in poly(ethylene oxide) hydrogels. Journal of Biomedical Materials Research, 59, 63-72.

BUCKLAND, J. 2013. Rheumatoid arthritis: tocilizumab monotherapy and adalimumab monotherapy go head to head in RA. Nature Reviews Rheumatology, 9.

BUENO, E. M., LAEVSKY, G. \& BARABINO, G. A. 2007. Enhancing cell seeding of scaffolds in tissue engineering through manipulation of hyrodynamic parameters. Journal of Biotechnology, 129, 516-531.

CALIARI, S. R., GONNERMAN, E. A., GRIER, W. K. \& WEISGERBER, D. W. 2015. Collagen scaffold arrays for combinatorial screening of biophysical and biochemical regulators of cell behaviour. Advanced Healthcare Materials, 4, 58-64.

CAMARERO-ESPINOSA, S., ROTHEN-RUTISHAUSER, B., FOSTER, E. J. \& WEDER, C. 2016. Articular cartilage: from formation to tissue engineering. Biomaterials Science, 4, 727-882.

CAPLAN, A. I. 2013. Cell sources for tissue engineering: mesenchymal stem cells. In: RATNER, B. D., HOFFMAN, A. S., SCHOEN, F. J. \& LEMONS, J. E. (eds.) Biomaterials Science. 3 ed.: Academic Press.

CAPLAN, A. I. \& BRUDER, S. P. 2001. Mesenchymal stem cells: building blocks for molecular medicine in the 21st century. Trends in Molecular Medicine, 7, 259-264.

CARLETTI, E., MOTTA, A. \& MIGLIARESI, C. 2011. Scaffolds for Tissue Engineering and 3D Cell Culture. Methods in Molecular Biology. Humana Press.

CHAN, B. P. \& LONG, K. W. 2008. Scaffolding in tissue engineering: general approaches and tissue-specific considerations. European Spine Journal, 17, 467-479.

CHAN, J. K. C. 2014. The wonderful colors of the hematoxylin-eosin stain in diagnostic surgical pathology. International Journal of Surgical Pathology, 22, 12-32.

CHANDRAN, P. L. \& HORKAY, F. 2012. Aggrecan, an unusual polyelectrolyte: review of solution behaviou and physiological implications. Acta Biomaterialia, 8, 3-12.

CHAPLIN, D. D. 2010. Overview of the immune response. Journal of Allergy and Clinical Immunology, 125, S3-S23.

CHEEMA, U. \& BROWN, R. A. 2013. Rapid Fabrication of Living Tissue Models by Collagen Plastic Compression: Understanding Three-Dimentional Cell Matrix Repair In Vitro. Advances In Wound Care, 2, 176-184.

CHEN, D., SHEN, J., ZHAO, W., WANG, T., HAN, L., HAMILTON, J. L. \& IM, H.-J. 2017. Osteoarthritis: toward a comprehensive understanding of pathological mechanism. Bone Research [Online], 5. Available: https://www.nature.com/articles/boneres201644. 
CHENG, A. \& GENEVER, P. G. 2010. SOX9 determines RUNX2 transactivity by directing intracellular degradation. Journal of Bone and Mineral Research, 25, 2680-2689.

CHENG, X., SHAO, Z., LI, C., YU, L., RAJA, M. A. \& LIU, C. 2017a. Isolation, characterization and evaluation of collagen from jellyfish Rhopilema esculentum Kishinouye for use in hemostatic applications. PLoS One, 12.

CHENG, X., SHAO, Z., LI, C., YU, L., RAJA, M. A. \& LIU, C. 2017b. Isolation, characterization and evaluation of collagen from jellyfish Rhopilema esculentum Kishinouye for use in hemostatic applications. PLoS One [Online], 12. Available: https://www.ncbi.nlm.nih.gov/pmc/articles/PMC5245839/.

CHICATUN, F., GRIFFANTI, G., MCKEE, M. D. \& NAZHAT, S. N. 2017. Collagen/chitosan composite scaffolds for bone and cartilage tissue engineering. In: AMBROSIO, L. (ed.) Biomedical Composites. 2 ed.: Woodhead Publishing.

CHOI, Y. S., HAN, S. K., KIM, J., YANG, J.-S., JEON, J., RYU, S. H. \& KIM, S. 2010. ConPlex: a server for the evolutionary conservation analysis of protein complex structures. Nucleic Acids Research, 38, W450-W456.

CHU, C. R., SZCZODRY, M. \& BRUNO, S. 2010. Animal models for cartilage regeneration and repair. Tissue Engineering: Part B, 16, 105-115.

CHUNG, C. \& BURDICK, J. A. 2008. Engineering cartilage tissue. Advanced Drug Delivery Reviews, 60, 243-262.

CLARK, W. T. \& RADIVOJAC, P. 2011. Analysis of protein function and its prediction from amino acid sequence. Proteins, 79, 2086-2096.

COHEN, N. P., FOSTER, R. J. \& MOW, V. C. 1998. Composition and Dynamics of Articular Cartilage: Structure, Function, and Maintaining Healthy State. Journal of Orthopaedic \& Sports Physical Therapy, 28, 203-215.

COLAS, E., PEDROLA, N., DEVIS, L., ERTEKIN, T., CAMPOY, I., MATÍNEZ, E., LLAURADÓ, M., RIGAU, M., OLIVAN, M., GARCIA, M., CABRERA, S., GILMORENO, A., XERCAVINS, J., CASTELLVI, J., GARCIA, A., CAJAL, S. R. Y., MORENO-BUENO, G., DOLCET, X., ALAMEDA, F., PALACIOS, J., PRAT, J., DOLL, A., MATIAS-GUIU, X., ABAL, M. \& REVENTOS, J. 2012. The EMT signaling pathways in endometrial carcinoma. Clinical and Translational Oncology, 14, 715-720.

COLLARILE, M., SAMBRI, A., LULLINI, G., CADOSSI, M. \& ZORZI, C. 2017. Biophysical stimulation improves clinical results of matrix-assisted autologous chondrocyte implantation in the treatment of chondral lesions of the knee. Knee Surgery, Sports Traumatology, Arthroscopy, 26, 1223-1229.

COOK, J. L., HUNG, C. T., KUROKI, K., STOKER, A. M., COOK, C. R., PFEIFFER, F. M., SHERMAN, S. L. \& STANNARD, J. P. 2014. Animal models of cartilage repair. Bone Joint Research, 3, 89-94.

COOKE, M. J., PHILLIPS, S. R., SHAH, D. S. H., ATHEY, D., LAKEY, J. H. \& PRZYBORSKI, S. A. 2008. Enhanced cell attachment using a novel cell culture surface presenting functional domains from extracellular matrix proteins. Cytotechnology, 56, 71-79.

CORRADETTI, B., TARABALLI, F., CORBO, C., CABRERA, F., PANDOLFI, L., MINARDI, S., WANG, X., EPS, J. V., BAUZA, G., WEINER, B. \& TASCIOTTI, E. 2017. Immune tuning scaffold for the local inducation of a pro- 
regenerative environment Scientific Reports [Online], 7. Available: https://www.nature.com/articles/s41598-017-16895-0.

CORRADETTI, B., TARABALLI, F., MINARDI, S., EPS, J. V., CABRERA, F., FRANCIS, L. W., GAZZE, S. A., FERRARI, M., WEINER, B. K. \& TASCIOTTI, E. 2016. Chondroitin sulfate immobilized on a biomimetic scaffold modulates inflammation while driving chondrogenesis. Tissue Engineering and Regenerative Medicine, 5, 670-682.

COUPER, K. N., BLOUNT, D. G. \& RILEY, E. M. 2008. IL-10: the master regulator of immunity to infection. The Journal of Immunology, 180, 5771-5777.

CRAVEDI, P., FAROUK, S., ANGELETTI, A., EDGAR, L., TAMBURRINI, R., DUSUIT, J., PERIN, L. \& ORLANDO, G. 2017. Regenerative immunology: the immunological reaction to biomaterials. Transplant International, 30, 1199-1208.

CRAWFORD, K., PURRO, E. \& OUANO, D. C. 2015. GMP explained: GMP vs reagent grade [Online]. Available: https://www.listlabs.com/blog/gmpexplained-gmp-vs-reagent/ [Accessed].

CROFFORD, L. J. 2013. Use of NSAIDs in treating patients with arthritis. Arthritis research \& therapy, $15, \mathrm{~S} 2$.

CRONODON. 2016. Building bodies of jelly - jellyfish [Online]. Available: http://cronodon.com/BioTech/Jellyfish.html [Accessed].

DAMSKY, C. H. \& ILIC, D. 2002. Integrin signaling: it's where the action is. Current Opinions in Cell Biology, 14, 594-602.

DANCEVIC, C. M. \& MCCULLOCH, D. R. 2014. Current and emerging therapeutic strategies for preventing inflammation and aggrecanase-mediated cartilage destruction in arthritis. Arthritis Research and Therapy, 16.

DAVIDENKO, N., SCHUSTER, C. F., BAX, D. V., FARNDALE, R. W., HAMAIA, S., BEST, S. M. \& CAMERON, R. E. 2016. Evaluation of cell binding to collagen and gelatin: a study of the effect of 2D and 3D architecture and surface chemistry. Journal of Materials Science: Materials in Medicine, 27.

DAVIDENKO, N., SCHUSTER, C. F., BAX, D. V., RAYNAL, N., FARNDALE, R. W., BEST, S. M. \& CAMERON, R. E. 2015. Control of crosslinking for tailoring collagen-based scaffolds stability and mechanics. Acta Biomaterialia, 25, 131-142.

DAWSON, E., MAPILI, G., ERICKSON, K., TAQVI, S. \& ROY, K. 2008. Biomaterials for stem cell differentiation. Advanced Drug Delivery Reviews, 60, 215228.

DELGADO, L. M., SHOLOGU, N., FULLER, K. \& ZEUGOLIS, D. I. 2017. Acetic acid and pepsin result in high yield, high purity and low macrophage response collagen for biomedical applications. Biomedical Materials [Online], 12. Available: http://iopscience.iop.org/article/10.1088/1748605X/aa838d/meta.

DERKUS, B., ARSLAN, Y. E., BAYRAC, A. T., KANTARCIIOGLU, I., EMREGUL, K. C. \& EMREGUL, E. 2016. Development of a novel aptasensor using jellyfish collagen as matrix and thrombin detection in blood samples obtained from patients with various neurodisease. Sensors and Actuators B: Chemical, 228, 725-736.

DEWAN, A. K., GIBSON, M. A., ELISSEEFF, J. H. \& TRICE, M. E. 2014. Evolution of autologous chondrocyte repair and comparison to other cartilage repair 
techniques. BioMed Research International [Online], 2014. Available: https://www.hindawi.com/journals/bmri/2014/272481/.

DEXHEIMER, V., FRANK, S. \& RICHTER, W. 2012. Proliferation as a requirement for in vitro chondrogenesis of human mesenchymal stem cells. Stem Cells and Development, 21, 2160-2169.

DEYL, Z., MIKŠÍK, I. \& ECKHARDT, A. 2003. Preparative procedures and purity assessment of collagen proteins. Journal of Chromatography B, 790, 245275.

DHANDAYUTHAPANI, B., YOSHIDA, Y., MAEKAWA, T. \& KUMAR, D. S. 2011. Polymeric scaffolds in tissue engineering application: a review. International Journal of Polymer Science [Online], 2011. Available: https://www.hindawi.com/journals/ijps/2011/290602/.

DIEGELMANN, R. F. \& EVANS, M. C. 2004. Wound healing: an overview of acute, fibrotic and delayed healing. Frontiers in Bioscience, 1, 283-289.

DING, D., CHOU, H., HUNG, W., LIU, H. \& CHU, T. 2013. Human adipose-derived stem cells cultured in keratinocyte serum free medium: donor's age does not affect the proliferation and differentiation capacities. Journal of Biomedical Science, 20.

DOEGE, K. J. \& FESSLER, J. H. 1986. Folding of carboxyl domain and assembly of procollagen I. Journal of Biological Chemistry, 261, 8924-8935.

DOLDER, J. V. D. \& JANSEN, J. A. 2006. The response of osteoblast-like cells towards collagen type I coating immobilized by $\mathrm{p}$ nitrophenylcholoroformate to titanium. Journal of Biomedical Materials Research, 83A, 712-719.

DOMINICI, M., BLANC, K. L., MUELLER, I., SLAPER-CORTENBACH, I., MARINI, F. C., KRAUSE, D. S., DEANS, R. J., KEATING, A., PROCKOP, D. J. \& HORWITZ, E. M. 2006. Minimal criteria for defining multipotent mesenchymal stromal cells. The international society for cellular therapy position statement. Cryotherapy, 8, 315-317.

DONG, C. \& LV, Y. 2016. Application of collagen scaffold in tissue engineering: recent advances and new perspectives. Polymers for Advanced Technologies, 8.

DONKOR, E. S., DAYIE, N. T. K. D. \& ADIKU, T. K. 2014. Bioinformatics with basic local alignment search tool (BLAST) and fast alignment (FASTA). Journal of Bioinformatics and Sequence Analysis, 6, 1-6.

DOWTHWAITE, G. P., BISHOP, J. C., REDMAN, S. N., KHAN, I. M., ROONEY, P., EVANS, D. J. R., HAUGHTON, L., BAYRAM, Z., BOYER, S., THOMSON, B., WOLFE, M. S. \& ARCHER, C. W. 2004. The surface of articular cartilage contains a progenitor cell population. Journal of Cell Science, 117, 889897.

DUAN, L., LI, J., LI, C. \& LI, G. 2013. Effects of $\mathrm{NaCl}$ on the rheological behaviour of collagen solution. Korea-Australia Rheology Journal, 25, 137-144.

DUAN, X. \& SHEARDOWN, H. 2005. Crosslinking of collagen with dendrimers. Journal of Biomedical Materials Research, 75A, 510-518.

DUNKIN, B. S. \& LATTERMANN, C. 2013. New and Emerging Techniques in Cartilage Repair: MACI. Operative Techniques in Sports Medicine, 21, 100107. 
DUNN, C. L., KELLY, R. W. \& CRITCHLEY, H. O. D. 2003. Decidualization of the human endometrial stromal cell: an enigmatic transformation. Reproductive BioMedicine Online, 7, 151-161.

DUROWOJU, I. B., BHANDAL, K. S., HU, J., CARPICK, B. \& KIRKITADZE, M. 2017. Disfferential scanning calorimetry - a method for assessing the thermal stability and confirmation of protein antigen. Journal of Visualized Experiments [Online], 2017.

DUVAL, K., GROVER, H., HAN, L.-H., MOU, Y., PEGORARO, A. F., FREDBERG, J. \& CHEN, Z. 2017. Modeling physiological events in 2D vs. 3D cell culture. Physiology, 32, 266-277.

DZIKI, J. L., HULEIHEL, L., SCARRITT, M. E. \& BADYLAK, S. F. 2017. Extracellular matrix bioscaffolds as immunomodulatory biomaterials. Tissue Engineering: Part A, 23, 1152-1159.

ECHTERMEYER, F., BERTRAND, J., DREIER, R., MEINECKE, I., NEUGEBAUR, K., FUERST, M., LEE, Y. J., SONG, Y. W., HERZOG, C., THEILMEIER, G. \& PAP, T. 2009. Syndecan-4 regulates ADAMTS5 activation and cartilage breakdown in osteoarthritis. Nature Medicine, 15, 1072-1076.

EHLERS, E. M., FUSS, M., ROHWEDEL, J., RUSSLIES, M., KÜHNEL, W. \& BEHRENS, P. 1999. Development of a biocomposite to fill out articular cartilage lesions. Light, scanning and transmission electron microscopy of sheep chondrocytes cultured on collagen I/III sponge. Annals of Anatomy, 181, 513-518.

EHRLICH, H., DEUTZMANN, R., BRUNNER, E., CAPPELLINI, E., KOON, H., SOLAZZO, C., YANG, Y., ASHFORD, D., THOMAS-OATES, J., LUBECK, M., BAESSMANN, C., LANGROCK, T., HOFFMAN, R., WÖRHEIDE, G., REITNER, J., SIMON, P., TSURKAN, M., ERESKOVSKY, A. V., KUREK, D., BAZHENOV, V. V., HUNOLDT, S., MERTIG, M., VYALIKH, D. V., MOLODTSOV, S. L., KUMMER, K., WORCH, H., SMETACEK, V. \& COLLINS, M. J. 2010.

Mineralization of the metre-long biosilica structures of glass sponges is templated on hydroxylated collagen. Nature Chemistry, 2, 1084-1088.

EL-SERAG, H. B. 2011. Hepatocellular carcinoma. New England Journal of Medicine, 365, 1118-1127.

ELLIOT, J. T., WOODWARD, J. T., LANGENBACH, K. J., TONA, A., JONES, P. L. \& PLANT, A. L. 2005. Vacular smooth muscle cell response on thin films of collagen. Matrix Biology, 24, 489-502.

ELVENES, J., KNUTSEN, G., JOHANSEN, O., MOE, B. T. \& MARTINEZ, I. 2009. Development of a new method to harvest chondroprogenitor cells from underneath cartilage defects in the jnees. Journal of Orthopaedic Science, $14,410-417$.

EMSLEY, J., KNIGHT, C. G., FARNDALE, R. W., BARNES, M. J. \& LIDDINGTON, R. C. 2000. Structural basis of collagen recognition by integrin a2b1. Cell 101, 47-56.

ENGELHOLM, L. H., INGVARSEN, S., JÜRGENSEN, H. J., HILLIG, T., MADSEN, D. H., NIELSEN, B. S. \& BEHRENDT, N. 2009. The collagen receptor uPARAP/Endo180. Frontiers in Bioscience, 1, 2103-2114.

ERGGELET, C. \& VAVKEN, P. 2016. Microfracture for the treatement of cartilage defects in the knee joint - a golden standard? Journal of Clinical Orthopaedics and Trauma, 7, 145-152. 
ESTES, B. T. \& GUILAK, G. 2011. Three-dimensional culture systems to induce chondrogenesis of adipose-derived stem cells. Methods in Molecular Biology, 702, 201-217.

ESTRELLA, R. P., WHITELOCK, J. M., PACKER, N. H. \& KARLSSON, N. G. 2010. The glycosylation of human synovial lubricin: implications for its role in inflammation. Biochemical Journal, 429, 359-367.

EXPOSITO, J.-Y., CLUZEL, C., GARRONE, R. \& LETHIAS, C. 2002. Evolution of Collagens. The Anatomical Record, 268, 302-316.

EXPOSITO, J.-Y., LARROUX, C., CLUZEL, C., VALCOURT, U., LETHIAS, C. \& DEGNAN, B. M. 2008. Demosponge and sea anemone fibrillar collagen diversity reveals the early emergence of $\mathrm{A} / \mathrm{C}$ clades and the maintenance of the modular structure of type V/XI collagens from sponge to human. Journal of Biological Chemistry [Online], 283.

EXPOSITO, J.-Y., VALCOURT, U., CLUZEL, C. \& LETHIAS, C. 2010. The fibrillar collagen family. International Journal of Molecular Sciences, 11, 407-426.

EYRE, D. 2002. Articular cartilage and changes in Arthritis: Collagen of articular cartilage. Arthritis Research, 4, 30-35.

EYRE, D. R., WU, J. J., FERNANDES, R. J., PIETKA, T. A. \& WEIS, M. A. 2002 . Recent developments in cartilage research: matrix biology of the collagen II/IX/XI heterofibril network. Biochemical Society Transactions, 30, 893899.

FAHY, N., FARRELL, E., RITTER, T., RYAN, A. E. \& MURPHY, J. M. 2015. Immune modulation to improve tissue engineering outcomes for cartilage repair in the osteoarthritic joint. Tissue Engineering: Part B, 21, 55-66.

FAULK, D. M., LONDONO, R., WOLF, M. T., RANALLO, C. A., CARRUTHERS, C. A., WILDERMANN, J. D., DEARTH, C. L. \& BADYLAK, S. F. 2014. ECM hydrog el coating mitigated the chronic inflammatory response to polypropylene mesh. Biomaterials, 35, 8585-8595.

FINNSON, K. W., PARKER, W. L., DIJKE, P. T., THORIKAY, M. \& PHILIP, A. 2008. ALK1 opposes ALK5/Smad3 signaling and expression of extracellular matrix components in human chondrocytes. Journal of Bone and Mineral Research, 23, 896-906.

FOX, A. J. S., BEDI, A. \& RODEO, S. A. 2009. The basic science of articular cartilage. Sports Health, 1, 461-468.

FRANTZ, C., STEWART, K. M. \& WEAVER, V. M. 2010. The extracellular matrix at a glance. Journal of Cell Science, 123, 4195-4200.

FRANZ, S., RAMMELT, S., SCHARNWEBER, D. \& SIMON, J. C. 2011. Immune responses to implants - a review of implications for the design of immunomodulatory biomaterials. Biomaterials, 32, 6692-6709.

FRANZKE, C.-W., BRUCKNER, P. \& BRUCKNER-TUDERMAN, L. 2005. Collagenous transmembrane proteins: recent insights into biology and pathology. Journal of Biological Chemistry, 280, 4005-4008.

FRIEDL, P. \& GILMOUR, D. 2009. Collective cell migration in morphogenesis, regeneration and cancer. Nature Reviews Molecular Cell Biology, 10, 445457.

FUNDERBURGH, J. L. 2002. Keratan sulfate biosynthesis. IUBMB Life, 54, 187194.

FUSS, M., EHLERS, E. M., RUSSLIES, M., ROHWEDEL, J. \& BEHRENS, P. 2000. Characteristics of human chondrocytes, osteoblasts and fibroblasts 
Bibliography

seeded onto a type I/III collagen sponge under different culture conditions. A light, scanning and transmission electron microscopy study. Annals of Anatomy, 182, 303-310.

GABAY, C. 2006. Interleukin-6 and chronic inflammation. Arthritis Research \& Therapy 8, S3.

GANDAVARAPU, N. R., ALGE, D. L. \& ANSETH, K. S. 2014. Osteogenic differentiation of human mesenchymal stem cells on a5 integrin binding peptide hydrogels is dependent on substrate elasticity. Biomaterial Science, 2, 352-361.

GARCÍA-CARVAJAL, Z. Y., GARCIADIEGO-CÁZARES, D., PARRA-CID, C., AGUILARGAYTÁN, R., VELASQUILLO, C., IBARRA, C. \& CAMONA, J. S. C. 2013. Cartilage Tissue Engineering: The Role of Extracellular Matrix (ECM) and Novel Strategies. In: ANDRADES, J. A. (ed.) Regenerative Medicine and Tissue Engineering.

GARVIN, J., QI, J., MALONEY, M. \& BANES, A. J. 2004. Novel system for engineering bioartificial tendons and application of mechanical load. Tissue Engineering, 9, 967-979.

GELSE, K., PÖSCHL, E. \& AIGNER, T. 2003. Collagens - structure, function, and biosythesis. Advanced Drug Delivery Reviews, 55, 1531-1546.

GHASEMI, M. \& DEHPOUR, A. R. 2009. Ethical considerations in animal studies. Journal of Medical Ethics and History of Medicine, 2.

GHASEMI-MOBARAKEH, L., PRABHAKARAN, M. P., TIAN, L., SHAMIRZAEIJESHVAGHANI, E., DEHGHANI, L. \& RAMAKRISHNA, S. 2015. Structural properties of scaffolds: crucial parameters towards stem cells differentiation. World Journal of Stem cells, 7, 728-744.

GLEGHORN, J. P. \& BONASSAR, L. J. 2008. Lubrication mode analysis of articular cartilage using Stribeck surfaces. Journal of Biomechanics, 41, 1910-1918.

GLOWACKI, J. \& MIZUNO, S. 2007. Collagen scaffolds for tissue engineering. Biopolymers, 89, 338-344.

GLYN-JONES, S., PALMER, A. J. R., AGRICOLA, R., PRICE, A. J., VINCENT, T. L., WEINANS, H. \& CARR, A. J. 2015. Osteoarthritis. The Lancet, 386, 376387.

GOLDBERG, A. J., LEE, D. A., BADER, D. L. \& BENTLEY, G. 2005. Culture in a TGFB-containing medium enhances the reexpression of a chondrocytic phenotype in passaged human chondrocytes in pellet culture. The Bone \& Joint Journal, 87, 128-134.

GOLDMANN, W. H., AUERNHEIMER, V., THIEVESSEN, I. \& FABRY, B. 2013. Vinculin, cell mechanics and tumour cell invasion. Cell Biology International, 37, 397-405.

GOLDRING, M. B. 2012. Chondrogenesis, chondrocyte differentiation, and articular cartilage metabolism in health and osteoarthritis. Therapeutic Advances in Musculoskeletal Disease, 4, 269-285.

GOLDRING, M. B. \& GOLDRING, S. R. 2007. Osteoarthritis. Journal of Cellular Physiology, 213, 626-634.

GÓMEZ-GUILLÉN, M. C., GIMÉNEZ, B., LÓPEZ-CABALLERO, M. E. \& MONTERO, M. P. 2011. Functional and bioactive properties of collagen and gelatin from alternative sources: a review. Food Hydrocolloids, 25, 1813-1827.

GOODING, C. R., BARTLETT, W., BENTLEY, G., SKINNER, J. A., CARRINGTON, R. \& FLANAGAN, A. 2006. A prospective, randomised study comparing two 
techniques of autologous chondrocyte implantation for osteochondral defects in the knee: periosteum covered versus type I/III collagen covered. Knee, 13, 203-210.

GORGIEVA, S. \& KOKOL, V. 2011. Collagen- vs. gelatine-based biomaterials and their biocompatibility: review and perspectives. In: PIGNATELLO, R. (ed.) Biomaterials Applications for Nanomedicine. InTech.

GREEN, J. D., TOLLEMAR, V., DOUGHERTY, M., YAN, Z., YIN, L., YE, J., COLLIER, Z., MOHAMMED, M. K., HAYDON, R. C., LUU, H. H., KANG, R., LEE, M. J., HO, S. H., HE, T.-C., SHI, L. L. \& ATHIVIRAHAM, A. 2015. Multifaceted signaling regulators of chondrogenesis: implications in cartilage regeneration and tissue engineering. Genes \& Diseases, 2, 307-327.

GRIMAUD, E., HEYMANN, D. \& RÉDINI, F. 2002. Recent advances in TGF-B effects on chondrocyte metabolism: potential therapeutic roles of TGF-B in cartilage disorders. Cytokine \& Growth Factor Reviews, 13, 241-257.

GRUN, B., BENJAMIN, E., SINCLAIR, J., TIMMS, J. F., JACOBS, I. J., GAYTHER, S. A. \& DAFOU, D. 2009. Three-dimensional in vitro cell biology models of ovarian and endometrial cancer. Cell Proliferation, 42, 219-228.

GRUNDY, R. L., WHITE, M. Y., MURRAY, C. I., KANE, L. A., FU, Q., STANLEY, B. A. \& EYK, J. E. V. 2009. Preparation of proteins and peptides for mass spectrometry analysis in a bottom-up proteomics workflow. Current Protocols in Molecular Biology.

GU, J., LU, Y., LI, F., QIAO, L., WANG, Q., LI, N., BORGIA, J. A., DENG, Y., LEI, G. \& ZHENG, Q. 2014. Identification and characterisation of the novel Col10a1 regulatory mechanism during chondrocyte hypertrophic differentiation. Cell Death \& Disease [Online], 5.

GUO, T., YU, L., LIM, C. G., GOODLEY, A. S., XIAO, X., PLACONE, J. K., FERLIN, K. M., NGUYEN, B.-N. B., HSIEH, A. H. \& FISHER, J. P. 2016. Effect of dynamic culture and periodic compression on human mesenchymal stem cell proliferation and chondrogenesis. Annals of Biomedical Engineering, 44, 2103-2113.

HACHIM, D., LOPRESTI, S. T., YATES, C. C. \& BROWN, B. N. 2017. Shifts in macrophage phenotype at the biomaterial interface via IL-4 eluting coatings are associated with imporved implant integration. Biomaterials, 112, 95-107.

HANDORF, A. M., CHAMERLAIN, C. S. \& LI, W.-J. 2015. Endogenously produced indian hedgehog regulates TGFB-driven chondrogenesis of human bone marrow stromal/stem cells. Stem cells and development, 24, 995-1007.

HARTUNG, T. \& DASTON, G. 2009. Are in vitro tests suitable for regulatory use? Toxicological Sciences, 111, 233-237.

HARVEY, S. J. \& THORNER, P. S. 2005. Type IV collagen: a network for development, differentiation and disease. Advances in Developmental Biology, 15, 1-64.

HASHIM, P., RIDZWAN, M. S. M., BAKAR, J. \& HASHIM, D. M. 2015. Collagen in food and beverage industries. International Food Research Journal, 22, 18.

HEATH, C. A. 2000. Cells for tissue engineering. Trends in Biotechnology, 18, 1719.

HEINO, J. 2007. The collagen family members as cell adhesion proteins. Bioessays, 29, 1001-1010. 
HELMUS, M. N., GIBBONS, D. F. \& CEBON, D. 2008. Biocompatibility: meeting a key functional requirement of next-generation medical devices. Toxicologic Pathology, 36, 70-80.

HENDREN, L. \& LARSON, P. 2009. A review of the differences between normal and osteoarthritis articular cartilage in human knee and ankle joints. Foot \& Ankle Specialist, 19, 171-176.

HENRIKSEN, K. \& KARSDAL, M. A. 2016. Type I Collagen. Biochemistry of Collagens, Laminins and Elastin. Academic Press.

HENROTIN, Y., MATHY, M., SANCHEZ, C. \& LAMBERT, C. 2010. Chondroitin sulfate in the treatment of osteoarthritis: from in vitro studies to clinical recommendations. Musculoskeletal Disease, 2, 335-348.

HOFFMAN, A. S. 2002. Hydrogels for biomedical engineering. Advanced Drug Delivery Reviews, 43, 3-12.

HOLLANDER, A. P., DICKINSON, S. C., SIMS, T. J., SORANZO, C. \& PAVESIO, A. 2003. Quantitative analysis of repair tissue biopsies following chondrocyte implantation. Novartis Foundation Symposium, 249, 218229.

HOLLISTER, S. J. 2005. Porous scaffold design for tissue engineering. Nature Materials, 4, 518-524.

HORII, Y., MURAGUCHI, A., SUEMATSU, S., MATSUDA, T., YOSHIZAKI, K., HIRANO, T. \& KISHIMOTO, T. 1988. Regulation of BSF-2/IL-6 production by human mononuclear cells. Macrophage-dependent synthesis of BSF2/IL- 6 by T cells. Journal of Immunology, 141, 1529-1935.

HOSSEINKHANI, M., MEHRABANI, D., KARIMFAR, M. H., BAKHTIYARI, S., MANAFI, A. \& SHIRAZI, R. 2014. Tissue engineered scaffolds in regenerative medicine. World Journal of Plastic Surgery, 3, 3-7.

HOYER, B., BERNHARDT, A., LODE, A., HEINEMANN, S., SEWING, J., KLINGER, M., NOTBOHM, H. \& GELINSKY, M. 2014. Jellyfish collagen scaffolds for cartilage tissue engineering Acta Biomaterialia, 10, 883-892.

HUBMACHER, D. \& APTE, S. S. 2013. The biology of the extracellular matrix: novel insights. Current Opinion in Rheumatology, 25, 65-70.

HUNTER, D. J. \& FELSON, D. T. 2006. Osteoarthritis. BMJ, 332, 639-642.

HUNZIKER, E. B. 2001. Articular cartilage repair: basic science and clinical progress. A review of the current status and prospects. Osteoarthritis and Cartilage, 10, 432-463.

HUNZIKER, E. B., KAPFINGER, E. \& GEISS, J. 2007. The structural architecture of adult mammalian articular cartilage evolves by a synchronized process of tissue resorption and neoformation during postnatal development. Osteoarthritis and Cartilage, 15, 403-413.

HUTMACHER, D. W. 2000. Scaffolds in tissue engineering bone and cartilage. Biomaterials, 21, 2529-2543.

HYNES, R. O. 2002. Integrins: bidirectional, allosteric signaling machines. Cell, $110,673-687$.

HYNES, R. O. 2012. The evolution of metazoan extracellular matrix. Journal of Cell Biology, 196, 671-679.

HYNES, R. O. \& NABA, A. 2012. Overview of the matrisome - an inventory of the extracellular matrix constituents and functions. Cold Spring Harbor Perspectives in Biology [Online], 4. 
IKADA, Y. 2006. Challenges in tissue engineering. Journal of Royal Society Interface, 3, 589-601.

IKEDA, K., WANG, L. H., TORRES, R., ZHAO, H., OLASO, E., ENG, F. J., LABRADOR, P., KLEIN, R., LOVETT, D., YANCOPOULOS, G. D., FRIEDMAN, S. L. \& LIN, H. C. 2002. Discoidin domain receptor 2 interacts with Src and Shc following its activation by type I collagen 277, 21, 19206-19212.

IWASA, J., ENGEBRETSEN, L., SHIMA, Y. \& OCHI, M. 2009. Clinical application of scaffolds for cartilage tissue engineering. Knee Surgery, Sports Traumatology, Arthroscopy, 17, 561-577.

IYER, S. S. \& CHENG, G. 2012. Role of interleukin 10 transcriptional regulation in inflammation and autoimmune diease. Critical Reviews in Immunology, 32, 23-63.

JACOBI, M., VILLA, V., MAGNUSSEN, R. A. \& NEYRET, P. 2011. MACI - a new era? Sports Medicine Arthroscopy Rehabilitation Therapy Technology, 3.

JAFARI-SABET, M., NASIRI, H. \& ATAEE, R. 2016. The effect of cross-linking agents and collagen concentrations on properties of collagen scaffolds. Journal of Archives in Military Medicine [Online], 4. Available: http://jammonline.com/en/articles/20846.html.

JAKUBZICK, C. V., RANDOLPH, G. J. \& HENSON, P. M. 2017. Monocyte differentiation and antigen-presenting functions. Nature Reviews Immunology, 17, 349-362.

JAMES, C.-B. \& UHL, T. L. 2001. A review of articular cartilage pathology and the use of glucosamine sulfate. Journal of Athletic Training, 36, 413-419.

JANSEN, K. A., DONATO, D. M., BALCIOGLU, H. E., SCHMIDT, T., DANEN, E. H. J. \& KOENDERINK, G. H. 2015. A guide to mechanobiology: where biology and physics meet. Biochimica et Biophysica Acta-Molecular Cell Research, 1853, 3043-3052.

JAY, G. D. \& HONG, B. S. 1992. Characterisation of a bovine synovial fluid lubricating factor. II. Comparison with purified ocular and salivary mucin. . Connective Tissue Research, 28, 89-98.

JAYADEV, R. \& SHERWOOD, D. R. 2017. Basement membranes. Current Biology, 27, R207-R211.

JAYASURIYA, C. T. \& CHEN, Q. 2015a. Potential benefits and limitations of utilising chondroprogenitors in cell-based cartilage therapy. Connective Tissue Research, 56, 265-271.

JAYASURIYA, C. T. \& CHEN, Q. 2015b. Potential benefits and limitations of utilizing chondroprogenitors in cell-based cartilage therapy. Connective Tissue Research, 56, 265-271.

JERUSHALMY, Z., ENGLENDER, T. \& SHAKLAI, M. 1988. Phorbol-myristateacetate induced platelet aggregation in the presence of inhibitors. Acta Haematology, 80, 210-215.

JEUKEN, R. M., ROTH, A. K., PETERS, R. J. R. W., DONKELAAR, C. C. V., THIES, J. C., RHIJN, L. W. V. \& EMANS, P. J. 2016. Polymers in cartilage defect repair of the knee: current status and future prospects. Polymers for Advanced Technologies, 8.

JIN, C. Z., CHO, J.-H., CHOI, B. J., WANG, L. M., KIM, M. S., PARK, S. R., YUN, J. J., OH, H. J. \& MIN, B.-H. 2011. The maturity of tissue-engineered cartilage in vitro affects the repairability for osteochondral defect. Tissue Engineering Part A, 17, 3057-3065. 
JONES, A. R. C., CHEN, S., CHAI, D. H., STEVENS, A. L., GLEGHORN, J. P., BONASSAR, L. J., GRODZINSKY, A. J. \& FLANNERY, C. R. 2009. Modulation of lubricin biosynthesis and tissue surface properties following cartilage mechanical injury. Arthritius \& Rhematism, 60, 133-142.

JONES, K. S. 2008. Effects of biomaterial-induced inflammation on fibrosis and rejection. Seminars in Immunology, 20, 130-136.

JORDAN, J. M., HELMICK, C. G., RENNER, J. B., LUTA, G., DRAGOMIR, A. D., WOODARD, J., FANG, F., SCHWARTZ, T. A., ABBATE, L. M., CALLAHAN, L. F., KALSBEEK, W. D. \& HOCHBERG, M. C. 2007. Prevalence of knee symptoms and radiographic and symptomatic knee osteoarthritis in African Americans and Caucasians: the Johnston County osteoarthritis project. Journal of Rhematology, 34, 172-180.

JOUBERT, M. K., DESHPANDE, M., YANG, J., REYNOLDS, H., BRYSON, C., FOGG, M., BARKER, M. P., HERSKOVITZ, J., GOLETZ, T. J., ZHOU, L., MOXNESS, M., FLYNN, G. C., NARHI, L. O. \& JAWA, V. 2016. Use of in vitro assay to assess immunogenicity risk of antibody-based biotherapeutics. PLoS One [Online], 11.

JULKUNEN, P., HARJULA, T., IIVARINEN, J., MARJANEN, J., SEPPÄNEN, K., NÄRHI, T., AROKOSKI, J., LAMMI, M. J., BRAMA, P. A., JURVELIN, J. S. \& HEMINEN, H. J. 2009. Biomechanical. biochemical and structural correlations in immature and mature rabbit articular cartilage. Osteoarthritis and Cartilage, 17, 1628-1638.

KALLURI, R. 2003. Angiogenesis: basement membranes: structure, assembly and role in tumour angiogenesis. Nature Reviews Cancer, 3, 422-433.

KAPOOR, M., MARTEL-PELLETIER, J., LAJEUNESSE, D., PELLETIER, J. P. \& FAHMI, H. 2011. Role in proinflammatory cytokines in the pathophysiology of osteoarthritis. Nature Reviews Rheumatology, 7, 3342.

KARIM, A. A. \& BHAT, R. 2009. Fish gelatin: properties, challenges, and prospects as an alternative to mammalian gelatins. Food Hydrocolloids, 23, 563-576.

KARLSSON, C. \& LINDAHL, A. 2009. International Review of Cell and Molecular Biology, Academic Press.

KASHI, A. M., TAHERMANESH, K., CHAICHIAN, S., JOGHATEI, M. T., MORADI, F., TAVANGAR, S. M., SADAT, A., NAJAFABADI, M., LOTFIBAKHSHAIESH, N., BEYRANVAND, S. P., ANVARI-YAZDI, A. F. \& ABEH, S. M. 2014. How to prepare biological samples and live tissues for scanning electron microscopy (SEM). Galen Medical Journal, 3.

KAWALEC-CARROLL, J. S., HETHERINGTON, V. J., DOCKERY, D. S., SHIVE, C., TARGONI, O. S., LEHMANN, P. V., NADLER, D. \& PRINS, D. 2006. Immunogenicity of unprocessed and photooxidized bovine and human osteochondral grafts in collagen-sensitive mice. BMC Musculoskeletal Disorders, 7.

KAWASAKI, K., USHIODA, R., ITO, S., IKEDA, K., MASAGO, Y. \& NAGATA, K. 2014. Deletion of the collagen-specific molecular chaperone Hsp47 causes endoplasmic reticulum stress-mediated apoptosis of hepatic stellate cells. Journal of Biological Chemistry, 290, 3639-3646.

KAYABOLEN, A., KESKIN, D., AYKAN, A., KARSLIOGLU, Y., ZOR, F. \& TEZCANER, A. 2017. Native extracellular matrix/fibroin hydrogels for adipose tissue 
engineering with enhanced vascularisation. Biomedical Materials [Online], 12.

KELLER, B. O., SUI, J., YOUNG, A. B. \& WHITTAL, R. M. 2008. Interferences and contaminants encountered in modern mass spectrometry. Analytical Chimica Acta, 627, 71-81.

KENNEDY, M. A. 2010. A brief review of the basics of immunology: the innate and adaptive response. Veterinary Clinics of North America: Small Animal Practice, 40, 369-379.

KHAN, I. M., BISHOP, J. C., GILBERT, S. \& ARCHER, C. W. 2009. Clonal chondroprogenitors maintain telomerase activity and Sox 9 expression during extended monolayer culture and retain chondrogenic potential. Osteoarthritis and Cartilage, 17, 518-528.

KHAN, I. M., FRANCIS, L., THEOBALD, P. S., PERNI, S., YOUNG, R. D., PROKOPOVICH, P., CONLAN, R. S. \& ARCHER, C. W. 2013. In vitro growth factor-induced bio engineering of mature articular cartilage. Biomaterials, 34, 1478-1487.

KHAN, I. M., GILBERT, S. J., SINGHRAO, S. K., DUANCE, V. C. \& ARCHER, C. W. 2008. Cartilage integration: evaluation of the reasons for failure of integration during cartilage repair. A review. European Cells and Materials, 16, 26-39.

KHAN, R. \& KHAN, M. H. 2013. Use of collagen as a biomaterial: an update. Journal of Indian Society of Peridontology, 17, 539-542.

KHOSHNOODI, J., CARTAILLER, J.-P., ALVARES, K., VEIS, A. \& HUDSON, B. G. 2006. Molecular recognition in the assembly of collagens: terminal noncollagenous domains are key recognition modules in the formation of triple helical protomers. Journal of Biological Chemistry, 281, 38117 38121.

KIEW, P. L. \& DON, M. M. 2013. The influence of acetic acid concentration on the extractibility of collagen from the skin of hybrid clarias sp. and its physicochemical properties: a preliminary study. Focusing on Modern Food Industry, 2, 123-128.

KIM, H. E., DALAL, S. S., YOUNG, E., LEGATO, M. J., WEISFELDT, M. L. \& D'ARMIENTO, J. 2000. Disruption of the myocardial extracellular matrix leads to cardiac dysfunction. The Journal of Clinical Investigation, 106, 857-866.

KIM, S.-H., TURNBULL, J. \& GUIMOND, S. 2011. Extracellular matrix and cell signalling: the dynamic cooperatio of integrin, proteoglycan and growth factor receptor. Journal of Endocrinology, 209, 139-151.

KIM, Y. K., CHEN, E. Y. \& LIU, W. F. 2016. Biomolecular strategies to modulate the macrophage response to implanted materials. Journal of Material Chemistry B, 4, 1600-1609.

KING, L. K., MARCH, L. \& ANANDACOOMARASAMY, A. 2013. Obesity \& osteoarthritis. 185-193, 138, 185-193.

KIRKLAND, S. C. 2009. Type I collagen inhibits differentiation and promotes a stem cell like phenotype in human colorectal carcinoma cells. British Journal of Cancer, 101, 320-326.

KLEIN, T. J., MALDA, J., SAH, R. L. \& HUTMACHER, D. W. 2009. Tissue engineering of articular cartilage with biomimetic zones. Tissue Engineering. Part B, Reviews, 15, 143-157. 
KNUDSON, C. B. \& KNUDSON, W. 2001. Cartilage proteoglycans. Seminars in Cell \& Developmental Biology, 12, 69-78.

KNUPP, C. \& SQUIRE, J. M. 2005. Molecular packing in network-forming collagens. Advances in Protein Chemistry, 70, 375-403.

KOBAYASHI, S., MEIR, A. \& URBAN, J. 2007. Effect of cell density on the rate of glycosaminoglycan accumulation by disc and cartilage cells in vitro. Journal of Orthopaedic Research, 26, 493-503.

KOCK, L., DONKELAAR, C. C. V. \& ITO, K. 2012. Tissue engineering of functional articular cartilage: the current status. Cell and Tissue Research, 347, 613627.

KOIDE, T. \& NAGATA, K. 2005. Collagen Biosynthesis. Collagen. Berlin, Heidelberg: Springer.

KOMORI, T. 2018. Runx2, an inducer of osteoblast and chondrocyte differentiation. Histochemistry and Cell Biology, 149, 313-323.

KOU, P. M. \& BABENSEE, J. E. 2011. Macrophage and dendritic cell phenotypic diversity in the context of biomaterial. Journal of Biomedical Materials Research, 96, 239-260.

KRAAN, P. M. V. D., DAVIDSON, E. N. B. \& BERG, W. B. V. D. 2010. Bone morphogenetic proteins and articular cartilage: to serve and protect or a wolf in sheep clothing's? Osteoarthritis and Cartilage, 18, 735-741.

KRAEUTLER, M. J., BELK, J. W., PURCELL, J. M. \& MCCATHY, E. C. 2018. Microfracture versus autologous chondrocyte implantation for articular cartilage lesions in the knee. The American Journal of Sports Medicine, 46, 995-999.

KREULEN, C., GIZA, E. \& WALTON, J. 2017. Seven-year follow-up of matrixinduced autologous implantation in talus articular defects. Foot \& Ankle Specialist, 11, 133-137.

KRIMM, S. \& BANDEKAR, J. 1986. Vibrational spectroscopy and conformation of peptides, polypeptides, and proteins. Advanced Protein Chemistry, 38, 181-364.

KROON, L. M. G. D., NARCISI, R., DAVIDSON, E. N. B., CLEARY, M. A., BEUNINGEN, H. M. V., KOEVOET, W. J. L. M., OSCH, G. J. V. M. V. \& KRAAN, P. M. V. D. 2015. Activin receptor-like kinase receptors ALK5 and ALK1 are both required for TGFB-induced chondrogenic differentiation of human bone marrow-derived mesenchymal stem cells. PLoS One [Online], 10. Available: https://www.ncbi.nlm.nih.gov/pmc/articles/PMC4697836/.

KROPP, C., MASSAI, D. \& ZWEIGERDT, R. 2017. Progress and challenges in large scale expansion of human pluripotent stem cells. Process Biochemistry, 59, 244-254.

KULAR, J. K., BASU, S. \& SHARMA, R. I. 2014. The extracellular matrix: structure, composition, age-related differences, tools for analysis and applications for tissue engineering. Journal of Tissue Engineering [Online], 5.

Available:

http://journals.sagepub.com/doi/full/10.1177/2041731414557112.

KUPCSIK, L., STODDART, M. J., LI, Z., BENNEKER, L. M. \& ALINI, M. 2010. Improving chondrogenesis: potential and limitations of SOX9 gene transfer and mechanical stimulation for cartilage tissue engineering. Tissue Engineering: Part A, 16, 1845-1855. 
LACY, P. \& STOW, J. L. 2011. Cytokine release from innate immune cells: association with diverse membrane trafficking pathways. Blood, 118, 918.

LAKIN, B. A., GRASSO, D. J., SHAH, S. S., STEWART, R. C., BANSAL, P. N., FREEDMAN, J. D., GRINSTAFF, M. W. \& SNYDER, B. D. 2013. Cationic agent contrast-enhanced computed tomography imaging of cartilage correlates with the compressive modulus and coefficient of friction. Osteoarthritis and Cartilage, 21, 60-68.

LANG, N. R., ÜNSTER, S., METZNER, C., KRAUSS, P., SCHÜRMANN, S., LANGE, J., AIFANTIS, K. E., FRIEDRICH, O. \& FABRY, B. 2013. Estimating the 3D pore size distribution of biopolymer networks from directionally biased data. Biophysical Journal, 105, 1967-1975.

LAPIDOTH, G. D., BARAN, D., PSZOLLA, G. M., NORN, C., ALON, A., TYKA, M. D. \& FLEISHMAN, S. J. 2015. AbDesign: an algorithm for the combinatorial backbone design guided by natural conformations and sequences Proteins, 83, 1385-1406.

LATTOUF, R., YOUNES, R., LUTOMSKI, D., NAAMAN, N., GODEAU, G., SENNI, K. \& CHANGOTADE, S. 2014. Picrosirius red staining: a useful tool to appraise collagen networks in normal and pathological tissues. Journal of Histochemistry \& Cytochemistry, 62, 751-758.

LEBLEU, V. S., MACDONALD, B. \& KALLURI, R. 2007. Structure and function of basement membranes. Experimental Biology and Medicine, 232, 11211129.

LEE, C. H. \& LEE, Y. 2016. Wound Healing Biomaterials, Woodhead Publishing.

LEE, J., LEE, J. Y., CHAE, B. C., JANG, J., LEE, E. \& SON, Y. 2017. Fully dedifferentiated chondrocytes expanded in specific mesenchymal stem cell growth medium with FGF2 obtains mesenchymal stem cell phenotype in vitro but retains chondrocyte phenotype in vivo. Cell Transplantation, 26, 1673-1687.

LEE, J. L. \& STREULI, C. H. 2014. Integrins and epithelial cell polarity. Journal of Cell Science, 127, 3217-3225.

LEE, M. \& VASIOUKHIN, V. 2008. Cell polarity and cancer - cell and tissue polarity as a non-canonical tumor suppressor. Journal of Cell Science, $121,1141-1150$.

LEE, S., CHOI, E., CHA, M.-J. \& HWANG, K.-C. 2015. Cell adhesion and long term survival of transplanted mesenchymal stem cells: a prerequisite for cell therapy. Oxidative Medicine and Cellular Longevity.

LEE, S.-H. \& SHIN, H. 2007. Matrices and scaffolds for delivery of bioactive molecules in bone and cartilage tissue engineering. Advanced Drug Delivery Reviews, 59, 339-359.

LEE, W. Y.-W. \& WANG, B. 2017. Cartilage repair by mesenchymal stem cells: clinical trial update and perspectives. Journal of Orthopaedic Translation, 9, 76-88.

LEITINGER, B. 2003. Molecular analysis of collagen binding by the human discoidin domain receptors, DDR1 and DDR2. Identification of collagen binding sites in DDR2. Journal of Biological Chemistry, 278, 16761-16769.

LEITINGER, B. 2011. Transmembrane collagen receptors. The Annual Review of Cell and Developmental Biology, 27, 265-290. 
LI, S., SENGERS, B. G., OREFFO, R. O. C. \& TARE, R. S. 2015. Chondrogenic potential of human articular chondrocytes and skeletal stem cells: a comparative study. Journal of Biomaterials Applications, 29, 824-836.

LIBERIO, M. S., SADOWSKI, M. C., SOEKMADJI, C., DAVIS, R. A. \& NELSON, C. C. 2014. Differential effects of tissue culture coating substrated on prostate cancer cell adherence, morphology and behaviour. PLoS One [Online], 9.

LIEBERTHAL, J., SAMBAMURTHY, N. \& SCANZELLO, C. R. 2015. Inflammation in joint injury and post-traumatic osteoarthritis. Osteoarthritis and Cartilage, 23, 1825-1834.

LIETMAN, S. A. 2016. Induced pluripotent stem cells in cartilage repair. World Journal of Orthopaedics, 7, 149-155.

LINKER, R., GOLD, R. \& LUHDER, F. 2009. Function of neurotrophic factors beyond the nervous system: inflammation and autoimmune demyelination Critical Reviews in Immunology, 29, 43-68.

LIU, A. P., CHAUDHURI, O. \& PAREKH, S. H. 2017. New advances in probing cellextracellular matrix interactions. Integrative Biology, 9, 383-405.

LIU, L., CHEN, G., CHAO, T., RATNER, B. D., SAGE, E. H. \& JIANG, S. 2008. Reduced foreign body reaction to implanted biomaterials by surface treatment with oriented osteopontin. Journal of Biomaterial Science Polymer Edition, 19, 821-835.

LIU, X., FENG, Q., BACHHUKA, A. \& VASILEV, K. 2014. Surface modification by allylamine plasma polymerization promotes osteogenic differentiation of human adipose-derived stem cells. ACS Applied Materials Interfaces, 6, 9733-9741.

LIU, Y., GOLDBERG, A. J., DENNIS, J. E., GRONOWICZ, G. A. \& KUHN, L. T. 2012. One-step derivation of mesenchymal stem cell (MSC)-like cells from human pluripotent stem cells on a fibrillar collagen coating. PLoS One [Online], 7.

LODISH, H., BERK, A., ZIPURSKY, S. L., MATSUDAIRA, P., BALTIMORE, D. \& DARNELL, J. 2000a. Collagen: the fibrous proteins of the matrix. Molecular Cell Biology. W. H. Freeman.

LODISH, H., BERK, A., ZIPURSKY, S. L., MATSUDAIRA, P., BALTIMORE, D. \& DARNELL, J. 2000b. Molecular Cell Biology, New York, W. H. Freeman.

LOH, Q. L. \& CHOONG, C. 2013. Three-dimensional scaffolds for tissue engineering applications: role of porosity and pore size. Tissue Engineering: Part B, Reviews, 19, 485-502.

LU, P., TAKAI, K., WEAVER, V. M. \& WERB, Z. 2011. Extracellular matrix degradation and remodeling in development and disease. Cold Spring Harbor Perspectives in Biology, 3.

LU, P., WEAVER, V. M. \& WERB, Z. 2012. The extracellular matrix: a dynamic niche in cancer progression. The Journal of Cell Biology, 196.

LU, T., LI, Y. \& CHEN, T. 2013. Techniques for fabrication and construction of three-dimensional scaffolds for tissue engineering. International Journal of Nanomedicine, 8, 337-350.

LYNN, A. K., YANNAS, I. V. \& BONFIELD, W. 2004. Antigenicity and immunogenicity of collagen. Journal of Biomedical Materials Research, 71B, 343-354. 
MA, B., WANG, X., WU, C. \& CHANG, J. 2014. Crosslinking strategies for preparation of extracellular matrix-derived cardiovascular scaffolds. Regenerative Biomaterials, 1, 81-89.

MADDEN, T. 2013. The BLAST sequence analysis tool. The NCBI Handbook.

MAGOMBEDZE, G., EDA, S. \& STABEL, J. 2015. Predicting the role of IL-10 in the regulation of the adaptive immune responses in Mycobacterium avium Subsp. paratuberculosis infections using mathematical models. PLoS One [Online], 10.

MAHBOUDI, H., KAZEMI, B., SOLEIMANI, M., HANAEE-AHVAZ, H., GHANBARIAN, H., BANDEHPUR, M., ENDERAMI, S. E., KEHTARI, M. \& BARATI, G. 2018. Enhance chondrogenesis for human bone marrow mesencymal stem cell (BMSC) on nanofiber-based polyethersulfone (PES) scaffold. Gene, 643, 98-106.

MAHLA, R. S. 2016. Stem cells applications in regenerative medicine and disease therapeutics. International Journal of Cell Biology [Online], 2016. Available: https://www.ncbi.nlm.nih.gov/pmc/articles/PMC4969512/.

MAKRIS, E. A., GOMOLL, A. H., MALIZOS, K. N., HU, J. C. \& ATHANASIOU, K. A. 2015. Repair and tissue engineering techniques for articular cartilage. Nature Reviews Rheumatology, 11, 21-34.

MANCÒ, A., GODERECCI, R., RUGHETTI, A., GIORGI, S. D., NECOZIONE, S., BERNARDI, A. \& CALVISI, V. 2016. Microfracture versus microfracture and platelet-rich plasma: athroscopic treatment of knee chondral lesions. A two-year follow-up study. Joints, 4, 142-147.

MANSFIELD, J. C. \& WINLOVE, C. P. 2012. A multi-modal multiphoton investigation of microstructure in the deep zone and calcified cartilage. Journal of Anatomy, 220, 405-416.

MAO, A. S. \& MOONEY, D. J. 2015. Regenerative medicine: current therapies and future directions. PNAS, 112, 14452-14459.

MAO, A. S., SHIN, J.-W. \& MOONEY, D. J. 2016. Effects of substrate stiffness and cell-cell contact on mesenchymal stem cell differentiation. Biomaterials, 98, 184-191.

MARASTONI, S., LIGRESTI, G., LORENZON, E., COLOMBATTI, A. \& MONGIAT, M. 2008. Extracellular matrix: a matter of life and death. Connective Tissue Research, 49, 203-206.

MARCUS, P., BARI, C. D., DELL'ACCIO, F. \& ARCHER, C. W. 2014. Articular chondroprogenitor cells maintain chondrogenic potential but fail to form functional matrix when implanted into muscles of SCID mice. Cartilage, 5, 231-240.

MARIANI, E., PULSATELLI, L. \& FACCHINI, A. 2014. Signaling pathways in cartilage repair. International Journal of Molecular Sciences, 15, 86678698.

MARINI, J. C., FORLINO, A., BÄCHINGER, H. P., BISHOP, N. J., BYERS, P. H., PAEPE, A. D., FASSIER, F., FRATZL-ZELMAN, N., KOZLOFF, K. M., KRAKOW, D., MONTPETIT, K. \& SEMLER, O. 2017. Osteogenesis imperfecta. Nature Reviews Disease Primers [Online], 3.

MARION, N. W. \& MAO, J. J. 2006. Mesenchymal stem cells and tissue engineering. Methods Enzymology, 420, 339-361. 
MARK, K. V. D., GAUSS, V., MARK, M. V. D. \& MULLER, P. 1977. Relationship between cell shape and type of collagen synthesised as chondrocytes lose their cartilage phenotype in culture. Nature, 267, 521-532.

MARTEL-PELLETIER, J., TAT, S. K. \& PELLETIER, J. P. 2010. Effects of chondroitin sulfate in the pathophysiology of the osteoarthritic joint: a narrative review. Osteo arthritis and Cartilage, 18, S7-S11.

MARTIN-PIEDRA, M. A., GARZON, I., OLIVEIRA, A. C., ALFONSO-RODRIGUEZ, C. A., CARRIEL, V., SCIONTI, G. \& ALAMINOS, M. 2014. Cell viability and proliferation capability of long-term human dental pulp stem cell cultures. Cytotherapy, 16, 266-277.

MATOS, L. L. D., TRUFELLI, D. C., MATOS, M. G. L. D. \& PINHAL, M. A. D. S. 2010. Immunohistochemistry as an important tool in biomarkers detection and clinical practice. Biomarker Insights, 5, 9-20.

MATSIKO, A., GLEESON, J. \& O'BRIEN, F. J. 2015. Scaffold mean pore size influences mesenchymal stem cell chondrogenic differentiation and matrix deposition. Tissue Engineering: Part A, 21, 486-497.

MAZIVEYI, M. \& ALAHARI, S. K. 2017. Cell matrix adhesions in cancer: the proteins that form the glue. Oncotarget, 8, 48471-48487.

MAZOR, M., LESPESSAILLES, E., COUSIER, R., DANIELLOU, R., BEST, T. M. \& TOUMI, H. 2014. Mesenchymal stem-cell potential in cartilage repair: an update. Journal of Cellular and Molecular Medicine, 18, 2340-2350.

MCCARTHY, H. S., RICHARDSON, J. B., PARKER, J. C. E. \& ROBERTS, S. 2016. Evaluating joint morbidity after chondral harvest for autologous chondrocyte implantation (ACI). Cartilage, 7, 7-15.

MCELROY, K., MOUTON, L., PASQUIER, L. D., QI, W. \& EBERT, D. 2011. Characterisation of a large family of polymorphic collagen-like proteins in the endospore-forming bacterium Pasteuria ramosa. Research in Microbiology, 162, 701-714.

MCKEE, C. \& CHAUDHRY, G. R. 2017a. Advances and challenges in stem cell culture. Colloid Surfaces B: Biointerfaces, 159, 62-77.

MCKEE, C. \& CHAUDHRY, G. R. 2017b. Advances and challenges in stem cell culture. Colloids and Surfaces B: Biointerfaces, 159, 62-77.

MCNARY, S. M., ATHANASIOU, K. A. \& REDDI, A. H. 2012. Engineering lubrication in articular cartilage. Tissue Engineering. Part B, Reviews, 18, 88-100.

MEDICI, D. \& NAWSHAD, A. 2010. Type I collagen promotes epithelialmesencymal transistion through ILK-dependent activation of NF-KB and LEF-1. Matrix Biology, 29, 161-165.

MEENA, C., MENGI, S. A. \& DESHPANDE, S. G. 1999. Biomedical and industrial applications of collagen. Proceedings of the Indian Academy of Sciences Chemical Sciences, 111, 319-329.

MELTON, D. 2008. Stembook, Cambridge (MA).

MEYER, K., LINKER, A., DAVIDSON, E. A. \& WEISSMANN, B. 1953. The mucopolysaccharides of bovine cornea. Journal of Biological Chemistry, 205, 611-616.

MI, S., CHEN, B., WRIGHT, B. \& CONNON, C. J. 2010. Plastic compression of a collagen gel forms a much improved scaffold for ocular surface tissue engineering over conventional collagen gels. Journal of Biomedical Materials Research, 95A, 447-453. 
MIMURA, T., IMAI, S., KUBO, M., ISOYA, E., ANDO, K., OKUMURA, N. \& MATSUSUE, Y. 2008. A novel exogenous concentration-gradient collagen scaffold augments full thickness articular cartilage repair. Osteoarthritis and Cartilage, 16, 1083.

MINAS, T. 2011. A primer in cartilage repair and joint preservation of the knee, Elsevier Health Sciences.

MONSORO-BURQ, A. H. 2005. Sclerotome development and morphogenesis: when experimental embryology meets genetics. International Journal of Developmental Biology, 49, 301-308.

MONTES, G. S. \& JUNQUEIRA, L. C. U. 1991. The use of the picrosiriuspolarization method for the study of the biopathology of collagen. Mem. Inst. Oswaldo Cruz, 86, 1-11.

MOOKHTIAR, K. A. \& WART, H. E. V. 1992. Clostridium Histolyticum collagenasesL a new look at some old enzymes. Matrix, 1, 116-126.

MORISHIGE, H., SUGAHARA, T., NISHIMOTO, S., MURANAKA, A., OHNO, F., SHIRAISHI, R. \& DOI, M. 2011. Immunostimulatory effects of collagen from jellyfish in vivo. Cytotechnology, 63, 481-492.

MOSSER, D. M. \& ZHANG, X. 2009. Interleukin 10: new perspectives on an old cytokine. Immunology Reviews, 226, 205-218.

MOUNT, D. W. 2004. Alignment of pairs of sequences. In: MOUNT, D. W. (ed.) Bioinformatics: Sequence and Genome Analysis. 2 ed.: Cold Spring Harbour Laboratory Press.

MOUW, J. K., OU, G. \& WEAVER, V. M. 2014. Extracellular matrix assembly: a multiscale deconstruction. Nature Reviews Molecular Cell Biology, 15, 771-785.

MOZDZIAK, P. E., PULVERMACHER, P. M., SCHULTZ, E. \& SCHELL, K. 2000. Hoescht fluorescence intensity can be used to separate viable bromodeoxyuridine-labeled cells from viable non-bromodeoxyuridinelabeled cells. Cytometry, 41, 89-95.

MUHAMMED, F. \& SULTANA, R. 2008. New record of edible jellyfish, Rhizostoma pulmo (Cnidaria: Schphoza: Rhizostomitidae) from Pakistani waters. Marine Biodiversity Records, 1.

MULLER, W. A. 2013. Getting leukocytes to the site of inflammation. Veterinary Pathology, 50, 7-22.

MUNIRAH, S., SAMSUDIN, O. C., AMINUDDIN, B. S. \& RUSZYMAH, B. H. I. 2010. Expansion of human articular chondrocytes and formation of tissue engineered cartilage: a step towards exploring a potential use of matrixinduced cell therapy. Tissue and Cell, 42, 282-292.

MURPHY, C. M., HAUGH, M. G. \& O'BRIEN, F. J. 2010. The effect of mean pore size on cell attachment, proliferation and migration in collagenglycosaminoglycan scaffolds for bone tissue engineering. Biomaterials, 31, 461-466.

MURRAY, I. R. \& PÉAULT, B. 2015. Q\&A: Mesenchymal stem cells - where do they come from and is it important? BMC Biology, 13.

MUSHTAQ, S., CHOUDHARY, R. \& SCANZELLO, C. R. 2011. Non-surgical treatment of osteoarthritis-related pain in the elderly. Current Reviews in Musculoskeletal Medicine, 4, 113-122. 
MUSSON, D. S., MCINTOSH, J., CALLON, K. E., CHHANA, A., DUNBAR, P. R., NAOT, D. \& CORNISH, J. 2013. The need for thorough in vitro testing biomaterial scaffolds: two case studies. Procedia Engineering, 59, 138-143.

MUSSON, D. S., NAOT, D., CHHANA, A., MATTHEWS, B. G., MCINTOSH, J. D., LIN, S. T. C., CHOI, A. J., CALLON, K. E., DUNBAR, P. R., LESAGE, S., COLEMAN, B. \& CORNISH, J. 2015. In Vitro evaluation of a novel non-Mulberry silk scaffold for use in tendon regeneration. Tissue Engineering: Part A, 21, 1539-1551.

MUSUMECI, G., AIELLO, F. C., SZYCHLINSKA, M. A., ROSA, M. D., CASTROGIOVANNI, P. \& MOBASHERI, A. 2015. Osteoarthritis in the XXIst century: risk factors and behaviours that influence disease onset and progression. International Journal of Molecular Sciences, 16, 6093-7112.

MUSUMECI, G., CASTROGIOVANNI, P., LEONARDI, R., TROVATO, F. M., SZYCHLINSKA, M. A., GIUNTA, A. D., LORETO, C. \& CASTORINA, S. 2014. New perspectives for articular cartilage repair treatment through tissue engineering: A contemporary review. World Journa of Orthopedics, 5, 8088.

MWALE, F., STACHURA, D., ROUGHLEY, P. \& ANTONIOU, J. 2006. Limitations of using aggrecan and type $\mathrm{X}$ collagen as markers of chondrogenesis in mesenchymal stem cell differentiation. Journal of Orthopaedic Research, 8, 1791-1798.

NAAHIDI, S., JAFARI, M., LOGAN, M., WANG, Y., YUAN, Y., BAE, H., DIXON, B. \& CHEN, P. 2017. Biocompatibility of hydrogel-based scaffolds for tissue engineering applications. Biotechnology Advances, 35, 530-544.

NAGAI, N., NAKAYAMA, Y., ZHOU, Y.-M., TAKAMIZAWA, K., MORI, K. \& MUNEKATA, M. 2008. Development of salmon collagen vascular graft: mechanical and biological properties and preliminary implantation study. Journal of Biomedical Materials Research, 87, 432-439.

NAKAGAWA, S., PAWELEK, P. \& GRINNELL, F. 1989. Long-term culture of fibroblasts in contracted collagen gels: effects on cell growth and biosynthetic activity. Journal of Investigative Dermatology, 93, 792-798.

NEEL, E. A. A., CHEEMA, U., KNOWLES, J. C., BROWN, R. A. \& NAZHAT, S. N. 2006. Use of multiple unconfined compression for control of collagen gel scaffold density and mechanical properties. Soft Matter, 2, 986-992.

NELSON, T. J., BEHFAR, A. \& TERZIC, A. 2008. Strategies for therapeutic repair: the $\mathrm{R} 3$ regenerative medicine paradigm. Clinical Translational Science, 1, 168-171.

NG, K. W., KUGLER, L. E., DOTY, S. B., ATESHIAN, G. A. \& HUNG, C. T. 2009. Scaffold degradation elevates the collagen content and dynamic compressive modulus in engineered articular cartilage. Osteoarthritis and Cartilage, 17, 220-227.

NIETHAMMER, T. R., LIMBRUNNER, K., BETZ, O. B., GÜLECYÜZ, M. F., PIETSCHMANN, M. F., FEIST, M. \& MÜLLER, P. E. 2016. Analysis of the autologous chondrocyte quality of matrix-based autologous chondrocyte implantation in the knee joint. International Orthopaedics, 40, 205-212.

NILSSON, B., EKDAHL, K. N., MOLLNESS, T. E. \& LAMBRIS, J. D. 2007. The role of complement in biomaterial-induced inflammation. Molecular Immunology, 44, 82-94. 
NISHIMOTO, S., GOTO, Y., MORISHIGE, H., SHIRAISHI, R., DOI, M., AKIYAMA, K., YAMAUCHI, S. \& SUGAHARA, T. 2008. Mode of action of the immunostimulatory effect of collagen from jellyfish. Bioscience, Biotechnology, and Biochemistry, 72, 2806-2814.

NISHIMURA, R., WAKABAYASHI, M., HATA, K., MATSUBARA, T., HONMA, S., WAKISAKA, S., KIYONARI, H., SHIOI, G., YAMAGUCHI, A., TSUMAKI, N., AKIYAMA, H. \& YONEDA, T. 2012. Osterix regulates calcification and degradation of chondrogenic matrices through matrix metalloproteinase 13 (MMP13) expression in association with transcription factor Runx2 during endochondral ossification. Journal of Biological Chemistry, 287, 33179-33190.

NIXON, A. J., RICKEY, E., BUTLER, T. J., SCIMECA, M. S., MORAN, N. \& MATTHEWS, G. L. 2015. A chondrocyte infiltrated collagen type I/III membrane (MACI implant) improves cartilage healing in the equine patellofemoral joint model. Osteoarthritis and Cartilage, 23, 648-660.

O'BRIEN, F. J. 2011. Biomaterials \& scaffolds for tissue engineering. MaterialsToday, 14, 88-95.

O'BRIEN, F. J., HARLEY, B. A., YANNAS, I. V. \& GIBSON, L. J. 2005. The effect of pore size on cell adhesion in collagen-GAG scaffolds. Biomaterials, 26, 433-441.

O'BRIEN-BALL, C. \& BIDDLE, A. 2017. Reprogramming to developmental plasticity in cancer stem cells. Developmental Biology, 430, 266-274.

ONG, C.-T. \& CORCES, V. G. 2011. Enhancer function: new insights into the regulation of tissue-specific gene expression. Nature Reviews Genetics, 12, 283-293.

ONTARIO, H. Q. 2005. Athroscopic lavage and debridement for osteoarthritis of the knee: an evidence based analysis. Ontario Health Technology Assessment Series, 5, 1-37.

OVEREEM, A. W., BRYANT, D. M. \& IJZENDOORN, S. C. D. V. 2015. Mechanisms of apical-basal axis orientation and epithelial lumen positioning. Trends in Cell Biology, 25, 476-485.

PACAK, C. A., POWERS, J. M. \& COWAN, D. B. 2011. Ultrarapid Purification of Collagen Type I for Tissue Engineering Applications. Tissue Engineering: Part C, 17, 879-885.

PAN, Z. K., CHEN, L.-Y., COCHRANE, C. G. \& ZURAW, B. L. 2000. fMet-Leu-Phe stimulates proinflammatory cytokine gene expression in human peripheral blood monocytes: the role of phosphatidylinositol 3-kinase. The Journal of Immunology, 164, 404-411.

PARENTEAU-BAREIL, R., GAUVIN, R. \& BERTHOD, F. 2010. Collagen-based biomaterials for tissue engineering applications. Materials, 3, 1863-1887.

PARIHAR, A., EUBANK, T. D. \& DOSEFF, A. I. 2010. Monocytes and macrophages regulate immunity through dynamic networks of survival and cell death. Journal of Innate Immunology, 2, 204-215.

PARISI, L., TOFFOLI, A., GHIACCI, G. \& MACALUSO, G. M. 2018. Tailoring the interface of biomaterials to design effective scaffolds. Journal of Functional Biomaterials, 9.

PARK, J. S., CHU, J. S., TSOU, A. D., DIOP, R., TANG, Z., WANG, A. \& LI, S. 2011. The effect of matrix stiffness on the differentiation of mesenchymal stem cells in response to TGF-B. Biomaterials, 32, 3921-3930. 
PARKIN, J. \& COHEN, B. 2001. An overview of the immune system. The Lancet, 357, 1777-1789.

PAWELEC, K. M., BEST, S. M. \& CAMERON, R. E. 2016. Collagen: a network for regenerative medicine. Journal of Material Chemistry $B, 4,6484-6496$.

PAYNE, K. J. \& VEIS, A. 1988. Fourier transform IR spectroscopy of collagen and gelatin solutions: deconvolution of the amide I band for conformational studies. Biopolymers, 27, 1749-1760.

PEARLE, A. D., WARREN, R. F. \& RODEO, S. A. 2005. Basic science of articular cartilage and osteoarthritis. Clinics in Sports Medicine, 24, 1-12.

PELLETIER, J.-P., MARTEL-PELLETIER, J., RANNOU, F. \& COOPER, C. 2016. Efficacy and safety of oral NSAIDs and analgesics in the management of osteoarthritis: evidence from real-life setting trials and surveys. Seminars in Arthritis and Rhematism, 45, S22-S27.

PENNOCK, N. D., WHITE, J. T., CROSS, E. W., CHENEY, E. E., TAMBURINI, B. A. \& KEDL, R. M. 2013. T cell responses: naive to memory and everything in between. Advances in Physiology Education, 37, 273-283.

PERTSEMLIDIS, A. \& FONDON, J. W. 2001. Having a BLAST with bioinformatics (and avoiding BLASTphemy). Genome Biology, 2.

PETERS, M. C. \& MOONEY, D. J. 1997. Synthetic extracellular matrices for cell transplantation. Porous Material Tissue Engineering, 250, 43-52.

PHELPS, E. A. \& GARCIA, A. J. 2009. Update on therapeutic vascularization strategies. Regenerative Medicine, 4, 65-80.

PHULL, A.-R., EO, S.-H., ABBAS, Q., AHMED, M. \& KIM, S. J. 2016. Applications of chondrocyte-based cartilage engineering: an overview. BioMed Research International [Online], 2016. Available: https://www.ncbi.nlm.nih.gov/pmc/articles/PMC5007317/.

PISITKUN, T., HOFFERT, J. D., SAEED, F. \& KNEPPER, M. A. 2012. NHLBI AbDesigner: an online tool for design of peptide-directed antibodies. American Journal of Physiology - Cell Physiology, 302, C154-C164.

PLANT, A. L., BHADRIRAJU, K., SPURLIN, T. A. \& ELLIOT, J. T. 2009. Cell response to matrix mechanics: focus on collagen. Biochimica et Biophysica Acta Molecular Cell Research, 1793, 893-902.

POTTEN, C. S. \& LOEFFLER, M. 1990. Stem cells: attributes, cycles, spirals, pitfalls and uncertainties. Lessons for and from the crypt. Development, 110, 1001-1020.

PRABHAKARAN, M. P., VENUGOPAL, J., GHASEMI-MOBARAKEH, L., KAI, D., JIN, G. \& RAMAKRISHNA, S. 2012. Stem cells and nanostructures for advanced tissue regeneration. Biomedical applicaions of polymeric nanofibers, Berlin, Springer.

PRITZKER, K. P. H., GAY, S., JIMENEZ, S. A., OSTERGAARD, K., PELLETIER, J.-P., REVELL, P. A., SALTER, D. \& BERG, W. B. V. D. 2006. Osteoarthritis cartilage histopathology: grading and staging. Osteoarthritis and Cartilage, 14, 13-29.

PUGLIANO, M., VANBELLINGHEN, X., SCHWINTÉ, P., BENKIRANE-JESSEL, N. \& KELLER, L. 2017. Combined jellyfish collagen type II, human stem cells and Tgf-B3 as a therapeutic implant for cartilage repair. Journal of Stem Cell Research \& Therapy, 7.

PUTRA, A. B. N., NISHI, K., SHIRAISHI, R., DOI, M. \& SUGAHARA, T. 2014. Jellyfish collagen stimulated production of TNF-a and IL-6 by J774.1 cells through 
the activation of NF-kB and JNK via TLR4 signaling pathways. Molecular Immunology, 58, 32-37.

RADINSKY, D., MUSCHLER, J. \& BISSELL, M. J. 2002. Order and disorder: the role of extracellular matrix in epithelial cancer. Cancer Investigation, 20, 139153.

RADLEY, G., PIEPER, I. L. \& THORNTON, C. A. 2017. The effect of ventricular assist device-associated biomaterials on human blood leukocytes. Journal of Biomedical Materials Research, 106, 1730-1738.

RAGETLY, G. R., GRIFFON, D. J., LEE, H. B., FREDERICKS, L. P., GORDON-EVANS, W. \& CHUNG, Y. S. 2010. Effect of chitosan scaffold microstructure on mesenchymal stem cell chondrogenesis. Acta Biomaterialia, 6, 14301436.

RAMIREZ, C. N., OZAWA, T., TAKAGI, T., ANTCZAK, C., SHUM, D., GRAVES, R., HOLLAND, E. C. \& DJABALLAH, H. 2011. Validation of a high-content screening assay using whole-well imaging of transformed phenotypes. Assay Drug Development Technology, 9, 247-261.

RAMSHAW, J. A. M., PENG, Y. Y., GLATTAUER, V. \& WEKMEISTER, J. A. 2009. Collagens as biomaterials. Journal of Materials Science: Materials in Medicine, 20, S3-S8.

RAO, S. S. \& WINTER, J. O. 2009. Adhesion molecule-modified biomaterials for neural tissue engineering. Frontiers in Neuroengineering, 2.

RASTOGI, A., SARKAR, S. \& CHAKRABARTY, D. 2017. Partial purification and identification of a metalloproteinase with anticoagulant activity from Rhizostoma pulmo (Barrel Jellyfish). Toxicon, 132, 29-39.

RATNER, B. D. 2011. The biocompatibility manifesto: biocompatibility for the twenty-first century. Journal of Cardiovascular Translational Research, 4, 523-527.

RAVICHANDRAN, R., SUNDARRAJAN, S., VENUGOPAL, J. R., MUKHERJEE, S. \& RAMAKRISHNA, S. 2012. Advances in polymeric systems for tissue engineering and biomedical applications. Macromolecular Bioscience, 12, 286-311.

REDMAN, S. N., OLDFIELD, S. F. \& ARCHER, C. W. 2005. Current strategies for articular cartilage repair. European Cells and Materials, 9, 23-32.

REILINGH, M. L., LAMBERS, K. T. A., DAHMEN, J., OPDAM, K. T. M. \& KERKHOFFS, G. M. M. J. 2017. The subchondral bone healing after fixation of an osteochondral talar defect is superior in comparison with microfracture Knee Surgery, Sports Traumatology, Arthroscopy, 26, 2177-2182.

REINHOLZ, G. G., LU, L., SARIS, D. B. F., YASZEMSKI, M. J. \& O'DRISCOLL, S. W. 2004. Animal models for cartilage reconstruction. Biomaterials, 25, 1511-1521.

RENARD, B. Y., TIMM, W., KIRCHNER, M., STEEN, J. A. J., HAMPRECHT, F. A. \& STEEN, H. 2010. Estimating the confidence of peptide identifications without decoy databases. Letters to Analytical Chemistry, 82, 4314-4318.

RENTSCH, C., SCHNEIDERS, W., MANTHEY, S., RENTSCH, B. \& RAMMELT, S. 2014. Comprehensive histological evaluation of bone implants. Biomatter [Online], 4.

RESPONTE, D. J., NATOLI, R. M. \& ATHANASIOU, K. A. 2012. Identification of potential biophysical and molecular signalling mechanisms underlying 
hyaluronic acid enhancement of cartilage formation. Journal of the Royal Society Interface, 9, 3564-3573.

REST, M. V. D., AUBERT-FOUCHER, E., DUBLET, B., EICHENBERGER, D., FONT, B. \& GOLDSCHMIDT, D. 1991. Structure and function of the fibril-associated collagens. Biochemical Society Transactions, 19, 820-824.

REST, M. V. D. \& GARRONE, R. 1991. Collagen family of proteins. FASEB Journal, 5, 2814-2823.

RIAZ, T., ZEESHAN, R., ZARIF, F., ILYAS, K., MUHAMAD, N., SAFI, S. Z., RAHIM, A., RIZVI, S. A. A. \& REHMAN, I. U. 2018. FTIR analysis of natural and synthetic collagen. Applied Spectroscopy Reviews, 53, 703-746.

RIBEIRO, A. R., BARBAGLIO, A., BENEDETTO, C. D., RIBEIRO, C. C., WILKIE, I. C., CARNEVALI, M. D. C. \& BARBOSA, M. A. 2011. New insights into mutable collagenous tissue: correlations between the microstructure and mechanical state of a sea urchin ligament. PLoS One [Online], 6.

RICARD-BLUM, S. 2011. The collagen family. Cold Spring Harbor Perspectives in Biology [Online], 3. Available: http://www.ncbi.nlm.nih.gov/pmc/articles/PMC3003457/.

RICARD-BLUM, S., REST, M. V. D. \& DUBLET, B. 2000. Unconventional collagens. Types VI, VII, VIII, IX, X, XIV, XVI and XIX., Oxford University Press.

RICARD-BLUM, S. \& RUGGIERO, F. 2005. The collagen superfamily: from the extracellular matrix to the cell membrane. Pathologie Biologie, 53, 430442.

ROBERTS, S., MENAGE, J., SANDELL, L. J., EVANS, E. H. \& RICHARDSON, J. B. 2009. Immunohistochemical study of collagen types I and II and procollagen IIA in human cartilage repair tissue following autologous chondrocyte implantation. The Knee, 16, 398-404.

RÖDER, A., GARCIA-GARETA, E., THEODOROPOULOS, C., RISTOIVSKI, N., BLACKWOOD, K. A. \& WOODRUFF, M. A. 2015. An assessment of cell culture plate surface chemistry for in vitro studies of tissue engineering scaffolds. Journal of Functional Biomaterials, 6, 1054-1063.

RODRIGUES-PASCUAL, F. \& SLATTER, D. A. 2016. Collagen cross-linking: insights on the evolution of metazoan extracellular matrix. Scientific Reports [Online], 6. Available: https://www.nature.com/articles/srep37374.pdf.

RODRÍGUEZ, M. I. A., BARROSO, L. G. R. \& SÁNCHEZ, M. L. 2017. Collagen: a review on its sources and potential cosmetic applications. Journal of Cosmetic Dermatology, 17, 20-26.

ROHBAN, R. \& PIEBER, T. R. 2017. Mesenchymal stem and progenitor cells in regeneration: tissue specificity and regenerative potential. Stem Cells International [Online], 2017. Available: https://www.hindawi.com/journals/sci/2017/5173732/.

ROSENBAUM, A. J., GRANDE, D. A. \& DINES, J. S. 2008. The use of mesenchymal stem cells in tissue engineering. A global assessment. Organogenesis, 4, 23-27.

ROUGHLEY, P. J. \& MORT, J. S. 2014. The role of aggrecan in normal osteoarthritic cartilage. Journal of Experimental Orthopaedics, 1.

RUDNICK, P. A., CLAUSER, K. R., KILPATRICK, L. E., TCHEKHOVSKOI, D. V., NETA, P., BLONDER, N., BILLHEIMER, D. D., BLACKMAN, R. K., BUNK, D. M., CARDASIS, H. L., HAM, A.-J. L., JAFFE, J. D., KINSINGER, C. R., MESRI, M., 
NEUBERT, T. A., SCHILLING, B., TABB, D. L., TEGELER, T. J., VEGAMONTOTO, L., VARITATH, A. M., WANG, M., WANG, P., WHITEAKER, J. R., ZIMMERMAN, L. J., CARR, S. A., FISHER, S. J., GIBSON, B. W., PAULOVICH, A. G., REGNIER, F. E., RODRIGUEZ, H., SPIEGELMAN, C., TEMPST, P., LIEBLER, D. C. \& STEIN, S. E. 2010. Performance metrics for liquid chromatograpgy tandem mass spectrometry systems in proteomics analyses. Molecular Cell Proteomics, 9, 225-241.

SABZEVARI, S., EBRAHIMPOUR, A., ROUDI, M. K. \& KACHOOEI, A. R. 2016. High tibial osteotomy: a systematic review and current concept. The Archives of Bone and Joint Surgery, 4, 204-212.

SAHA, K., POLLOCK, J. F., SCHAFFER, D. V. \& HEALY, K. E. 2007. Designing synthetic materials to control stem cell phenotype. Current Opinions in Chemical Biology, 11, 381-387.

SAITO, T. \& KAWAGUCHI, H. 2010. HIF-2a as a possible therapeutic target of osteoarthritis. Osteoarthritis and Cartilage, 18, 1552-1556.

SAMPOGNA, G., GURAYA, S. Y. \& FORGIONE, A. 2015. Regenerative medicine: historical roots and potential strategies in modern medicine. Journal of Microscopy and Ultrastructure, 3, 101-107.

SAMSONRAJ, R. M., RAGHUNATH, M., NURCOMBE, V., HUI, J. H., WIJNEN, A. J. V. \& COOL, S. M. 2017. Concise review: multifaceted characterisation of human mesenchymal stem cells for use in regenerative medicine. Stem Cells Translational Medicine, 6, 2173-2185.

SCHEIDELER, L., FUGER, C., SCHILLE, C., RUPP, F., WENDEL, H. P., HORT, N., REICHEL, H. P. \& GEIS-GERSTORFER, J. 2013. Comparison of different in vitro tests for biocompatibility screening of Mg alloys. Acta Biomaterialia, 9, 8740-8745.

SCHELLER, J., CHALARIS, A., SCHMIDT-ARRAS, D. \& ROSE-JOHN, S. 2011. The pro- and anti-inflammatory properties of the cytokine interleukin-6. Biochimica et Biophysica Acta - Molecular Cell Research, 1813, 878-888.

SCHINDLER, M., NUR-E-KAMAL, A., AHMED, I., KAMAL, J., LIU, H.-Y., AMOR, N., PONERY, A. S., CROCKETT, D. P., GRAFE, T. H., CHUNG, H. Y., WEIK, T., JONES, E. \& MEINERS, S. 2006. Living in three dimensions. Cell Biochemistry and Biophysics, 45, 215-227.

SCHMIDT, M. M., DORNELLES, R. C. P., MELLO, R. O., KUBOTA, E. H., MAZUTTI, M. A., KEMPKA, A. P. \& DEMIATE, I. M. 2015. Collagen extraction process. International Food Research Journal, 23, 913-922.

SCHROCK, J. B., KRAEUTLER, M. J., HOUCK, D. A., MCQUEEN, M. B. \& MCCARTY, E. C. 2017. A cost-effectiveness analysis of surgical treatment modalities for chondral lesions of the knee: microfracture, osteochondral autograft transplantation, and autologous chondrocyte implantation. Orthopaedic Journal of Sports Medicine [Online], 5. Available: https://www.ncbi.nlm.nih.gov/pmc/articles/PMC5418910/.

SCHULTZ, M., MOLLIGAN, J., SCHON, L. \& ZHANG, Z. 2015. Pathology of the calcified zone of articular cartilage in post-traumatic osteoarthritis in rat knees. PLoS One [Online], 10. Available: https://www.ncbi.nlm.nih.gov/pmc/articles/PMC4373850/.

SCHUTTE, S. C. \& TAYLOR, R. N. 2012. A tissue-engineered human endometrial stroma that responds to cues for secretory differentiation, decidualization, and menstuation. Fertility and Sterility, 97, 997-1003. 
SERPOOSHAN, V., MUJA, N., MARELLI, B. \& NAZHAT, S. N. 2010. Fibroblast contractility and growth in plastic compressed collagen gel scaffolds with microstructures correlated with hydraulic permeability. Journal of Biomedical Materials Research, 96, 609-620.

SERRA, R., JOHNSON, M., FILVAROFF, E. H., LABORDE, J., SHEEHAN, D. M., DERYNCK, R. \& MOSES, H. L. 1997. Expression of a truncated, kinase defective TGF-B type II receptor in mouse skeletal tissue promotes terminal chondrocyte differentiation and osteoarthritis. Journal of Cell Biology, 139, 541-552.

SEWING, J., KLINGER, M. \& NOTBOHM, H. 2017. Jellyfish collagen matrices conserve the chondrogenic phenotype in two- and three- dimensional collagen matrices. Journal of Tissue Engineering and Regenerative Medicine, 11, 916-925.

SEYFRIED, N. T., MCVEY, G. F., ALMOND, A., MAHONEY, D. J., DUDHIA, J. \& DAY, A. J. 2004. Expression and purification of functionally active hyaluronanbinding domains from human cartilage link protein, aggrecan and versican. Journal of Biological Chemistry, 280, 5435-5448.

SHAW, L. M. \& OLSEN, B. R. 1991. FACIT collagens: diverse molecular bridges in extracellular matrices. Trends in Biochemical Sciences, 16, 191-194.

SHI, S.-R., SHI, Y. \& TAYLOR, C. R. 2011. Antigen retrieval immunohistochemistry. Journal of Histochemistry \& Cytochemistry, 59, 13-32.

SHOULDERS, M. D. \& RAINES, R. T. 2009. Collagen structure and stability. Annual Review of Biochemistry, 78, 929-958.

SILJANDER, P. R.-M., HAMAIA, S., PEACHY, A. R., SLATTER, D. A., SMETHURST, P. A., OUWEHAND, W. H., KNIGHT, C. G. \& FARNDALE, R. W. 2004. Integrin activation state determines selectivity for novel recognition sites in fibrillar collagens. Journal of Biological Chemistry, 279, 47763-47772.

SILVA, T. H., MOREIRA-SILVA, J., MARQUES, A. L. P., DOMINGUES, A., BAYON, Y. \& REIS, R. L. 2014. Marine origin collagens and its potential applications. Marine Drugs, 12, 5881-5901.

SILVIPRIYA, K. S., KUMAR, K. K., BHAT, A. R., KUMAR, B. D., JOHN, A. \& LAKSHMANAN, P. 2015. Collage: animal sources and biomedical application. Journal of Applied Pharmaceutical Science, 5, 123-127.

SOEHNLEIN, 0. 2012. Multiple roles for neutrophils in atherosclerosis. Circulation Research, 110, 875-888.

SOININEN, R., TIKKA, L., CHOW, L. P., PIHLAJANIEMI, T., KURKINEN, M., PROCKOP, D. J., BOYD, C. D. \& TRYGGVASON, K. 1986. Large introns in the 3 ' end of the gene for pro alpha1 (IV) chain of human basement membrane collagen. PNAS, 83, 1568-1572.

SOMAIAH, C., KUMAR, A., MAWRIE, D., SHARMA, A., PATIL, S. D., BHATTACHARYYA, J., SWAMINATHAN, R. \& JAGANATHAN, B. G. 2015 a. Collagen promotes higher adhesion, survival and proliferation of mesenchymal stem cells. PLoS One.

SOMAIAH, C., KUMAR, A., MAWRIE, D., SHARMA, A., PATIL, S. D., BHATTACHARYYA, J., SWAMINATHAN, R. \& JAGANATHAN, B. G. $2015 \mathrm{~b}$. Collagen promotes higher adhesion, survival and proliferation of mesenchymal stem cells. PLoS One [Online], 10. 
SOMOZA, R. A., WELTER, J. F., CORREA, D. \& CAPLAN, A. I. 2014. Chondrogenic differentiation of mesenchymal stem cells: challenges and unfulfilled expectations. Tissue Engineering: Part B 20, 596-608.

SONG, E., KIM, S. Y., CHUN, T., BYUN, H.-J. \& LEE, Y. M. 2006. Collagen scaffolds derived from a marine source and their biocompatibility. Biomaterials, 27, 2951-2961.

SOTELO, C. G., COMESÃNA, M. B., ARIZA, P. R. \& PÉREZ-MARTIN, R. I. 2015. Characterization of collagen from different discarded fish species of the west coast of the Iberian Peninsula. Journal of Aquatic Food Product Technology, 25, 388-399.

SRIDHARAN, G. \& SHANKAR, A. A. 2012. Toluidine blue: a review of its chemisity and clinical utility. Journal of Oral and Maxillofacial Pathology, 16, 251-255.

STANTON, H., MELROSE, J., LITTLE, C. B. \& FOSANG, A. H. 2011. Proteoglycan degradation by the ADAMTS family of proteinases. Biochimica et Biophysica Acta - Molecular Basis of Disease, 1812, 1616-1629.

STEEN, H. \& MANN, M. 2004. The ABC's (and XYZ's) of peptide sequencing. Nature Reviews Molecular Cell Biology, 5, 699-711.

STOCKWELL, R. A. 1978. Chondrocytes. Journal of Clinical Pathology, 31, 7-13.

STRIZ, I., BRABCOVA, E., KOLESAR, L. \& SEKERKOVA, A. 2014. Cytokine networking of innate immunity cells: a potential target of therapy. Clinical Science, 128, 593-612.

SUBHAN, F., IKRAM, M., SHEHZAD, A. \& GHAFOOR, A. 2015. Marine collagen: an emerging player in biomedical applications. Journal of Food Science and Technology, 52, 4703-4707.

SUCHY, T., ŠUPOVÁ, M., SAUEROVÁ, P., VERDÁNOVA, M., SUCHARDA, Z., RYGLOVÁ, Š., ŽALOUDKOVÁ, M., SEDLÁČEK, R. \& KALBÁČOVÁ, M. H. 2015. The effects of different cross-linking conditions on collagen-based nanocomposite scaffolds - an in vitro evaluation using mesenchymal stem cells. Biomedical Materials [Online], 10. Available: http://iopscience.iop.org/article/10.1088/17486041/10/6/065008/meta.

SUGIURA, H., YUNOKI, S., KONDO, E., IKOMA, T., TANAKA, J. \& YASUDA, K. 2009. In vivo biologival response and bioresorption of tilipia scale collagen as a potential biomaterial. Journal of Biomaterials Science, 20, 1353-1368.

TAKAHARA, K., SCHWARZE, U., IMAMURA, Y., HOFFMAN, G. G., TORIELLO, H., SMITH, L. T., BYERS, P. H. \& GREENSPAN, D. S. 2002. Order of intron removal influences multiple splice outcomes, including a two-exon skip, in a COL5A1 acceptor-site mutation that results in abnormal proalpha1(V) N-propeptides and Ehlers-Danlos syndrome type I. The American Journal of Human Genetics, 71, 451-465.

TAKAMATSU, A., OHKAWARA, B., MIKAKO, I., MASUDA, A., SAKAI, T., ISHIGURO, N. \& OHNO, K. 2014. Verapamil protects against cartilage degradation in osteoarthritis by inhibiting Wnt/B-catenin signaling. PLoS One [Online], 9. Available: http://www.ncbi.nlm.nih.gov/pmc/articles/PMC3962439/.

TALUKDAR, S., NGUYEN, Q. T., CHEN, A. C., SAH, R. L. \& KUNDU, S. C. 2011. Effect of initial cell seeding density on 3D-engineered silk fibroin scaffolds for articular cartilage tissue engineering. Biomaterials, 32, 8927-8937. 
Bibliography

TARABALLI, F., BAUZA, G., MCCULLOCH, P., HARRIS, J. \& TASCIOTTI, E. 2017. Concise review: biomimetic functionalization of biomaterials to stimulate the endogenous healing process of cartilage and bone tissue. Stem Cells Translational Medicine, 6, 2186-2196.

TEMENOFF, J. S. \& MIKOS, A. G. 2000. Review: tissue engineering for regeneration of articular cartilage. Biomaterials, 21, 431-440.

TERZI, A., STORELLI, E., BETTINI, S., SIBILLANA, T., ALTAMURA, D., SALVATORE, L., MADAGHIELE, M., ROMANO, A., SILIQI, D., LADISA, M., CARO, L. D., QUATTRINI, A., VALLI, L., SANNINO, A. \& GIANNINI, C. 2018. Effects of processing on structural, mechanical and biological properties of collagen-based substrates for regenerative medicine. Scientific Reports, 8.

TESHIMA, R., ONO, M., YAMASHITA, Y., HIRAKAWA, H., NAWATA, K. \& MORIO, Y. 2004. Immunohistochemical collagen analysis of the most superficial layer in adult articular cartilage. Journal of Orthopaedic Science, 9, 270273.

THORESON, A. R., HIWATARI, R., AN, K.-N., AMADIO, P. C. \& ZHAO, C. 2015. The effect of 1-ethyl-3(3-dimethylaminopropyl) carbodiimide suture coating on tendon repair strength and cell viability in a canine model. Journal of Hand Surgery, 40, 1986-1991.

TIRYAKI, V. M., ADIA-NIMUWA, U., AYRES, V. M., AHMED, I. \& SHREIBER, D. I. 2015. Texture-based segmentation and a new cell shape index for quatitative analysis of cell spreading in AFM images Cytometry Part A, 87, 1090-1100.

TRONCI, G., DOYLE, A., RUSSELL, S. J. \& WOOD, D. J. 2013. Triple-helical collagen hydrogels via covalent aromatic functionalization with 1,3phenolenediacetic acid. Journal of Material Chemistry $B, 1,5478-5488$.

TURNER, M. D., NEDJAI, B., HURST, T. \& PENNINGTON, D. J. 2014. Cytokines and chemokines: at the crossroads of cell signalling and inflammatory disease. Biochimica et Biophysica Acta - Molecular Cell Research, 1843, 2563-2582.

UITTO, J., BOOTH, B. A. \& POLAK, K. L. 1980. Collagen biosythesis by human skin fibroblasts. II. Isolation and futher characterisation of type I and type III procollagens syntesised in culture. Biochimica et Biophysica Acta Molecular Cell Research, 624, 545-561.

ULLAH, I., SUBBARAO, R. B. \& RHO, G. J. 2015. Human mesenchymal stem cells current trends and future prospective. Bioscience Reports [Online], 35. Available: https://www.ncbi.nlm.nih.gov/pmc/articles/PMC4413017/.

VEIT, G., KOBBE, B., KEENE, D. R., PAULSSON, M., KOCH, M. \& WAGENER, R. 2006. Collagen XXVIII, a novel von Willebrand factor A domaincontaining protein with many imperfections in the collagenous domain. Journal of Biological Chemistry, 281, 3494-3504.

VELNAR, T., BUNC, G., KLOBUCAR, R. \& GRADISNIK, L. 2016. Biomaterials and host versus graft response: a short review. Bosnian Journal of Basic Medical Sciences, 16, 82-90.

VENUGOPAL, B., MOGHA, P., DHAWAN, J. \& MAJMUDER, A. 2018. Cell density overrides the effect of substrate stiffness on human mesenchymal stem cells morphology and proliferation. Biomaterial Science, 6, 1109-1119. 
VERNON-PARRY, K. D. 2000. Scanning electron microscopy: an introduction. IIIVs Review, 13, 40-44.

VERRECCHIA, F., CHU, M. L. \& MAUVIEL, A. 2001. Identification of novel TGF$\mathrm{B} /$ Smad gene targets in dermal dibroblasts using a combined cDNA microarray/promoter transactivation approach. Journal of Biological Chemistry, 276, 17058-17062.

VICKERS, S. M., SQUITIERI, L. S. \& SPECTOR, M. 2004. Effects of cross-linking type II collagen-GAG scaffolds on chondrogenesis in vitro: dynamic pore reduction promotes cartilage formation Tissue Engineering, 10, 621-631.

VIDAL, B. D. C. \& MELLO, M. L. S. 2011. Collagen type I amide I band infrared spectroscopy. Micron, 42, 283-289.

VINATIER, C., BOUFFI, C., MERCERON, C., GORDELADZE, J., BRONDELLO, J. M., JORGENSEN, C., WEISS, P., GUICHEUX, J. \& NOËL, D. 2009. Cartilage tissue engineering: towards a biomaterial-assisted mesenchymal stem cell therapy. Current Stem Cell Research \& Therapy, 4, 318-329.

VINCENT, L. \& ENGLER, A. J. 2011. Effect of substrate modulus on cell function and differentiation. In: DUCHEYNE, P. (ed.) Comprehensive Biomaterials. Oxford: Elsevier.

VINOD, E., BOOPALAN, P. R. J. V. C. \& SATHISHKUMAR, S. 2017. Reserve or resident progenitors in cartilage? Comparative analysis of chondrocytes vesus chondroprogenitors and their role in cartilage repair. Cartilage, 9, 1-12.

WAHL, D. A. \& CZERNUSZKA, J. T. 2006. Collagen-hydroxyapatite composites for hard tissue repair. European Cells and Materials, 11, 43-56.

WALDSTEIN, W., PERINO, G., GILBERT, S. L., MAHER, S. A., WINDHAGER, R. \& BOETTNER, F. 2015. OARSI osteoarthritis cartilage histopathology assessment system: a biomechanical evaluation in the human knee. Journal of Orthopaedic Research, 34, 135-140.

WANG, M., SAMPSON, E. R., JIN, H., LI, J., KE, Q. H., IM, H.-J. \& CHEN, D. 2013. MMP13 is a critical target gene during the progression of osteoarthritis. Arthritis Research and Therapy, 15.

WANG, M., SHEN, J., JIN, H., IM, H.-J., SANDY, J. \& CHEN, D. 2011. Recent progress in understanding molecular mechanisms of cartilage degeneration during osteoarthritis. Annals of the New York Academy of Sciences, 1240, 61-69.

WANG, W., RIGUEUR, D. \& LYONS, K. M. 2014. TGFB signaling in cartilage development and maintenance. Birth Defects Research Part C: Embryo Today: Reviews, 102, 37-51.

WATTS, A. E., ACKERMAN-YOST, J. C. \& NIXON, A. J. 2013. A comparison of three-dimensional culture systems to evaluate in vitro chondrogenesis of equine bone marrow-derived mesenchymal stem cells. Tissue Engineering Part A, 19, 2275-2283.

WHATMORE, A. M. 2001. Streptococcus pyogenes scIB encodes a putative hypervariable surface protein with a collagen-like repetitive structure. Microbiology, 147, 419-429.

WILES, K., FISHMAN, J. M., COPPI, P. D. \& BIRCHALL, M. A. 2016. The host immune response to tissue-engineered organs: current problems and future directions. Tissue Engineering: Part B, 22, 208-219. 
WILLIAMS, A. R., HARE, J. M., DIMMELER, S. \& LOSORDO, D. 2011. Mesenchymal stem cells: biology, pathophysiology, translational findings, and therapeutic implications for cardiac disease. Circulation Research, 109, 923-940.

WILLIAMS, D. F. 2008. On the mechanisms of biocompatibility. Biomaterials, 29, 2941-2953.

WILLIAMS, R., KHAN, I. M., RICHARDSON, K., NELSON, L., MCCARTHY, H. E., ANALBELSI, T., SINGHRAO, S. K., DOWTHWAITE, G. P., JONES, R. E., BAIRD, D. M., LEWIS, H., ROBERTS, S., SHAW, H. M., DUDHIA, J., FAIRCLOUGH, J., BRIGGS, T. \& ARCHER, C. W. 2010. Identification and clonal characterisation of a progenitor cell sub-population in normal human articular cartilage. PLoS One [Online], 5. Available: http://journals.plos.org/plosone/article?id=10.1371/journal.pone.0013 246 - pone-0013246-g005.

WILSON, C. W. \& CHUANG, P. T. 2010. Mechanism and evolution of cytosolic Hedgehog signal transduction Development, 137, 2079-2094.

WILSON, R. 2014. The extracellular matrix: an underexplored but important proteome. Expert Review of Proteomics, 7, 803-806.

WINDT, T. S. D., VONK, L. A., BRITTBERG, M. \& SARIS, D. B. F. 2013. Treatment and prevention of (early) osteoarthritis using articular cartilage repair fact or fiction? A systematic review. Cartilage, 4, 5S-12S.

WINGATE, K., BONANI, W., TAN, Y., BRYANT, S. J. \& TAN, W. 2012. Compressive elasticity of three-dimensional nanofiber matrix directs mesenchymal stem cell differentiation to vascular cells with endothelial or smooth cell markers. Acta Biomaterialia, 8, 1440-1449.

WINGATE, K., FLOREN, M., TAN, Y., TSENG, P. O. \& TAN, W. 2014. Synergism of matrix stiffness and vascular endothelial growth factor on mesenchymal stem cells for vascular endothelial regeneration. Tissue Engineering: Part A, 20, 2503-2512.

WOLF, M. T., CARRUTHERS, C. A., DEARTH, C. L., CRAPO, P. M., HUBER, A., BURNSED, O. A., LONDONO, R., JOHNSON, S. A., DALY, K. A., STAHL, E. C., FREUND, J. M., MEDBERRY, C. J., CAREY, L. E., NIEPONICE, A., AMOROSO, N. J. \& BADYLAK, S. F. 2014. Polypropylene surgical mesh coated with extracellular matrix mitigates the host foreign body response. Journal of Biomedical Materials Research, 102, 234-246.

WU, J. J., WEIS, M. A., KIM, L. S. \& EYRE, D. R. 2010. Type III collagen, a fibril network modifier in articular cartilage. Journal of Biological Chemistry, 285, 18537-18544.

WU, X., LIU, Y., LIU, A. \& WANG, W. 2017. Improved thermal-stability and mechanical properties of type I collagen by crosslinking with casein, keratin and soy protein isolate using transglutaminase. International Journal of Biological Macromolecules, 98, 292-301.

XU, H., RAYNAL, N., STATHOPOULOS, S., MYLLYHARJU, J., FARNDALE, R. W. \& LEITINGER, B. 2011. Collagen binding specificity of the discoidin domain receptors: binding sites on collagens II and III and molecular determinants for collagen IV recognition by DDR1. Matrix Biology, 30, 16-26.

YAMADA, S., YAMAMOTO, K., IKEDA, T., YANAGIGUCHI, K. \& HAYASHI, Y. 2014. Potency of fish collagen as a scaffold for regenerative medicine. BioMed 
Bibliography

Research International [Online], 2014. Available:

https://www.hindawi.com/journals/bmri/2014/302932/.

YAMAGUCHI, K., LAVETY, J. \& LOVE, R. M. 1976. The connective tissues of fish.

VIII. Comparative studies on hake, cod and catfish collagens. Journal of Food Technology, 11, 389-399.

YAMASHITA, A., NISHIKAWA, S. \& RANCOURT, D. E. 2010. Identification of five developmental processes during chondrogenic differentiation of embryonic stem cells. PLoS One [Online], 5. Available: http://journals.plos.org/plosone/article?id=10.1371/journal.pone.0010 998.

YAMAUCHI, M. \& SRICHOLPECH, M. 2012. Lysine post-translational modifications of collagen. Essays in Biochemistry, 52, 113-133.

YANG, H. \& SHU, Z. 2014. The extraction of collagen protein from pigskin. Journal of Chemical Pharmacology, 6, 683-687.

YANG, K. C., WU, C. C., CHENG, Y. H., KUO, T. F. \& LIN, F. H. 2008.

Chitosan/gelatin hydrogel prolonged the function of insulinoma/agarose microspheres in vivo during xenogenic transplantation. Transplantation Proceedings, 40, 3623-3626.

YANG, S., LIU, F., WANG, Q. J., ROSENBERG, S. A. \& MORGAN, R. A. 2011. The shedding of CD62L (L-Selectin) regulates the acquisition of lytic activity in human tumor reactive T lymphocytes. PLoS One [Online], 6. Available: http://journals.plos.org/plosone/article?id=10.1371/journal.pone.0022 $\underline{560}$.

YANG, Y. L. \& KAUFMAN, L. J. 2009. Rheology and confocal reflectance microscopy as probes of mechanical properties and structures during collagen and collagen/hyaluronan self-assembly. Biophysical Journal, 96, 1566-1585.

YANNAS, I. V., LEE, E., ORGILL, D. P., SKRABUT, E. M. \& MMURPHY, G. F. 1989. Sythesis and characterization of a model extracellular matrix that induces partial regeneration of adult mammalian skin. PNAS, 86, 933937.

YODMUANG, S., MAROLT, D., MARCOS-CAMPOS, I., GADJANSKI, I. \& VUNJAKNOVAKOVIC, G. 2015. Synergistic effects of hypoxia and morphogenetic factors on early chondrogenic commitment of human embryonic stem cells in embryoid body culture. Stem Cell Reviews, 11, 228-241.

YOKOMIZO, R., YAMADA, K., IIDA, Y., KIYOKAWA, T., UEDA, K., SAIT O, M., YANAIHARA, N., NAKAMURA, M. \& OKAMOTO, A. 2017. Dedifferentiated endometrial carcinoma: a report of three cases and review of the literature. Molecular and Clinical Oncology, 7, 1008-1012.

YORK, P. J., WYDRA, F. B. \& BELTON, M. E. 2017. Joint preservation techniques in orthopaedic surgery. Sports Health, 9, 545-554.

YU, D.-A., HAN, J. \& KIM, B.-S. 2012. Stimulation of chondrogenic differentiation of mesenchymal stem cells. International Journal of Stem Cells, 5, 16-22.

YU, Z., AN, B., RAMSHAW, J. A. \& BRODSKY, B. 2014. Bacterial collagen-like proteins that form triple-helical structures. Journal of Structural Biology, 186, 451-461.

YUASA, T., OTANI, T., KOIKE, T., IWAMOTO, M. \& ENOMOTO-IWAMOTO, M. 2008. Wnt/B-catenin signaling stimulates matrix catabolic genes and 
Bibliography

activity in articular chondrocytes: its possible role in joint degeneration. Laboratory Investigation, 88, 264-274.

YUSUF, E. 2016. Pharmacologic and non-pharmacologic treatment of osteoarthritis. Current Treatment Options in Rheumatology, 2, 111-125.

ZHANG, G. 2012. Biomimicry in biomedical research. Organogenesis, 8, 101-102.

ZHANG, H., ZHOU, L. \& ZHANG, W. 2014a. Control of scaffold degradation in tissue engineering: a review. Tissue Engineering: Part B, 20, 492-502.

ZHANG, L., HU, J. \& ATHANASIOU, K. A. 2009. The role of tissue engineering in articular cartilage repair and regeneration. Critical Reviews in Biomedical Engineering, 37, 1-57.

ZHANG, Q., LU, H., KAWAZOE, N. \& CHEN, G. 2014b. Pore size effect of co llagen scaffolds on cartilage regeneration. Acta Biomaterialia, 5, 2005-2013.

ZHANG, X.-H., LIANG, X., LIANG, X.-H., WANG, T.-S., QI, Q.-R., DENG, W.-B., SHA, A.-G. \& YANG, Z.-M. 2013. The mesenchymal-epithelial transition during in vitro decidualization. Reproductive Sciences, 20, 354-360.

ZHOU, G., ZHENG, Q., ENGIN, F., MUNIVEZ, E., CHEN, Y., SEBALD, E., KRAKOW, D. \& LEE, B. 2006. Dominance of SOX9 function over RUNX2 during skeletogenesis. PNAS, 103, 19004-19009.

ZHU, D., TONG, X., TRINH, P. \& YANG, F. 2017. Mimicking cartilage tissue zonal organisation by engineering tissue-scale gradient hydrogels as 3D cell niche. Tissue Engineering: Part A, 24, 1-10.

ZHU, J. \& KAUFMAN, L. J. 2014. Collagen I self assembly: revealing the developing structures that generate turbidity. Biophysical Journal, 106, 1822-1831.

ZHU, Y., OGANESIAN, A., KEENE, D. R. \& SANDELL, L. J. 1999. Type IIA procollagen containing the cysteine-rich amino propeptide is deposited in the extracellular matrix of prechondrogenic tissue and binds to TGFbeta1 and BMP-2. Journal of Cell Biology, 144, 1069-1080.

ZORLUTUNA, P., VRANA, N. E. \& KHADEMHOSSEINI, A. 2013. The expanding world of tissue engineering: the building blocks and new applications of tissue engineered constructs. IEEE Reviews Biomedical Engineering, 6, 47-62.

ZUSCIK, M. J., HILTON, M. J., ZHANG, X., CHEN, D. \& O'KEEFE, R. J. 2008. Regulation of chondrogenesis and chondrocyte differentiation by stress. The Journal of Clinical Investigation, 118, 429-438. 